RECENED

$$
\text { ORNUM-4922 }
$$

FEB 1 G 1996

$$
\text { OSTI }
$$

Benchmarking Analysis of Three Multimedia Models: RESRAD, MMSOILS, and MEPAS
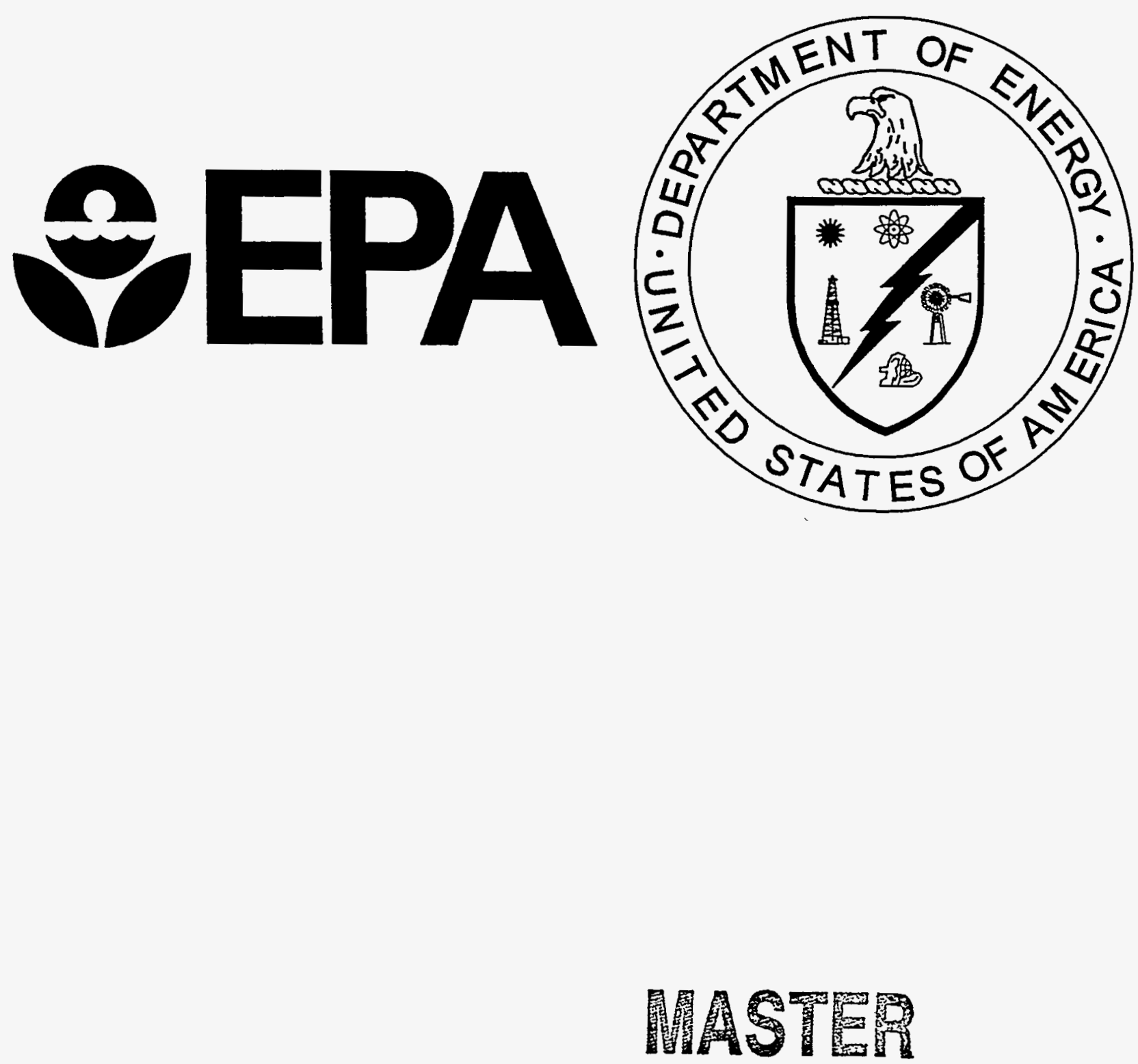

DSTTRIBUTION OF THIS DOCUMENT IS UNLIMITED TR 
This report has been reproduced directly from the best available copy.

Available to DOE and DOE contractors from the Office of Scientific and Technical Information, P.O. Box 62, Oak Ridge, TN 37831; prices available from 615-576-8401 (fax 615-576-2865).

Available to the public from the National Technical Information Service, U.S. Department of Commerce, 5285 Port Royal Rd., Springfield, VA

22161.

\section{DISCLAIMER}

This report was prepared as an account of work sponsored by an agency of the United States Government. Neither the United States Government nor any agency thereof, nor any of their employees, makes any warranty, express or implied, or assumes any legal liability or responsibility for the accuracy, completeness, or usefulness of any information, apparatus, product, or process disclosed, or represents that its use would not infringe privately owned rights. Reference herein to any specific commercial product, process, or service by trade name, trademark, manufacturer, or otherwise does not necessarily constitute or imply its endorsement, recommendation, or favoring by the United States Government or any agency thereof. The views and opinions of authors expressed herein do not necessarily state or reflect those of the United States Government or any agency thereof. 


\title{
Benchmarking Analysis of Three Multimedia Models: RESRAD, MMSOILS, and MEPAS
}
J. J. Cheng ${ }^{1}$
W. Mills ${ }^{3}$
J. G. Droppo ${ }^{2}$
L. Owens ${ }^{5}$
E. R. Faillace ${ }^{1}$
D. L. Strenge ${ }^{2}$
E. K. Gnanapragasam ${ }^{1}$
J. F. Sutherland ${ }^{5}$
R. Johns ${ }^{3}$
G. Whelan ${ }^{2}$
G. Laniak ${ }^{4}$
C. $Y \mathbf{u}^{\mathbf{l}}$
C. Lew $^{3}$

Date Issued-November 1995

\author{
Prepared by \\ Argonne National Laboratory? \\ Argonne, Illinois \\ Pacific Northwest National Laboratory ${ }^{2}$ \\ Richland, Washington \\ Tetra Tech, Inc. ${ }^{3}$ \\ Lafayette, California \\ United States Environmental Protection Agency ${ }^{4}$ \\ Athens, Georgia \\ University of Tennessee \\ Knoxville, Tennessee \\ Prepared for \\ United States Department of Energy \\ Office of Environmental Management \\ under budget and reporting code EW 20 \\ and \\ United States Environment Protection Agency \\ Office of Research and Development \\ Washington, D.C. \\ Produced by \\ OAK RIDGE NATIONAL LABORATORY \\ managed by \\ LOCKHEED MARTIN ENERGY SYSTEMS, INC. \\ for the \\ United States DEPARTMENT OF ENERGY \\ under contract DE-AC05-84OR21400
}




\section{ACKNOWLEDGMENTS}

In January 1990, the Secretary of Energy decided that DOE would prepare a Programmatic Environmental Impact Statement (PEIS) on the proposed integrated Environmental Restoration and Waste Management Program. The primary task of the environmental restoration component is to assess conditions at DOE sites, facilities, and installations contaminated with radioactive, hazardous, and mixed wastes. In January 1992, DOE established an Advisory Board to provide an independent review of the PEIS. Following a review during the second quarter of fiscal year 1993, DOE chose the Multimedia Environmental Pollutant Assessment System (MEPAS) methodology for implementation within the PEIS to assess various waste-site conditions and alternatives at the major DOE weapons complexes.

In December 1993 in response to public comment as to how MEPAS compared to other multimedia modeling approaches, DOE, under the leadership of Dr. Curtis Travis, initiated the first multimedia benchmarking exercise. This interagency effort was successful, in large part, because of the management skills of Dr. Travis and his staff at Oak Ridge National Laboratory (ORNL). The authors of this report would like to extend their personal gratitude to Dr. Travis for his insight in initiating and supporting this multimedia benchmarking effort.

This report is the shared responsibility of many individuals representing two federal agencies at six nationwide locations. While the authors provided a plan, directed the execution, and drafted the report, numerous individuals provided indispensable contributions to the study, such as activities providing sponsorship, participating in technical discussions, preparing and executing models, producing graphics, and processing and editing the document. The authors would like to express their collective appreciation to the following contributors:

Argonne National Laboratory: S. Y. Chen, Ken Cornelius, Loren Habegger, Tony Dvorak

Oak Ridge National Laboratory: Jill Morris

Pacific Northwest National Laboratory: John Buck, Karl Castleton, Andre deHamer, Gariann Gelston, John McDonald, Chikashi Sato, Jim Stroh, Kimberly Valentine

Tetra Tech, Inc.: Patti Heath, Mary Porcella, Jenny Taylor

United States Department of Energy: Paul Beam, Kelvin Kelkenberg, Hal Peterson, Andy Wallo, Alexander Williams, William Wisenbaker

United States Environmental Protection Agency: Robert Ambrose, David Brown, Robert Carsel

University of Tennessee, Knoxville: Beth Ladd

Finally, the authors wish to express their appreciation to the following individuals who provided an independent peer review of the study as reported. Peer reviewers also provided their views regarding the need for and technical direction related to future activities. Their feedback is important in finalizing this report and in establishing the focus for future benchmarking efforts.

Yoram Cohen, Ph.D., University of California, Los Angeles (UCLA)

Laurence Miller, Ph.D., University of Tennessee, Knoxville

Mitchell Small, Ph.D., Carnegie Mellon University, Pittsburgh, Pennsylvania 



\begin{abstract}
Multimedia modelers from the United States Environmental Protection Agency (EPA) and the United States Department of Energy (DOE) collaborated to conduct a comprehensive and quantitative benchmarking analysis of three multimedia models. The three models-RESRAD (DOE), MMSOILS (EPA), and MEPAS (DOE)-represent analytically based tools that are used by the respective agencies for performing human exposure and health risk assessments. The study is performed by individuals who participate directly in the ongoing design, development, and application of the models.

A list of physical/chemical/biological processes related to multimedia-based exposure and risk assessment is first presented as a basis for comparing the overall capabilities of RESRAD, MMSOILS, and MEPAS. Model design, formulation, and function are then examined by applying the models to a series of hypothetical problems. Major components of the models (e.g., atmospheric, surface water, groundwater) are evaluated separately and then studied as part of an integrated system for the assessment of a multimedia release scenario to determine effects due to linking components of the models. Seven modeling scenarios are used in the conduct of this benchmarking study: (1) direct biosphere exposure, (2) direct release to the air, (3) direct release to the vadose zone, (4) direct release to the saturated zone, (5) direct release to surface water, (6) surface water hydrology, and (7) multimedia release.

Study results show that the models differ with respect to (1) environmental processes included (i.e., model features) and (2) the mathematical formulation and assumptions related to the implementation of solutions (i.e., parameterization). The following examples represent a few of the important findings resulting from the benchmarking process.
\end{abstract}

\title{
Important Differences in Model Features
}

- MMSOILS and MEPAS simulate advection and dispersion in the subsurface but do not consider dilution in a well (RESRAD simulates advection only but considers dilution in a well).

- MMSOILS and MEPAS simulate the water balance at the surface due to precipitation (RESRAD requires the user to input related data).

- RESRAD simulates radionuclide transport in the groundwater system with nuclide-specific retardation for transformation products.

- RESRAD and MEPAS compute radiological dose (MMSOILS does not).

\section{Important Differences in Model Formulations}

- Unsaturated Zone Moisture Content

Each model presents different mathematical constructs for calculating moisture content in the vadose zone. The moisture content is used directly in calculating retardation factors, pore-water and contaminant velocities, dispersion, and travel times, which in turn impact contaminant levels. Key differences include (1) RESRAD's use of an effective porosity and (2) MMSOILS' allowance of water movement at moisture contents below field capacity. Results show, for example, that the plug flow travel times calculated by MMSOILS will always be equal to or greater than RESRAD's, and MEPAS' will always be equal to or greater than MMSOILS'. 
- Transport of Radionuclide Decay Products

In both the vadose zone and the saturated zones, MEPAS assumes that products of radionuclide decay travel at the same velocity (retarded due to soil/water partitioning) as the parent. RESRAD allows for varying rates of transport for each radionuclide in the decay chain. As a result, RESRAD's prediction for the decay-products are more distrubuted in time, whereas for MEPAS, progeny formation mirrors the shape of the parent's concentration-versus-time curve.

- Surface Water

MMSOILS applies a one-dimensional, plug-flow model and assumes that any influx of contamination to the river is instantaneously and uniformly mixed laterally across the river. MEPAS applies a two-dimensional model and therefore does not assume that the contaminant is instantaneously and uniformly mixed across the width of the river. Near-field predictions of contaminant concentrations can differ significantly depending on the dilutional characteristics of river flow (i.e., volume, velocity, and width). Model predictions merge in the far-field locations when fully-mixed conditions occur.

- Soil Fluxes Due to Volatization

From a multimedia perspective, all models couple predicted volatile and aqueous phase emissions from a contaminated soil so that total mass emitted equals the initial inventory. However, estimates of contaminant fluxes to the atmosphere and groundwater may differ significantly among the models as a result of the different uses and assumptions related to soil moisture. MMSOILS assumes that the soil pore space is dry when estimating volatilization, MEPAS and RESRAD account for existing soil moisture. Because the contaminant diffusion coefficient is nonlinearly related to the fraction of pore space occupied by air, the predicted volatile fluxes can differ by orders of magnitude, which in turn inflences the amount of contaminant available for leaching to groundwater.

- Risk Calculations

Techniques used by the models to compute exposure and risk also differ, largely because of the different purposes for the codes. For example, MEPAS computes 70-year average media concentrations consistent with the calculation of 70-year lifetime health impact estimates. RESRAD and MMSOILS use the peak exposure concentrations for evaluation of annual health impact estimates. The effect of this difference upon exposure and risk estimates varies from no effect (when peak concentrations are maintained for 70-plus years) to greater than an order of magnitude. 


\section{CONTENTS}

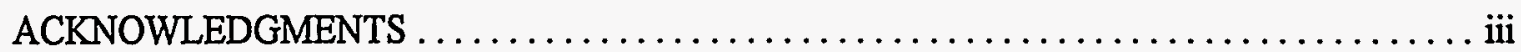

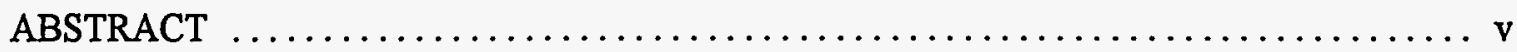

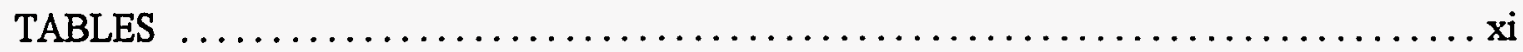

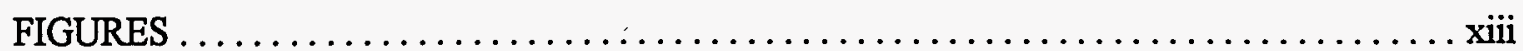

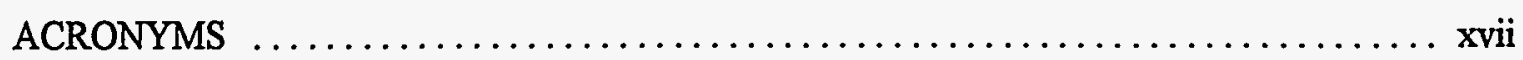

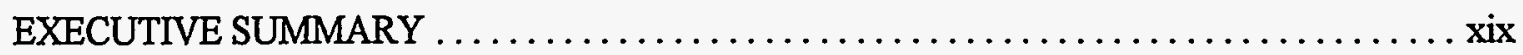

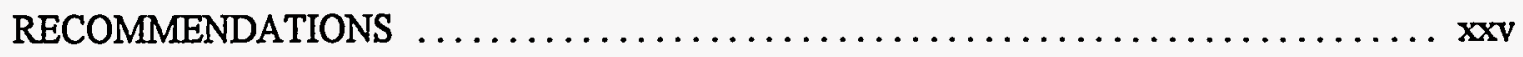

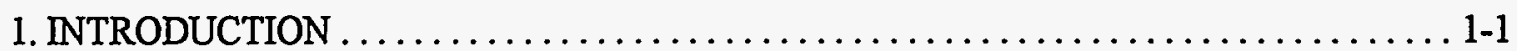

1.1 STUDY OBJECTIVES $\ldots \ldots \ldots \ldots \ldots \ldots \ldots \ldots \ldots \ldots \ldots \ldots \ldots \ldots \ldots \ldots \ldots \ldots \ldots, 1$

1.2 STUDY APPROACH $\ldots \ldots \ldots \ldots \ldots \ldots \ldots \ldots \ldots \ldots \ldots \ldots \ldots \ldots, 1-3$

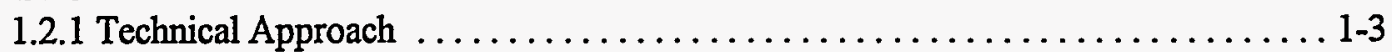

1.2 .2 Logistical Approach $\ldots \ldots \ldots \ldots \ldots \ldots \ldots \ldots \ldots \ldots \ldots \ldots \ldots \ldots \ldots \ldots \ldots \ldots \ldots, 4$

1.3 REPORT ORGANIZATION $\ldots \ldots \ldots \ldots \ldots \ldots \ldots \ldots \ldots \ldots \ldots \ldots \ldots \ldots \ldots \ldots \ldots \ldots \ldots, 1-5$

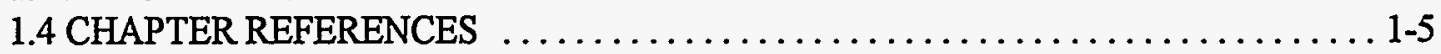

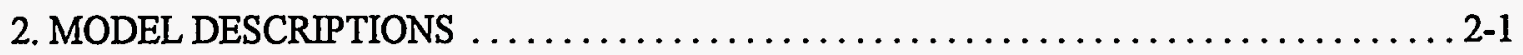

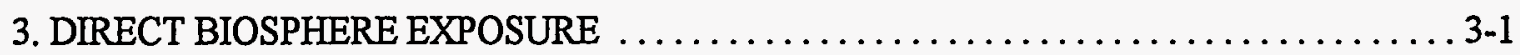

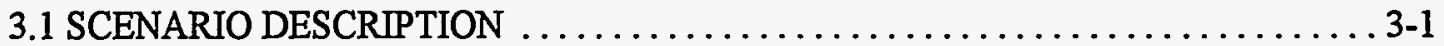

3.2 MODELING ASSUMPTIONS AND APPROACH $\ldots \ldots \ldots \ldots \ldots \ldots \ldots \ldots \ldots, 3-1$

3.2.1 Chemical Cancer Risk ................................

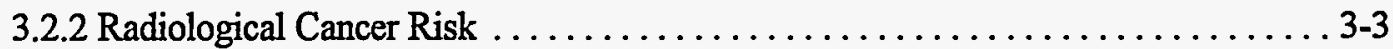

3.2.3 External Radiation .................................... 3-4

3.3 COMPARISON OF MODEL PREDICTIONS $\ldots \ldots \ldots \ldots \ldots \ldots \ldots \ldots \ldots \ldots \ldots, 4$

3.4 RESULTS AND DISCUSSION $\ldots \ldots \ldots \ldots \ldots \ldots \ldots \ldots \ldots \ldots \ldots \ldots \ldots \ldots, \ldots, 4$

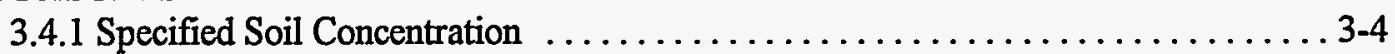

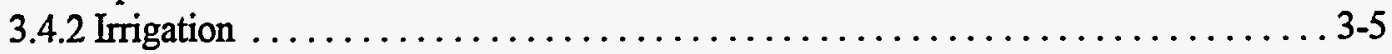

3.4.3 Concentration in Soil from Contaminated Irrigation Water $\ldots \ldots \ldots \ldots \ldots \ldots .3-5$

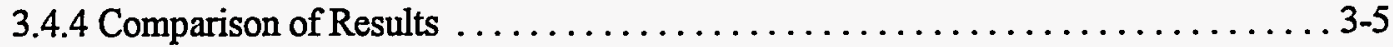

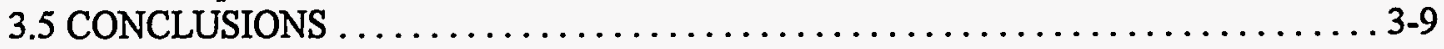

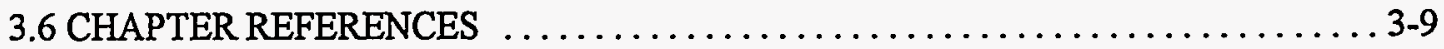

4. DIRECT AIR RELEASE $\ldots \ldots \ldots \ldots \ldots \ldots \ldots \ldots \ldots \ldots \ldots \ldots \ldots \ldots \ldots \ldots \ldots \ldots, 1$

4.1 SCENARIO DESCRIPTION $\ldots \ldots \ldots \ldots \ldots \ldots \ldots \ldots \ldots \ldots \ldots \ldots \ldots \ldots \ldots \ldots \ldots \ldots, 1$

4.2 MODELING ASSUMPTIONS AND APPROACH $\ldots \ldots \ldots \ldots \ldots \ldots \ldots \ldots \ldots, 4-1$

4.3 COMPARISON OF CALCULATED RESULTS $\ldots \ldots \ldots \ldots \ldots \ldots \ldots \ldots \ldots, 4-2$

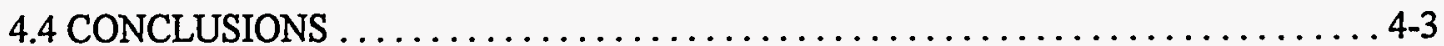




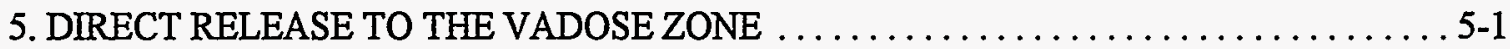

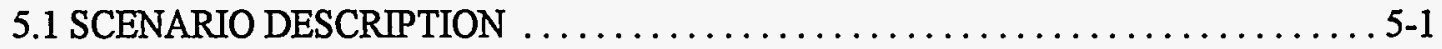

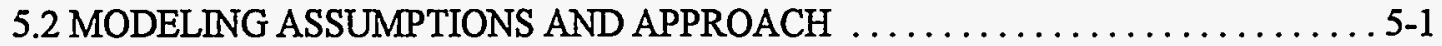

5.2 .1 RESRAD ......................................... $5-2$

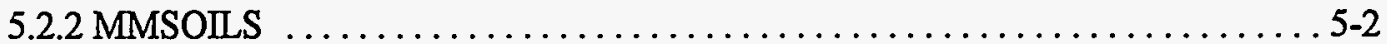

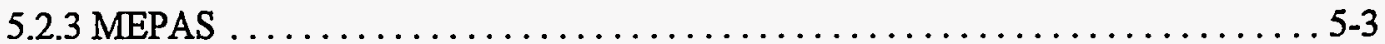

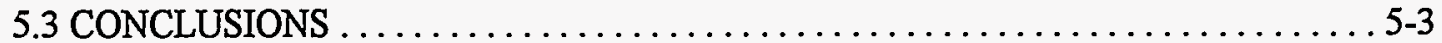

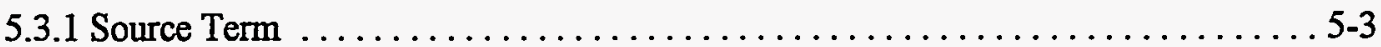

5.3.2 Mathematical Constructs Affecting Contaminant Transport ............ 5-4

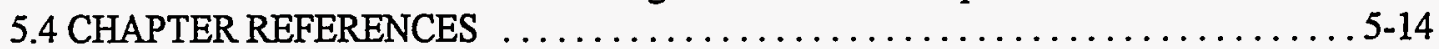

6. DIRECT RELEASE TO SATURATED ZONE $\ldots \ldots \ldots \ldots \ldots \ldots \ldots \ldots \ldots \ldots \ldots \ldots .1$

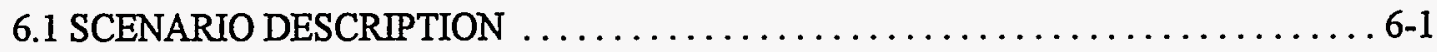

6.2 MODELING ASSUMPTIONS AND APPROACH $\ldots \ldots \ldots \ldots \ldots \ldots \ldots \ldots \ldots .6$.

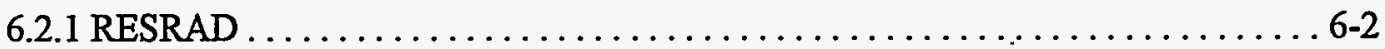

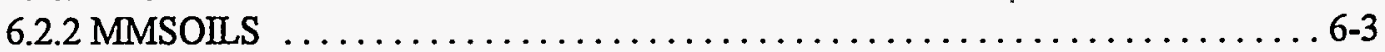

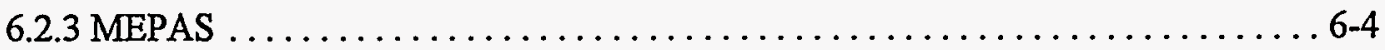

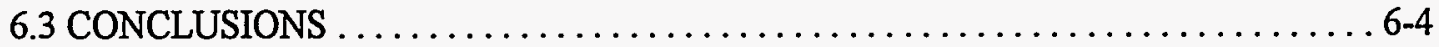

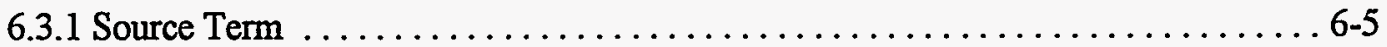

$6.3 .20-\mathrm{m}$ Receptor Location .......................... 6

$6.3 .3150-\mathrm{m}$ and $1500-\mathrm{m}$ Receptor Locations . . . . . . . . . . . . . . . . . . . .

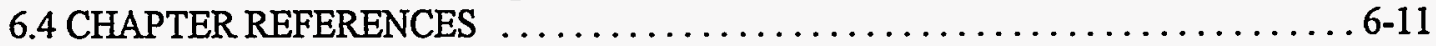

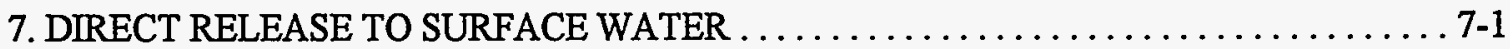

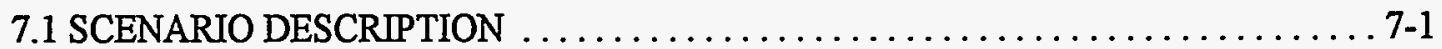

7.2 MODELING ASSUMPTIONS AND APPROACH $\ldots \ldots \ldots \ldots \ldots \ldots \ldots \ldots \ldots \ldots \ldots \ldots .2$

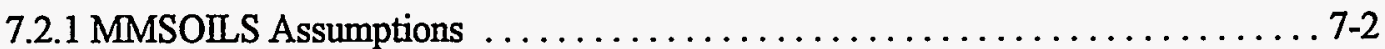

7.2.2 MEPAS Assumptions . . . . . . . . . . . . . . . . . . . .

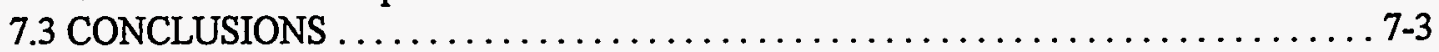

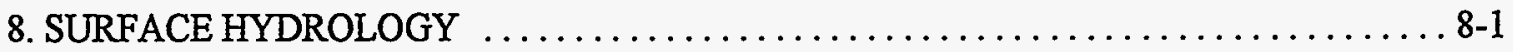

8.1 MODELING ASSUMPTIONS AND APPROACH $\ldots \ldots \ldots \ldots \ldots \ldots \ldots \ldots \ldots \ldots . \ldots \ldots$

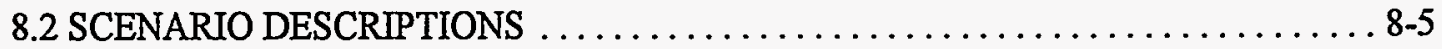

8.3 COMPARISON OF CALCULATED RESULTS $\ldots \ldots \ldots \ldots \ldots \ldots \ldots \ldots \ldots \ldots .6 \ldots \ldots \ldots \ldots \ldots$

8.3.1 Daytona Beach, Florida Scenario . . . . . . . . . . . . . . . . . . 8 6

8.3.2 Fresno, California, Scenario . . . . . . . . . . . . . . . . . . . . . 8-7

8.4 CONCLUSIONS . . . . . . . . . . . . . . . . . . . . . . . . . . . . . 8.8

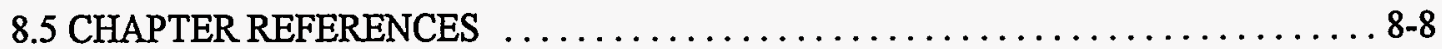

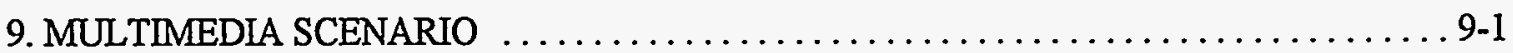

9.1 FACILITY AND SOURCE DESCRIPTION . . . . . . . . . . . . . . . . 9.1

9.1.1 Landfill Characteristics ................................ 9-2

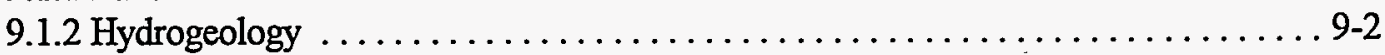

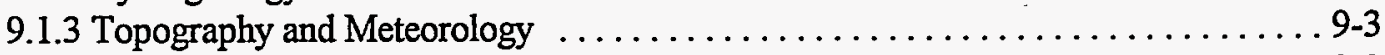

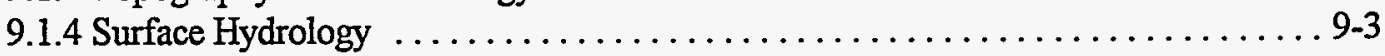

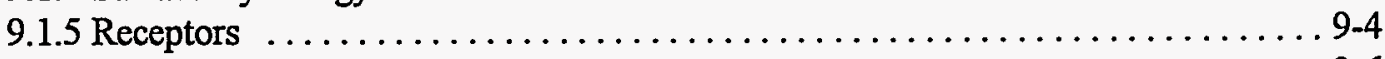

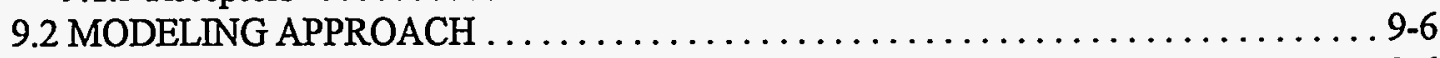

9.2.1 Conceptual Site Model ............................ 9.6

9.2.2 Representation of the Scenario in Multimedia Models .............. 9-11 
9.3 BENCHMARKING RESULTS AND DISCUSSION FOR RESRAD, MMSOILS, AND

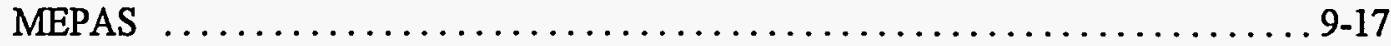

9.3.1 Unsaturated and Saturated Zone Pathway $\ldots \ldots \ldots \ldots \ldots \ldots \ldots \ldots \ldots .9 .17$

9.3.2 Atmospheric Pathway $\ldots \ldots \ldots \ldots \ldots \ldots \ldots \ldots \ldots \ldots \ldots \ldots \ldots \ldots \ldots, 9.28$

9.3.3 Surface Water Pathway ........................... 9-37

9.3.4 Total Risks to Multimedia Receptors ......................... 9-38

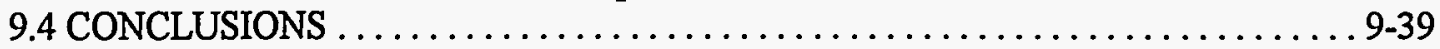

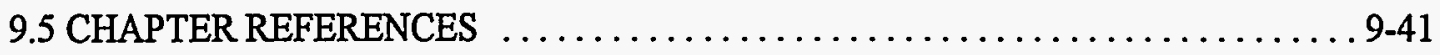

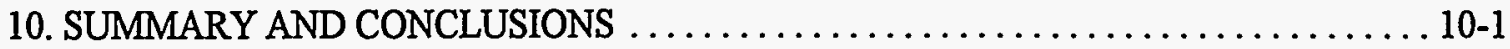

10.1 SCENARIO-SPECIFIC SUMMARY AND CONCLUSIONS $\ldots \ldots \ldots \ldots \ldots \ldots 10-1$

10.1.1 Direct Biosphere Exposure Summary and Conclusions . . . . . . . . . . . . 10-1

10.1.2 Direct Air Release Summary and Conclusions ................... 10-2

10.1.3 Direct Release to the Vadose Zone Summary and Conclusions .......... 10-3

10.1.4 Direct Release to the Saturated Zone Summary and Conclusions . . . . . . . . . . 10-4

10.1.5 Direct Release to Surface Water Summary and Conclusions . . . . . . . . . . 10-6

10.1.6 Surface Water Hydrology Summary and Conclusions . . . . . . . . . . . . . 10-7

10.1.7 Multimedia Scenario Summary and Conclusions . . . . . . . . . . . . 10-8

APPENDIX A: Step-by-Step Analysis of the Multimedia Models $\ldots \ldots \ldots \ldots \ldots \ldots \ldots$ A-1

APPENDIX B: Additional Model Information $\ldots \ldots \ldots \ldots \ldots \ldots \ldots \ldots \ldots \ldots \ldots \ldots$, B-1

APPENDIX C: Parameters and Units Associated with Chapters 5, 6, and $9 \ldots \ldots \ldots \ldots \ldots$ C-1 


\section{TABLES}

1.1 Summary of Benchmarking Scenarios and Model Comparison Endpoints . . . . . . . . . 1-7

2.1 Summary comparison of multimedia model capabilities $\ldots \ldots \ldots \ldots \ldots \ldots \ldots .6 \ldots$

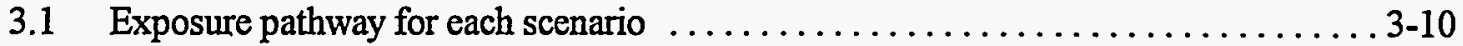

3.2 Concentration of contaminants in initially contaminated medium $\ldots \ldots \ldots \ldots \ldots . . .11$

3.3 Contaminant dependent risk and transfer factors . . . . . . . . . . . . . . . . . 3-11

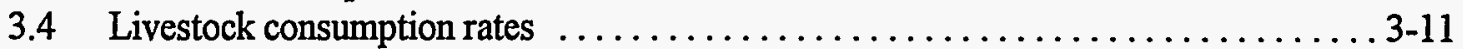

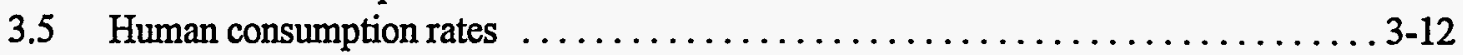

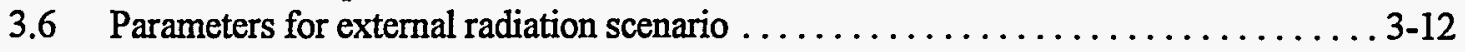

3.7 Risk from direct biosphere exposure to carbon tetrachloride $\ldots \ldots \ldots \ldots \ldots \ldots . . \ldots$ 3-13

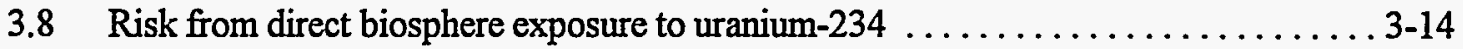

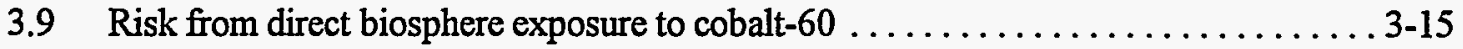

3.10 Parameters not specified in the description of scenario $\mathrm{S} 1 \ldots \ldots \ldots \ldots \ldots \ldots .15$

3.11 Parameters not specified in the description of scenario W1 ............... 3-16

3.12 Parameters not specified in the description of scenario W2 $\ldots \ldots \ldots \ldots \ldots \ldots .16$

3.13 Parameters not specified in the description of scenario W6 .............. 3-17

3.14 Parameters not specified in the description of scenario W7 $\ldots \ldots \ldots \ldots \ldots \ldots . . .18$

3.15 Parameters not specified in the description of scenario $W 9 \ldots \ldots \ldots \ldots \ldots .18$

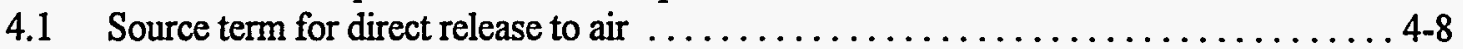

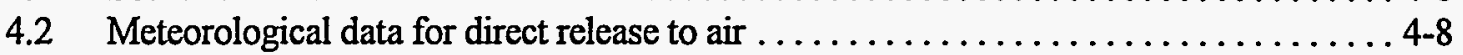

4.3 Wind speed group midpoints for direct release to air $\ldots \ldots \ldots \ldots \ldots \ldots \ldots \ldots \ldots$ 4-8

4.4 Calm events per wind stability class for direct release to air $\ldots \ldots \ldots \ldots \ldots \ldots \ldots .4$

4.5 Joint frequency data for direct release to air . . . . . . . . . . . . . . . . . 4-9

4.6 Computed thorium air concentrations for the direct air release scenario . . . . . . . 4-10

4.7 Direct air release: computed thorium soil concentrations at 1000-m downwind . . . . 4-10

5.1 Characteristics of the source, vadose zones \#1 and \#2, and chemical properties . . . 5-16

5.2 Moisture content employed in RESRAD, MMSOILS, and MEPAS . . . . . . . . 5-17

5.3 Pore-water and contaminant velocities, and retardation factors employed in RESRAD, MMSOILS, and MEPAS ........................... 5-18

5.4 Dispersion coefficients employed in MMSOILS and MEPAS . . . . . . . . . . . . . 5-19

5.5 Contaminant plug-flow travel times indicative of RESRAD, MMSOILS,

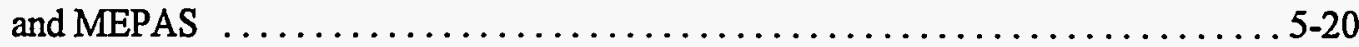

5.6 Ratio of uranium-238 plug-flow travel times and ratio of actual times to peak for RESRAD, MMSOILS, and MEPAS ............................ 5-21

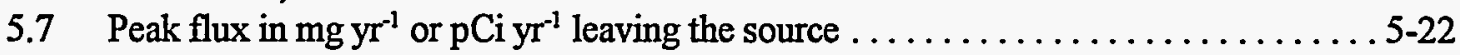

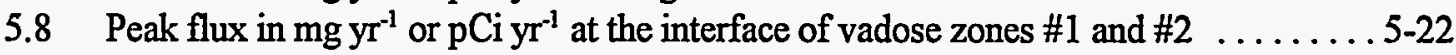

5.9 Peak flux in $\mathrm{mg} \mathrm{yr}^{-1}$ or ${\mathrm{pCi} \mathrm{yr}^{-1} \text { at the water-table surface } \ldots \ldots \ldots \ldots \ldots \ldots \ldots \ldots \ldots \ldots \ldots}^{2}-22$

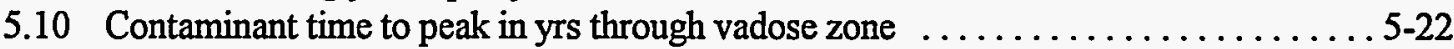

5.11 Contaminant time-to-peak in yrs at the water-table surface $\ldots \ldots \ldots \ldots \ldots \ldots \ldots$ 5-22

6.1 Site parameters for direct release to the saturated zone $\ldots \ldots \ldots \ldots \ldots \ldots \ldots 6-13$

6.2 Dispersivities for direct release to the saturated zone $(\alpha) \ldots \ldots \ldots \ldots \ldots \ldots 6-13$

6.3 Contaminant specific information for direct discharge to the saturated zone ......6-13

6.4 Peak concentration and time-to-peak at the $0-\mathrm{m}$ receptor for direct release

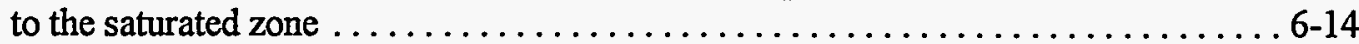

6.5 Peak concentration and time to peak at the $150-\mathrm{m}$ receptor for direct release to the saturated zone $\ldots \ldots \ldots \ldots \ldots \ldots \ldots \ldots \ldots \ldots \ldots \ldots \ldots \ldots \ldots .14$ 
6.6 Peak concentration and time to peak at the $1500-\mathrm{m}$ receptor for direct release

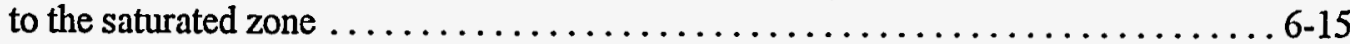

7.1 Input parameter assumptions for direct release to surface water $\ldots \ldots \ldots \ldots \ldots \ldots 7-5$

7.2 Summary of peak concentrations and times to peak concentration for direct discharge to surface water for active operational releases $\ldots \ldots \ldots \ldots \ldots \ldots \ldots \ldots \ldots .7 . \ldots \ldots$

8.1 Surface hydrology data: Daytona Beach, Florida . . . . . . . . . . . . . 8-10

8.2 Surface hydrology data: Fresno, California .................... 8-11

8.3 Annual average estimates of hydrological parameters : Daytona Beach, Florida, Scenario .................................. 8-12

8.4 Annual average estimates of hydrological parameters : Fresno,

California, Scenario ................................... 8-13

9.1 Characteristics of the landfill ............................. 9-44

9.2a Characteristics of contaminants at the site $\ldots \ldots \ldots \ldots \ldots \ldots \ldots \ldots \ldots . . \ldots \ldots .44$

$9.2 \mathrm{~b}$ Soil-water distribution coefficients $\left(K_{d}\right.$ Values $\left.{ }^{1}\right)$ for decay products

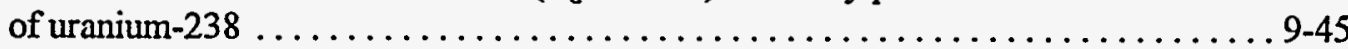

9.3 Characteristics of vadose zone soils at the facility ................... $9-45$

9.4 Characteristics of saturated zone soils and the aquifer at the facility .......... 9-46

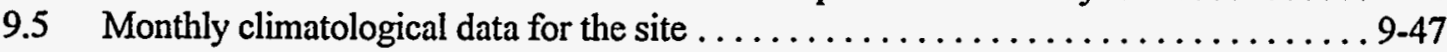

9.6 Joint frequency wind speed data for the facility $\ldots \ldots \ldots \ldots \ldots \ldots \ldots \ldots \ldots . .46$

9.7 Characteristics of river downgradient of the source $\ldots \ldots \ldots \ldots \ldots \ldots \ldots . \ldots 92$

9.8 Exposure and intake parameters for the multimedia modeling scenario ........ 9-53

9.9a Contaminant-dependent transfer, dose conversion, and slope factors used by RESRAD and MMSOILS .................................... 9-55

9.9b Contaminant-dependent transfer, dose conversion, and slope factors used by MEPAS and MMSOILS ..................................... 966

9.10 Summary of tables and figures that contain benchmarking results $\ldots \ldots \ldots \ldots \ldots 9-57$

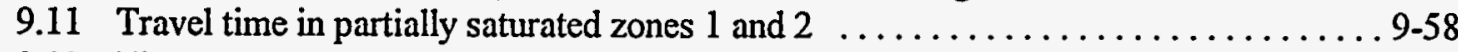

9.12 Time to peak concentration at onsite and offsite wells $\ldots \ldots \ldots \ldots \ldots \ldots \ldots$ 9-58

9.13 Maximum chemical concentrations in groundwater at onsite and offsite wells ..... 9-59

9.14 Maximum dose and risk to onsite and offsite receptors-groundwater pathway . . . . 9-60

9.15 Comparison of MEPAS and RESRAD surface erosion rates ............... 9-61

9.16 Maximum air concentration, maximum chi $\mathrm{q}^{-1}$, and maximum deposition rates at the maximum offsite exposure point: 810 m northeast of the center of the source . . . . 9-62

9.17 Maximum dose and risk to the receptor located at the facility boundary, $366 \mathrm{~m}$ to the north

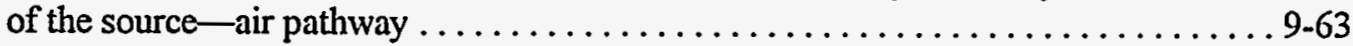

9.18 Maximum dose and risk at the maximum offsite exposure point, located $810 \mathrm{~m}$ to the northeast of the source-air pathway $\ldots \ldots \ldots \ldots \ldots \ldots \ldots \ldots \ldots \ldots .6 .64$

9.19 Maximum surface water concentration, dose, and risk to surface water receptor . . . 9 9-65

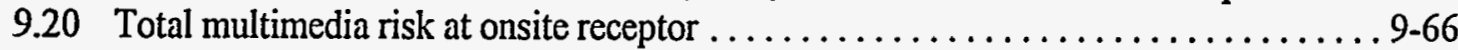

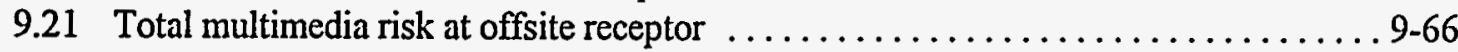




\section{FIGURES}

4.1 Illustration of Direct Air Release Scenario ....................... 4-5

4.2 Computed Air Concentrations as a Function of Distance for RESRAD/CAP88, MMSOILS, and MEPAS . . . . . . . . . . . . . . . . . .

4.3 Computed Time-Varying Soil Concentrations at $1.0 \mathrm{~km}$ from the Release Point for RESRAD/CAP88, MMSOILS, and MEPAS . . . . . . . . . . 4-7

5.1 Schematic Illustrating the Direct Discharge to the Vadose Zone Problem . . . . . . . 5-23

5.2 Source-Term Time-Varying Fluxes of Methylene Chloride Entering Vadose Zone \#1 for RESRAD, MMSOILS, and MEPAS .............. 5-24

5.3 Source-Term Time-Varying Fluxes of Uranium-238 Entering Vadose Zone \#1 for RESRAD, MMSOILS, and MEPAS ................... 5-25

5.4 Time-Varying Fluxes of Methylene Chloride Exiting Vadose Zone \#1 for RESRAD, MMSOILS, and MEPAS .......................... $5-26$

5.5 Time-Varying Fluxes of Uranium-238 Exiting Vadose Zone \#1 for RESRAD, MMSOILS, and MEPAS . .......................... 5-27

5.6 Time-Varying Fluxes of Methylene Chloride Exiting Vadose Zone \#2 at the Water-Table Surface for RESRAD, MMSOILS, and MEPAS

5.7 Time-Varying Fluxes of Uranium-238 Exiting Vadose Zone \#2 at the Water-Table Surface for RESRAD, MMSOILS, and MEPAS

6.1 Schematic Diagram Illustrating Direct Release to the Saturated Zone ............ 6-16

6.2 Simplified Schematic Diagram Illustrating the Offsite Conceptual Model utilized by RESRAD for Direct Release to the Saturated Zone ............. 6-17

6.3 Simplified Schematic Diagram Illustrating the,Offsite Conceptual Model utilized by MMSOILS for Direct Release to the Saturated Zone ............. 6-18

6.4 Source-Term Time-Varying Fluxes of Nitrate Entering the Saturated Zone for RESRAD, MMSOILS, and MEPAS ................... 6-19

6.5 Source-Term Time-Varying Fluxes of Uranium-234 Entering the Saturated Zone for RESRAD, MMSOILS, and MEPAS $\ldots \ldots \ldots \ldots \ldots \ldots \ldots \ldots \ldots .6 .20$

6.6 Source-Term Time-Varying Fluxes of Thorium-230 Entering the Saturated Zone

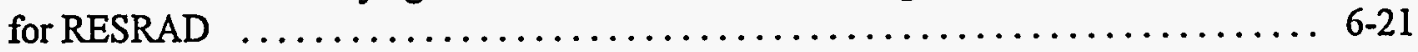

6.7 Source-Term Time-Varying Fluxes of Radium-226 Entering the Saturated Zone

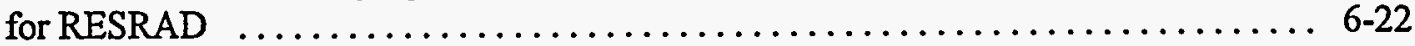

6.8 Source-Term Time-Varying Fluxes of Lead-210 Entering the Saturated Zone

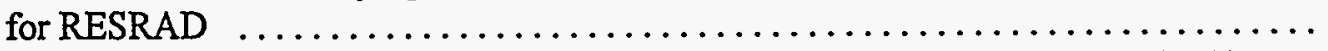

6.9 Time-Varying Concentrations of Nitrate at the Edge of the Waste Site for RESRAD, MMSOILS, and MEPAS

6.10 Time-Varying Concentrations of Uranium-234 at the Edge of the Waste Site for RESRAD, MMSOILS, and MEPAS ..................... $6-25$

6.11 Time-Varying Concentrations of Thorium-230 at the Edge of the Waste Site for

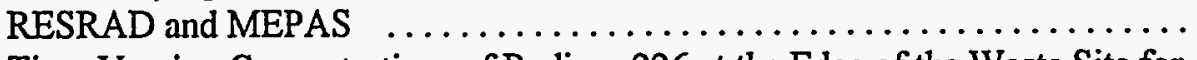

6.12 Time-Varying Concentrations of Radium-226 at the Edge of the Waste Site for

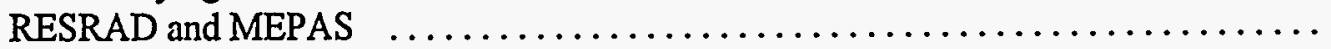

6.13 Time-Varying Concentrations of Lead-210 at the Edge of the Waste Site for

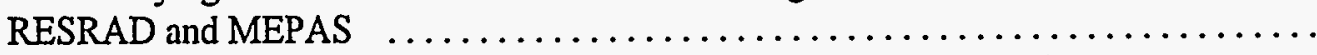

6.14 Time-Varying Concentrations of Nitrate at the 150-m Receptor Location for RESRAD, MMSOILS, and MEPAS 
6.15 Time-Varying Concentrations of Uranium-234 at the 150-m Receptor Location for RESRAD, MMSOILS, and MEPAS . .................. $6-30$

6.16 Time-Varying Concentrations of Thorium-230 at the $150-\mathrm{m}$ Receptor Location for RESRAD and MEPAS ............................ $6-31$

6.17 Time-Varying Concentrations of Radium-226 at the 150-m Receptor Location for RESRAD and MEPAS ............................... $6-32$

6.18 Time-Varying Concentrations of Lead-210 at the $150-\mathrm{m}$ Receptor Location for RESRAD and MEPAS .............................. $6-33$

619 Time-Varying Concentrations of Nitrate at the 1500-m Receptor Location for RESRAD, MMSOILS, and MEPAS ...................... 6-34

6.20 Time-Varying Concentrations of Uranium-234 at the $1500-\mathrm{m}$ Receptor Location for RESRAD, MMSOILS, and MEPAS ....................... 6-35

6.21 Time-Varying Concentrations of Thorium-230 at the 1500-m Receptor Location for RESRAD and MEPAS ................................ 6-36

6.22 Time-Varying Concentrations of Radium-226 at the 1500-m Receptor Location for RESRAD and MEPAS .............................. $6-37$

6.23 Time-Varying Concentrations of Lead-210 at the $1500-\mathrm{m}$ Location for RESRAD

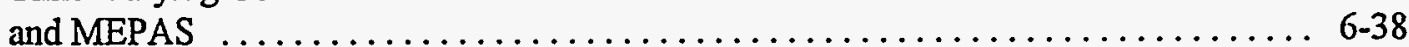

7.1 Schematic Illustrating the Direct Discharge to Surface Water Problem ........... 7-6

7.2 Schematic Illustrating the Conceptual Site Model utilized by MMSOILS for Direct

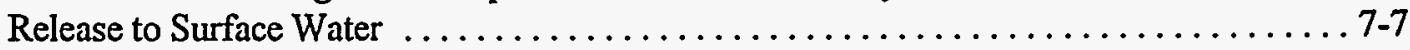

7.3 Time-Varying Fluxes of Ethylene Glycol at the River's Edge for the Operational Release Scenario ................................. 7-8

7.4 Time-Varying Fluxes of Thorium-228 at the River's Edge for the Operational Release Scenario ..................................... 7

7.5 Time-Varying Fluxes of Tritium at the River's Edge for the Operational Release Scenario ................................... 7-10

7.6 Time-Varying Concentrations of Ethylene Glycol at Spatially Near- and Far-Field Receptors for the Operational Release Scenario .................... 7-11

7.7 Time-Varying Concentrations of Thorium-228 at Spatially Near- and Far-Field Receptors for the Operational Release Scenario .................. 7-12

7.8 Time-Varying Concentrations of Tritium at Spatially Near- and Far-Field Receptors for the Operational Release Scenario .................... 7-13

8.1 Monthly PET Values for Daytona Beach, Florida for MMSOILS and MEPAS ...... 8-14

8.2 Monthly AET Values for Daytona Beach, Florida for MMSOILS and MEPAS ..... 8-15

8.3 Monthly Infiltration Values for Daytona Beach, Florida for MMSOILS and MEPAS . 8 8-16

8.4 Monthly PET Values for Fresno, California for MMSOILS and MEPAS . . . . . . . 8-17

8.5 Monthly AET for Fresno, California for MMSOILS and MEPAS . . . . . . . . 8-18

8.6 Monthly Infiltration for Fresno, California for MMSOILS and MEPAS . . . . . . . . 8-19

9.1 Schematic of the Landfill Source, Soil Strata, and Locations of Wells and River ..... 9-67

9.2 Locations of Groundwater Receptor at Site Boundary and Offsite ............ 9-68

9.3 Locations of Air Receptor at site Boundary and Maximally Exposed Individual ..... 9-69

9.4 Location of the Surface Water Receptor ...................... 9-70

9.5 The Natural Radioactive Decay Chain Beginning with Uranium-238 and Ending with Lead -206 ................................... 9-71

9.6 Time-Varying Fluxes of Methylene Chloride from Landfill to PSZ1 for RESRAD, MMSOILS, and MEPAS 
9.7 Time-Varying Fluxes of Uranium-238 from Landfill to PSZl for RESRAD, MMSOILS, and MEPAS ............................. 9-73

9.8 Time-Varying Fluxes of Methylene Chloride from PSZ1 to PSZ2 for RESRAD, MMSOILS, and MEPAS .............................. 9-74

9.9 Time-Varying Fluxes of Methylene Chloride from PSZ2 to SZ for RESRAD, MMSOILS, and MEPAS .............................. 9-75

9.10 Time-Varying Fluxes of Uranium-238 from PSZ1 to PSZ2 for RESRAD, MMSOILS, and MEPAS . ........................ 9-76

9.11 Time-Varying Fluxes of Uranium-238 from PSZ2 to SZ for RESRAD, MMSOILS,

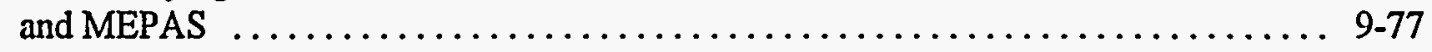

9.12 Time-Varying Fluxes of Uranium-238 at Three Locations in the Unsaturated Zone

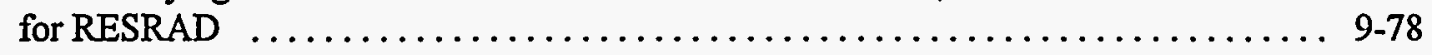

9.13 Time-Varying Fluxes of Throium-230 at Three Locations in the Unsaturated Zone for RESRAD .................................. 9-79

9.14 Time-Varying Fluxes of Radium-226 at Three Locations in the Unsaturated Zone

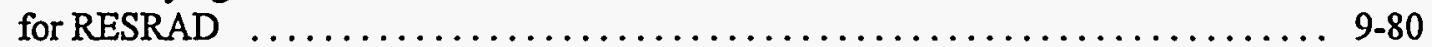

9.15 Time-Varying Fluxes of Lead-210 at Three Locations in the Unsaturated Zone for RESRAD ....................................... 9-81

9.16 Time-Varying Fluxes of Polonium-210 at Three Locations in the Unsaturated Zone

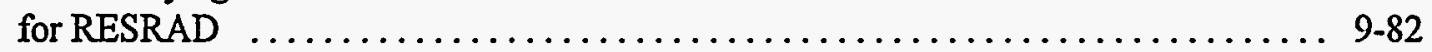

9.17a Time-Varying Concentrations of Methylene Chloride in Groundwater for Onsite Well for RESRAD, MMSOILS and MEPAS $\ldots \ldots \ldots \ldots \ldots \ldots \ldots \ldots . . \ldots .83$

9.17b Time-Varying Concentrations of Methylene Chloride in Groundwater for Offsite Well for RESRAD, MMSOILS and MEPAS ................. 9-84

9.18a Time-Varying Concentrations of Uranium-238 in Groundwater for Onsite Well for RESRAD, MMSOILS and MEPAS $\ldots \ldots \ldots \ldots \ldots \ldots \ldots \ldots \ldots \ldots . \ldots . . \ldots \ldots$

9.18b Time-Varying Concentrations of Uranium-238 in Groundwater for Offsite Well

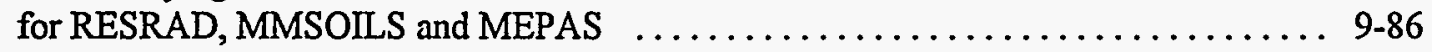

9.19 Time-Varying Concentrations of Thorium-234 for Onsite and Offsite Wells

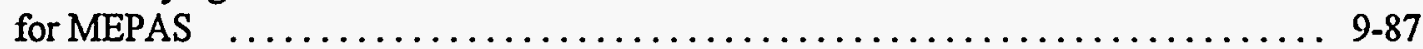

9.20a Time-Varying Concentrations of Uranium-234 in Groundwater for Onsite Well

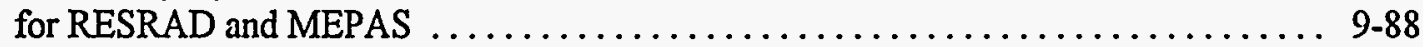

9.20b Time-Varying Concentrations of Uranium-234 in Groundwater for Offsite Well for RESRAD and MEPAS .............................. 9-89

9.21a Time-Varying Concentrations of Thorium-230 in Groundwater for Onsite Well

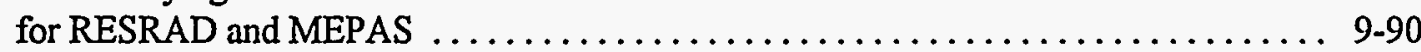

9.21b Time-Varying Concentrations of Thorium-230 in Groundwater for Offsite Well

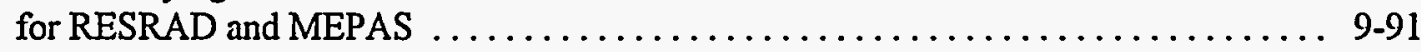

9.22a Time-Varying Concentrations of Radium-226 in Groundwater for Onsite Well for RESRAD and MEPAS . . . . . . . . . . . 9.92

9.22b Time-Varying Concentrations of Radium-226 in Groundwater for Offsite Well for RESRAD and MEPAS . . . . . . . . . . . . . . . . . . . . . . $9-93$

9.23 Time-Varying Concentrations of Radon-222 for Onsite and Offsite Wells for MEPAS . 9-94

9.24a Time-Varying Concentrations of Lead-210 in Groundwater for Onsite Well for RESRAD and MEPAS ............................. 9-95

9.24b Time-Varying Concentrations of Lead-210 in Groundwater for Offsite Well for RESRAD and MEPAS . . . . . . . . . . . . .

9.25 Time-Varying Concentrations of Bismuth-210 for Onsite and Offsite Well for MEPAS 9-97

9.26a Time-Varying Concentrations of Polonium-210 in Groundwater for Onsite Well for RESRAD and MEPAS 
9.26b Time-Varying Concentrations of Polonium-210 in Groundwater for Offsite Wells for RESRAD and MEPAS . .......................... 9-99

9.27a Time-Varying Concentrations of Uranium-238 and Thorium-234

Based on an Initial Uranium-238 Concentration of $1 \mathrm{pCi} \mathrm{L}^{-1} \ldots \ldots \ldots \ldots \ldots . . .69$

9.27b Time-Varying Concentrations of Uranium-234 and Thorium-230

Based on an Initial Uranium-238 Concentration of $1 \mathrm{pCi} \mathrm{L}^{-1} \ldots \ldots \ldots \ldots \ldots$ 9-101

9.27c Time-Varying Concentrations of Radium-226 and Radon-222

Based on an Initial Uranium-238 Concentration of $1 \mathrm{pCi} \mathrm{L}^{-1} \ldots \ldots \ldots \ldots \ldots$. $6-102$

9.27d Time-Varying Concentrations of Lead-210, Bismuth-210, and Polonium-210

Based on an Initial Uranium-238 Concentration of $1 \mathrm{pCi} \mathrm{L}^{-1} \ldots \ldots \ldots \ldots \ldots \ldots$ 9-103

9.27e Time-Varying Concentrations of Lead-206 Based on an Initial Uranium-238

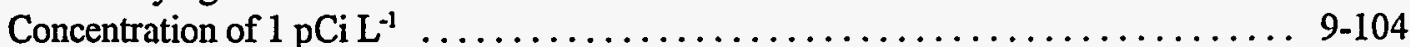

9.28 Time-Varying Emission Rate to Atmosphere for Methylene Chloride for RESRAD, MMSOILS, and MEPAS .................................. 9-105

9.29 Time-Varying Air Emission Rate for Uranium-238 for RESRAD and MEPAS ..... 9-106

9.30 Time-Varying Air Concentrations of Methylene Chloride at Maximum Offsite Exposure Point for RESRAD, MMSOILS, and MEPAS ............... 9-107

9.31 Time-Varying Fluxes of Methylene Chloride from SZ to SW for RESRAD, MMSOILS, and MEPAS ............................. 9-108

9.32 Time-Varying Fluxes of Uranium-238 from SZ to SW for RESRAD, MMSOILS, and MEPAS 


\section{ACRONYMS}

$\begin{array}{ll}\text { AEA } & \text { Atomic Energy Act } \\ \text { AET } & \text { actual evapotranspiration } \\ \text { CERCLA } & \text { Comprehensive Environmental Response, Compensation, and Liability Act } \\ \text { EPA } & \text { United States Environmental Protection Agency } \\ \text { DOE } & \text { United States Department of Energy } \\ \text { MEI } & \text { maximally exposed individual } \\ \text { MEPAS } & \text { Multimedia Environmental Pollutant Assessment System } \\ \text { NEPA } & \text { National Environmental Policy Act } \\ \text { PET } & \text { potential evapotranspiration } \\ \text { RCRA } & \text { Resource Conservation and Recovery Act } \\ \text { RESRAD } & \text { RESidual RADioactivity }\end{array}$




\section{EXECUTIVE SUMMARY}

As a result of historic nuclear weapons production programs, the United States Department of Energy (DOE) has produced radioactive and hazardous waste at sites spanning the DOE Complex. Surrounding populations, by virtue of their proximity to the contaminated sites, may become exposed to chemical and/or radiological contaminants and potentially endure adverse health impacts as a consequence. The United States Environmental Protection Agency (EPA), as tangible evidence of its commitment to ensuring and sustaining human health and ecological system protection, has developed and currently enforces environmental protection laws and regulations. In acknowledgment of the potential health and ecological threats posed by hazardous waste sites, DOE has initiated extensive exposure and risk assessment programs that often use environmental systems simulation modeling to capture the complex nature of the processes involved in contaminant release and transport scenarios.

In October 1990, in response to a directive from the Secretary of Energy, DOE declared its intent to prepare a Programmatic Environmental Impact Statement to examine the integration of DOE's environmental restoration and waste management activities. A joint EPA-DOE benchmarking exercise was originated in December 1993 to compare the multimedia model chosen for use in the Programmatic Environmental Impact Statement (i.e., MEPAS) with other widely used multimedia models. Multimedia models are tools used to simulate the release, transformation, and transport of contaminants in the environment. Modeling of releases to multiple media captures the complex nature of environmental system processes and can be employed to estimate potential exposures and health risks posed by contaminants migrating through atmospheric, groundwater, and surface water pathways.

This comprehensive benchmarking study serves as a basis for comparing and contrasting the constructs and performance characteristics of three prevalent multimedia models: RESRAD, MMSOILS, and MEPAS. The study is performed by individuals who participated directly in the design and development of the models (i.e., Argonne National Laboratory for RESRAD, EPA/Tetra Tech, Inc., for MMSOILS, and Pacific Northwest National Laboratory for MEPAS.)

Model design, formulation, and function are thoroughly examined to engender model familiarity and expand cognizance of some of the innermost workings of the multimedia models. Steps in the benchmarking include formation of datasets, selection of endpoints (e.g., environmental concentrations, doses, risks, etc.), execution of the models, and comparison of outputs from the models. In addition, model assumptions and formulations are analyzed to identify the sources of model output differences. Differences in model endpoint estimates arise from contrasts in the models' technical formulations and performance characteristics as well as from dissimilarities in scenario interpretations and assumptions by the modelers.

Major components of the models (e.g., atmospheric, surface water, groundwater) are evaluated separately and then studied as part of an integrated system for a multimedia release scenario to determine effects due to linking components of the models. Seven modeling scenarios are used to isolate various components of the models. These scenarios include: (1) direct biosphere exposure, (2) direct release to the air, (3) direct release to the vadose zone, (4) direct release to the saturated zone, (5) direct release to surface water, (6) surface water hydrology, and (7) multimedia release. The following sections highlight major conclusions drawn from the analysis of each scenario. 


\section{Direct Biosphere Exposure}

The direct biosphere exposure scenario isolates the exposure/risk components of the three models. Various test cases are used to estimate cancer risk from a single, initially contaminated medium, via a single exposure pathway. The exposure pathways include dermal contact, inhalation of volatiles, ingestion of tainted food (leafy and nonleafy vegetables, meat, milk, water, and fish), incidental ingestion of soil, and external radiation. Carbon tetrachloride and uranium-234 are the contaminants chosen for all but the external radiation scenario which considers uranium-234 and cobalt- 60 .

Differences in model methodologies produce varying results for particular test cases. All test cases produce equivalent endpoint estimates except for those cases involving irrigation, dermal absorption, or external radiation. For scenarios considering irrigation, the codes use different conceptual models for computing the accumulation of contaminants in agricultural soil following irrigation with contaminated water. In addition, while both RESRAD and MEPAS allow a choice between overhead and ditch irrigation systems, MMSOILS considers only ditch irrigation. In considering dermal absorption from water, differences in the utilization of absorption rates causes contrasts in endpoint estimates. MMSOILS uses an equilibrium absorption rate, while RESRAD and MEPAS use higher absorption rates during the initial transient state before equilibrium is reached thereby estimating higher risk estimates than does MMSOILS. For scenarios involving external radiation, RESRAD is capable of considering the finite thickness of the source and shielding effects produced by uncontaminated cover material, whereas MEPAS does not adjust for these effects.

Another example of model technical formulation differences is the manner in which high chemical intake conditions are managed. MMSOILS and MEPAS assume an exponential exposure-risk relationship that limits to unity the cancer risk produced by high chemical intake conditions, while RESRAD uses a linear exposure-risk relationship that does not cap cancer risk estimates.

\section{Direct Release to Air}

The direct release to air scenario entails steady state emissions from an area source for a singular set of ambient conditions. The comparison endpoints include resultant contaminant air concentrations and soil concentrations (due to plume deposition) estimated at locations downwind of the release area.

No major differences exist in the technical formulation of the three models' atmospheric components; therefore, contrasts in air concentration predictions are small. However, MMSOILS does use a virtual distance correction to account for the size of the source that produces lower air concentration estimates at close distances. Soil deposition concentration estimates are approximately the same but do not agree as closely as the air concentrations estimates among the three models.

\section{Direct Release to the Vadose Zone}

The direct release to the vadose (unsaturated) zone scenario simulates the leaching of methylene chloride and uranium-238 from an unlined landfill to a vadose zone with two homogeneous layers. The endpoints for this study include contaminant fluxes from the source to the first vadose zone layer, fluxes at the interface of the two layers, fluxes at the water-table surface, peak fluxes, and times to peak.

Mathematical construct variations among the models contribute to differences in endpoint estimates. For example, the models under examination differ in the manner in which they simulate the transport of contaminants through the vadose zone. RESRAD simulates contaminant transport through pure translation (i.e., advection) and allows parent and daughter nuclides to travel at different velocities. 
MMSOILS and MEPAS use similar one-dimensional advective-dispersive algorithms in which MEPAS assumes that parent and daughter nuclides travel at the same speed, while MMSOILS does not consider daughter nuclides. MMSOILS and MEPAS predict potentially lower contaminant concentrations as compared to models which include the impacts from advection only and exclude the effects of dispersion.

Variations in source term releases (i.e., exponential or constant-pulse) produce differences in the transport results for the models depending on the nature of the release. RESRAD assumes that contaminant leaching is linearly proportional to the source inventory and takes the form of a decreasing exponential function. MMSOILS allows the user to construct the desired leaching pattern through manipulating source-term input parameters, and MEPAS provides the user with the option of choosing the form of release (e.g., steady-state, exponential, log-normal, etc.) or accepting the constant-pulse (i.e., step function) release scenario.

Differences also exist in the models' methods for computing moisture content, dispersion coefficients, and travel times. Due to the different mathematical constructs for calculating moisture content, RESRAD ordinarily predicts shorter travel times and higher concentrations than MMSOILS and MEPAS, MEPAS predicts slightly longer times to peak when compared to MMSOILS (except at the interface of the two vadose zones where the times to peak are comparable), and MEPAS predicts the longest travel time followed by MMSOILS and RESRAD.

\section{Direct Release to the Saturated Zone}

The direct release to the saturated zone (i.e., groundwater) scenario involves the release of nitrate and uranium-234 from an unlined landfill into a homogeneous, isotropic aquifer. The endpoints for this scenario include contaminant fluxes from the source to the saturated zone, contaminant concentrations at three receptor locations, peak concentrations, and times to peak concentrations.

Contrasting technical formulations in the models contribute to differences in endpoint estimates. For this scenario, variations in source term releases (i.e., exponential or constant-pulse) produce differences in the transport results for the models depending on the nature of the release. RESRAD assumes that contaminant leaching is linearly proportional to the source inventory and takes the form of a decreasing exponential function. MMSOILS allows the user to construct the desired leaching pattern through manipulating source-term input parameters, and MEPAS provides the user with the option of choosing the form of release (e.g., steady-state, exponential, log-normal, etc.) or accepting the constantpulse (i.e., step function) release scenario.

In addition, RESRAD simulates contaminant transport in the saturated zone through pure translation (i.e., advection) and simulates radionuclide decay during transit allowing parent and daughter nuclides to travel at different velocities. MMSOILS and MEPAS use similar one-dimensional advective,

three-dimensional dispersive algorithms in which MEPAS assumes that ingrowth and decay occur at the end of the journey with parent and daughter nuclides traveling at the same speed, while MMSOILS does not consider daughter nuclides.

RESRAD assumes that a pumping well withdraws contaminated water from the aquifer. To approximate the effects of dilution from pumping, RESRAD employs a dilution factor. The aquifer concentrations computed by MMSOILS and MEPAS are unaffected by a pumping well; therefore, the pumping rate used in a RESRAD simulation can significantly lower the aquifer concentration as compared to those predicted by MMSOILS or MEPAS. 
MEPAS simulates three-dimensional dispersion. As the contamination enters the aquifer, advection moves the contaminants downgradient before they have an opportunity to become fully mixed beneath the waste site (i.e., zero distance from the edge of the waste site). The benchmarking problem suggested using fully mixed conditions beneath the waste site. MMSOILS provides an option to simulate fully mixed conditions over the aquifer depth, and RESRAD simulates fully mixed conditions within a strip of the aquifer. Because the contamination has not reached fully mixed conditions beneath the waste site, MEPAS predicts higher centerline maximum concentrations than does RESRAD or MMSOILS. At farther distances from the source, MMSOILS and MEPAS assume fully mixed conditions over the aquifer depth. Both MMSOILS and MEPAS incorporate the effects of longitudinal dispersion that tend to lower the estimated contaminant concentrations in comparison to RESRAD's predictions.

\section{Direct Release to Surface Water}

The direct release to surface water scenario involves the discharge of ethylene glycol, thorium-228, and tritium from a pipe on a riverbank into a small steady-state river. The endpoints for this scenario include contaminant fluxes into the river, contaminant fluxes at a near-field location, and contaminant fluxes at a far-field location.

RESRAD does not include a river model; therefore, variations in the constructs of MMSOILS and MEPAS are evaluated for this scenario. For surface water (e.g., river) releases, MMSOILS assumes that instantaneous mixing occurs completely across a river when the contaminants are released into the water. MEPAS, however, does not assume instantaneous, uniform mixing of contaminants but assumes that contaminants disperse laterally as they move downstream until fully mixed conditions occur, thereby producing near-field estimates of contaminant concentrations in the river that are higher than those predicted by MMSOILS. The far-field concentrations predicted by both models agree closely since full mixing conditions are assumed at downstream locations.

\section{Surface Water Hydrology}

The surface water hydrology scenario compares the manner in which the models simulate water balance at the soil surface and in the upper layer of soil (i.e., root zone). Surface water balance is examined under two conditions: (1) high rainfall/high permeability and (2) low rainfall/high permeability. Endpoints for this scenario include average annual and average monthly potential evapotranspiration, actual evapotranspiration, runoff, and infiltration. Since only MMSOILS and MEPAS include algorithms for estimating infiltration and runoff, RESRAD is excluded from this analysis.

Both MMSOILS and MEPAS employ similar methods for simulating water balance at the soil surface providing similar estimates of potential evapotranspiration, actual evapotranspiration, runoff, and infiltration on both a monthly and annual basis. MMSOILS and MEPAS do use different techniques for computing monthly soil moisture storage fluctuations; however, the model outputs are not significantly impacted by this difference in model formulations.

Another contrast in model function may be encountered when studying regions with colder climates (i.e., sub-zero temperatures). MEPAS is capable of differentiating between snowfall and rainfall, while MMSOILS is not. Runoff and infiltration may be significantly impacted by this difference in model capability. In addition, the techniques used by the two models for estimating potential evapotranspiration are different. MEPAS uses three techniques and selects the lowest value for further application, while MMSOILS uses the Thornwaite method, if site-specific pan evaporation data are not available. The Thornwaite method may not produce reasonable estimates for some regions. 


\section{Multimedia Scenario}

The multimedia scenario involves the analysis of a release of contaminants from a landfill at a hazardous waste facility. The contaminants released from the landfill include methylene chloride, uranium-238, and associated daughter products of uranium-238. The landfill waste layer is covered by a clean overburden. The partially saturated zone (PZ) located below the landfill is composed of a silty clay loam layer (PZ1) and a sandy clay layer (PZ2). The PZ2 overlies an isotropic aquifer. A stream located $2000 \mathrm{~m}$ downgradient of the landfill partially intercepts the aquifer. Contaminant transport through the atmospheric, groundwater, and surface water pathways is simulated, and exposure and health impacts via multiple exposure routes are determined.

The groundwater pathway includes exposure via ingestion of drinking water extracted from the wells, ingestion of leafy and root vegetables irrigated with well water, and ingestion of meat and milk from livestock that drink well water. For the atmospheric pathway, the following exposure routes apply: inhalation of ambient air, ingestion of leafy and root vegetables contaminated by deposition, ingestion of meat and milk from livestock that ingest contaminated soil and fodder, dermal contact with contaminated soil, and external gamma radiation. The surface water pathway includes two exposure routes: ingestion of fish and dermal contact with contaminated water while swimming.

Differences in these model characteristics contribute to differences found in the endpoint estimates. The following conclusions are the results of the multimedia benchmarking scenario:

- $\quad$ RESRAD, MMSOILS, and MEPAS couple predicted volatile and aqueous phase emissions from the landfill so that the total mass emitted equals the initial inventory.

- $\quad$ Predictions of total methylene chloride mass that volatilizes differs by a factor of 10 among models. This occurs because MEPAS uses a different volatilization algorithm than the other models and because all three models use different soil water contents; however, a specific investigation of the differences between the algorithms is not considered.

- MMSOILS- and MEPAS- predicted advective travel times and times-to-peak concentrations are generally comparable through the unsaturated and saturated zones and through the river, and RESRAD's predictions of advective travel times are typically $25 \%$ of the predicted by the other two models.

- For the saturated zone, MMSOILS considers dissolved phase decay only, not absorbed phase decay, and contaminants that decay in both phases may have overestimated concentrations at significant distances from the source.

- The highest predicted risks occur from groundwater exposure to methylene chloride mainly through drinking water ingestion. RESRAD predicts the highest onsite risk $\left(2.5 \times 10^{-3}\right)$ followed by MEPAS $\left(4.9 \times 10^{-4}\right)$ and MMSOILS $\left(1.3 \times 10^{-4}\right)$. The RESRAD results are based on a peak concentration that is much greater than the concentration that is sustained over 70 yrs. Although MMSOILS uses a peak concentration, the peak concentration is similar to the 70-yr average concentration because of dispersion. Only MEPAS actually calculates the 70-yr average concentration for use in risk calculations.

- Predicted concentrations in the river are much less than those in the groundwater due to the dilutional effect of the river, so the predicted risks due to exposure to river water are small. 
- The RESRAD-predicted risk from onsite air exposure to methylene chloride is $2.1 \times 10^{-6}$. Both MMSOILS and MEPAS predict risks of less than $7.1 \times 10^{-8}$. This difference occurs primarily because RESRAD uses a peak methylene chloride concentration to predict risks whereas the other models use 70-yr-average concentrations to predict risks.

- For atmospheric transport of uranium-238, equivalent risks are produced by RESRAD and MEPAS when similar surface soil conditions are assumed. However, the matching of total soil surface erosion rates in the RESRAD and MEPAS runs resulted in an order of magnitude difference in air-pathway risks. Although both RESRAD and MEPAS consider surface runoff processes, in this multimedia scenario RESRAD sends most of the surface material to surface runoff, and MEPAS removes all the material to soil suspension.

xxiv 


\section{RECOMMENDATIONS}

One of the primary motivating factors in pursuing this work is the belief that the next step in the evolution of multimedia models is to develop a consensus understanding of the current state-of-the-science and state-of-the-practice of multimedia modeling. With this consensus understanding, the community of multimedia modelers can move the state-of-the-science and -practice forward in a logical, coordinated, and efficient manner. As a result of having conducted this study, the authors propose the following specific activities for pursuing the goals of consensus and future development.

1. Organize and package, in digital form, the data and model executables used in this study and make them available to interested modelers.

2. Design and execute a second and third phase of this benchmarking study. The activities included in the second phase are the following:

\section{Second Phase}

a. Expand the field of models included in this study. Criteria for selecting additional multimedia models should include (1) models used by other agencies (e.g., DOD, NRC) for similar purposes and (2) models that contain capabilities not found in RESRAD, MMSOILS, and MEPAS.

b. Design additional multimedia scenarios. The scenarios should address variations, either individually or collectively, in climate and meteorology, sources of contamination, and transport media characteristics.

c. Design a scenario to compare the models' capabilities to perform uncertainty analyses (e.g., Monte Carlo simulation).

d. Design a scenario to focus on how the multimedia models maintain mass balance, primarily from the perspective of mass fluxes from the contaminant source to the multiple media.

\section{Third Phase}

Design and execute a study to benchmark the models with real data at real sites. The models first would be calibrated to site conditions with a detailed comparison of both the "goodness of fit" and the parameter values used in the models to develop the calibration. Subsequently, the models would be applied to a second set of site data for the purpose of conducting model validation. This effort would provide valuable insights to the implementation character of the models and their individual and collective limitations with respect to applications.

3. Develop standard scenarios, input data files, and comparative end points for benchmarking multimedia models.

4. Design a benchmarking study to compare the analytical-based multimedia models with numerical models that address the heterogeneous nature of the transport media. Two objectives are related to this recommendation. First, the effort would allow for the development of guidelines for the selection and application of multimedia models for assessing human exposure and risk. Second, the 
results of such a study would be a significant contribution to developing efforts to provide a more complete quantification of the uncertainty involved in analytical-based model applications.

5. Review the capabilities of existing multimedia models and the multimedia problems faced by federal agencies and develop a priority list of features and capabilities that should be added to the models.

6. Publish results in a series of articles in refereed journals to add credibility to the study and disseminate results on a wider basis.

7. Develop an interagency consensus understanding of the current state-of-the-science (i.e., model development) and state-of-the-practice (i.e., model application) regarding multimedia modeling. This will serve as a point of consolidation and mutual agreement from which all multimedia interests can move forward in a logical, coordinated, and efficient manner.

8. Evaluate the pros and cons of a multi-agency effort to consolidate existing multimedia models into a consensus framework (e.g., shared computer modeling system) whose future development would be a collaborative effort. Designed properly the framework could facilitate future benchmarking efforts, allow access to a variety of models, and provide generic capabilities to enhance the application of individual models (e.g., uncertainty analysis shells, data visualization software, access to standard databases).

9. Develop detailed technical guidance related to (1) the process of multimedia-based exposure modeling (i.e., problem definition, modeling objectives development, site characterization, model selection, model preparation/execution, interpretation and presentation of modeling results) and (2) the application of models to specific classes of multimedia-based problems (e.g., site-specific screening/detailed assessment, regional/national ranking). The guidance should be developed with a significant focus on case study examples. 


\section{INTRODUCTION}

The United States Environmental Protection Agency (EPA) is charged with developing, implementing, and enforcing regulations concerned with protecting human and ecological health from the myriad of chemical and nonchemical stressors imposed on the environment as a result of man's activities. The United States Department of Energy (DOE), in response to existing and emerging regulatory requirements for environmental protection, has developed a significant program for assessing exposure and risk at its facilities. In pursuing these activities, DOE and EPA share a common need to understand the environmental processes (physical, biological, and chemical) that collectively release, transform, and transport contaminants resulting in exposure and a probability of deleterious health effects. At both EPA and DOE, computer models are key tools for organizing the knowledge of environmental science for application in the decision-making process.

The need for environmental systems modeling is growing rapidly due to the combination of increasing technical scope and complexity related to questions of risk-based cause and effect and the need to explicitly address cost effectiveness in the development and implementation of environmental regulations. From a technical perspective, the movement is evolving away from media and chemical specificity with respect to regulatory initiatives toward a more holistic multimedia-based assessment and balancing of human and ecological risks. The multimedia approach involves the simultaneous tracking of environmental stress (e.g., hazardous contaminants) from a source through air, water, and soil to locations where human populations or ecological concerns may be exposed. For human endpoints, subsequent exposure via ingestion, inhalation, external radiation, and dermal contact pathways is estimated and used with health effects measures (e.g., cancer potency factors/slope factors) to derive risk.

In January 1990, the Secretary of Energy decided that DOE would prepare a Programmatic Environmental Impact Statement on the proposed integrated Environmental Restoration and Waste Management Program. The primary task of the environmental restoration component is to assess conditions at DOE sites, facilities, and installations contaminated with radioactive, hazardous, and mixed wastes. In January 1992, DOE established an Advisory Board to provide an independent review of the Programmatic Environmental Impact Statement. Following a review during the second quarter of fiscal year 1993, DOE chose the MEPAS methodology for implementation within the Programmatic Environmental Impact Statement to assess various waste site conditions and alternatives at the major DOE weapons complexes. In December 1993 in response to public comment as to how MEPAS compared to other "multimedia" modeling approaches, DOE initiated a benchmarking exercise that initially included some of the more widely distributed multimedia models: RESRAD (Yu et al. 1993), MMSOILS (EPA 1992), and MEPAS (Buck et al. 1995). This report presents the results of these activities.

\subsection{STUDY OBJECTIVES}

The primary purpose of this study is to develop a comprehensive and quantitative benchmarking comparison of the technical formulation and performance characteristics of three multimedia models: RESRAD, MMSOLS, and MEPAS. These models are designed for use in regulatory development and standard setting related to site-specific hazardous waste issues. Fundamental to this effort is the elucidation of how and to what extent differences in model assumptions and formulations result in differences in model estimates. 
Benchmarking is a type of verification in which a test problem (including input and output results) is used to ensure correct model operation or to compare software. Benchmarking usually embodies the comparison of two or more computer codes that have been applied to a standardized problem. Benchmarking can be used to (1) confirm that two models provide the same results when applied to the same problem and/or (2) identify the differences between models in terms of their assumptions and limitations. Benchmarking is a component of verification and differs from validation. Verification represents a demonstration that software correctly solves mathematical equations and performs the data processing that it was designed to perform. It also represents an assurance that a computer code correctly performs operations specified in a numerical model. Validation represents a demonstration that a computer model (data and software) adequately describes physical reality over the range of variables of interest. It also represents an assurance that a model as embodied in a computer code is a correct representation of the process or system for which it is intended.

Although several recent benchmarking studies on multiple pathway models can be found in the literature, these benchmarking studies were performed by the same model users running all the models benchmarked. In this benchmarking study, model implementation is performed by the model developers themselves (i.e., Argonne National Laboratory for RESRAD, EPA/Tetra Tech, Inc., for MMSOILS, and Pacific Northwest Laboratory for MEPAS). Because the model users are also the model developers, some intermediate results that are not the normal model output are benchmarked also. This allows a better understanding of the models and a better explanation of model differences.

Achieving this objective is particularly challenging because there are no standard protocols for conducting benchmarking studies of multimedia models (see Mackay, 1988, for discussion of the need to develop new means for reviewing and verifying increasingly complex environmental models). Therefore, the following secondary objectives are pursued, although not explicitly reported as part of this study.

1. To develop methods for benchmarking multimedia models, including developing datasets, establishing protocols for preparing and executing the models, establishing standard outputs for comparison, and developing methods for explaining and describing the sources of differences between model estimates.

2. To establish a collegial arrangement between EPA and DOE regarding the future development and application of multimedia modeling tools.

In an effort to clearly describe the boundaries of this study, the following activities and goals are not included as part of this effort.

1. This is not a model validation study. That is, it is not the intent of this study to determine how well the models predict exposures and risks relative to actual monitored releases, environmental concentrations, mass fluxes, exposures, or health effects.

2. This study is not intended to conclude that one model is "better" or "worse" than the others. The choice of which model to use is a problem-specific issue. This study, however, does provide the reader with information that is useful in helping make that selection.

3. This study does not test any specific methodology for applying the models to support regulatory and remedial action assessment needs (e.g., the DOE Programmatic Environmental Impact Statement, the EPA Regulatory Impact Analyses for Corrective Action). The actual application of the models for specific problems is a separate, albeit very important, issue. 
RESRAD, MMSOILS, and MEPAS are included, to the exclusion of other models, for two principal reasons. First, the models represent analytically-based mathematical approaches to site-specific multimedia modeling. Second, the models included in this study have been or are being considered for use, by either DOE or EPA, in connection with national scale environmental impact analyses.

It is recognized that other multimedia models exist which are similar to the three included in this study (Salhotra et al. 1990, Hung 1989, Leigh et al. 1992, Napier et al. 1988). In addition, compartmental models of multimedia systems exist (Mackay et al. 1991, Cohen et al. 19909, McKone et al. 1987) and are designed to simulate pollutant fate and transport in nonsite-specific or regional environments. It is the intent of the authors to determine the appropriateness of including additional models in future benchmarking efforts.

\subsection{STUDY APPROACH}

The approach taken to conduct this study includes a technical and logistical component. The technical component comprises the following steps: development of an overall benchmarking strategy, development of problem datasets, specification of model endpoints for comparison, configuration and execution of models, and identification and interpretation of differences between model estimates. The logistical component of the approach involves the coordination of efforts and the communication network established for the necessary interactions among authors. Twelve modelers are involved in the conduct of this study, and they reside in five locations distributed throughout the United States. Because no standard exists for conducting these activities, both the technical and logistical components of the approach reflect the authors' collective experience and creativity.

\subsubsection{Technical Approach}

To develop a strategy for comparing multimedia model formulation and performance, it is important to consider the nature of risk assessment itself. Risk occurs as a result of a sequence of events, i.e., contaminant release to the environment, contaminant fate and transport through the various environmental media (including food chain), contaminant contact with human receptors, contaminant uptake, and a health effect. Multimedia risk models simulate this sequential process. In comparing the structure and performance of RESRAD, MMSOILS, and MEPAS, the strategy is to first isolate and benchmark each major model component (e.g., atmospheric transport) and then benchmark the complete and integrated multimedia release, fate, transport, exposure, and risk assessment models. This will clearly distinguish between differences caused by specific model components and those resulting from the manner in which the components are linked to form a predictive model of the complete multimedia system.

To compare the models' media-specific characteristics, individual problem scenarios that isolate specific transport zones are formulated. The strategy is to apply each model to a series of direct release scenarios. Each direct release scenario includes a specified time series flux of contaminants and a description of the receiving medium. Scenarios included are direct release to (1) the vadose zone, (2) the saturated zone, (3) the atmosphere, and (4) a surface water (river).

Scenarios are also developed to isolate the surface hydrology and exposure/risk components of the models. The surface hydrology scenario is designed to compare the manner in which the models distribute precipitation among infiltration, evaporation, runoff, and transpiration. The direct exposure

scenario is designed to compare the manner in which the models estimate exposure. For this scenario, contaminant concentrations are specified, a priori, in each primary exposure media (i.e., groundwater, 
surface water, soil). Also specified in this scenario are uptake and transfer rates related to the contaminants' movement through the food chain and human exposure characteristics (e.g., breathing rate, fish consumption rate) that dictate to what extent a person is exposed to a contaminant. The models are then used to compute the magnitude of exposure and related risk.

To compare the performance of the models with all components functioning, a hypothetical multimedia problem is simulated. In this test the manner and degree that individual differences in model formulation propagate through the sequence of steps involved in estimating exposure and risk are investigated.

Table 1.1 (page 1-6) includes, in summary form, a description of the benchmarking scenarios and a list of specific model endpoints that are used for comparison purposes. Two points are relevant here. First, in many instances the models do not routinely output data reflecting the specified endpoints. In those instances, the models are modified so that the relevant information is output. These modifications change only the data selected for output, not the model formulation. The second point is that due to limitations related to study resources there are some scenarios which were considered by the authors but were not included. A list of additional scenarios that would be helpful in the benchmarking context are included in the recommendations chapter of the report (Chapter 11).

In all tests the individual models are configured and executed only by the modeler(s) responsible for the particular model. That is, RESRAD, MMSOILS, and MEPAS are executed only by those modelers intimately familiar (i.e., from a developers perspective) with the individual model's design and software. At the conclusion of each test, outputs from the models are compared, and discussions, sometimes extensive, are held to determine the reasons for differences. When differences are discovered to be a result of assumptions made by the modelers, then the assumptions are reworked and the model is executed again. When all differences are determined to be a result of model formulation, the comparison is considered complete. The only exceptions to this protocol are associated with the direct biosphere exposure and the multimedia scenarios. Sufficient time was not available to resolve all issues related to different interpretations and assumptions made by modelers concerning the conceptualization of the problem for modeling or selection of individual parameter values. Where differences due to modeler assumptions occur, the differences are discussed specifically.

\subsubsection{Logistical Approach}

The key aspect of the logistical approach is communication. To conduct a study of this nature it is imperative that means of communication be made a high priority. In addition, because of the diverse expertise of the modelers and the geographic distance between home bases, it is necessary to coordinate several strategies for maximizing productive communication. The following strategies were developed and implemented for the study:

1. A single location is used as a focal point for the transmittal of all digital and hardcopy communications.

2. Critical discussions involving technical issues and decisions are held at a single location with all modelers present. For the conduct of this study, three face-to-face meetings occurred, varying in duration from 2 to 4 days.

3. Individual modelers were charged with drafting each chapter of the report. This required assimilating results from other models, leading discussions related to differences, and drafting (and redrafting) the chapter write-ups. 
4. Discussions related to incremental technical progress are conducted via regular conference calls.

5. The telephone, telefacsimile, and internet are used for exchange of information between individual modelers working on specific issues.

\subsection{REPORT ORGANIZATION}

This report is organized to reflect the sequential nature of the technical approach. Chapter 2 provides a summary description of the three models being benchmarked. Chapters 3 through 8 describe the tests for direct biosphere exposure, direct release to the atmosphere, direct release to the vadose zone, direct release to the saturated zone, direct release to a river, and surface hydrology, respectively. Each of these chapters contains a detailed description of the problem and related data, a discussion of any relevant modeling assumptions and the modeling approach, a graphics-based comparison of results, and a discussion of all differences between model results.

Chapter 9 describes the multimedia problem and related data along with a complete comparison of individual model results. This chapter describes the cumulative differences between model results as a function of contaminant movement from the source area into the various media and subsequent transport to locations where exposure and risk are assumed to occur. In addition, Chapter 10 presents a study of the summary and conclusions.

\subsection{CHAPTER REFERENCES}

Buck, J. W., G. Whelan, J. G. Droppo, Jr., D. L. Strenge, K. J. Castleton, J. P. McDonald, C. Sato, and G. P. Streile. 1995. Multimedia Environmental Pollutant Assessment System (MEPAS) Application Guidance, Guidelines for Evaluating MEPAS Input Parameters for Version 3.1. PNL-10395, Pacific Northwest Laboratory, Richland, Washington.

Cohen, Y., W. Tsai, S. L. Chetty, and G. Mayer. 1990. Dynamic partitioning of organic chemicals in regional environments: A multimedia screening-level modeling approach, Envir. Sci. and Tech. 24:1549-1558.

EPA (U.S. Environmental Protection Agency). 1992. MMSOILS: Multimedia Contaminant Fate, Transport, and Exposure Model. Documentation and User's Manual, Office of Research and Development, Washington, D.C.

Hung, C. Y., 1989. User's Guide for the SYSCPG Program-A PC Version of the PRESTO-EPA-CPG Operation System, EPA 520/1-89-017, U.S. Environmental Protection Agency, Washington, D.C.

Leigh, C. D., et al. 1992. User's Guide for GENII-S: A Code for Statistical and Deterministic Simulations for Radiation Doses to Humans from Radionuclides in the Environment, SAND910561A, Sandia National Laboratories, Albuquerque, NM.

Mackay, D. 1988. On reviewing environmental models, Envir. Sci. and Tech. 22(2):116.

Mackay, D. 1991. Multimedia Environmental Models-The Fugacity Approach, Lewis Publishers, Chelsea, MI. 
Napier, B. A., et al. 1988. GENIL The Hanford Environmental Radiation Dosimetry Software System, Vols. 1 and 2, PNL-6584, Pacific Northwest Laboratory, Richland, WA.

McKone, T. E., L. B. Gratt, M. J. Lyon, and B. W. Perry. 1987. GEOTOX Multimedia Compartment Model User's Guide, UCRL-15913, Lawrence Livermore National Laboratory.

Salhotra, A. M., P. Mineart, S. Sharp-Hansen, and T. Allision. 1990. Multimedia Exposure Assessment Model (MULTMED) for Evaluating the Land Disposal of Wastes, Volume 1: Model Theory, prepared for the Environmental Research Laboratory, U.S. Environmental Protection Agency, Athens, GA.

Yu, C., A. J. Zielen, J.-J. Cheng, Y. C. Yuan, L. G. Jones, D. J. LePoire, Y. Y Wang, C. O. Loureiro, E. Gnanapragasm, E. Faillace, A. Wallo III, W. A. Williams, and H. Peterson. 1993. Manual for Implementing Residual Radioactive Material Guidelines Using RESRAD, Version 5.0, ANL/EAD/LD-2, Argonne National Laboratory. 
Table 1.1. Summary of benchmarking scenarios and model comparison endpoints

\begin{tabular}{|c|c|c|c|}
\hline BENCHMARK SCENARIO DESCRIPTION & PRIMARY INPUTS & CONTAMINANTS & COMPARATIVE ENDPOINTS \\
\hline $\begin{array}{l}\text { DIRECT BIOSPHERE EXPOSURE (Section 3) } \\
\text { Calculation of cancer risk due to exposure via ingestion, inhalation, } \\
\text { external radiation, and dermal contact for the following exposure scenarios } \\
\text { Direct Exposure to Contaminated Water } \\
\text { Exposure to Food Tainted with Contaminated Water } \\
\text { Direct Exposure to Contaminated Soils } \\
\text { Exposure to Food Tainted with Contaminated Soil }\end{array}$ & $\begin{array}{l}\text { Contaminant concentration in soil and } \\
\text { water } \\
\text { Human exposure factors } \\
\text { Contaminant risk and transfer factors } \\
\text { Livestock consumption rates }\end{array}$ & $\begin{array}{l}\text { Carbon Tetrachloride } \\
\text { Uranium-234 } \\
\text { Cobalt-60 }\end{array}$ & Risk of excess cancer incidence \\
\hline $\begin{array}{l}\text { DIRECT RELEASE TO AIR (Section 4) } \\
\text { Steady-state emission from area source }\end{array}$ & $\begin{array}{l}\text { One combination of wind speed, wind } \\
\text { direction, stability class } \\
\text { Contaminant half-lives } \\
\text { Mixing height } \\
\text { Offsite soil mixing depth } \\
\text { Contaminant deposition rates }\end{array}$ & $\begin{array}{l}\text { Thorium-228 } \\
\text { Radium-224 } \\
\text { Radon-220 }\end{array}$ & $\begin{array}{l}\text { 1) Steady-state concentration vs distance from } \\
\text { source } \\
\text { 2) Soil concentration vs time (at offsite location } \\
\text { due to deposition) }\end{array}$ \\
\hline $\begin{array}{l}\text { DIRECT RELEASE TO VADOSE ZONE (Section 5) } \\
\text { Direct release of contaminants from landfill to vadose zone containing two } \\
\text { layers }\end{array}$ & $\begin{array}{l}\text { Source characteristics } \\
\text { Steady-state infiltration rate } \\
\text { Soil characteristics per layer } \\
\text { Contaminant characteristics }\end{array}$ & $\begin{array}{l}\text { Methylene Chloride } \\
\text { Uranium-238 }\end{array}$ & $\begin{array}{l}\text { 1) Contaminant flux vs time } \\
\text { - at source/layer } 1 \text { interface } \\
\text { - at layer } 1 / \text { /ayer } 2 \text { interface } \\
\text { - at layer } 2 / \text { water table interface } \\
\text { 2) Peak fluxes and time to peak at each interface }\end{array}$ \\
\hline $\begin{array}{l}\text { DIRECT RELEASE TO SATURATED ZONE (Section 6) } \\
\text { Direct release from unlined waste site to aquifer for } 25 \mathrm{yrs}\end{array}$ & $\begin{array}{l}\text { Source characteristics } \\
\text { Aquifer characteristics } \\
\text { Contaminant characteristics }\end{array}$ & $\begin{array}{l}\text { Nitrate } \\
\text { Uranium-234 } \\
\text { Thorium-230 } \\
\text { Radium-226 } \\
\text { Lead-210 }\end{array}$ & $\begin{array}{l}\text { 1) Contaminant flux vs time from source } \\
\text { 2) Contaminant concentrations vs time at } \\
\text { distances of } 0 \mathrm{~m}, 150 \mathrm{~m} \text {, and } 1500 \mathrm{~m} \\
\text { 3) Peak concentrations and times to peak at each } \\
\text { distance }\end{array}$ \\
\hline $\begin{array}{l}\text { DIRECT RELEASE TO SURFACE WATER (Section 7) } \\
\text { Discharge of contaminants into small constant flow river }\end{array}$ & $\begin{array}{l}\text { River characteristics } \\
\text { Contaminant characteristics }\end{array}$ & $\begin{array}{l}\text { Ethylene glycol } \\
\text { Thorium-228 } \\
\text { Tritium }\end{array}$ & $\begin{array}{l}\text { 1) Contaminant flux vs time to river } \\
\text { 2) Contaminant concentration vs. time at } 100 \mathrm{~m} \\
\text { and } 10,000 \mathrm{~m} \text { downstream }\end{array}$ \\
\hline
\end{tabular}


Table 1.1. (continued)

\begin{tabular}{|c|c|c|c|}
\hline BENCHMARK SCENARIO DESCRIPTION (Cont'd) & $\underline{\text { PRIMARY INPUTS }}$ & CONTAMINANTS & COMPARATIVE ENDPOINTS \\
\hline $\begin{array}{l}\text { SURFACE HYDROLOGY (Section } 8 \text { ) } \\
\text { Simulate surface water balance under high rainfall/high permeability and } \\
\text { low rainfall/high permeability conditions. }\end{array}$ & $\begin{array}{l}\text { Surface soil characteristics } \\
\text { Average monthly meteorological data } \\
\text { Curve number }\end{array}$ & None & $\begin{array}{l}\text { 1) Annual average potential evapotranspiration, } \\
\text { actual evapotranspiration, runoff, and infiltration } \\
\text { 2) Average monthly potential evapotranspiration, } \\
\text { actual transpiration, runoff, and infiltration }\end{array}$ \\
\hline $\begin{array}{l}\text { FULL MULTIMEDIA RELEASE, TRANSPORT, EXPOSURE, AND } \\
\text { RISK (Section 9) } \\
\text { Simulate multimedia release and transport of contaminants from buried } \\
\text { waste (landfill). }\end{array}$ & $\begin{array}{l}\text { Source characteristics } \\
\text { Soils characteristics } \\
\text { Hydrogeology } \\
\text { Topography } \\
\text { Meteorology } \\
\text { River Characteristics } \\
\text { Exposure Pathways } \\
\text { Exposure Factors } \\
\text { Contaminant Characteristics }\end{array}$ & $\begin{array}{l}\text { Methylene Chloride } \\
\text { Uranium-238 } \\
\text { Thorium-234 } \\
\text { Uranium-234 } \\
\text { Thorium-230 } \\
\text { Radium-226 } \\
\text { Radon-222 } \\
\text { Lead-210 } \\
\text { Bismuth-210 } \\
\text { Polonium-210 }\end{array}$ & $\begin{array}{l}\text { Source Releases } \\
\text { Contaminant flux vs time per media } \\
\text { Vadose Zone } \\
\text { Travel times per layer } \\
\text { Contaminant flux vs time per layer } \\
\text { Groundwater } \\
\text { Time to peak concentration at wells } \\
\text { Maximum concentration at wells } \\
\text { Concentration vs. time at wells } \\
\text { Flux vs time at surface water interface } \\
\text { Surface Water } \\
\text { Maximum concentration at downstream receptors } \\
\text { Atmosphere } \\
\text { Emission rate vs time } \\
\text { Maximum concentration at offsite receptor } \\
\text { Concentration vs. time (Methylene Chloride } \\
\text { only - at offsite receptor) } \\
\text { Dispersion factor (chi q } q^{-1} \text { ) at offsite receptor } \\
\text { Maximum deposition rate at offsite receptor } \\
\text { Maximum Dose and Risk } \\
\text { Occuring at onsite/offsite receptor.locations } \\
\text { - air pathway } \\
\text { - groundwater pathway } \\
\text { - surface water } \\
\text { - multimedia }\end{array}$ \\
\hline
\end{tabular}




\section{MODEL DESCRIPTIONS}

This chapter presents, in summary form, descriptive information concerning the multimedia models included in this study, i.e., RESRAD, MMSOILS, and MEPAS. The reader who is interested in detailed assumptions and mathematical formulations of the models is referred to the specific model theory and application manuals (Sect. 1.4). A summary listing of each model's computer requirements, contact person(s), and related reference material is included in Appendix B.

Exhibits 2.1,2.2, and 2.3 provide a summary description of each model's design scope and intended applications. Table 2.1 (page 2-6) is constructed to serve two purposes: first, to list the common, or generic, components of multimedia models used for assessing human exposure and risk resulting from the release of hazardous chemicals and radionuclides and second, to provide a comparison among the benchmark models. The comparison is intended to correlate the models on a component-by-component basis as well as compare them collectively with the list of generic multimedia model components. The reader will note that (1) there is significant similarity among the models and, at the same time, significant differences and (2) none of the models address certain issues important in a multimedia risk assessment context. This is indicative of the fact that while the models collectively address a majority of the technical components of multimedia modeling, there is a need for the continuing development of multimedia models.

RESRAD, MMSOILS, and MEPAS are, from a mathematical perspective, a combination of analytical, semianalytical, and numerical solutions to media-specific transport equations and empirical expressions. The empirical expressions include algorithms for estimating contaminant source release rates, intermedia fluxes, contaminant uptake by plants and animals, human exposure, and health risk. Overall, the models are classified as analytical as opposed to value-based or numerical models. These models typically are used for performing (1) screening-level analyses of potential exposures and risks and (2) site-specific predictive assessments of exposures and risks. Recognizing that various technical communities (e.g., model developers, model users) may define these terms differently, the following discussion is intended to establish the authors' meaning.

As screening level assessment tools, the models are typically applied to answer the following types of questions:

1. Does a particular source or site containing hazardous chemicals pose a potentially significant threat to human health?

2. What is the relative threat posed by various chemicals found at a specific site?

3. What is the relative degree of hazard posed by different sites?

4. Which exposure pathways are most significant?

5. What are the relative risk reduction potentials associated with various remediation strategies?

In these screening applications, the models' numerical estimates are typically interpreted as measures of the potential magnitude of exposure and risk and not as specific numerical estimates. Examples of the application of these models to assess and prioritize risks from numerous sites include EPA's Environmental Impact Analysis for RCRA Corrective Action (EPA 1993) and DOE's Programmatic Environmental Impact Statement. 
RESRAD, MMSOILS, and MEPAS are also used to predict site-specific exposure and risk. The need for site-specific analyses span a large continuum ranging from predicting the near-field and shortterm distribution of contaminants and risks at relatively homogeneous sites to predicting far-field and long-term distributions of contaminants at sites where extreme heterogeneities exist. It is not possible to strictly define where along the continuum one can and cannot properly apply these models. Each modeling project is different, and the selection of and application strategy for a particular model is driven by the combination of decision objectives, the degree of site complexity, the extent and nature of site characterization data, the level of uncertainty that can be tolerated, and the experience/skill of the modeler. Therefore, the collection of models included in this study are applied to site-specific environmental impact analyses as required by the National Environmental Policy Act (NEPA), the Atomic Energy Act (AEA), the Comprehensive Environmental Response, Compensation, and Liability Act (CERCLA), and the Resource Conservation and Recovery Act (RCRA).

\section{Chapter Reference}

EPA (United States Environmental Protection Agency). 1993. Regulatory Impact Analysis for Final Rulemaking on Corrective Action for Solid Waste Management Units, Washington, D.C. 


\section{Exhibit 2.1. RESRAD model design summary}

The RESRAD model was initially developed in the early 1980's to calculate site-specific residual radioactive material guidelines and radiation dose/risk to an onsite individual (worker, resident, or recreationist) at a radioactively contaminated site. The RESRAD code was developed by Argonne National Laboratory for the United States Department of Energy (DOE). It has been adopted by DOE (Order 5400.5 and 10CFR 834) for the derivation of soil clean-up criteria and dose calculations. RESRAD is a multimedia risk assessment code. The pathways considered include direct external exposure; dust inhalation; radon; and ingestion of plant foods, meat, milk, aquatic foods, water, and soil.

The RESRAD code has been continuously improved and updated to incorporate comments from users; new features and models are incorporated to increase the code's capability and flexibility. The RESRAD code has been expanded to include chemical contaminants. This RESRAD-CHEM code implements the same methodology as the RESRAD code except it also considers inhalation of volatile compounds and dermal absorption pathways but excludes the external radiation pathway. The RESRAD code is also being expanded for offsite risk assessments. The RESRAD 5.0 manual provides guidance on conducting risk assessments for offsite receptors in the interim. For the offsite atmospheric dispersion modeling, the United States Environmental Protection Agency (EPA) model CAP88PC is being linked with RESRAD. For offsite groundwater transport modeling, in addition to advection, ingrowth and decay, and dilution in a pumping well, the dispersion process is being incorporated. The RESRAD code has a built-in capability to do sensitivity analysis on input parameters and also has the capability to do uncertainty analysis on input parameters and data bases using the Latin Hypercube sampling technique.

RESRAD has undergone several benchmarking analyses and independent verifications and has been included in the International Atomic Energy Agency's VAMP and BIOMOVS II projects (intemational efforts to compare environmental transport models). Many supplemental documents have been prepared for the RESRAD family of codes. In particular, a data collection handbook was prepared to provide guidance on how to collect site-specific data for use in the RESRAD code for the derivation of site-specific clean-up criteria and for site-specific risk assessments. 


\section{Exhibit 2.2. MMSOILS model design summary}

The MMSOILS model is a methodology for estimating the human exposure and health risk associated with releases of chemical contaminates from hazardous waste sites. The methodology includes a multimedia model addressing the transport of a chemical through ground water, surface water, soil, the atmosphere, and aquatic/terrestrial food chains. The human exposure pathways considered in MMSOILS include soil ingestion, air inhalation of volatiles and particulates, dermal contact, ingestion of drinking water, consumption of fish, consumption of plants grown on contaminated soil, and consumption of animals grazing on contaminated pasture. For multimedia exposure, the methodology provides estimates of human exposure through individual pathways and cumulative exposure through all pathways considered. The risk associated with the total exposure dose is calculated based on chemical-specific toxicity data.

MMSOILS is intended primarily for screening hazard potential at a site and the relative comparison of (1) hazards posed by individual chemicals at a site, (2) hazards at different waste sites, and (3) risk reduction potential of alternative remediation activities based on user-supplied source term modifications. Stated differently, MMSOILS primarily is intended to determine whether a site/source represents a potential threat to human health.

MMSOILS can be also be used, under certain conditions, to provide an estimate of health risks for a specific site. Factors influencing the decision to use MMSOILS for sitespecific estimates include (1) the inherent limitations of the model (e.g., assumptions of homogeneous conditions in the transporting media), (2) the complexity (i.e., degree of heterogeneity) associated with the site, (3) the amount of data available for characterizing the source of contamination and the flow and transport media, and (4) the degree of uncertainty that can be tolerated. 


\section{Exhibit 2.3. MEPAS model design summary}

MEPAS is a risk computational tool that evaluates health impacts to exposed individuals and surrounding populations caused by the release of chemical and radioactive contaminants into the environment and their migration and fate in the groundwater, surface water, overland, and atmospheric pathways. MEPAS was originally developed by Pacific Northwest Laboratory (PNL) for the United States Department of Energy (DOE) to prioritize the investigation and remediation of DOE's hazardous, radioactive, and mixed waste sites in a scientific and objective manner based on relative health impact using readily available site information. MEPAS has since evolved into a risk computational tool that indicates the magnitude of environmental concentrations and public health impacts caused by releases of contaminants from both active and inactive sources.

MEPAS is an integrated system of analytical, semi-analytical, and empirically based mathematical models that simulates the release of contaminants from sources, migration and fate of these contaminants through various environmental media, concentrations at designated receptor locations, and health effects to specified sensitive receptors caused by exposure to these contaminants. MEPAS was formulated to address long-term average environmental conditions resulting from releases to the environment from point and area sources. Currently, MEPAS does not address acute exposures to environmental contamination. The transport and exposure models that comprise MEPAS are coupled through a user-friendly shell that includes an extensive database containing 476 contaminants, which is being expanded to contain more than 800 contaminants. 
Table 2.1. Summary comparison of multimedia model capabilities

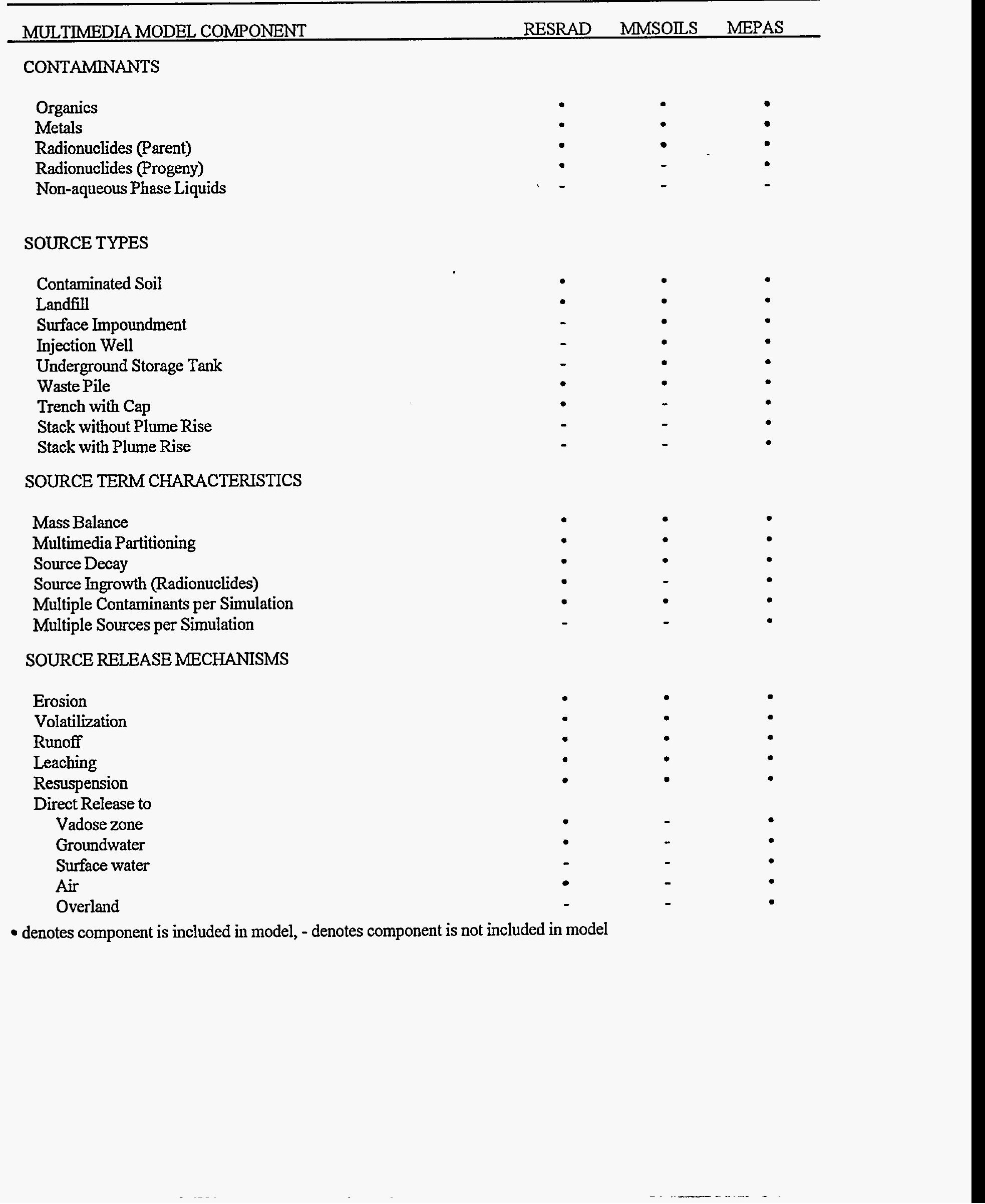


Table 2.1. (continued)

MULTIMEDIA MODEL COMPONENT

RESRAD

MMSOILS

MEPAS

MEDIA-SPECIFIC FLOW

AIR

Box Model (0-D, complete mixing)

Steady State Joint-Frequency-of-Occurrence

(Wind Speed, Stability Class, Direction)

Channeling of Winds

SURFACE WATER

Surface Hydrology (Precipitation - Runoff, Infiltrate, ET)

Surface Water (1-D Steady State)

Surface Water (n-D Dynamic)

Wetlands

GROUNDWATER

Vadose zone (SS infiltration $\rightarrow$ soil moisture)

Vadose zone (1-D Dynamic)

Vadose zone multiphase flow

Groundwater (1-D Steady State)

Groundwater (n-D Dynamic)

NOTE: Steady State (SS) implies flows input to model

MEDIA-SPECIFIC CONTAMINANT TRANSPORT

ATMOSPHERE

Near Field (0-D, complete mixing)

Far Field - Simple Terrain (Gaussian Plume)

Far Field - Complex Terrain

SURFACE WATER

Overland (advection only)

Simple Water Bodies (0-D, complete mixing)

Streams \& Rivers

$1-\mathrm{D}$ advection \& dispersion

1-D advection, 2-D dispersion

$\mathrm{n}-\mathrm{D}$ advection \& dispersion

Lakes \& Reservoirs

1-D advection \& dispersion

$\mathrm{n}-\mathrm{D}$ advection \& dispersion

GROUNDWATER

Vadose Zone (1-D advection only)

Vadose Zone (1-D advection \& dispersion)

Homogeneous Aquifer (1-D advection only)

Homogeneous Aquifer (1-D advection, $n-D$ dispersion)

Heterogeneous Aquifer ( $\mathrm{n}-\mathrm{D}$ advection \& dispersion)

Radionuclide-specific retardation factor for transformation products

- denotes component is included in model, - denotes component is not included in model 
Table 2.1. (continued)

\begin{tabular}{|c|c|c|}
\hline \multicolumn{3}{|c|}{ MULTIMEDIA MODEL COMPONENT } \\
\hline \multicolumn{3}{|c|}{ CONTAMINANT TRANSFORMATION \& FATE PROCESS } \\
\hline \multicolumn{3}{|c|}{ 1st Order Decay (no decay products) } \\
\hline \multicolumn{3}{|c|}{1 st Order Decay (with chained decay products) } \\
\hline \multicolumn{3}{|c|}{ non-1st order decay } \\
\hline \multicolumn{3}{|c|}{ Linear partitioning (water/air, water/soil) } \\
\hline \multicolumn{3}{|c|}{ Nonlinear partitioning (water/soil) } \\
\hline \multicolumn{3}{|c|}{ Chemical Reaction/Speciation } \\
\hline \multicolumn{3}{|c|}{ NOTE: Processes simulated in one or more media } \\
\hline \multicolumn{3}{|c|}{ INTERMEDIA CONTAMINANT FLUXES } \\
\hline Surface soil & $\rightarrow$ & Air (volatilization, resuspension) \\
\hline Surface soil & & Vadose zone (leaching) \\
\hline Surface soil & & Overland (erosion, runoff) \\
\hline Overland & & Offsite surface soil \\
\hline Overland & & Surface water (erosion, runoff) \\
\hline Surface water & & Aquatic organisms (uptake) \\
\hline Surface water & & Sediment (sedimentation) \\
\hline Vadose zone & & Groundwater (percolation) \\
\hline Vadose zone & & Air (volatilization) \\
\hline Groundwater & $\rightarrow$ & Surface water \\
\hline Air & $\rightarrow$ & Surface soil (deposition) \\
\hline Air & $\rightarrow$ & Surface water (deposition) \\
\hline Air & & Vegetation (deposition) \\
\hline Soil, Irrigation & & Vegetation (uptake, deposition) \\
\hline Vegetation, Soi & $\rightarrow$ & Dairy animals (uptake) \\
\hline
\end{tabular}

EXPOSURE PATHWAYS

Ingestion (plant, meat, milk, aquatic food, water, soil)

Inhalation (gases, particulates)

External Radiation

Dermal

\section{HUMAN HEALTH ENDPOINTS/RISK MEASURES}

Radiological Dose

Cancer (Risk)

Noncancer (Hazard Quotient)

Individual (mean, MEI)

Population (distribution, cumulative)

- denotes component is included in model, - denotes component is not included in model 


\section{DIRECT BIOSPHERE EXPOSURE}

\subsection{SCENARIO DESCRIPTION}

The relatively simple direct biosphere exposure scenarios are designed to uncover and highlight the different methodologies used by the three models (RESRAD, MMSOILS, and MEPAS) in their biospheric exposure formulations to aid in accounting for the differences in the predictions for the multimedia scenario. The end point for the direct biosphere exposure test scenarios is the excess cancer risk to a $70-\mathrm{kg}$ individual following $70 \mathrm{yrs}$ of exposure. In addition to excess cancer incidence risk, each of the models also output some or all of the following end points: intake rates, hazard indices, and radiological dose. The inclusion of these end points in the direct biospheric test scenarios would not have provided additional information on the workings of the models.

Each direct biosphere exposure test scenario focuses on cancer risk from a single, initially contaminated medium, via a single exposure pathway. The initially contaminated media considered are soil, and water; exposure involving air as the initially contaminated medium is not considered. The exposure pathways are shown in Table 3.1 (all tables for this chapter are presented in order beginning on page 3-10). The contaminants for all but the last test scenario (S9) are carbon tetrachloride and uranium-234; cobalt-60 and uranium-234 are the contaminants for the external radiation scenario (S9). Table 3.2 lists concentrations of the contaminants in the initially contaminated media for the different scenarios. Test scenarios W6, W7, W9, and W11 involve irrigating initially clean soil with contaminated water, the resulting concentrations of the contaminants in the soil are calculated by the models. The fate of and the risks due to the transformation products of uranium-234 were not considered in these simplified scenario tests. The parameters specified for the direct biosphere exposure scenario are shown in Tables 3.3-3.5. Test scenario S9 consists of four cases to illustrate the effects of a finite contaminated depth and the shielding due to uncontaminated cover; the parameters for the four cases are shown in Table 3.6.

\subsection{MODELING ASSUMPTIONS AND APPROACH}

EPA slope factors are used by all three models (RESRAD, MMSOILS, and MEPAS) to estimate cancer risk. The slope factor represents the probability of cancer incidence as a result of a unit daily intake or exposure over a lifetime. Slope factors for radionuclides and chemical carcinogens are published in Integrated Risk Information System (IRIS) (EPA 1994a) and Health Effects Assessment Summary Tables (HEAST) (EPA 1994b). The slope factors for radionuclides were derived on the basis of the linear nonthreshold dose-response model. Accordingly, radiological cancer risk can be calculated as the product of the slope factor and the radionuclide intake or exposure to external radiation (Eq. 3.1). Because of the relatively low intakes likely to occur from environmental exposure, Eq. 3.1 can also be used to relate chemical cancer risks to intake directly (EPA 1989). Under high chemical intake conditions (i.e., when the cancer risk is greater than 0.01 ), an alternate equation, called the "one-hit equation" (Eq. 3.2), is recommended by EPA (1989). The one-hit equation limits the cancer risk to unity.

$$
\begin{gathered}
\text { Risk = Slope Factor * Intake Quantity (or exposure) } \\
\text { Risk }=1-\exp [- \text { Slope Factor * Intake Quantity (or exposure)] }
\end{gathered}
$$


RESRAD uses Eq. 3.1 to estimate risk, whereas MMSOILS, which deals only with nonradioactive chemicals, uses Eq. 3.2. MEPAS uses Eq. 3.1 for radionuclides and Eq. 3.2 for chemicals. Both methods agree within $1 \%$ when the risk is 0.02 or less. The maximum risk computed in the direct biosphere exposure scenario is 0.11 , where the difference between the two methods is about $5 \%$. Cancer risk computation for chemical carcinogens is discussed in Sect. 3.2.1, and the calculations for radionuclides are discussed in Sect.3.2.2.

\subsubsection{Chemical Cancer Risk}

The computation of the intake depends on the exposure pathway. The intake through the ingestion pathway is the product of the amount of contaminated food or water ingested over the exposure period and the concentration of the chemical in the food or water. The computation of the concentration of the contaminants in different media is discussed briefly in Sects. 3.2.1.1 through 3.2.1.4; the reader should refer to the respective manuals for additional details.

The product of the inhalation rate, the exposure duration, and the concentration in the atmosphere gives the quantity taken in by the inhalation pathway. The quantity of chemicals absorbed from contaminated water through the skin is proportional to the concentration in water, the permeability coefficient of the skin, the area of the exposed skin, and the number of contact events during the exposure period and is dependent on the contact time (with contaminated water) of each event. The quantity of chemicals absorbed from soil is the product of the concentration in soil, the skin adherence factor, absorption fraction, the area of the exposed skin, and the number of contact events (with contaminated soil) during the exposure period. The absorption fraction is dependent on the chemical and the time in contact with the soil for each event. The life-time average daily absorption or intake rate is obtained by dividing the total quantity absorbed or total intake by the body weight of the individual in $\mathrm{kg}$ and by 25,550 , the number of days in 70 yrs (the average life time used for evaluation of cancer risk slope factors). The product of the life-time average daily adsorption or intake rate and the slope factor is the chemical cancer risk. The EPA has not published slope factors for dermal absorption; therefore, the ingestion slope factors are used.

\subsubsection{Concentration in water}

The concentration in water is usually estimated by considering the physical and chemical processes of transport and storage (including advection, dispersion, diffusion, contaminant-soil interaction, and mixing) from the source of contamination to the consumer, the chemical degradation occurring during this transport, and any water extraction and purification process (e.g., dilution, sedimentation, coagulation, filtration, carbon adsorption, ion exchange, and aeration). To focus specifically on the exposure calculations the concentration in water was specified for all water-dependent test scenarios number W1 through W12 in this direct biosphere exposure scenario.

\subsubsection{Concentration in soil}

The soil concentration depends on replenishment from atmospheric deposition and contaminated irrigation water, dilution by soil mixing, degradation of the chemical, and removal due to erosion, volatilization, and leaching. This quantity was specified for test scenarios S1 through S9, while it was estimated by each model for test scenarios W6, W7, W9, and W11. 


\subsubsection{Concentration in vegetables}

The vegetation can be tainted by contaminants in the atmosphere, soil, or irrigation water. The deposition from the atmosphere onto the plant, translocation to the edible portion of the plant, and removal and dilution in the plant determine the concentration in the plant due to contaminants in the atmosphere.

Transfer of contaminants from soil to vegetation is characterized by a soil-to-edible plant transfer factor which is the ratio of the equilibrium concentration in edible portions of the plant (on a dry or wet weight basis) and the concentration in the soil (dry weight basis) upon which the plant is rooted. The same process can also be represented by the quotient of two factors; the soil moisture-to-plant transfer factor and the soil/water distribution coefficient. The soil/water distribution coefficient is the ratio between the concentration of the contaminant in soil (dry weight basis) and the concentration in soil solution (volume basis) in adsorption equilibrium with the soil. The soil moisture-to-plant transfer factor is the ratio between the equilibrium concentration of the contaminant in the edible plant and the concentration in soil moisture (volume basis). RESRAD and MEPAS use the soil-to-plant transfer factor, whereas MMSOILS uses both the soil-to-plant transfer factor and the soil moisture-to-plant transfer factor.

The (foliar) deposition pathway will be effective in contaminating the vegetation if irrigation water is applied to both the plant and soil (overhead irrigation). Root uptake following build up of contaminants in the soil from contaminated irrigation water is effective in transferring contaminants from irrigation water to the vegetation (for all forms of irrigation).

\subsubsection{Concentration in meat and milk}

Meat and milk are contaminated bỳ ingestion of contaminated livestock water and animal feed, incidental ingestion of soil, and inhalation. Livestock inhalation of contaminated air is not considered in this study. The product of the feed-to-animal product transfer factor, the livestock consumption rates, and the concentration in the item consumed gives the concentration in the animal product.

\subsubsection{Radiological Cancer Risk}

The methodology for evaluating radiological excess cancer risk depends on whether the radiation is internal or external. Internal radiation exposure occurs when radionuclides are ingested, inhaled, or absorbed through the skin. Radionuclides present in the soil, atmosphere, and water bodies can irradiate a person externally.

\subsubsection{Internal radiation}

The computation of the intake quantity depends on the exposure pathway. The quantity taken in by the ingestion pathway is the product of the amount of contaminated food or water ingested over the exposure period and the concentration of the radionuclide in the food or water. The computation of the concentration of the contaminants in different media is discussed briefly in the concentration in water and concentration in soil subparagraphs of this subsection and Sects. 3.2.1.3 and 3.2.1.4; the reader should refer to the respective manuals for additional details. The product of the inhalation rate, the exposure duration, and the concentration in the atmosphere gives the quantity taken in by the inhalation pathway. The total intake quantity is multiplied by the slope factor to obtain the cancer risk. The dermal pathway is discussed in the dermal contact subparagraph of this subsection. 
Concentration in water. The concentration in water is usually estimated by considering the physical and chemical process of transport and storage (including advection, dispersion, diffusion, contaminant-soil interaction, and mixing) from the contamination to the consumer, the radioactive transformations (decay and ingrowth) occurring during this transport, and any water extraction, and purification processes (e.g., dilution, sedimentation, coagulation, filtration, ion exchange, and aeration). The concentration in water was specified for all water-dependent test scenarios numbered WI through W12 in this direct biosphere exposure scenario.

Concentration in soil. The soil concentration depends on replenishment from atmospheric deposition, and contaminated irrigation water, dilution by soil mixing, radioactive ingrowth and decay, and removal due to erosion and leaching. This quantity was specified for test scenarios S1 through S9, while it was estimated (differently) by each model for test scenarios W6, W7, W9, and W11.

Dermal contact. Dermal contact with radionuclides may occur during contact with contaminated water or contaminated soil. The absorption of radionuclides is evaluated by MEPAS using the same models as for chemical dermal contact exposures. Because EPA has not published slope factors for dermal absorption of radionuclides, MEPAS estimates the risk (from the amount absorbed) using dose conversion factors (dose per amount absorbed) and a health effects conversion factor (risk per dose). Therefore, the slope factor used by MEPAS for dermal absorption of uranium-234 is $3.8 \times 10^{-9}$, $\left(=6.1 \times 10^{-6} \mathrm{rem} \mathrm{pCi}^{-1} * 6.2 \times 10^{-4}\right.$ risk rem $\left.^{-1}\right)$.

\subsubsection{External Radiation}

The EPA slope factor is the excess cancer risk due to a year's exposure from an infinitely large and deep, uncovered contaminated region of unit activity concentration. Factors to account for the finite depth and area of the contaminated zone, the shape of the zone, and shielding from uncontaminated cover may be applied to the slope factor. Additional shielding from building components must also be considered.

\subsection{COMPARISON OF MODEL PREDICTIONS}

The predictions of the three models for the direct biosphere exposure scenarios for carbon tetrachloride, uranium-234, and cobalt-60 are shown in Tables 3.7,3.8, and 3.9, respectively.

\subsection{RESULTS AND DISCUSSION}

The modeling assumptions, modelers' interpretation of the scenario, and the approach taken by the modelers contribute to the differences in the predictions of the three models. The intention, although not achieved in this benchmark scenario, was to systematically eliminate modeler-based sources of differences in model results. These factors are discussed in Sects. 3.4.1 and 3.4.2. Significant differences exist in the manner in which the three models estimate the effects of irrigation; these differences are discussed in Sect. 3.4.3. Section 3.4.4 compares the results of all the test scenarios included in the direct exposure scenario.

\subsubsection{Specified soil concentration}

One of the differing interpretations that affects all soil pathways relates to the specified soil concentration. The RESRAD and MMSOILS modelers assumed that the specified soil concentration 
would be maintained constant throughout the 70-yr exposure period and therefore did not consider the depletion of carbon tetrachloride due to volatilization, leaching, and degradation. In addition, the RESRAD user did not consider the changes in the quantity of the nuclides and their transformation products due to decay, ingrowth, and leaching. The MEPAS user accounted for the depletion of the radionuclides due to radioactive decay and the removal of carbon tetrachloride due to volatilization which was assumed to occur at a half-life of 12.1 days based on previous experience. Therefore, the MEPAS results for carbon tetrachloride for test scenarios S1 through S6 will be $6.8 \times 10^{-4}$ times $(\approx 1 / 1400)$ that of the other two models, while the results for cobalt-60 (test scenario S9) will be 0.11 times $(=1 / 9)$ the RESRAD predictions.

\subsubsection{Irrigation}

Neither the method nor the rate of irrigation was specified in the scenario description. The RESRAD and MEPAS modelers assumed overhead (sprinkler) irrigation, where part of the contaminants are taken up by the leaves and the rest is available for root uptake; however, the MMSOILS modeler assumed that irrigation was applied to the soil. The RESRAD, MMSOILS, and MEPAS modelers assumed irrigation rates of $0.2,0.2$ and $1.2 \mathrm{~m} \mathrm{y}^{-1}$ respectively. Because the risk is directly proportional to the irrigation rate, the MEPAS result for irrigation related pathways would be six times that of the RESRAD results. The MMSOILS results would be even lower due to the method of irrigation.

\subsubsection{Concentration in soil from contaminated irrigation water}

The three models use different methodologies to estimate the concentration in soil due to irrigating with contaminated water. RESRAD considers the input from irrigation water and removal due to leaching of contaminants from agricultural soil to determine the soil concentration at the end of the growth period of the crop. MMSOILS computes the equilibrium soil concentration, where the input from irrigation water is equal to the losses due to degradation, soil erosion, and recharge (leaching). MEPAS calculates the average concentration in soil during the 70-yr exposure period by considering the input from irrigation water and losses due to volatilization and decay. The reader should refer to the respective manuals for further details.

\subsubsection{Comparison of Results}

Model predictions for test scenarios involving dermal absorption, irrigation, or external radiation differ because of the different formulations used by the models. These differences are discussed in Sects. 3.4.4.1, 3.4.4.2, 3.4.4.3, 3.4.4.7, 3.4.4.9, 3.4.4.13, 3.4.4.17, and 3.4.4.19. The model predictions for all remaining test scenarios involving contaminated soil are caused entirely by modeler-based differences in the interpretation of the scenario as discussed in Sect.3.4.1.

\subsubsection{Dermal contact with soil (S1)}

Predictions for cancer risk due to exposure to carbon tetrachloride by dermal absorption from soil are virtually identical for RESRAD and MMSOILS; MEPAS results are greater by a factor of 21 . Two factors combine to explain this difference. First, as discussed in Sect. 3.4.1, MEPAS results are expected to be $6.8 \times 10^{-4}$ times the RESRAD and MMSOILS results due to the differing interpretations of the specified soil concentrations. The second is the treatment of absorption factor. The MEPAS and MMSOILS modelers specified values of unity (1) and $3.5 \times 10^{-5}$, respectively. The RESRAD modeler allowed the code to compute the factor based on the event duration and the properties of the contaminants using EPA methodology (EPA 1992). The low value of absorption fraction reflects the 
high volatility of carbon tetrachloride. Eliminating these differences would result in all models estimating nearly the same risk due to dermal contact with soil.

All three models use the ingestion slope factor to evaluate risk from dermal contact because EPA has not published slope factors for dermal absorption. MEPAS divides the ingestion slope factor for chemicals by the gastrointestinal tract absorption fraction to account for dermal absorption reaching the blood directly. MEPAS used a gastrointestinal tract absorption fraction of 1.0 for this exercise.

\subsubsection{Dermal contact while swimming (W1)}

The MEPAS prediction for cancer risk due to exposure to carbon tetrachloride by this pathway is about five times that of RESRAD; the RESRAD prediction is more than three times that of MMSOILS. Some of the factors required for this pathway were not specified in the scenario description; the values assumed by the modelers are given in Table 3.11. MMSOILS uses the steady state expression for absorption; therefore, the quantity absorbed is directly proportional to the event duration. RESRAD and MEPAS use EPA methodology (EPA 1992) to account for the initial transient state which occurs at each event before steady state is reached. The initial absorption rate is rapid and gradually decreases over a characteristic time to the steady state value. The amount of carbon tetrachloride absorbed, computed according to this methodology for an event of 0.5 -hour duration, is 3.4 times that computed under the steady state assumption. This factor is the source of the difference between the RESRAD and MMSOILS predictions. The different exposure frequencies assumed by RESRAD and MEPAS account for the differences in the predictions of these two models.

\subsubsection{Dermal contact while showering (W2)}

The MEPAS and RESRAD predictions for this pathway are about six times that of MMSOILS for carbon tetrachloride. The values assumed by the model users for factors not specified in the scenario description are presented in Table 3.12. All three models use the same methodology as for dermal contact while swimming (see discussion in Sect. 3.4.4.2). The amount of carbon tetrachloride absorbed, computed according to the EPA methodology (EPA 1992) for a 10-minute shower, is 5.9 times that computed under the steady state assumption. This is the source of the difference between the MMSOILS prediction and the predictions of the other two models.

\subsubsection{Ingestion of contaminated drinking water (W5)}

The MEPAS, MMSOILS, and RESRAD predictions for this pathway are in agreement.

\subsubsection{Ingestion of contaminated soil ( $\mathrm{S} 2)$}

The MMSOILS and RESRAD predictions for carbon tetrachloride are in agreement and are more than 1400 times that of MEPAS; this difference is due to the volatilization factor discussed in Sect. 3.4.1. The RESRAD and MEPAS predictions for uranium-234 are in agreement.

\subsubsection{Ingestion of leafy vegetables contaminated by root uptake from soil (S3)}

The RESRAD and MMSOILS predictions for carbon tetrachloride are in agreement and are more than 1400 times that of MEPAS; this difference is due entirely to the volatilization factor discussed in Sect. 3.4.1. The RESRAD and MEPAS predictions for uranium-234 are in agreement. 


\subsubsection{Ingestion of leafy vegetables contaminated by irrigation water (W6)}

The MEPAS predictions for risk via this pathway for both carbon tetrachloride and uranium-234 are approximately five times those of RESRAD; the RESRAD prediction for carbon tetrachloride is about seven times the MMSOILS prediction. The values assumed by the model users for factors not specified in the scenario description are shown in Table 3.13. Two primary factors are responsible for the differences in model estimates. First, the MEPAS modelers assumed an irrigation rate six times greater than did the MMSOILS and RESRAD modelers. Second, the MEPAS and RESRAD models include foliar deposition and related plant uptake while MMSOILS does not include this feature. For this scenario test, foliar deposition dominates the root uptake for leafy vegetables.

\subsubsection{Ingestion of nonleafy plants contaminated by root uptake from soil (S4)}

The RESRAD and MMSOILS predictions for carbon tetrachloride are in agreement and are more than 1400 times that of MEPAS; this difference is due to the volatilization factor discussed in Sect. 3.4.1. The RESRAD and MEPAS predictions for uranium-234 are in agreement. The methodology used in RESRAD and MEPAS for the nonleafy vegetables for root uptake from contaminated soil is identical to the methodology for leafy vegetables. The MMSOILS methodology for nonleafy vegetables is different than that for leafy vegetables because (1) the soil-to-plant transfer factor is replaced by the ratio of the root concentration factor to the soil/water distribution coefficient and (2) the fraction of plant that is dry is not used. This difference in formulation between the models will not impact the predictions when a consistent set of parameter values is used in the different models.

\subsubsection{Ingestion of nonleafy vegetables contaminated by irrigation water (W7)}

The MEPAS predictions for both uranium-234 and carbon tetrachloride are more than four times and twice those of RESRAD, respectively; the RESRAD prediction for carbon tetrachloride is about one and a half times that of MMSOILS. The methodology used in RESRAD and MEPAS for the nonleafy vegetables for the irrigation pathway is identical to the methodology for leafy vegetables; however, the values of some of the parameters (Table 3.14) are different. The contributions of the foliar uptake and root uptake pathways are of a similar magnitude in this test scenario. Therefore, the differences in the results are likely due to the factors discussed in Sects. 3.4.2 and 3.4.3.

\subsubsection{Ingestion of meat tainted by fodder grown on contaminated soil (S5)}

The RESRAD and MMSOILS predictions for carbon tetrachloride are in agreement and are more than 1400 times that of MEPAS; this difference is due to the volatilization factor discussed in Sect. 3.4.1. The RESRAD and MEPAS predictions for uranium-234 are in agreement. All three models use a procedure similar to that for leafy vegetables to evaluate the concentration of the contaminants in fodder.

\subsubsection{Ingestion of meat tainted by incidental consumption of contaminated soil (S6)}

The RESRAD and MMSOILS predictions for carbon tetrachloride are in agreement and are more than 1400 times that of MEPAS; this difference is due to the volatilization factor discussed in Sect. 3.4.1. The RESRAD and MEPAS predictions for uranium-234 are in agreement.

\subsubsection{Ingestion of meat tainted by contaminated livestock water (W8)}

The MEPAS, MMSOILS, and RESRAD predictions for this pathway are in agreement. 


\subsubsection{Ingestion of meat tainted by fodder irrigated with contaminated water (W9)}

The MEPAS and RESRAD predictions for carbon tetrachloride are similar and are more than seven times that of the MMSOILS. The MEPAS prediction for uranium-234 is more than twice that of RESRAD. All three models use a procedure similar to that for leafy vegetables to evaluate the concentration of contaminants in fodder. The parameter values that differ from those shown in Table 3.13 are presented in Table 3.15. The MEPAS predictions also include the contributions of incidental soil ingestion. As with leafy vegetables, the foliar uptake pathway dominates the root uptake pathway for the conditions assumed for this scenario (MMSOILS does not include this process). The fact that the MEPAS and RESRAD results agree in spite of the different values used for a number of parameters including the irrigation rate and the different formulations discussed in Sect. 3.4.3 is coincidental.

\subsubsection{Ingestion of milk tainted by fodder grown on contaminated soil (S7)}

The RESRAD and MMSOILS predictions for carbon tetrachloride are in agreement and are more than 1400 times that of MEPAS; this difference is due to the volatilization factor discussed in Sect. 3.4.1. The RESRAD and MEPAS predictions for uranium-234 are in agreement.

\subsubsection{Ingestion of milk tainted by incidental consumption of contaminated soil (S8)}

The RESRAD and MMSOILS predictions for carbon tetrachloride are in agreement and are more than 1400 times that of MEPAS; this difference is due to the volatilization factor discussed in Sect. 3.4.1. The RESRAD and MEPAS predictions for uranium-238 are in agreement.

\subsubsection{Ingestion of milk tainted by contaminated livestock water (W10)}

The MEPAS, MMSOILS, and RESRAD predictions for this pathway are in agreement.

\subsubsection{Ingestion of milk tainted by fodder irrigated with contaminated water (W11)}

The MEPAS prediction for carbon tetrachloride is 10 times that of RESRAD, and the RESRAD prediction is more than seven times that of the MMSOILS. The MEPAS prediction for uranium-238 is about 20 times that of RESRAD. The MEPAS predictions also include the contributions of incidental soil ingestion. As with leafy vegetables, the foliar uptake pathway dominates the root uptake pathway for the conditions assumed for this test scenario (MMSOILS does not include this process). Both RESRAD and MEPAS assumed that the dairy cows are fed forage and used the crop yields listed in Table 3.15. The differences in the results are likely caused by the factors discussed in Sects. 3.4.2 and 3.4.3.

\subsubsection{Ingestion of fin fish (W12)}

The MEPAS, MMSOILS, and RESRAD predictions for this pathway are in agreement.

\subsubsection{Direct external radiation (S9)}

The MEPAS prediction for uranium-234 is in agreement with the RESRAD prediction for the two cases of this test scenario without cover. The RESRAD predictions for the two cases with a $0.15-\mathrm{m}$ cover are about 25 times lower than the two cases without cover. This is because the RESRAD predictions for risk from external radiation consider the finite thickness of the source and the shielding provided by the 
uncontaminated cover material, while the MEPAS predictions do not adjust for these effects. The RESRAD predictions for cobalt- 60 for all four cases are higher than the MEPAS prediction. The reason for this is MEPAS adjusts for the radioactive decay of cobalt-60 during the period of exposure whereas RESRAD does not. The predictions for Case A of test scenario S9 differ by a factor of 0.11 (or 1/9) as described in Sect. 3.4.1. The RESRAD predictions for the two cases with a $0.15-\mathrm{m}$ cover are about 5 times lower than the two cases without cover.

\subsection{CONCLUSIONS}

The differences between the predictions of the three models for ingestion pathways that do not involve irrigation or dermal contact can be attributed solely to the differing interpretations of the specified contaminant concentration in soil as elaborated in Sect. 3.4.1. The incorporation of the revised EPA methodology (EPA 1992) in some models/pathways was one reason for disagreement between the predictions for dermal pathways; the use of different exposure parameters was also a reason for this disagreement. Major differences exist in the formulations for pathways involving irrigation. The three codes use different conceptual models to determine the concentration of contaminants accumulated in the soil following irrigation (Sect. 3.4.3). The models also permit different methods for application of irrigation water (Sect. 3.4.2).

\subsection{CHAPTER REFERENCES}

EPA (United States Environmental Protection Agency). 1989. Risk Assessment Guidance for Superfund, Volume I - Human Health Evaluation Manual, Interim Final, Office of Emergency and Remedial Response, OSWER Directive 9285.7-01a, Washington, DC.

EPA. 1992. Dermal Exposure Assessment; Principles and applications, Interim Report, Report No. EPA/600/8-91/011B, Office of Health and Environmental Assessment, Washington, DC.

EPA. 1994a. Integrated Risk Information System. Assistant Administrator for Water, Office of Science and Technology, Washington, DC.

EPA. 1994b. Health Effects Assessment Summary Tables, FY-1994 Annual, Report No. EPA/540/R94/020, Office of Solid Waste and Emergency Response, Washington, DC. 
Table 3.1. Exposure pathway for each scenario

\begin{tabular}{|c|c|c|}
\hline Scenario & Exposure Pathway & Exposure Grouping \\
\hline$W 1^{*}$ & dermal contact while swimming in contaminated water & \\
\hline W2 & dermal contact while showering in contaminated water & Direct Exposure to \\
\hline W3 & inhalation while showering in contaminated water & Contaminated Water \\
\hline W4 & ingestion while showering in contaminated water & \\
\hline W5 & ingestion of contaminated drinking water & \\
\hline W6 & $\begin{array}{l}\text { ingestion of leafy vegetables irrigated with contaminated } \\
\text { water }\end{array}$ & \\
\hline W7 & $\begin{array}{l}\text { ingestion of nonleafy vegetables irrigated with } \\
\text { contaminated water }\end{array}$ & \\
\hline W8 & ingestion of meat tainted by contaminated livestock water & $\begin{array}{l}\text { Indirect Exposure to } \\
\text { Contaminated Water via }\end{array}$ \\
\hline W9 & $\begin{array}{l}\text { ingestion of meat tainted by fodder irrigated with } \\
\text { contaminated water }\end{array}$ & $\begin{array}{l}\text { Transfer to Food Chain and } \\
\text { Subsequent Human }\end{array}$ \\
\hline W10 & ingestion of milk tainted by contaminated livestock water & Consumpirion \\
\hline W11 & $\begin{array}{l}\text { ingestion of milk tainted by fodder irrigated with } \\
\text { contaminated water }\end{array}$ & \\
\hline W12 & ingestion of fin fish raised in contaminated water & \\
\hline $\mathrm{Sl}^{\mathrm{b}}$ & dermal contact with contaminated soil & Direct Exposure to \\
\hline S2 & ingestion of contaminated soil & Contaminated Soil \\
\hline S3 & ingestion of leafy vegetables grown on contaminated soil & \\
\hline S4 & $\begin{array}{l}\text { ingestion of nonleafy vegetables grown on contaminated } \\
\text { soil }\end{array}$ & \\
\hline S5 & $\begin{array}{l}\text { ingestion of meat tainted by fodder grown on contaminated } \\
\text { soil }\end{array}$ & $\begin{array}{l}\text { Indirect Exposure to } \\
\text { Contaminated Soil via }\end{array}$ \\
\hline S6 & $\begin{array}{l}\text { ingestion of meat tainted by incidental consumption of } \\
\text { contaminated soil }\end{array}$ & $\begin{array}{c}\text { Transfer to the Food Chain } \\
\text { and Subsequent Human } \\
\text { Consumption }\end{array}$ \\
\hline S7 & $\begin{array}{l}\text { ingestion of milk tainted by fodder grown on contaminated } \\
\text { soil }\end{array}$ & \\
\hline S8 & $\begin{array}{l}\text { ingestion of milk tainted by incidental consumption of } \\
\text { contaminated soil }\end{array}$ & \\
\hline S9 & external radiation from contaminated soil & $\begin{array}{l}\text { Direct Exposure to } \\
\text { Radiation }\end{array}$ \\
\hline
\end{tabular}

'W denotes test cases involving water as the initially contaminated medium; the numbering was sequential from dermal to inhalation to ingestion.

' $S$ denotes test cases involving soil as the initially contaminated medium; the numbering was sequential from dermal to inhalation to ingestion. 
Table 3.2. Concentration of contaminants in initially contaminated medium

\begin{tabular}{lrrrrrr}
\hline Scenario & \multicolumn{5}{c}{ Concentration of contaminants } \\
\cline { 2 - 7 } & \multicolumn{7}{c}{ Carbon tetrachloride } & Uranium-234 & \multicolumn{2}{c}{ Cobalt-60 } \\
\cline { 2 - 7 } & $\begin{array}{r}\text { water } \\
\mathrm{mg} \mathrm{L}^{-1}\end{array}$ & $\begin{array}{r}\text { soil } \\
\mathrm{mg} \mathrm{kg}^{-1}\end{array}$ & $\begin{array}{r}\text { water } \\
\mathrm{pCi} \mathrm{L}^{-1}\end{array}$ & $\begin{array}{r}\text { soil } \\
\mathrm{pCi} \mathrm{g}^{-1}\end{array}$ & $\begin{array}{r}\text { water } \\
\mathrm{pCi} \mathrm{L}^{-1}\end{array}$ & $\begin{array}{r}\text { soil } \\
\mathrm{pCi} \mathrm{g}^{-1}\end{array}$ \\
\hline W1 through W12 & 32 & 0 & 1 & 0 & 0 & 0 \\
S1 through S8 & 0 & 1 & 0 & 1 & 0 & 0 \\
S9 & 0 & 0 & 0 & 1 & 0 & 1 \\
\hline
\end{tabular}

Table 3.3. Contaminant dependent risk and transfer factors

\begin{tabular}{|c|c|c|c|}
\hline & & \multicolumn{2}{|c|}{ Contaminant } \\
\hline & & $\begin{array}{c}\text { Carbon } \\
\text { Tetrachloride } \\
\end{array}$ & Uranium-234 \\
\hline Slope factor, ingestion & $\begin{array}{r}\text { risk }{ }^{\left(\mathrm{mg} \mathrm{kg} \mathrm{kg}^{-1} \mathrm{~d}^{-1}\right)^{-1}} \\
\text { risk pCi-1 }\end{array}$ & $\begin{array}{r}0.13 \\
-\end{array}$ & $1.6 \times 10^{-11}$ \\
\hline Slope factor, inhalation & $\begin{array}{r}\text { risk }\left(\mathrm{mg} \mathrm{kg}^{-1} \mathrm{~d}^{-1}\right)^{-1} \\
\text { risk pCi-1 }\end{array}$ & $\begin{array}{r}0.053 \\
-\end{array}$ & $2.6 \times 10^{-8}$ \\
\hline Slope factor, external radiation & risk $\mathrm{yr}^{-1} \operatorname{per}\left(\mathrm{pCi}^{-1}\right)$ & - & $3.0 \times 10^{-11}$ \\
\hline $\begin{array}{l}\text { Transfer factor, soil to edible plant } \\
\text { ( } \equiv 15 \% \text { dry) } \\
\text { Transfer factor, soil moisture to edible root }\end{array}$ & $\begin{array}{l}\mathrm{g} \text { dry soil ( } \mathrm{g} \text { wet vegetable })^{-1} \\
\mathrm{~g} \text { dry soil ( } \mathrm{g} \text { dry vegetable) } \\
\mathrm{mL}(\mathrm{g} \text { wet vegetable) }\end{array}$ & $\begin{array}{r}0.29 \\
1.93 \\
0.638\end{array}$ & $\begin{array}{r}0.0035 \\
- \\
-\end{array}$ \\
\hline Soil/water distribution coefficient & $\mathrm{mL} \mathrm{g}^{-1}$ & 2.2 & - \\
\hline Transfer factor, feed to animal meat & $\mathrm{d} \mathrm{kg}^{-1}$ & $1.1 \times 10^{-5}$ & $2.0 \times 10^{-4}$ \\
\hline Transfer factor, feed to milk & $\mathrm{dL}^{-1}$ & $3.5 \times 0^{-6}$ & $6.0 \times 10^{-4}$ \\
\hline Transfer factor, water to fin fish & $\mathrm{L} \mathrm{kg}^{-1}$ & 17 & 50 \\
\hline
\end{tabular}

Table 3.4. Livestock consumption rates

\begin{tabular}{llrr}
\hline & & Beef cattle & Dairy cow \\
\hline Livestock water & $\mathrm{L} \mathrm{d}^{-1}$ & 50 & 60 \\
Feed (wet) & $\mathrm{kg} \mathrm{d}^{-1}$ & 68 & 55 \\
Soil & $\mathrm{kg} \mathrm{d}^{-1}$ & 0.5 & 0.5 \\
\hline
\end{tabular}


Table 3.5. Human consumption rates

\begin{tabular}{lcc}
\hline Drinking water & $2.0 \mathrm{~L} \mathrm{~d}^{-1}$ & $730 \mathrm{~L} \mathrm{yr}^{-1}$ \\
Fresh leafy vegetables & $0.021 \mathrm{~kg} \mathrm{~d}^{-1}$ & $7.665 \mathrm{~kg} \mathrm{gr}^{-1}$ \\
Fresh nonleafy vegetables & $0.13 \mathrm{~kg} \mathrm{~d}^{-1}$ & $47.45 \mathrm{~kg} \mathrm{yr}^{-1}$ \\
Meat & $0.065 \mathrm{~kg} \mathrm{~d}^{-1}$ & $23.725 \mathrm{~kg} \mathrm{yr}^{-1}$ \\
Milk & $0.075 \mathrm{~L} \mathrm{~d}^{-1}$ & $27.375 \mathrm{~L} \mathrm{yr}^{-1}$ \\
Fin fish & $0.0065 \mathrm{~kg} \mathrm{~d}^{-1}$ & $2.3725 \mathrm{~kg} \mathrm{yr}^{-1}$ \\
Soil & $0.0001 \mathrm{~kg} \mathrm{~d}^{-1}$ & $0.0365 \mathrm{~kg} \mathrm{yr}^{-1}$ \\
\hline
\end{tabular}

Table 3.6. Parameters for external radiation scenario

\begin{tabular}{lll}
\hline Scenario & Depth of contamination & Depth of cover \\
\hline S9-A & $1.0 \mathrm{~m}$ & $0 \mathrm{~m}$ \\
S9-B & $0.15 \mathrm{~m}$ & $0 \mathrm{~m}$ \\
S9-C & $1.0 \mathrm{~m}$ & $0.15 \mathrm{~m}$ \\
S9-D & $0.15 \mathrm{~m}$ & $0.15 \mathrm{~m}$ \\
\hline
\end{tabular}


Table 3.7. Risk from direct biosphere exposure to carbon tetrachloride

\begin{tabular}{|c|c|c|c|}
\hline Scenario & $\begin{array}{l}\text { RESRAD } \\
\text {-CHEM } \\
\end{array}$ & MMSOILS & MEPAS \\
\hline W1: dermal contact while swimming & $6.1 \times 10^{-4}$ & $1.8 \times 10^{-4}$ & $2.9 \times 10^{-3}$ \\
\hline W2: dermal contact while showering & $2.5 \times 10^{-2}$ & $4.2 \times 10^{-3}$ & $2.5 \times 10^{-2}$ \\
\hline W3: inhalation while showering & - & - & $2.2 \times 10^{-1}$ \\
\hline W4: ingestion while showering & - & - & $6.0 \times 10^{-4}$ \\
\hline W5: ingestion of contaminated drinking water & $1.2 \times 10^{-1}$ & $1.1 \times 10^{-1}$ & $1.1 \times 10^{-1}$ \\
\hline $\begin{array}{l}\text { W6: ingestion of leafy vegetables irrigated with contaminated } \\
\text { water }\end{array}$ & $2.1 \times 10^{-32}$ & $3.2 \times 10^{-4 b}$ & $1.0 \times 10^{-2}$ \\
\hline $\begin{array}{l}\text { W7: ingestion of nonleafy vegetables irrigated with } \\
\text { contaminated water }\end{array}$ & $2.9 \times 10^{-3}=$ & $2.0 \times 10^{-3 b}$ & $6.7 \times 10^{-3}=$ \\
\hline W8: ingestion of meat tainted by contaminated livestock water & $2.1 \times 10^{-6}$ & $2.1 \times 10^{-6}$ & $2.1 \times 10^{-6}$ \\
\hline $\begin{array}{l}\text { W9: ingestion of meat tainted by fodder irrigated with } \\
\text { contaminated water }\end{array}$ & $5.3 \times 10^{-62}$ & $7.4 \times 10^{-7 b}$ & $5.6 \times 10^{-6} \mathrm{as}$ \\
\hline W10: ingestion of milk tainted by contaminated livestock water & $9.4 \times 10^{-7}$ & $9.4 \times 10^{-7}$ & $9.4 \times 10^{-7}$ \\
\hline $\begin{array}{l}\text { W11: ingestion of milk tainted by fodder irrigated with } \\
\text { contaminated water }\end{array}$ & $1.6 \times 10^{-68}$ & $2.2 \times 10^{-7 b}$ & $1.6 \times 10^{-520}$ \\
\hline W12: ingestion of fin fish raised in contaminated water & $6.6 \times 10^{-3}$ & $6.5 \times 10^{-3}$ & $6.5 \times 10^{-3}$ \\
\hline Sl: dermal contact with soil ${ }^{d}$ & $6.3 \times 10^{-11}$ & $6.2 \times 10^{-11}$ & $1.3 \times 10^{-9}$ \\
\hline S2: ingestion of contaminated soile & $1.9 \times 10^{-7}$ & $1.9 \times 10^{-7}$ & $1.3 \times 10^{-10}$ \\
\hline S3: ingestion of leafy vegetables grown on contaminated soil ${ }^{e}$ & $1.1 \times 10^{-5}$ & $1.1 \times 10^{-5}$ & $7.7 \times 10^{-9}$ \\
\hline $\begin{array}{l}\text { S4: ingestion of nonleafy vegetables grown on contaminated } \\
\text { soil }^{\circ}\end{array}$ & $7.0 \times 10^{-5}$ & $7.0 \times 10^{-5}$ & $4.8 \times 10^{-8}$ \\
\hline $\begin{array}{l}\text { S5: ingestion of meat tainted by fodder grown on contaminated } \\
\text { soil }^{\circ}\end{array}$ & $2.6 \times 10^{-8}$ & $2.6 \times 10^{-8}$ & $1.8 \times 10^{-11}$ \\
\hline $\begin{array}{l}\text { S6: ingestion of meat tainted by incidental consumption of } \\
\text { contaminated soil }\end{array}$ & $6.6 \times 10^{-10}$ & $6.6 \times 10^{-10}$ & $4.5 \times 10^{-13}$ \\
\hline $\begin{array}{l}\text { S7: ingestion of milk tainted by fodder grown on contaminated } \\
\text { soil }^{\mathrm{e}}\end{array}$ & $7.8 \times 10^{-9}$ & $7.7 \times 10^{-9}$ & $5.3 \times 10^{-12}$ \\
\hline $\begin{array}{l}\text { S8: ingestion of milk tainted by incidental consumption of } \\
\text { contaminated soil }\end{array}$ & $2.4 \times 10^{-10}$ & $2.4 \times 10^{-10}$ & $1.7 \times 10^{-13}$ \\
\hline
\end{tabular}

- RESRAD-CHEM estimates risk from inhalation of vapor in indoor air, following volatilization from all household uses of water, but does not separately report the contribution from showering.

- indicates that the model does not simulate exposure from this pathway

a sprinkler irrigation

$\mathrm{b}$ ditch irrigation

c includes incidental consumption of contaminated soil

$\mathrm{d}$ differences in model predictions are caused partly by differences in modeler interpretations of the scenario

e differences in model predictions are caused entirely by differences in modeler interpretations of the scenario 
Table 3.8. Risk from direct biosphere exposure to uranium-234

Scenario

W1: dermal contact while swimming

W2: dermal contact while showering

W4: ingestion while showering

W5: ingestion of contaminated drinking water

W6: ingestion of leafy vegetables irrigated with contaminated water

W7: ingestion of nonleafy vegetables irrigated with contaminated water

W8: ingestion of meat tainted by contaminated livestock water

W9: ingestion of meat tainted by fodder irrigated with contaminated water

W10: ingestion of milk tainted by contaminated livestock water

WI1: ingestion of milk tainted by fodder irrigated with contaminated water

W12: ingestion of fin fish raised in contaminated water

S1: dermal contact with soil

S2: ingestion of contaminated soil

S3: ingestion of leafy vegetables grown on contaminated soil

S4: ingestion of nonleafy vegetables grown on contaminated soil

S5: ingestion of meat tainted by fodder grown on contaminated soil

S6: ingestion of meat tainted by incidental consumption of contaminated soil

S7: ingestion of milk tainted by fodder grown on contaminated soil

S8: ingestion of milk tainted by incidental consumption of contaminated soil

S9: external radiation from contaminated soil:
A: $1.0 \mathrm{~m}$ deep without cover
B: $0.15 \mathrm{~m}$ deep without cover
C: $1.0 \mathrm{~m}$, with $0.15 \mathrm{~m}$ cover
D: $0.15 \mathrm{~m}$, with $0.15 \mathrm{~m}$ cover

RESRAD MMSOILS MEPAS

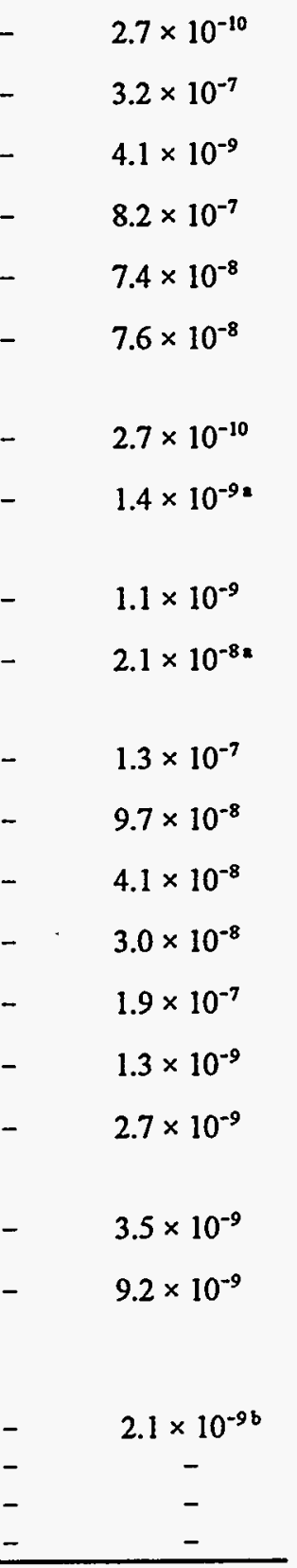

- indicates that the model does not simulate exposure from this pathway, MMSOILS does not compute radiological risk

$a$ includes incidental consumption of contaminated soil

b MEPAS computes risk for an infinitely thick contaminated layer with no clean cover, while RESRAD accounts for thickness of contaminated layer and shielding from clean cover 
Table 3.9. Risk from direct biosphere exposure to cobalt- 60

S9: external radiation from contaminated soil:

A: $1.0 \mathrm{~m}$ deep without cover

B: $0.15 \mathrm{~m}$ deep without cover

C: $1.0 \mathrm{~m}$, with $0.15 \mathrm{~m}$ cover

D: $0.15 \mathrm{~m}$, with $0.15 \mathrm{~m}$ cover

$6.0 \times 10^{-4}$
$4.8 \times 10^{-4}$
$1.2 \times 10^{-4}$
$9.9 \times 10^{-5}$
$-\quad 6.6 \times 10^{-5 b}$
$-\quad-$
$-\quad-$
$-\quad-$

- indicates that the model does not simulate exposure from this pathway, MMSOILS does not compute radiological risk a differences in model predictions are caused entirely by differences in modeler interpretations of the scenario b MEPAS computes risk for an infinitely thick contaminated layer with no clean cover, while RESRAD accounts for thickness of contaminated layer and shielding from clean cover

Table 3.10. Parameters not specified in the description of scenario S1

(Dermal contact with soil)

Parameters

RESRAD MMSOILS

MEPAS

Surface area of skin in contact with soil

$\mathrm{m}^{2}$

0.5

0.5

0.58

Soil adherence factor (to skin)

$\mathrm{mg} \mathrm{cm} \mathrm{cm}^{-2}$ event $^{-1}$

0.2

0.2

0.2

Exposure frequency

events $\mathrm{yr}^{-1}$

350

350

365

Gastrointestinal tract absorption fraction

$\mathrm{n} / \mathrm{a}$

$\mathbf{n} / \mathbf{a}$

Absorption fraction, $\mathrm{CCl}_{4}$

$\left(3.5 \times 10^{-5}\right)$

$3.5 \times 10^{-5}$

Event duration

hr event ${ }^{-1}$

12

$\mathbf{n} / \mathbf{a}$ n/a

n/a Not applicable

() Computed by the code 
Table 3.11. Parameters not specified in the description of scenario $W 1$ (Dermal contact while swimming in contaminated water)

\begin{tabular}{lrrrr}
\hline Parameters & RESRAD & MMSOILS & MEPAS \\
\hline Surface area of skin contact & $\mathrm{m}^{2}$ & 2.0 & 2.0 & 2.0 \\
Permeability constant (of skin) $\mathrm{CCl}_{4}$ & $\mathrm{~cm} \mathrm{hr}^{-1}$ & 0.022 & 0.022 & 0.022 \\
Exposure frequency & events yr $^{-1}$ & 5 & 5 & 24 \\
Event duration & $\mathrm{hr} \mathrm{event}^{-1}$ & 0.5 & 0.5 & 0.5 \\
\hline
\end{tabular}

Table 3.12. Parameters not specified in the description of scenario W2 (Dermal contact while showering in contaminated water)

\begin{tabular}{lrrrr} 
Parameters & RESRAD & MMSOLS & MEPAS \\
\hline Surface area of skin contact & $\mathrm{m}^{2}$ & 2.0 & 2.0 & 2.0 \\
Permeability constant (of skin) $\mathrm{CCl}_{4}$ & $\mathrm{~cm} \mathrm{hr}^{-1}$ & 0.022 & 0.022 & 0.022 \\
Exposure frequency & events yr $^{-1}$ & 350 & 350 & 365 \\
Event duration & $\mathrm{hr} \mathrm{event}$ & 0.167 & 0.167 & 0.167 \\
\hline
\end{tabular}


Table 3.13. Parameters not specified in the description of scenario W6 (Ingestion of leafy vegetables irrigated with contaminated water)

\begin{tabular}{|c|c|c|c|c|}
\hline Parameters & & RESRAD & MMSOILS & MEPAS \\
\hline Irrigation mode & & overhead & ditch & overhead \\
\hline Irrigation & $\mathrm{m} \mathrm{yr}^{-1}$ & 0.2 & 0.2 & 1.2 \\
\hline Bulk density agricultural field & $\mathrm{kg} \mathrm{m}^{-3}$ & 1500 & 1500 & 1600 \\
\hline Mixing depth in agricultural field & $\mathrm{m}$ & 0.15 & $0.1 \dagger$ & 0.15 \\
\hline (agricultural areal/effective surface) density & $\mathrm{kg} \mathrm{m}^{-2}$ & $225 \dagger$ & $150 \dagger$ & 240 \\
\hline Bulk density of contaminated zone & $\mathrm{kg} \mathrm{m}^{-3}$ & 1500 & $\mathrm{n} / \mathrm{a}$ & 1500 \\
\hline Thickness of contaminated zone & $\mathrm{m}$ & 0.15 & $\mathrm{n} / \mathrm{a}$ & 0.15 \\
\hline Computed recharge rate & $\mathrm{m} \mathrm{yr}^{-1}$ & 0.5 & 0.5 & $\mathrm{n} / \mathrm{a}$ \\
\hline $\begin{array}{l}\text { Soil/water distribution coefficient } \\
\text { carbon tetrachloride } \\
\text { uranium-238 }\end{array}$ & $\begin{array}{l}\mathrm{mL} \mathrm{g}^{-1} \\
\mathrm{~mL} \mathrm{~g}^{-1}\end{array}$ & $\begin{array}{r}2.2 \\
50\end{array}$ & 2.2 & $\begin{array}{l}\mathrm{n} / \mathrm{a} \\
\mathrm{n} / \mathrm{a}\end{array}$ \\
\hline Fraction of plant that is dry & & not used & 0.15 & $0.25 t$ \\
\hline Exposure frequency (plant consumption/yr) & events $\mathrm{yr}^{-1}$ & 365 & 365 & 365 \\
\hline $\begin{array}{l}\text { Fraction of deposited contaminants initially } \\
\text { retained on vegetation }\end{array}$ & & $0.25 \dagger$ & $\mathrm{n} / \mathrm{a}$ & 0.25 \\
\hline foliage to edible plant translocation factor & ' & $1 \uparrow$ & $\mathrm{n} / \mathrm{a}$ & 1 \\
\hline $\begin{array}{l}\text { Plant (weathering) removal constant } \\
\text { Weathering decay half life }\end{array}$ & $\begin{array}{r}\mathrm{yr}^{-1} \\
\mathrm{~d}\end{array}$ & $\begin{array}{r}20 \dagger \\
12.6\end{array}$ & $\mathbf{n} / \mathbf{a}$ & $\begin{array}{r}18.1 \\
14 \dagger\end{array}$ \\
\hline Growing season / time of plant exposure & $\mathrm{d}$ & $91.25 y \dagger$ & $\mathrm{n} / \mathrm{a}$ & 60 \\
\hline Crop yield (wet weight) & $\mathrm{kg} \mathrm{m}^{-2}$ & $1.5 \dagger$ & $\mathrm{n} / \mathrm{a}$ & 2.0 \\
\hline
\end{tabular}

$\dagger$ Not user changeable

n/a Not applicable 


\section{3-18}

Table 3.14. Parameters not specified in the description of scenario W7 (Ingestion of nonleafy vegetables irrigated with contaminated water)

Parameters RESRAD MMSOLS MEPAS

Foliage to edible plant translocation factor $0.1 \dagger$ $\mathrm{n} / \mathrm{a}$ 0.1

Growing season/time of plant exposure d $62.05 t$ $\mathrm{n} / \mathrm{a}$ 60

Crop yield (wet weight) $\mathrm{kg} \mathrm{m}^{-2}$ $0.7 \dagger$ n/a

$\dagger$ Not user changeable

n/a Not applicable

Table 3.15. Parameters not specified in the description of scenario W9

(Ingestion of meat tainted by fodder irrigated with contaminated water)

Parameter

Foliage to edible plant translocation factor

Growing season/time of plant exposure

Crop yield (wet weight)
RESRAD "MMSOILS

MEPAS

$n / a$

0.1

d

$29.2 \uparrow$

$\mathrm{n} / \mathrm{a}$

30

$\dagger$ Not user changeable

$1.1 \uparrow$

$\mathrm{n} / \mathrm{a}$ 0.7

\section{n/a Not applicable}




\section{DIRECT AIR RELEASE}

\subsection{SCENARIO DESCRIPTION}

The direct air release scenario involves a steady state emission of one material (thorium-228) from an area source for a period of 10 yrs. As illustrated in Fig. 4.1, comparisons are made at receptor locations located downwind of the release area (all figures and tables are presented in order beginning on page 4-5). The endpoints for comparison are the resultant air and soil environmental concentrations computed by the three models.

The objective of this scenario is to have a relatively simple air release case for comparing the outputs of the models based on a single set of conditions. This scenario contrasts to the typical application of these models where the air and surface concentrations are the average and sum, respectively, of values computed over the natural range of ambient conditions. For the direct air release, one set of wind speed, wind direction, and dispersion rate is selected. The causes of any differences in the results are much easier to trace by modeling for a single set of ambient atmospheric conditions.

\subsection{MODELING ASSUMPTIONS AND APPROACH}

The three models were run for the direct air release scenario. A constant emission of thorium-228 was assumed to occur for 10 yrs (i.e., no degradation of the source term with time). The average air concentrations resulting from this release will not change with time, and the soil concentrations resulting from deposition from the plume to underlying soil will steadily increase over the 10 yrs. However, the thorium-228 is assumed to decay in the environment after its release; this decay results in reduced parent concentrations and ingrowth of decay products in the soil.

MMSOILS uses one of two algorithms for estimating atmospheric concentrations. Within $100 \mathrm{~m}$ of a source, a box model is used. At distances of $100-\mathrm{m}$ or greater, a sector-averaged Gaussian plume model with source depletion is used. Reflections due to limited vertical mixing heights are not considered. Dry deposition is calculated using a deposition velocity which must be input by the user.

MEPAS has one algorithm for estimating atmospheric concentrations. At distances of $100 \mathrm{~m}$ or greater, a sector-averaged Gaussian plume model with source depletion is used. Onsite evaluations for air dispersion in the test case are made using the maximum exposures at $100 \mathrm{~m}$. MEPAS does account for reflections due to limited vertical mixing heights. In MEPAS, dry deposition from the air to surfaces is computed based on contaminant chemical and physical properties as well as ambient conditions (wind speed, turbulence, and local surface cover roughness). MEPAS accounts for wet deposition using inputs of annual precipitation amount and storm frequencies.

To calculate contaminant concentration at offsite locations, the RESRAD modeler used the EPA's Clean Air Act Assessment Model, CAP88, which is currently being linked with RESRAD for offsite dispersion calculations. CAP88 has a sector-averaged Gaussian plume model with source depletion similar to MEPAS and MMSOILS. Reflections due to limited vertical mixing heights are considered. Dry deposition is calculated using fixed values of deposition velocities that are not modifiable by the user; a value of $0.0018 \mathrm{~m} \mathrm{~s}^{-1}$ is used for thorium-228. CAP88 also accounts for wet deposition by allowing the user to enter the annual precipitation rate.

Definition of the parameters for this scenario addresses different approaches used by the models for dry deposition. As noted previously, MEPAS computes a spatial and temporal array of deposition 
velocities. By contrast, in CAP88 and MMSOILS dry deposition is characterized by an average value of deposition velocity for each contaminant applied to all conditions. In the base case scenario, CAP88 uses a value of $0.0018 \mathrm{~m} \mathrm{~s}^{-1}$ for thorium-228, and MMSOILS was run with $0.001 \mathrm{~m} \mathrm{~s}^{-1}$ for deposition velocity. For the MEPAS base case scenario, a set of input parameters is selected to represent equivalent environmental conditions. In the base case scenario, the average deposition velocity for all conditions estimated by MEPAS $\left(0.001 \mathrm{~m} \mathrm{~s}^{-1}\right)$ is a similar value to those used in the base case run for the two other models. In the MEPAS analysis, pollutant and surface characteristics are selected that give the desired magnitude of deposition velocity for the atmospheric conditions assumed in this scenario. To help better document the relationship between the deposition velocity and particle size assumptions, special cases with enhanced dry deposition were run with two models (MEPAS, assuming deposition of a larger particle size; MEPAS, assuming deposition on different surface covers; and MMSOILS with a higher deposition velocity).

The ambient meteorological conditions are generated as a joint frequency data set (contains tables of frequency of occurrence for a matrix of wind speed, wind direction, and dispersion conditions) with non-zero occurrences only in neutral (D) stability conditions within one wind speed class. This restricted joint frequency table is defined such that computations are made for only one set of ambient atmospheric conditions. This approach has the advantage that the resultant concentrations are computed as single dispersion expressions rather than being a summation of dispersion expressions.

To a certain extent, the scenario definitions in this benchmarking scenario are biased to processes common to all the models. That is, certain special features of the models were minimized, or not used, to allow comparisons of the common features of the models. Because one of the three models did not account for wet deposition, the ambient conditions for the test scenario are defined to minimize the wet deposition. The assumption of a very low annual precipitation rate and frequency sets the wet deposition influences to near-zero. In addition, the selected end points for comparisons were logically limited to products that at least two of the models produced or could be easily derived from model outputs.

The assumed emission rate of thorium-228 is shown in Table 4.1. Half-lives for thorium-228 and two of its decay products are also noted on Table 4.1. In addition, the thorium-228 particles are assumed to have a diameter of $0.6 \mu-$ a typical value for ambient aerosols. The meteorological data for the direct air release are listed in Tables 4.2, 4.3,4.4, and 4.5. The roughness assumption of $10 \mathrm{~cm}$ is a default value for MEPAS that should give results equivalent to models not accounting for the influences of the local roughness. The estimated value of $0.001 \mathrm{~m} \mathrm{~s}^{-1}$ for deposition velocity is typical for ambient aerosols.

The variation of soil concentration with time is derived from model outputs of soil deposition rates. The benchmarking staff computed the equivalent accumulation of material that occurs with the computations of each model. Therefore, only the first point in the time series is a direct model output. All other values are generated using an external emulation of the model's internal computations.

\subsection{COMPARISON OF CALCULATED RESULTS}

Table 4.6 contains the air concentrations computed with the three models. In addition to the base case runs that correspond to the direct air release scenario, the table includes several entries that illustrate the influence of using deposition parameters appropriate for larger particle sizes.

The air concentrations for the direct air release scenario (base case runs) listed in Table 4.6 are plotted as a function of distance in Fig. 4.2. For the(se) equivalent base cases (MMSOILS and 
RESRAD/CAP88 with deposition velocities of $0.001 \mathrm{~m} \mathrm{~s}^{-1}$ and $0.0018 \mathrm{~m} \mathrm{~s}^{-1}$, respectively; MEPAS with a particle diameter size of $0.6 \mu$ and a default surface roughness of $10 \mathrm{~cm}$ ), the air concentrations have nearly the same magnitude at the listed distances. For the cases selected to illustrate the variation with the deposition assumptions, the air concentrations decrease reflecting the increased plume depletion by deposition. Larger deposition velocities with MMSOILS and a larger particle size with MEPAS both result in lower concentrations as one progresses away from the site. Because the release is steady state, no variation of air concentration is expected with time.

The inputs for only the two special deposition cases were selected to show the trends in enhanced deposition rates with changes in the inputs. The two special deposition cases are not designed to be equivalent; therefore, they are not designed for direct comparison. The two special deposition cases show trends for alternative input values. The selected alternative values do not necessarily represent equivalent deposition cases; therefore, the two special cases are not designed for comparison of the magnitude of the deposition rates.

The magnitude of the air concentrations for the base case scenario are essentially the same at distances of $1 \mathrm{~km}$ and greater from the site. At closer distances the air concentrations predicted by MEPAS and CAP88 are close also. At the closest distance, the MMSOILS predicted concentrations are about a factor of 2 lower than predicted by the other two models. The difference in concentrations is the result of the use of a different area-correction approach in MMSOILS. The MMSOILS code uses a virtual distance correction to account for the size of the area. This virtual distance approach is expected to underpredict concentrations near the source by over accounting for the areal dispersion. The MEPAS code uses the potentially conservative approach of approximating the influence of an areal release on initial dispersion by modeling the release as emissions from a centrally located point source within the area.

Unlike the air concentrations, the soil concentrations vary with time as deposited material accumulates in the soil (Table 4.7). The base case soil concentrations in a cultivated 15-cm layer computed as a function of time at a location $1000 \mathrm{~m}$ from the center of the area are plotted in Fig. 4.3. The soil concentrations for the base cases have the same shape and approximate magnitude. The MEPAS base case is based on a default surface roughness value of $10 \mathrm{~cm}$. The MEPAS soil concentrations are between the MMSOILS and RESRAD/CAP88 results. The fact that the range of MEPAS outputs is comparable to the range of outputs from the three models implies that the use of different roughness lengths in MEPAS would not change the overall model comparison results.

\subsection{CONCLUSIONS}

The air concentration comparisons show that nearly identical results are obtained with the three models for the direct air release scenario. A difference of a factor of 2 occurs in the MMSOILS predicted concentrations near the source as the result of different initial dilution formulations. For this comparison, the very close agreement reflects use of the same, or equivalent, dispersion formulations. This comparison shows that MMSOILS, MEPAS, and CAP88 models give equivalent air concentration predictions for the selected set of conditions.

The deposition comparisons show the three models are giving approximately the same results. At the $1.0-\mathrm{km}$ distance, the magnitude of these predicted deposition rates reflects mainly the predicted air concentrations and the deposition velocities. The larger soil concentrations computed in the base case for RESRAD/CAP88 are the result of using a larger dry deposition velocity than MMSOILS. The base 


\section{4-4}

case results of MEPAS being run with a set of equivalent conditions show good agreement with the other two sets of results.

For MEPAS, the output parameters varied significantly within a normal range of parameter selection. For MMSOILS, the output parameters were sensitive to the selected value of deposition velocity. For both these models, the computed air concentrations were shown to vary with the assumed deposition rate in a fashion that was consistent with the RESRAD/CAP88 results. In addition, the range of soil concentrations in special cases, which were based on a range of surface roughnesses, was comparable to the range of soil concentrations observed between the models in the base case.

The comparisons between these models in this direct air release scenario show that the models give approximately the same values for the benchmarking end points for a singular set of ambient conditions. Because model differences may vary with ambient conditions, this result can only be interpreted as an indication of equivalency between the models. 


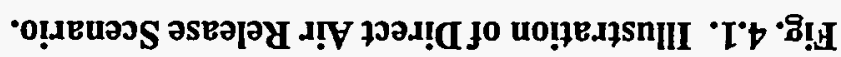

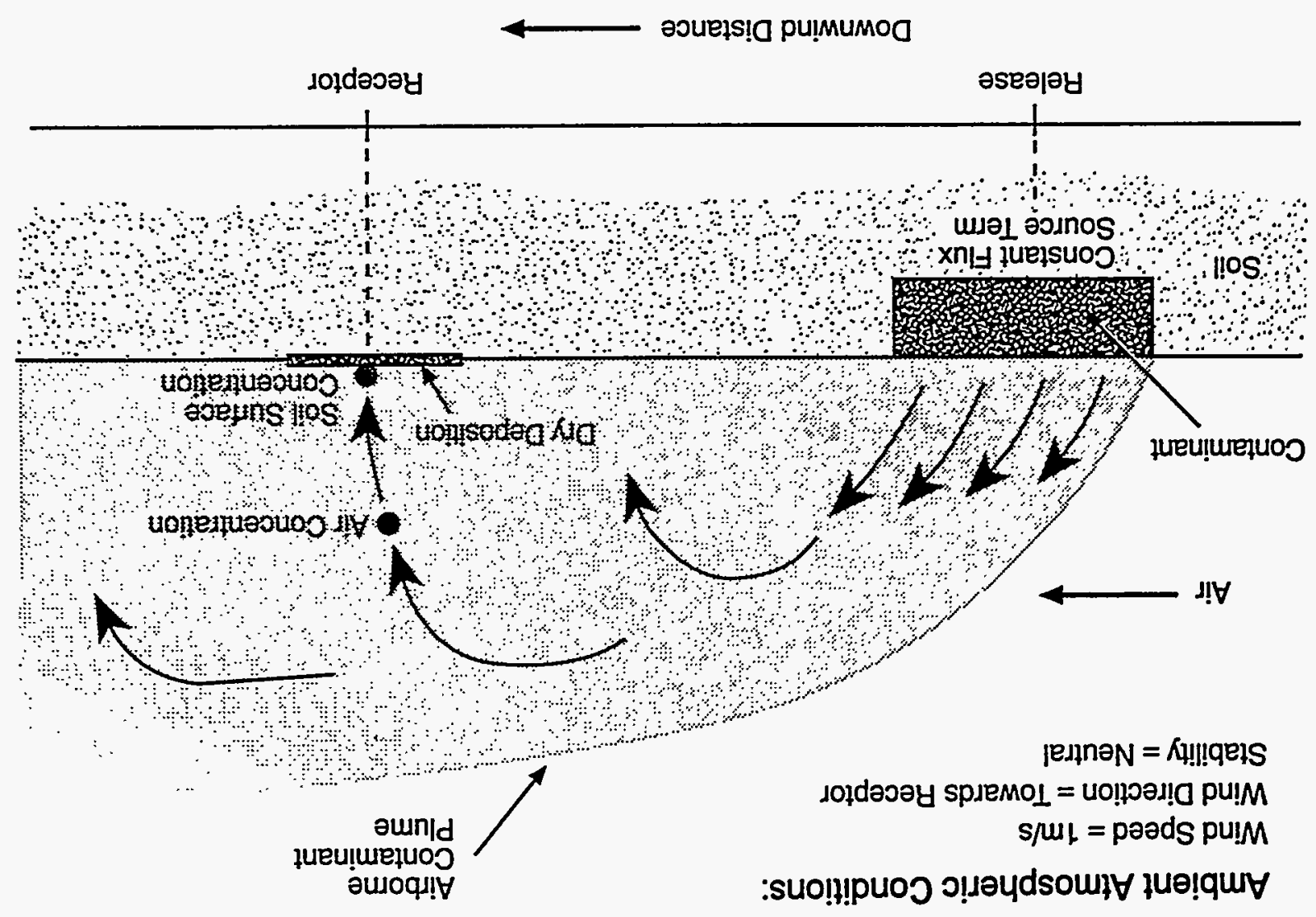


Direct Release to Air - Base Case Scenario

Thorium-228 - Air Concentrations

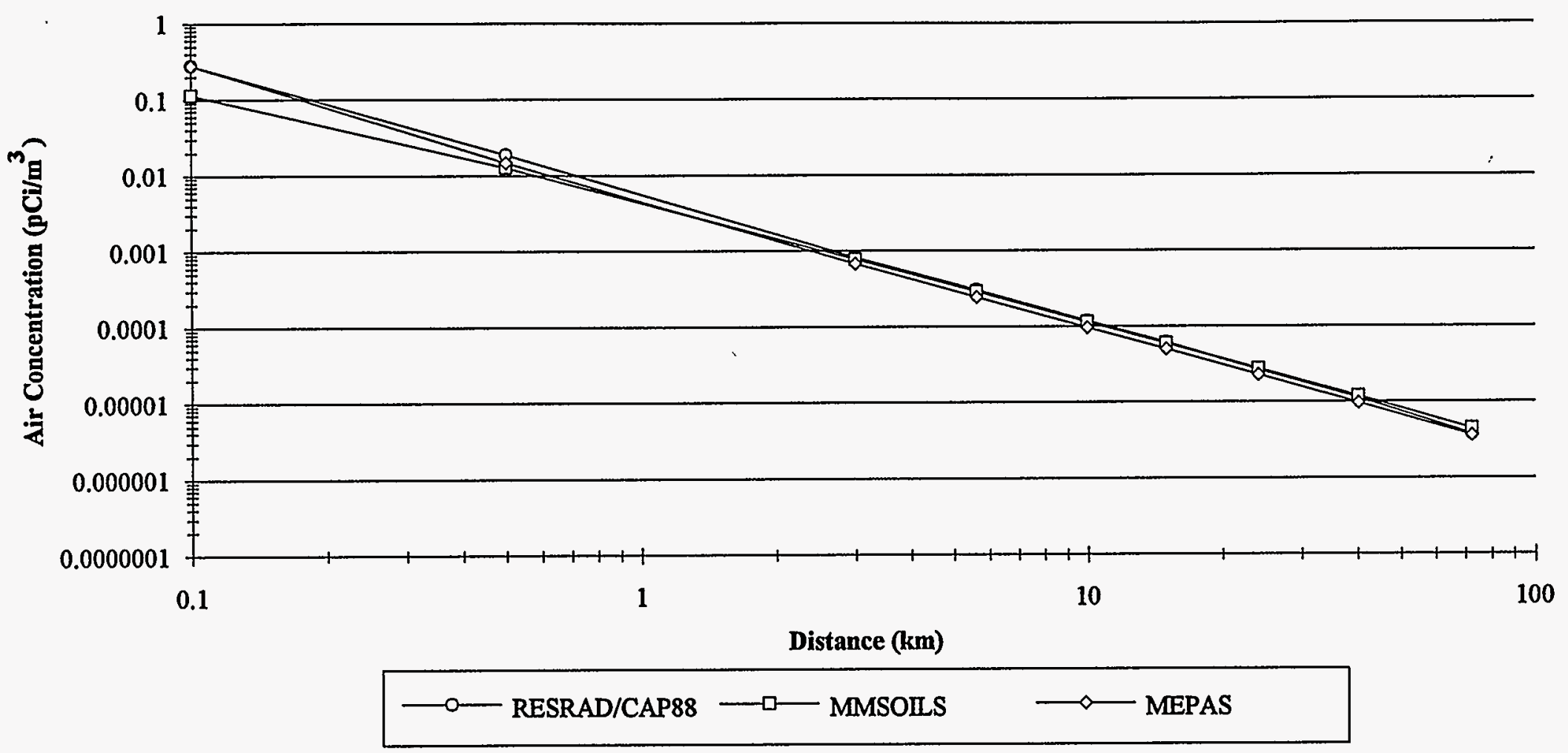

Fig. 4.2. Computed Air Concentrations as a Function of Distance for RESRAD/CAP88, MMSOILS, and MEPAS. 


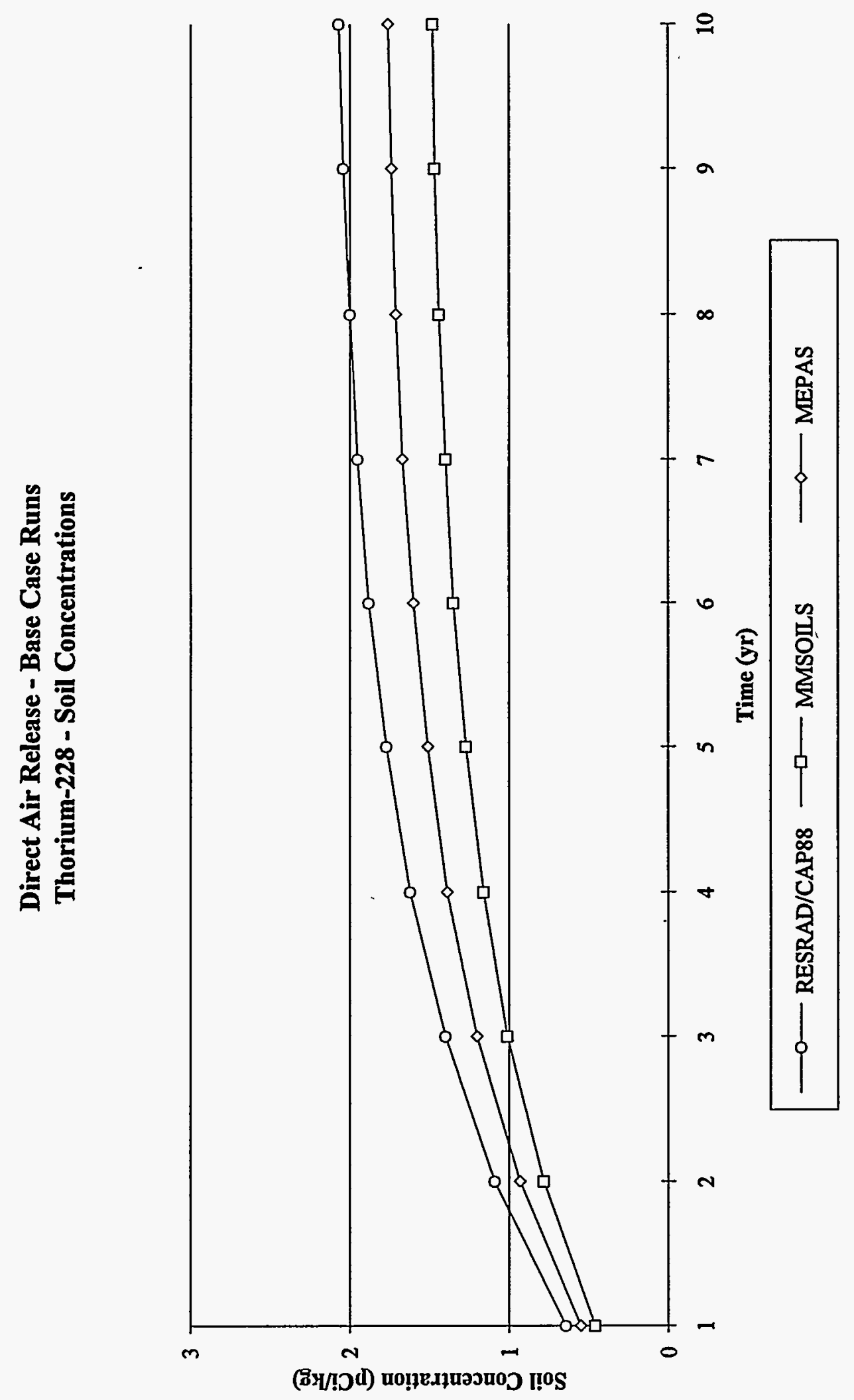

言 
Table 4.1. Source term for direct release to air

\begin{tabular}{ccc}
\hline Contaminant & Flux & $\mathbf{T}_{12}$ \\
\hline Thorium-228 & $1 \mathrm{pCi} \mathrm{m}^{2} \mathrm{~s}^{-1}$ & $1.93 \mathrm{yr}$ \\
Radium-224 & & $3.66 \mathrm{~d}$ \\
Radon-220 & & $55.6 \mathrm{~s}$ \\
\hline
\end{tabular}

Table 4.2. Meteorological data for direct release to air

Roughness length (all directions)

Deposition

Soil mixing depth at destination

Average morning mixing height

Average afternoon mixing height

Number of thunderstorms per yr

Annual mean air temperature

Annual precipitation

Number of precipitation days per yr

\section{$10 \mathrm{~cm}$}

$0.001 \mathrm{~m} \mathrm{~s}^{-1}$

$15 \mathrm{~cm}$

$900 \mathrm{~m}$

$2600 \mathrm{~m}$

1

$55 \mathrm{~F}$

0.2 in.

Table 4.3. Wind speed group midpoints for direct release to air

\begin{tabular}{lllllll}
\hline Wind speed group & 1 & 2 & 3 & 4 & 5 & 6 \\
Midpoints & 1 & 2 & 3 & 4 & 5 & 6 \\
\hline
\end{tabular}

Table 4.4. Calm events per wind stability class for direct release to air

\begin{tabular}{llllllll}
\hline Stability class & A & B & C & D & E & F & G \\
Calm events & 0 & 0 & 0 & 0 & 0 & 0 & 0 \\
\hline
\end{tabular}


Table 4.5. Joint frequency data for direct release to air

\begin{tabular}{cccccccc}
\hline Direction & Stability class & $\mathbf{1}$ & $\mathbf{2}$ & $\mathbf{3}$ & $\mathbf{4}$ & $\mathbf{5}$ & $\mathbf{6}$ \\
\hline & $\mathrm{A}, \mathrm{B}, \mathrm{C}, \mathrm{D}, \mathrm{E}, \mathrm{F}$, and G & 0 & 0 & 0 & 0 & 0 & 0 \\
N & D & 1 & 0 & 0 & 0 & 0 & 0 \\
NNE & D & 0 & 0 & 0 & 0 & 0 & 0 \\
NE & D & 0 & 0 & 0 & 0 & 0 & 0 \\
ENE & D & 0 & 0 & 0 & 0 & 0 & 0 \\
E & D & 0 & 0 & 0 & 0 & 0 & 0 \\
ESE & D & 0 & 0 & 0 & 0 & 0 & 0 \\
SE & D & 0 & 0 & 0 & 0 & 0 & 0 \\
SSE & D & 0 & 0 & 0 & 0 & 0 & 0 \\
S & D & 0 & 0 & 0 & 0 & 0 & 0 \\
SSW & D & 0 & 0 & 0 & 0 & 0 & 0 \\
SW & D & 0 & 0 & 0 & 0 & 0 & 0 \\
WSW & D & 0 & 0 & 0 & 0 & 0 & 0 \\
W & D & 0 & 0 & 0 & 0 & 0 & 0 \\
WNW & D & 0 & 0 & 0 & 0 & 0 & 0 \\
NW & D & 0 & 0 & 0 & 0 & 0 & 0 \\
NNW & & 0 & 0 & 0 & 0 \\
\hline & & 0 & 0 & 0 & 0
\end{tabular}


Table 4.6. Computed thorium air concentrations for the direct air release scenario

\begin{tabular}{|c|c|c|c|c|c|}
\hline \multicolumn{6}{|c|}{ Thorium Air Concentration $\left(\mathrm{pCi} / \mathrm{m}^{3}\right)$} \\
\hline & Ambient & Typical & Typical & Larger & Higher \\
\hline & Particle & Deposition & Deposition & Particle & Deposition \\
\hline & Diameter & Velocity & Velocity & Diameter & Velocity \\
\hline & Base & Base & Base & Special & Special \\
\hline Distance & Case $^{\mathbf{a}}$ & Case $^{b}$ & Case $^{\mathfrak{c}}$ & Case $^{d}$ & Case $^{\circ}$ \\
\hline$(\mathrm{km})$ & MEPAS & MMSOILS & CAP88 & MEPAS & MMSOILS \\
\hline 0.1 & 0.277 & 0.114 & 0.282 & 0.242 & 0.114 \\
\hline 0.5 & 0.0147 & 0.0126 & 0.0189 & 0.0104 & 0.0118 \\
\hline 1.0 & 0.00435 & - & - & 0.00275 & - \\
\hline 3 & 0.000683 & 0.000775 & 0.000825 & 0.000343 & 0.000563 \\
\hline 5.63 & 0.000244 & 0.000286 & 0.000303 & 0.0001 & 0.000187 \\
\hline 10 & $9.63 \mathrm{E}-05$ & 0.000114 & 0.000118 & $3.22 \mathrm{E}-05$ & $6.59 \mathrm{E}-05$ \\
\hline 15 & $4.96 \mathrm{E}-05$ & 5.95E-05 & $6.12 \mathrm{E}-05$ & $1.31 \mathrm{E}-05$ & $3.08 \mathrm{E}-05$ \\
\hline 24.1 & 2.29E-05 & $2.76 \mathrm{E}-05$ & $2.68 \mathrm{E}-05$ & 4.59E-06 & $1.22 \mathrm{E}-05$ \\
\hline 40.2 & $9.70 \mathrm{E}-06$ & $1.19 \mathrm{E}-05$ & $1.12 \mathrm{E}-05$ & $1.26 \mathrm{E}-06$ & 4.20E-06 \\
\hline 72.4 & $3.59 \mathrm{E}-06$ & 4.42E-06 & 3.73E-06 & $2.65 \mathrm{E}-07$ & $1.10 \mathrm{E}-06$ \\
\hline
\end{tabular}

MEPAS base case: particles with diameter of $0.6 \mu$ and a uniform regional surface roughness of $10 \mathrm{~cm}$.

"MMSOILS base case: deposition velocity of $0.001 \mathrm{~m} \mathrm{~s}^{-1}$.

'CAP88 base case: fixed deposition velocity of $0.0018 \mathrm{~m} \mathrm{~s}^{-1}$.

MEPAS enhanced deposition case: larger particles (diameter of $6.0 \mu$ ).

MMSOILS enhanced deposition case: larger deposition velocity $\left(0.005 \mathrm{~m} \mathrm{~s}^{-1}\right)$.

Table 4.7. Direct air release: computed thorium soil concentrations at 1000-m downwind

\begin{tabular}{|c|c|c|c|c|c|}
\hline \multirow{4}{*}{$\begin{array}{l}\text { Time } \\
\text { (yrs) }\end{array}$} & \multicolumn{4}{|c|}{ Cumulative Soil Concentration (pCi/g) } & \multirow{4}{*}{$\begin{array}{l}\text { Rougher } \\
\text { Terrain } \\
\text { MEPAS }\end{array}$} \\
\hline & Base & Base & Base & Smoother & \\
\hline & Case & Case & Case & Terrain & \\
\hline & MEPAS $^{b}$ & MMSOILS & CAP88 ${ }^{d}$ & MEPAS $^{\mathrm{e}}$ & \\
\hline 1 & 0.550 & 0.46 & 0.643 & 0.418 & 0.619 \\
\hline 2 & 0.933 & 0.781 & 1.09 & 0.698 & 1.05 \\
\hline 3 & 1.20 & 1.01 & 1.40 & 0.898 & 1.35 \\
\hline 4 & 1.39 & 1.16 & 1.62 & 1.04 & 1.56 \\
\hline 5 & 1.51 & 1.27 & 1.77 & 1.13 & 1.71 \\
\hline 6 & 1.60 & 1.35 & 1.88 & 1.20 & 1.81 \\
\hline 7 & 1.67 & 1.4 & 1.95 & 1.25 & 1.88 \\
\hline 8 & 1.71 & 1.44 & 2.00 & 1.28 & 1.93 \\
\hline 9 & 1.74 & 1.47 & 2.04 & 1.30 & 1.96 \\
\hline 10 & 1.76 & 1.48 & 2.07 & 1.32 & 1.98 \\
\hline
\end{tabular}

'The soil concentrations are externally computed values using model outputs. None of the models (MEPAS, MMSOILS, or CAP88) currently provides the time series of this parameter as a direct output.

${ }^{b}$ Computed from MEPAS base case: particles with diameter of $0.6 \mu$ and a uniform regional surface roughness of 10-cm.

"Computed from MMSOILS base case: deposition velocity of $0.001 \mathrm{~m} \mathrm{~s}^{-1}$.

¿Computed from RESRAD/CAP88 base case: fixed deposition velocity of $0.0018 \mathrm{~m} \mathrm{~s}^{-1}$.

'Computed from MEPAS smoother terrain case: uniform regional surface roughness of 1-cm.

Computed from MEPAS rougher terrain case: uniform regional surface roughness of $50-\mathrm{cm}$. 


\section{DIRECT RELEASE TO THE VADOSE ZONE}

The vadose-zone component transports contaminants vertically though a vadose zone to a water-table surface. Heterogeneities in the vadose zone are accounted for by subdividing the vadose zone into multiple layers with homogeneous properties. RESRAD, MMSOILS, and MEPAS consider multiple layers to describe the vadose zone. This chapter reviews a scenario simulating the direct release of contaminants to a vadose zone with two layers. Only results associated with the source and vadose zone are presented.

\subsection{SCENARIO DESCRIPTION}

An unlined waste site directly discharges methylene chloride and uranium-238 to the vadose zone, which contains two layers. Contaminants then migrate through these two vadose zones to the water-table surface. The first and second vadose zones are assumed to be 10.4 and $100 \mathrm{~m}$ thick, respectively. The characteristics of the source, vadose zones \#1 and \#2, and chemical properties are presented in Table 5.1 (all tables and figures for this chapter are presented in order beginning on page 5-16). No overland nunoff, surface erosion, surface resuspension, or volatilization are assumed to occur; there is no ponding at the surface. Degradation/decay takes place at the source and in the environment. Figure 5.1 conceptually illustrates the problem.

A known steady-state infiltration rate (i.e., specific discharge or Darcy velocity) from the source is assumed as $1.27 \times 10^{-2} \mathrm{~m} \mathrm{yr}^{-1}$. Water and contaminant movement through the vadose zones are considered to be unidirectional and one-dimensional in the vertical direction. Methylene chloride and uranium-238 source-term inventories are assumed as $8.38 \times 10^{12} \mathrm{mg}$ and $112 \mathrm{Ci}$, respectively. Constant flux rates are assumed as $5.78 \times 10^{8} \mathrm{mg} \mathrm{yr}^{-1}$ and $3.55 \times 10^{9} \mathrm{pCi} \mathrm{yr}^{-1}$ for the nonradionuclide (i.e., denoted chemical herein) and radionuclide, respectively. Contaminant releases from the source are assumed to be constant. The durations of the release for methylene chloride and uranium-238 which occur over approximately $14,500 \mathrm{yrs}$ (i.e., $8.38 \times 10^{9} \mathrm{~g} / 5.78 \times 10^{5} \mathrm{~g} \mathrm{yr}^{-1}$ ) and $31,550 \mathrm{yrs}$ (i.e., $112 \mathrm{Ci} / 3.55 \times 10^{-3}$

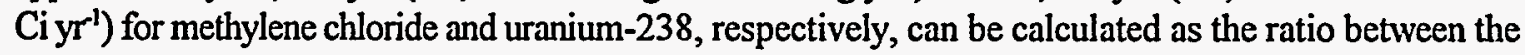
inventory and mass flux rate. Solubility limits are not considered in this benchmarking problem. RESRAD, MMSOILS, and MEPAS all provide options for checking for solubiity limits, where appropriate.

This analysis investigates the release and transport of methylene chloride and uranium-238, as described in the initial paragraphs of this chapter, and represents the results of a comparison of the models as they would be implemented by any user; therefore, differences in the codes' assumptions are only explored from the standpoint of the output results. End points for the comparison for each contaminant include time-varying contaminant fluxes from the source to the first vadose zone at the interface between the vadose zones and at the water-table surface (i.e., entering the saturated zone). Peak fluxes and times to peak flux are also tabulated for each contaminant at each location. If a saturated zone had followed in the benchmarking exercise, as illustrated in Chapter 9, these fluxes and times to peak as predicted by the models within the vadose zone would remain unaffected by the presence of the saturated zone. Although Fig. 5.1 displays a water-table surface, no credit is given to contaminant transport in the saturated zone. For transport in the saturated zone, refer to Chapter 6.

\subsection{MODELING ASSUMPTIONS AND APPROACH}

RESRAD, MMSOILS, and MEPAS use similar, although not the same, approaches to simulate the movement of moisture and contaminants through the vadose zone. To account for heterogeneities, each 
model subdivides the vadose zone into multiple layers, whose properties may vary from layer to layer. Moisture movement is assumed to be vertically downward and one-dimensional. Moisture backup into overlying soil layers, resulting in ponded water at the surface, is not accounted for in any of the models, although excess water associated with the initial surface layer is removed through overland runoff. Other characteristics of the models are presented in the following sections.

Although RESRAD and MEPAS handle decay products for radionuclides in the subsurface environment, progeny formation is not addressed in this chapter, because MMSOILS does not consider decay products. Progeny formation is considered in Chapters 6 and 9.

\subsubsection{RESRAD}

RESRAD contains a one-dimensional, plug-flow, vadose-zone model. Contaminant movement is assumed to occur by pure translation, and concentrations are calculated as the ratio of contaminant and water fluxes. The water flux rates are a function of an "effective" moisture content, which defines that portion of the total volume through which flow occurs.

RESRAD is specifically designed to start with a waste site containing contaminated soil with a known soil concentration. RESRAD simulates (1) the release of contaminants to a vadose zone and (2) transport through multiple layers to the water-table surface. The source term model partitions the contaminants for simultaneous release to the vadose zone and air, including leaching, erosion through particle suspension, and progeny formation. To help ensure mass balance at the source, the form of the release (i.e., time-varying emission rates) of contaminants to a specified medium in RESRAD (1) is autocorrelated to mass, (2) has been predetermined to have an exponential form, (3) is internally computed by the model, and (4) is not a direct input by the user. However, the user does have some control in modifying the form of the release through input parameters in the RESRAD source term model. For releases to the subsurface environment, RESRAD assumes that the leaching of contaminants is linearly proportional to the source inventory and is described by a time-varying release that has an exponential distribution for nonradioactive chemicals (known as "chemicals" herein) and parent radionuclides.

\subsubsection{MMSOILS}

MMSOILS is specifically designed to start with a waste-site situation (e.g., landfill, waste pile, etc.). The MMSOILS source-term model contains two options for leaching contaminants from the waste site. The release can be described by (1) mass flux rates that decrease over time, if applicable, or (2) a constant source concentration (or flux), designated by the user or calculated by the source term module, where the inventory degrades exponentially, if applicable. In this particular problem, MMSOILS assumes a constant source concentration and simulates (1) the release of contaminants to a vadose zone, based on precipitation-generated leaching and a water-mass balance at the surface, and (2) transport through multiple layers to the water-table surface. The source term model partitions the contaminants for simultaneous release to the vadose zone, air, and overland by erosion and considers first-order degradation without progeny formation. Removal of contaminants to the air (e.g., volatilization and particle resuspension) and by soil erosion were not considered in this problem; therefore, they were turned off in MMSOILS. The source term module performs a water-mass balance at the source to estimate an infiltration rate, which is used to calculate time-varying contaminant fluxes leaching from the waste site.

MMSOILS is a finite-element, plug-flow-with-dispersion model that numerically solves the one-dimensional advective-dispersive equation for contaminant transport through the vadose zone. MMSOILS assumes steady-state, flow conditions (vertically downward) and mechanical dispersion (i.e., shear diffusion and turbulent diffusion) in the flow direction. The pore-water velocity is based on a calculated moisture content for each layer. MMSOILS provides time-varying concentrations at medium 
boundaries (e.g., between vadose zone layers and at the water-table surface). Chemical degradation during transport is only calculated in the aqueous phase; no degradation is calculated while the chemical is adsorbed to the soil (Sharp-Hansen et al. 1993).

\subsubsection{MEPAS}

MEPAS is a plug-flow-with-dispersion model that solves the one-dimensional (vertically downward) advective-dispersive equation for groundwater transport. MEPAS assumes constant flow and hydrodynamic dispersion (i.e., molecular, shear-flow, and turbulent diffusions). MEPAS contains special provisions so the user can define direct time-varying releases into any medium; as such, MEPAS was able to simulate the constant-pulse release of methylene chloride and uranium-238 from an area source into the vadose zone.

\subsection{CONCLUSIONS}

The "direct release to the vadose zone" benchmarking case investigates the leaching of contaminants from a waste site with no other emissions being considered. Results are in the form of timevarying fluxes from the source and at the lower boundary of each vadose zone; these results are presented in Figs. 5.2 through 5.7 and Tables 5.7 through 5.11. To more clearly present the comparison between RESRAD, MMSOILS, and MEPAS, this section has been divided into the following subsections:

1. Source Term-A source term discussion is presented to highlight the assumptions, similarities, and differences between the models. Time-varying fluxes of methylene chloride and uranium- 238 from the source are presented and compared.

2. Mathematical Constructs Affecting Contaminant Transport-This section lays the foundation for discussing vadose-zone differences in the output between RESRAD, MMSOILS, and MEPAS; these models contain sufficiently different mathematical constructs, which can significantly impact the temporal and spacial distribution of contaminants in the vadose zone.

3. Time-Varying Fluxes in the Vadose Zone-This section presents the results of transporting methylene chloride and uranium-238 through two vadose zones. Discussions are also presented to explain similarities and differences between the models.

\subsubsection{Source Term}

Figures 5.2 and 5.3 present time-varying flux rates of methylene chloride and uranium-238, respectively, from the source for RESRAD, MMSOILS, and MEPAS. Table 5.7 presents the peak flux from the source for each contaminant for each model. The peak fluxes are all the same because at time zero each model started with the same peak flux.

RESRAD, MMSOILS, and MEPAS have specific source-term options from which they develop time-varying fluxes from the source. RESRAD contains a fixed source-term code which assumes that the leaching of contaminants is linearly proportional to the source inventory and is described with a decreasing exponential function. The exponential-type release in RESRAD for methylene chloride and uranium-238 is illustrated in Figs. 5.2 and 5.3, respectively. Although each model contains different source-term algorithms and options, they all conserve mass for this benchmarking problem. 
MMSOILS is a precipitation-driven source-term, waste-management model with user-designated options for generating the time-varying contaminant fluxes from the source. With MMSOILS, the user does not input a particular time-varying flux directly but must construct a simple leaching pattern by interactively manipulating the input parameters to the source-term management model. As such, for this benchmarking report, MMSOILS produces a constant time-varying release from the source beginning at year 24, as illustrated in Figs. 5.2 and 5.3 for methylene chloride and uranium-238, respectively. The 24-yr shift occurs because the source term module in MMSOILS assumes that the soil cover above the waste site is initially dry such that the infiltrating water must wet the cover layer before water (and contaminants) can move from the source and enter the first vadose zone.

MEPAS contains a source-term code that allows the user to choose the form of the release from the waste site (e.g., exponential, uniform, log-normal, steady state, or any other form the user desires). If the user wants to choose the distribution, the user has to directly input the time-varying release rates, and these rates do not have to be represented by any known function. Otherwise, MEPAS releases the contamination as a constant pulse, as illustrated by Figs. 5.2 and 5.3. For this problem, MEPAS assumes a constant release (i.e., step function) starting with time zero.

\subsubsection{Mathematical Constructs Affecting Contaminant Transport}

Because RESRAD, MMSOILS, and MEPAS define different time-varying releases from the source (i.e., exponential versus constant-pulse) to the vadose zone, inherent differences will exist when comparing the vadose-zone transport results between the models. In addition to variations in the sourceterm releases, the models also contain mathematical constructs that are responsible for temporally and spacially distributing the contaminants differently. The mathematical constructs are responsible for differences in pore-water and contaminant velocities, travel times, and peak fluxes. This section discusses the different mathematical constructs and how they impact the results as the contaminants are transported through the vadose zone.

The temporal and spacial distribution of contaminants through the vadose zone are described differently by the models; this distribution is affected by:

- time-varying contaminant fluxes from the source, which ultimately impact the time to peak and the magnitude of the flux as the contaminants migrate through the vadose zone;

- $\quad$ flow equations upon which the vadose-zone models are based, which drive the contaminants vertically downward through the different layers (e.g., RESRAD is based on the plug-flow model, which transports contaminants through pure translation. MMSOILS and MEPAS are based on solutions to the one-dimensional advective-dispersive equation, where advection and dispersion redistribute the contamination); and

- moisture content, which can significantly impact the retardation factor, pore-water and contaminant velocities, dispersion, and contaminant travel times in the flow direction.

Source-term releases are discussed in Sect. 5.3.1. Section 5.2 briefly discusses the flow equations upon which each model is based. Because moisture content and its use by the different models have a profound impact on the benchmarking results, moisture content and its impacts on pore-water and contaminant velocities, dispersion coefficient, and plug-flow travel time are each discussed separately, as they relate to RESRAD, MMSOILS, and MEPAS. 


\subsubsection{Moisture content}

Each model presents different mathematical constructs for calculating moisture content in the vadose zone. The moisture content is directly used in calculating retardation factors, pore-water and contaminant velocities, dispersion, and travel times, which in turn impact contaminant levels.

Many vadose-zone models base their moisture content estimation on a variation of an equation that was proposed by Gardner (1960) and discussed by Gardner et al. (1970), Campbell (1974), Clapp and Hornberger (1978), and Hillel (1980):

$$
\theta=n\left(\frac{K_{\theta}}{K_{s}}\right)^{m}
$$

in which

$$
m=\frac{1}{2 b+3}
$$

where

$\theta=$ the moisture content based on Eq. 5.1 (fraction)

$\mathrm{K}_{\mathrm{\theta}}=$ the hydraulic conductivity ( $\mathrm{m} \mathrm{yr}^{-1}$ )

$\mathrm{K}_{\mathrm{z}}=$ the saturated hydraulic conductivity $\left(\mathrm{m} \mathrm{yr}^{-1}\right)$

$\mathrm{n}=$ total porosity (fraction)

$\mathrm{m}=$ empirically based parameter that is a functionof soil properties (dimensionless)

b = constant based on soil type (dimensionless)

It has been shown empirically that the moisture content can be estimated using the infiltration rate (Hanks and Ashcroft 1980):

$$
\theta=n\left(\frac{K_{\theta}}{K_{s}}\right)^{m}=n\left(\frac{v_{d}}{K_{s}}\right)^{m}=n\left(\frac{i}{K_{s}}\right)^{m}
$$

where

$$
\begin{aligned}
& v_{\mathrm{d}}=\text { the Darcy velocity }\left(\mathrm{m} \mathrm{yr}^{-1}\right) \text {, which is equivalent to the Darcy infiltration rate for } \\
& \mathrm{i}=\text { the first vadose-zone layer } \\
& \text { the infiltration rate (i.e., Darcy velocity) }\left(\mathrm{m} \mathrm{yr}^{-1}\right)
\end{aligned}
$$

The total porosity represents the upper limit for the moisture content. Because Eq. 5.3 only accounts for the relationship between the hydraulic conductivity and moisture content, it does not consider or account for the predisposition of the moisture that may already exist in the soil. 
When defining the moisture content for the first vadose-zone layer, the infiltration rate is used in Eq. 5.3 calculations, if the infiltration rate does not exceed the saturated hydraulic conductivity. When the infiltration rate exceeds the saturated hydraulic conductivity, it is set equal to the saturated hydraulic conductivity (i.e., $\mathrm{i}=\mathrm{K}$ ). This conditional check is performed for each succeeding vadose-zone layer in RESRAD and MEPAS but not in MMSOILS.

RESRAD, MMSOILS, and MEPAS begin with Eqs. 5.2 and 5.3 as the basic equations for estimating moisture content. The actual moisture content that is used in each model is presented as follows:

1. RESRAD uses a modified version of Eq. 5.3 to define its moisture content:

$$
\theta_{e}=\theta\left(\frac{n_{e}}{n}\right)
$$

where

$$
\begin{aligned}
& \theta_{0}=\text { an effective moisture content in the vadose zone (fraction) } \\
& n_{0}=\text { an effective porosity in the vadose zone (fraction) }
\end{aligned}
$$

RESRAD defines the effective porosity as the ratio of the volume of the voids through which the water actually moves to the total volume. For example, water cannot move through dead-end pore spaces; therefore, the total void space (i.e., total porosity) is unavailable for transport. RESRAD defines the effective moisture content as the ratio of volume of the moisture that moves through the vadose zone to the total volume. For example, moisture which is bound to the soil or in dead-end pore spaces is not available for transport. The effective moisture content is used to define the pore-water velocity and plug-flow travel time.

2. MMSOILS uses Eq. 5.3 in all of its calculations. MMSOILS assumes that water will move through the vadose zone layers at the moisture content calculated in Eq. 5.3. Under normal circumstances, MMSOILS internally calculates moisture content in the vadose zone. For this benchmarking exercise, MMSOILS was modified to ensure that its moisture content matched that of MEPAS.

3. MEPAS uses Eq. 5.3 in all of its calculations where the moisture content is greater than or equal to the soil field capacity. By definition, the field capacity identifies the point when gravity drainage begins or ceases (Fetter 1988, Hanks and Ashcroft 1980). For example, if the moisture content is increased in a soil layer (e.g., infiltration due to precipitation or snowmelt), the field capacity identifies the moisture level where water flow begins under gravity drainage; if the moisture content is decreased in a soil layer (e.g., drainage or drying out), the field capacity identifies the point where water flow due to gravity ceases. Moisture content below field capacity results in no movement of the water in the vadose zone, although contaminant diffusion can occur. Because steady-state infiltration results in a moisture content at or above field capacity (accounting for evapotranspiration and other losses), MEPAS assumes that the moisture content is always at or above field capacity of the layer, as described by Eq. 5.3. When Eq. 5.3 estimates a moisture content below field capacity, MEPAS assumes field capacity, which is consistent with the assumption of water movement. 
Table 5.2 summarizes the moisture-content equations that are employed in RESRAD, MMSOILS, and MEPAS.

\subsubsection{Pore-water and contaminant velocities and retardation factor}

The moisture content directly affects the pore-water velocity, which can be defined by the following equation, although not necessarily employed, as defined by all of the models:

$$
\mathrm{v}_{\mathrm{p}}=\frac{\mathrm{v}_{\mathrm{d}}}{\theta}=\frac{\mathrm{i}}{\theta}
$$

where

$$
\mathrm{v}_{\mathrm{p}}=\text { the pore-water velocity }\left(\mathrm{m} \mathrm{yr}^{-1}\right) \text {. }
$$

The pore-water velocity is the "actual" speed of the water, while the Darcy velocity is not a velocity but the specific discharge (i.e., water discharge per cross-sectional area of waste site).

The moisture content also affects the retardation factor which can be defined by the following equation, although not necessarily employed, as defined by all of the models:

$$
\mathrm{R}_{\mathrm{f}}=1+\frac{\beta_{\mathrm{d}} \mathrm{K}_{\mathrm{d}}}{\theta}
$$

where

$\mathrm{R}_{\mathrm{f}}=$ the retardation factor (dimensionless)

$B_{d}=$ the soil bulk density $\left(\mathrm{g} \mathrm{cm}^{-3}\right)$

$\mathrm{K}_{\mathrm{d}}=$ the distribution coefficient $\left(\mathrm{mL} \mathrm{g}^{-1}\right)$

The contaminant velocity is a function of the pore-water velocity and retardation factor which can be defined by the following equation, although not necessarily employed, as defined by all of the models:

$$
v_{c}=\frac{v_{p}}{R_{f}}=\frac{v_{d}}{\theta+\beta_{d} K_{d}}
$$

where

$$
\mathrm{v}_{\mathrm{c}}=\text { the contaminant velocity }\left(\mathrm{m} \mathrm{yr}^{-1}\right)
$$


Beginning with Eqs. 5.2 through 5.4, as the basis for estimating flow and contaminant velocities, RESRAD, MMSOILS, and MEPAS define pore-water and contaminant velocities and retardation factors as follows:

1. RESRAD couples Eqs. 5.3 and 5.4 with Eq. 5.5 to define a pore-water velocity that is based on the effective porosity. The pore-water velocity equation employed in RESRAD is presented in Table 5.3. RESRAD also defines its retardation factor by Eq. 5.6. By coupling RESRAD's pore-water velocity, as presented in Table 5.3 with Eq. 5.6, the plug-flow contaminant velocity is defined as a function of the effective porosity, as presented in Table 5.3.

2. Because MMSOILS assumes that water will move through the vadose-zone layers at the moisture content calculated by Eq. 5.3, the pore-water and contaminant velocities are defined by Eqs. 5.5 and 5.7 , respectively.

3. When the moisture content is equal to or greater than the field capacity, MEPAS assumes that water will move through the vadose-zone layers at the moisture content calculated by Eq. 5.3; as such, the pore-water and contaminant velocities are defined by Eqs. 5.5 and 5.7, respectively. When Eq. 5.3 estimates a moisture content less than field capacity, the moisture content is set equal to the field capacity in Eqs. 5.5 through 5.7, as illustrated in Table 5.3.

Table 5.3 summarizes pore-water and contaminant velocities and retardation factors that are employed in RESRAD, MMSOILS, and MEPAS.

\subsubsection{Dispersion coefficient and dispersivity}

Moisture content affects the dispersion coefficient in MMSOILS and MEPAS. Because RESRAD is a plug-flow model, dispersion is not considered. Moisture content has the following effect on the dispersion coefficient:

$$
\mathrm{D}=\mathrm{D}_{\mathrm{mec}}+\mathrm{D}_{\mathrm{mol}}
$$

in which

$$
D_{\text {mec }}=v_{p} \alpha=\frac{v_{d} \alpha}{\theta}
$$

where

$$
\begin{aligned}
& \mathrm{D}=\text { the hydrodynamic dispersion coefficient }\left(\mathrm{m}^{2} \mathrm{yr}^{-1}\right) \\
& \mathrm{D}_{\text {mec }}=\text { the mechanical dispersion coefficient }\left(\mathrm{m}^{2} \mathrm{yr}^{-1}\right) \\
& \mathrm{D}_{\text {mol }}=\text { the molecular diffusion coefficient }\left(\mathrm{m}^{2} \mathrm{yr}^{-1}\right) \\
& \alpha=\text { the dispersivity in the flow direction }(\mathrm{m})
\end{aligned}
$$

The dispersion coefficient is used to determine the degree of spread associated with contaminant movement in the vertical direction (i.e., flow direction). MMSOILS internally calculates dispersivities 
and dispersion coefficients in the vadose zone. MEPAS allows the user to input the dispersivities or provides guidance for calculating them.

The dispersion coefficients and dispersivities for MMSOILS and MEPAS are calculated as follows:

1. MMSOILS defines its dispersion with the mechanical dispersion coefficient as described by Eq. 5.9, in which dispersivity in the flow direction is defined as follows (Salhotra et al. 1993):

$$
\alpha=0.02+0.022 \sum_{i=1}^{n} H_{i}
$$

where

$$
\begin{array}{ll}
\mathrm{H}_{\mathbf{i}}= & \text { the thickness of vadose-zone layer } \mathrm{i}(\mathrm{m}) \\
\mathrm{i} & =\text { the index on the number of vadose-zone layers } \\
\mathrm{n} & =\text { the number of vadose-zone layers }
\end{array}
$$

When the total thickness of the entire vadose zone (i.e., $10.4 \mathrm{~m}+100 \mathrm{~m}$ ) is greater than $44.5 \mathrm{~m}$, one $m$ is assigned to the dispersivity of all layers. This procedure is used to avoid excessively high dispersivities. Because the thickness of the vadose zone is $110.4 \mathrm{~m}$, a dispersivity for both layers was assigned as $1 \mathrm{~m}$. Using Eq. 5.9, the dispersion coefficients assigned by MMSOILS for the first and second vadose zones are $\left.0.034 \mathrm{~m}^{2} \mathrm{y}^{-1}\left[0.0127 \mathrm{~m} \mathrm{yr}^{-1}\right)(1 \mathrm{~m}) /(0.375)\right]$ and $0.040 \mathrm{~m}^{2} \mathrm{yr}^{-1}[(0.0127 \mathrm{~m}$ $\left.\mathrm{yr}^{-1}(\mathrm{~lm}) /(0.32)\right]$. In an attempt to be consistent with MEPAS for this benchmarking exercise, MMSOILS was assigned a moisture content equal to field capacity of $37.5 \%$ and $32.0 \%$ for the first and second layers, respectively.

2. MEPAS defines its dispersion coefficient with Eq. 5.8, where the molecular diffusion coefficient is defined as $0.019 \mathrm{~m}^{2} \mathrm{yr}^{-1}$ (Mills et al. 1985). Although dispersivity is an input parameter in MEPAS, when a dispersivity value is unavailable, MEPAS guardedly suggests the following relationship for calculating dispersivities for each layer (Gelhar et al. 1985):

$$
\alpha_{i}=0.01 \mathrm{H}_{\mathrm{i}}
$$

where

$$
\alpha_{i}=\text { the dispersivity for the I-th vadose-zone layer (m) }
$$

MEPAS does not calculate the dispersivity for each layer by summing the thicknesses of all vadosezone layers. Each dispersivity in MEPAS is individually user-supplied for each layer. For this benchmarking case, the modelers employed Eq. 5.11 to estimate dispersivities of $0.10 \mathrm{~m}$ and $1.00 \mathrm{~m}$ for the first and second layers, respectively. Equation 5.8 is valid as long as the moisture content is equal to or greater than the field capacity. When the moisture content is calculated as being less than field capacity, the moisture content is set equal to field capacity. The moisture contents in the first and second layers equal $24.5 \%$ and $28.6 \%$, respectively, using Eq. 5.3. The 
field capacities equal $37.5 \%$ and $32.0 \%$, respectively; therefore, the moisture contents in MEPAS are automatically set to $37.5 \%$ and $32.0 \%$, resulting in dispersion coefficients equaling $0.022 \mathrm{~m}^{2}$ $\left.\left.\mathrm{yr}^{-1}\left[0.0127 \mathrm{~m} \mathrm{yr}^{-1}\right)(0.1 \mathrm{~m}) / 0.375\right)+\left(0.019 \mathrm{~m}^{2} \mathrm{yr}^{-1}\right)\right]$ and $0.059 \mathrm{~m}^{2} \mathrm{yr}^{-1}\left[\left(0.0127 \mathrm{~m} \mathrm{yr}^{-1}\right)(1 \mathrm{~m}) /(0.32)\right.$ $\left.+\left(0.019 \mathrm{~m}^{2} \mathrm{yr}^{-1}\right)\right]$.

Table 5.4 summarizes the equations that describe the dispersion coefficients used by MMSOILS and MEPAS.

\subsubsection{Time to peak flux and plug-flow contaminant travel time}

Moisture content can have a significant impact on contaminant travel times. The time to peak associated with a non-degrading/decaying contaminant that is instantaneously released from a source to a vadose zone with one-dimensional flow and dispersion is as follows (Whelan et al. 1987):

$$
t_{p}=\frac{\left[\left(\frac{H v_{p}}{R_{f}}\right)^{2}+\left(\frac{D}{R_{f}}\right)^{2}\right]^{1 / 2}-\left(\frac{D}{R_{f}}\right)}{\left(\frac{v_{p}}{R_{f}}\right)^{2}}
$$

where

$t_{p}=$ the plug-flow-with-dispersion time to peak concentration (yr)

Although this is the time to peak for the concentration, it should represent a close approximation for the time to peak flux because the flux equation is based on the concentration equation. Without dispersion (i.e., $\mathrm{D}=0$ ), Eq. 5.12 becomes

$$
t_{t}=\frac{H R_{f}}{V_{p}}=\left(\theta+\beta_{d} K_{d}\right)\left(\frac{H}{v_{d}}\right)
$$

where

$$
t_{t}=\text { the plug-flow travel time }(y r)
$$

Equation 5.13 is the expression for pure advective flow with instantaneous sorption.

Plug-flow travel times can help discern differences in contaminant movement between RESRAD, MMSOILS, and MEPAS. Plug-flow travel times without considering dispersion and degradation/decay are calculated as the ratio of the travel distance to the plug-flow contaminant velocity (i.e., $\mathrm{H} / \mathrm{v}_{\mathrm{c}}$ ). Because each model defines its moisture content differently, each of their plug-flow travel times may be different. A summary of the contaminant plug-flow travel times that are indicative of RESRAD, MMSOILS, and MEPAS is presented as follows: 
1. The contaminant plug-flow velocity in RESRAD is defined using an effective porosity, as presented in Table 5.3. By dividing the contaminant velocity into the travel length, the plug-flow travel time in RESRAD is defined in Table 5.5, which represents a slight modification to Eq. 5.13.

2. If MMSOILS did not include dispersion in its calculations, its plug-flow travel time would be indicative of its contaminant velocity as presented in Table 5.3, which uses Eq. 5.7 in its calculations. As such, the plug-flow travel time that is indicative of MMSOILS can be described by Eq. 5.13 , as illustrated in Table 5.5 .

3. As with the MMSOILS case, if MEPAS did not include dispersion in its calculations, its plug-flow travel time would be indicative of its contaminant velocity as presented in Table 5.3. The plug-flow travel time that would be indicative of the MEPAS formulations are presented in Table 5.5 for the conditions where the moisture content is calculated as being (1) greater than or (2) less than or equal to the field capacity.

Tables 5.3 and 5.5 describe the mathematical constructs that are contained in RESRAD, regardless of degradation/decay. Tables 5.3 and 5.5 present equations for MMSOILS and MEPAS that are only for plug-flow conditions and do not represent the actual contaminant velocities or times to peak because these equations do not consider dispersion or degradation/decay, which can affect contaminant velocities and times to peak. However, use of plug-flow equations, such as those presented in Tables 5.3 and 5.5, can help explain why, in the absence of degradation/decay and dispersion, RESRAD's travel times will never be longer than MMSOILS' travel times, which will never be longer than MEPAS' travel times.

Based on the plug-flow travel time equations in Table 5.5, the ratio of plug-flow travel times between RESRAD, MMSOILS, and MEPAS can be calculated as follows:

1. MMSOILS' plug-flow travel time will always be equal to or greater than RESRAD's plug-flow travel time by the following factor:

$$
t_{M M / R}=\frac{n}{n_{e}}
$$

where

$t_{\text {MMR }}=$ the ratio of plug-flow travel times between MMSOILS and RESRAD

2. MEPAS' plug-flow travel time will always be equal to or greater than RESRAD's plug-flow travel time by the factor shown in the following equation box. 


$$
t_{M / R}=\left(\frac{n}{n_{e}}\right)\left(\frac{\theta_{f c}+\beta_{d} K_{d}}{\theta+\beta_{d} K_{d}}\right)
$$

where

$$
t_{M R}=\quad \text { the ratio of plug-flow travel times between MEPAS and RESRAD }
$$

3. MEPAS' plug-flow travel time will always be equal to or greater than MMSOILS's plug-flow travel time by the following factor:

$$
t_{M M M}=\frac{\theta_{f c}+\beta_{d} K_{d}}{\theta+\beta_{d} K_{d}}
$$

where

$$
t_{\text {MMM }}=\text { the ratio of plug-flow travel times between MEPAS and MMSOILS }
$$

The ratios of the plug-flow travel times between RESRAD, MMSOILS, and MEPAS are summarized in Table 5.6 and represent the condition where Eq. 5.3 estimates a moisture content below field capacity, as is the case in this vadose-zone benchmarking problem. As Table 5.6 illustrates, RESRAD travel times are shorter than MMSOILS's travel times, which are shorter than MEPAS' travel times.

\subsubsection{Time-Varying Fluxes in the Vadose Zone}

The comparison between RESRAD, MMSOILS, and MEPAS presents the time varying fluxes of methylene chloride and uranium-238 in Figs. 5.4 through 5.7 and Tables 5.6 through 5.11. Figures 5.4 and 5.5 present the time-varying flux rates of methylene chloride and uranium-238, respectively, exiting from the first vadose zone for RESRAD, MMSOILS, and MEPAS. Figures 5.6 and 5.7 present the time-varying flux rates of methylene chloride and uranium-238, respectively, for RESRAD, MMSOILS, and MEPAS at the water-table surface (i.e., interface between the second vadose and saturated zones).

Table 5.6 summarizes uranium-238 ratios of theoretical plug-flow travel times and actual times to peak exiting from the first and second vadose zones for RESRAD, MMSOILS, and MEPAS. Tables 5.7 through 5.9 summarize the peak fluxes from the source, first vadose zone, and second vadose zone, respectively, for methylene chloride and uranium-238 for RESRAD, MMSOILS, and MEPAS. Tables 5.10 and 5.11 summarize times to peak from the first and second vadose zones, respectively, for RESRAD, MMSOILS, and MEPAS. The time to peak identifies the time when the peak flux occurs on the flux versus time curve. 
Because RESRAD is a plug-flow model, the exponential shape of the time-varying fluxes entering the first vadose zone exactly match the shape of the time-varying fluxes exiting the first and second vadose zones, accounting for degradation/decay. Therefore, pure-translation occurs over the vadose-zone thickness, as illustrated in Figs. 5.2, 5.4, and 5.6 for methylene chloride and Figs. 5.3, 5.5, and 5.7 for uranium-238. The half-lives of methylene chloride and uranium-238 are long enough (i.e., no degradation and $4.46 \times 10^{9} \mathrm{yr}$, respectively) so as not to impact the output results. Tables 5.7 through 5.9 also show for RESRAD that the peak fluxes for methylene chloride and uranium-238 remain constant at $5.8 \times 10^{8}$ $\mathrm{mg} \mathrm{yr}^{-1}$ and $3.6 \times 10^{9} \mathrm{pCi} \mathrm{yr}^{1}$ from the source to the water-table sur-face, indicating pure translation. Tables 5.10 and 5.11 report RESRAD travel times exiting the first and second vadose zones for methylene chloride as 166 and 1920 yrs, respectively, and for uranium-238 as $6.66 \times 10^{4}$ and $5.96 \times 10^{5}$ yr. These travel times can be calculated using the RESRAD plug-flow equation in Table 5.5.

MMSOILS and MEPAS results at the interface between the first and second vadose zones, as illustrated in Figs. 5.4 through 5.7, are similar because both codes are one-dimensional, plug-flow-withdispersion models. In Fig. 5.4, the methylene chloride curves for MMSOILS and MEPAS reach a constant flux rate because the duration of the release is significantly longer than the travel time through either vadose zone, such that the duration of the release is much larger than the width of the dispersed front on the leading and trailing edges of the hydrograph, resulting in a constant peak flux. Mass continuity is maintained, as the contaminant flux rate into the layer eventually equals the flux rate out of the layer. This constant flux rate is illustrated in Figs. 5.4 and 5.6 and summarized in Tables 5.7 through 5.9, which report the same peak fluxes for methylene chloride for RESRAD, MMSOILS, and MEPAS. The methylene chloride results are expected because it is not significantly retarded in the vadose zone (i.e., retardation factor of approximately unity) and the contaminant moves at the pore-water velocity.

When the travel time is sufficiently longer than the duration of the release for MMSOILS and MEPAS, as illustrated by uranium-238 in Figs. 5.5 and 5.7, the peak height is reduced and a Gaussian shape is observed. Because the retardation factor is large (i.e., $1+1.4 \cdot 75 / 0.375 \approx 280$ ) and the contaminant velocity small, the effects of dispersion and a flattening of the curve become evident for MMSOILS and MEPAS. RESRAD predicts higher flux rates over shorter durations, while MMSOILS and MEPAS predict lower flux rates over longer durations. RESRAD's uranium-238 fluxes exiting the second vadose zone are approximately an order of magnitude higher as compared to MMSOILS or MEPAS.

In addition to differences in time varying fluxes, each model defines its travel time differently (e.g., Table 5.5), as such significant differences in arrival times may occur. For example, using the RESRAD formulations presented Table 5.5, RESRAD predicts a significantly shorter travel time for methylene chloride than that estimated for MMSOILS or MEPAS (e.g., see Tables 5.10 and 5.11). As Sect. 5.3.2 notes, RESRAD predicts significantly less travel times than MMSOILS or MEPAS because it bases its pore-water velocity on an effective porosity (see Tables 5.2,5.3, and 5.5). The moisture contents in the first and second layers equal $24.5 \%$ and $28.6 \%$, respectively, using Eq. 5.3. The field capacities equal $37.5 \%$ and $32.0 \%$, respectively. For this benchmarking problem, RESRAD effective porosities were set equal to $37.5 \%$ and $32.0 \%$ for the first and second vadose zones, respectively. As such, RESRAD will not produce times to peak that are more than MMSOILS or MEPAS in this benchmarking exercise. MMSOILS's time to peak is also shorter than MEPAS, but this difference is less pronounced than that associated with RESRAD.

Because uranium-238 does not asymptotically approach a constant value, as methylene chloride does, it more clearly illustrates the travel time differences that exist between the models. Table 5.6 summarizes the ratio of uranium-238 plug-flow travel times indicative of RESRAD, MMSOILS, and 
MEPAS. This table also presents the ratios of times to peak from the simulation output results exiting the first and second vadose zones. Although the plug-flow travel times only approximate the times to peak for MMSOILS and MEPAS, they provide insight as to why RESRAD will never predict longer travel times than MMSOILS, which will never predict longer travel times than MEPAS. Table 5.6 clearly illustrates this fact as all of the ratios in the table are greater than unity. Even though the ratio of the travel times between RESRAD and MMSOILS/MEPAS are less than two, it should be remembered that the travel time differences are on the order of 15,000 yrs for the first layer and 180,000 yrs for the second layer. Tables 5.10 and 5.11 illustrate these travel time differences. If degradation/decay was an important mechanism in this benchmarking exercise, RESRAD would have produce flux values exiting the first and second vadose zones that would have been significantly higher than those predicted by MMSOILS or MEPAS.

Tables 5.10 and 5.11 also show that MEPAS' times to peak are slightly longer than MMSOILS' times to peak. MMSOILS structured its vadose-zone model to ensure that their moisture contents equal the moisture contents in MEPAS, which were set equal to the field capacities for each layer. The differences in the results are most likely due to (1) the different approaches that MMSOILS and MEPAS use in calculating their dispersion coefficients (see Eqs. 5.9 and 5.10, respectively) and (2) solution schemes for solving the advective-dispersive equation; MMSOILS uses a finite-element technique, while MEPAS uses the analytical solution.

\subsection{CHAPTER REFERENCES}

Campbell, G. S. 1974. A Simple Method for Determining Unsaturated Conductivity from Moisture Retention Data, Soil Sci. 117:311-314.

Clapp, R. B. and G. M. Hornberger. 1978. Empirical Equations for Some Soil Hydraulic Properties, Water Resour. Res. 14(4):601-604.

Fetter, C. W. 1988. Applied Hydrogeology, Second Edition, Merrill Publishing, Columbus, Ohio.

Gardner, W. R. 1960. Soil Water Relations in Arid and Semi-Arid Conditions, UNESCO 15:37-61.

Gardner, W. R, D. Hillel, and Y. Benyamini. 1970. Post-Irrigation Movement of Soil Water. I. Redistribution, Water Resour. Res. 6:851-861.

Gelhar, L. W., A. Mantoglou, C. Welty, and K. R. Rehfeldt. 1985. A Review of Field-Scale Physical Solute Transport Processes in Saturated and Unsaturated Porous Media, EPRI EA-4190, Project 2485-5, Electric Power Research Institute, Palo Alto, California.

Hanks, R. J. and G. L. Ashcroft. 1980. Applied Soil Physics, Springer-Verlag, New York.

Hillel, D. 1980. Fundamentals of Soil Physics, Academic Press, New York.

Mills, W. B., D. B. Porcella, M. J. Ungs, S. A. Gherini, K. V. Summers, L. Mok, G. L. Rupp, and G. L. Bowie. 1985. WATER QUALITY ASSESSMENT: A Screening Procedure for Toxic and Conventional Pollutants in Surface Water, EPA/600/6-85/002, Environmental Research Laboratory, Office of Research and Development, U.S. Environmental Protection Agency, Athens, Georgia. 


\section{$5-15$}

Salhotra, A. M., P. Mineart, S. Sharp-Hansen, T. Allison, R. Johns, and W. B. Mills. 1993. Multimedia Exposure Assessment Model (MULTIMED) for Evaluating the Land Disposal of Wastes - Model Theory, EPA-EPA/600/R-93/131, U.S. Environmental Protection Agency, Office of Research and Development, Environmental Research Laboratory, Athens, Georgia.

Sharp-Hansen, S., C. Travers, P. R. Hummel, Jr., and T. Allison. 1993. A Subtitle D Landfill Application Manual for the Multimedia Exposure Assessment Model (MULTMED), EPA/600/R-3/082, U.S. Environmental Protection Agency. Office of Research and Development, Athens, Georgia.

Whelan, G., D. L. Strenge, J. G. Droppo, Jr., B. L. Steelman, and J. W. Buck. 1987. The Remedial Action Priority System (RAPS): Mathematical Formulations, DOE/RL/87-09, PNL-6200, Pacific Northwest Laboratory, Richland, Washington. 
Table 5.1. Characteristics of the source, vadose zones \#1 and \#2, and chemical properties

Source:

Infiltration Rate (specific discharge) $=1.27 \times 10^{-2} \mathrm{~m} \mathrm{yr}^{-1}$

Length of Waste Site $=244 \mathrm{~m}$

Width of Waste Site $=12.2 \mathrm{~m}$

Surface Area $=2.97 \times 10^{3} \mathrm{~m}^{2}$

Vadose Zone \#1:

Thickness below Source $=10.4 \mathrm{~m}$

$\mathrm{z}$-Direction Dispersion Coefficient in MMSOILS $=0.034 \mathrm{~m}^{2} \mathrm{yr}^{-1}$

z-Direction Dispersion Coefficient in MEPAS $=0.022 \mathrm{~m}^{2} \mathrm{yr}^{-1}$

Bulk Density $=1.4 \mathrm{~g} \mathrm{~cm}^{-3}$

Total Porosity $=0.486$

Field Capacity $=0.375$

Saturated Hydraulic Conductivity $=4018 \mathrm{~m} \mathrm{yr}^{-1}$

Specific Discharge (Darcy Velocity) $=1.27 \times 10^{-2} \mathrm{~m} \mathrm{yr}^{-1}$

Soil-Type Exponent $=7.75$

Vadose Zone \#2:

Thickness $=100 \mathrm{~m}$

$\mathrm{z}$-Direction Dispersion Coefficient in MMSOILS $=0.040 \mathrm{~m}^{2} \mathrm{yr}^{-1}$

z-Direction Dispersion Coefficient in MEPAS $=0.059 \mathrm{~m}^{2} \mathrm{yr}^{-1}$

Bulk Density $=1.5 \mathrm{~g} \mathrm{~cm}^{-3}$

Total Porosity $=0.43$

Field Capacity $=0.32$

Saturated Hydraulic Conductivity $=203.8 \mathrm{~m} \mathrm{yr}^{-1}$

Specific Discharge (Darcy Velocity) $=1.27 \times 10^{-2} \mathrm{~m} \mathrm{yr}^{-1}$

Soil-Type Exponent $=10.4$

Contaminant Characteristics:

Methylene Chloride

Inventory $=8.40 \times 10^{9} \mathrm{~g}$

Solubility Limit $=$ none assumed

Half-Life $=$ no degradation assumed

Distribution Coefficient:

- Vadose Zone \#1 $=0.01 \mathrm{~mL} \mathrm{~g}^{-1}$

- Vadose Zone \#2=0.008 $\mathrm{mL} \mathrm{g}^{-1}$

Uranium-238

Activity (Inventory) $=1.12 \times 10^{2} \mathrm{Ci}$

Solubility Limit $=$ none assumed

Half-Life $=4.46 \times 10^{9}$

Distribution Coefficient:

- Vadose Zone \#I $=75.0 \mathrm{~mL} \mathrm{~g}^{-1}$

- Vadose Zone \#2 $=60.0 \mathrm{~mL} \mathrm{~g}^{-1}$ 
Table 5.2. Moisture content employed in RESRAD, MMSOILS, and MEPAS

MODEL MOISTURE CONTENT USED BY MODEL*

RESRAD

$$
\theta_{e}=n\left(\frac{v_{d}}{K_{s}}\right)^{m}\left(\frac{n_{e}}{n}\right)=n\left(\frac{i}{K_{s}}\right)^{m}\left(\frac{n_{e}}{n}\right)
$$

MMSOILS

$$
\begin{gathered}
\theta=n\left(\frac{v_{d}}{K_{s}}\right)^{m}=n\left(\frac{i}{K_{s}}\right)^{m} \\
\theta=n\left(\frac{v_{d}}{K_{s}}\right)^{m}=n\left(\frac{i}{K_{s}}\right)^{m} \quad \text { if } \theta \succ \theta_{f c}
\end{gathered}
$$

MEPAS

$$
\theta=\theta_{\mathrm{fc}} \quad \text { if } \theta \leq \theta_{\mathrm{fc}}
$$

${ }^{\prime} \theta_{c}=$ effective moisture content (see Eq. 5.4), $\theta=$ moisture content as defined by Eq. 5.3, and $\theta_{f c}=$ moisture content at field capacity. 
Table 5.3. Pore-water and contaminant velocities, and retardation factors employed in RESRAD, MMSOLS, and MEPAS

\begin{tabular}{|c|c|c|c|c|}
\hline MODEL & PORE-WATER VELOCITY $Y^{\circ}$ & CONTAMINANT VELOCITY & RETARDATIO & ACTOR \\
\hline RESRAD & $v_{p}=\frac{v_{d}}{\theta_{e}}=\left(\frac{v_{d}}{\theta}\right)\left(\frac{n}{n_{e}}\right)$ & $v_{c}=\left(\frac{v_{d}}{\theta+\beta_{d} K_{d}}\right)\left(\frac{n}{n_{c}}\right)$ & $\mathrm{R}_{\mathrm{f}}=1+$ & $\frac{d_{d} K_{d}}{\theta}$ \\
\hline MMSOILS & $v_{p}=\frac{v_{d}}{\theta}$ & $v_{c}=\frac{v_{d}}{\theta+\beta_{d} K_{d}}$ & $\mathrm{R}_{\mathrm{f}}=1+$ & $\frac{{ }_{d} K_{d}}{\theta}$ \\
\hline \multirow{2}{*}{ MEPAS } & $v_{p}=\frac{v_{d}}{\theta}$ & $v_{c}=\frac{v_{d}}{\theta+\beta_{d} K_{d}}$ & $\mathrm{R}_{\mathrm{f}}=1+\frac{\beta_{\mathrm{d}} \mathrm{K}_{\mathrm{d}}}{\theta}$ & if $\theta \succ \theta_{\mathrm{fc}}$ \\
\hline & $v_{p}=\frac{v_{d}}{\theta_{f c}}$ & $v_{c}=\frac{v_{d}}{\theta_{f c}+\beta_{d} K_{d}}$ & $\mathrm{R}_{\mathrm{f}}=1+\frac{\beta_{\mathrm{d}} \mathrm{K}_{\mathrm{d}}}{\theta_{\mathrm{fc}}}$ & if $\theta \preceq \theta_{\mathrm{fc}}$ \\
\hline
\end{tabular}

${ }^{2} \theta_{\mathrm{c}}=$ effective moisture content (see Eq. 5.4), $\theta=$ moisture content as defined by Eq. 5.3, and $\theta_{\mathrm{fc}}=$ moisture content at field capacity. 
Table 5.4. Dispersion coefficients employed in MMSOILS and MEPAS

MMSOILS

$$
\mathrm{D}=\frac{\mathrm{v}_{\mathrm{d}} \alpha}{\theta}
$$

MEPAS

$$
\begin{array}{ll}
D=\frac{v_{d} \alpha}{\theta}+D_{\text {mol }} & \text { if } \theta \succ \theta_{f c} \\
D=\frac{v_{d} \alpha}{\theta_{f c}}+D_{\text {mol }} & \text { if } \theta \leq \theta_{\mathrm{fc}}
\end{array}
$$

${ }^{2} \theta=$ moisture content as defined by Eq. 5.3 , and $\Theta_{f c}=$ moisture content at field capacity. 
Table 5.5. Contaminant plug-flow travel times indicative of RESRAD, MMSOILS, and MEPAS

MODEL

RESRAD

$$
t_{t}=\left(\theta+\beta_{d} K_{d}\right)\left(\frac{H}{v_{d}}\right)\left(\frac{n_{e}}{n}\right)
$$

MMSOILS

$$
t_{t}=\left(\theta+\beta_{d} K_{d}\right)\left(\frac{H}{v_{d}}\right)
$$

$$
\begin{array}{ll}
t_{t}=\left(\theta+\beta_{d} K_{d}\right)\left(\frac{H}{v_{d}}\right) & \text { if } \theta>\theta_{f c} \\
t_{t}=\left(\theta_{f c}+\beta_{d} K_{d}\right)\left(\frac{H}{v_{d}}\right) & \text { if } \theta \leq \theta_{f c}
\end{array}
$$

${ }^{2} \theta=$ moisture content as defined by Eq. 5.3, and $\Theta_{\mathrm{fc}}=$ moisture content at field capacity. 
Table 5.6. Ratio of uranium-238 plug-flow travel times and ratio of actual times to peak for RESRAD, MMSOILS, and MEPAS

\begin{tabular}{|c|c|c|c|c|c|}
\hline \multirow{3}{*}{$\begin{array}{l}\text { RATIO OF } \\
\text { MODELS }\end{array}$} & \multicolumn{3}{|c|}{ RATIOOE PLUG-FIOW TRAVEL TIMES } & \multicolumn{2}{|c|}{ RATIO OF TIMES TO PEAK } \\
\hline & \multirow[t]{2}{*}{ EQUATIONS" } & \multicolumn{2}{|c|}{$\begin{array}{l}\text { RATIOS BASED ON EQUA- } \\
\text { TIONS, EXITING LAYER: }\end{array}$} & \multicolumn{2}{|c|}{$\begin{array}{l}\text { RATIOS BASED ON OUTPUT RE- } \\
\text { SULTS, EXITING LAYER: }\end{array}$} \\
\hline & & 1 & 2 & 1 & 2 \\
\hline $\begin{array}{l}\text { MMSOILS } \\
\text { RESRAD }\end{array}$ & $t_{M M / R}=\frac{n}{n_{e}}$ & 1.3 & 1.3 & 1.1 & 1.3 \\
\hline$\frac{\text { MEPAS }}{\text { RESRAD }}$ & $t_{M / R}=\left(\frac{n}{n_{e}}\right)\left(\frac{\theta_{f c}+\beta_{d} K_{d}}{\theta+\beta_{d} K_{d}}\right)$ & 1.3 & 1.3 & 1.4 & 1.3 \\
\hline$\frac{\text { MEPAS }}{\text { MMSOILS }}$ & $t_{M / M M}=\frac{\theta_{f c}+\beta_{d} K_{d}}{\theta+\beta_{d} K_{d}}$ & 1.00 & 1.00 & 1.3 & 1.06 \\
\hline
\end{tabular}

"t $t_{\text {MasR }}$ is the ratio of plug-flow travel times between MMSOILS and RESRAD.

$t_{M R}$ is the ratio of plug-flow travel times between MEPAS and RESRAD.

$t_{M r a M}$ is the ratio of plug-flow travel times between MEPAS and MMSOLS.

Because Eq. 5.3 calculates a moisture less than field capacity, MEPAS assigns the field capacity to the moisture content. 


\section{5-22}

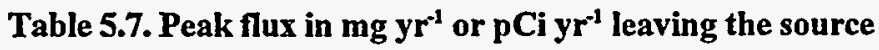

\begin{tabular}{cccc}
\hline CONTAMINANT & RESRAD & MMSOLLS & MEPAS \\
\hline Methylene Chloride & $5.8 \times 10^{8}$ & $5.8 \times 10^{8}$ & $5.8 \times 10^{8}$ \\
Uranium-238 & $3.6 \times 10^{9}$ & $3.6 \times 10^{9}$ & $3.6 \times 10^{9}$ \\
\hline
\end{tabular}

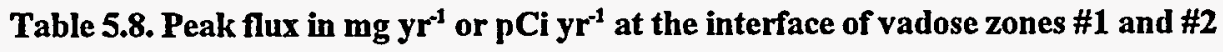

\begin{tabular}{cccc}
\hline CONTAMMNANT & RESRAD & MMSOILS & MEPAS \\
\hline Methylene Chloride & $5.8 \times 10^{8}$ & $5.8 \times 10^{8}$ & $5.8 \times 10^{8}$ \\
Uranium-238 & $3.6 \times 10^{9}$ & $1.1 \times 10^{9}$ & $1.5 \times 10^{9}$ \\
\hline
\end{tabular}

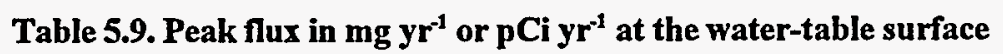

\begin{tabular}{cccc}
\hline CONTAMINANT & RESRAD & MMSOILS & MEPAS \\
\hline Methylene Chloride & $5.8 \times 10^{8}$ & $5.8 \times 10^{8}$ & $5.8 \times 10^{8}$ \\
Uranium-238 & $3.6 \times 10^{9}$ & $3.3 \times 10^{8}$ & $3.6 \times 10^{8}$ \\
\hline
\end{tabular}

Table 5.10. Contaminant time-to-peak in yrs through vadose zone \#1

\begin{tabular}{cccc}
\hline CONTAMINANT & RESRAD & MMSOILS & MEPAS \\
\hline Methylene Chloride & 166 & $696-895^{*}$ & $662-828^{*}$ \\
Uranium-238 & $6.7 \times 10^{4}$ & $7.2 \times 10^{4}$ & $9.3 \times 10^{4}$ \\
\hline
\end{tabular}

* A range is provided because the results asymptotically approach a constant solution.

Table 5.11. Total contaminant time-to-peak in yrs at the water-table surface

\begin{tabular}{cccc}
\hline CONTAMINANT & RESRAD & MMSOILS & MEPAS \\
\hline Methylene Chloride & 1920 & $3530-3930^{\circ}$ & $4130-4510^{-}$ \\
Uranium-238 & $6.0 \times 10^{5}$ & $7.5 \times 10^{5}$ & $8.0 \times 10^{5}$ \\
\hline
\end{tabular}

A range is provided because the results asymptotically approach a constant solution. 


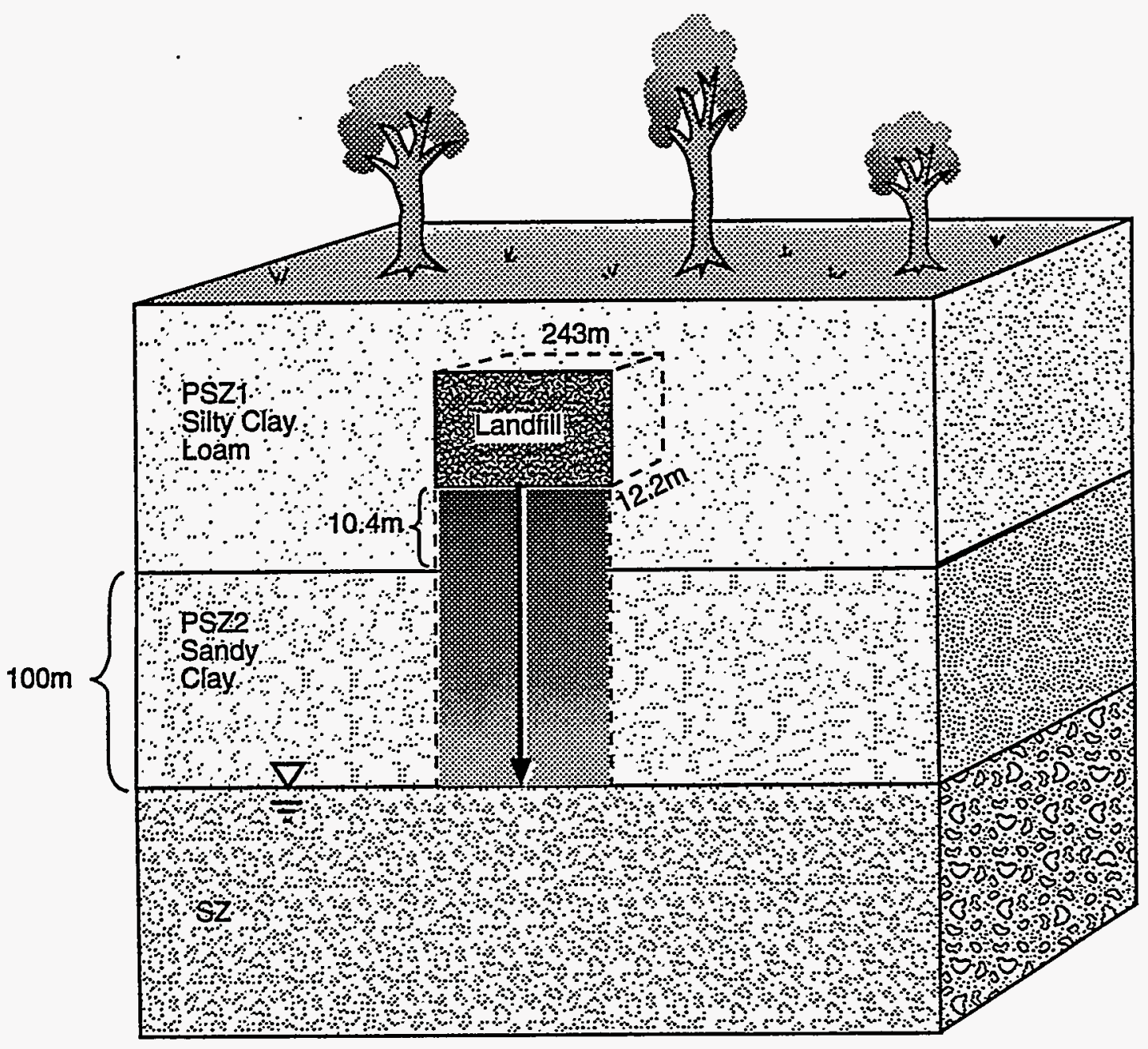

$\begin{aligned} \text { PSZ1 } & =\text { Partially saturated zone } 1 \\ \text { PSZ2 } & =\text { Partially saturated zone } 2 \\ \text { SZ } & =\text { Saturated zone (Not modeled) }\end{aligned}$

Fig. 5.1. Schematic Illustrating the Direct Discharge to the Vadose Zone Problem. 
Direct Release to the Vadose Zone

Methylene Chloride - Flux at the Source Term/PSZ1 Interface

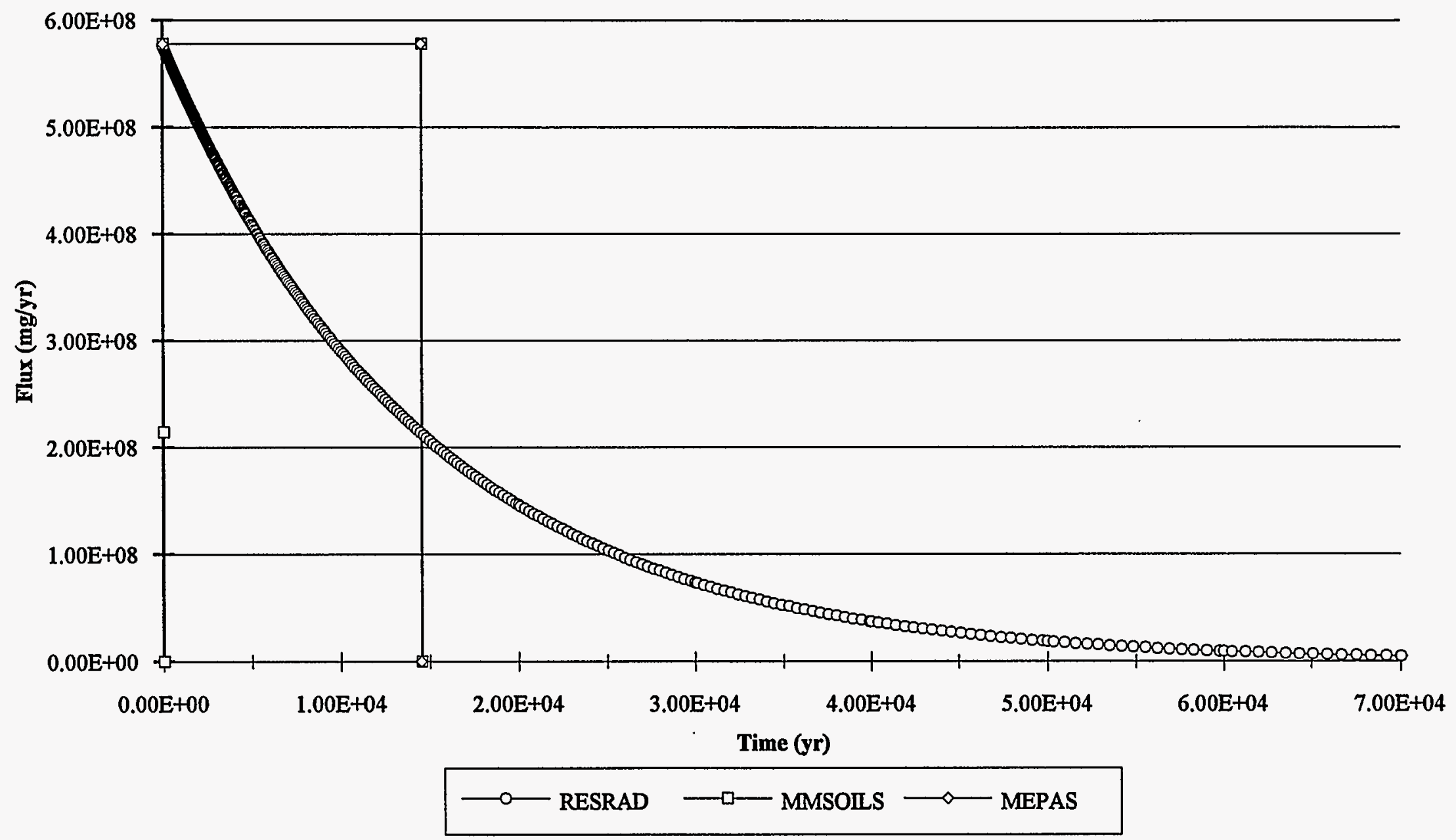

[MMSOIS and MEPAS results appear to plot on top of each other.]

Fig. 5.2. Source-Term Time-Varying Fluxes of Methylene Chloride Entering Vadose Zone \#1 for RESRAD, MMSOILS, and MEPAS. 
Direct Release to the Vadose Zone

Uranium-238 - Flux at the Source Term/PSZ1 Interface

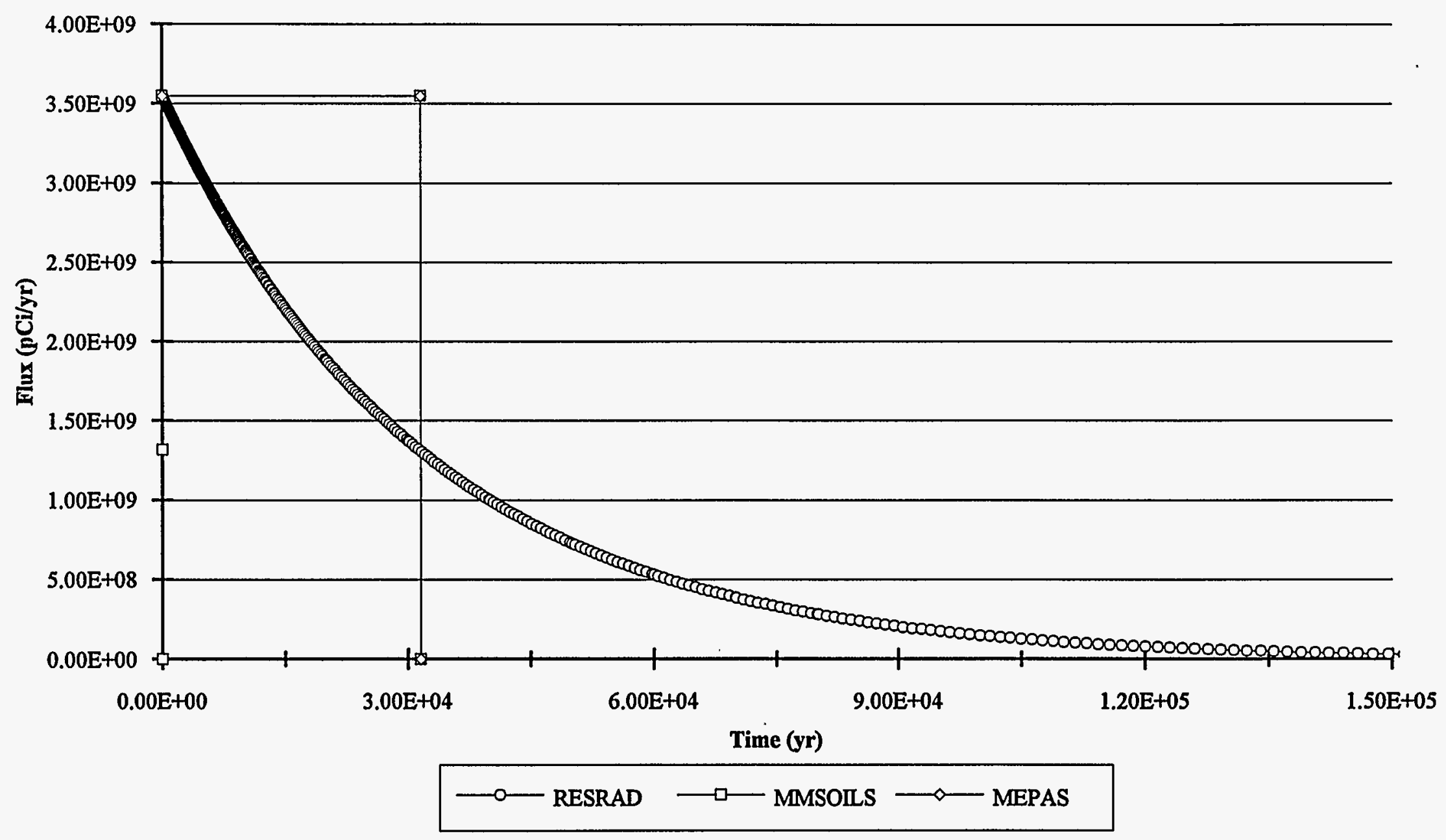

[MMSOILS and MEPAS results appear to plot on top of each other.]

Fig. 5.3. Source-Term Time-Varying Fluxes of Uranium-238 Entering Vadose Zone \#1 for RESRAD, MMSOILS, and MEPAS. 
Direct Release to the Vadose Zone

Methylene Chloride - Flux at the PSZ1/PSZ2 Interface

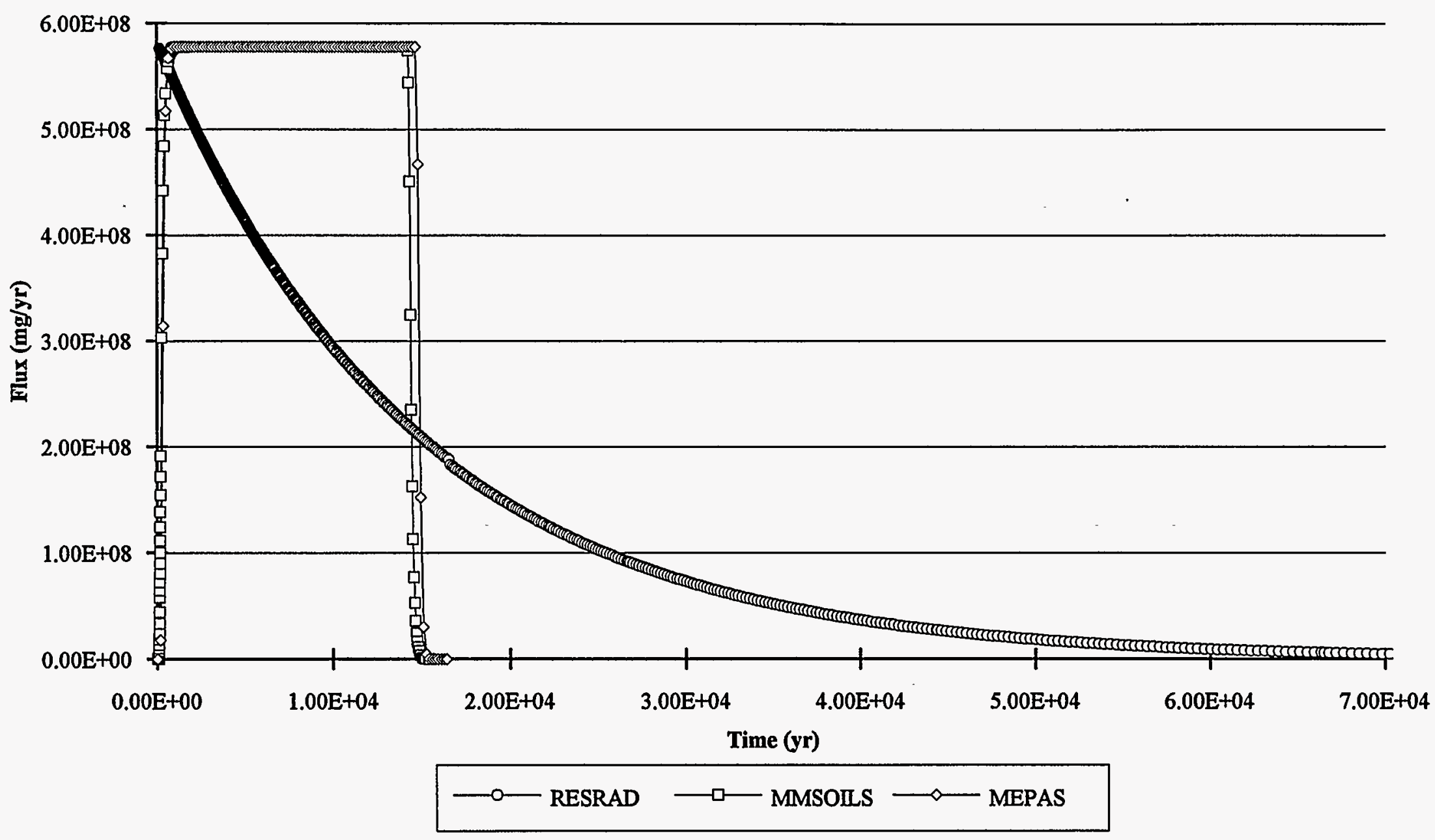

[MMSOILS and MEPAS results appear to plot on top of each other.]

Fig. 5.4. Time-Varying Fluxes of Methylene Chloride Exiting Vadose Zone \#1 for RESRAD, MMSOILS, and MEPAS. 
Direct Release to the Vadose Zone

Uranium-238 - Flux at the PSZ1/PSZ2 Interface

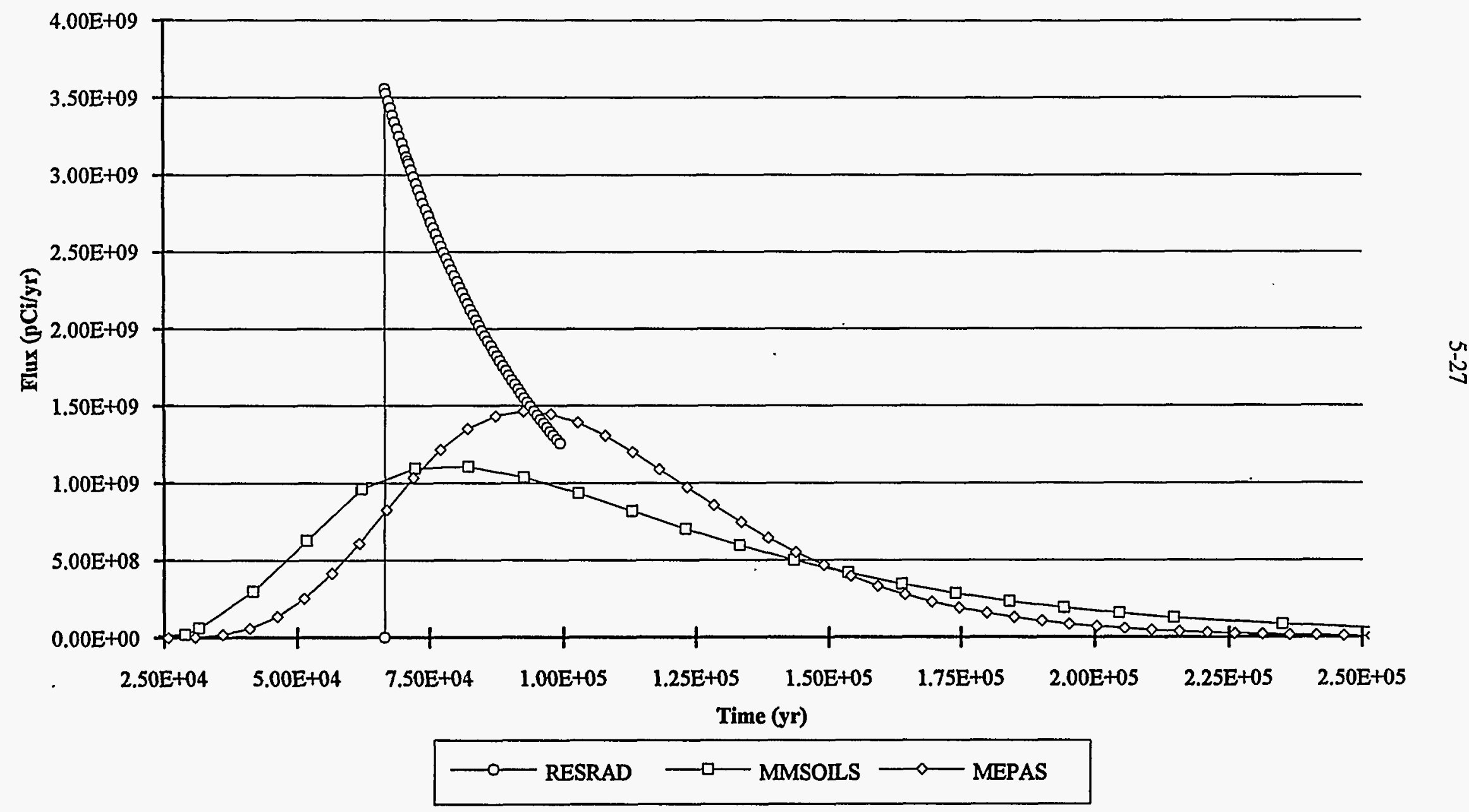

Fig. 5.5. Time-Varying Fluxes of Uranium-238 Exiting Vadose Zone \#1 for RESRAD, MMSOIS, and MEPAS. 
Direct Release to the Vadose Zone

Methylene Chloride - Flux at the PSZ2/SZ Interface

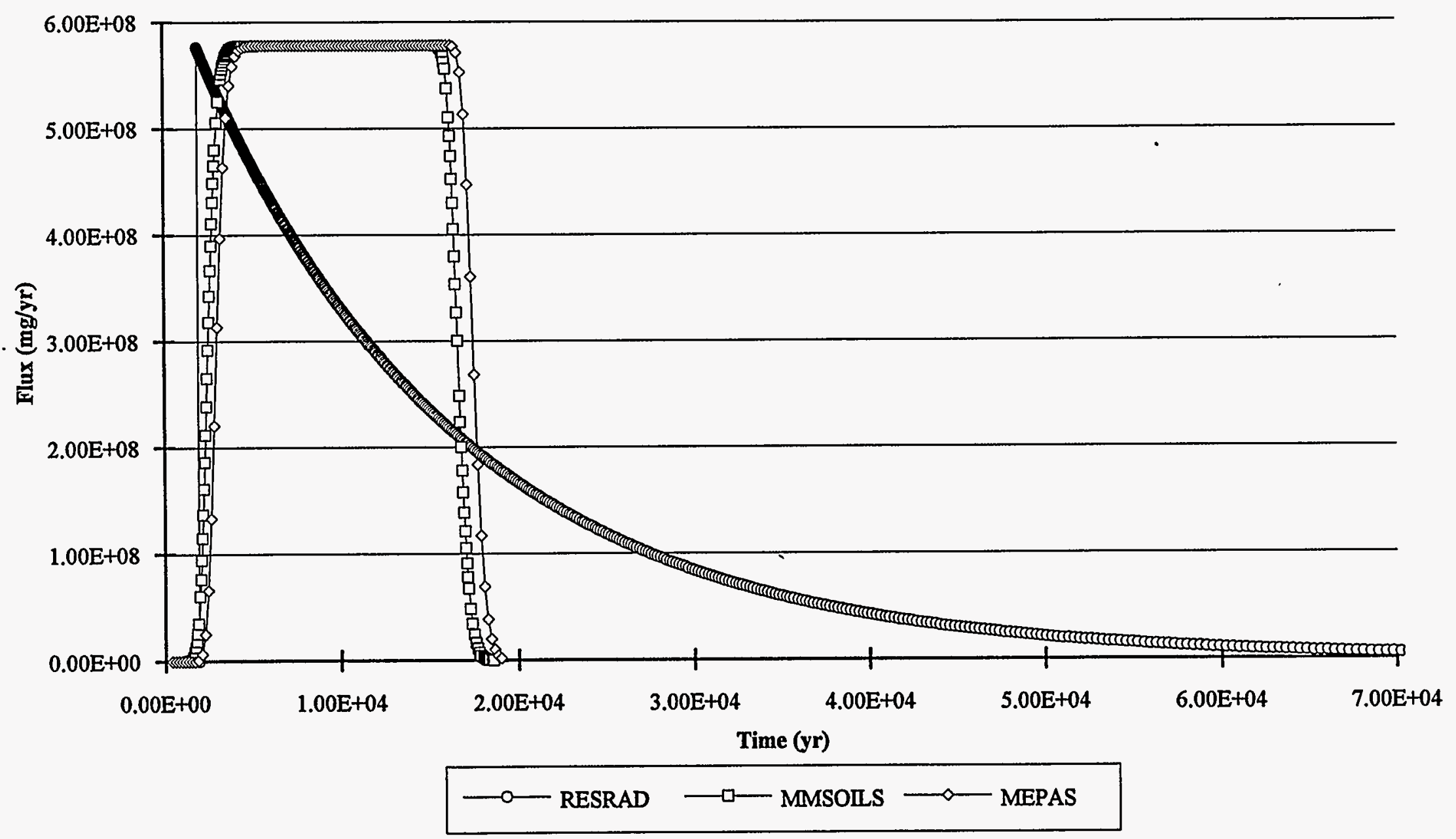

Fig. 5.6. Time-Varying Fluxes of Methylene Chloride Exiting Vadose Zone \#2 at the Water-Table Surface for RESRAD, MAMSOILS, and MEPAS. 


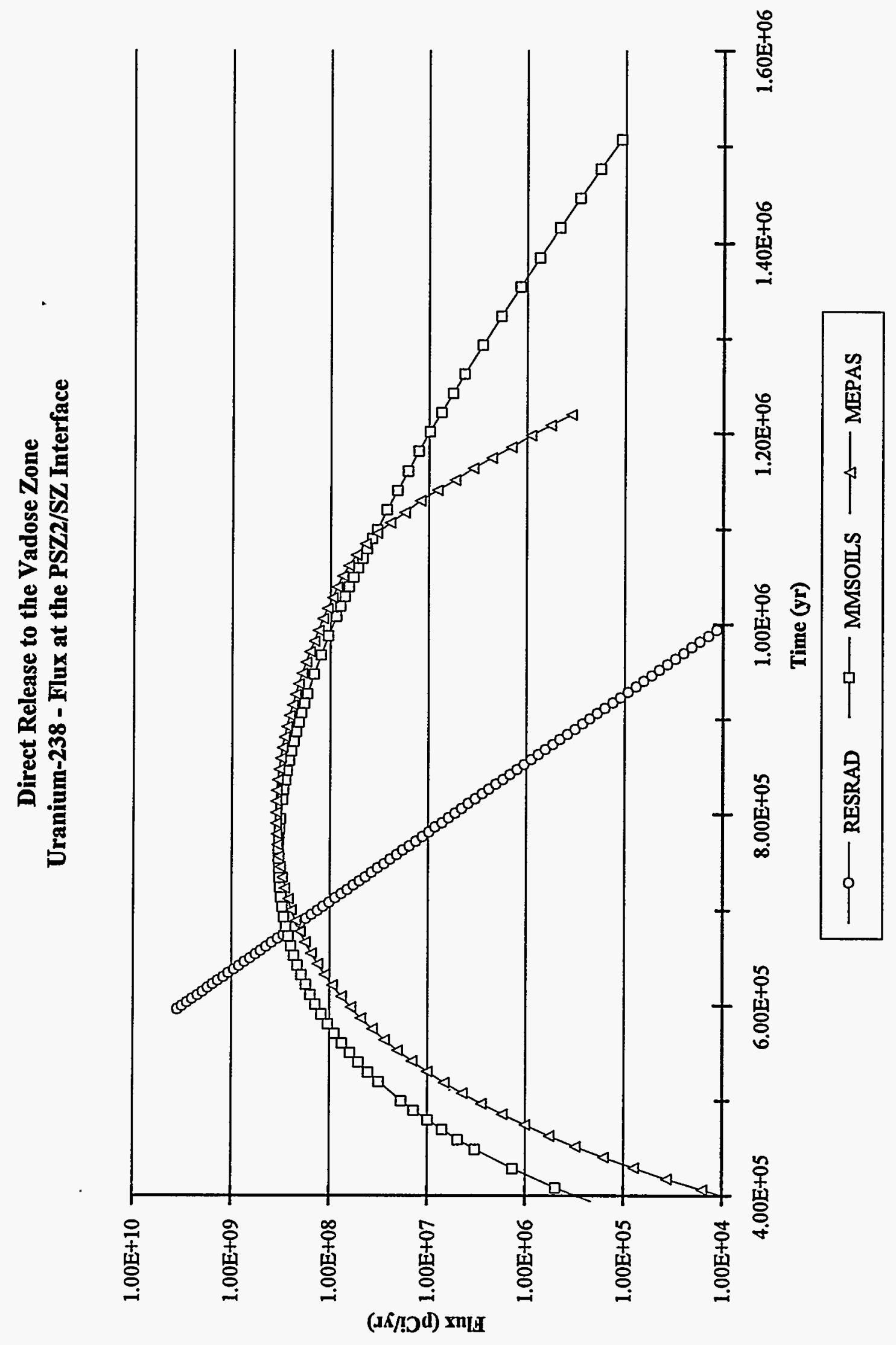

是 


\section{DIRECT RELEASE TO SATURATED ZONE}

The saturated zone or groundwater component is an important pathway because it provides water to drinking-water and irrigation wells and surface water bodies (e.g., rivers, lakes, reservoirs, estuaries, etc.). The groundwater component in RESRAD, MMSOILS, MEPAS provides estimates of time or spatially varying contaminant fluxes and/or concentrations as output, depending upon the model. Contaminant concentrations at receptor locations (e.g., receptor wells) provide contaminant levels for the exposure/risk calculations. Depending upon the model, the groundwater component includes the major mechanisms of constituent mobility (i.e., adsorption/desorption), persistence (i.e., degradation/decay), advection, diffusion, and dispersion. This benchmarking effort investigates the release of contaminants directly into a saturated zone and their migration and fate to three receptor locations from the source. Although source-term information may be required to run some of the models, this benchmarking scenario intentionally does not address modeling of the source term. The intent of this comparison is to correlate saturated zone components and not source-term components.

\subsection{SCENARIO DESCRIPTION}

An active-operational, unlined waste site directly discharges nitrate and uranium-238 into an aquifer. The three main decay products of uranium-238 are considered in this assessment: thorium-230, radium-226, and lead-210. The areal length and width of the waste site is 37.5 by $37.5 \mathrm{~m}$. This benchmarking scenario assesses only the fate of the contaminants after they have been released into the environment and intentionally does not address the activities associated with the source. It is assumed that the saturated zone continually receives waste such that the contaminants enter the saturated zone at a constant rate over a 25 -yr period. It is also assumed that degradation/decay and progeny formation take place in the environment only. After $25 \mathrm{yrs}$, the source stops, and no waste is discharged into the environment after this time. Nitrate and uranium-238 source-term inventories are assumed as $1.05 \times 10^{9} \mathrm{mg}$ and $1.05 \times 10^{6} \mathrm{pCi}$, respectively. Given the inventory and period of release, the known constant flux rates are $4.20 \times 10^{7} \mathrm{mg} \mathrm{yr}^{-1}$ (i.e., $1.05 \times 10^{9} \mathrm{mg} / 25 \mathrm{yrs}$ ) and $4.20 \times 10^{4} \mathrm{pCi} \mathrm{yr}^{-1}$ (i.e., $1.05 \times 10^{6} \mathrm{pCi} / 25 \mathrm{yrs}$ ) for nitrate and uranium-238, respectively. No other sinks or sources are considered.

The saturated zone is assumed to be 5-m thick with a Darcy flow velocity (i.e., specific discharge) of $10 \mathrm{~m} \mathrm{yr}^{-1}$. The aquifer is assumed to be homogeneous and isotropic. The groundwater flow is assumed to be unidirectional in the direction of the receptor locations. Contaminants are assumed to migrate through the saturated zone to three different receptor distances from the downgradient edge of the waste site: $0 \mathrm{~m}, 150 \mathrm{~m}$, and $1500 \mathrm{~m}$. For the models that require a well-pumping rate (i.e., RESRAD), water is assumed to be pumped from a well at each receptor location at a rate of $250 \mathrm{~m}^{3} \mathrm{yr}^{-1}$. The receptor locations are assumed to be points at the water-table surface along the plume centerline. The characteristics of the saturated zone are presented in Tables 6.1 and 6.2 (all tables and figures for this chapter are presented in subsequent order beginning on page 6-13). Figure 6.1 conceptually illustrates the problem, and Table 6.3 presents contaminant fluxes, distribution coefficients $\left(\mathrm{K}_{\mathrm{d}} \mathrm{s}\right)$, contaminant halflives, and total inventories.

Comparisons for the benchmarking between RESRAD, MMSOILS, and MEPAS are presented for the parent contaminants (i.e., nitrate and uranium-238), as well as for the decay products, at the source and at each of the three receptor locations. End points for the comparison for each contaminant include 
time-varying contaminant fluxes from the source to the saturated zone ${ }^{1}$ and time-varying contaminant concentrations at distances $0-\mathrm{m}, 150-\mathrm{m}$, and $1500-\mathrm{m}$ from the downgradient edge of the waste site. Peak concentrations and times to peak concentration are also tabulated for each contaminant at each receptor location.

\subsection{MODELING ASSUMPTIONS AND APPROACH}

RESRAD, MMSOILS, and MEPAS assume constant, unidirectional flow in a single-layered aquifer, containing homogeneous and isotropic properties. The flow in the aquifer is assumed to remain constant for each of the models, including at the pumping (i.e., withdrawal) wells; therefore, no drawdown is specifically accounted for at the receptor wells. RESRAD, MMSOILS, and MEPAS simulate the release of contaminants from the source and subsurface transport differently. Although each model contains a source-term component that provides different options for calculating emission rates, the focus of this chapter is to benchmark contaminant movement within the saturated zone. A brief discussion of source-term assumptions is presented, but a more in-depth discussion is presented in Chapter 9.

\subsubsection{RESRAD}

RESRAD contains a one-dimensional, plug-flow, groundwater model. RESRAD is currently being updated to address the effects of lateral dispersion at offsite locations. The effects of longitudinal and vertical dispersion are also being considered for inclusion in a later version of RESRAD. For the current analysis, the onsite well calculations were manually modified according to the approximation procedure by Yu et al. (1993) to calculate offsite well concentrations. RESRAD also assumes that the aquifer is unconfined, and the regional infiltration translates the off-site plume vertically downward and addresses dilution at a pumping well. Figure 6.2 illustrates the constructs of the benchmarking problem as conceptualized by RESRAD.

RESRAD is specifically designed to model the multiple transport pathways associated with a waste site containing contaminated soil with a known soil concentration. RESRAD simulates the release of contaminants to a saturated zone and transport to a receptor location (i.e., withdrawal well) (see Fig. 6.2). The source-term model conserves mass by partitioning contaminants for simultaneous release to multiple media (e.g., subsurface, air, and overland), although direct release to the saturated zone represents the focus of this chapter. Chapter 9 presents more information on the release of contaminants to multiple pathways. Time-varying emissions are not directly input by the user, although the user does have some control in modifying the form of the release through the source-term input parameters. The RESRAD source-term model assumes that the amount of contaminants leached is linearly proportional to the source inventory that is available for leaching. This results in an exponential distribution for nonradioactive chemicals (known as "chemicals" herein) and parent radionuclides. Because RESRAD's source-term

\footnotetext{
${ }^{1}$ The source-term boundary conditions associated with MMSOILS present time-varying fluxes at the vadosezone and saturated-zone interface and do not represent direct discharge from the source to the saturated zone. An explanation is provided in Sections 6.2 and 6.3.
} 
module automatically distributes contaminant emissions to the air, overland, and subsurface environments, the following assumptions are implemented to simulate a constant release directly to the saturated zone:

- There are five vadose-zone layers in RESRAD, and all five layers of the vadose zone are set to zero thickness.

- RESRAD assumes an exponential release from the source. To meet the constructs of the problem (i.e., constant release for $25 \mathrm{yrs}$ ), a very small leaching rate constant is assumed.

- An initial soil contaminant concentration is assumed, such that the total inventory specified by the benchmarking problem would be leached during the 25-yr period.

- To eliminate contaminant releases to the air pathway through suspension, a clean overburden is assumed to exist, such that the overburden would be eroded away during the 25 -yr release period.

- Once the clean overburden has been removed, a high erosion rate is assumed to ensure that the contaminated zone (and the remaining contaminant inventory) is rapidly removed, thereby terminating the contaminant release after 25 yrs.

RESRAD tracks radionuclide ingrowth and decay in the source-term and during transport in the saturated zone. Parent and progeny adsorption/desorption are also considered during transport; therefore, decay products can travel at a velocity that is different from their parents.

\subsubsection{MMSOILS}

MMSOILS is a plug-flow-with-dispersion model that solves the three-dimensional advective-dispersive equation for groundwater transport. MMSOILS assumes constant one-dimensional flow and three-dimensional mechanical dispersion (i.e., shear and turbulent diffusion). It provides three-dimensional, time-varying concentrations surrounding a specified receptor location. When the distance from the flow centerline is greater than zero (either laterally or vertically), the concentration decreases in a Gaussian manner.

MMSOILS is specifically designed to start with a waste-site situation (e.g., landfill, waste pile, etc.) that simulates (1) the release of contaminants to a vadose zone, (2) transport through a vadose zone to the saturated zone, and (3) contaminant transport in the saturated zone to specified receptor locations. MMSOILS is flexible enough to meet the constructs of the problem by simulating a constant concentration- (and resulting flux-) pulse release into the vadose zone. Transport through a thin vadose zone is modeled to provide time-varying fluxes to the saturated zone. EPA (1992) notes that the

"conceptual link between the vadose and saturated zones is a mixing zone in the aquifer directly beneath the waste site. The mixing zone is used as a volumetric source of contamination for the groundwater calculations. The amount of dilution is controlled by the ratio of the horizontal water flux to the vertical water flux through the mixing zone ..."

The depth of the mixing zone is called the "depth of penetration," which is estimated from parameters including an infiltration rate and vertical dispersivity (i.e., advective and dispersive components) (Salhotra 1993, EPA 1992). A schematic of the approach, as conceptualized by MMSOILS, is presented in Fig. 6.3. The depth of penetration in the saturated zone is assumed to occur over the full thickness of 
the aquifer; therefore, at the initial time of the simulation, the contaminants are fully mixed over the thickness of the aquifer with areal dimensions equivalent to the length and width of the waste site.

MMSOILS cannot simulate a direct release into the saturated zone without first simulating release from a waste site. For the benchmarking problem, a waste site was created, as shown in Fig. 6.2, that generated the desired contaminant fluxes to the saturated zone through a thin (i.e., $0.05 \mathrm{~m}$ ) vadose zone. The release was assumed over a penetration depth into the saturated zone, which equaled the aquifer depth; therefore, the concentration within the aquifer immediately beneath the waste site is uniformly mixed vertically, and two-dimensional transport from the waste-site is simulated. When the penetration depth is less than the depth of the aquifer, the concentration in the aquifer beneath the source would vary vertically (due to vertical dispersion), and one-dimensional advective and three-dimensional dispersive transport would be simulated.

Because one endpoint of MMSOILS is to calculate groundwater concentrations in an undisturbed flow field, the assumption of a pumping well is not required or allowed, as the effects of pumping disturb the physics of a uniform-flow field and violate the assumptions of the model. Because MMSOILS does not account for radionuclide progeny formation, decay products are not presented with the MMSOILS assessment. Chemical degradation and radionuclide decay are only calculated in the aqueous phase; no degradation/decay is calculated while the contaminant is adsorbed to the soil (Sharp-Hansen et al. 1993).

\subsubsection{MEPAS}

MEPAS is a plug-flow-with-dispersion model that solves the three-dimensional advective-dispersive equation for groundwater transport. MEPAS assumes constant one-dimensional flow and three-dimensional hydrodynamic dispersion (i.e., molecular, shear-flow, and turbulent diffusion). It provides three-dimensional, temporally and spatially varying concentrations surrounding at a specified receptor location. To ensure that the dispersion coefficients between MMSOILS and MEPAS were equivalent for the benchmarking exercise, MEPAS modified its dispersivities. The modifications were relatively minor because the effect of molecular diffusion was small.

MEPAS contains special provisions so the user can define direct time-varying releases into any medium. As such, MEPAS was able to simulate the constant release from an area source directly to the saturated zone. The conceptual model associated with MEPAS for this benchmarking problem is illustrated in Fig. 6.1.

Because one endpoint of MEPAS is to calculate groundwater concentrations in an undisturbed flow field, the assumption of a pumping well is not required or allowed, as the effects of pumping disturb the physics of a uniform-flow field and violate the assumptions of the model. MEPAS calculates progeny formation (i.e., ingrowth and decay) for radionuclides. Progeny formation is calculated after the parent has reached the receptor; as such, decay products are assumed to travel at the same speed as the parent.

\subsection{CONCLUSIONS}

The "direct release to the saturated zone" benchmarking case investigates the leaching of contaminants from a waste site with no other emissions being considered. Results are in the form of time-varying fluxes from the "source" and time-varying concentrations at three different receptor locations: 0, 150, and $1500 \mathrm{~m}$ from the downgradient edge of the source. MMSOILS and MEPAS simulations are constructed such that the latter two receptor locations (i.e., 150 and $1500 \mathrm{~m}$ ) assume fully mixed conditions in the vertical direction. The characteristics that have been assumed for the saturated zone are 
presented in Tables 6.1 and 6.2. Table 6.1 presents source-term and saturated-zone properties, including aquifer depth, infiltration rate (i.e., Darcy velocity or specific discharge), effective and total porosities, and bulk density. Table 6.2 presents the $\mathrm{x}$ and $\mathrm{y}$ dispersivities for the $0-, 150-$, and $1500-\mathrm{m}$ receptor distances. Because fully mixed conditions were assumed in the vertical direction for MMSOILS, the $z$ dispersivities were not specifically defined for MMSOILS. Because MEPAS does not assume fully mixed conditions in the vertical direction, the modelers assigned a high dispersivity value in an attempt to promote full mixing so the results would be comparable to those of MMSOILS. Any value large enough to promote fully mixed conditions could have been assigned; the modelers assigned a value of $3.0 \times 10^{19} \mathrm{~m}$. Because the thickness of the aquifer, not dispersivity, is the determining parameter under fully mixed conditions, the high dispersivity value will not adversely impact the results. If fully mixed conditions were not specified by the problem, then a more realistic number would have been used.

\subsubsection{Source Term}

As with the vadose zone assessment (see Chapter 5, Sect. 5.3.1), RESRAD, MMSOILS, and MEPAS have specific source-term options from which they develop time-varying fluxes from the source to the saturated zone. RESRAD, for example, begins with a soil concentration and then calculates an exponential release with a very small rate coefficient. Because nitrate and uranium- 238 have very long half-lives and because the duration of the release is short (i.e., $25 \mathrm{yrs)}$ ), the exponential release appears as a constant step-function release (see Figs. 6.4 and 6.5). Chapter 5 discusses the exponential release and illustrates the ramifications of a source term, which has a long duration of release (e.g., 14,500 and $31,550 \mathrm{yrs}$ ). RESRAD's source-term appears to be constant, and mass is conserved in the RESRAD simulation.

MMSOILS uses source-term and vadose-zone models to generate time-varying contaminant fluxes to the saturated zone; as such, these models produce time-varying releases, whose peak values are shifted in time from time zero. Although the user cannot input a particular time-varying flux directly to the saturated zone with MMSOILS, the user is able to manipulate the source-term and vadose-zone modules to construct a constant-leaching pattern, as illustrated in Figs. 6.4 and 6.5. Mass is conserved with these approximations.

MEPAS contains a source-term code that allows the user to choose the form of the release from the waste site (e.g., exponential, uniform, log-normal, steady state, or any other form the user desires). If the user wants to choose the distribution, the user directly inputs the time-varying release rates, and these rates do not have to be represented by any known function. Otherwise, MEPAS releases the contamination as a constant pulse, as illustrated by Figs. 6.4 and 6.5. MEPAS assumed a constant release (i.e., step function) starting with time zero.

Because there are differences in the source terms between the three models (see Figs. 6.4 and 6.5), the final results associated with this modeling exercise will be affected. Chapters 7 and 9 provide a more in-depth discussion of how some of these subtle source-term differences can manifest themselves, as the contaminants move from the source to receptors.

Saturated-zone boundary conditions and information are presented in Figs. 6.4 through 6.8 and Table 6.3. Figures 6.4 and 6.5 present time-varying flux rates to the saturated zone for nitrate and uranium-238 for RESRAD, MMSOILS, and MEPAS. Although the constructs of the problem note that in-growth and decay only occur after release from the source, RESRAD tracks radionuclide in-growth and decay in the source-term and during transport in the saturated zone; as such, time-varying flux rates to the saturated zone from the source for the uranium-238 decay products are presented for RESRAD in Figs. 6.6 through 6.8. These figures illustrate how the decay-products increase with time as uranium- 
238 decays. Although MEPAS allows the user to directly release contaminants to the saturated zone with or without progeny formation, MEPAS did not simulate decay-product release to meet the constructs of the scenario (i.e., no decay-product formation at the source). Although MMSOILS does not consider progeny formation, it did not simulate decay-product release and thereby met the constructs of the scenario.

Table 6.3 summarizes parent contaminant information and boundary conditions to the saturated zone. The constant flux for nitrate and uranium-238 are presented. The flux rates associated with the decay products are not summarized because the scenario assumes that there is no degradation/decay and radionuclide ingrowth at the source. Because distribution coefficients (i.e., $\mathrm{K}_{\mathrm{d}} \mathrm{s}$ ) are site and chemical dependent, the values presented in Table 6.3 DO NOT necessarily represent ones that are indicative of any particular site. Although the $\mathrm{K}_{\mathrm{d}} \mathrm{s}$ used in this benchmarking are within ranges published in the literature, their use in this application does not necessarily imply that they are the correct values for other applications. Utilization of any of the $\mathrm{K}_{\mathrm{d}} \mathrm{s}$ by this benchmarking effort should not be interpreted as lending credibility to a single, constituent value for other applications.

\subsubsection{0-m Receptor Location}

Figures 6.9 through 6.13 and Table 6.4 summarize the benchmarking simulation at $0 \mathrm{~m}$ from the downgradient edge of the source for RESRAD, MMSOILS, and MEPAS. Figures 6.9 through 6.13 present time-varying concentrations of nitrate, uranium-238, thorium-230, radium-226, and lead-210, respectively. As with the source-term plots (i.e., Figs. 6.6 through 6.8), decay-product information for MMSOILS is not presented in Figs. 6.11 through 6.13 because MMSOILS does not consider progeny formation. However, RESRAD and MEPAS present time-varying decay-product concentrations in Figs. 6.11 through 6.13.

RESRAD and MMSOILS/MEPAS differ in the manner in which they conceptualize and calculate groundwater contaminant concentrations at downgradient receptors, including the $0-\mathrm{m}$ receptor location. As noted earlier, MMSOILS and MEPAS (1) assume that the flow field is undisturbed, (2) directly solve the advective-dispersive equation, (3) use these calculations to represent the concentrations in the aquifer at the receptor location, and (4) do not require a withdrawal for calculating concentrations in the aquifer.

RESRAD provides temporally varying concentrations at specified locations within the aquifer but requires a withdrawal rate from a pumping well to define a mixing volume and receptor concentrations. The onsite well is located at the downgradient edge of the waste site (i.e., $0 \mathrm{~m}$ from the edge of the waste site). The concentration is assumed to be fully and uniformly mixed within the pumping well's zone of influence (see Fig. 6.3). The onsite well concentration is calculated as a function of the source concentration and an onsite Dilution Factor:

$$
\mathrm{C}_{\mathrm{w}}=\text { (Dilution Factor) }\left(\mathrm{C}_{\text {sourco }}\right)
$$

where

$\mathrm{C}_{\mathrm{w}}=$ the dissolved concentration at the well $\left[(\mathrm{mg}\right.$ or $\left.\mathrm{pCi}) \mathrm{L}^{-1}\right]$
$\mathrm{C}_{\text {source }}=$ the contamination at the source $\left[(\mathrm{mg}\right.$ or $\left.\mathrm{pCi}) \mathrm{L}^{-1}\right]$

The onsite Dilution Factor relates the contaminant concentration at the source to the concentration at the well (fraction). 
Yu et al. (1993) presents the relationships between the onsite Dilution Factor, well-pumping rate, and depth of the well below the water-table surface for this benchmarking problem. With a well depth of $5 \mathrm{~m}$ and a pumping rate of $250 \mathrm{~m}^{3} \mathrm{yr}^{-1}$, the Dilution Factor equals $9.53 \times 10^{-3}$. If the pumping rate was altered (not part of this problem), the Dilution Factor would remain constant until the pumping rate reached $1875 \mathrm{~m}^{3} \mathrm{yr}^{-1}$. Any pumping rate greater than $1875 \mathrm{~m}^{3} \mathrm{yr}^{-1}$ could significantly reduce the Dilution Factor, thereby illustrating that the Dilution Factor is not necessarily independent of the pumping rate.

RESRAD concentrations in Figs. 6.9 and 6.10 are very similar to those predicted by MMSOILS. The close prediction by RESRAD, with respect to magnitude, only represents an artifact of a low pumping rate (i.e., $250 \mathrm{~m}^{3} \mathrm{yr}^{-1}$ ) that uses a solution that defaults to the same calculation as assuming fully mixed conditions below the waste site. If the pumping rate had been different [e.g., $250 \mathrm{~m}^{3} \mathrm{~d}^{-1}$ $\left.\left(91,000 \mathrm{~m}^{3} \mathrm{yr}^{-1}\right)\right]$, the concentration at the well would have been significantly smaller (e.g., $\approx 49$ times smaller). However, for MMSOILS, because the receptor location is so close to the source, longitudinal and lateral dispersion have not had an opportunity to sufficiently reduce the peak concentration. The duration of the release in MMSOILS is also significantly longer than the travel time such that the duration of the release is much larger than the width of the dispersed front on the leading and trailing edges of the hydrograph, resulting in a constant peak concentration.

MEPAS calculates the three-dimensional solution to the advective-dispersive equation for a planar source (when the source does not penetrate below the water-table source; see Fig. 6.1). In an attempt to simulate fully mixed conditions at the edge of the waste site, a high vertical dispersivity was assumed in MEPAS for the saturated zone. Even a high dispersivity did not produce fully mixed conditions beneath the waste site at the $0-\mathrm{m}$ distance from the downgradient edge of the waste site. Because advection (i.e., pore-water velocity) dominates vertical dispersion, the pore-water velocity will move the contaminants in the flow direction beyond the $0-\mathrm{m}$ distance before the contaminants have a chance to fully mix in the vertical direction, as illustrated by Fig. 6.1. For the waste to migrate to the bottom of the aquifer before the pore-water velocity transports the contamination downgradient, the pore-water velocity would have to be significantly smaller than that defined for this problem. As such, the centerline maximum concentrations of the parent contaminants predicted by MEPAS are higher than those estimated by RESRAD and MMSOILS (factor of $\approx 4.7$ ), as illustrated by Figs. 6.9 and 6.10 and Table 6.4.

Figures 6.11 through 6.13 present RESRAD and MEPAS time-varying, concentration estimates for the uranium-238 decay products at zero distance from the downgradient edge of the waste site. Direct comparisons of the decay-product concentration results between RESRAD and MEPAS should be tempered with the knowledge that:

1. RESRAD assumed ingrowth and decay in and emission rates from the source, and MEPAS assumed no progeny formation at the source, although it has the capability for such calculations.

2. Different retardation factors are being used by RESRAD and MEPAS. RESRAD uses the effective porosity to calculate its pore-water velocity and the total porosity to calculate its retardation factor. MEPAS uses the effective porosity in calculating both the pore-water velocity and retardation factor. The total porosity is defined as the ratio of volume of flowing and nonflowing water divided by the total volume (Fetter 1988). Effective porosity is defined as the ratio of the volume of the void spaces through which water flows divided by the total volume (Fetter 1988). The total porosity is always equal to or larger than the effective porosity. The retardation factor relates pore-water and contaminant velocities. The retardation factors for uranium-238, thorium-230, radium-226, and lead-210 for RESRAD, using $K_{d} s$ reported in Table 6.3 , are $18,20100,24$, and 4, respectively. 
MEPAS assumes that the decay products travel at the same speed as the parent, which has a retardation factor of 31 .

3. Different travel times are associated with RESRAD and MEPAS. A discussion of travel times is presented later in this section.

4. Different approaches for mixing the contaminants at the receptor are used by RESRAD and MEPAS. RESRAD calculates the concentration in a fully penetrating pumping well at the specified receptor location using a well pumping rate. MEPAS uses solutions to the three-dimensional, advective-dispersive equation to determine contaminant concentrations at the receptor.

5. Different approaches are used in calculating ingrowth. RESRAD decays the parent to its decay products in transit to the receptor, allowing the decay products to move at a different speed than their parent. MEPAS assumes that the decay products move at the same speed as their parent and calculates ingrowth and decay at the receptor.

A more in-depth decay-product discussion occurs in the succeeding section.

Table 6.4 summarizes the results associated with Figs. 6.9 through 6.13. Peak concentrations and times to peak of each contaminant are presented for each model. A range is provided for several of the contaminants for the time to peak because the concentration asymptotically approaches a constant value. The highest concentrations are for MEPAS because MEPAS is not simulating fully mixed conditions vertically beneath the waste site, as is MMSOILS. RESRAD appears to be simulating fully mixed conditions (although it is not) only because a fully penetrating well is specified for its simulation, and the pumping rate is low. RESRAD's and MEPAS' times to peak for the nitrate and uranium-238 are smaller than that of MMSOILS because they assume that the constant release from the waste site began at year zero, while MMSOILS first simulated a constant release to the saturated zone at year 5.

The decay-product results, as presented in Figs. 6.11 through 6.13, present a shallower curve associated with RESRAD than that associated with MEPAS. Because MEPAS uses the Bateman equation (Bateman 1910, Whelan et al. 1987) in calculating progeny formation, the decay-products' shapes will reflect that of the parent (i.e., uranium-238 in Fig. 6.10). RESRAD accounts for ingrowth and decay while in transit, thereby creating the longer and flatter concentration-versus-time curves. Progeny formation is discussed in more detail in Sect. 6.3.3.

The shortest times to peak for the parent constituents are associated with the RESRAD results. In general, MMSOILS' and MEPAS' contaminant times to peak for the parents will almost always be longer than those associated with RESRAD. In addition to considering longitudinal dispersion, MMSOILS and MEPAS use the effective porosity (i.e., $25 \%$ ) to calculate pore-water velocity and retardation factor. RESRAD uses the effective porosity to calculate pore-water velocity and total porosity (i.e, $44.2 \%$ ) to calculate retardation factor. The ratio of plug-flow travel times between MMSOILS/MEPAS and RESRAD can be calculated as follows:

$$
t_{M R}=\left(\frac{n}{n_{c}}\right)\left(\frac{n_{e}+\beta_{d} K_{d}}{n+\beta_{d} K_{d}}\right)
$$


where

$t_{M / R}=$ the ratio of plug-flow travel times between MMSOILS/MEPAS and RESRAD

$\mathrm{n}=$ the total porosity

$\mathrm{n}_{\mathrm{c}}=$ the effective porosity

$B_{\mathrm{d}}=$ the soil bulk density

$\mathrm{K}_{\mathrm{d}}=$ the contaminant distribution coefficient.

As this equation illustrates, MMSOILS/MEPAS will produce plug-flow travel times that are up to 1.8 (i.e., $44.2 \% \div 25 \%$ ) times longer than those produced by RESRAD. These travel-time differences should not be of significant concern for onsite assessments but may be significant for offsite receptors, especially for contaminants with relatively short degradation/decay half-lives.

\subsubsection{0-m and 1500-m Receptor Locations}

Figures 6.14 through 6.18 and Table 6.5 summarize the benchmarking simulation at $150 \mathrm{~m}$ from the downgradient edge of the source for RESRAD, MMSOILS, and MEPAS. Figures 6.14 through 6.18 present time-varying concentrations of nitrate, uranium-238, thorium-230, radium-226, and lead-210, respectively. Figures 6.19 through 6.23 and Table 6.6 summarize the benchmarking simulation at $1500 \mathrm{~m}$ from the downgradient edge of the source for RESRAD, MMSOILS, and MEPAS. Figures 6.19 through 6.23 present time-varying concentrations of nitrate, uranium-238, thorium-230, radium-226, and lead-210, respectively. At 150 and $1500 \mathrm{~m}$ from the downgradient edge of the waste site, MMSOILS and MEPAS simulate a fully mixed condition in the vertical direction, so the contamination is assumed to be uniformly mixed over the aquifer depth of $5 \mathrm{~m}$.

Because RESRAD is based on a plug-flow model, it may produce results that are significantly different from MEPAS or MMSOILS, which are plug-flow-with-dispersion models. Chapter 5 (Sect. 5.3) discusses the impacts associated with using a plug-flow model versus a plug-flow-with-dispersion model in the vadose zone, and similar conclusions can be reached in the saturated zone.

When the travel time of the contaminant is long relative to the duration of the release from the source (e.g., ratio of contaminant travel time to release duration is sufficiently greater than unity), the concentration peak height will be reduced, and a Gaussian shape will be observed, as illustrated in Figs. 6.15 and $6.20 .^{2}$ The plug-flow model (i.e., RESRAD) does not redistribute the contamination in the flow direction as it moves through the saturated zone; only translation occurs, although it can occur at a retarded rate. Although the operational version of RESRAD only accounts for pure translation and does not consider dispersion, the concentration results presented in Figs. 6.14 through 6.23 have been manually reduced by a dilution factor that accounts for lateral dispersion but not vertical or longitudinal dispersion. The dilution factor that accounts for lateral dispersion in RESRAD is a function of distance, as is the case in MMSOILS and MEPAS. The mathematical construct of the operation used by RESRAD is presented in Yu et al. (1993). However, MMSOILS and MEPAS spatially redistribute the contamination in the longitudinal, vertical, and lateral directions.

Figures 6.14 and 6.19 and Figs. 6.15 and 6.20 illustrate that the peak centerline concentrations for nitrate and uranium-234, respectively, decrease as the contaminant migrates from the $150-\mathrm{m}$ well to the

\footnotetext{
${ }^{2}$ Typical Gaussian curves for concentration versus time are skewed right.
} 
1500-m well. Although these trends are followed by each of the models, MMSOILS' and MEPAS' peak centerline concentrations are lower than those reported by RESRAD, as the contamination moves from the $150-\mathrm{m}$ location to the $1500-\mathrm{m}$ location, because the mass is more dispersed both spatially and temporally (see Figs. 6.14, 6.15, 6.19 and 6.20 and Tables 6.5 and 6.6). Because the contamination is uniformly mixed in the vertical direction at the $150-\mathrm{m}$ and $1500-\mathrm{m}$ locations for all of the models, vertical dispersion does not account for differences in the results between the models. As nitrate migrates from the $150-\mathrm{m}$ to the $1500-\mathrm{m}$ location, the peak concentrations, as predicted by RESRAD, decrease by a factor of $\approx 9(10 / 1.1)$, while these same concentrations decrease by a factor of $\approx 15(9.7 / 0.64)$ for MMSOILS and MEPAS. Likewise, for uranium-234, the RESRAD concentrations decrease by a factor of $9\left(9.9 \times 10^{-3} / 1.1 \times 10^{-3}\right)$, while those for MMSOILS and MEPAS decrease by a factor of $\approx 80(1.9 \times$ $\left.10^{-3} / 2.4 \times 10^{-5}\right)$. The effects and differences between RESRAD and MMSOILS/MEPAS would be even more pronounced if the parent constituents had half-lives similar to or less than the travel time.

Because the effects of lateral dispersion in each model is a function of travel distance, the dilution factor in RESRAD appears to account for lateral dispersion in a way that is consistent with MMSOILS and MEPAS, although this topic was not specifically investigated. Because the effects of longitudinal and vertical dispersion are neutralized in Fig. 6.14, the impacts of lateral dispersion for each of the models appear similar, as each of the models estimates the peak concentration as $\approx 10 \mathrm{mg} \mathrm{L}^{-1}$ nitrate. Although the results are similar when longitudinal and vertical dispersion are neutralized, accounting for significant degradation/decay could result in significant differences between the models.

Figures $6.15,6.19$, and 6.20 demonstrate that RESRAD also predicts higher centerline concentrations over a shorter duration, while MMSOILS and MEPAS predict lower concentrations over significantly longer durations. For RESRAD, the plume passing the receptor location has the same shape as the source-term flux, while MMSOILS and MEPAS predict a more dispersed plume passing the receptor location (see Figs. 6.14, 6.15, 6.19, and 6.20). These figures also indicate that the impacts from the MMSOILS and MEPAS analyses for parent constituents will occur for significantly longer durations than for RESRAD analyses.

RESRAD and MEPAS differ in the way that they deal with progeny formation, thereby contributing to differences in receptor concentrations for decay products. Because it is extremely cumbersome to concurrently model three-dimensional advective-dispersive groundwater transport with multiple chain decay (e.g., four or more decay products), the conceptual designs of RESRAD and MEPAS resulted in model development trade-offs.

RESRAD was originally developed to handle only radioactive constituents and was specifically designed for onsite assessments (i.e., immediately in or below the waste site). Because of these constructs, RESRAD opted to use a groundwater transport code that is based on pure translation (i.e., plug flow or pure advection), which is fully coupled with algorithms that handle ingrowth and decay during transport. For mainly onsite assessments with contamination near the surface, a relatively simple, plug-flow groundwater code is generally appropriate. RESRAD, however, also modifies the plug-flow transport calculations in the saturated zone, using a dilution factor at the receptor based on (1) a user-defined, pumping-well withdrawal rate and (2) manually manipulated modifiers to account for lateral dispersion (Yu et al. 1993).

MEPAS, on the other hand, was originally developed to handle both chemicals and radionuclides and was specifically developed for offsite assessments, where groundwater transport becomes an important mechanism in spatially and temporally redistributing the contaminant plume. With MEPAS, the chemicals can form transformation products, while the radionuclides have decay product formation. 
MEPAS opted to use a groundwater transport code that is based on advection and three-dimensional dispersion, which is fully coupled with algorithms that handle in-growth and decay at the receptor.

Figures 6.16 through 6.18 and 6.21 through 6.23 present RESRAD and MEPAS time-varying concentration estimates for uranium-238 decay products at 150 and $1500 \mathrm{~m}$, respectively, from the downgradient edge of the waste site. RESRAD simulates ingrowth and decay in transit, as the parent migrates from the source to the receptor locations. By performing ingrowth and decay in transit, each decay product can be assigned a different distribution coefficient (i.e., $\mathrm{K}_{\mathrm{d}}$ ). MEPAS assumes that the decay products move at the same speed as the parent and calculates ingrowth at the receptor location using the well-known Bateman equation (Bateman 1910; Whelan et al. 1987).

The differences in the RESRAD and MEPAS approaches are graphically illustrated in Figs. 6.16 through 6.18 and 6.21 through 6.23 . When the decay product has a significantly larger $\mathrm{K}_{\mathrm{d}}$ than its parent (e.g., uranium-238 and thorium-230 at 5 and $6000 \mathrm{~mL} \mathrm{~g}^{-1}$, respectively) and the parent and decay product have long half-lives (245,000 and 77,000 yrs for uranium-238 and thorium-230, respectively), a pseudo-constant concentration should pass the receptor location. Because progeny formation begins at the waste site where the parent first decays, the decay-product concentration should be relatively constant (assuming a long half-life) for the time it takes the decay product to travel from the waste site to the receptor location. Figure 6.16 illustrates this characteristic of RESRAD. In addition, when the retardation factor is significantly greater than unity, dispersion can be an important mechanism in temporally and spatially redistributing the contaminant, as illustrated by the MEPAS results. However, the actual shape of the curves associated with the decay products should resemble a combination of the RESRAD and MEPAS results. For example, the actual curve in Fig. 6.16 should be dominated by a pseudo-constant concentration, as illustrated by the RESRAD results; these results should then be tempered with a lengthening and flattening of the rising and falling limbs, as illustrated by MEPAS. Because the contaminant half-lives are relatively long, the pseudo-constant condition should represent the dominant characteristic of the concentration curves. As noted in Sect. 6.3.2, direct comparisons of the decay-product results between RESRAD and MEPAS should be tempered with the knowledge that different assumptions inherently exist in the models with respect to different contaminant velocities, travel times, approaches for calculating concentrations at the receptor, and approaches for calculating ingrowth.

Tables 6.5 and 6.6 summarize the net impact on peak concentrations and times to peak at the $150-\mathrm{m}$ receptor and $1500-\mathrm{m}$ receptor, respectively. Although these tables indicate that each model produces similar times to peak, the temporal distribution of the contamination is significantly different. For example, MMSOILS and MEPAS results for the parents are more distributed in time because these models include longitudinal dispersion, whereas RESRAD transports the parents' contamination through pure translation. Likewise, RESRAD's results for the decay-products are more distributed in time, whereas MEPAS uses an approach where progeny formation mirrors the shape of the parent's concentration-versus-time curve.

\subsection{CHAPTER REFERENCES}

Bateman, H. 1910. The Solution of a System of Differential Equations Occurring in the Theory of Radioactive Transformations, Proc. Cambridge Philos. Soc. 16:423-427.

EPA (U.S. Environmental Protection Agency). 1992. MMSOILS: Multimedia Contaminant Fate, Transport, and Exposure Model - Documentation and User's Manual, Office of Research and Development, Washington, D.C. (Draft) 


\section{$6-12$}

Fetter, C. W. 1988. Applied Hydrogeology, Second Edition, Merrill Publishing, Columbus, Ohio.

Salhotra, A. M., P. Mineart, S. Sharp-Hansen, T. Allison, R. Johns, and W. B. Mills. 1993. Multimedia Exposure Assessment Model (MULTIMED) for Evaluating the Land Disposal of Wastes -- Model Theory, EPA-EPA/600/R-93/131, U.S. Environmental Protection Agency, Office of Research and Development, Environmental Research Laboratory, Athens, Georgia.

Whelan, G., D. L. Strenge, J. G. Droppo, Jr., B. L. Steelman, and J. W. Buck. 1987. The Remedial Action Priority System (RAPS): Mathematical Formulations, PNL-6200, Pacific Northwest Laboratory, Richland, Washington.

Yu, C., A. J. Zielen, J.-J Cheng, T. C. Yuan, L. G. Jones, D. J. LePoire, Y. Y. Wang, C. O. Loureiro, E. Gnanapragasam, E. Faillace, A. Wallo III, W. A. Williams, and H. Peterson. 1993. Manual for

- Implementing Residual Radioactive Material Guidelines using RESRAD, Version 5.0, Argonne National Laboratory, Argonne, Illinois.

Yu, C., W. A. Jester, and A. R. Jarrett. 1985. A General Solute Transport Model and Its Applications in Contaminant Migration Analysis, Proceedings of the National Water Well Association Conference on Practical Applications of Ground Water Models, pp.353-372. 
Table 6.1. Site parameters for direct release to the saturated zone

\begin{tabular}{l|c}
\hline Site Length and Width & $37.5 \mathrm{~m} \mathrm{by} 37.5 \mathrm{~m}$ \\
Darcy Infiltration Rate & $0.0127 \mathrm{~m} \mathrm{yr}^{-1}$ \\
Aquifer Thickness & $5 \mathrm{~m}$ \\
Darcy Velocity & $10 \mathrm{~m} \mathrm{yr}^{-1}$ \\
Effective Porosity & $25.0 \%$ \\
Total Porosity & $44.2 \%$ \\
Release Duration & $25 \mathrm{yr}^{-1}$ \\
Pore-Water Velocity & $40 \mathrm{~m} \mathrm{yr}^{-1}$ \\
Bulk Density & $1.48 \mathrm{~g} \mathrm{~cm}^{-3}$ \\
\hline
\end{tabular}

Table 6.2. Dispersivities for direct release to the saturated zone ( $\alpha)$

\begin{tabular}{cccc}
\hline Distance (m) & 0 & 150 & 1500 \\
Longitudinal & 1.5 & 15 & 150 \\
Dispersivity (m) & 0.3 & 3.0 & 30 \\
$\quad$ Lateral & Dispersivity (m) & & \\
\hline
\end{tabular}

Table 6.3. Contaminant specific information for direct discharge to the saturated zone

\begin{tabular}{ccccc}
\hline Contaminant & $\begin{array}{c}\text { Flux } \\
{\left[(\mathrm{g} \text { or } \mathrm{pCi}) \mathrm{yr}^{-1}\right]}\end{array}$ & $\begin{array}{c}\mathrm{K}_{\mathrm{d}} \\
\left(\mathrm{mL}^{-1}\right)\end{array}$ & $\begin{array}{c}\mathrm{t}_{1 / 6} \\
(\mathrm{vr})\end{array}$ & $\begin{array}{c}\text { Mass } \\
(\mathrm{g} \text { or } \mathrm{pCi})\end{array}$ \\
\hline Nitrate & 42,000 & 0 & -- & $1.05 \times 10^{6}$ \\
Uranium-234 & 42,000 & 5 & $2.45 \times 10^{5}$ & $1.05 \times 10^{6}$ \\
Thorium-230 & -- & 6000 & $7.70 \times 10^{4}$ & - \\
Radium-226 & -- & 7 & $1.60 \times 10^{3}$ & - \\
Lead-210 & -- & 1 & $2.23 \times 10^{1}$ & - \\
\hline
\end{tabular}


Table 6.4. Peak concentration and time-to-peak at the $0-\mathrm{m}$ receptor for direct release to the saturated zone

\begin{tabular}{ccccccc}
\hline & \multicolumn{2}{c}{ RESRAD } & \multicolumn{2}{c}{ MMSOILS } & \multicolumn{2}{c}{ MEPAS } \\
\cline { 2 - 7 } CONTAMINANT & $\begin{array}{c}\text { Concentra- } \\
\text { tion [(mg or } \\
\left.\mathrm{pCi}) \mathrm{L}^{-1}\right]\end{array}$ & $\begin{array}{c}\text { Time } \\
\text { (yr) }\end{array}$ & $\begin{array}{c}\text { Concentra- } \\
\text { tion [(mg or } \\
\left.\mathrm{pCi}) \mathrm{L}^{-1}\right]\end{array}$ & $\begin{array}{c}\text { Time } \\
\text { (yr) }\end{array}$ & $\begin{array}{c}\text { Concentra- } \\
\text { tion [(mg or } \\
\left.\mathrm{pCi}) \mathrm{L}^{-1}\right]\end{array}$ & $\begin{array}{c}\text { Time } \\
\text { (yr) }\end{array}$ \\
\hline Nitrate & 22 & 1 & 22 & $3-5^{*}$ & 98 & $0.6-1.0^{*}$ \\
Uranium-234 & $2.2 \times 10^{-2}$ & 17 & $1.8 \times 10^{-2}$ & 28 & $9.8 \times 10^{-2}$ & $18-19^{*}$ \\
Thorium-230 & $4.4 \times 10^{-9}$ & $37-38^{*}$ & -- & -- & $1.3 \times 10^{-5}$ & $16-19^{*}$ \\
Radium-226 & $1.8 \times 10^{-8}$ & $40-41^{*}$ & -- & -- & $3.9 \times 10^{-8}$ & $17-19^{*}$ \\
Lead-210 & $3.2 \times 10^{-9}$ & $44-45^{*}$ & -- & -- & $5.2 \times 10^{-9}$ & $17-19^{*}$ \\
\hline
\end{tabular}

A range is provided because the results asymptotically approach a constant solution.

Table 6.5. Peak concentration and time-to-peak at the $150-\mathrm{m}$ receptor for direct release to the saturated zone

\begin{tabular}{cccccccc}
\hline & \multicolumn{2}{c}{ RESRAD } & \multicolumn{2}{c}{ MMSOLS } & \multicolumn{2}{c}{ MEPAS } \\
\cline { 2 - 7 } CONTAMINANT & $\begin{array}{c}\text { Concentra- } \\
\text { tion [(mg or } \\
\left.\mathrm{pCi}) \mathrm{L}^{-1}\right]\end{array}$ & Time $(\mathrm{yr})$ & $\begin{array}{c}\text { Concentra- } \\
\text { tion [(mg or } \\
\left.\mathrm{pCi}) \mathrm{L}^{-1}\right]\end{array}$ & $\begin{array}{c}\text { Time } \\
(\mathrm{yr})\end{array}$ & $\begin{array}{c}\text { Concentra- } \\
\text { tion [(mg or } \\
\left.\mathrm{pCi}) \mathrm{L}^{-1}\right]\end{array}$ & $\begin{array}{c}\text { Time } \\
(\mathrm{yr})\end{array}$ \\
\hline Nitrate & 10 & 5 & 9.7 & $12-17^{*}$ & 9.7 & $10-14^{*}$ \\
Uranium-234 & $9.9 \times 10^{-3}$ & 83 & $1.9 \times 10^{-3}$ & 125 & $1.9 \times 10^{-3}$ & 121 \\
Thorium-230 & $2.0 \times 10^{-9}$ & $105-108^{*}$ & -- & -- & $2.2 \times 10^{-6}$ & 129 \\
Radium-226 & $7.1 \times 10^{-8}$ & $129-139^{*}$ & -- & -- & $6.1 \times 10^{-8}$ & 129 \\
Lead-210 & $7.1 \times 10^{-8}$ & $129-139^{*}$ & -- & -- & $3.8 \times 10^{-8}$ & 129 \\
\hline
\end{tabular}

- A range is provided because the results asymptotically approach a constant solution. 


\section{$6-15$}

Table 6.6. Peak concentration and time-to-peak at the $1500-\mathrm{m}$ receptor for direct release to the saturated zone

\begin{tabular}{ccccccc}
\hline & \multicolumn{2}{c}{ RESRAD } & \multicolumn{2}{c}{ MMSOLS } & \multicolumn{2}{c}{ MEPAS } \\
\cline { 2 - 7 } CONTAMINANT & $\begin{array}{c}\text { Concentra- } \\
\text { tion [(mg or } \\
\left.\mathrm{pCi}) \mathrm{L}^{-1}\right]\end{array}$ & Time (yr) & $\begin{array}{c}\text { Concentra- } \\
\text { tion [(mg or } \\
\left.\mathrm{pCi}) \mathrm{L}^{-1}\right]\end{array}$ & $\begin{array}{c}\text { Time } \\
\text { (yr) }\end{array}$ & $\begin{array}{c}\text { Concentra- } \\
\text { tion [(mg or } \\
\left.\mathrm{pCi}) \mathrm{L}^{-1}\right]\end{array}$ & $\begin{array}{c}\text { Time } \\
(\mathrm{yr})\end{array}$ \\
\hline Nitrate & 1.1 & 39 & $6.4 \times 10^{-1}$ & 48 & $6.4 \times 10^{-1}$ & 47 \\
Uranium-234 & $1.1 \times 10^{-3}$ & 684 & $2.4 \times 10^{-5}$ & 950 & $2.4 \times 10^{-5}$ & 959 \\
Thorium-230 & $2.2 \times 10^{-10}$ & $704-707^{*}$ & -- & -- & $2.2 \times 10^{-7}$ & 1,120 \\
Radium-226 & $6.0 \times 10^{-8}$ & $944-963$ & -- & -- & $4.6 \times 10^{-8}$ & 1,200 \\
Lead-210 & $2.7 \times 10^{-7}$ & $944-954$ & -- & -- & $4.4 \times 10^{-8}$ & 1,200 \\
\hline
\end{tabular}

- A range is provided because the results asymptotically approach a constant solution. 


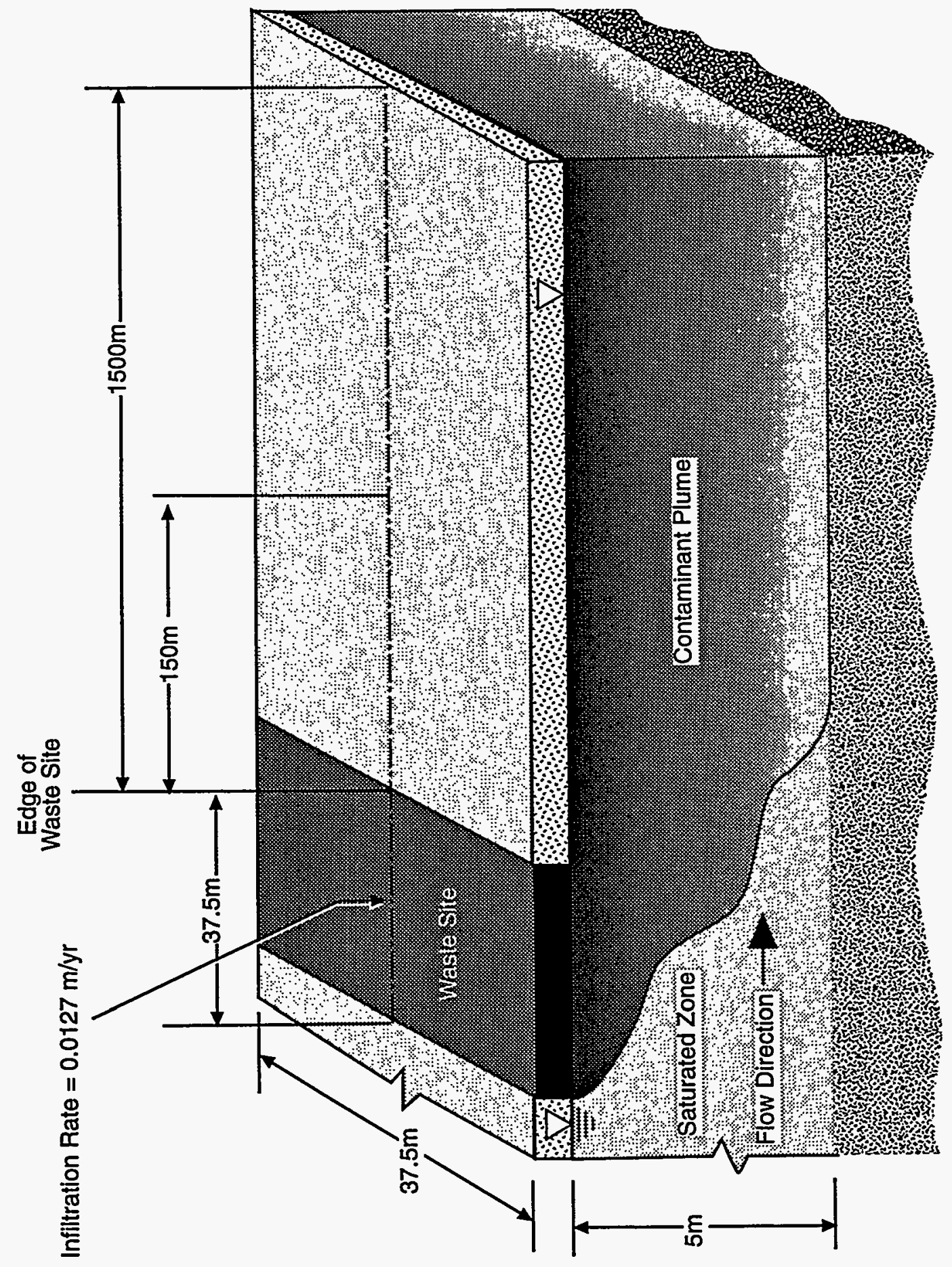

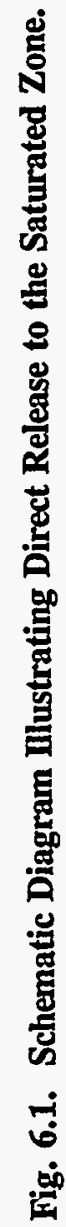

$山$
$\frac{1}{0}$
0
0
$\frac{5}{2}$
$\frac{1}{2}$ 

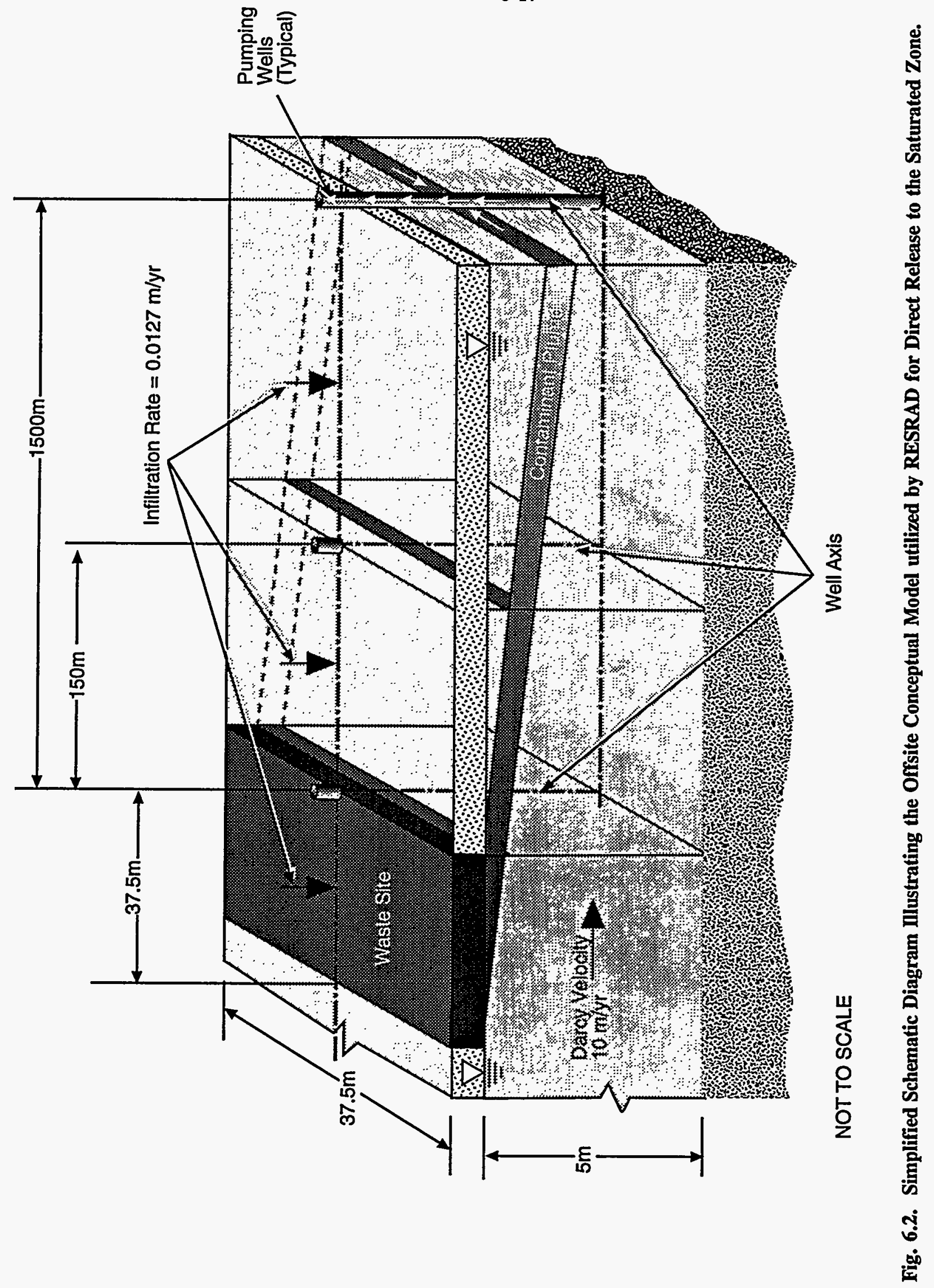
6-18
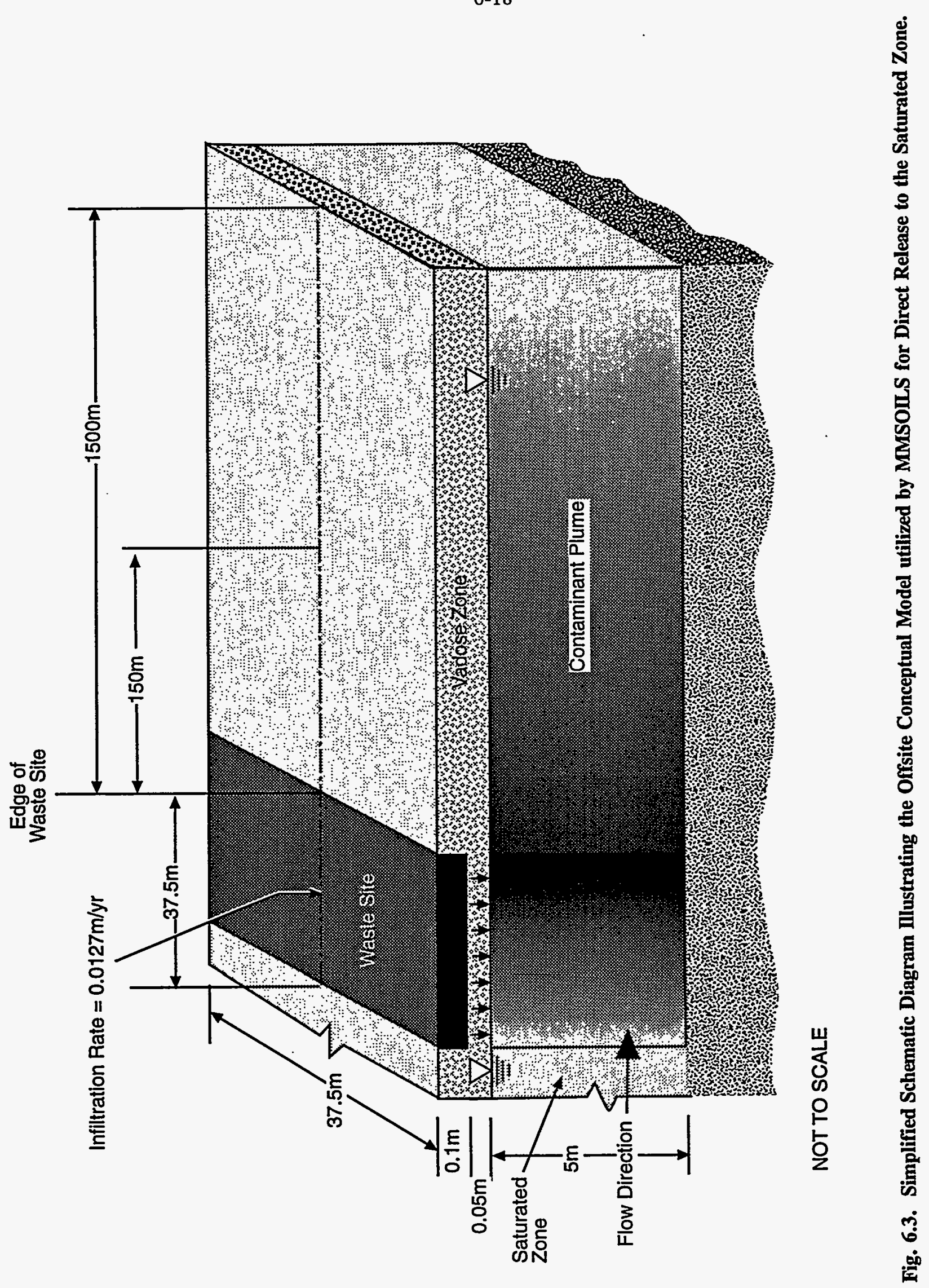
Direct Release to the Saturated Zone

Nitrate - Flux to the Aquifer

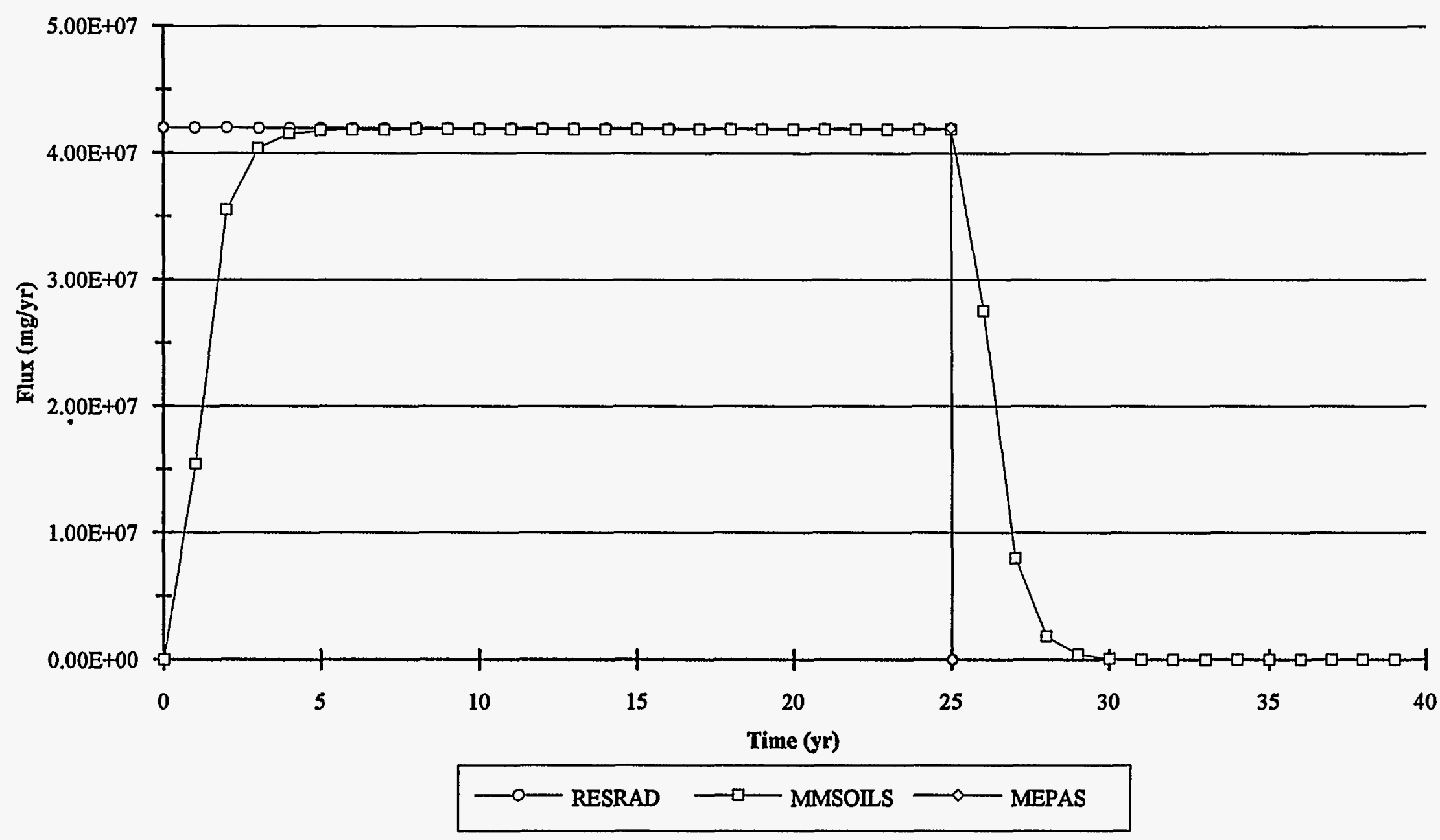

Fig. 6.4. Source-Term Time-Varying Fluxes of Nitrate Entering the Saturated Zone for RESRAD, MMSOUS, and MEPAS. 
Direct Release to the Saturated Zone

Uranium-234 - Flux to the Aquifer

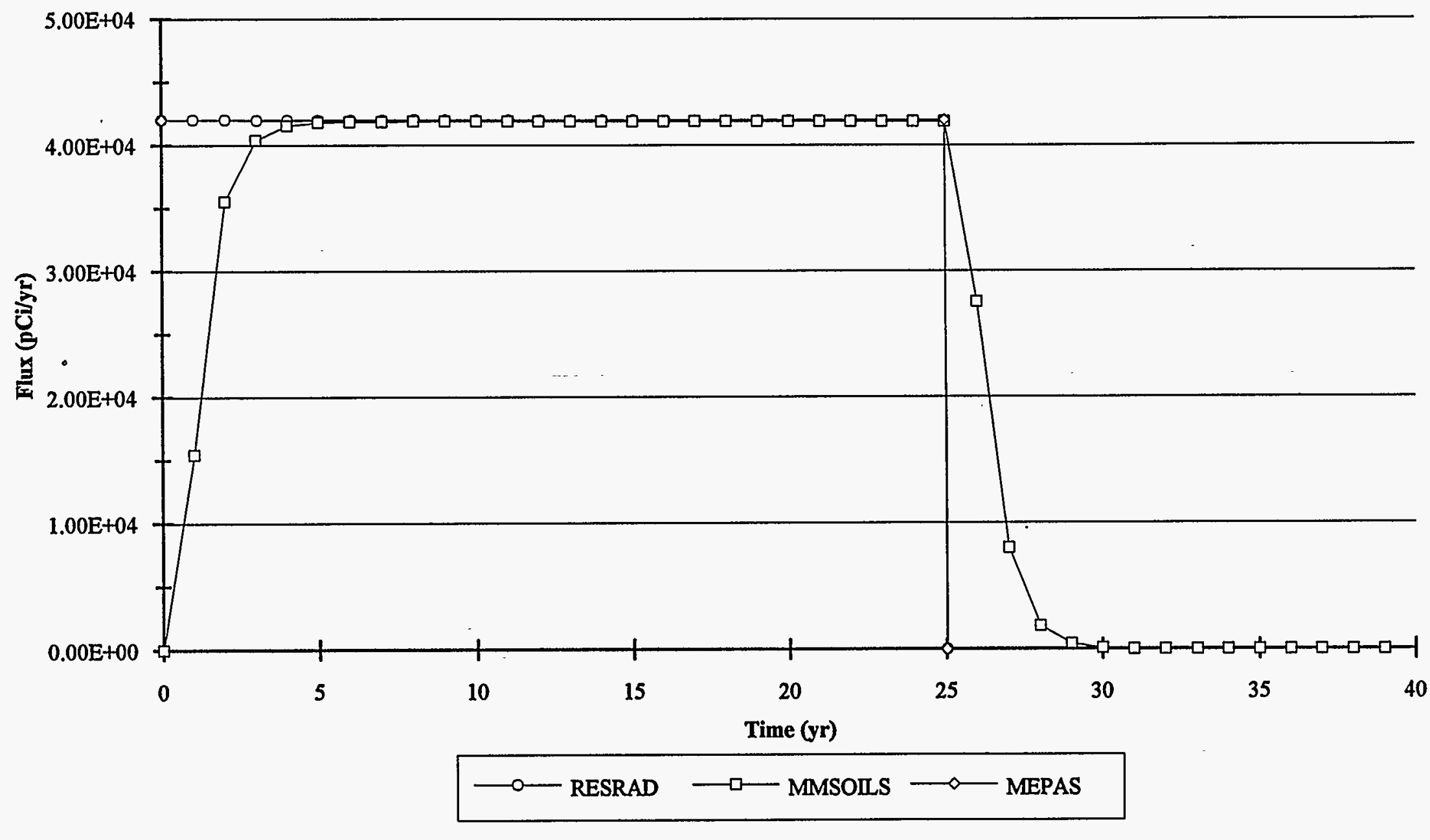

Fig. 6.5. Source-Term Time-Varying Fluxes of Uranium-234 Entering the Saturated Zone for RESRAD, MMSOULS, and MEPAS. 
Direct Release to the Saturated Zone

Thorium-230 - Flux to the Aquifer

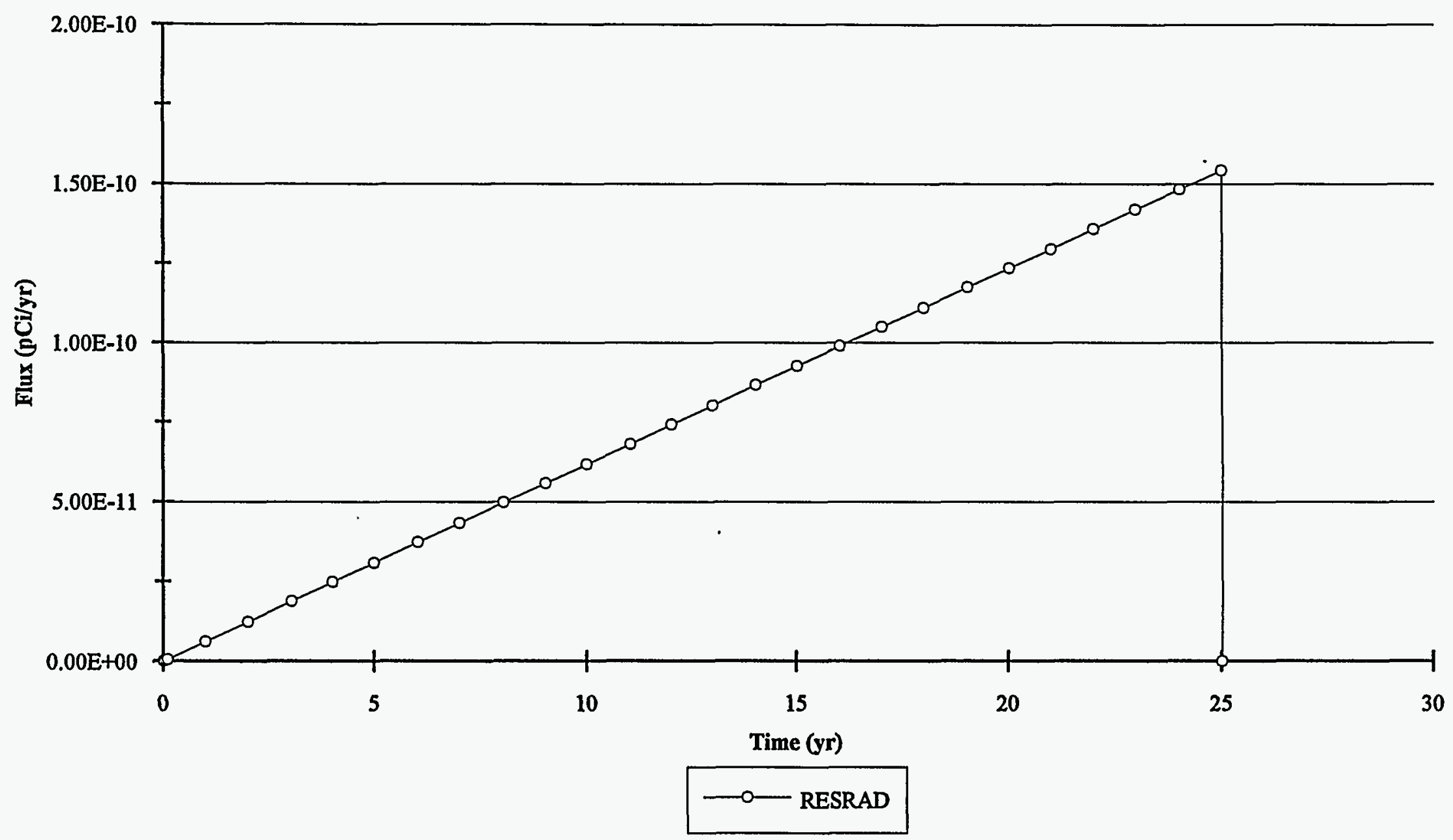

Fig. 6.6. Source-Term Time-Varying Fluxes of Thorium-230 Entering the Saturated Zone for RESRAD. 
Direct Release to the Saturated Zone

Radium-226 - Flux to the Aquifer

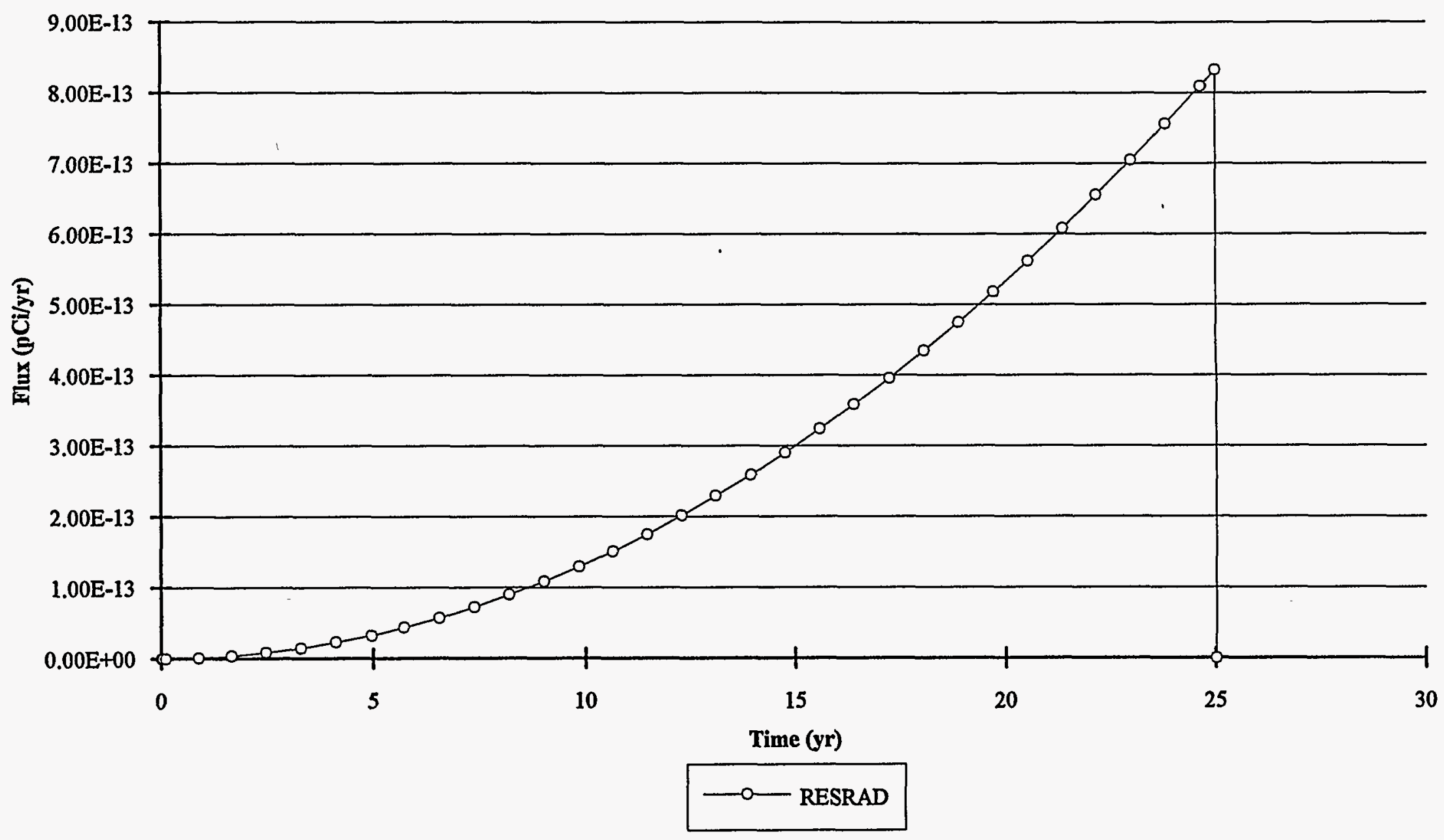

Fig. 6.7. Source-Term Time-Varying Fluxes of Radium-226 Entering the Saturated Zone for RESRAD. 


\section{Direct Release to the Saturated Zone}

Lead-210 - Flux to the Aquifer

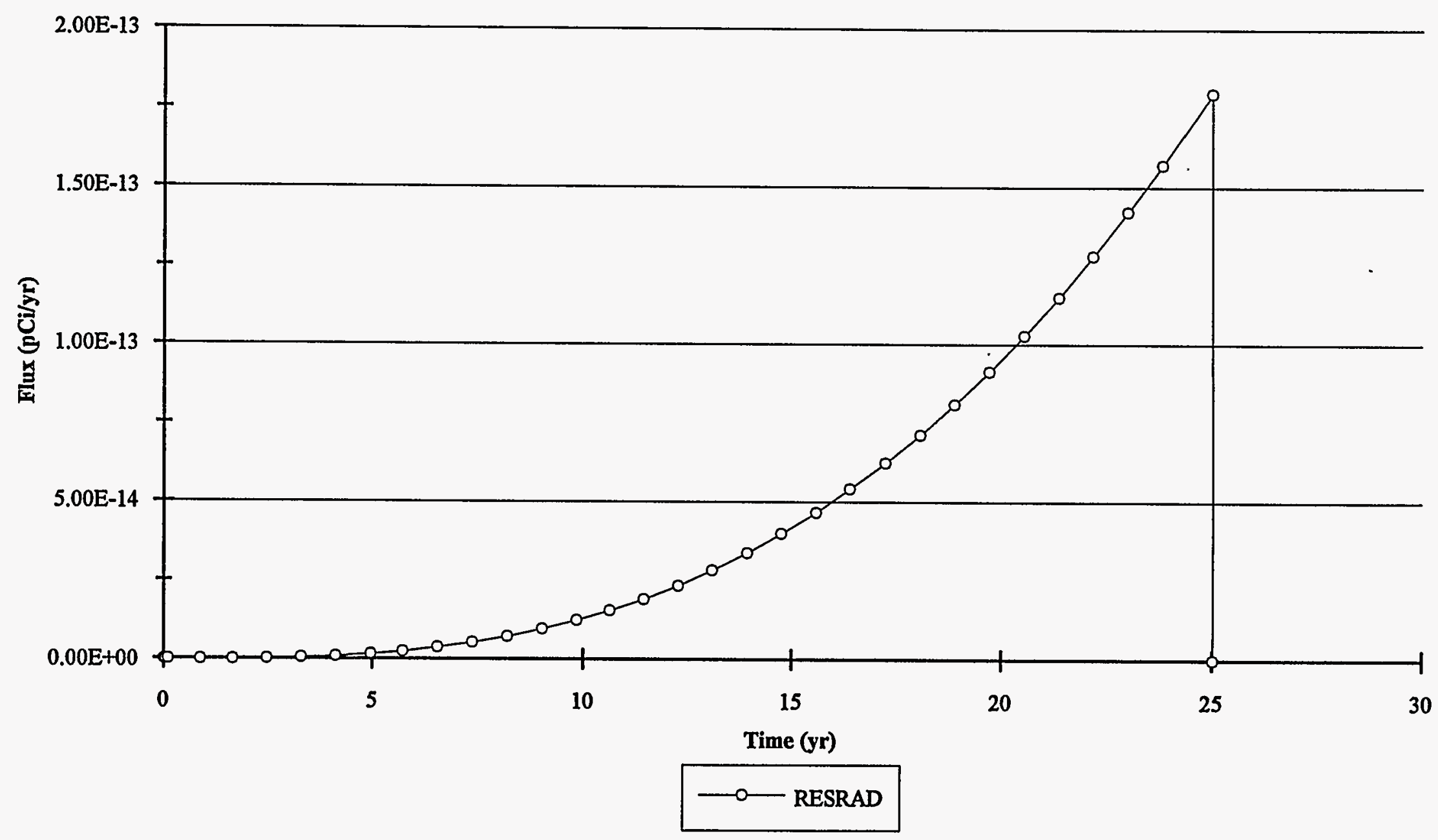

Fig. 6.8. Source-Term Time-Varying Flures of Lead-210 Entering the Saturated Zone for RESRAD. 
Direct Release to the Saturated Zone

Nitrate - Concentrations at $0 \mathrm{~m}$

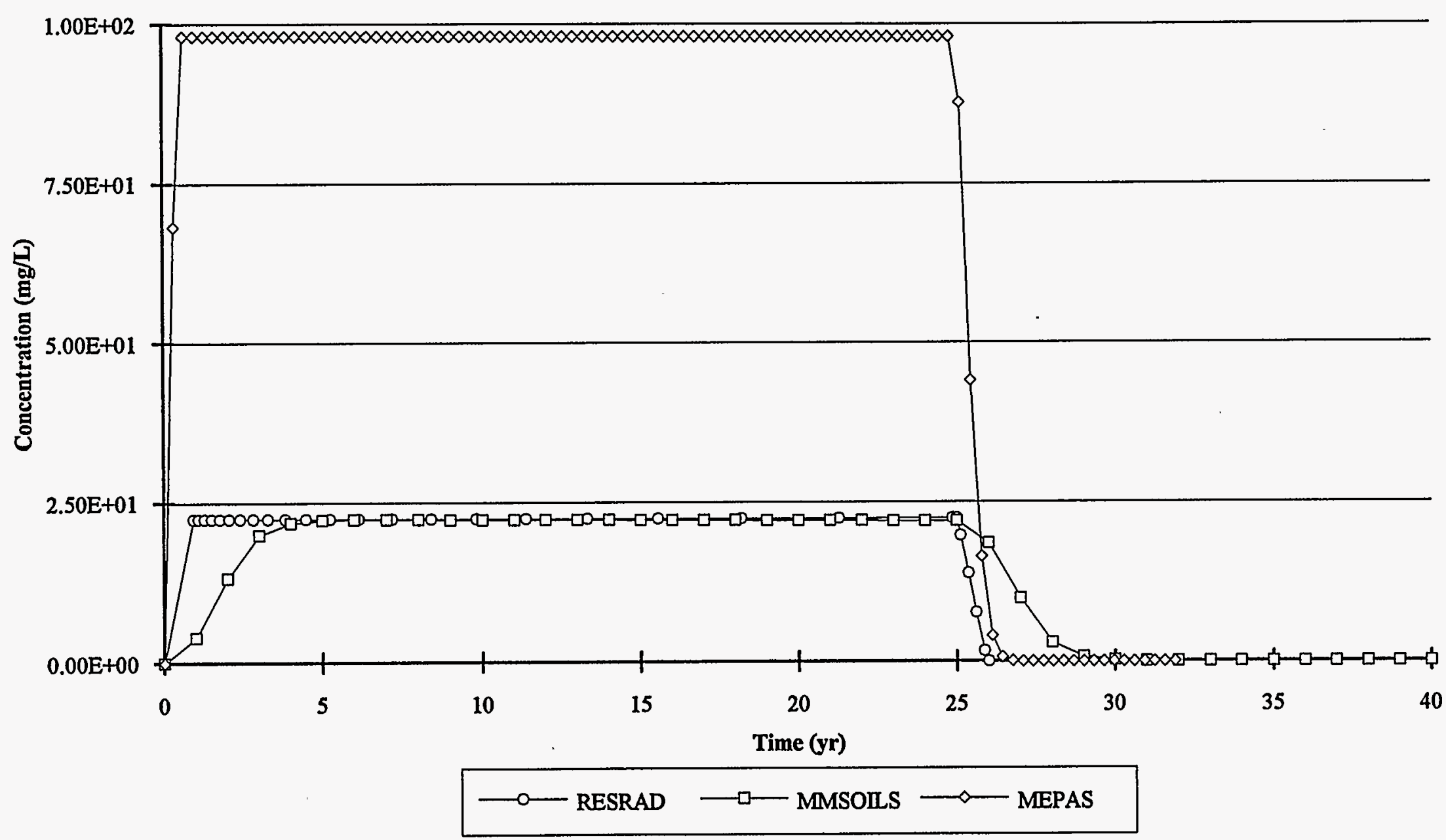

Fig. 6.9. Time-Varying Concentrations of Nitrate at the Edge of the Waste Site for RESRAD, MMSOILS, and MEPAS. 


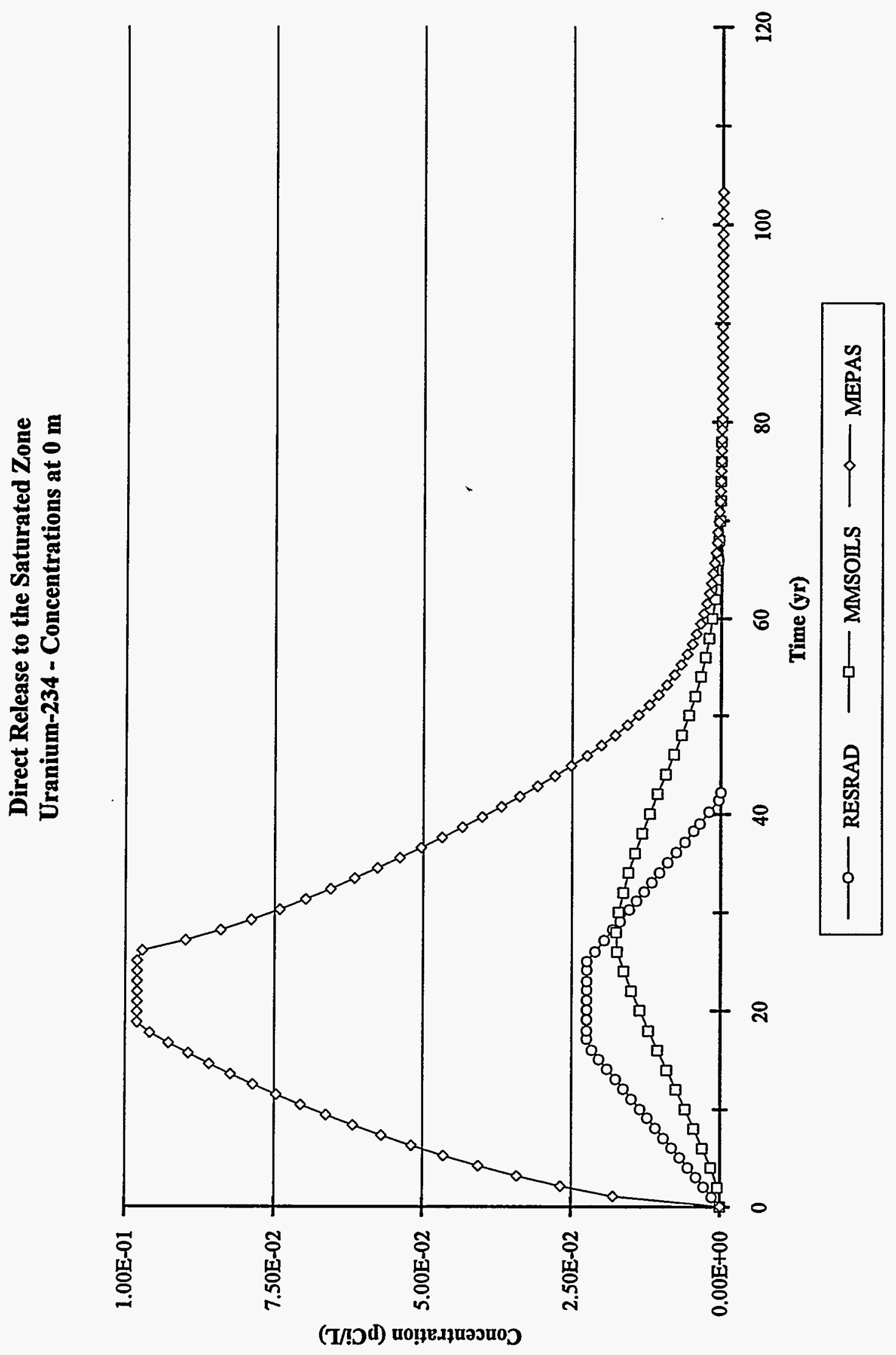

是 
Direct Release to the Saturated Zone

Thorium-230 - Concentrations at $0 \mathrm{~m}$

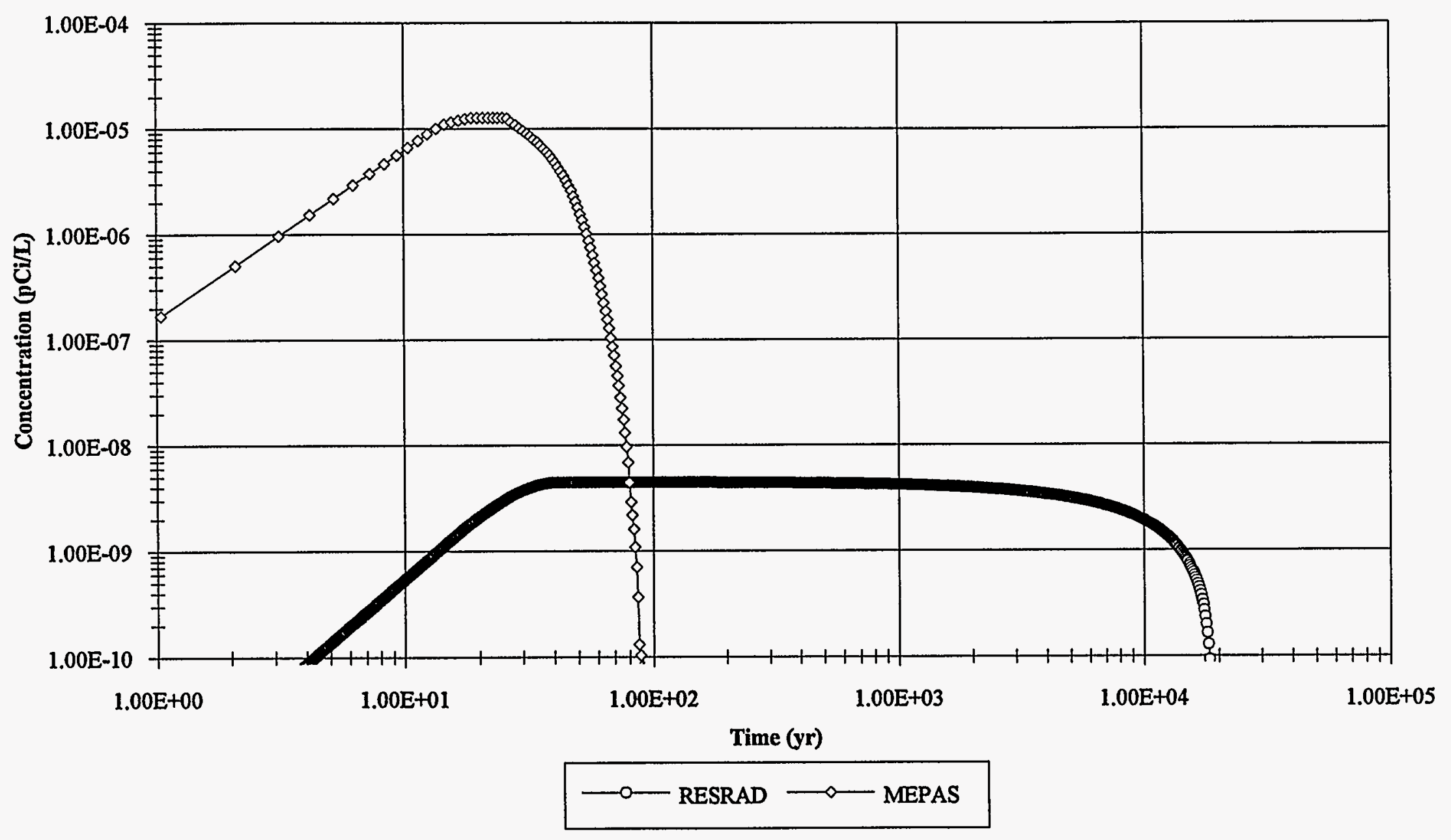

Fig. 6.11. Time-Varying Concentrations of Thorium-230 at the Edge of the Waste Site for RESRAD and MEPAS. 
Direct Release to the Saturated Zone

Radium-226 - Concentrations at $0 \mathrm{~m}$

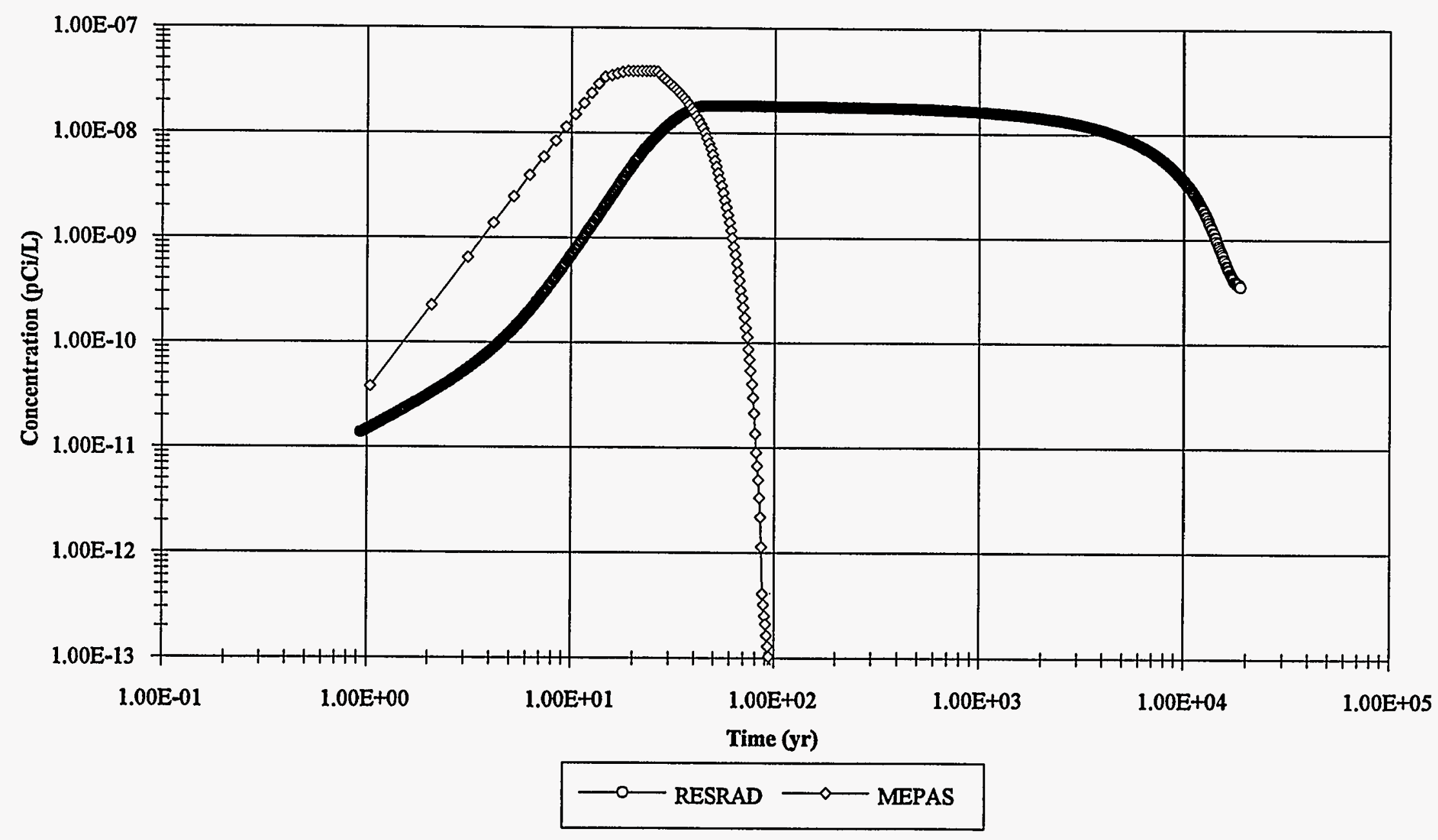

Fig. 6.12. Time-Varying Concentrations of Radium-226 at the Edge of the Waste Site for RESRAD and MEPAS. 
Direct Release to the Saturated Zone

Lead-210 - Concentrations at $0 \mathrm{~m}$

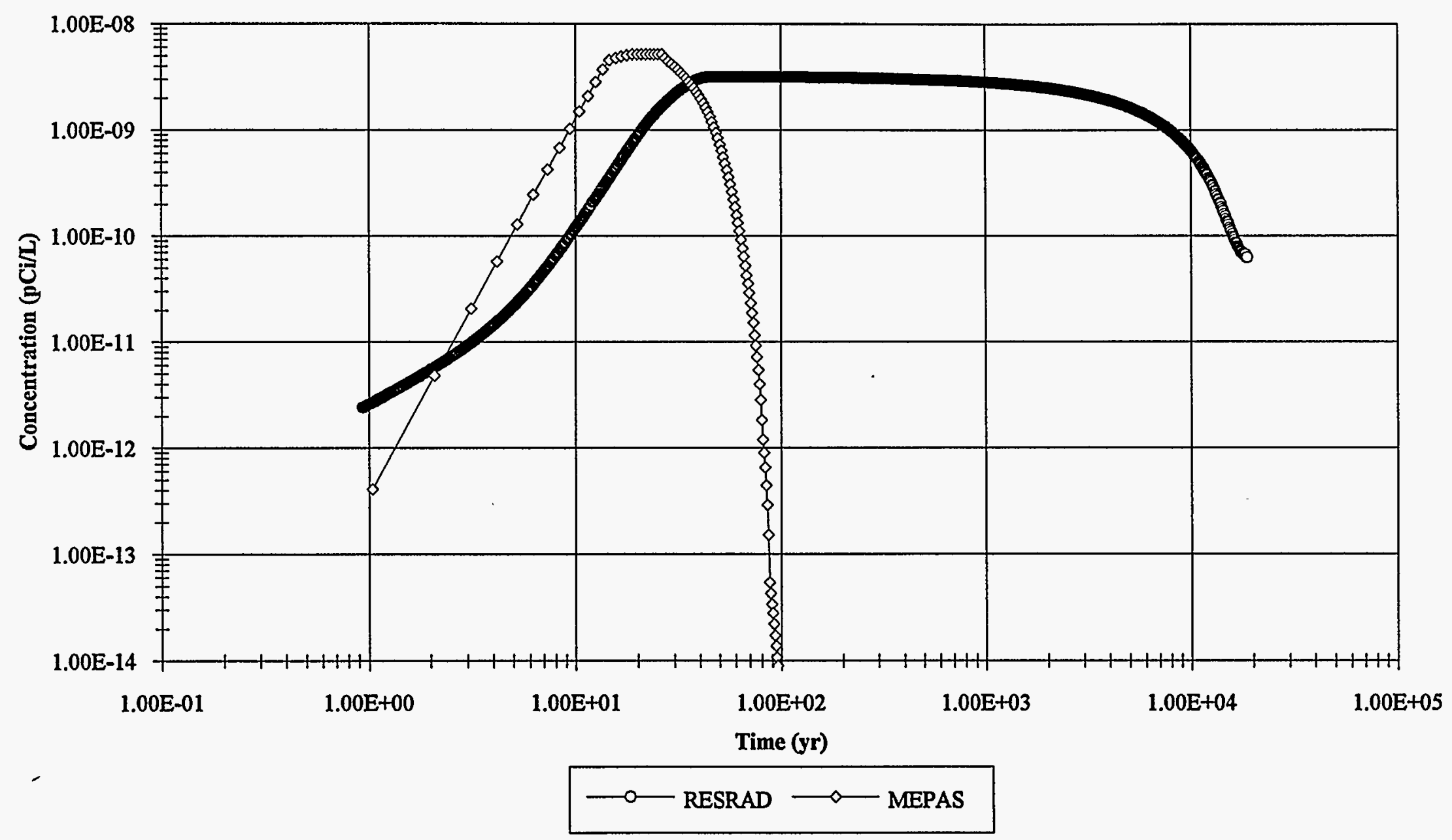

Fig. 6.13. Time-Varying Concentrations of Lead-210 at the Edge of the Waste Site for RESRAD and MEPAS. 


\section{Direct Release to the Saturated Zone}

Nitrate - Concentrations at $150 \mathrm{~m}$

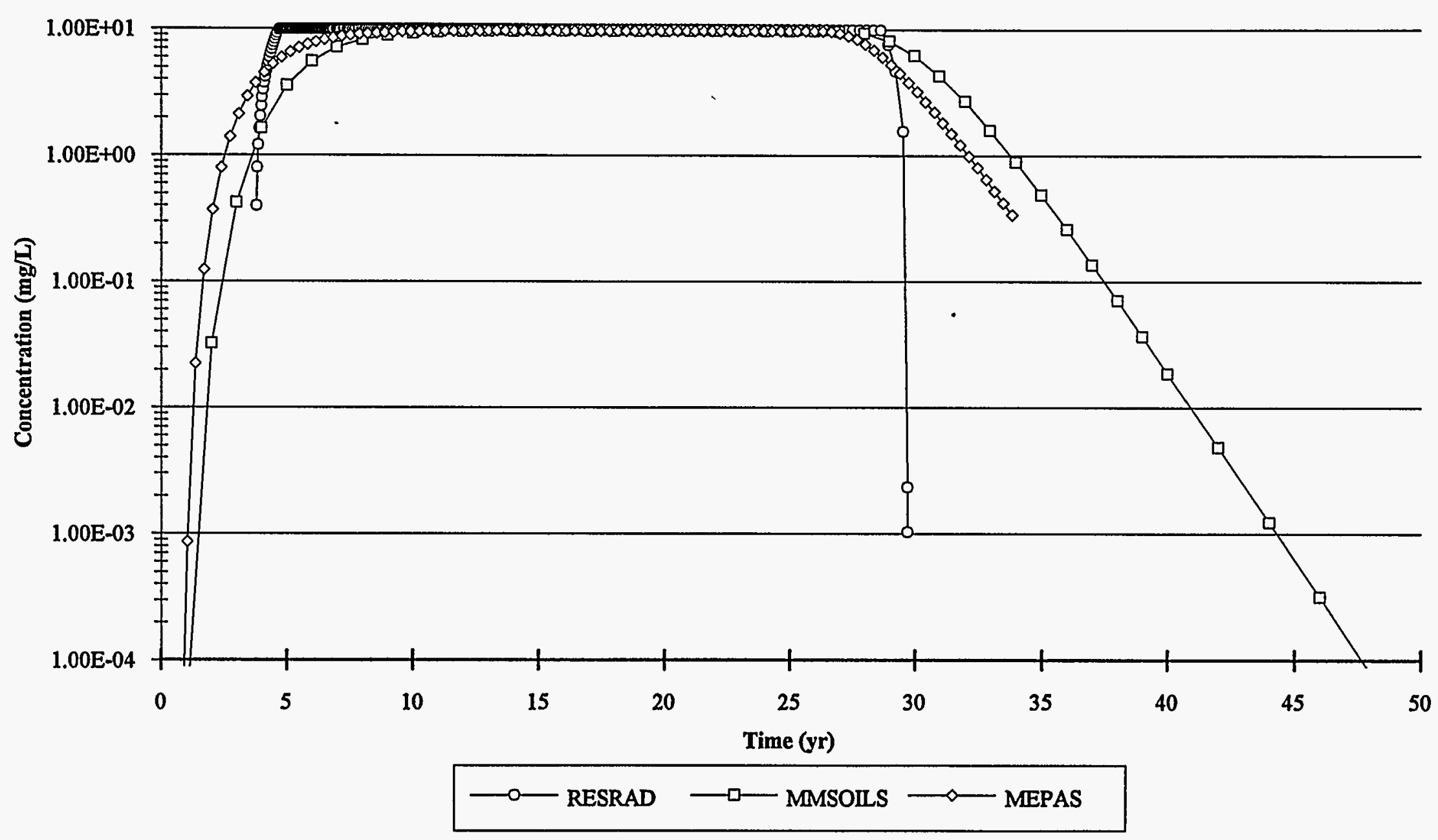

Fig. 6.14. Time-Varying Concentrations of Nitrate at the 150-m Receptor Location for RESRAD, MMSOHS, and MEPAS. 
Direct Release to the Saturated Zone

Uranium-234 - Concentrations at $150 \mathrm{~m}$

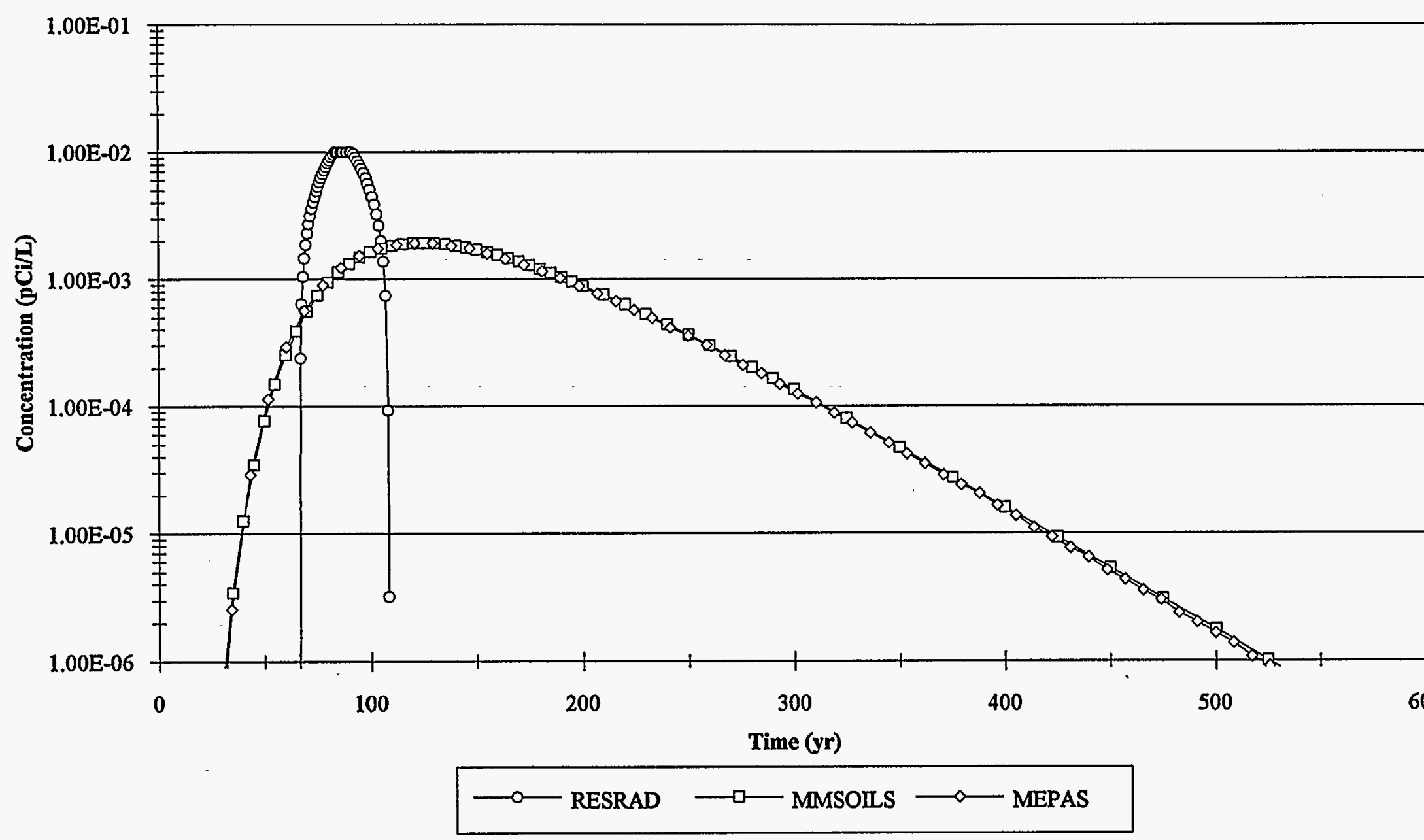

Fig. 6.15. Time-Varying Concentrations of Uranium-234 at the 150-m Receptor Location for RESRAD, MMSOILS and MEPAS. 
Direct Release to the Saturated Zone

Thorium-230 - Concentrations at $150 \mathrm{~m}$

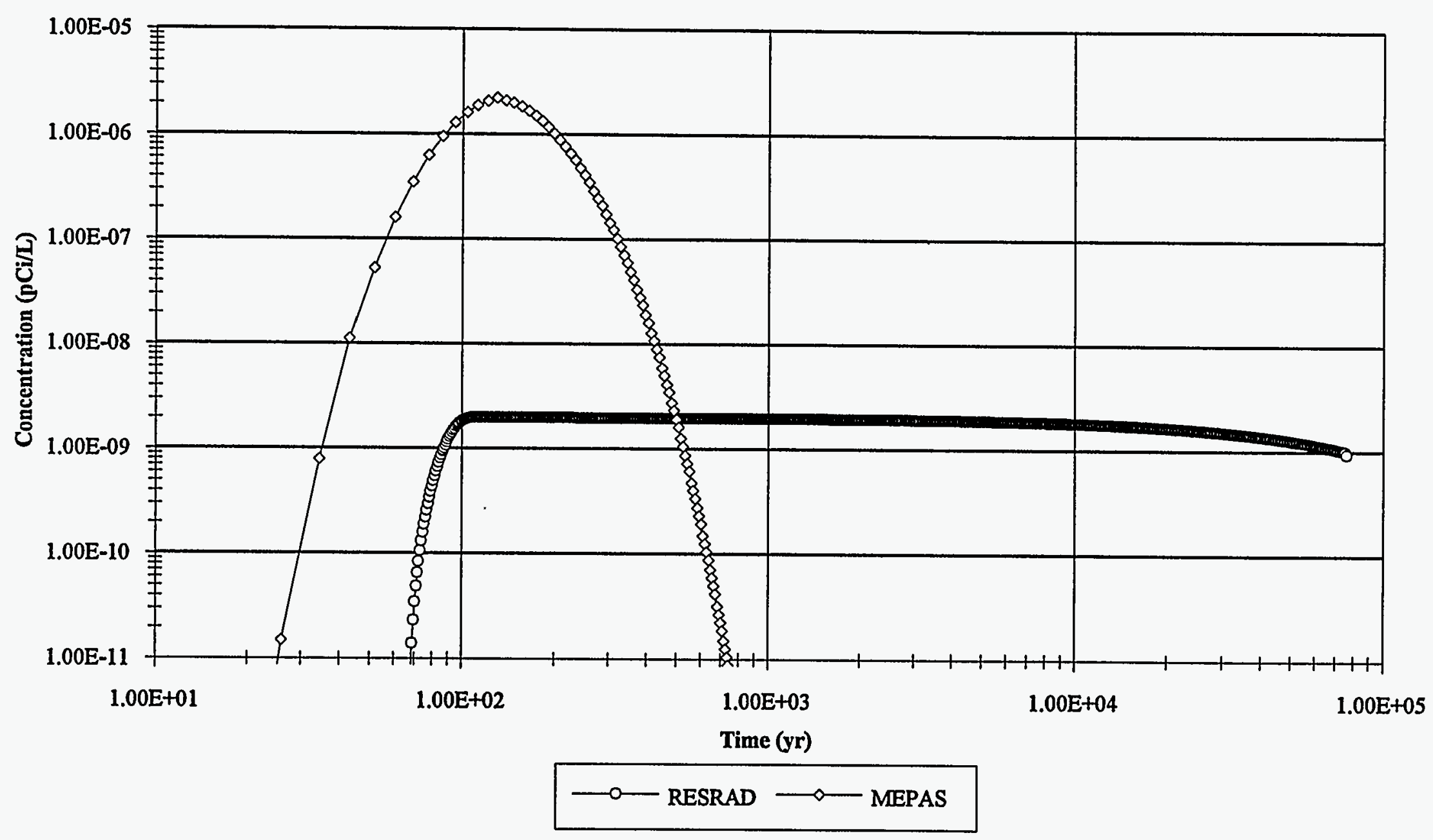

Fig. 6.16. Time-Varying Concentrations of Thorium-230 at the 150-m Receptor Location for RESRAD and MEPAS. 
Direct Release to the Saturated Zone

Radium-226 - Concentrations at $150 \mathrm{~m}$

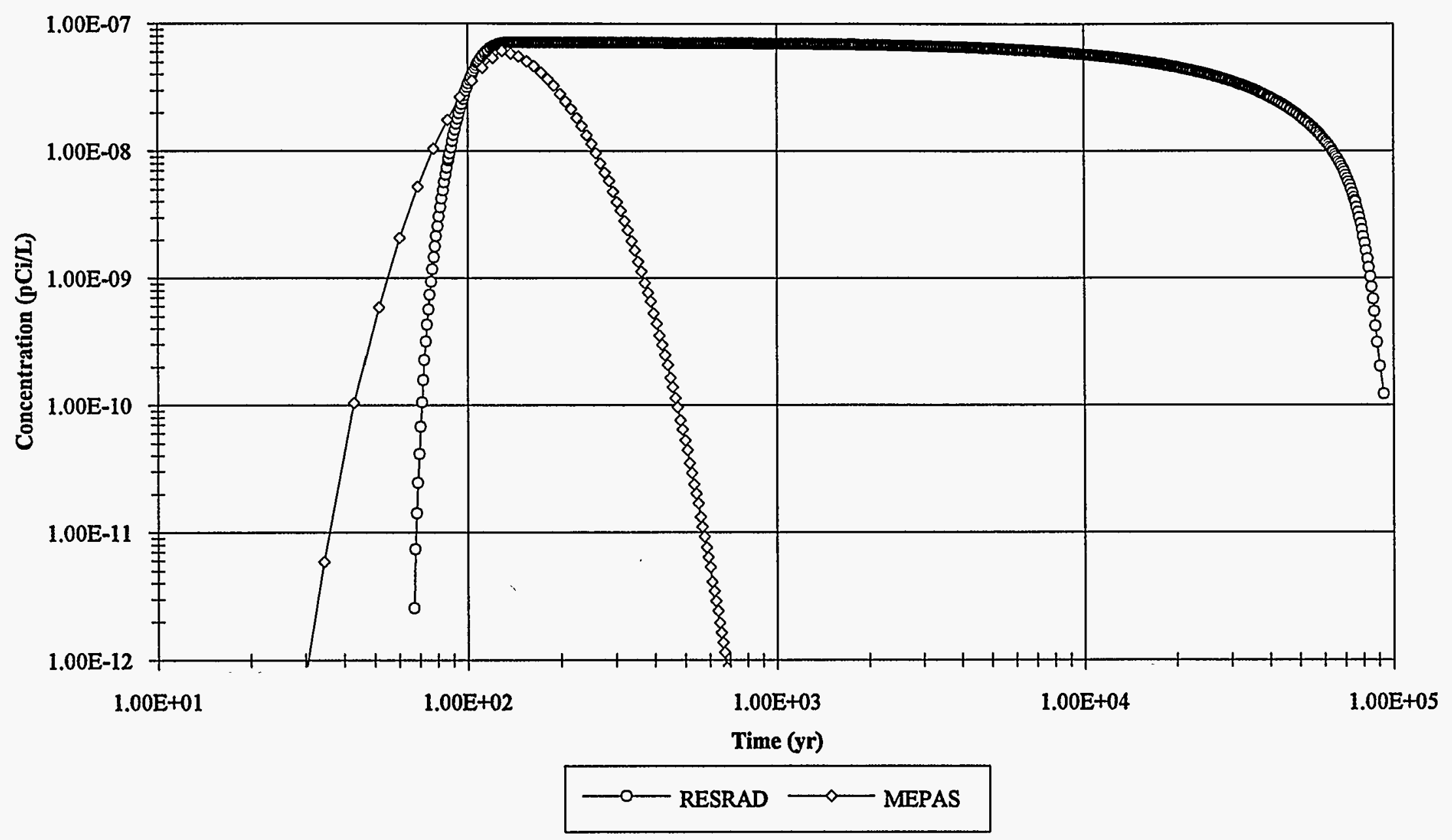

Fig. 6.17. Time-Varying Concentrations of Radium-226 at the 150-m Receptor Location for RESRAD and MEPAS. 
Direct Release to the Saturated Zone

Lead-210 - Concentrations at $150 \mathrm{~m}$

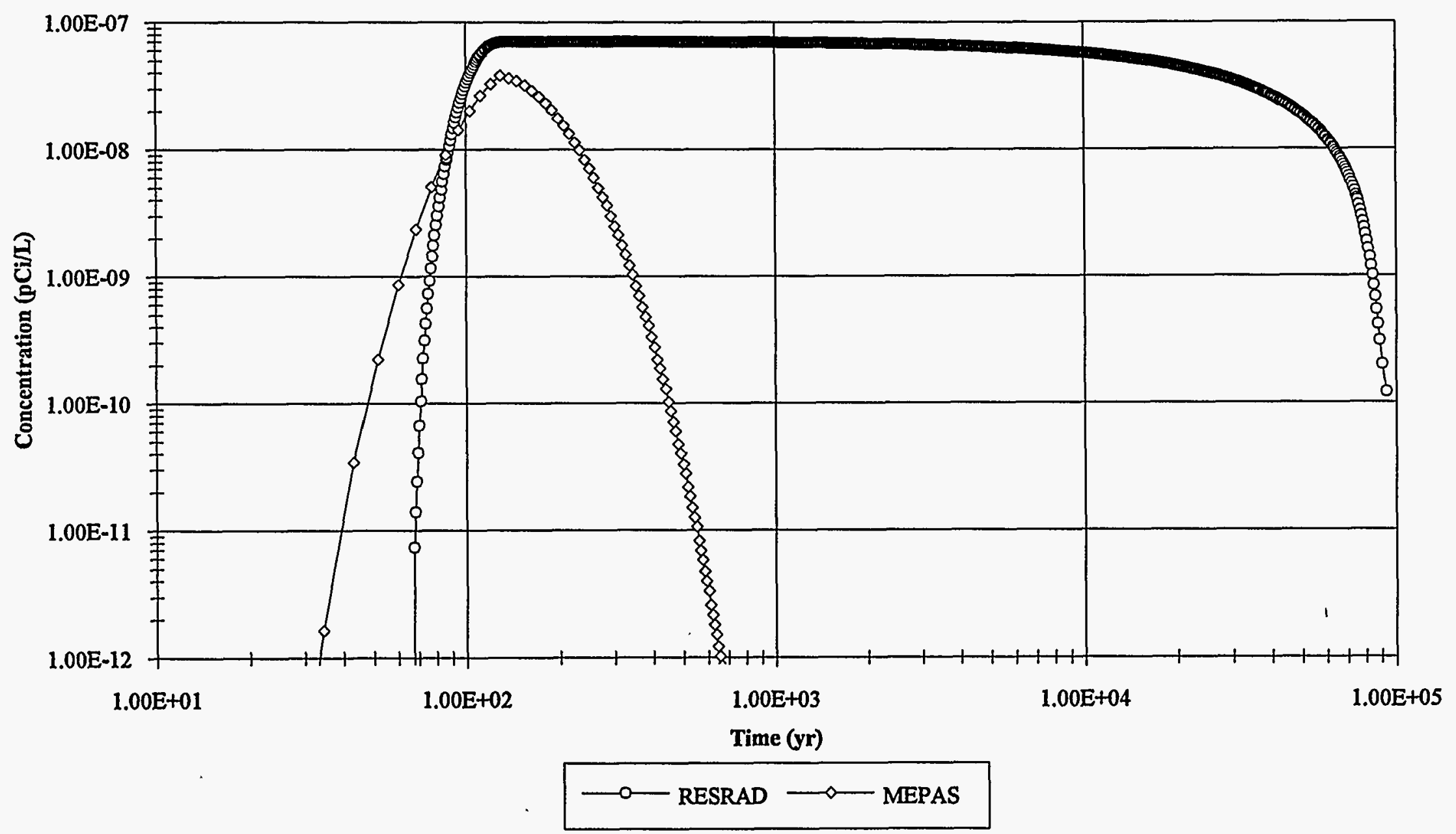

Fig. 6.18. Time-Varying Concentrations of Lead-210 at the 150-m Receptor Location for RESRAD and MEPAS. 
Direct Release to the Saturated Zone

Nitrate - Concentrations at 1500 m

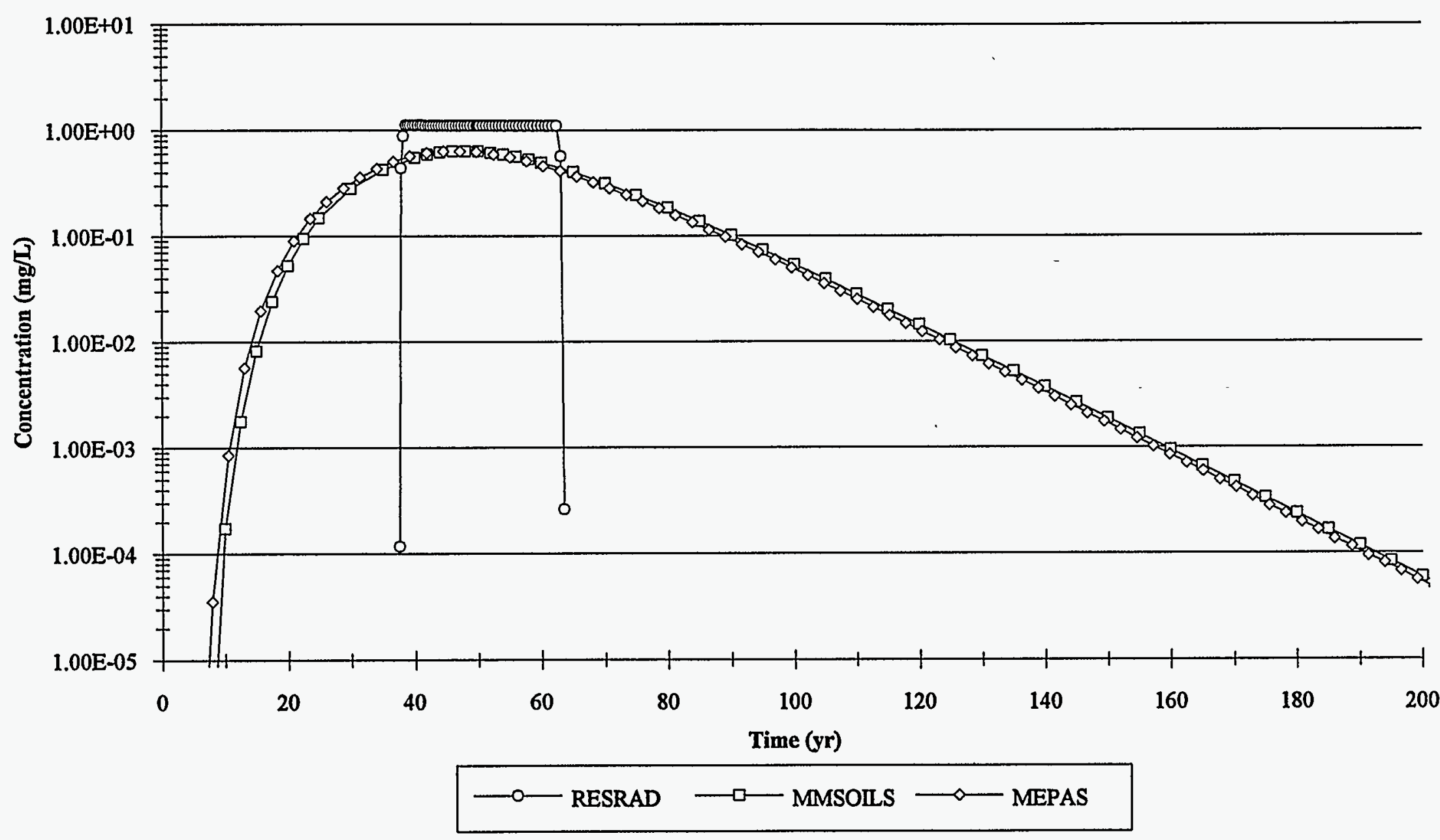

Fig. 6.19. Time-Varying Concentrations of Nitrate at the 1500-m Receptor Location for RESRAD, MMSOIS, and MEPAS. 
Direct Release to the Saturated Zone

Uranium-234 - Concentrations at 1500 m

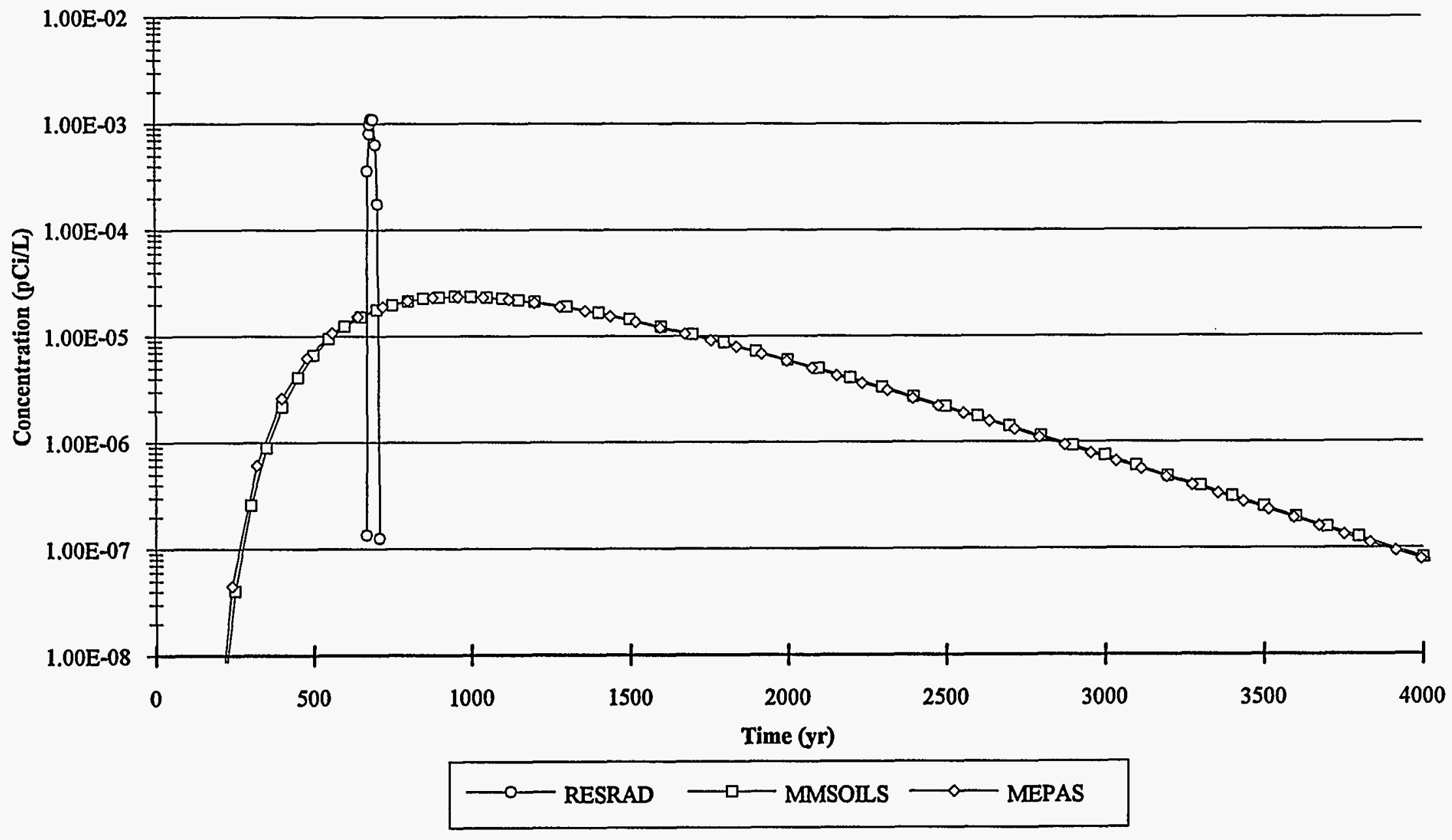

Fig. 6.20. Time-Varying Concentrations of Uranium-234 at the 1500-m Receptor Location for RESRAD, MMSOILS, and MEPAS. 
Direct Release to the Saturated Zone

Thorium-230 - Concentrations at 1500 m

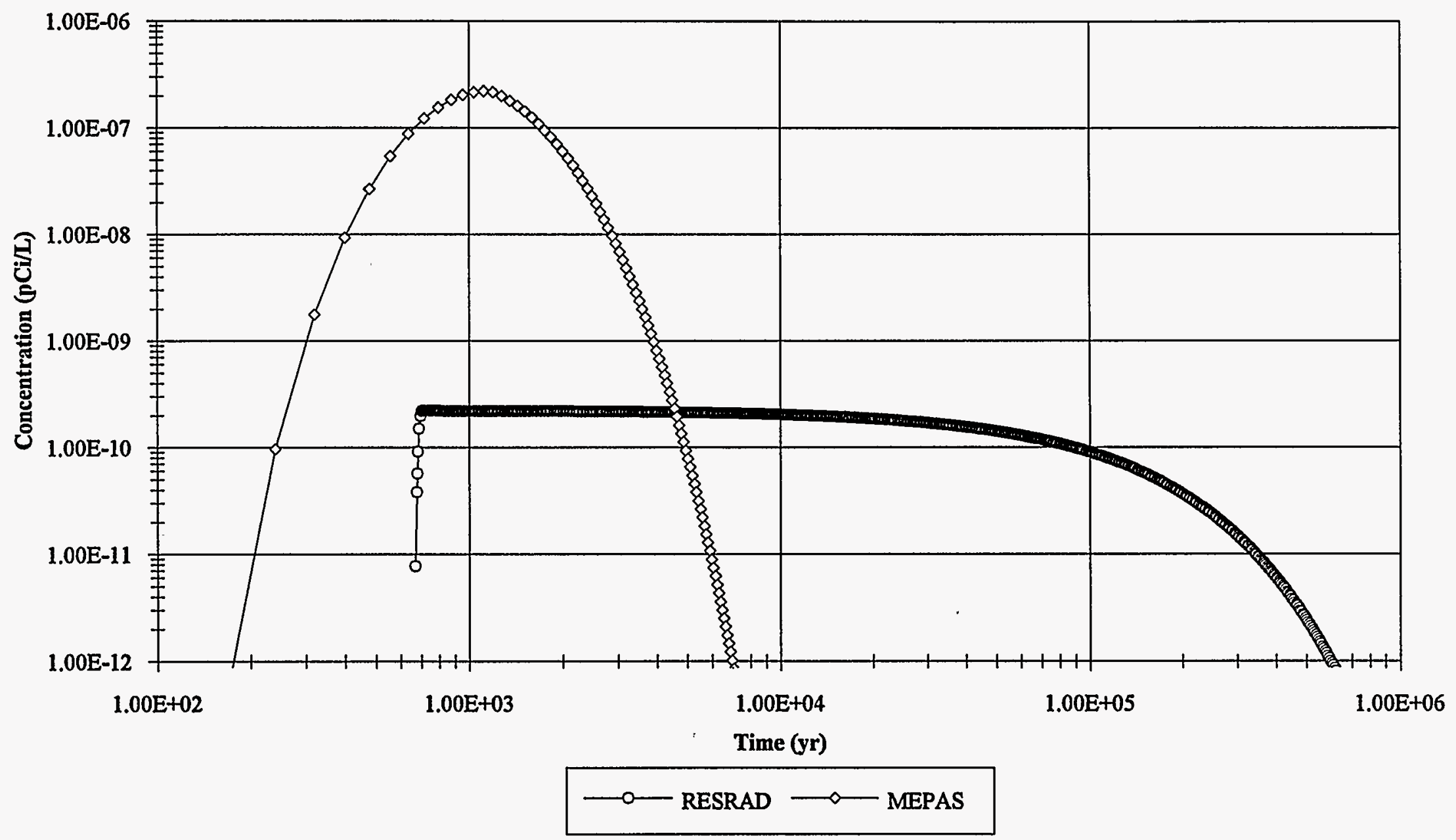

Fig. 6.21. Time-Varying Concentrations of Thorium-230 at the 1500-m Receptor Location for RESRAD and MEPAS. 
Direct Release to the Saturated Zone

Radium-226 - Concentrations at 1500 m

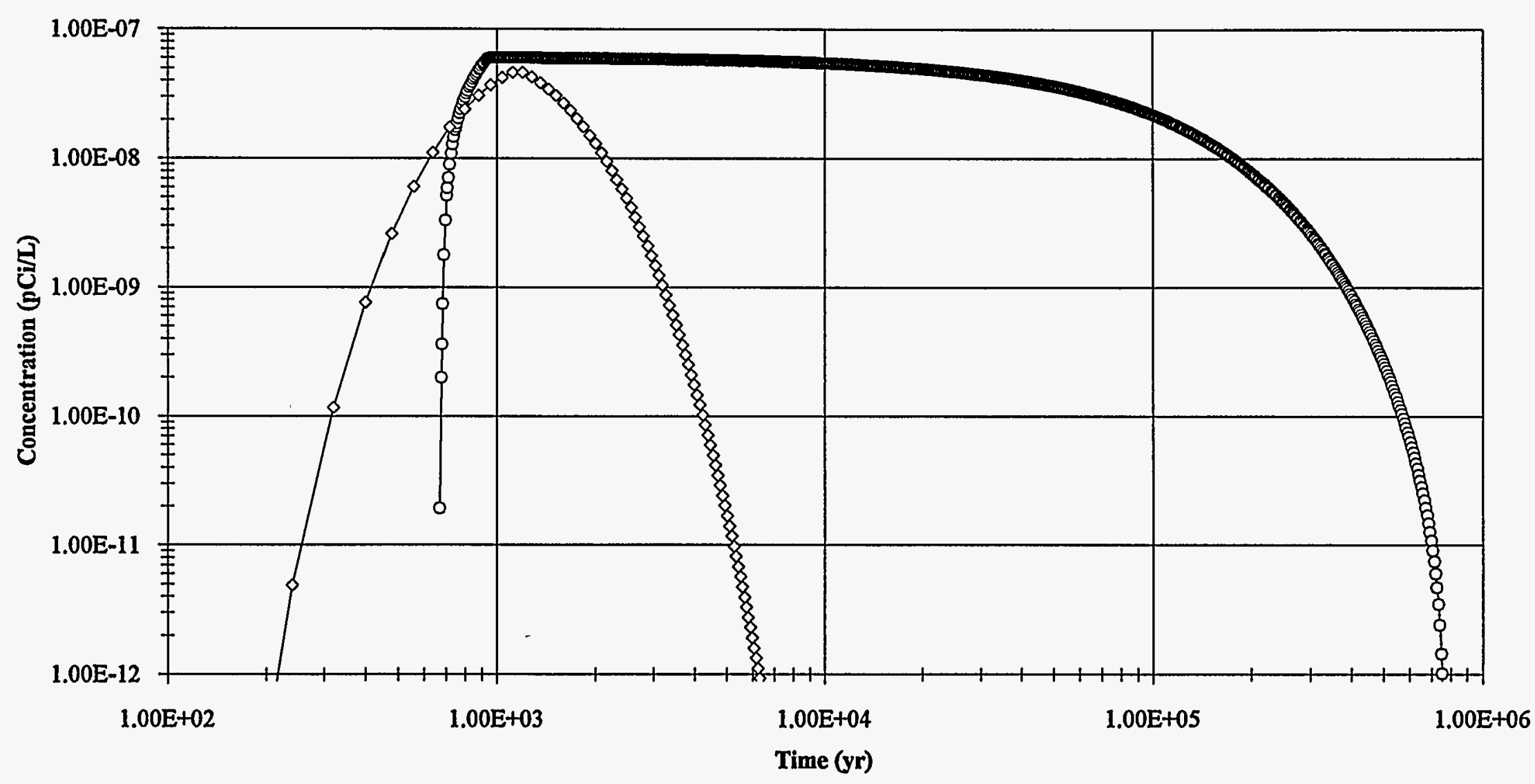

Fig. 6.22. Time-Varying Concentrations of Radium-226 at the 1500-m Receptor Location for RESRAD and MEPAS. 
Direct Release to the Saturated Zone

\section{Lead-210 - Concentrations at $1500 \mathrm{~m}$}

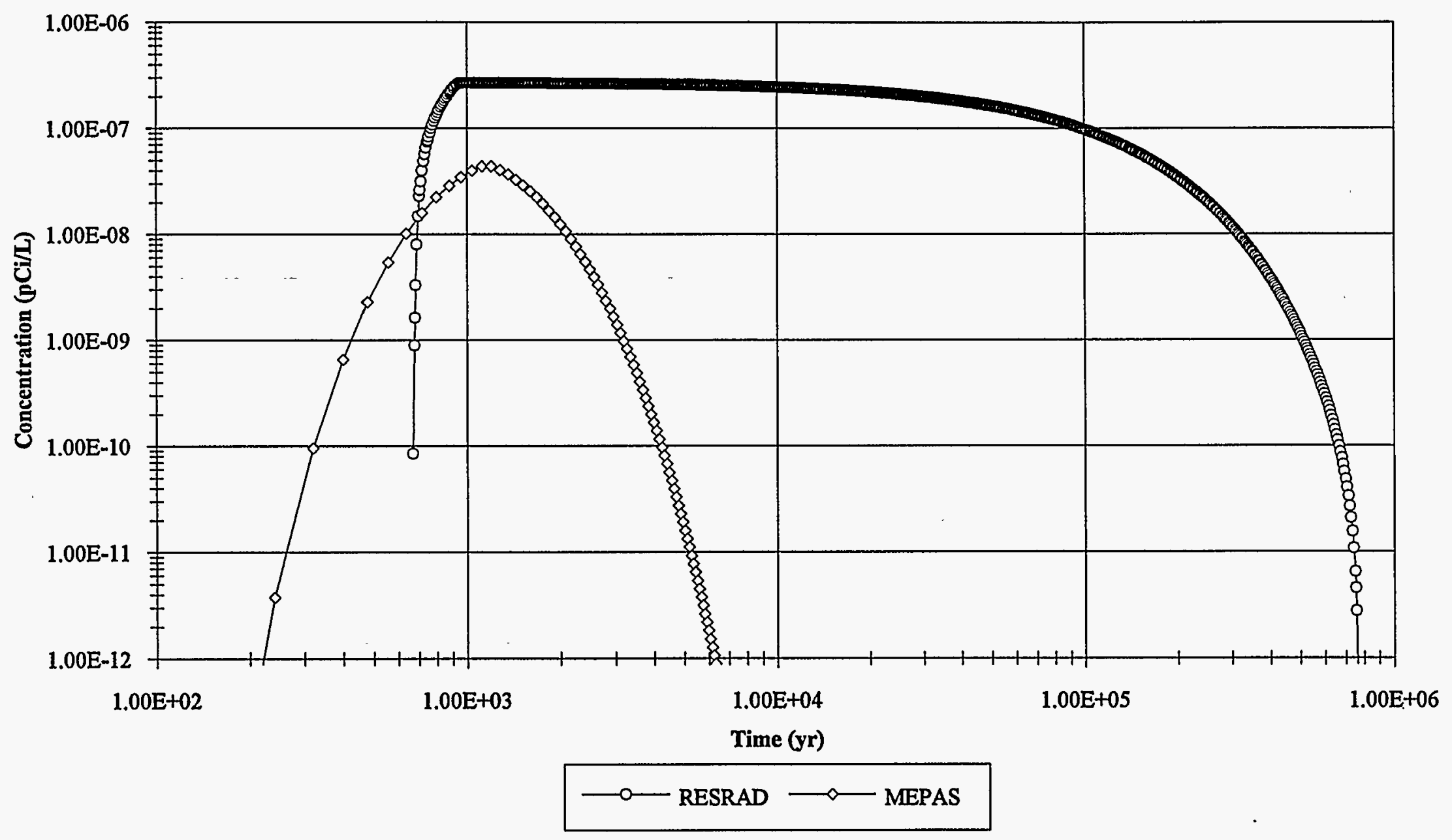

Fig. 6.23. Time-Varying Concentrations of Lead-210 at the 1500-m Location for RESRAD and MEPAS. 


\section{DIRECT RELEASE TO SURFACE WATER}

The surface water component may be a very important pathway for transporting contaminants to locations where the human population may be (1) directly exposed through ingestion (e.g., drinking water), dermal contact (e.g., swimming and bathing), and external dose for radionuclides or (2) indirectly exposed through irrigation to crops and crop uptake and animal consumption of crops with subsequent human ingestion. Although the term "surface water" could address rivers, lakes, reservoirs, wetlands, holding ponds, impoundments, estuaries, seas, oceans, etc., only the riverine environment is addressed in this section. Although neither MMSOILS nor MEPAS currently have modules developed for saline water bodies, MEPAS has developed modules for wetlands and lakes and is developing a module for estuaries. Because RESRAD does not contain a surface water component [other than a natural onsite pond (i.e., one that does not receive treated or untreated effluent), a comparison will be made between MMSOILS and MEPAS. This section reviews a scenario simulating the direct release of contaminants to a river and the migration of contaminants to downstream receptors.

\subsection{SCENARIO DESCRIPTION}

Ethylene glycol, thorium-228, and tritium are assumed to be released from a point source (e.g., a pipe) into a river in the form of a liquid discharge. The river is assumed to have a constant width and depth of $30.5 \mathrm{~m}$ and $3.05 \mathrm{~m}$, respectively. The river is assumed to be straight with steady-state, constant, unidirectional flow and a flow velocity of $0.61 \mathrm{~m} \mathrm{~s}^{-1}$. The contaminants are assumed to enter the river along one of the banks and migrate downstream, mixing laterally across the river as they move. The liquid discharge from a point source to the river is assumed to be small in relation to the discharge of the river. Inflow or outflow along the river (e.g., tributary inflow), other than the source, is not considered in this problem. Volatilization of contaminants from the river water and adsorption/desorption of contaminants are not considered. Contaminant degradation/decay is assumed to be first order. Decay products associated with thorium-228 were not considered as part of the comparison in this chapter. For more information on progeny formation and their impacts in the environment, refer to Chapters 6 and 9. A schematic illustrating the surface water problem is presented in Fig. 7.1. Table 7.1 presents the assumptions associated with the source term and river (all figures and tables for this chapter are presented in order beginning on page 7-5).

The surface water benchmarking effort between MMSOILS and MEPAS is based on an active-operational release scenario. For an active-operational release, the release into the river is assumed to be continually updated with contamination, so there is no apparent degradation/decay in the source; there is only degradation/decay in the environment. The contaminant release to the river is assumed to occur over a 10-yr time frame with a maximum inflow rate of $3.17 \times 10^{-5} \mathrm{mg} \mathrm{s}^{-1}$ for the ethylene glycol and $3.17 \times 10^{4} \mathrm{pCi} \mathrm{s}^{-1}$ each for thorium-228 and tritium. Ten grams and $10 \mathrm{Ci}$ are assumed to be released over the 10-yr period for the chemical and each radionuclide, respectively.

Spatially near- and far-field receptor scenarios are associated with this benchmarking effort; these are as follows:

- Spatially Near-field Receptor-Under near-field conditions, the contaminant plume has not made its way laterally across the river and therefore is not fully mixed across the width of the river at the near-field receptor. The near-field location is $100 \mathrm{~m}$ from the center of the source-term discharge point. 
- Spatially Far-field Receptor-Under far-field conditions, the contaminant plume has made its way laterally across the entire width of the river, and fully mixed conditions in the lateral direction are assumed. The far-field location is $10,000 \mathrm{~m}$ from the center of the source-term discharge point.

End points for comparison for each of the contaminants include (1) time-varying contaminant fluxes into the river and (2) time-varying contaminant concentrations at the near- and far-field receptors. The downstream concentrations are associated with the side of the river where the source originates.

\subsection{MODELING ASSUMPTIONS AND APPROACH}

Because the surface water component of MMSOILS and MEPAS are based on analytical solutions to the advective-dispersive equation, seasonal or secondary flow patterns and meandering are not considered in this modeling exercise. Because both MMSOILS and MEPAS assume instantaneous and fully mixed conditions in the vertical direction, vertical dispersion is not accounted for. In most rivers, the depth is small relative to the width; therefore, fully mixed conditions in the vertical direction are not considered unreasonable. Both models also assume that advection in the longitudinal (i.e., flow) direction tends to dominate longitudinal dispersion; therefore, longitudinal dispersion is not considered by either model. Volatilization of contaminants from the river water and adsorption/desorption of contaminants to suspended or bed sediments are not specifically addressed by the models, although the loss could be accounted for by using the first-order loss rate, which is currently included in each model. Specific modeling assumptions associated with each model are presented in the two succeeding sections.

\subsubsection{MMSOILS Assumptions}

MMSOILS is a one-dimensional, plug-flow, surface water model and assumes that any influx of contamination to the river is instantaneously and uniformly mixed laterally across the river; therefore, MMSOILS simulates fully mixed conditions in both the vertical and lateral directions. MMSOILS does not consider flow into (e.g., tributaries) or out of (e.g., losing reach) the river at downstream locations. MMSOILS was specifically designed to start with a waste-site situation (e.g., landfill, waste pile, etc.) and does not simulate direct discharges to surface water bodies. To simulate a point source discharge to a river, it is necessary to "manipulate" the MMSOILS model to effectively pass the point-source discharge from a contaminated source, through vadose and saturated zones, to the river's edge with minimal modification to the time-varying contaminant mass flux. This is accomplished by including a very thin vadose zone and very short saturated zone with appropriate parameter values to minimize the impact on mass flux. A schematic of the approach that MMSOILS used to address the direct release to the river is presented in Fig. 7.2. Because only the surface water component of each model is benchmarked, the boundary conditions at the river's edge represents the initial point of comparison between MMSOILS and MEPAS.

\subsubsection{MEPAS Assumptions}

MEPAS contains special provisions so the user can define direct time-varying releases into any medium; as such, MEPAS simulated the time-varying releases at the river's edge as defined by MMSOILS. Although MEPAS allows for inflow from tributaries or outflow to the groundwater system along the river, inflow/outflow was not considered in this comparison to help facilitate a comparison for the benchmarking. MEPAS also accounts for progeny formation from radionuclides. Decay products associated with thorium-228 are not considered as part of the comparison in this chapter because MMSOILS is specifically designed to address only chemicals and parent radionuclides but no progeny. 
MEPAS is a two-dimensional, surface water model, based on analytical solutions to the advective-dispersive equation, and does not assume that the contamination is instantaneously and uniformly mixed across the width of the river. MEPAS assumes that any influx of contamination to the river disperses its way across the river, as the contaminant moves downstream; therefore, its plume makes its way across the river until fully mixed conditions are attained. MEPAS assumes fully mixed conditions in the vertical direction.

\subsection{CONCLUSIONS}

Results of the comparison between MMSOILS and MEPAS are presented in Figs. 7.3 through 7.8 and Table 7.2. A discussion of spatially near- and far-field receptors is included and illustrates the major differences between the two river models. The near- and far-field receptors are $100 \mathrm{~m}$ and $10,000 \mathrm{~m}$ downstream from the center of the surface water source, respectively.

Figures 7.3 through 7.5 present the time-varying fluxes generated by MMSOILS to the surface water environment for ethylene glycol, thorium-228, and tritium, respectively, for the active-operational release scenario. To maintain consistency, MEPAS used the boundary conditions stipulated by MMSOILS as its time-varying flux boundary conditions to the river, as illustrated by Figs. 7.3 through 7.5; therefore, MMSOILS and MEPAS assume the exact same boundary conditions at the river's edge. The masses under the curves at the rivers edge in Figs. 7.3 through 7.5 equal the assumptions stated by the problem (i.e., $10 \mathrm{~g}$ for ethylene glycol and $10 \mathrm{Ci}$ for each radionuclide).

After a contaminant has been released into the river, its concentration can decrease due to both dilution and degradation/decay. Dilution impacts the concentration because as the contaminant migrates downstream, it mixes with more water until fully mixed conditions are attained. Degradation/decay is sufficiently important if the half life of the contaminant is similar to or less than the travel time to the receptor. The concentration in the river will not change as the contaminant migrates downstream if fully mixed conditions have already been attained, and the contaminant's half-life is sufficiently large.

Figures 7.6 through 7.8 present the time-varying concentrations at the near- and far-field receptors for ethylene glycol, thorium-228, and tritium, respectively, for MMSOILS and MEPAS. Because MMSOILS instantaneously mixes contaminants, as they enter the river at the source, the reduction in contaminant concentrations is not influenced by lateral spreading and dilution, as the contaminants migrate downstream to the receptors. Figure 7.2 illustrates how MMSOILS instantaneously mixes the contaminants across the river at the source. Figures 7.6 through 7.8 demonstrate and Table 7.2 documents that the near- and far-field concentrations for MMSOILS are equivalent.

Because dilution does not influence instream contaminant levels, degradation/decay represents the only mechanism for reducing downstream concentrations in MMSOILS. The plug-flow travel times in the river to the near- and far-field receptors are $1.64 \times 10^{2}$ and $1.64 \times 10^{4} \mathrm{yr}$, respectively. The half-lives of ethylene glycol, thorium-228, and tritium are at $5.5 \times 10^{-4}, 1.91$, and 12.3 yrs, respectively. The radionuclides are fully mixed at both receptor locations for MMSOILS and do not decay sufficiently to alter their in-stream concentrations. Because thorium-228 and tritium have the same boundary conditions and half-lives that are significantly longer than the travel times, their concentrations are equal to each other at both receptor locations. The time-varying curves for thorium-228 and tritium are presented in Figs. 7.7 and 7.8, respectively, for MMSOILS, demonstrating that near- and far-field concentrations are equivalent. Because only ethylene glycol has a half-life similar to or less than the travel time to the receptor, degradation/decay affects only ethylene glycol's in-stream concentrations, as ethylene glycol migrates to the near- and far-field receptors. Figure 7.6 presents the ethylene glycol results for MMSOILS. 


\section{$7-4$}

Because MEPAS accounts for plume migration in the lateral direction and the plume is not fully mixed across the river at the near-field receptor, dilution will change the contaminant concentrations of ethylene glycol, thorium-228, and tritium, as the contaminants migrate downstream from the source from the near-field to the far-field receptors. As with MMSOILS, MEPAS also demonstrates that only ethylene glycol's concentration is sufficiently impacted by degradation. Figures 7.6 through 7.8 present MEPAS time-varying concentration curves for ethylene glycol, thorium-228, and tritium, respectively, at the near- and far-field receptor locations. In MEPAS, ethylene glycol's concentrations are affected by dilution and degradation, while thorium-228 and tritium are affected by dilution only.

Figures 7.6 through 7.8 illustrate that all of the time-varying concentration curves for both MMSOILS and MEPAS predict nearly constant values at each of the receptors. The curves become nearly constant because the duration of the release from the source is significantly longer than the travel time through the river. The near-field results for MEPAS are also significantly higher (e.g., factor of $\approx 4$ ) than those of MMSOILS because MMSOILS simulated fully mixed conditions at the near-field receptor, while MEPAS simulated partially mixed conditions. When fully mixed conditions are simulated by both models (e.g., far-field receptor location), the results are nearly identical (see Figs. 7.6 through 7.8). 
Table 7.1. Input parameter assumptions for direct release to surface water

Source-Term Type: Point Source

Surface Water:

Width $=30.5 \mathrm{~m}$

Depth $=3.05 \mathrm{~m}$

Flow Velocity $=0.61 \mathrm{~m} \mathrm{~s}^{-1}$

Discharge $=56.7 \mathrm{~m}^{3} \mathrm{~s}^{-1}$

Distance to Near Receptor $=100 \mathrm{~m}$

Distance to Far Receptor $=10,000 \mathrm{~m}$

Contaminant Characteristics:

Ethylene Glycol

Inventory $=10 \mathrm{~g}$

Half-Life $=1.73 \times 10^{4} \mathrm{~s}(0.2 \mathrm{~d})$

Thorium-228

Inventory $=10 \mathrm{Ci}$

Half-Life $=6.03 \times 10^{7} \mathrm{~s}(1.91 \mathrm{yr})$

Hydrogen-3

Inventory $=10 \mathrm{Ci}$

Half-Life $=3.88 \times 10^{8} \mathrm{~s}(12.3 \mathrm{yr})$

Table 7.2. Summary of peak concentrations and times to peak concentration for direct discharge to surface water for active operational releases

\begin{tabular}{ccccccc}
\hline & \multicolumn{2}{c}{ Ethylene Glycol } & \multicolumn{2}{c}{ Thorium-228 } & \multicolumn{2}{c}{ Hydrogen-3 } \\
\cline { 2 - 7 } Scenario & $\begin{array}{c}\text { Concentra- } \\
\text { tion } \\
\left(\mathrm{mg} \mathrm{L}^{-1}\right)\end{array}$ & $\begin{array}{c}\text { Time to } \\
\text { Peak } \\
(\mathrm{yr})\end{array}$ & $\begin{array}{c}\text { Concentra- } \\
\text { tion } \\
\left(\mathrm{pCi} \mathrm{L}^{-1}\right)\end{array}$ & $\begin{array}{c}\text { Time to } \\
\text { Peak } \\
(\mathrm{yr})\end{array}$ & $\begin{array}{c}\text { Concentra- } \\
\text { tion } \\
\left.(\mathrm{pCi} \mathrm{L})^{-1}\right)\end{array}$ & $\begin{array}{c}\text { Time to } \\
\text { Peak } \\
(\mathrm{yr})\end{array}$ \\
\hline \multicolumn{7}{c}{ Active-operational Release } \\
\hline $\begin{array}{c}\text { MMSOILS } \\
(100 \mathrm{~m})^{2}\end{array}$ & $5.4 \times 10^{-10}$ & $4-5^{b}$ & $5.4 \times 10^{-1}$ & $4-5$ & $5.4 \times 10^{-1}$ & $4-5$ \\
$\begin{array}{c}\text { MMSOILS } \\
(10,000 \mathrm{~m})^{*}\end{array}$ & $2.8 \times 10^{-10}$ & $4-5$ & $5.4 \times 10^{-1}$ & $4-5$ & $5.4 \times 10^{-1}$ & $4-5$ \\
$\begin{array}{c}\text { MEPAS } \\
(100 \mathrm{~m})^{\circ}\end{array}$ & $2.2 \times 10^{-9}$ & $4-5$ & 2.2 & $4-5$ & 2.2 & $4-5$ \\
$\begin{array}{c}\text { MEPAS } \\
(10,000 \mathrm{~m})^{\circ}\end{array}$ & $2.8 \times 10^{-10}$ & $4-5$ & $5.5 \times 10^{-1}$ & $4-5$ & $5.5 \times 10^{-1}$ & $4-5$ \\
\hline
\end{tabular}

"Fully mixed conditions.

b range is provided because the results asymptotically approach a constant value.

Partially mixed conditions. 


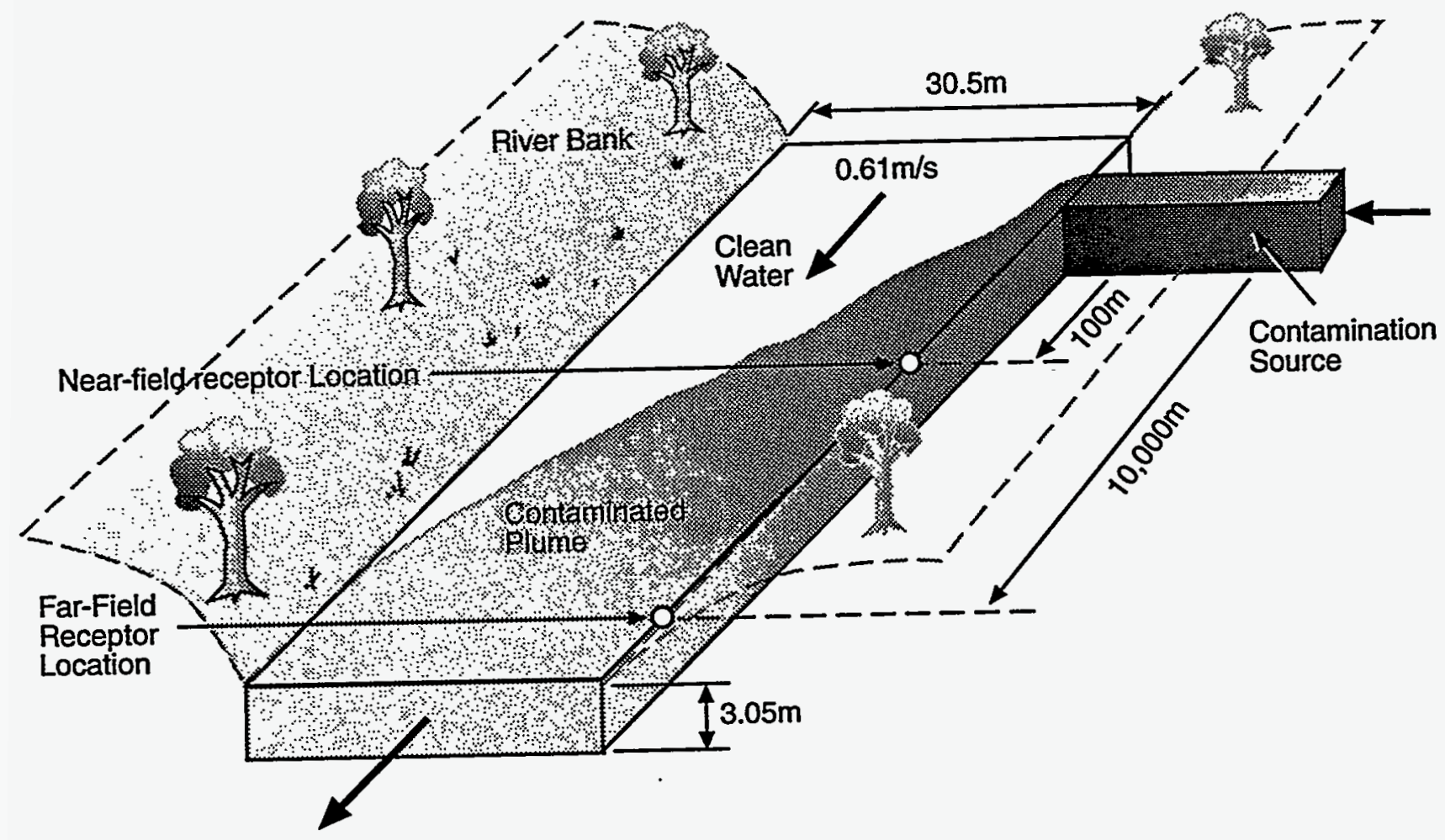

Fig. 7.1. Schematic Illustrating the Direct Discharge to Surface Water Problem. 

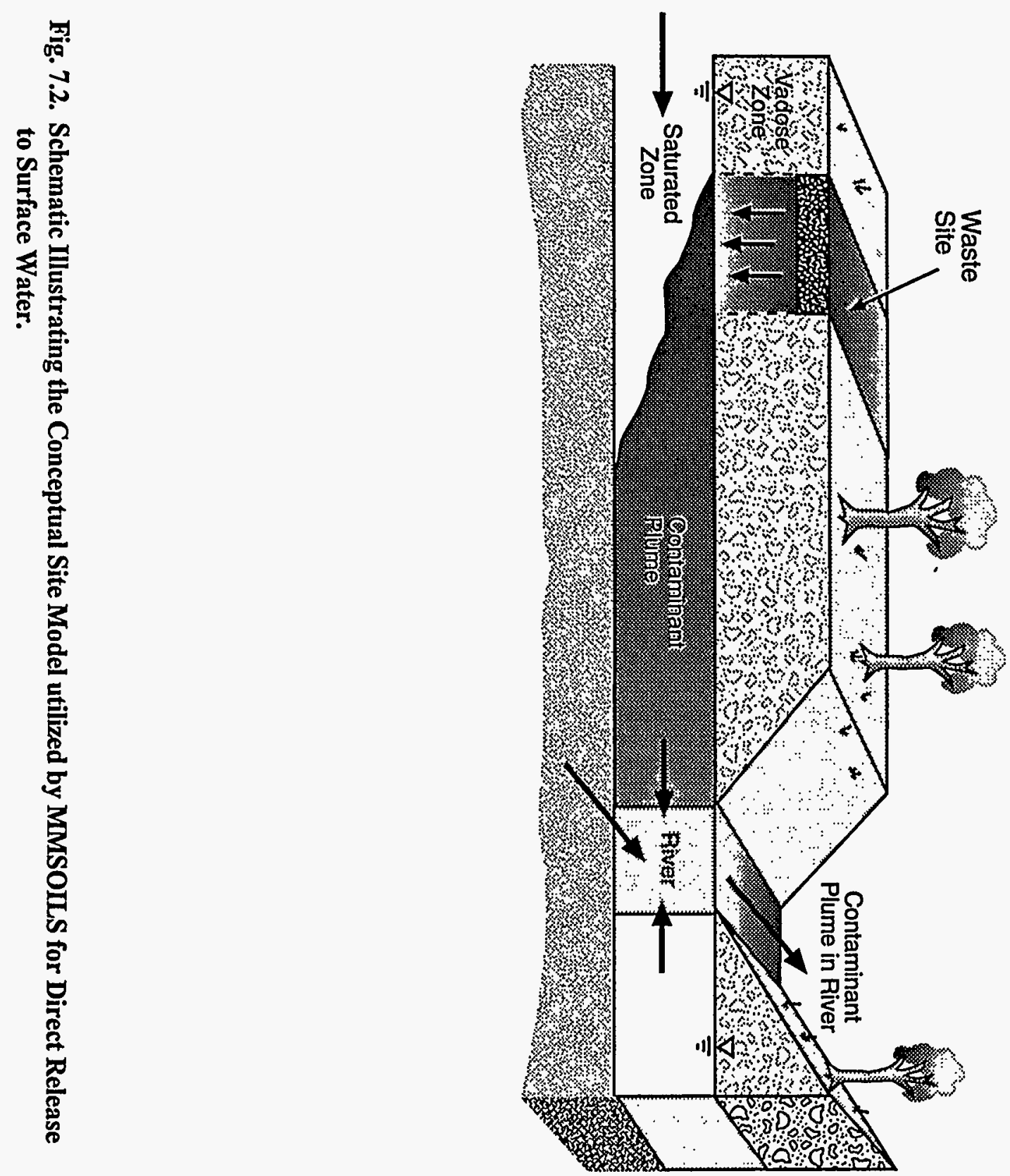
Direct Release to Surface Water

Ethylene Glycol - Flux to Surface Water

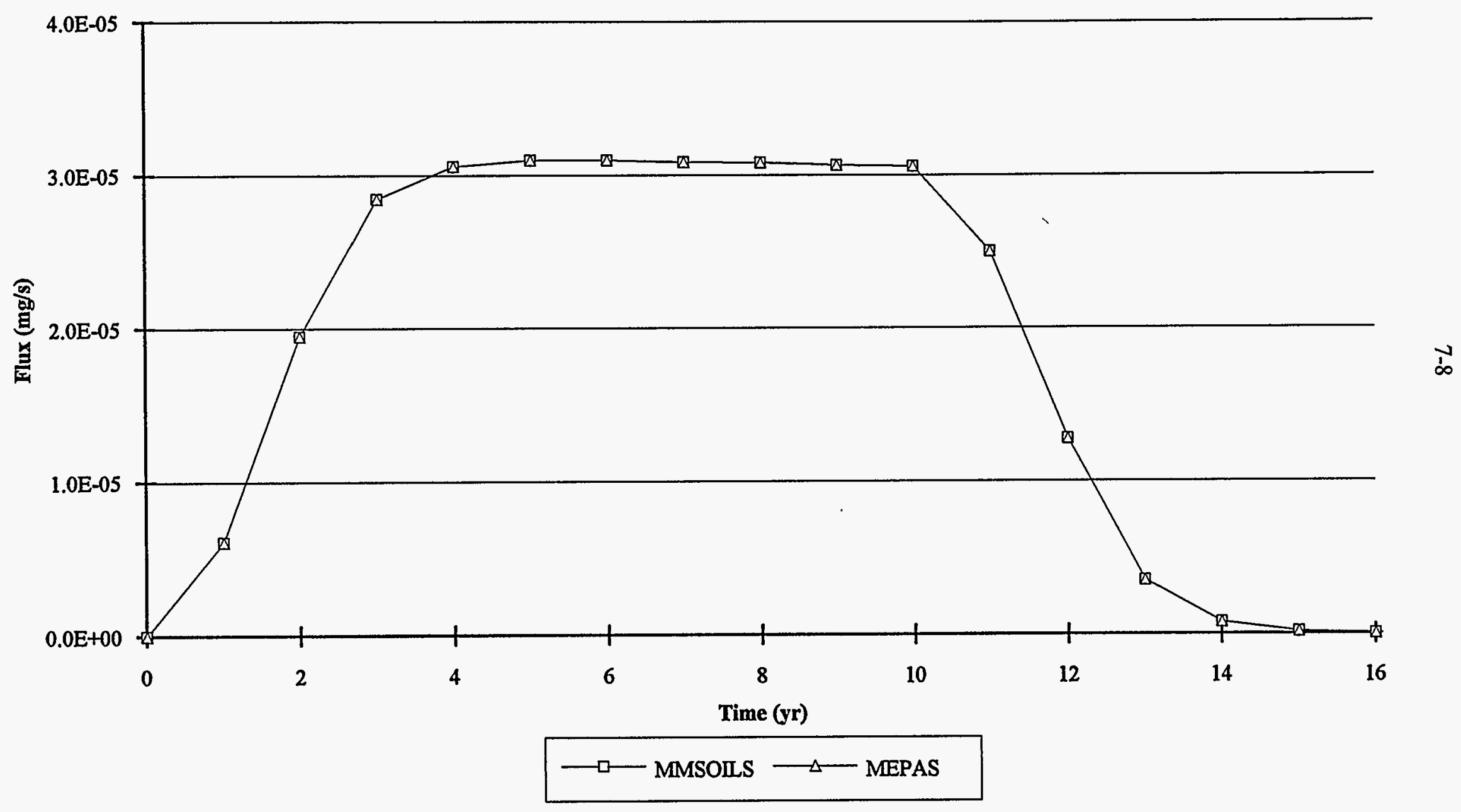

Fig. 7.3. Time-Varying Fluxes of Ethylene Glycol at the River's Edge for the Operational Release Scenario. 
Direct Release to Surface Water

Thorium-228 - Flux to Surface Water

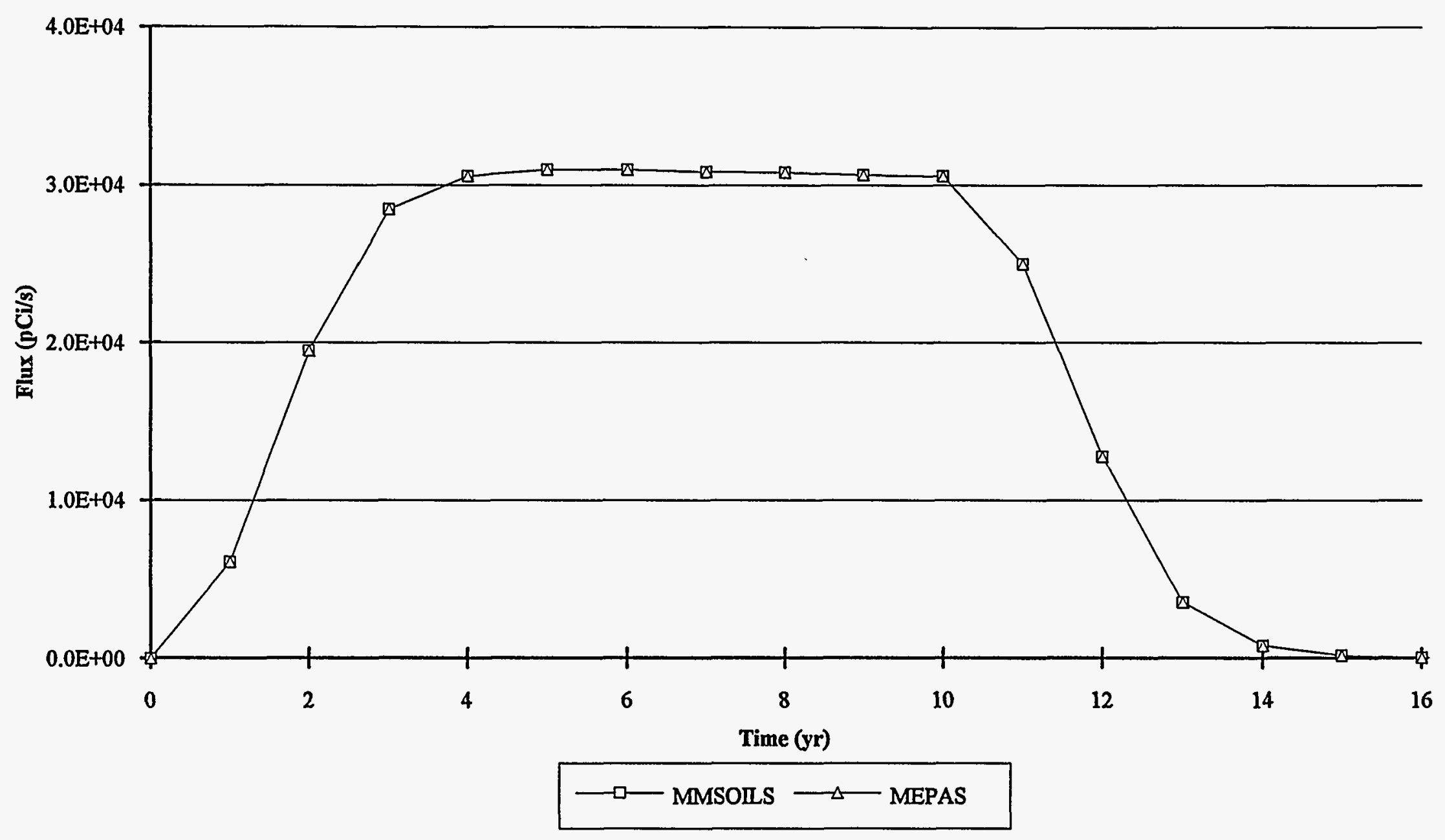

Fig. 7.4. Time-Varying Fluxes of Thorium-228 at the River's Edge for the Operational Release Scenario. 
7-10

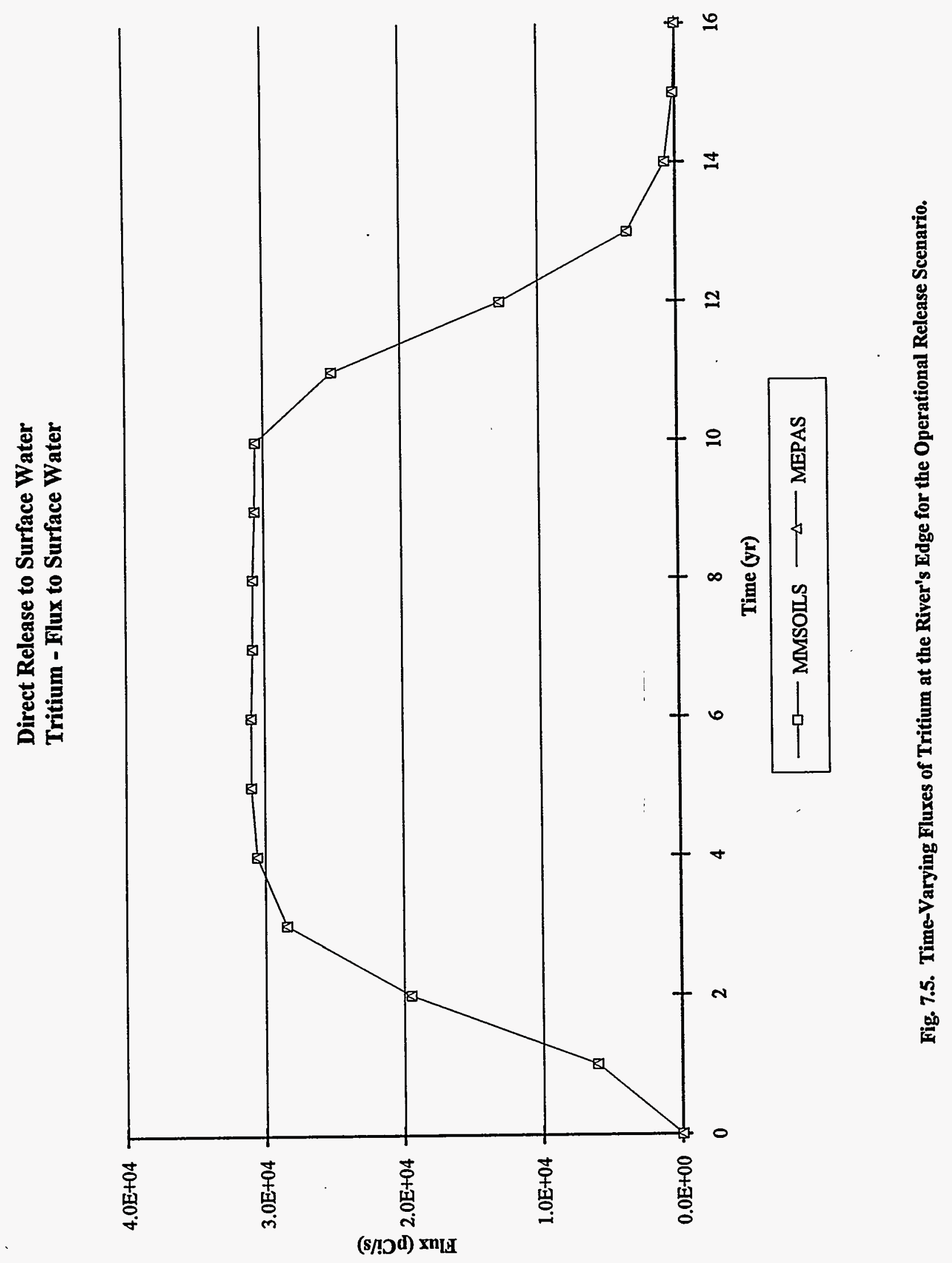




\section{Direct Release to Surface Water}

\section{Ethylene Glycol Concentrations}

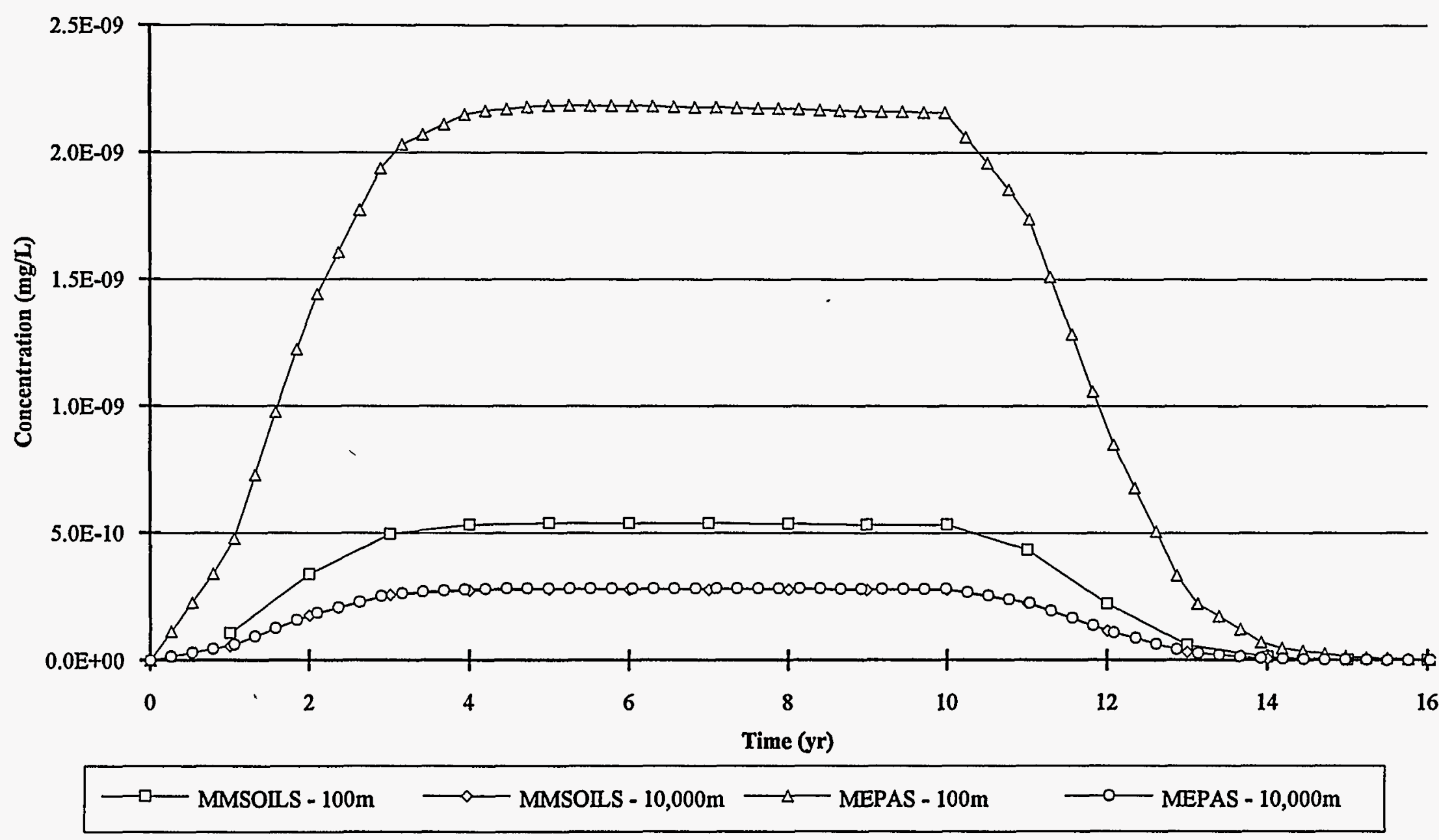


Direct Release to Surface Water

Thorium-228 Concentrations

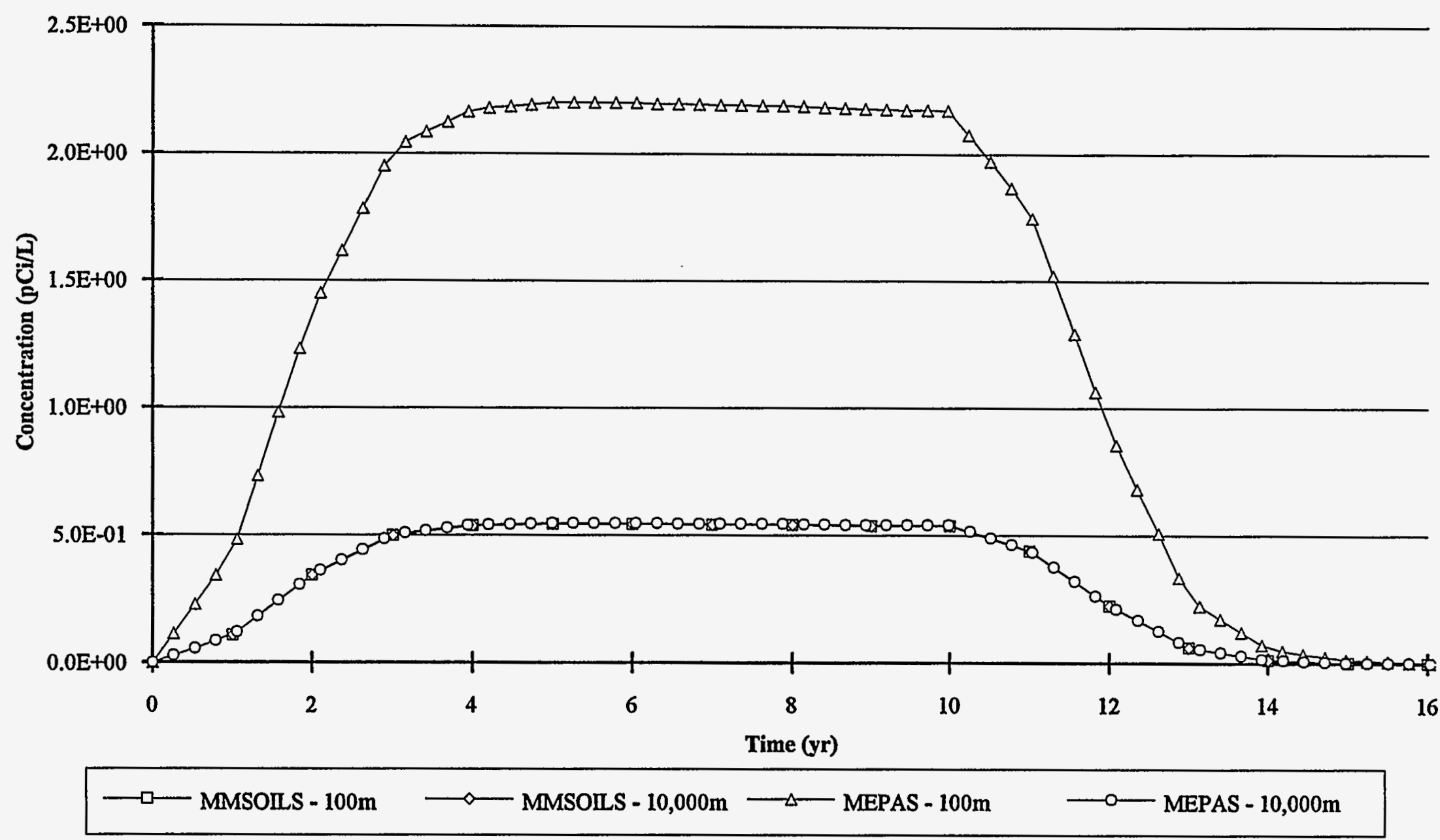

Fig. 7.7. Time-Varying Concentrations of Thorium-228 at Spatially Near- and Far-Field Receptors for the Operational Release Scenario. 


\section{Direct Release to Surface Water}

Tritium Concentrations

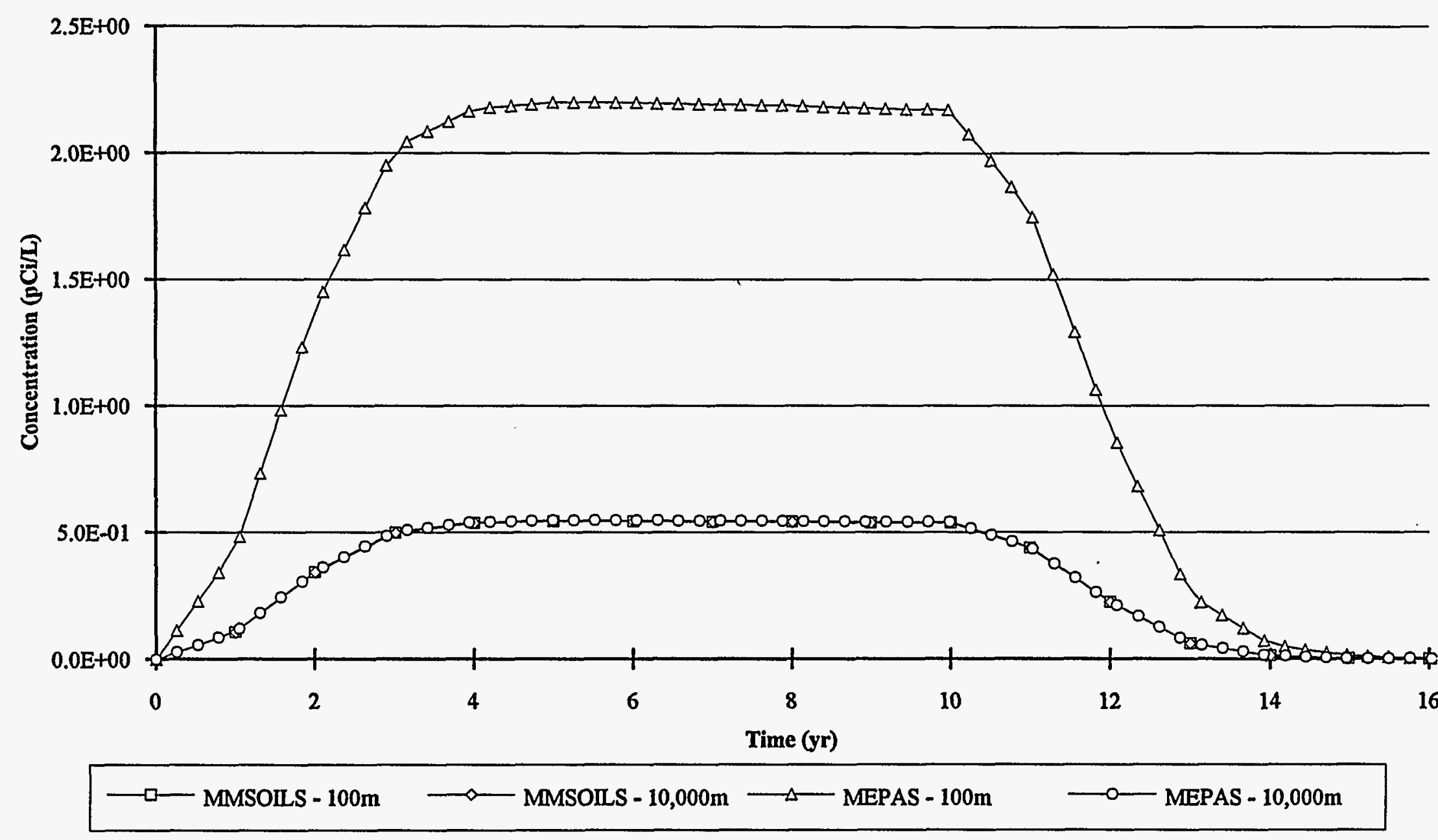


7-14 


\section{SURFACE HYDROLOGY}

The objective of the surface hydrology test is to quantitatively compare the manner in which the models simulate the water balance at the soil surface and in the upper layer of soil (i.e., the root zone). While each model requires a precipitation related infiltration rate and runoff to simulate contaminant movement in the vadose zone and via overland runoff, only MEPAS and MMSOILS include algorithms for estimating infiltration and runoff. Therefore, for purposes of this study only MEPAS and MMSOILS are included in the benchmarking tests.

RESRAD requires the user to input values for average annual precipitation, runoff, evapotranspiration, and irrigation and calculates infiltration as the net difference between water inputs at the surface (i.e., precipitation and irrigation) and water losses (i.e., runoff and evapotranspiration). RESRAD provides guidance for estimating the necessary inputs within the model's User's Manual and Data Collection Handbook.

Both MMSOILS and MEPAS employ similar methods for simulating the water balance at the soil surface. The models process average monthly meteorological data to estimate monthly average runoff, evapotranspiration, and infiltration. The models sum the monthly values to produce average annual values of water flux from the surface to either a waste unit (e.g., a landfill), the unsaturated zone, or offsite locations via runoff. These fluxes are then used in the transport routines to simulate the movement of contaminants through the various media receiving the water. The following discussion provides an overview of the methods used to simulate the water balance. For a more detailed description of the model constructs the reader is referred to the individual model user's manual.

\subsection{MODELING ASSUMPTIONS AND APPROACH}

As described in MEPAS documentation (Whelan et al. 1987) the estimation of runoff, evapotranspiration, and infiltration is conducted in a series of 14 steps. These 14 steps are summarized here along with important implementation differences between MEPAS and MMSOILS. Within those steps where model differences are not noted the reader should assume that both MEPAS and MMSOILS perform identically.

STEP 1: Unadjusted average monthly temperature.

Both MEPAS and MMSOILS use average monthly air temperature data at the hazardous waste site. Temperature data, as well as other required climatological data, are routinely accessed through national databases maintained by the U.S. Department of Commerce.

\section{STEP 2: Adjusted average monthly temperature.}

This step adjusts the temperature to the site elevation using adiabatic lapse rates. While MEPAS performs this step, MMSOILS does not.

\section{STEP 3: Potential EvapotranspirationA (PET)}

Evapotranspiration represents soil water loss from the combined effects of soil and plant surface evaporation and plant transpiration. PET reflects the amount of water that, if available from a combination of rainfall and soil water storage, would be released back to the atmosphere via evapotranspiration. 
There are a number of techniques available for estimating PET. Each technique is applicable, more or less, within specific climatological settings. The most notable distinction among the methods is whether the technique is applicable under relatively humid or arid conditions. The accuracy of the methods decreases sharply when applied outside the conditions for which the method is developed.

MEPAS and MMSOILS employ different methods for estimating PET. MEPAS contains three estimation techniques [Modified Blaney-Criddle, Penman Method, and Penman Method with Correction Factor]. These methods are based on average air temperature, minimum relative humidity, ratio of actual to maximum possible sunshine hours, and average wind speeds. The Penman Method with Correction Factor is also based on the maximum relative humidity and latitude. The modified Blaney-Criddle method is most applicable to arid regions while the Penman methods, being more theoretically based, are applicable to a wider range of moisture conditions. MEPAS applies all methods in each simulation and selects the lowest estimate of PET for further use in the model application. The intent here is to error on the conservative side when estimating PET. Conservative here means that infiltration, and therefore contaminant movement in the subsurface, will be maximized when PET is minimized.

MMSOILS allows the user two options. The first option uses site-specific pan evaporation data (which are accessed from weather station data) multiplied by a user supplied pan correction factor. Pan evaporation represents the amount of water that would be evaporated from an open water body. The correction factor reflects the mitigating effects of such factors as vegetative cover, soil characteristics, solar radiation and relative humidity. MMSOILS also contains a method of estimating PET developed by Thornthwaite (see Dunne and Leopold 1978). This technique is a function of the heat index which in turn is a function of average temperature and is adjusted for latitude (which is used to estimate the effect of length of daylight hours per day). The Thornthwaite method was developed for application in continental regions within mid-latitude zones.

STEP 4: Monthly precipitation as rainfall.

The monthly precipitation as rainfall is as reported at the nearest weather station.

\section{STEP 5: Monthly precipitation as snowfall.}

MMSOILS does not differentiate between types of precipitation (i.e., snow, rain, etc.); all precipitation is considered rainfall. MEPAS differentiates between snow and rain by defining all precipitation occurring during a month when the adjusted monthly temperature is below freezing to be in the form of snowfall and therefore unavailable for runoff, evapotranspiration, and infiltration.

\section{STEP 6: Precipitation adjusted for snowmelt.}

Again MMSOILS does not include this step. MEPAS assumes that snowfall accumulates on the land surface until the first month arrives with an adjusted average monthly temperature above $0^{\circ} \mathrm{C}$. The maximum amount of water available for infiltration, nunoff, and evapotranspiration is therefore the sum of any previously accumulated snowfall and the current month's precipitation as rainfall. The amount of water that is actually available for infiltration, runoff, and evapotranspiration is equal to or less than the maximum and is calculated as the current month's precipitation as rainfall plus any accumulated snow that melts due to radiation, convection, rainfall, and vapor condensation. If snowmelt is less than the maximum accumulated snowfall, then the remaining amount of accumulated snowfall is carried over to the succeeding month. 
STEP 7: Monthly overland runoff.

The Soil Conservation Service Curve Number technique is used by both MMSOILS and MEPAS. MEPAS assumes that overland runoff occurs only in months when the average temperature is above freezing. Curve numbers representing hydrologic soil group, land use, and hydrologic soil cover of the location of interest under average soil moisture conditions are input by the user. Both MEPAS and MMSOILS modify this Curve Number to reflect the average antecedent moisture conditions related to precipitation events occurring during each month.

MMSOILS and MEPAS define three antecedent moisture conditions: AMC-I (lowest runoff potential), AMC-II (average conditions), and AMC-III (highest runoff potential). Operating on an average monthly basis, MMSOILS computes, for each month, an average 5-day rainfall that is then used in conjunction with Soil Conservation Service-based thresholds to decide which AMC condition to use for estimating the monthly Curve Number. The Soil Conservation Service methods for estimating the Curve Number distinguish between the growing season and the dormant season resulting in a different correlation between the 5-day rainfall value and the selection of the appropriate antecedent moisture condition (i.e., I, II, III) for estimating the Curve Number.

Unlike MMSOILS, the AMC in MEPAS is based on regional aridity characteristics of zonal soils of the United States (Shirazi et al. 1985). The user determines the AMC by identifying the site location on a U.S. map of aridity characteristics and reading the AMC. The AMC in MEPAS is assumed constant for the entire year. The AMC is used to determine the appropriate curve number for estimating the monthly overland runoff based on the SCS CN technique.

STEP 8: Maximum infiltration.

The maximum infiltration represents the difference between the precipitation (adjusted for snowmelt in MEPAS) and overland runoff.

\section{STEP 9: Potential infiltration.}

The potential infiltration represents the difference between the maximum infiltration and the PET. Potential infiltration is computed each month and may be positive or negative, with negative values representing a net water deficiency (i.e., dry conditions, no infiltration).

\section{STEP 10: Accumulated potential water loss.}

In the estimation of the water balance, both models first attempt to satisfy PET with precipitation (i.e., maximum infiltration as referred to in Step 8). During dry seasons, when PET is greater than maximum infiltration, there exists a potential for satisfying the PET by extracting moisture previously stored in the soil. This potential water loss is used to determine, in a later step, the fraction of stored soil moisture that will be lost during months when PET is greater than the computed maximum infiltration. Both MEPAS and MMSOILS base their respective soil retention estimation procedures on work performed by Thornthwaite and Mather (1957). However, each model implements a different variation of the Thornthwaite and Mather techniques.

MEPAS accumulates the potential water loss during the dry season (i.e., the series of months where PET is greater than potential infiltration). MMSOILS does not accumulate this deficit explicitly, rather it simply uses the deficit within the month it occurs to estimate changes in soil moisture storage and, eventually, actual evapotranspiration (AET). 
STEP 11: Soil moisture storage.

This step identifies the soil moisture retained in the soil root zone at the end of each month. The soil moisture storage is computed using the potential infiltration (i.e., maximum infiltration less PET), the previous month's soil moisture, and a method for estimating soil moisture retention when PET is greater than maximum infiltration.

If maximum infiltration exceds PET and the previous month's soil moisture storage is equal to the soil's field capacity, then the current month's soil moisture storage will remain at field capacity. If maximum infiltration exceeds PET and a moisture deficit exists (i.e., soil moisture is below field capacity), the excess will first replenish soil moisture up to field capacity with further excess infiltrating. On the other hand, when PET exceeds maximum infiltration (i.e., dry conditions), there is a potential to extract soil moisture to satisfy PET. To estimate soil moisture retention under these conditions, MMSOILS uses a linear function that estimates that the amount of soil water storage that will be retained under dry conditions is equal to the ratio of existing soil moisture levels and the maximum water holding capacity of the soil (i.e., field capacity).

MEPAS uses a more comprehensive soil moisture retention estimation technique that is based on retention tables provided by Thornthwaite and Mather (1957). These relationships are non-linear and reflect the increased moisture retention capability that occurs as the soil is depleted of moisture.

Finally, to execute either of the techniques on a monthly basis, it is necessary to establish an initial soil moisture. The specification of the initial soil moisture is done for the month preceding the first month of the dry season. In humid areas, where annual rainfall exceeds annual PET, the initial soil moisture is typically equal to the field capacity of the soil. In dry areas, where the annual rainfall is significantly less than the annual PET, the soil will have an average annual water deficit. Establishing the initial soil moisture under these conditions is more problematic. MMSOILS first arbitrarily assumes an initial soil moisture equal to 0.8 times the field capacity. MMSOILS then performs the monthly water balance calculations for the year, saving the value of soil moisture computed for the final month. This soil moisture is then used as the initial value for a second year of simulation, thereby resulting in the water balance reported by the model.

In MEPAS, the initial soil moisture is established through a method of successive approximations (see MEPAS' user's manual). Basically, the objective of the method is to iteratively arrive at an estimate of initial soil moisture based on the cumulative potential water loss during the dry season (computed in Step 10) and the cumulative water excess in the wet season.

STEP 12: Change in soil moisture storage.

The change in soil moisture storage for a current month is computed as the difference of the current and previous months' soil moisture.

\section{STEP 13: Actual evapotranspiration (AET).}

The actual evapptranspiration reflects the amount of moisture that is evapotranspired during the month. AET will equal PET if the PET is less than or equal to the summation of the maximum infiltration and the available soil moisture. If PET is greater than this total, the actual evapptranspiration equals the total moisture available (i.e., maximum infiltration plus available soil moisture). This is the case for both MEPAS and MMSOILS. 


\section{STEP 14: Infiltration.}

The infiltration is the net excess water, above field capacity, available during the month. It is computed as the difference between net precipitation (which is the monthly precipitation in MMSOILS and the precipitation adjusted for snowfall in MEPAS) and losses occurring due to runoff, evapotranspiration, and changes in soil moisture.

To summarize the steps for estimating runoff and infiltration, MEPAS and MMSOILS simulate the water balance at the soil surface in a very similar manner. Each model performs the water balance on an average monthly basis, with annual estimates based on a summation of monthly estimates. Principal differences between the models occur with respect to the following areas: (1) precipitation as snowfall, (2) estimation of PET, and (3) estimation of soil moisture retention during periods when PET exceeds maximum infiltration. The benchmarking efforts are focused on selecting scenarios that will allow the reader to appreciate the impacts of the various differences in model construct.

The benchmarking efforts for surface hydrology include two scenarios. The following section describes the scenarios and presents the data necessary to execute the tests.

\subsection{SCENARIO DESCRIPTIONS}

Two scenarios are used to benchmark MMSOILS and MEPAS with respect to surface hydrology. The scenarios represent two relatively extreme hydrological conditions: high rainfall/highly permeable soil and low rainfall/highly permeable soil. Both scenarios reflect conditions of high PET. While these scenarios do not simulate all of the models' features (e.g., snowmelt), they do provide for a comparison of the models under conditions where differences in model formulation have a clear impact on model estimates. To conduct these tests, data from two geographic sites are selected for model simulations. The

first site, Daytona Beach, Florida, represents high rainfall and high permeability. The second site, Fresno, California, represents low rainfall and high permeability.

Tables 8.1 and 8.2 list the soil and meteorological data developed to simulate the surface hydrology. (tables and figures for this chapter are presented in order beginning on page 8-10.) The data reflect actual meteorological data at weather stations located in the two cities. The soil data are representative of the areas and were extracted from a SoilConservation Service national soils database.

\subsection{COMPARISON OF CALCULATED RESULTS}

MMSOILS and MEPAS predictions of annual and average monthly runoff, PET, actual evapptranspiration, and infiltration are used as the points of comparison in this benchmarking test. Results of three simulations for each scenario are included-one using MEPAS and two using MMSOILS. MMSOILS is executed twice to highlight the difference between the two techniques available for estimating PET. MMSOILS allows the user to select a method developed by Thornthwaite or to apply a user supplied pan correction factor to local pan evaporation data. This represents the only difference between the two MMSOILS simulations. It should be noted here that the user supplied pan correction factor is simply multiplied by the pan evaporation to calculate PET. As such, the resulting PET cannot be considered a model-based prediction; it is a reflection of actual local conditions.

Simulation results are discussed in order of scenario, annual average estimates, and average monthly estimates. Section 8.3.1 describes the high rainfall, high permeability, and high PET scenario 
representing Daytona Beach, Florida. Section 8.3.2 describes the low rainfall, high permeability, and high PET scenario representing Fresno, California.

\subsubsection{Daytona Beach, Florida Scenario}

Table 8.3 lists the annual average estimates of runoff, PET, AET, and infiltration for each of the simulations. MMSOILS estimates that approximately $0.7 \mathrm{~cm}$ of the total rainfall of approximately 125 $\mathrm{cm}$ will run off while MEPAS predicts no runoff to occur. The runoff predicted by MMSOILS occurs in a single month when antecedent moisture conditions, based on the 5-day average rainfall for the month, are computed to be relatively high, resulting in a modification of the curve number upward (in this scenario from a value of 70 to 85 ). The increase in curve number translates into a decreased water retention capability of the soil, and therefore a fraction of the rainfall is predicted to runoff. MEPAS, as described in Step 7 of the surface hydrology algorithm in Sect. 8.1, applies a constant value of antecedent moisture condition and, as a result, a constant curve number throughout the year. The MEPAS curve number value is 70 . Therefore, with a lower curve number than MMSOILS, sufficient water retention to assimilate all precipitation is predicted, and no runoff occurs.

Predictions of annual PET vary from a low of $112.6 \mathrm{~cm}$ for the MMSOILS simulation applying the Thornthwaite method to a high of $140.4 \mathrm{~cm}$ for the MMSOILS simulation using site-specific pan evaporation data. MEPAS predicts a PET of $123.0 \mathrm{~cm}$. The reader should remember that the MEPAS estimate actually represents the minimum of three estimates computed in the model.

Looking at the monthly PET values (Fig. 8.1), it can be inferred that MEPAS and the MMSOILS simulation using site-specific pan evaporation data track each other rather closely, with the MEPAS values consistently slightly lower than the MMSOILS values. The MMSOILS results using the Thornthwaite method, on the other hand, do not track so closely. During the wet season, the Thornthwaite method estimates lower PET than MEPAS and the pan evaporation-based MMSOILS values, and during the dry season, the method predicts higher values.

AET is a function of the amount of water available for evapotranspiration, which in turn is a function of the combination of PET, precipitation, runoff, and soil moisture storage. MMSOILS, using pan evaporation data, and MEPAS predict similar AET values of $116.7 \mathrm{~cm}$ and $111.3 \mathrm{~cm}$, respectively. MMSOILS, using the Thornthwaite method, predicts a value of AET equal to $102.7 \mathrm{~cm}$. This is more a function of the low value of PET than the manner in which MMSOILS accounts for soil moisture changes.

Looking at the monthly AET values (Fig. 8.2), a much closer correlation between all methods is seen. Differences are greatest during the low PET months (i.e., wet season) with the Thornthwaite consistently estimating lower AET than the MEPAS or MMSOILS using pan evaporation methods.

Infiltration estimates range from a high of $21.5 \mathrm{~cm}$ for MMSOILS using the Thornthwaite method to a low of $7.4 \mathrm{~cm}$ for MMSOILS using the pan evaporation-based method. MEPAS predicts an infiltration of $13.3 \mathrm{~cm}$ yr. This represents nearly a factor of 3 difference which would result in potentially significant differences in contaminant flux through the unsaturated zone and thereby the mass of contaminant available for release and transport through other media (e.g., volatilization to atmosphere)

Figure 8.3 shows the estimates of monthly infiltration for the three simulations. None of the models predict non-zero infiltration for the months April through July. The models differ significantly in the remaining months as to magnitude of infiltration. MEPAS estimates infiltration during six of the remaining eight months. MMSOILS, using pan evaporation-based PET methods, predicts infiltration 
in only three of the remaining eight months. MMSOILS, using the Thornthwaite method, predicts infiltration in seven of the remaining eight months. Therefore, overall, MEPAS and MMSOILS using Thornthwaite predict more frequent infiltration than does the MMSOILS using the pan evaporation method. This is primarily due to the consistently lower estimates of PET produced by MEPAS and the MMSOILS using Thornthwaite. The consistently lower PET values translate into more moisture remaining in the soil under dry conditions and therefore a higher likelihood that subsequent rains will result in infiltration, i.e., soil moisture in excess of field capacity.

\subsubsection{Fresno, California, Scenario}

Table 8.4 lists the annual average estimates of runoff, PET, AET, and infiltration for each of the simulations.

Each of the model simulations estimates that no runoff will occur for this scenario. This is not an unexpected result given the high PET and extremely low rainfall.

Predictions of PET vary from a low of $90.2 \mathrm{~cm}$ for the MMSOILS simulation applying the Thornthwaite method to a high of $127.8 \mathrm{~cm}$ for the MMSOILS simulation using the pan correction factor and pan evaporation data. MEPAS predicts a PET of $115.4 \mathrm{~cm}$. The MMSOILS result using pan evaporation data again reflects site-specific data and not a prediction from the model. .

Figure 8.4 shows the monthly PET values for each of the simulations. Unlike the Daytona Beach, Florida, scenario, all three simulations for the Fresno, California, scenario track each other very closely in terms of monthly directional changes. MEPAS tracks the MMSOILS pan evaporation method very closely, estimating slightly lower PET for each month. The MMSOILS simulation using the Thornthwaite method is consistently less than the other simulations, with differences being most significant during the transition from wet season to dry season, i.e., March through June. This suggests that while temperature and heat index dominates PET during the transition from dry to wet season, it is not the dominant determinant of PET during the transition from wet to dry seasons.

MMSOILS, using pan evaporation data, and MEPAS predict similar AET values of $24.1 \mathrm{~cm}$ and $24.3 \mathrm{~cm}$, respectively. MMSOILS, using the Thornthwaite method, predicts an approximately $25 \%$ lower value of AET equal to $17.5 \mathrm{~cm}$. Notice the dramatic difference between PET and AET for this scenario, relative to the Daytona Beach, Florida, scenario. Soil moisture retention during dry periods, in this case lasting a number of months, plays a major role in predicting the AET.

Figure 8.5 shows the monthly values of AET for each of the simulations. As with PET, MEPAS and the MMSOILS simulation using pan evaporation data agree very closely throughout the year. MMSOILS using the Thornthwaite method shows excellent agreement with the other methods for months April through November. For months December through March the Thornthwaite method in MMSOILS predicts significantly less AET.

Infiltration estimates range from a high of $10.5 \mathrm{~cm}$ for MMSOILS using the Thornthwaite method to a low of $3.7 \mathrm{~cm}$ for MEPAS. MMSOILS, using the pan evaporation-based method, estimates an infiltration of $3.9 \mathrm{~cm}$, slightly higher than MEPAS.

Figure 8.6 shows the monthly infiltration for each of the simulations. Unlike the Daytona Beach, Florida, scenario the Fresno, California, scenario shows good agreement among the models with respect to which months contain infiltration. All models predict infiltration from December through February. MMSOILS using the Thornthwaite method also predicts infiltration in March. All other months are void 
of infiltration. MEPAS and MMSOILS using pan evaporation data predict nearly identical infiltration rates; however, MMSOILS using Thornthwaite predicts consistently higher rates of infiltration. The reason for this can be seen in the AET plots presented in Fig. 8.5, which show that AET estimates for MMSOILS simulation using the Thornthwaite method are consistently lower than the other methods, thereby increasing the likelihood of infiltration.

\subsection{CONCLUSIONS}

In reviewing the results of the surface hydrology benchmark tests, the following general observations are made.

1. All of the model simulations provide similar estimates of average annual and average monthly runoff, potential and AET, and infiltration.

2. The use of the Thornthwaite method for estimating PET consistently results in lower estimates than either MEPAS or MMSOILS when using pan evaporation data. This probably is due to the at best marginal applicability of the Thornthwaite method to the two geographic locations used in the scenario. The Thornthwaite method is intended for use in mid-latitude continental regions where temperature is expected to dominate PET.

3. While MEPAS and MMSOILS use different techniques for computing monthly soil moisture storage fluctuations, the end result, for these scenarios, is similar estimates.

4. If site-specific pan evaporation data are not available, then the only option for use in MMSOILS for estimating PET is the Thornthwaite method. While this method provides reasonable estimates for some regions it does not provide for consistency of estimation as does the MEPAS model which applies three methods for estimating PET at each site and selects the lowest value for further application.

5. The scenarios presented do not allow for any conclusions to be rendered regarding the models' methods for estimating runoff. Both scenarios include high PET and therefore minimum likelihood of runoff. It would be useful in the future to add a scenario where runoff is potentially significant (for example a site in the northeast United States or Mississippi where high rainfall is matched with relatively low permeability soils).

6. MEPAS differentiates between snowfall and rainfall while MMSOILS does not. The benchmarking tests included here do not address this difference. The effect of subzero temperatures on runoff and infiltration may well be important for applications in the northern U.S. Future benchmarking efforts should explicitly include this capability.

\subsection{CHAPTER REFERENCES}

Dunne, T. and L. B. Leopold. 1978. Water in Environmental Planning, W.H. Freeman and Co., New York, New York.

NOAA (National Oceanic and Atmospheric Administration). 1984. Local Climatological Data: Annual Summaries, National Environmental Satellite, Data, and Information Service, National Climatic Data Center, Ashville, North Carolina. 
Shirazi, M. A., S. A. Peterson, and J. W. Hart. 1985. Computer-Based Mapping for Management of Hazardous Waste, working paper, U.S. Environmental Protection Agency, Corvallis, Oregon (as reported by Whelan et al. 1987).

Thornthwaite, C. W. and J. R. Mather. 1957. Instructions and Tables for Computing Potential Evapotranspiration and the Water Balance, Publications in Climatology, Vol. X, No. 3. Drexel Institute of Technology, Laboratory of Climatology, Centerton, New Jersey.

Whelan, G., D. L. Strenge, J. G. Droppo, Jr., B. L. Steelman, and J. W. Buck. The Remedial Action Priority System (RAPS): Mathematical Formulations, PNL-6200, Pacific Northwest Laboratory, Richland, Washington. 
Table 8.1. Surface hydrology data: Daytona Beach, Florida

Pan Coefficient for evaporation Maximum cover (\%)

Curve number

Depth of root zone $(\mathrm{cm})$

Bulk density $\left(\mathrm{g} \mathrm{cm}^{-3}\right)$

Field capacity water content $\left(\mathrm{cm} \mathrm{cm}^{-1}\right)$

Wilting point water content $\left(\mathrm{cm} \mathrm{cm}^{-1}\right)$

Residual water content $\left(\mathrm{cm} \mathrm{cm}^{-1}\right)$

Saturated conductivity ( $\mathrm{cm} \mathrm{hr}^{-1}$ )

Summary of Meteorological Data

Station Name:

Approximate Latitude:

Years of record:

Month Totaldays AVG\#PRECIP
Processed

Processed

$\begin{array}{llll}\text { Jan } & 1116 & 6.3 & 0.5746 \mathrm{E}+01 \\ \text { Feb } & 1017 & 7.3 & 0.7727 \mathrm{E}+01 \\ \text { Mar } & 1116 & 7.3 & 0.8241 \mathrm{E}+01 \\ \text { Apr } & 1080 & 5.0 & 0.6501 \mathrm{E}+01 \\ \text { May } & 1116 & 7.9 & 0.8169 \mathrm{E}+01 \\ \text { Jun } & 1080 & 11.3 & 0.1560 \mathrm{E}+02 \\ \text { Jul } & 1116 & 12.2 & 0.1407 \mathrm{E}+02 \\ \text { Aug } & 1116 & 12.5 & 0.1624 \mathrm{E}+02 \\ \text { Sep } & 1080 & 12.1 & 0.1718 \mathrm{E}+02 \\ \text { Oct } & 1116 & 9.4 & 0.1255 \mathrm{E}+02 \\ \text { Nov } & 1080 & 6.1 & 0.6175 \mathrm{E}+01 \\ \text { Dec } & 1116 & 6.8 & 0.6590 \mathrm{E}+01\end{array}$

0.77

25.

70

10.

1.5

0.16

0.08

0.045

30.
AVG_PRECIP $\mathrm{cm} /$ month

(1)

\section{$0.8781 E+01 \quad 0.1436 E+02$}

$0.1019 \mathrm{E}+02 \quad 0.1519 \mathrm{E}+02$

$0.1512 E+02 \quad 0.1782 E+02$

$0.1971 \mathrm{E}+02 \quad 0.2076 \mathrm{E}+02$

$0.2160 \mathrm{E}+02 \quad 0.2384 \mathrm{E}+02$

$0.1954 \mathrm{E}+02 \quad 0.2625 \mathrm{E}+02$

$0.1985 \mathrm{E}+02 \quad 0.2724 \mathrm{E}+02$

$0.1909 \mathrm{E}+02 \quad 0.2713 \mathrm{E}+02$

$0.1571 \mathrm{E}+02 \quad 0.2629 \mathrm{E}+02$

$0.1356 \mathrm{E}+02 \quad 0.2290 \mathrm{E}+02$

$0.1043 \mathrm{E}+02 \quad 0.1838 \mathrm{E}+02$

$0.8668 \mathrm{E}+01 \quad 0.1536 \mathrm{E}+02$

Annual

Total

13149

104.1

$0.1248 E+03$

$0.1823 E+03$

AVG_WND AVG_SOL $\mathrm{cm} \mathrm{s}^{-1} \quad$ langleys

$0.4023 E+03 \quad 0.2880 E+03$

$0.4499 E+03 \quad 0.3598 E+03$

$0.4470 E+03 \quad 0.4498 E+03$

$0.4381 E+03 \quad 0.5582 E+03$

$0.4069 \mathrm{E}+03 \quad 0.5628 \mathrm{E}+03$

$0.3809 E+03 \quad 0.5190 E+03$

$0.3396 \mathrm{E}+03 \quad 0.5094 \mathrm{E}+03$

$0.3263 \mathrm{E}+03 \quad 0.4998 \mathrm{E}+03$

$0.3800 E+03 \quad 0.4378 E+03$

$0.4157 \mathrm{E}+03 \quad 0.3887 \mathrm{E}+03$

$0.3889 E+03 \quad 0.3352 E+03$

$0.4039 E+03 \quad 0.2788 E+03$ 


\section{8-11}

Table 8.2. Surface hydrology data: Fresno, California

Pan coefficient for evaporation

Maximum cover (\%)

Curve number

Depth of root zone (cm)

Bulk density $\left(\mathrm{g} \mathrm{cm}^{-3}\right)$

Field capacity water content $\left(\mathrm{cm} \mathrm{cm}^{-1}\right)$

Wilting point water content $\left(\mathrm{cm} \mathrm{cm}^{-1}\right)$

Residual water content $\left(\mathrm{cm} \mathrm{cm}^{-1}\right)$

Saturated conductivity $\left(\mathrm{cm} \mathrm{hr}^{-1}\right)$
0.67

25.

70

16.

1.5

0.16

0.08

0.045

30.

Summary of Meteorological Data

Station Name:

Approximate Latitude:

w93193

Years of record:

36 degrees, 30 minutes

1950-1983

Month Total_days Processed
AVG_PAN

$\mathrm{cm} / \mathrm{month}$

$0.3787 \mathrm{E}+01$

$0.5934 \mathrm{E}+01$

$0.1108 \mathrm{E}+02$

$0.1728 \mathrm{E}+02$

$0.2544 E+02$

$0.2802 \mathrm{E}+02$

$0.3037 \mathrm{E}+02$

$0.2626 \mathrm{E}+02$

$0.1565 \mathrm{E}-01$

$0.5597 \mathrm{E}-01$

$0.5192 \mathrm{E}+00$

$0.1212 \mathrm{E}+01$

$0.3432 \mathrm{E}+01$

$0.4021 E+01$
$0.1946 \mathrm{E}+02$

$0.1308 \mathrm{E}+02$

$0.6144 \mathrm{E}+01$

$0.3754 \mathrm{E}+01$
AVG_TEMP celsius

$0.7431 E+01$

$0.1033 \mathrm{E}+02$

$0.1232 \mathrm{E}+02$

$0.1565 E+02$

$0.1996 \mathrm{E}+02$

$0.2397 \mathrm{E}+02$

$0.2726 \mathrm{E}+02$

$0.2618 E+02$

$0.2343 E+02$

$0.1822 \mathrm{E}+02$

$0.1186 \mathrm{E}+02$

$0.7623 E+01$
AVG_WND $\mathrm{cm} \mathrm{s}^{-1}$

$0.2414 \mathrm{E}+03$ $0.2603 E+03$

$0.3040 E+03$

$0.3263 \mathrm{E}+03$

$0.3621 \mathrm{E}+03$

$0.3710 E+03$

$0.3263 E+03$

$0.3040 \mathrm{E}+03$

$0.2682 \mathrm{E}+03$

$0.2378 \mathrm{E}+03$

$0.2146 \mathrm{E}+03$

$0.2235 \mathrm{E}+03$
AVG_SOL langleys

$0.1786 \mathrm{E}+103$

02689E+103

$0394 \mathrm{E}+03$

05401E+0B

$0.6612 \mathrm{E}+03$

$0.6888 E+03$

$0.6886 \mathrm{E}+03$

$0.6187 \mathrm{E}+03$

OS167E+0B

0.3955E+0B

0243TE+03

$0.1763 \mathrm{E}+03$

Annual

Total

12418

40.1

0.2799E+02

$0.1906 E+03$ 


\section{8-12}

Table 8.3. Annual average estimates of hydrological parameters : Daytona Beach, Florida Scenario (Total Rainfall : $124.9 \mathrm{~cm}$ )

\begin{tabular}{lccc}
\hline Parameter & MEPAS & MMSOILS $^{2}$ & MMSOILS $^{\mathbf{b}}$ \\
\hline Runoff (cm) & 0.0 & 0.68 & 0.68 \\
PET (cm) & 123.0 & 140.4 & 112.6 \\
AET (cm) & 111.3 & 116.8 & 102.7 \\
Infiltration (cm) & 13.3 & 7.4 & 21.5 \\
\hline
\end{tabular}

"MMSOILS using pan correction factor applied to pan evaporation data for estimating PET

"MMSOILS using the Thornthwaite method for estimating PET 


\section{$8-13$}

Table 8.4. Annual average estimates of hydrological parameters : Fresno, California Scenario (Total Rainfall : 28 cm)

\begin{tabular}{lccc}
\hline Parameter & MEPAS & MMSOLS $^{\mathbf{2}}$ & MMSOLS $^{\mathrm{b}}$ \\
\hline Runoff (cm) & 0.0 & 0.0 & 0.0 \\
PET (cm) & 115.4 & 127.8 & 90.2 \\
AET (cm) & 24.3 & 24.1 & 17.5 \\
Infiltration (cm) & 3.7 & 3.9 & 10.5 \\
\hline
\end{tabular}

"MMSOILS using pan correction factor applied to pan evaporation data for estimating PET

MMSOILS using the Thomthwaite method for estimating PET 


\section{Potential Evapotranspiration}

Daytona Beach, Florida

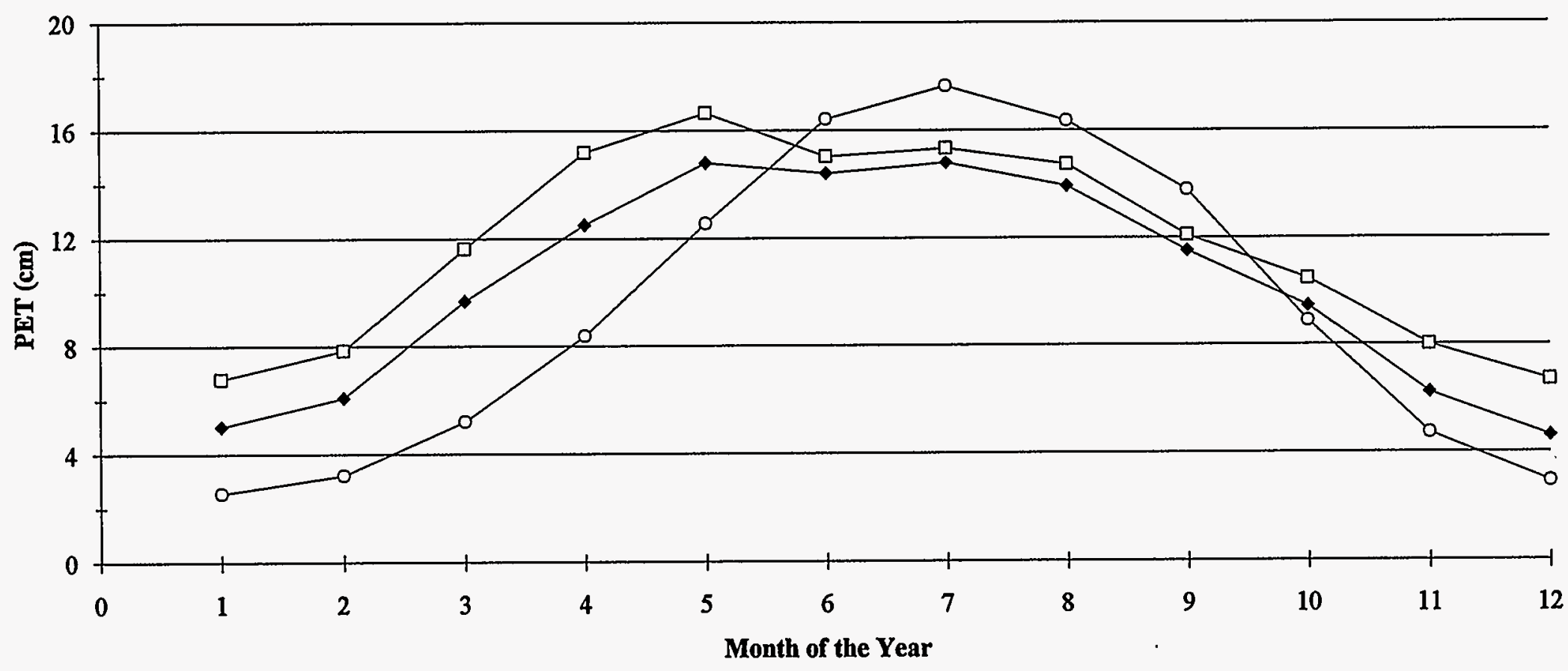

Fig, 8.1. Monthly PET Values for Daytona Beach, Florida for MMSOILS and MEPAS. 
Actual Evapotranspiration

Daytona Beach, Florida

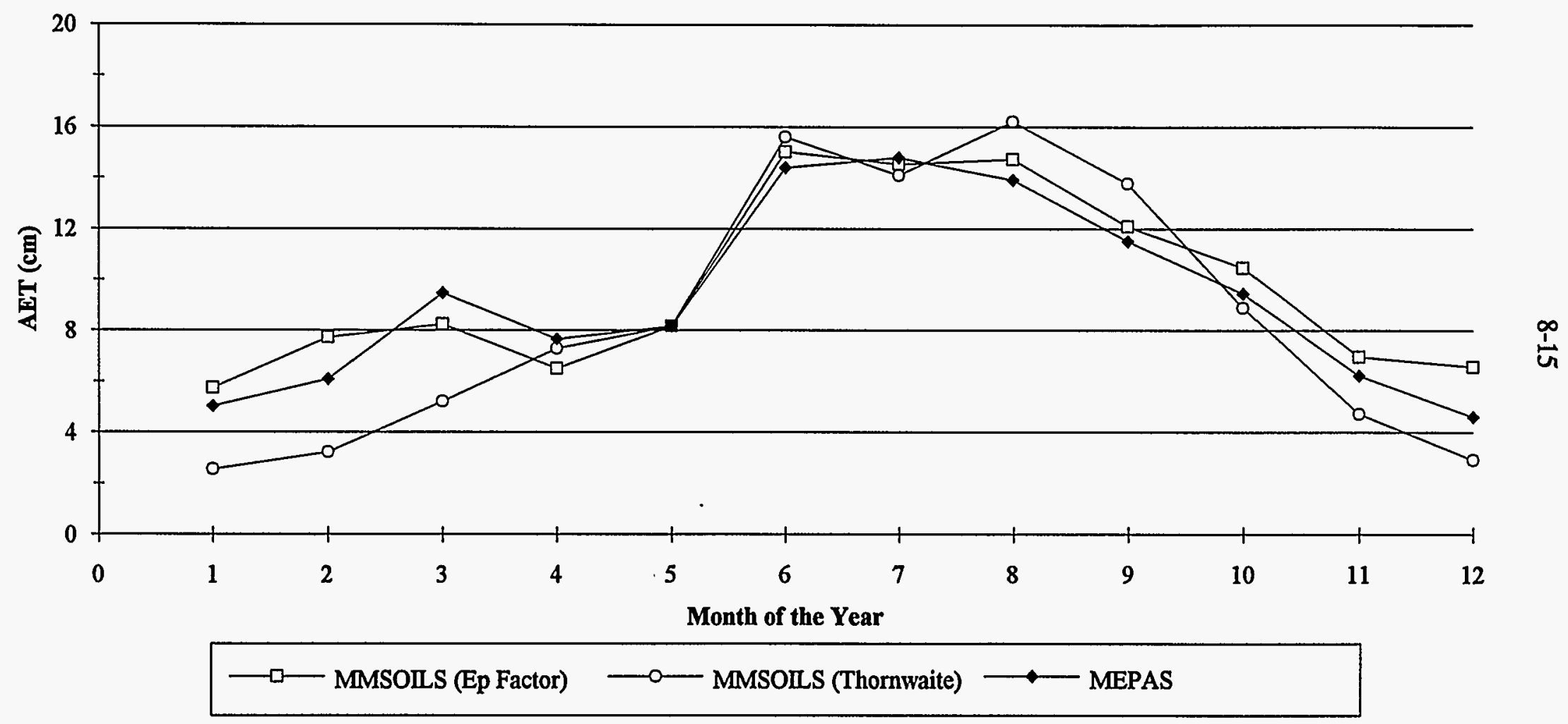

Fig. 8.2. Monthly AET Values for Daytona Beach, Florida for MMSOILS and MEPAS. 
Infiltration

Daytona Beach, Florida

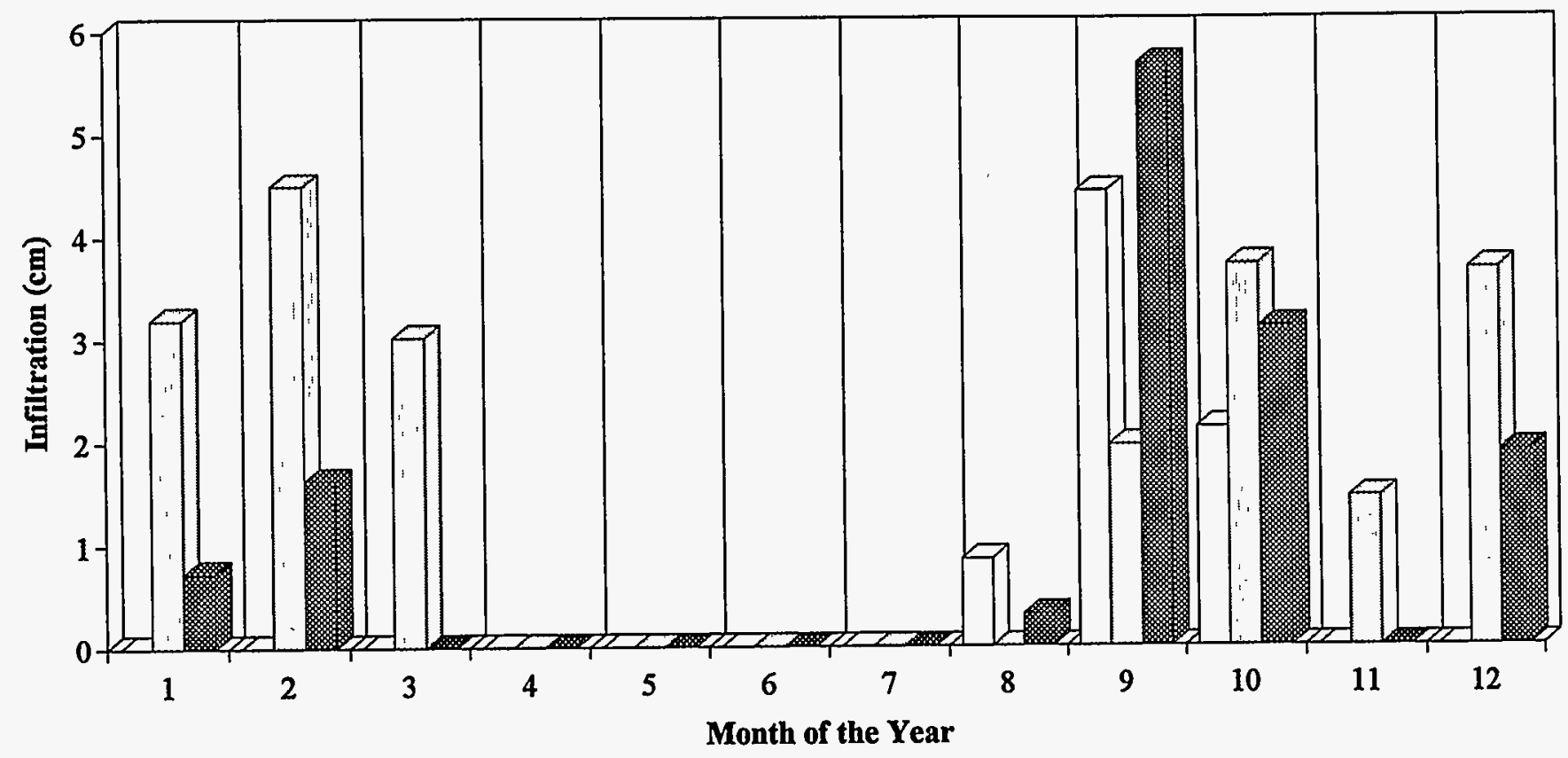

Fig. 8.3. Monthly Infiltration Values for Daytona Beach, Florida for MMSOILS and MEPAS. 


\section{Potential Evapotranspiration}

Fresno, California

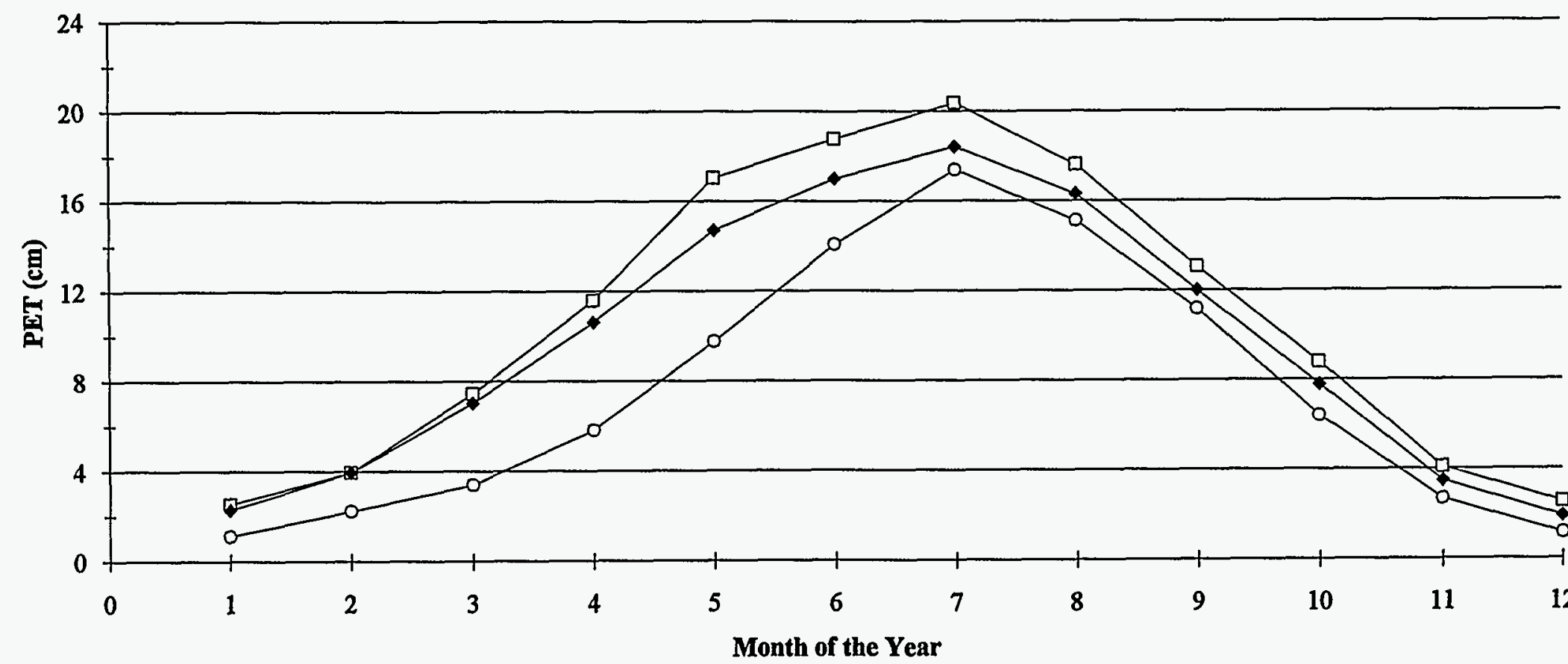

Fig. 8.4. Monthly PET Values for Fresno, California for MMSOILS and MEPAS. 


\section{Actual Evapotranspiration}

Fresno, California

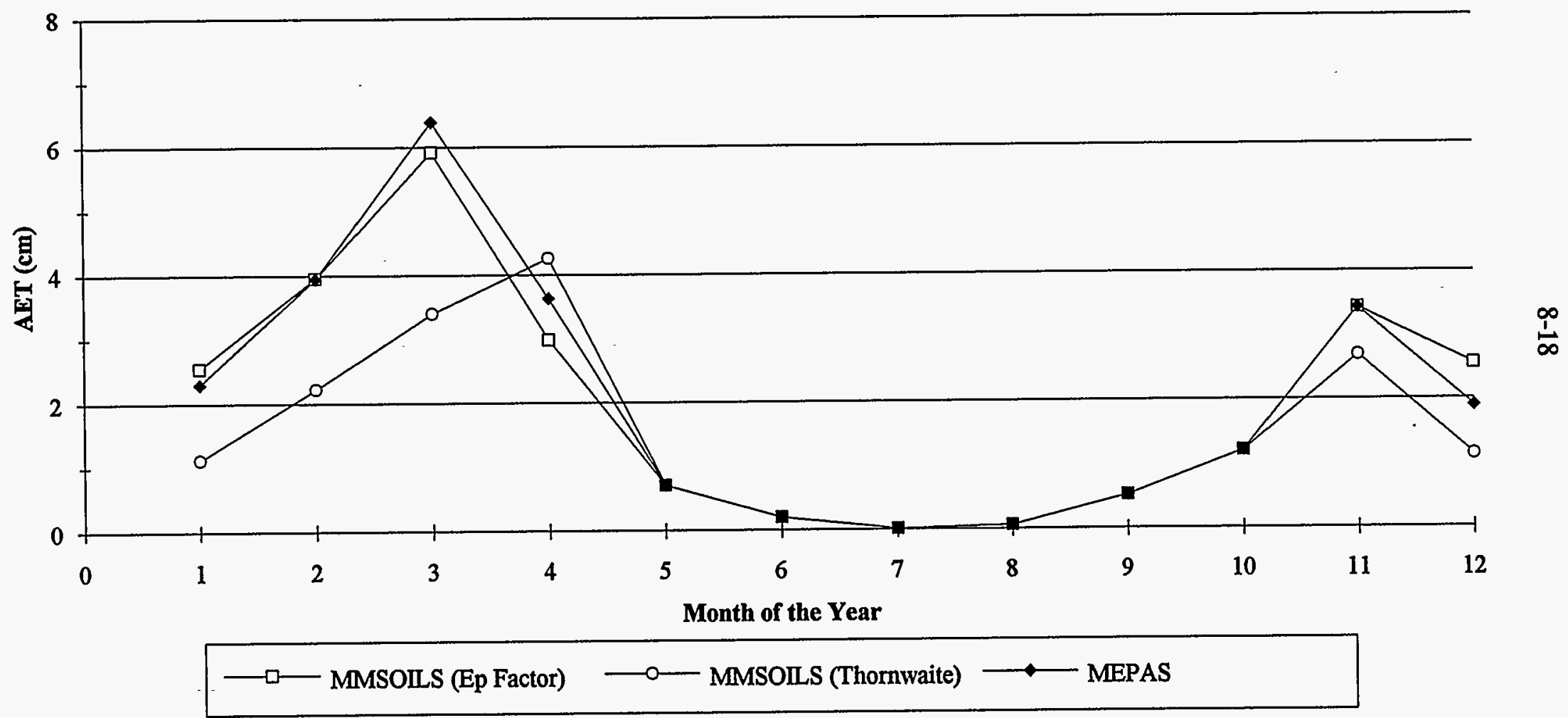

Fig. 8.5. Monthly AET for Fresno, California for MMSOILS and MEPAS. 


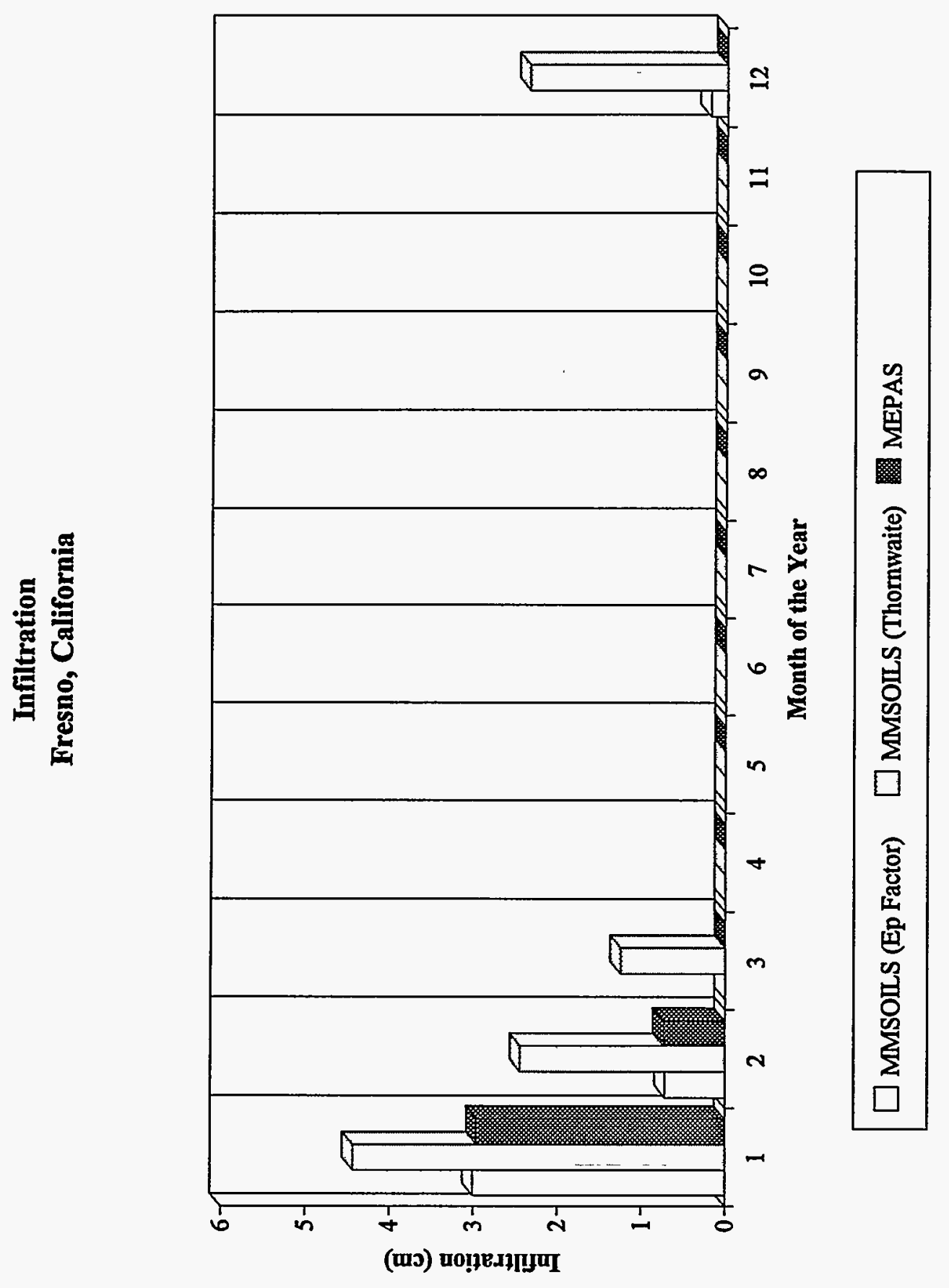

号 
8-20 


\section{MULTIMEDIA SCENARIO}

The benchmarking test results for the three models (RESRAD, MMSOILS, and MEPAS) presented in previous sections provide a basis for comparison of contaminant transport through a single medium; however, these single medium comparisons do not evaluate the cross-media exchanges that are unique to multimedia models. The purpose of the multimedia scenario is to analyze how each of the three models (1) apportions the contaminants to the various releases, (2) simulates contaminant transport through the environment, (3) simulates the accumulation of contaminants at offsite locations and the build up of contaminants in the food chain, and (4) estimates the radiological and contaminant effects of the contaminants on humans.

The multimedia scenario described in this chapter involves modeling a landfill, or source, at a hazardous waste facility. The models are configured to simulate release of contaminants from the source. The source is assumed to have been investigated so that an estimate of total contaminant inventory and volume of contaminated soil is available. Transport of contaminants through the groundwater, air, and surface water is simulated, followed by prediction of exposure and health impacts via the multiple exposure routes. It is noted that infiltration of moisture through the unsaturated zone is not simulated; rather, the same specified regional infiltration rate is used by all models.

Although broadly based on a real site, the site conditions are defined to provide an illustrative benchmarking case. As a result, the outputs for the benchmarking comparisons are not representative of a real site.

The multimedia waste source chosen for this evaluation is hereafter referred to as a landfill. To streamline the generation of data necessary to characterize the landfill for modeling, the landfill is patterned after a waste site where a preliminary site investigation has been completed. However, detailed investigations of the site and environmental setting have not been undertaken; therefore, the limited data available preclude the use of more detailed numerical models. Although waste sites can contain several types of contaminants, including radionuclides, inorganics, and organics, in this multimedia benchmarking scenario, only one organic and one radionuclide and its decay products are simulated. Therefore, the simulated landfill includes contaminants from these two major contaminant groups: organics and radionuclides.

Sample calculations are provided throughout this chapter to give the reader an understanding for how the data are used and confirm model predictions. The calculations have been placed in equation boxes to distinguish them from the body of the text. The calculations can be skipped without loss of continuity or information.

\subsection{FACILITY AND SOURCE DESCRIPTION}

The facility where the landfill is located is assumed to be a weapons assembly and disassembly facility. Nuclear weapons are temporarily staged and nuclear material is stored on an interim basis at the facility.

Several solid waste management units (SWMUs) are located at the facility. This benchmarking exercise considers only one (an unlined landfill) and does not address contaminant releases associated with either the remaining SWMUs or facility operations. 
More than 30 yrs ago, the landfill was used for the disposal of laboratory wastes, some of which were placed in drums, boxes, and bags. The integrity of the waste containers is unknown. Therefore, the landfill contains contaminants that have the potential to migrate offsite.

\subsubsection{Landfill Characteristics}

The landfill is $243.8 \mathrm{~m}$ in length and $12.2 \mathrm{~m}$ in width, for a total surface area of $2974 \mathrm{~m}^{2}$ and is covered by $0.8 \mathrm{~m}$ of overburden. Table 9.1 presents the landfill characteristics, and the landfill, along with two nearby wells and a river, is shown in Fig. 9.1 (tables and figures are presented in order beginning on page 9-44). Both the wells and the river are downgradient of the landfill in terms of groundwater flow direction. The longest side of the landfill $(243.8 \mathrm{~m})$ is oriented in the north-south direction. In the east-west direction, the landfill is $12.2 \mathrm{~m}$ wide.

The contaminants present at the landfill are methylene chloride and uranium-238. No decay products of uranium-238 are present at the beginning of the simulation. The estimated inventories, soil-water distribution coefficients $\left(\mathrm{K}_{\mathrm{d}}\right.$ values), and other characteristics of methylene chloride, uranium-238, and progeny are listed in Tables $9.2 \mathrm{a}$ and $9.2 \mathrm{~b}$. As shown in Table 9.2b, the soil-water distribution coefficients for the decay products of uranium-238 simulated by MEPAS are all the same. This is a requirement of the approach used by MEPAS to solve for the decay products and is discussed in more detail in Sect. 9.2.2.3. The RESRAD solution approach is different from that of MEPAS and does not require that the soil-water distribution coefficients for the simulated decay products be the same (see Sect 9.2.2.1). It should also be noted that both MEPAS and RESRAD analyze different subsets of the complete uranium-238 decay chain. However, the risk contributions from all decay products are accommodated by both models (see footnotes in Tables $9.9 \mathrm{a}$ and $9.9 \mathrm{~b}$ ).

The soil-water distribution coefficient for methylene chloride is between $0.005 \mathrm{~mL} \mathrm{~g}^{-1}$ (in the saturated zone) and $0.01 \mathrm{~mL} \mathrm{~g}^{-1}$ [in the source and partially saturated zone 1 (PSZ1)]. These distribution coefficients are small and indicate that little of the methylene chloride is adsorbed to the soil. Rather, most of the methylene chloride is present in the aqueous phase, and since Henry's Law constant is high, vapor phase concentrations are significant as well. In contrast to the distribution coefficients for methylene chloride, those for uranium-238 are significantly higher (from $30 \mathrm{~mL} \mathrm{~g}^{-1}$ in the saturated zone to $75 \mathrm{~mL} \mathrm{~g}^{-1}$ in the source and in PSZ1). Therefore, adsorption of the uranium-238 to the soil matrix is significant. In addition, since the saturated vapor pressure of uranium-238 is zero, the vapor phase is nonexistent.

\subsubsection{Hydrogeology}

The soils at the facility consist primarily of finely textured, easily eroded soils of the Pullman series (see Fig. 9.1 and Tables 9.3 and 9.4). The shallowest layer (PSZ1), which extends from the surface to $15 \mathrm{~m}$ below grade, is categorized as a silty clay loam. This layer includes $0.8 \mathrm{~m}$ of overburden and 3.8 $\mathrm{m}$ of source thickness, and extends $10.4 \mathrm{~m}$ below the source. PSZl overlays $100 \mathrm{~m}$ of sandy clay (PSZ2), which, in turn, overlies an aquifer of loamy sand. The water table is present at a depth of $115 \mathrm{~m}$ below grade, and the aquifer has a saturated thickness of $120 \mathrm{~m}$. The aquifer is unconfined and is recharged at a rate of $1.27 \mathrm{~cm} \mathrm{yr}^{-1}$ (see Fig. 9.1). The aquifer pore water velocity is $0.4 \mathrm{~m}^{-1}$ day $^{-1}$ (see the calculation in the following equation box). 


\section{Aquifer Pore Water Velocity}

The pore water velocity $\left(V_{P}\right)$ in the aquifer is $0.4 \mathrm{~m}^{-1} \mathrm{y}^{-1}$, as indicated in Fig. 9.1. The pore water velocity is calculated based on the following formula:

$$
V_{p}=\frac{K_{H} S}{\theta_{e}}
$$

where

$$
\begin{array}{lll}
\mathrm{V}_{\mathrm{p}} & = & \text { pore water velocity }\left(\mathrm{m} \mathrm{yr}^{-1}\right) \\
\mathrm{K}_{\mathrm{H}} & = & \text { hydraulic conductivity }\left(\mathrm{m} \mathrm{yr}^{-1}\right) \\
\mathrm{S} & = & \text { hydraulic gradient }\left(\mathrm{m} \mathrm{m}^{-1}\right) \\
\theta_{\mathrm{e}} & = & \text { effective porosity (fraction) }
\end{array}
$$

Using the data in Table 9.4, the pore water velocity is:

$$
\begin{aligned}
\mathrm{V}_{\mathrm{P}} & =1,314 \mathrm{~m} \mathrm{yr}^{-1} \times 0.02 \mathrm{~m} \mathrm{~m}^{-1} \div 0.18 \\
& =146 \mathrm{~m} \mathrm{yr}^{-1} \\
& =0.4 \mathrm{~m} \mathrm{day}^{-1}
\end{aligned}
$$

\subsubsection{Topography and Meteorology}

The facility is situated at $1100 \mathrm{~m}$ above mean sea level. The ground surface is generally level with a gentle slope of $0.0025 \mathrm{~m} \mathrm{~m}^{-1}$ downward to the north. Twenty-five percent of the landfill is covered by short, sparse grass. The area surrounding the landfill has similar vegetation, which covers about $75 \%$ of the ground surface.

In the vicinity of the facility, the climate is semiarid. The area averages 69 days per yr of precipitation greater than 0.01 in. (see Table 9.5). Forty-nine thunderstorm days occur per year on average. The annual precipitation is $48.5 \mathrm{~cm}$, and most precipitation falls during the late spring and summer. Average monthly air temperatures vary from a low of $1.67^{\circ} \mathrm{C}$ in January to a high of $25.6^{\circ} \mathrm{C}$ in July.

Joint frequency wind speed data for the facility are shown in Table 9.6. The data consist of stability classes A through G, 6 wind speed categories, and 16 compass sectors of $22.5^{\circ}$ each. The north sector is tended by an angle of $22.5^{\circ}$, with $11.25^{\circ}$ on each side of the north direction. The wind direction is predominantly from the south-southwest, although cold air masses generate a frequent northerly and westerly wind from November through March. The average annual morning mixing height (i.e., height to stable air) is $328 \mathrm{~m}$, and the average afternoon mixing height is $1973 \mathrm{~m}$.

\subsubsection{Surface Hydrology}

"The facility drains to a river located approximately $2000 \mathrm{~m}$ down slope of the source. The river is fed by overland flow from the watershed, from river flow upstream of the watershed, and from groundwater discharge directly from the aquifer. Average annual river depth, width, and velocity are shown in Table 9.7. 


\subsubsection{Receptors}

Two locations where individuals reside, one hypothetical and one actual, have been identified for this benchmarking effort. At each location, the individual is exposed to the contamination that migrates from the landfill and is distributed in the environment (e.g., water, air, and soil).

The hypothetical receptor uses groundwater from a well that is situated at the site boundary. The individual and the well are located $366 \mathrm{~m}$ to the north of the center of the landfill (see Fig. 9.2). The second individual is situated $810 \mathrm{~m}$ to the northeast of the center of the landfill (i.e., $573 \mathrm{~m}$ to the north and $573 \mathrm{~m}$ to the east of the center of the source) and uses a groundwater from a well that is located $670 \mathrm{~m}$ to the north of the center of the landfill (see Fig. 9.3). The location of this individual is based on actual population data and represents the maximally exposed individual (MEI) within a 50-mi radius. The location of the MEI was based on preliminary MEPAS simulations.

In addition, both individuals are exposed through the atmospheric pathway due to emissions (i.e., volatilization and suspension) from the landfill to the air and from a nearby river used for recreational activities. The river is contaminated from groundwater that migrates from the landfill and is located $2000 \mathrm{~m}$ north from the center of the landfill. The recreational activities within the river occur $100 \mathrm{~m}$ downstream from where groundwater contamination enters the river.

The transport pathways (i.e., groundwater, air, and surface water) and their corresponding exposure routes for both individuals are summarized as follows:

\section{Groundwater Pathway}

- drinking water extracted from the wells,

- crop irrigation from well water (leafy and nonleafy vegetable ingestion and ingestion of meat and milk from livestock that graze on irrigated crops), and

- feed water for farm animals (ingestion of meat and milk from livestock that drink the well water).

\section{Air Pathway}

- inhalation of volatiles and particulates emitted from the landfill and transported through the atmosphere,

- food chain intakes that result from deposition of volatiles and particulates (leafy and nonleafy vegetable ingestion and meat and milk ingestion from livestock),

- $\quad$ soil ingestion and soil dermal contact, and

- external gamma radiation from soil (radionuclides only). 
Surface Water Pathway

- ingestion of fish and

- dermal contact while swimming.

The exposure and intake parameters used by the three models are listed in Table 9.8. A common set of input data is used for the three models, with the exception of the weathering decay half-life of contaminants in crops. A value of 12.6 days is fixed by RESRAD and user-specified by MMSOILS; a value of 14 days is fixed in MEPAS. References for the values are also provided in the table. Most of the data are standard EPA default values.

Contaminant-dependent transfer factors, dose conversion factors, and slope factors used by RESRAD, MMSOILS, and MEPAS are shown in Tables 9.9a and 9.9b, respectively. The values used by MMSOILS apply only to methylene chloride and are consistent with the data used by both RESRAD and MEPAS. In one instance, a difference does exist: MMSOILS uses a soil moisture-to-root factor of $0.0171 \mathrm{~mL} \mathrm{~g}^{-1}$ for methylene chloride, whereas the other two models do not use this factor. Instead, they use the soil uptake factor of 1.71 (mg soil) (mg wet plant) ${ }^{-1}$ (shown in Tables 9.9a and 9.9b).

Although the input data in Tables $9.9 \mathrm{a}$ and $9.9 \mathrm{~b}$ are generally the same for RESRAD and MEPAS, some differences do exist. Both codes assume short-lived radionuclides are in secular equilibrium with their long-lived parent radionuclide, and their contaminant fate and transport are not explicitly simulated. However, each code makes different assumptions regarding the short-lived radionuclides as discussed in the footnotes to Tables $9.9 \mathrm{a}$ and $9.9 \mathrm{~b}$. The dose/risk factors for the short-lived radionuclides are incorporated into those for their longer-lived parent radionuclides.

Human health impacts from exposure to radionuclides are traditionally represented by radiation dose or by risk of developing cancer. For benchmarking illustration, different reference approaches were selected for the dose and risk computations. Radiation dose is evaluated from intake or external exposure using methods and models published in Annals of the International Commission of Radiological Protection (ICRP 1975). The methods currently accepted by regulatory agencies in the United States are those presented in ICRP Publication 30 (ICRP 1979-1988). Cancer incidence is evaluated from the radiation dose or by use of slope factors defined by the EPA for specific radionuclides and exposure routes (inhalation, ingestion, and external exposure to contamination in soil). The analyses performed for this benchmark study are based on the dose factors generated using methods of ICRP Publication 30 as published in Federal Guidance Report Nos. 11 and 12 (Eckerman et al. 1988, Eckerman and Ryman 1993). The cancer risk analyses use the EPA slope factors, which provide estimates of cancer incidence to a member of the general population. The slope factors are taken from the Health Effects Assessment Summary Tables (HEAST) (EPA 1994). At the time this report was nearing completion, revised HEAST data were released. However, this report does not reflect those revisions.

The reported risk values from radionuclide exposures are based on continuous exposure over a 70-yr lifetime. The reported dose values are for annual exposure with a 50-yr committment period. RESRAD calculates the annual dose directly from the media concentrations with intake for one year. For the benchmark scenarios, MEPAS calculates the total dose from a 70-yr lifetime exposure period and divides this result by 70 to obtain values for annual doses (for reporting in the tables). For pathways that involve direct use of the exposed medium (e.g., inhalation of air or ingestion of water), the results using the RESRAD and MEPAS methods should give the same value, provided the water concentration is not a function of time. For pathways involving accumulation in an exposure medium (e.g., deposition and 
accumulation in soil from irrigation), MEPAS may estimate higher soil concentrations (on the average) over the 70-yr exposure period.

\subsection{MODELING APPROACH}

A conceptual model of the site and its receptors is constructed based on a review of the available site characterization data and the regional hydrologic and atmospheric conditions presented in Sect. 9.1.

\subsubsection{Conceptual Site Model}

The conceptual site model is developed as a basis for implementing a baseline screening-level contaminant fate and transport modeling analysis and risk assessment. The conceptual site model does not consider the potentially more complex physical, chemical, and biological processes that may be addressed in more mechanistic environmental fate and transport models, nor are remedial alternatives evaluated. The conceptual site model considers groundwater, atmospheric, and surface water pathways. In addition, the conceptual site model presented in Fig. 9.1 simplifies the site hydrogeologic, hydrologic, and atmospheric conditions to allow for representation of these features in each of the three multimedia models. In Figs. 9.1 and 9.4, the surface elevation near the river is depicted as steeply sloping because the average slope of the land near the site is too gentle to reach the surface of the river.

\subsubsection{Source model}

The source or landfill consists of a 3.8-m-thick waste layer buried in the silty clay loam unit of PSZ1. The waste layer is buried $0.8 \mathrm{~m}$ below ground surface and is overlain by a clean cover of materials from the PSZI unit. The waste unit is $243.8 \mathrm{~m}$ in length in the north-south direction and $12.2 \mathrm{~m}$ in width in the east-west direction. The landfill is unlined and does not have either a cap, a containment system, or a leachate collection system. The contaminants, which may have been disposed of in containers, are assumed to have mixed with the soil. Therefore, no barriers impede water or vapor migration. Contaminants are released from the landfill into (1) the partially saturated zone by leaching with infiltrating rainfall, (2) the atmosphere by volatilization, (3) the offsite soils or surface waters by erosion, and (4) the atmosphere by suspension. Mechanisms (3) and (4) take place when the contaminated zone is exposed directly to the ground surface, if the initial inventory has not been depleted.

The mass of methylene chloride in the landfill is initially $100,000 \mathrm{~kg}$. The mass corresponds to a methylene chloride concentration of $6320 \mathrm{mg} \mathrm{kg}^{-1}$ in the waste layer as shown in Table 9.2. This concentration is calculated based on the total methylene chloride inventory and the total mass of soil in the landfill. The bulk density $\left(1400 \mathrm{~kg} \mathrm{~m}^{-3}\right)$ is assumed to be the bulk density of PSZI (see Table 9.3). The calculations are shown in the following equation box.

\section{Total Methylene Chloride Concentration}

The initial total methylene chloride concentration in the source is given by:

$$
C_{m c}^{t}=\frac{M_{i}}{H_{s} L_{s} W_{s} \rho_{b}}
$$




$\begin{array}{|lll|}\text { where } & \\ \mathrm{M}_{\mathrm{i}} & = & \text { total methylene chloride inventory }(\mathrm{mg}) \\ \mathrm{H}_{3} & = & \text { source thickness }(\mathrm{m}) \\ \mathrm{L}_{\mathrm{z}} & = & \text { source length }(\mathrm{m}) \\ \mathrm{W}_{\mathrm{s}} & = & \text { source width }(\mathrm{m}) \\ \rho_{\mathrm{b}} & = & \text { soil bulk density }(\mathrm{kg} \mathrm{soil} \mathrm{m}) \\ \mathrm{C}_{\mathrm{mo}} & = & \text { total methylene chloride concentration in soil from all phases }\left(\mathrm{mg} \mathrm{kg}^{-1}\right) \\ \text { Using the above formula and data, the total methylene chloride concentration is: }\end{array}$

Based on the source characteristics and properties of the methylene chloride, some of the methylene chloride is present as free product that occupies approximately $0.5 \%$ of the void space. At this low saturation, the free-phase methylene chloride is trapped in the soil pore space and is immobile.

The calculations that lead to this percent of free product are provided in the following text. As shown in the following figure, the methylene chloride in the landfill is present in four discrete phases: soil water (aqueous), soil vapor (vapor), soil solid (adsorbed), and nonaqueous (free product).

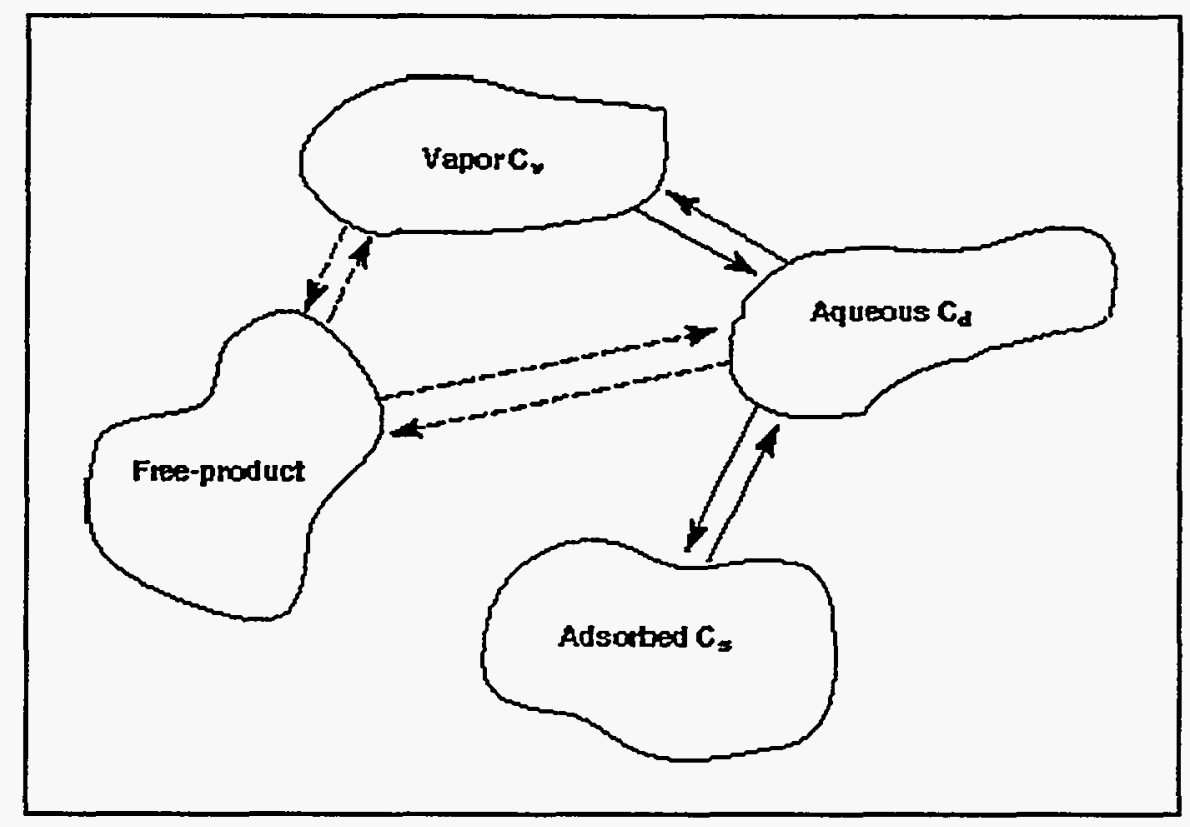

As shown in the following equation box, the total concentration of $6320 \mathrm{mg} \mathrm{kg}^{-1}$ is in excess of the capacity of the soil water, soil vapor, and soil solid phases to accommodate that mass. The maximum contaminant concentration that can be present in the three phases is estimated to be $4284 \mathrm{mg} \mathrm{kg}^{-1}$. The calculations are presented in the following equation box. 


\section{Initial Contaminant Concentration in Three Phases}

The initial contaminant concentration in dissolved, vapor, and adsorbed phases is:

$$
C_{m c}^{s}=\left(C_{d} / \rho_{b}\right) \times\left(\theta_{w}+K_{d} \rho_{b}+\left(\theta_{t}-\theta_{w}-\theta_{m c}\right) K_{h}\right)
$$

where

$\mathrm{C}_{\mathrm{me}}^{\mathrm{s}}=$ soil contaminant concentration excluding nonaqueous phase (mg kg-1)

$\mathrm{C}_{\mathrm{d}}=$ soil water methylene chloride concentration $\left(\mathrm{mg} \mathrm{L}^{-1}\right)$ at the methylene chloride solubility limit of $15,300 \mathrm{mg} \mathrm{L}^{-1}$ (this is the maximum aqueous phase concentration)

$\rho_{\mathrm{b}} \quad=\quad$ waste bulk density $\left(1.4 \mathrm{~kg} \mathrm{~L}^{-1}\right)$

$\theta_{\mathrm{w}}=$ soil water content $(0.375$, field capacity)

$\theta_{\mathrm{t}}=$ soil porosity $(0.4)$

$\theta_{\mathrm{mc}}=$ soil free-product content (assumed 0.002 for this calculation)

$\mathrm{K}_{\mathrm{d}}=$ soil methylene chloride distribution coefficient $\left(0.01 \mathrm{~L} \mathrm{~kg}^{-1}\right)$

$\mathrm{K}_{\mathrm{h}}=$ dimensionless Henry's constant for methylene chloride (0.13) $(=41.6 \times 0.003125$, where 0.003125 is the dimensional Henry's constant shown in Table 9.2a and 41.6 is a conversion factor)

Using the appropriate data:

$$
\begin{aligned}
\mathrm{C}_{\mathrm{mc}}^{\mathrm{s}}= & \left(15,300 \mathrm{mg} \mathrm{L}^{-1} / 1.4 \mathrm{~kg} \mathrm{~L}^{-1}\right) \mathrm{x} \\
& \left(0.375+0.01 \mathrm{~L} \mathrm{~kg}^{-1}\left[1.4 \mathrm{~kg} \mathrm{~L}^{-1}\right]+[0.4-0.375-0.002] 0.13\right) \\
= & 4284 \mathrm{mg} \mathrm{kg}^{-1}
\end{aligned}
$$

The difference in mass between the total inventory and the capacity of the soil water, soil vapor, and soil solid phases is present as nonaqueous phase mass $\left(\mathrm{C}_{\mathrm{mc}}^{\mathrm{f}}\right)$, which occupies $0.5 \%$ of the pore space. The nonaqueous saturation of $0.5 \%$ is well below the 3 to $10 \%$ residual nonaqueous saturation of a nonwetting organic phase in soil and can be considered immobile (see Eqs. 9.4, 9.5, and 9.6). However, because the methylene chloride volatilizes and leaches in infiltrating water, eventually the nonaqueous phase methylene chloride, as well as other phases, are depleted over time.

The uranium-238 activity in the landfill is $6 \mathrm{Ci}$ and corresponds to a uranium-238 concentration of $379.2 \mathrm{pCi} \mathrm{g}^{-1}$. Based on a specific activity of $3.36 \times 10^{5} \mathrm{pCi}^{-1}$, the concentration of uranium-238 by weight is $1130 \mathrm{mg} \mathrm{kg}^{-1}$. (See Eqs. 9.7 and 9.8.)

\section{Fraction of Pore Space Occupied By Nonaqueous Phase}

$$
\begin{aligned}
& C_{m c}^{f}\left(m^{-1}\right)=C_{m c}^{t}\left(m g ~ k g^{-1}\right)-C_{m c}^{s}\left(m g ~ k g^{-1}\right)=6320-4284=2036 \mathrm{mg} \mathrm{kg}^{-1} \\
& \theta_{m c}=\left(C_{m c}^{f} \rho_{b}\right) / \rho_{m c}=\left(2036 \mathrm{mg} \mathrm{kg}^{-1} \times 1.4 \mathrm{~kg} \mathrm{~L}^{-1}\right) /\left(1,325,000 \mathrm{mg} \mathrm{L}^{-1}\right)=0.002 \\
& \mathrm{~S}_{m c}=\theta_{m c} \theta_{t}=0.002 / 0.4=0.005 \text { or } 0.5 \text { percent }
\end{aligned}
$$


where

$\mathrm{C}_{\mathrm{me}}^{\mathrm{f}} \quad=\quad$ concentration of methylene chloride present in free phase $\left(\mathrm{mg} \mathrm{kg}^{-1}\right)$

$\theta_{\mathrm{mc}}=$ pore volume occupied by free phase methylene chloride (volume of methylene chloride free phase divided by total volume)

$\rho_{\mathrm{me}}=$ methylene chloride liquid phase density $\left(1,325,000 \mathrm{mg} \mathrm{L}^{-1}\right)$

$\mathrm{S}_{\mathrm{mc}}=$ methylene chloride saturation (volume of methylene chloride free phase divided by pore volume)

Initial Activity and Mass Concentration of Uranium-238

The initial activity of uranium-238 is calculated from:

$$
C_{\mathrm{ai}}=\frac{\mathrm{M}_{\mathrm{i}}}{\mathrm{H}_{\mathrm{s}} \mathrm{L}_{\mathrm{s}} \mathrm{W}_{\mathrm{s}} \rho_{\mathrm{b}}}
$$

where

$\mathrm{C}_{\mathrm{ai}}=\quad$ initial activity of uranium-238 $\left(\mathrm{pCi} \mathrm{g}^{-1}\right)$

$\mathrm{M}_{\mathrm{i}}=$ initial inventory of uranium-238 expressed as activity $(\mathrm{pCi})$

$\mathrm{H}_{2}=$ source thickness (m)

$\mathrm{L}_{\mathrm{s}}=$ source length $(\mathrm{m})$

$\mathrm{W}_{\mathrm{s}}=\quad$ source width $(\mathrm{m})$

$\mathrm{C}_{\mathrm{b}}=\quad$ soil bulk density $\left(\mathrm{kg} \mathrm{m}^{-3}\right)$

Using the appropriate data, the initial activity is:

$$
\mathrm{C}_{2 \mathrm{i}}=\frac{6 \mathrm{Ci} \times 10^{12} \mathrm{pCi} \mathrm{Ci}^{-1}}{(3.8)(243.8)(12.2) \mathrm{m}^{3} \times 1,400 \mathrm{~kg} \mathrm{~m}^{-3} \times 10^{3} \mathrm{~g} \mathrm{~kg}^{-1}}=379.2 \mathrm{pCi} \mathrm{g}^{-1}
$$

The initial mass concentration of uranium-238 is then found from:

$$
C_{i}=\frac{C_{a i}}{S_{a}^{-}}
$$

where

$$
\mathrm{S}_{\mathrm{a}}=\quad \text { specific activity of uranium-238 }
$$

Using the appropriate value of specific activity, $C_{i}$ becomes:

$$
\mathrm{C}_{\mathrm{i}}=\frac{379.2 \mathrm{pCi}(\mathrm{g} \mathrm{soil})^{-1}}{3.36 \times 10^{5} \mathrm{pCi} \mathrm{g}^{-1} \mathrm{U}-238}=0.00113 \frac{\mathrm{g} \mathrm{U}-238}{\mathrm{~g} \text { soil }}=1130 \mathrm{mg} \mathrm{kg}^{-1}
$$

The wastes are assumed to have been placed into the landfill in a single year; at which time, the wastes are immediately available for release and transformation. The formation of radioactive decay 
products, subsequent to the initial disposal, is considered in both the landfill and in the environment but both RESRAD and MEPAS (MMSOILS does not simulate the decay products). Transformation of methylene chloride is not considered in either the landfill or the environment, although volatilization is considered.

The complete natural chain of uranium-238 radioactive decay is shown in Fig. 9.5. The names of all decay products, their half-lives, and main types of radiation emitted [alpha $(\alpha)$, beta $(\beta)$, or gamma $[\gamma]$ rays) are provided in the figure. The chain begins with uranium-238 and ends with stable lead-206. The decay chain includes both long-lived and short-lived decay products. After uranium-238 with a half-life $(\tau)$ of $4.46 \times 10^{9} \mathrm{yrs}$, the longest-lived element is uranium-234, and the shortest-lived element is polonium-214 ( $\tau=2.45 \times 10^{5} \mathrm{yr}$ and $\tau=164 \times 10^{-6} \mathrm{~s}$, respectively). The two models that simulate the uranium-238 decay chain (RESRAD and MEPAS) each employ different assumptions to simulate a subset of these elements. The particular assumptions used by the models are discussed in Sect. 9.2.2.

\subsubsection{Environmental media model}

The partially saturated zone located beneath the landfill consists of the remainder of the silty clay loam layer (PSZl), which is $10.4 \mathrm{~m}$ thick, and the sandy clay layer, which is $100 \mathrm{~m}$ thick. Soil properties (see Table 9.3) are assumed to be homogeneous. Landfill leachate migrates downward with the percolating soil water in the partially saturated zone, where contaminants in the leachate also sorb to the soil matrix during transport. Landfill contaminants also migrate upward through the clean soil cover by diffusion through the soil gas, and contaminants partition into the soil water and solid phases during vapor phase transport.

The saturated zone located beneath the source consists of loamy sandy materials that comprise an isotropic aquifer that is $120 \mathrm{~m}$ thick. Aquifer characteristics, given in Table 9.4, are assumed to be homogeneous, and groundwater flow in the aquifer is unidirectional at a pore-water velocity of $0.4 \mathrm{~m}$ day $^{-1}$. Contaminants enter the saturated zone with the leachate under the landfill and then are transported offsite by groundwater. Contaminants sorb to aquifer solids during transport, retarding the contaminant migration rate relative to the groundwater velocity. The effects of adsorption on uranium-238 retardation are much greater than the effects of adsorption on methylene chloride retardation because the distribution coefficient is so much greater for uranium-238.

The surface water pathway consists of a river that is $30.5 \mathrm{~m}$ wide and $3.05 \mathrm{~m}$ deep and has a mean velocity of $0.61 \mathrm{~m} \mathrm{~s}^{-1}$ (see Table 9.7). This corresponds to a mean discharge, $\mathrm{Q}$, of $56.7 \mathrm{~m}^{3} \mathrm{~s}^{-1}$, as shown in Eq. 9.9.

\section{Mean Discharge in River}

The formula for the mean discharge in the river is:

$$
\mathrm{Q}=\mathrm{W}_{\mathrm{r}} \mathrm{H}_{\mathrm{r}} \mathrm{V}_{\mathrm{v}}
$$

where

$$
\begin{array}{ll}
\mathrm{Q}= & \text { mean river discharge }\left(\mathrm{m}^{3} \mathrm{~s}^{-1}\right) \\
\mathrm{W}_{\mathrm{r}}= & \text { width of river }(\mathrm{m}) \\
\mathrm{H}_{\mathrm{r}}= & \text { depth of river }(\mathrm{m}) \\
\mathrm{V}_{\mathrm{v}}= & \text { mean river velocity }\left(\mathrm{m} \mathrm{s}^{-1}\right)
\end{array}
$$


Using the data provided previously,

$Q=30.5 \mathrm{~m} \times 3.05 \mathrm{~m} \times 0.61 \mathrm{~m} \mathrm{~s}^{-1}$

$=56.7 \mathrm{~m}^{3} \mathrm{~s}^{-1}$

The river is located $2000 \mathrm{~m}$ downgradient from the center of the source and intercepts contaminated groundwater from the source. As a conservative assumption, all contaminants and associated decay products in the groundwater are fully intercepted by the river.

The atmospheric pathway consists of flat terrain subject to the annual wind speed variations and stability class conditions given in Table 9.6. Contaminants are emitted from the landfill due to volatilization and diffusion to the surface. In addition, the overburden above the landfill is assumed to erode eventually, thereby causing contaminated particulates to be transported through the atmosphere and subsequently deposited on the ground surface soils and vegetation. Although some of the uranium-238 is eroded via surface water runoff, this pathway is not tracked. Transformation of contaminants in the atmosphere is not considered, since transport times are short. However, transformation of contaminants deposited on the ground from the atmosphere is simulated.

\subsubsection{Representation of the Scenario in Multimedia Models}

The conceptual site model is used as a basis for developing contaminant fate and transport scenarios for use in RESRAD, MMSOILS, and MEPAS. However, not all aspects of this simplified conceptual site model are incorporated into all three models. In situations where the conceptual site model deviates from model assumptions, the conceptual site model is simplified to meet the assumptions of the model. No revisions are made to the models specifically to simulate features of the source, with the exception of revisions intended to correct known coding errors. This allows the models to be evaluated based on those features that are within the control of the user community, rather than on the features that could be accessed on a case-by-case basis by the model developers. For example, none of the three models explicitly simulates the fate of the nonaqueous phase methylene chloride in the landfill. Rather, the effect of the nonaqueous phase is approximated as a contaminant source term where concentration of methylene chloride in the aqueous phase is set equal to the aqueous solubility limit.

For the multimedia benchmarking scenario, each of the models generate coupled atmospheric and groundwater source terms. For MEPAS, the coupled approach is available as a multimedia source term code. The most significant model-specific approximations and assumptions are summarized in the following sections.

\subsubsection{RESRAD assumptions}

To analyze the site, RESRAD simulates waste leaching from the soil directly into the partially saturated zone. An exponential decay model is used to simulate waste release, where the initial leachate concentration is specified at the contaminant solubility limit of $15,300 \mathrm{mg} \mathrm{L}^{-1}$ for methylene chloride and is calculated to be $5046 \mathrm{pCi} \mathrm{L}^{-1}$ for uranium-238 (see Eq. 9.10). 


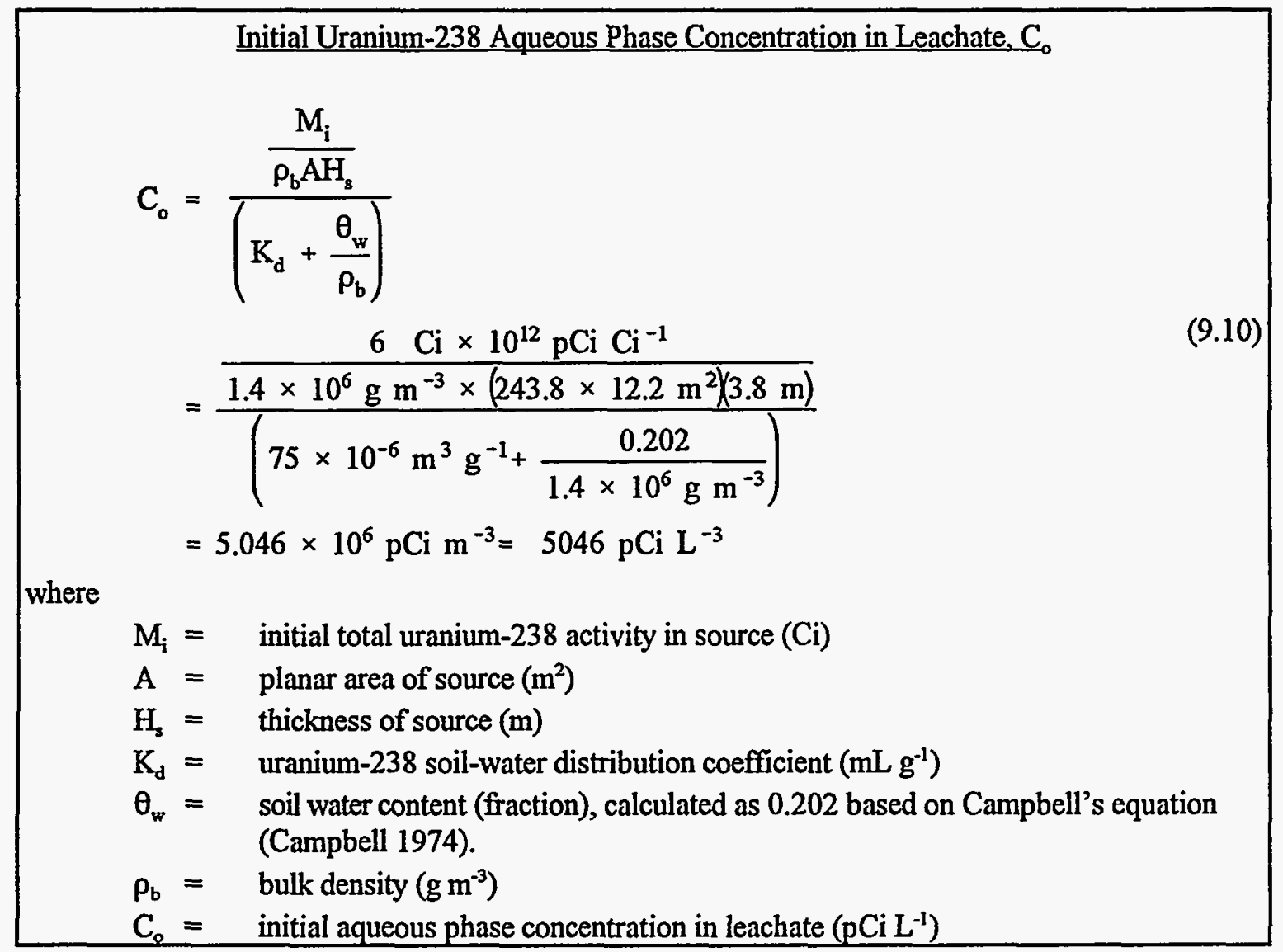

The leachate concentration at time $t$ for the first radionuclide is then calculated by RESRAD using the following first order exponential decay model:

$$
C_{d}=C_{o} \exp (-(k+\lambda) t)
$$

where

$\mathrm{C}_{\mathrm{d}}=$ leachate concentration at time $\mathrm{t}\left(\mathrm{mg} \mathrm{L}^{-1}\right.$ or $\left.\mathrm{pCi} \mathrm{L}^{-1}\right)$

$\mathrm{C}_{\mathrm{o}}=$ initial leachate concentration $\left(\mathrm{mg} \mathrm{L}^{-1}\right.$ or $\left.\mathrm{pCi} \mathrm{L}^{-1}\right)$

$\mathbf{k}=$ leach coefficient $\left(\mathrm{yr}^{-1}\right)$

$\mathrm{t}=$ time since beginning of leaching (yr)

$\lambda=$ radioactive decay constant $\left(\mathrm{yr}^{-1}\right)$

The leach rate is given by:

$$
k=\frac{q}{\theta_{w} R_{d} H_{s}}
$$

where

$R_{d}=$ retardation coefficient for uranium-238

$q=$ infiltration rate $\left(\mathrm{m} \mathrm{yr}^{-1}\right)$

$\theta_{\mathrm{w}}=$ water content (function)

$\mathrm{H}_{3}=$ source thickness 
$\mathrm{C}_{\mathrm{o}}$ can be expressed as

$$
C_{0}=\frac{M_{i}}{{A H_{s} R_{d} \theta_{w}}}
$$

which is identical to (9.10). Therefore, $\mathrm{k}$ can be re-expressed as:

$$
k=\frac{\mathrm{AqC}_{\mathrm{o}}}{\mathrm{M}_{\mathrm{i}}}
$$

The leach coefficient for uranium-238 is $3.184 \times 10^{-5} \mathrm{yr}^{-1}$, and the time for the uranium-238 concentration to decrease by half due solely to leaching is $21,800 \mathrm{yr}$, as shown in the following equation box:

\section{Leach Coefficient and Leach Half Life for Uranium-238}

Using equation 9.14:

$$
\begin{aligned}
\mathrm{k} & =\frac{(12.2 \mathrm{~m})(243.8 \mathrm{~m})\left(1.27 \times 10^{-2} \mathrm{~m} \mathrm{yr}^{-1}\right)\left(5046 \times 10^{3} \mathrm{pCi} \mathrm{L}^{-1} \times 10^{3} \mathrm{~L} \mathrm{~m}^{3}\right)}{6 \times 10^{12} \mathrm{pCi}} \\
& =3.177 \times 10^{-5} \mathrm{yr}^{-1} \\
\tau & =\frac{\ln 2}{\mathrm{k}}=\frac{\ln 2}{3.177 \times 10^{-5} \mathrm{yr}^{-1}}=21,800 \mathrm{yr}
\end{aligned}
$$

Therefore, many thousands of years are required for the uranium-238 to leach from the landfill. However, this illustrative calculation does not account for uranium-238 mass loss by erosion, as discussed in Sect. 9.4.2.1. The effect of erosion on the leachate release is allowed for by modifying Eq. $9.6 \mathrm{by} \mathrm{H}(\mathrm{t}) / \mathrm{H}(0)$. Once erosion of the source begins, the uranium loss rate is significantly higher than that due to leachate generation only.

RESRAD considers the volatilization of methylene chloride in addition to leaching by infiltrating water and erosion of the contaminated zone. Both leaching and volatilization are modeled as first order rate processes. The leach rate coefficient was computed as for uranium-238; the appropriate value of distribution coefficient in the contaminated zone was specified to ensure that the computed initial leachate concentration was at the solubility limit of methylene chloride. The emission rate during the first year, computed using a soil phase diffusion model, is used to calculate the volatilization rate coefficient. The pore vapor concentration in the contaminated zone is computed using Henry's Law constant assuming that the vapor phase is in equilibrium with the dissolved aqueous phase. The soil phase diffusion model uses the soil moisture content computed using the infiltration rate and the saturated hydraulic conductivity.

A number of additional assumptions in RESRAD are pertinent to the simulation. These include:

1. RESRAD does not simulate rivers (only ponds); therefore, the risk pathways associated with exposure to river water are not analyzed. 
2. RESRAD simulates advective transport and does not consider dispersion through the unsaturated and saturated zones, although it does include a "dilution factor" in the saturated zone to account for dispersion in the lateral direction.

3. A transfer function approach is used to calculate decay product concentration in unsaturated and saturated zones. This approach can accommodate different properties of the transformation products, such as different soil-water distribution factors $\left(\mathrm{K}_{\mathrm{D}} \mathrm{s}\right)$.

4. Soil erosion and entrainment is simulated above the landfill by specifying an erosion rate, which results in eventual exposure of uranium-238 to the surface and subsequent transport through the atmosphere. While soil removal from the source is considered, the approach does not accommodate deposition of particles at the source from upwind locations.

5. In contrast to the complete uranium-238 decay chain shown in Fig. 9.5, RESRAD typically simulates the following subset for fate and transport calculations:

uranium-238 $\rightarrow$ uranium-234 $\rightarrow$ thorium-230 $\rightarrow$ radium-226 $\rightarrow$ lead-210 $\rightarrow$ lead-206 (stable)

RESRAD also has the option to simulate the fate and transport of polonium-210, a progeny of lead210 , if the user specifies a cutoff half-life of 30 days instead of the default of 6 months. This feature was used for the multimedia scenario, and the transformation chain used to simulate fate and transport is:

$\begin{aligned} & \text { uranium-238 } \rightarrow \text { uranium-234 } \\ & \rightarrow \text { thorium-230 } \rightarrow \text { radium-226 } \\ & \text { lead-206 (stạble) }\end{aligned}$

The remaining decay products are assumed to be in secular equilibrium with their long-lived parent radionuclide and are discussed in Sect. 9.4.1. Furthermore, RESRAD does accommodate the possible radiological impacts of the radionuclides whose fate and transport are not explicitly simulated by incorporating their effects, if any, in dose and risk factors of their long-lived parent radionuclides that are simulated.

\subsubsection{MMSOILS assumptions}

MMSOILS simulates a landfill that leaches directly into the partially saturated zone, with a constant leachate concentration specified at the contaminant solubility limit of $15,300 \mathrm{mg} \mathrm{L}^{-1}$ for methylene chloride. The leachate concentration for uranium-238 is specified at $5057 \mathrm{pCi} \mathrm{L}^{-1}$ based on soil-water partitioning. The fluxes to the partially saturated zone are $578,000 \mathrm{~g} \mathrm{yr}^{-1}$ for methylene chloride (see Fig. 9.6) and $1.91 \times 10^{8} \mathrm{pCi} \mathrm{yr}^{-1}$ for uranium-238 (see Fig. 9.7) (the following equation box shows the calculations). 
Initial Methylene Chloride and Uranium-238 Leachate Mass Fluxes

The initial methylene chloride and uranium-238 leachate fluxes are calculated as:

$$
\dot{M}=W_{s} L_{s} q C_{i}
$$

where

$\dot{M}=$ initial flux of methylene chloride $\left(\mathrm{g} \mathrm{yr}^{-1}\right)$ or uranium-238 $\left(\mathrm{pCi} \mathrm{yr}^{-1}\right)$

$\mathrm{W}_{\mathrm{s}}=$ source width $(\mathrm{m})$

$\mathrm{L}_{\mathrm{s}}=\quad$ source length $(\mathrm{m})$

$\mathrm{q}=$ infiltration rate $\left(\mathrm{m} \mathrm{yr}^{-1}\right)$

$\mathrm{C}_{\mathrm{i}}=$ aqueous leachate concentration $\left(\mathrm{mg} \mathrm{L}^{-1}\right.$ for methylene chloride, or $\mathrm{pCi} \mathrm{L}^{-1}$ for uranium-238)

Using this formula, the calculated contaminant fluxes are:

$$
\begin{aligned}
& \dot{M}=\frac{\left(12.2 \mathrm{~m} \times(243.8 \mathrm{~m})\left(0.0127 \mathrm{~m} \mathrm{yr}^{-1}\right)\left(15,300 \mathrm{mg} \mathrm{L}^{-1}\right)\right.}{\left(0.001 \mathrm{~m}^{3} \mathrm{~g}^{-1}\right)\left(10^{3} \mathrm{mg} \mathrm{L}^{-1}\right)} \\
& =578,000 \mathrm{~g} \mathrm{yr}^{-1} \text {, methylene chloride } \\
& \dot{\mathrm{M}}=(12.2 \mathrm{~m})(243.8 \mathrm{~m})\left(0.0127 \mathrm{~m} \mathrm{yr}^{-1}\right)\left(5,057 \mathrm{pCi} \mathrm{L}^{-1}\right)\left(10^{3} \mathrm{~L} \mathrm{~m}^{3}\right) \\
& =1.91 \times 10^{8} \mathrm{pCi} \mathrm{yr}^{-1} \text {, uranium-238 }
\end{aligned}
$$

For each contaminant, MMSOILS calculates the duration of leachate generation from the total contaminant inventory, the annual leachate contaminant flux rate, and the annual atmospheric flux rate.

Atmospheric emissions of methylene chloride are estimated using a soil vapor phase diffusion model that assumes the methylene chloride is initially at its saturated vapor pressure. The atmospheric flux is time variable because the vapor phase concentration eventually decreases with time. The leaching and air emissions for MMSOILS are coupled such that a contaminant inventory mass balance is maintained between the atmospheric and groundwater emissions. MMSOILS does not consider the erosion of the clean soil cover and subsequent suspension and erosion of the buried waste; therefore, there are no uranium-238 emissions from the landfill. Decay products of uranium-238 are not analyzed because MMSOILS does not simulate the radioactive decay chain. However, source decay of uranium-238 was considered.

A number of additional assumptions in MMSOILS are pertinent to the simulation. These include:

1. Although the landfill is actually rectangular in shape, MMSOILS requires a square source area; therefore, the landfill is simulated as a square source with the correct surface area. Distances from the center of the square source to the receptors are calculated so that the distance from the source boundary to the receptor matches the data.

2. For organic contaminants, MMSOILS calculates the soil-water distribution coefficient from the product of the organic carbon distribution coefficient and the fraction of organic carbon on the soil matrix $\left(f_{o c}\right)$. However, the organic carbon content, specified as zero, is not consistent with the specified $\mathrm{K}_{\mathrm{d}}$. To remedy this conflict for methylene chloride, values of $f_{o c}$ are modified to produce 
the appropriate $\mathrm{K}_{\mathrm{d}}$ for each layer, according to the problem specification; these values are shown in Table 9.3.

3. MMSOILS does not accept atmospheric stability data for stability class $\mathrm{G}$, so values for stability class $\mathrm{G}$ are added to those for stability class $\mathrm{F}$.

4. The initial moisture content in the landfill waste layer is user-specified. To be consistent with MEPAS, the initial moisture content of the waste is specified to be at field capacity. However, for the overburden above the landfill, the initial moisture content is presently specified internally in MMSOILS to equal zero. This assumption results in a lag time for the generation of leachate, while the landfill cover absorbs infiltrating water.

5. MMSOILS simulates dissolved phase contaminant decay but not adsorbed phase contaminant decay in the saturated zone. For radionuclides, which decay in both phases, it is possible that MMSOILS could overpredict concentrations at significant travel times from the source. For this application, MMSOILS is applied to uranium-238, which has a half-life much longer than the time frame simulated, so the effects are minimal.

6. The saturated zone contaminant transport model uses effective porosity to calculate both retardation and pore water velocity.

7. The field capacity of PSZ1 and PSZ2 must be identical; 0.375 is used.

8. For offsite soils, MMSOILS uses a soil bulk density of $1500 \mathrm{~kg} \mathrm{~m}^{-3}$ and a mixing depth of $0.1 \mathrm{~m}$; areal soil density is not separately specified.

\subsubsection{MEPAS assumptions}

MEPAS simulates aqueous phase waste leaching directly to the partially saturated zone and vapor phase diffusion through the clean soil cover. Initial leachate concentration is specified at the contaminant solubility limit of $15,300 \mathrm{mg} \mathrm{L}^{-1}$ for methylene chloride; an initial uranium-238 leachate concentration of $4440 \mathrm{pCi} \mathrm{L}^{-1}$ is specified based on soil-water partitioning. The constant flux to the partially saturated zone is $578,000 \mathrm{~g} \mathrm{yr}^{-1}$ for 173 yrs for methylene chloride, and the initial flux for uranium-238 is $1.67 \times 10^{8} \mathrm{pCi} \mathrm{yr}^{-1}$. For each contaminant, the duration of leachate generation was estimated from the total contaminant inventory, the leachate contaminant flux rate, and the volatilization contaminant flux rate.

The MEPAS multimedia source option for coupled computation of emissions to air and leaching to groundwater is used. Atmospheric emissions of methylene chloride are estimated using a soil vapor phase diffusion model, assuming the methylene chloride is at its saturated vapor pressure. Dust and contaminant emission rates may be input or computed by MEPAS. For this scenario, the option to compute the uranium-238 emission rate based on site characteristics is used. Decay products of uranium-238 are simulated in the source and in the environment. Initial concentrations of decay products are assumed to be zero.

A number of additional assumptions in MEPAS are pertinent to the simulation:

1. MEPAS uses a set of EPA recommended dispersion curves that do not include dispersion curves for stability class G. Instead, MEPAS accepts stability class $G$ data and models those entries as stability class F. MEPAS accounts for the influence of the local surface cover on dispersion and 
deposition and therefore requires the definition of the surface characteristics for the contaminated site, region, and wind measurement sites.

2. Decay product concentrations are calculated by the Bateman approach (Bateman 1910). In the MEPAS groundwater transport model, the decay products are transported at the same velocity as the parent (uranium-238 in this scenario), so that certain contaminant-specific properties, such as retardation due to sorption, are only required for the parent radionuclide.

3. The initial unsaturated zone water content of the landfill cover is assumed to equal field capacity; therefore, leachate generation from the source is assumed to begin at time zero.

4. The following uranium-238 decay chain is simulated:

uranium-238 $\rightarrow$ thorium-234 $\rightarrow$ uranium-234 $\rightarrow$ thorium-230 $\rightarrow$ radium-226 $\rightarrow$ radon-222 $\rightarrow$ lead-210 $\rightarrow$ bismuth-210 $\rightarrow$ polonium-210 $\rightarrow$ lead-206 (stable)

\subsection{BENCHMARKING RESULTS AND DISCUSSION FOR RESRAD, MMSOILS, AND MEPAS}

Comparative endpoints for the multimedia scenario are summarized in Table 9.10. The results are presented in Tables 9.11 through 9.21 and Figs. 9.6 through 9.32 and are discussed in the following sections. Benchmarking results are presented by medium for the unsaturated and saturated zones, the atmosphere, and the surface water. Within each medium, contaminant transport results and then risks are presented. Finally, the risks to two receptors exposed to contaminants via multimedia pathways are summarized to provide a concise comparison between model predicted risks.

\subsubsection{Unsaturated and Saturated Zone Pathway}

Since the contaminants are originally placed in a landfill in the unsaturated zone, the contaminants must migrate through the remaining vadose zone below the landfill before they reach the water table. Although human exposure to contaminants does not occur in the unsaturated zone, this medium must be simulated before contaminant migration through the saturated zone can be simulated.

\subsubsection{Unsaturated zone}

For the unsaturated zone, benchmarking results consist of:

- $\quad$ advective travel times of contaminants through PSZ1 and PSZ2 (Table 9.11) (the definition of advective travel time was presented previously in Table 5.5) and

- contaminant fluxes from the waste management unit to PSZ1, fluxes from PSZ1 to PSZ2, and fluxes from PSZ2 to SZ (Figs. 9.6 through 9.16).

As shown in Table 9.11, the advective travel times of contaminants through PSZ1 and PSZ2 are relatively comparable for two of the models (MEPAS and MMSOILS). RESRAD predictions are significantly lower (by a factor of 4 ).

The travel times for MMSOILS and MEPAS are practically the same because $\theta_{w}$ and $\theta_{\mathrm{fc}}$ are small compared to the product $\rho_{b} K_{D}$ for uranium-238; therefore, the calculation for retardation is dominated 
by $p_{b} K_{D}$. RESRAD multiplies the travel time formula used by MMSOILS by the ratio of effective porosity to total porosity. This multiplication significantly changes predicted travel times and is the primary reason for the difference of a factor of 4 between RESRAD and the other two models. Percent differences between MMSOILS and MEPAS travel time predictions are greater for methylene chloride than for uranium-238 because the distribution coefficient is small $\left(0.01 \mathrm{~mL} \mathrm{gm}^{-1}\right)$; therefore, the moisture content differences are more important. Advective travel time calculations through PSZ1 are shown in the following equation box.

\section{Advective Travel Time Calculations Through PSZ1}

The formulas presented previously in Table 5.5 are used in this calculation to demonstrate how those formulas produce different estimates of travel time. The moisture content $\left(\theta_{w}\right)$ in PSZI is first calculated from a relationship developed by Campbell (1974) and used by all of the models:

$$
\theta_{w}=\theta_{t}\left(\frac{q}{K_{s}}\right)^{m}
$$

where

$$
\begin{aligned}
& \theta_{\mathrm{t}}=\text { total porosity } \\
& \mathrm{q}=\text { infiltration rate }\left(\mathrm{m} \mathrm{yr}^{-1}\right) \\
& \mathrm{m}=\frac{1}{2 \mathrm{~b}+3} \\
& \mathrm{~b}=\text { coefficient of moisture retention } \\
& \mathrm{K}_{\mathrm{s}}=\text { saturated hydraulic conductivity }\left(\mathrm{m} \mathrm{yr}^{-1}\right)
\end{aligned}
$$

For PSZ1, $b=7.75, K_{z}=4018 \mathrm{~m} \mathrm{yr}^{-1}, q=0.0127 \mathrm{~m} \mathrm{yr}^{-1}$, and $\theta_{\mathrm{t}}=0.486$. Therefore, $\mathrm{m}=0.0541$, and

$$
\theta_{w}=0.486\left(\frac{0.0127}{4018}\right)^{0.0541}=0.2449
$$

RESRAD calculates the travel time as (see Eq. 5.14)

$$
T_{\text {RESRAD }}=\frac{H R_{f}}{V_{P}}=\left(\theta_{w}+\rho_{b} K_{d}\right)\left(\frac{H}{q}\right)\left(\frac{\theta_{c}}{\theta_{t}}\right)
$$

where

$H=$ travel distance through PSZ1, m (see Fig. 9.1)

$\mathrm{R}_{\mathrm{f}}=$ retardation coefficient

$\mathrm{V}_{\mathrm{p}}=$ pore water velocity

For PSZ1 and uranium-238:

$$
\rho_{b}=1400 \mathrm{~kg} \mathrm{~m}^{-3}, \mathrm{~K}_{\mathrm{d}}=75.0 \mathrm{~mL} \mathrm{gm}^{-1}, \mathrm{H}=10.4 \mathrm{~m}, \theta_{\mathrm{c}}=0.12, \theta_{\mathrm{t}}=0.486
$$

so

$$
\mathrm{T}_{\text {RESRAD }}=[0.2449+(1.4)(75)]\left(\frac{10.4}{0.0127}\right)\left(\frac{0.12}{0.486}\right)=21,300 \mathrm{yrs}
$$


The travel time formula used by MMSOILS is the same as for RESRAD, except $\theta_{c}=\theta_{\mathrm{i}}$ :

$$
\mathrm{T}_{\text {MMSOILS }}=[0.2449+(1.4)(75)]\left(\frac{10.4}{0.0127}\right)=86,200 \mathrm{yrs}
$$

For MEPAS, Eq. 5.17 in Chapter 5 is applicable since the water content $(0.2449)$ is less than the specified field capacity $(0.375)$ :

$$
\mathrm{T}_{\text {MEPAS }}=\left(\theta_{\mathrm{fc}}+\rho_{\mathrm{b}} \mathrm{K}_{\mathrm{D}}\right)\left[\frac{\mathrm{H}}{\mathrm{q}}\right]=[0.375+(1.4)(75)]\left[\frac{10.4}{0.0127}\right]=86,300 \mathrm{yrs}
$$

The predicted contaminant fluxes that leach from the landfill are shown in Fig. 9.6 for methylene chloride and in Figs. 9.7 and 9.12 through 9.16 for the radionuclides. As shown in Fig. 9.6, the peak fluxes, the leaching duration, and the times to peak differ for the three models. Since the total mass leached is the area under the flux versus time plot, MEPAS predicts more mass leached than either RESRAD or MMSOILS. This is because MEPAS predicts that nearly $92 \%$ of the mass of methylene chloride is leached with the infiltrating water, while both RESRAD and MMSOILS predict that vapor phase transport of the volatile contaminant to the atmosphere account for most of the total inventory. These differences are due to different assumptions and different algorithms used by the models.

Both RESRAD and MEPAS predict that peak leachate fluxes occur immediately following the beginning of leachate generation, whereas for MMSOILS a lag period of approximately 24 yrs occurs before methylene chloride begins to leach. The reason for the 24-yr delay is because MMSOILS assumes the moisture content in the $0.8 \mathrm{~m}$ overburden is initially zero, whereas RESRAD and MEPAS both assume the moisture content is high enough that leaching occurs immediately (RESRAD assumes the water content is at its steady state value, as predicted by the Campbell equation; MEPAS assumes the moisture content is at field capacity). MMSOILS requires the moisture content to reach field capacity before leaching begins, so that a lag period of 23.6 yrs occurs. The calculations are presented in the following equation box.

\section{$\underline{\text { Lag Period Calculations for MMSOILS }}$}

The time required for the soil layer above the source to fill to field capacity, assuming an initially dry condition, is:

$$
T_{\text {lgg }}=\frac{H_{a} \theta_{f c}}{q}
$$

where

$$
\begin{array}{ll}
\mathrm{H}_{\mathrm{a}}= & \text { thickness of fill above the source }(\mathrm{m}) \\
\theta_{\mathrm{fc}}= & \text { moisture content at field capacity (dimensionless) } \\
\mathrm{q}= & \text { infiltration rate }\left(\mathrm{m} \mathrm{yr}^{-1}\right)
\end{array}
$$

For this application, $\mathrm{H}=0.8 \mathrm{~m}, \theta_{\mathrm{fc}}=0.375$, and $\mathrm{q}=0.0127 \mathrm{~m} \mathrm{yr}^{-1}$, so:

$$
\mathrm{T}_{\mathrm{lag}}=\frac{(0.8)(0.375)}{0.0127}=23.6 \mathrm{yrs}
$$

This 23.6-yr lag pertains to all contaminants and is independent of the retardation coefficient. For example, the same lag is shown in Fig. 9.7 for uranium-238, which adsorbs much more strongly than 
methylene chloride (as contrasted by their soil-aqueous distribution coefficients in the landfill of $75.0 \mathrm{~mL} \mathrm{gm}^{-1}$ and $0.01 \mathrm{~mL} \mathrm{gm}^{-1}$, respectively).

RESRAD, in contrast to both MMSOILS and MEPAS, assumes the contaminant concentration of leachate from the landfill decreases exponentially with time, as discussed previously in Sect. 9.2.2.1. This assumption results in an exponential shape of the flux versus time curve because the flux is proportional to concentration:

$$
\dot{M}=C_{d} q A
$$

where

$$
\begin{aligned}
& \left.\dot{\mathrm{M}}=\text { contaminant flux (mg } \mathrm{yr}^{-1} \text { or } \mathrm{pCi} \mathrm{yr}^{-1}\right) \\
& \mathrm{C}_{\mathrm{d}}=\text { leachate concentration }\left(\mathrm{mg} \mathrm{L}^{-1} \text { or } \mathrm{pCi} \mathrm{L}^{-1}\right) \\
& \mathrm{q}=\text { infiltration rate }\left(\mathrm{m} \mathrm{yr}^{-1}\right) \\
& \mathrm{A}=\text { planar area of source }\left(\mathrm{m}^{2}\right)
\end{aligned}
$$

\section{Because both $q$ and $A$ are constant, $\dot{M}$ is proportional to $C_{d}$.}

For this application, both MMSOILS and MEPAS assume that the methylene chloride leachate concentration remains constant over the duration of the release, and the concentration is specified to be the solubility limit of methylene chloride (see Sect. 9.2.2.2 for a more detailed discussion). Therefore, the flux is constant until all mass is leached; thereafter the flux is zero. In reality, once the free phase is depleted, assuming all other conditions remain constant, the concentration that leaches will begin to diminish over time. The duration of leaching is significantly affected by volatilization (as shown in Fig. 9.6) because the volatile fluxes of the methylene chloride from the landfill are significant. RESRAD and MMSOILS predict that the methylene chloride is depleted in approximately $80 \mathrm{yrs}$ and $60 \mathrm{yrs}$, respectively, in comparison to MEPAS predictions (more than 150 yrs). See Sect. 9.3.2.1 for further discussion on methylene chloride volatilization.

Figure 9.7 shows the predicted uranium-238 leachate flux from the landfill to PSZ1 for the three models. The RESRAD flux curve is still exponential (as it was in Fig. 9.6), but it does not appear exponential because the horizontal axis is logarithmic. In contrast to Fig. 9.6, which shows that MEPAS predicts the largest mass of leachate for methylene chloride, MMSOILS predicts the largest mass of leachate for uranium-238. MMSOILS predicts that all the uranium-238 will leach because it is the only model that does not account for resuspension or erosion of soil containing uranium-238.

The fluxes of methylene chloride through the unsaturated zones PSZ1 to PSZ2 and PSZ2 to SZ are shown in Figs. 9.8 and 9.9, respectively. The RESRAD-predicted fluxes appear as spikes; however, in reality, they are exponentially decaying curves similar to those depicted in Fig. 9.6. The RESRAD curves in Figs. 9.8 and 9.9 are similar to the curve in Fig. 9.6, except that the curves are translated in time according to the travel time, shown in Table 9.11.

In contrast to RESRAD, MMSOILS and MEPAS flux curves change from a top-hat shape to a bell shape because of dispersion. Therefore, the peak values are less than they are at the landfill, and the durations of fluxes through the PSZ1-PSZ2 and PSZ2-SZ interfaces are longer. Although the peak flux rates of methylene chloride from the landfill are the same for both MMSOILS and MEPAS, the peak fluxes are different in the unsaturated zone, primarily due to the difference in the release durations combined with the effect of dispersion. 
The times required for the peak fluxes predicted by MMSOILS and MEPAS to reach the PSZ1-PSZ2 interface are comparable to, but not exactly equal to, the advective travel times shown in Table 9.11. The time to peak is affected by factors, such as source duration and dispersion, that are not considered in the advective travel time calculations.

Flux curves for uranium-238 are shown in Figs. 9.10 and 9.11 . The time scales are significantly longer than for methylene chloride because uranium-238 adsorbs to the soil matrix, effectively slowing its rate of migration through the unsaturated zone. Once again the RESRAD-predicted flux appears as a spike, although the release duration is nearly 5000 yrs. As expected, the flux of uranium-238 predicted by MMSOILS is significantly greater than the flux predicted by MEPAS.

As uranium-238 migrates through the unsaturated zone, it decays to its progeny at a rate that corresponds to a half-life of $4.46 \times 10^{9}$ yrs (see Table $9.2 \mathrm{a}$ ). The residence time of uranium-238 in the unsaturated zone is too short for decay to influence the uranium-238 flux rates significantly. However, progeny of uranium-238 do form during this time. Flux rates of the progeny, as predicted by RESRAD, are shown in Figs. 9.12 through 9.16. The three curves in these figures denote fluxes from the landfill, from PSZ1 to PSZ2, and from PSZ2 to SZ. Neither MMSOILS nor MEPAS predicts these fluxes.

For each of the progeny, the fluxes increase with distance from the landfill. For example, the peak

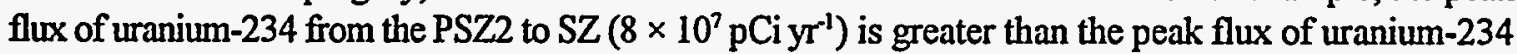
from the PSZ1 to PSZ2 $\left(1 \times 10^{7} \mathrm{pCi} \mathrm{yr}^{-1}\right)$, which in turn is greater than the peak flux of uranium-234 from the landfill $\left(7 \times 10^{5} \mathrm{pCi} \mathrm{yr}^{-1}\right)$. This is because progeny are being generated over time, and RESRAD does not disperse the peak flux. In addition, the flux duration increases with travel distance for a number of the progeny (e.g., thorium-230), due to their continuous formation and the differences between the travel velocities of the progeny and parents. Therefore, for example, because thorium- 230 travels slower than its parents (uranium-238 and uranium-234) in PSZ1, it will break through into PSZ2 along with the uranium nuclides at 21,300 yrs (Table 9.11). It will continue to cross the PSZ1-PSZ2 interface until the thorium-230 that left the contaminated zone, just before it was completely eroded away in year 4600 , reaches the interface in 27,300 yrs $(4,600+22,700)$. Similarly, the first thorium-230 to break through from PSZ2 into the saturated zone at year 173,000 would have traversed PSZ1 as uranium-238 and uranium-234 (21,300 yr), transformed into thorium-230 at the PSZ1-PSZ2 interface, and then traversed PSZ2 (152,000 yr). Thorium flux into the saturated zone continues until year 208,000 when the uranium that left the contaminated zone just before it eroded away reaches the water table and transforms into thorium-230 $(4600+21,300+182,000)$.

For some of the progeny (radium-226, lead-210, and polonium-210), the time when the peak fluxes occur are greatly in excess of their travel times. For radium-226, for example, the peak flux at the PSZ2-SZ interface occurs about 200,000 yrs following its release from the landfill (see Fig. 9.14), but the advective travel time to that location is about 52,000 yrs (see Table 9.11). The fact that the flux of radium-226 continues to increase at times later than the advective travel time is due to the arrival of thorium-230, the immediate parent of radium-226 at about 175,000 yrs, and finally the arrival of uranium-234 and uranium-238 at about 200,000 yrs.

The effects of the different approaches and assumptions used by the models have a significant effect on the comparative groundwater concentrations. These results are discussed in the following section. 


\subsubsection{Saturated zone}

The saturated zone benchmarking endpoints are as follows:

- Time to peak concentrations for all contaminants at onsite and offsite wells (Table 9.12).

- Maximum contaminant concentrations at onsite and offsite wells (Table 9.13).

- Maximum dose and risk to onsite and offsite receptors (Table 9.14).

- Contaminant concentration time series in groundwater at onsite and offsite wells (Figs. 9.17 through 9.26).

The times-to-peak concentrations in the groundwater (Table 9.12) follow the same general pattern as in the unsaturated zone: RESRAD predicts shorter times to peak than either MMSOILS or MEPAS, which generally predict times that agree with each other. The RESRAD-predicted times to peak for methylene chloride and uranium-238 are very close to the total travel time through the unsaturated zone. For methylene chloride, the advective contaminant travel time through the unsaturated zone is 653 yrs. The time to peak concentration at the saturated zone well is $657 \mathrm{yrs}$, which is a difference of only 4 yrs (calculations are presented in the following equation box).

\section{Advective Travel Time Calculations of RESRAD for Methylene Chloride}

$\begin{array}{ll}\text { Zone } & \text { Time } \\ \text { PSZ1 } & 52 \mathrm{yrs} \\ \text { PSZ2 } & 601 \mathrm{yrs} \\ \text { Total: } & 653 \mathrm{yrs}\end{array}$

$$
T_{g w}=\frac{D R_{d}}{V_{P}}=\frac{D}{V_{P}}\left(1+\frac{\rho_{b} K_{D}}{\theta_{t}}\right)
$$

where

$\mathrm{T}_{\mathrm{gw}}=$ travel time in saturated zone (yrs)

$R_{d}=$ retardation coefficient

$\mathrm{D}=$ distance to well from upgradient source boundary (m) $366+1 / 2(243.8)$

$\mathrm{V}_{\mathrm{p}}=$ pore water velocity $\left(0.4 \mathrm{~m} \mathrm{~d}^{-1}\right)$

$\mathrm{K}_{\mathrm{D}}=$ distribution coefficient for methylene chloride in $\mathrm{SZ}\left(0.005 \mathrm{~mL} \mathrm{~g}^{-1}\right)$

$\rho_{\mathrm{b}}=$ soil bulk density in $\mathrm{SZ}\left(1.5 \mathrm{~g} \mathrm{~mL}^{-1}\right)$

$\theta_{\mathrm{t}}=$ total soil porosity in $\mathrm{SZ}(0.43)$

Therefore,

$$
\begin{aligned}
T_{\mathrm{gw}} & =\frac{366+(0.5)(243.8)}{0.4 \times 365}\left(1+\frac{(0.005)(1.5)}{0.43}\right) \\
& =3 \mathrm{yrs}
\end{aligned}
$$


The RESRAD-predicted travel time through the saturated zone for the peak concentrations to reach the receptor wells is small compared to the travel time through the unsaturated zone. The same statement is true for MMSOILS and MEPAS: the time to peak at both onsite and offsite wells is dominated by the time required for the chemicals to migrate through the unsaturated zone, rather than through the groundwater. Furthermore, the additional time to peak from the onsite well to the offsite well is small. The incremental distance between wells is $670 \mathrm{~m}-366 \mathrm{~m}=304 \mathrm{~m}$. The groundwater pore water velocity is $0.4 \times 365=146 \mathrm{~m} \mathrm{yr}^{-1}$, the distribution coefficient for uranium-238 is $30 \mathrm{~mL} \mathrm{~g}^{-1}$ (typical of many of the radionuclides, as shown by the data in Tables $9.2 \mathrm{a}$ and 9.2b), and the retardation coefficient is 105 . The incremental time to peak predicted by RESRAD is about 200 yrs for the radionuclides; this is not shown in Table 9.12 due to roundoff of the travel times to the nearest thousand years. For the other two models, the same time estimates are given for peak concentrations at the onsite and offsite wells (Table 9.12). The effects of dispersion operating over so many years has dispersed the peaks so that predictions of time-to-peak concentrations at the two wells appear to be virtually the same. The calculation is presented in the following equation box.

Typical Advective Travel Time Through the Groundwater to Onsite Well for Radionuclides

Using the advective travel time formula for RESRAD reported in Table 5.5 applied to the saturated zone where $\mathrm{N}_{0}=\mathrm{n}$ :

$$
T=\left(\theta_{w}+\rho_{b} K_{D}\right) \frac{X}{\theta_{c} V_{p}}
$$

where

$$
\begin{aligned}
& \mathrm{T}=\text { advective travel time }(\mathrm{yr}) \\
& \theta_{\mathrm{w}}=\text { moisture content (fraction) } \\
& \rho_{\mathrm{b}}=\text { soil bulk density }\left(\mathrm{kg} \mathrm{m}^{-3}\right) \\
& \theta_{\mathrm{c}}=\text { effective porosity (fraction) } \\
& \mathrm{V}_{\mathrm{p}}=\text { pore water velocity }\left(\mathrm{m} \mathrm{yr}^{-1}\right) \\
& \mathrm{X}=\text { travel distance }
\end{aligned}
$$

The typical advective travel time between wells is:

$$
\mathrm{T}=(0.43+(1.5) 30) \frac{104}{(0.18)(146)}=180 \mathrm{yrs},
$$

approximately the travel time predicted by RESRAD.

For a specified location, RESRAD predicts that the time-to-peak concentrations for all the radionuclides will be approximately the same. A similar statement holds for MEPAS. For RESRAD, the peak concentrations occur approximately when the uranium-238 concentration peaks, although the radionuclides are traveling at different speeds due to different distribution coefficients (see Table 9.2b). For MEPAS, all radionuclides travel at the same speed (see Table 9.2b), and the calculations of progeny 
concentrations are based on the Bateman equations (Bateman 1910), discussed subsequently in more detail.

The peak concentrations predicted by the three models are shown in Table 9.13 at the onsite and offsite wells. Complete time series concentration plots for all the contaminants are shown in Figs. 9.17 through 9.26. Visual observation of these plots confirm that for each model peak concentrations occur at about the same time in the onsite and offsite wells and that RESRAD predicts earlier arrival of contaminants.

The concentrations predicted by both MMSOILS and MEPAS are located at the surface of the water table and are not averaged over the screen length. Furthermore, the flow field around the well is assumed to be completely undisturbed by the well (essentially the well is assumed not to be pumping). Both MMSOILS and MEPAS include vertical dispersion so the vertical extent of contamination increases with travel distance (until complete vertical mixing is attained).

The peak concentration reported by RESRAD is not located at the water table but is integrated over the well screen interval, since the actual plume thickness predicted by RESRAD is only $0.126 \mathrm{~m}$ [see Fig. K.1 in Yu et al. (1993)] and does not change with travel distance. However, since the plume is assumed to be moving slowly downward in the aquifer, the location of the contaminated zone on the well screen changes with travel distance. However, because the slope is only $2.75 \times 10^{-2}$ degrees (as calculated from the inverse tangent of groundwater-specific discharge divided by the infiltration rate), the plume is intercepted by both wells in the top meter of the screen. The pumping rate of the well does affect the concentration reported by RESRAD, in contrast to the other two models. However, at the pumping rate used $\left(250 \mathrm{~m}^{3} \mathrm{yr}^{-1}\right)$, the extracted concentration in the well is nearly independent of the well pumping rate. For more information on how the pumping well in RESRAD is simulated, refer to Yu et al. (1993).

As shown in Table 9.13, RESRAD generally predicts higher peak concentrations for both methylene chloride and the radionuclides than do the other two models. It is not surprising that the RESRAD peak is the highest since RESRAD does not include the concentration attenuating mechanism of dispersion, but the other two models do. However, RESRAD-predicted concentrations do decrease with distance, even without the effects of either vertical dispersion or decay but due solely to dilution in the lateral direction.

For methylene chloride, the peak concentrations predicted by MEPAS at both the onsite and offsite wells exceed those predicted by MMSOILS by a factor of 4 , although both models solve similar advection dispersion equations. MMSOILS, however, predicts that a larger fraction of the methylene chloride volatilizes than does MEPAS ( $84 \%$ vs. $8 \%$ ), leaving a much smaller mass (relative to MEPAS) released to the groundwater. The time series plots of methylene chloride in the groundwater presented in Fig. 9.17 show the results more clearly.

For the radionuclides, MMSOILS predicts only uranium-238 activity (it does not predict activities of decay products). Although MMSOILS considers only dissolved phase decay of radionuclides, it is not likely that the activity of uranium-238 is affected due to the short time frame relative to the half-life. For uranium-238, MMSOILS predicts activities that are about 10 times higher than MEPAS, as shown in Table 9.13. The time series plots are shown in Fig. 9.18. As discussed previously, MMSOILS predicts that all $6 \mathrm{Ci}$ of uranium-238 leach from the landfill, whereas MEPAS predicts $0.7 \mathrm{Ci}$ leaches. The remainder (approximately 5.3 Ci) is removed from the source by atmospheric entrainment of contaminated soil and subsequent migration through the atmosphere. 
For the MEPAS-predicted decay products, Table 9.13 shows that the peak uranium-238 activity $\left(0.064 \mathrm{pCi} \mathrm{L}^{-1}\right.$ at the onsite well) is the same as the first decay product, thorium-234. Similarly, the activities of the remaining decay products are nearly the same (e.g., the activities of radium-226 and radon-222 are $0.055 \mathrm{pCi} \mathrm{L}^{-1}$ at the onsite well). To explain how MEPAS predicts uranium-238 and progeny in the groundwater, the results for the onsite well are used (Table 9.13).

The uranium-238 activity is calculated from the three-dimensional advection-dispersion equation, using the appropriate data for uranium-238. However, for the uranium-238 progeny, MEPAS no longer uses the transport equations. Rather, Bateman's equations are used based on first having calculated the uranium-238 activity. Solutions to Bateman's equations for uranium-238 and progeny (thorium-234, uranium-234, thorium-230, radium-226, radon-222, lead-210, bismuth-210, polonium-210, and lead-206) are shown in Figs. 9.27a through 9.27e. Lead-206 is the terminal element in the uranium-238 decay chain and is not radioactive. The plots are all based on an initial activity of $1.0 \mathrm{pCi} \mathrm{L}^{-1}$ for uranium-238 and an initial activity of $0.0 \mathrm{pCi} \mathrm{L}^{-1}$ for the progeny $\left(1 \mathrm{pCi} \mathrm{L}{ }^{-1}\right.$ is chosen as a reference level and is not the actual concentration used in the benchmarking scenario). The plots show times to $10,000,000$ yrs, sufficient for the analysis in this example.

Although the uranium-238 activity appears to be constant over the time frame shown (Fig. 9.27a), in fact, uranium-238 is decaying at a rate in accordance with its half-life of $4.46 \times 10^{9} \mathrm{yr}$. Therefore, its activity appears to be constant (see plot) due to the short time frame $\left(10^{7} \mathrm{yr}\right)$ relative to its half-life. Figure $9.27 \mathrm{a}$ also shows the activity of thorium-234. Thorium-234 is formed directly from uranium-238 decay. Because the half-life of thorium-234 is so short (24.1 days) compared to that for uranium-238, its activity quickly approaches that of uranium-238 (within $1 \mathrm{yr}$ ) and stays at the activity of uranium-238 thereafter. Consequently, thorium-234 activity, according to the Bateman equation, equals the uranium-238 activity ( $0.0643 \mathrm{pCi} \mathrm{L}^{-1}$ for the onsite well). As shown in Fig. $9.27 \mathrm{~b}$, more than 2 million yrs are required for uranium-234 and thorium-230 to attain the activity of uranium-238. At $T=798,000$ yrs (see Table 9.11), uranium-234 and thorium-230 have attained activities that are $89 \%$ and $85 \%$, respectively, that of uranium- 238 . Therefore, the uranium-234 and thorium-230 activities are $0.89 \times 0.0643=0.057 \mathrm{pCi} \mathrm{L}^{-1}$ and $0.85 \times 0.0643=0.0547 \mathrm{pCi} \mathrm{L}^{-1}$. The remaining radioactive progeny, radium-226, radon-222, lead-210, bismuth-210, and polonium-210, have all attained the same activity (85\% of uranium-238), so their predicted activities are the same.

Since lead-206 is the stable endpoint of the decay chain and is a toxic element, its concentration is of potential concern. As shown in Fig. 9.27e, the concentration of lead-206 is less than $2 \times 10^{-6} \mathrm{mg} \mathrm{L}^{-1}$, which is far below levels of concern. Lead-206 is not calculated by MEPAS. The estimate provided previously is for benchmarking purposes only.

In contrast to MEPAS, RESRAD does not use the Bateman equation, unless the same value is specified for the distribution coefficient of all the nuclides in the transformation chain up to the element under consideration; radionuclide activities at the wells exhibit more differences than do the MEPAS predictions. These larger differences are caused, in part, by the fact that RESRAD allows different distribution coefficients in the unsaturated and saturated zones for the transformation products, whereas MEPAS assumes the distribution coefficients are the same as the parent radionuclide (see Table 9.2b). For example, the RESRAD-predicted peak activity for polonium-210 at the onsite well $\left(2.71 \mathrm{pCi} \mathrm{L}^{-1}\right)$ is higher than the activity of its first simulated parent, lead-210 $\left(0.89 \mathrm{pCi} \mathrm{L}^{-1}\right)$, as shown in Table 9.13. MEPAS predicts the concentrations are the same for these two radionuclides. 


\subsubsection{Maximum dose and risk to receptors via groundwater pathway}

The maximum dose and risk predictions to onsite and offsite receptors via exposure to groundwater are compiled in Table 9.14. The groundwater receptors are shown in Fig. 9.3. All pathways and contaminants that contribute to the total intake or dose and total risk are individually shown in Table 9.14 and include:

- drinking water ingestion,

- leafy vegetable ingestion,

- nonleafy vegetable ingestion,

- meat ingestion, and

- milk ingestion.

The health risks shown are excess lifetime cancer risks, assuming 70 yrs of exposure, and are calculated using the data reported earlier in Tables 9.8,9.9a, and 9.9b. Although methylene chloride can also exert toxic health effects, only the carcinogenic risks are calculated herein.

For methylene chloride, the pathway that produces the highest dose and risk is ingestion of water. At the onsite well, for example, the predicted dose ranges from $0.017 \mathrm{mg} \mathrm{kg}^{-1} \mathrm{day}^{-1}$ (MMSOILS) to $0.34 \mathrm{mg} \mathrm{kg}^{-1} \mathrm{day}^{-1}$ (RESRAD). The risks range from $1.3 \times 10^{-4}$ (MMSOLS) to $2.5 \times 10^{-3}$ (RESRAD) in direct proportion to intake. The calculations are presented in the following equation box.

Dose and Risk for Ingestion of Methylene Chloride in Groundwater

$$
\text { Ingestion }\left(\mathrm{mg} \mathrm{kg}^{-1} \mathrm{day}^{-1}\right)=\frac{\mathrm{CW} \times \mathrm{IRW} \times \mathrm{EF} \times \mathrm{ED}}{\mathrm{BW} \times \mathrm{AT} \times \mathrm{CFY}} \text { (EPA 1989) }
$$

where

$$
\begin{aligned}
& \mathrm{CW}=\text { contaminant concentration in drinking water }\left(\mathrm{mg} \mathrm{L}^{-1}\right) \\
& \mathrm{RW}=\text { ingestion rate of water }\left(\mathrm{L} \mathrm{day}^{-1}\right) \\
& \left.\mathrm{EF}=\text { exposure frequency (days } \mathrm{yr}^{-1}\right) \\
& \mathrm{ED}=\text { exposure duration }(\mathrm{yrs}) \\
& \mathrm{BW}=\text { body weight }(\mathrm{kg}) \\
& \mathrm{AT}=\text { averaging time [period over which exposure is averaged (yrs)] } \\
& \mathrm{CFY}=\text { conversion factor }\left(365 \mathrm{~d} \mathrm{yr}^{-1}\right)
\end{aligned}
$$

Using the data in Table $9.8\left(\mathrm{IRW}=2 \mathrm{~L} \mathrm{~d}^{-1} ; \mathrm{EF}=365\right.$ days $\mathrm{yr}^{-1} ; \mathrm{ED}=70 \mathrm{yr} ; \mathrm{BW}=70 \mathrm{~kg}$; $\mathrm{AT}=70 \mathrm{yr})$ and the contaminant concentrations reported in Table 9.13 (11.9 $\mathrm{mg} \mathrm{L}^{-1}-\mathrm{RESRAD}$;

(continued on next page) 
$0.58 \mathrm{mg} \mathrm{L}^{-1}$ - MMSOILS; $2.3 \mathrm{mg} \mathrm{L}^{-1}$ - MEPAS), the following intakes are calculated, where an example is provided for MMSOILS:

$$
\text { Intake (mg kg } \left.{ }^{-1} \text { day }^{-1}\right)=\left\{\begin{array}{l}
0.34, \text { RESRAD } \\
\frac{(0.58)(2)(365)(70)}{(70)(70)(365)}=1.7 \times 10^{-2}, \text { MMSOILS } \\
\left(6.5 \times 10^{-2}\right), \text { MEPAS }
\end{array}\right.
$$

These are the same values reported in Table 9.14. To calculate risk (R) from dose, the following formula is used:

$$
\mathrm{R}=\text { Intake } \times \mathrm{SF}
$$

where

$$
\mathrm{SF}=\text { oral slope factor }\left(0.0075 \mathrm{~kg} \text { day } \mathrm{mg}^{-1} \text {; see Table } 9.9 \mathrm{a} \text { and } 9.9 \mathrm{~b}\right)
$$

Therefore,

$$
R=\left\{\begin{array}{l}
(0.34)(0.0075)=2.5 \times 10^{-3}, \text { RESRAD } \\
\left(1.7 \times 10^{-2}\right)(0.0075)=1.3 \times 10^{-4}, \text { MMSOILS } \\
\left(6.5 \times 10^{-2}\right)(0.0075)=4.9 \times 10^{-4}, \text { MEPAS }
\end{array}\right.
$$

The RESRAD risk is based on the peak concentration, whereas the risks predicted by MEPAS are generated using 70-yr average concentrations. MMSOILS also uses the peak concentrations to calculate the risk; however, in this case, concentrations are at or near the peak for more than $70 \mathrm{yrs,}$ as shown in Fig. 9.17.

Ingestion of vegetables, particularly nonleafy vegetables, also provides relatively significant risks (3.6 $\times 10^{-4}$ for RESRAD to $7.7 \times 10^{-6}$ for MMSOILS at the onsite well). The lowest contributions of risk are from meat and milk ingestion; the predicted risks are four to five orders of magnitude less than the risks from the other pathways. This is because the meat and milk transfer factors are low for methylene chloride (see Tables 9.9a and 9.9b).

Dose and Risk for Ingestion of Uranium-238 in Drinking Water

$$
\text { Dose }\left(\mathrm{mrem}_{\mathrm{yr}}{ }^{-1}\right)=\frac{\mathrm{CW} \times \mathrm{IRW} \times \mathrm{DF} \times \mathrm{ED} \times \mathrm{CFY}}{\mathrm{AT}}
$$

where

$$
\begin{aligned}
& \mathrm{CW}=\text { radionuclide concentration in drinking water }\left(\mathrm{pCi} \mathrm{L}^{-1}\right) \\
& \mathrm{IRW}=\text { ingestion rate of water }\left(\mathrm{L} \mathrm{d}^{-1}\right) \\
& \mathrm{DF}=\text { dose conversion factor for ingestion }\left(\text { mrem } \mathrm{pCi}^{-1}\right)
\end{aligned}
$$




$$
\begin{aligned}
& \mathrm{ED}=\text { exposure duration }(\mathrm{yrs}) \\
& \mathrm{CFY}=\text { conversion factor }\left(\mathrm{d} \mathrm{yr^{-1 }}\right) \\
& \mathrm{AT}=\text { averaging time }(\mathrm{yrs})
\end{aligned}
$$

For uranium-238, DF $=2.5 \times 10^{-4} \mathrm{mrem} \mathrm{pCi}^{-1}$ for $\mathrm{RESRAD}$ (see Table 9.9a), DF $=2.6 \times 10^{-4}$ mrem $\mathrm{pCi}^{-1}$ for MEPAS (see Table 9.9b), CW $=3.93 \mathrm{pCi} \mathrm{L}^{-1}$ for RESRAD, $\mathrm{CW}=0.0643 \mathrm{pCi} \mathrm{L}^{-1}$ for MEPAS, and other data are as noted previously. Therefore, the dose is:

Dose $\left(\right.$ mrem $\left.\mathrm{yr}^{-1}\right)=\left\{\begin{array}{l}\frac{(3.93)(2)\left(2.5 \times 10^{-4}\right)(70)(365)}{70}=0.72, \text { RESRAD } \\ \frac{(0.0643)(2)\left(2.6 \times 10^{-4}\right)(70)(365)}{70}=1.2 \times 10^{-2}, \text { MEPAS }\end{array}\right.$

These doses are the same as reported in Table 9.14. Recall that the different DF factors used by RESRAD and MEPAS result from the fact that the models assume different contributions from the decay products (see footnotes in Tables $9.9 \mathrm{a}$ and $9.9 \mathrm{~b}$ ).

The risks are calculated directly from slope factors:

$$
\text { Risk (excess } 70 \mathrm{yr})=\mathrm{CW} \times \mathrm{IRW} \times \mathrm{ED} \times 365 \times \mathrm{SF}
$$

where

$$
\mathrm{SF}=\text { slope factor }
$$

For uranium-238, $\mathrm{SF}=2.8 \times 10^{-11}$ risk $\mathrm{pCi}^{-1}$ for $\mathrm{RESRAD}($ Table $9.9 \mathrm{a}) ; \mathrm{SF}=1.6 \times 10^{-11}$ risk $\mathrm{pCi}^{-1}$ for MEPAS (Table 9.9b), so:

$$
\text { Risk }=\left\{\begin{array}{l}
(3.93)(2)(70)(365)\left(2.8 \times 10^{-11}\right)=5.6 \times 10^{-6}, \text { RESRAD } \\
(0.0643)(2)(70)(365)\left(1.6 \times 10^{-11}\right)=5.3 \times 10^{-8}, \text { MEPAS }
\end{array}\right.
$$

\subsubsection{Atmospheric Pathway}

The benchmarking endpoints for the atmospheric pathway are as follows:

- Time series of emission rates to the atmosphere for methylene chloride (Fig. 9.28) and uranium-238 (Fig. 9.29).

- Time series of methylene chloride concentrations at maximum offsite exposure point (Fig. 9.30).

- Maximum air concentration, maximum atmospheric dispersion factor (chi $\mathrm{q}^{-1}$ ), and maximum deposition rates at the maximum offsite exposure point (Table 9.16).

- Maximum dose and risk to receptor located at site boundary (Table 9.17) and to the receptor located at the maximum offsite exposure point (Table 9.18). 
The emission rate predictions are discussed first, followed by discussions of predicted concentrations and dose and risks to the atmospheric receptors.

\subsubsection{Contaminant emission rates}

Contaminant emission rates for methylene chloride (as a vapor) and uranium-238 (associated with dust) are evaluated. First, the methylene chloride predictions are presented and discussed.

The predicted methylene chloride emission rates are shown in Fig. 9.28 for RESRAD, MMSOILS, and MEPAS. As the three curves show, the predicted emission rates are all quite different from each other:

- MMSOILS predicts a peak emission rate that is nearly an order of magnitude higher than RESRAD and four orders of magnitude higher than MEPAS.

- MMSOILS predicts that volatilization is nearly complete in 5 yrs, whereas both RESRAD and MEPAS predict that smaller rates of volatilization continue for a significantly longer time.

The reasons for these differences are that MEPAS uses a different volatilization algorithm from RESRAD and MMSOILS, and all three models use different soil moisture contents:

- RESRAD uses a diffusion equation to generate the volatile mass flux (EPA 1986). The methylene chloride is assumed to be initially buried to a depth of $0.8 \mathrm{~m}$, with a source thickness of $3.8 \mathrm{~m}$. The model predicts transient fluxes. In the RESRAD implementation, the water content is 0.245 calculated from the Campbell equation described previously, which is more than half of the total pore space (0.4).

- MMSOILS uses the same diffusion equation as RESRAD to generate the volatile mass flux (EPA 1986). The methylene chloride is assumed to be initially buried to a depth of $0.8 \mathrm{~m}$, with a source thickness of $3.8 \mathrm{~m}$. The model predicts transient fluxes. The volatilization model is described in Sect. 4.1.3 of the MMSOILS User's Manual (EPA 1992b). In the implementation of the MMSOILS model, the moisture content of the soil is always considered negligible. That is, all the pore space is assumed to be available for vapor occupancy. Therefore, MMSOILS predicts a higher emission rate and earlier depletion than the other two models. Since $\theta_{\mathrm{fc}}=0.375$ and $\theta_{\mathrm{t}}=0.4$, a significant amount of the pore space should be occupied by soil moisture and therefore would not be available for vapor occupancy. It should be noted that very low rates of atmospheric emissions still occur for up to 50 yrs. However, when aqueous phase leaching begins at $23.6 \mathrm{yrs}$, the aqueous phase leachate rate dominates until the source is depleted.

- To predict volatilization, MEPAS uses a diffusion equation (Streile 1995) that is a modification of the work of Thibodeaux and Hwang (1982) and is consistent with EPA (1988) guidance. The model predicts transient fluxes. The MEPAS predictions assume the soil moisture $\left(\theta_{w}=0.375\right)$ is at field capacity, so that the peak emission rate is significantly reduced compared to the peak emission rates of RESRAD and MMSOILS, but the duration of emissions is increased. 
In terms of total mass volatilized, the three models predict the following:

\begin{tabular}{lcc} 
Model & Mass Volatilized, gm & Percent of Inventory \\
\cline { 2 - 3 } RESRAD & $9.2 \times 10^{7}$ & 92 \\
MMSOILS & $8.3 \times 10^{7}$ & 83 \\
MEPAS & $8.4 \times 10^{6}$ & 8.4
\end{tabular}

\section{Effect of Soil Moisture on Effective Diffusion Coefficient}

To illustrate the significance of the different soil moisture content assumptions, the following calculations are provided. The effective vapor diffusion coefficient, $\mathrm{D}_{\text {eff }}$ through the soil is approximated by MMSOILS and MEPAS using the same formula:

$$
\mathrm{D}_{\text {eff }}=\frac{\theta_{\mathrm{a}}^{10 / 3} \mathrm{D}_{\mathrm{i}}}{\theta_{\mathrm{t}}^{2}}
$$

where:

$\theta_{\mathrm{a}}=$ air filled porosity (fraction)

$\mathrm{D}_{\mathrm{i}}=$ contaminant diffusion coefficient in air $\left(\mathrm{m}^{2} \mathrm{yr}^{-1}\right)$

$\theta_{\mathrm{t}}=$ total porosity (fraction)

The ratio of $D_{\text {eff }}$ used by MMSOILS and MEPAS is related to $\theta_{a}$ only, since $\theta_{t}$ and $D_{i}$ are the same for both models:

$$
\frac{D_{\text {eff }_{M M M}}}{D_{\text {eff }_{M}}}=\left(\frac{\theta_{a_{M M}}}{\theta_{a_{M}}}\right)^{10 / 3}
$$

For MMSOILS,

$$
\theta_{a}=\theta_{t}=0.40
$$

For MEPAS,

$$
\theta_{\mathrm{a}}=\theta_{\mathrm{t}}-\theta_{\mathrm{w}}=0.400-0.375
$$

Substituting these data,

$$
\frac{\mathrm{D}_{\text {eff }}}{\mathrm{D}_{\text {exf }}}=\left(\frac{0.4}{0.4-0.375}\right)^{10 / 3} \approx 10,300
$$

Therefore, the ratio of effective diffusivities is about $10^{4}$, approximately proportional to the ratio of peak diffusional fluxes.

Because methylene chloride is assumed to be present in the aqueous phase at its solubility limit $\left(15,300 \mathrm{~m} \mathrm{~L}^{-1}\right)$ and because the volatilization algorithms assign a vapor phase concentration based on 
Henry's Law, the validity of this approach may be in question because Henry's Law is developed with the limitation that the aqueous phase concentration is "low." Typically, "low" means a mole fraction of 0.02 or less in the aqueous phase (King 1969). As shown in the following calculations box, the mole fraction is 0.0032 , which is in the range of applicability of Henry's Law.

\section{Mole Fraction Calculations}

Mole fraction $=\frac{\text { moles } \mathrm{MC} \mathrm{L}^{-1}}{\text { moles } \mathrm{MC} \mathrm{L}^{-1}+\text { moles } \mathrm{H}_{2} \mathrm{O} \mathrm{L}^{-1}}$

moles $\mathrm{MC} \mathrm{L} \mathrm{L}^{-1}=15,300 \mathrm{mg} \mathrm{L}^{-1} \times 10^{-3} \mathrm{~g} \mathrm{mg}^{-1} \times \frac{1 \text { mole }}{84.9 \mathrm{~g}}=0.18$ moles $\mathrm{L}^{-1}$

moles $\mathrm{H}_{2} \mathrm{O}=1 \mathrm{~g} \mathrm{~cm}^{-3} \times 10^{3} \mathrm{~cm}^{3} \mathrm{~L}^{-1} \times 1$ mole $(18 \mathrm{~g})^{-1}=55.56$ moles $\mathrm{L}^{-1}$

so,

Mole fraction $=\frac{0.18}{0.18+55.56}=0.0032$

For particulate emissions of uranium-238, either RESRAD or MEPAS can have a wide range of values for this scenario. MEPAS simulations are made for a dusty site and a site with a stabilized surface; RESRAD simulation is for a stabilized surface. Because the problem was not uniquely defined and because ambiguity in definition produced large differences in model predictions, in this one case MEPAS evaluated the problem using two alternative assumptions. In real world applications with either MEPAS or RESRAD, the user can reduce the range of predicted emission rates by obtaining additional site information.

The uranium-238 emission rates predicted by MEPAS (for a dusty site only) and RESRAD are provided in Fig. 9.29. In RESRAD, the soil erosion rate and dust emission rate are not coupled. The user enters a soil erosion rate, which may be measured or derived from the Universal Soil Loss Equation, an empirical model that has been developed for predicting the rate of soil loss by water erosion. The dust emission rate from the landfill is calculated separately as the product of the dust concentration in air, the deposition velocity, and the surface area of the landfill. In the multimedia scenario, the soil erosion rate is assumed to be $0.001 \mathrm{~m} \mathrm{yr}^{-1}$, which results in a loss of $0.13 \mathrm{~g} \mathrm{~s}^{-1}$ of soil from the landfill area. The dust emission rate results in a loss of $3.0 \times 10^{-4} \mathrm{~g} \mathrm{~s}^{-1}$ of soil from the landfill area, which is less than $1 \%$ of the total mass of soil lost due to erosion. The current version of RESRAD does not model the overland flow of contaminants due to water erosion (runoff).

In MEPAS, the dust emission rate may be input or computed from source characteristics. The MEPAS dust emission computation option defines the susceptibility of the surface to wind and mechanical erosion. Parameters such as the fraction of vegetation cover, type of soil, and climatological 
data are defined in the scenario description. Additional parameters not specified in the multimedia scenario description are required to estimate the state of stabilization of the contaminated surface. ${ }^{3}$

The possible MEPAS implementations of the dust emission scenario range from a dusty site to a stabilized site. At dusty sites, MEPAS predictions of wind erosion of soil are comparable to the total soil erosion rate assumed in RESRAD. At stabilized sites, MEPAS predictions of the wind erosion rate are comparable to the air emission rate assumed by RESRAD. Two MEPAS simulations are reported to illustrate the possible range of particulate emission rates that are possible for the benchmarking scenario. The MEPAS runs listed in Table 9.15 assume the same total soil erosion rate as assumed by RESRAD. The MEPAS scenario \#1 (dusty site) assumes all of the soil loss is by atmospheric suspension. Therefore, the computed initial uranium-238 atmospheric emission rate is much higher than the RESRAD computed rate, which is also shown in the table. The MEPAS scenario \#2 illustrates a case where the uranium-238 atmospheric emission rate is nearly the same as for RESRAD. Because the site characteristics indicate that there is no overland flow, the soil erosion of the clean surface cover is entirely by wind erosion in the MEPAS simulation.

The RESRAD total erosion rate, $0.001 \mathrm{~m} \mathrm{yr}^{-1}$, is converted to $0.13 \mathrm{~g} \mathrm{~s}^{-1}$ using the soil bulk density of $1.4 \times 10^{6} \mathrm{~g} \mathrm{~m}^{-3}$ and an area of $2974 \mathrm{~m}^{2}$ for comparison with the MEPAS dust emission rates shown in Table 9.15. The RESRAD air emission rate of uranium-238 for the RESRAD run is computed as the product of a mass loading factor, contaminant concentration, and deposition velocity and is not directly connected to the assumed total erosion rate. Surface roughness and fraction crusted are not required inputs for RESRAD.

The results of the multimedia MEPAS run for the unstabilized surface (dusty site) is used for the multimedia benchmarking scenario. The larger air emission rate, when compared to RESRAD predictions, means that higher computed risks are to be expected for the MEPAS results. For comparison, MEPAS air pathway risks are also reported for the stabilized surface case where dust emissions are nearly equal to the RESRAD dust emissions. ${ }^{4}$

The MEPAS assumption that the uranium-238 air emission rates will begin approximately $800 \mathrm{yrs}$ after disposal is based on a computation using the assumed erosion rate of $0.001 \mathrm{~m} \mathrm{yr}^{-1}$ and the defined overburden depth of $0.8 \mathrm{~m}$ :

$$
\mathrm{T}=\frac{0.8 \mathrm{~m}}{0.001 \mathrm{~m} \mathrm{yr}^{-1}}=800 \mathrm{yrs}
$$

The RESRAD surface erosion rate is assumed in the MEPAS runs. This assumption is consistent with the air emission rates used for the MEPAS run for scenario \#1. However, the special case MEPAS run with lower air emission rates also used the erosion rate to determine the removal time for the cover; a more consistent approach would have been to compute an extended air emission starting time based on the air erosion rate. Both models assume that subsequent deposition of background particulates onto the source area is insignificant.

\footnotetext{
${ }^{3}$ The scenario is designed to run MEPAS using the RESRAD default dust emission rate as a known emission rate. A decision was made to have MEPAS also compute dust emission rates based on site characteristics to illustrate the range of suspension rates possible for this scenario.
}

This special case is reported for air results only, waterborne pathway results are based solely on the MEPAS run for the unstabilized surface. 
The uranium-238 emission rates used by MEPAS and RESRAD in the main multimedia benchmarking runs are shown in Fig. 9.29. The emission rates are nearly constant over the period of emissions, approximately 4600 yrs in duration. The MEPAS air pathway risk computations use the first 70 yrs during the period of emissions.

RESRAD assumes a soil mixing layer of $0.15 \mathrm{~cm}$, so dust emission of contaminated soil first occurs at 650 yrs. The emission rate increases to a maximum at $T=800$ yrs. Over the next 3650 yrs ( $T=800$ to $4450 \mathrm{yrs}$ ), continued erosion of the contaminated layer results in a slightly decreasing emission rate due to radioactive decay and leaching. The air emission rate falls quickly to zero after $\mathrm{T}=4450 \mathrm{yrs}$. Subsequent atmospheric emissions of the soil underlying the landfill are assumed to be negligible and are not simulated.

As earlier predictions showed, methylene chloride is able to diffuse through the overburden at a faster rate than the rate at which the overburden erodes. Therefore, although MMSOILS assumes a constant thickness of overburden $(0.8 \mathrm{~m})$ throughout the period of methylene chloride volatilization, this assumption is reasonable because volatilization occurs so quickly.

\subsubsection{Transport and dispersion through the atmosphere}

Maximum atmospheric concentrations, maximum atmospheric dispersion factors (chi $\mathrm{q}^{-1}$ ), and maximum deposition rates at the offsite maximum exposure point are provided in Table 9.16. Both MMSOILS and MEPAS have their own atmospheric transport models as part of their codes; RESRAD uses the CAP-88PC code. The joint frequency wind speed data shown previously in Table 9.6 were used by all the models. The joint frequency data for the onsite receptor, located at $366 \mathrm{~m}$ north of the site, indicate that the wind blows to the north $19 \%$ of the time, with the following wind speed distribution: $1-3 \mathrm{~m} \mathrm{~s}^{-1}(1.2 \%), 4-6 \mathrm{~m} \mathrm{~s}^{-1}(6.5 \%), 7-10 \mathrm{~m} \mathrm{~s}^{-1}(27.2 \%), 11-16 \mathrm{~m} \mathrm{~s}^{-1}(40.1 \%), 17-21 \mathrm{~m} \mathrm{~s}^{-1}$ (19.7\%), and greater than $21 \mathrm{~m} \mathrm{~s}^{-1}(5.3 \%)$. The wind blows toward the offsite receptor, located $810 \mathrm{~m}$ to the northeast, $10 \%$ of the time, with the following wind speed distribution: $1-3 \mathrm{~m} \mathrm{~s}^{-1}(1.3 \%), 4-6 \mathrm{~m} \mathrm{~s}^{-1}(9.3 \%), 7-10$ $\mathrm{m} \mathrm{s}^{-1}(35.2 \%), 11-16 \mathrm{~m} \mathrm{~s}^{-1}(39.0 \%), 17-21 \mathrm{~m} \mathrm{~s}^{-1}(14.9 \%)$, and greater than $21 \mathrm{~m} \mathrm{~s}^{-1}(0.4 \%)$.

The predicted times-to-peak concentrations shown in the table are the same for methylene chloride (within the lst yr) and for uranium-238 (RESRAD predicts and MEPAS assumes peak concentrations occur within the 800th yr). The RESRAD and MMSOILS-predicted peak methylene chloride concentrations at the receptor located $810 \mathrm{~m}$ to the northeast of the center of the source $\left(6.9 \times 10^{-3} \mathrm{mg}\right.$ $\mathrm{m}^{-3}$ and $2.2 \times 10^{-3} \mathrm{mg} \mathrm{m}^{-3}$, respectively) are significantly greater than the MEPAS-predicted maximum concentration $\left(3.3 \times 10^{-7} \mathrm{mg} \mathrm{m}^{-3}\right)$. Based on the emission rates shown in Fig. 9.28, the much lower MEPAS concentration is anticipated. The predicted uranium-238 peak concentration is higher than the RESRAD-predicted peak concentration by two orders of magnitude $\left(4.0 \times 10^{-5} \mathrm{pCi} \mathrm{m}^{-3} \mathrm{vs.} 4.0 \times 10^{-7} \mathrm{pCi}\right.$ $\mathrm{m}^{-3}$, respectively) for the MEPAS dusty site assumption and is the same order of magnitude as RESRAD for the MEPAS-stabilized site assumption.

Trends similar to those for peak concentrations are observable for maximum deposition rates, since the deposition rates are proportional to atmospheric concentrations (see the following calculation box). The maximum chi $\mathrm{q}^{-1}$ values for methylene chloride predicted by the three models agree more closely than do other results. The chi $q^{-1}$ values are independent of concentrations and emission rates and represent only the dispersion and removal processes. 
MEPAS Predicted Depositional Fluxes

$$
\dot{\mathrm{M}}_{\mathrm{d}}=\mathrm{V}_{\mathrm{d}} \mathrm{C}_{\mathrm{a}}
$$

where

$$
\begin{aligned}
& \dot{\mathrm{M}}_{\mathrm{d}}=\text { deposition rate }\left(\mathrm{mg} \mathrm{m}^{-2} \mathrm{~s}^{-1} \text { or } \mathrm{pCi} \mathrm{m} \mathrm{m}^{-2}\right) \\
& \mathrm{V}_{\mathrm{d}}=\text { deposition velocity }\left(\mathrm{m} \mathrm{s}^{-1}\right) \\
& \mathrm{C}_{\mathrm{a}}=\text { ground level atmospheric concentration at location where } \dot{\mathrm{M}}_{\mathrm{d}} \text { is predicted }(\mathrm{mg} \\
& \left.\mathrm{m}^{-3} \text { or } \mathrm{pCi} \mathrm{m}\right)
\end{aligned}
$$

For example, the deposition velocities used by MEPAS are

$$
V_{d}=\left\{\begin{aligned}
& 7.54 \times 10^{-7} \mathrm{~m} \mathrm{~s}^{-1}, \text { methylene chloride } \\
& 5.8 \times 10^{-2} \mathrm{~m} \mathrm{~s}^{-1}, \text { uranium-238 } \text { (this is an average of the range of depositional } \\
& \text { velocities computed by MEPAS) }
\end{aligned}\right.
$$

Therefore, the depositional fluxes are:

$$
\dot{\mathrm{M}}=\left\{\begin{array}{l}
2.2 \times 10^{-12} \mathrm{mg} \mathrm{m}^{-2} \mathrm{~s}^{-1}, \text { methlyene chloride } \\
1.7 \times 10^{-6} \mathrm{pCi} \mathrm{m}^{-2} \mathrm{~s}^{-1}, \text { uranium-238, (dusty site) }
\end{array}\right.
$$

\subsubsection{Predicted dose and risk to atmospheric receptors}

The predicted doses and risks to the two atmospheric receptors are presented in Tables 9.17 and 9.18. All three models predict risks from exposure to methylene chloride, but only RESRAD and MEPAS predict risks from exposure to radionuclides. The highest predicted risks from methylene chloride are via inhalation and are several orders of magnitude higher than risks from ingestion by vegetables. The lower risks from food chain intakes are related to the low deposition velocity of methylene chloride $\left(V_{d}=7.54 \times 10^{-7} \mathrm{~m} \mathrm{~s}^{-1}\right)$, which limits its accumulation in vegetables, meat, milk, and soil.

MMSOILS and MEPAS predict inhalation risks that are only an order of magnitude different, although peak emission rates differ by four orders of magnitude. The risks are less disparate because they are based on 70-yr-average concentrations. As shown previously, MMSOILS predicts that 10 times the mass is volatilized when compared to MEPAS predictions $\left(8.3 \times 10^{7} / 8.4 \times 10^{6} \approx 10\right)$. RESRAD uses peak concentrations to calculate the risks; since those concentrations are not sustained over $70 \mathrm{yrs}$, the peak concentrations are much higher than the 70-yr-average concentrations.

For the radionuclides, doses to the receptors result from resuspension of contaminated soil at the source and subsequent transport through the atmosphere to receptor locations. The mass loading of dust in air (sum from both background and source) is assumed to be $100 \mu \mathrm{g} \mathrm{m}^{-3}$ for both inhalation and foliar deposition. The thickness of the newly created contaminated zones at the onsite and offsite receptor 
locations is assumed to be $15 \mathrm{~cm}$. The following pathways are assumed to contribute to risks: ingestion of vegetables, meat, milk, and soil; inhalation of dust and radon; and external gamma radiation from soil.

For RESRAD, the risk and doses are calculated by scaling air concentrations to the dispersion factors (chi $\mathrm{q}^{-1}$ ) from a location above the contaminated source to two receptor locations (366 m north and $810 \mathrm{~m}$ northeast of the center of the contaminated source) obtained with the CAP-88PC code. The soil concentrations are calculated by first multiplying the deposition velocity $\left(0.001 \mathrm{~m} \mathrm{~s}^{-1}\right)$ by the air concentrations $\left(\mathrm{g} \mathrm{m}^{-3}\right)$ over a year. The resulting annual deposition rate is then multiplied by the number of years of effective deposition of contaminated dust (3800 yrs) and distributed over the top $15 \mathrm{~cm}$ of soil to obtain the mass fraction of offsite soil $\left(\mathrm{g} \mathrm{g}^{-1}\right)$ in the layer that originated from the contaminated site. Example dose and risk calculations are presented in the following equation box.

$$
\begin{aligned}
& \text { Example Dose and Risk Calculations from Inhalation } \\
& \text { Dose }\left(\mathrm{mg} \mathrm{kg}^{-1} \text { day }^{-1}\right)=\frac{\mathrm{CA} \times \mathrm{INR} \times \mathrm{EF} \times \mathrm{ED}}{\mathrm{BW} \times \mathrm{AT} \times \mathrm{CFY}}
\end{aligned}
$$

where

$$
\begin{aligned}
& \mathrm{CA}=\text { contaminant concentration in air }\left(\mathrm{mg} \mathrm{m}^{-3}\right) \\
& \mathrm{INR}=\text { inhalation rate of air }\left(\mathrm{m}^{3} \mathrm{day}^{-1}\right) \\
& \mathrm{EF}=\text { exposure frequency }\left(\text { days } \mathrm{yr}^{-1}\right) \\
& \mathrm{ED}=\text { exposure duration }(\mathrm{yrs}) \\
& \mathrm{BW}=\text { body weight }(\mathrm{kg}) \\
& \mathrm{AT}=\text { averaging time (yrs) } \\
& \mathrm{CFY}=365 \text { days } \mathrm{yr}^{-1}
\end{aligned}
$$

The following data are used for this example (as shown previously in Tables 9.8 and 9.16):

$$
\begin{aligned}
& \mathrm{INR}=20 \mathrm{~m}^{3} \mathrm{~d}^{-1} \\
& \mathrm{EF}=365 \mathrm{~d} \mathrm{yr}^{-1} \\
& \mathrm{ED}=70 \mathrm{yrs} \\
& \mathrm{BW}=70 \mathrm{~kg} \\
& \mathrm{AT}=70 \mathrm{yrs} \\
& \mathrm{CA}=6.9 \times 10^{-4} \mathrm{mg} \mathrm{m}^{-3} \text { (peak concentration predicted for RESRAD) } \\
& \mathrm{CA}=3.36 \times 10^{-5} \mathrm{mg} \mathrm{m}^{-3} \text { (70-yr arithmetic average for MMSOILS) } \\
& \mathrm{CA}=3.04 \times 10^{-6} \mathrm{mg} \mathrm{m}^{-3} \text { (70-yr average for MEPAS) }
\end{aligned}
$$


Using these data:

$$
\text { Dose }\left(\mathrm{mg} \mathrm{kg}^{-1} \mathrm{day}^{-1}\right)=\left\{\begin{array}{l}
\frac{\left(6.9 \times 10^{-4}\right)(20)(365)(70)}{(70)(70)(365)}=2.0 \times 10^{-4}, \text { RESRAD } \\
\frac{\left(3.36 \times 10^{-5}\right)(20)(365)(70)}{(70)(70)(365)}=9.6 \times 10^{-6}, \text { MMSOILS } \\
\frac{\left(3.04 \times 10^{-6}\right)(20)(365)(70)}{(70)(70)(365)}=8.7 \times 10^{-7}, \text { MEPAS }
\end{array}\right.
$$

Using a slope factor of $0.0016 \mathrm{~kg}$ day $\mathrm{mg}^{-1}$, the risks are:

$$
\text { Risk }=\left\{\begin{array}{l}
\left(2.0 \times 10^{-4}\right)(0.0016)=3.2 \times 10^{-7}, \text { RESRAD } \\
\left(9.6 \times 10^{-6}\right)(0.0016)=1.5 \times 10^{-8}, \text { MMSOILS } \\
\left(8.7 \times 10^{-7}\right)(0.0016)=1.4 \times 10^{-9}, \text { MEPAS }
\end{array}\right.
$$

For RESRAD, two cases are explored for each of the receptors. In the first case, the receptor is exposed to contamination from the year of maximum plume concentration (i.e., at $\mathrm{T}=800 \mathrm{yrs}$ ). In the second case, 3800 yrs of deposition (from $\mathrm{T}=650 \mathrm{yrs}$ to $\mathrm{T}=4450 \mathrm{yrs}$ ) result in the maximum offsite accumulation of contaminated soil, assumed to be distributed in the top $15 \mathrm{~cm}$ of soil; the contribution from root uptake is taken into account for the ingestion pathways. For both cases, the results indicate that the maximum dose and risk occurs at $\mathrm{T}=800 \mathrm{yrs}$ for the inhalation pathway and the meat and milk ingestion pathways. However, a higher dose and risk occurs after 4450 yrs for the plant ingestion pathway due to the significant contribution of root uptake. Since dose contributions from the external gamma and soil ingestion pathway increase with the amount of contaminants deposited at the receptor locations, the maximum dose and risk from these pathways occur at the time of maximum deposition $(T=4450 \mathrm{yrs})$. Since the inhalation dose due to the plume passage dominates the doses from all other pathways, the maximum total dose and risk occurs at $\mathrm{T}=800 \mathrm{yrs}$. The uranium- 238 progeny contribute less than $1 \%$ of the total dose and risk over the entire assessment period and are therefore not shown explicitly.

MEPAS simulations proceed in basically the same manner as described previously for RESRAD, but the long-term deposition soil accumulation scenario is not simulated. MEPAS-predicted risks for a dusty site assumption are typically 1 to 3 orders of magnitude higher than the RESRAD predictions. MEPAS predicted risks for a site with a stabilized surface are typically within an order of magnitude of the RESRAD values. The risks are higher for the dusty site because MEPAS predicts that essentially all of the eroded uranium- 238 is being re-entrained into the atmosphere and is subsequently transported to the receptor (and other locations).

RESRAD and MEPAS Predicted Risks Due To Inhalation of Uranium-238 at Offsite Receptor

$$
\text { Risk }=\mathrm{CA} \times \mathrm{INR} \times \mathrm{EF} \times \mathrm{ED} \times \mathrm{SF}
$$


where $\mathrm{SF}=$ slope factor for inhalation (risk $\left.\mathrm{pCi}^{-1}\right)$
and the other factors were defined earlier. For both $\mathrm{RESRAD}$ and MEPAS, $\mathrm{SF}=5.2 \times 10^{-8}{\mathrm{risk} \mathrm{pCi}^{-1}}$
(see Tables 9.9a and 9.9b). Using these data for uranium-238 inhalation:
Risk $=\left\{\begin{array}{l}\left(4.0 \times 10^{-7}\right)(20)(365)(70)\left(5.2 \times 10^{-8}\right)=1.1 \times 10^{-8}, \mathrm{RESRAD} \text { and MEPAS (dusty site) } \\ \left(1.8 \times 10^{-7}\right)(20)(365)(70)\left(5.2 \times 10^{-8}\right)=4.8 \times 10^{-9}, \text { MEPAS (stabilized site) }\end{array}\right.$
where the concentrations are taken from Table 9.16.

\subsubsection{Surface Water Pathway}

The benchmarking endpoints for the surface water pathway are as follows:

- maximum surface water concentrations, dose, and risk to surface water receptor (Table 9.19) and

- fluxes of methylene chloride and uranium-238 from the saturated zone to the surface water (Figs. 9.31 and 9.32).

Since RESRAD does not simulate rivers (only ponds), Table 9.19 contains predictions only for MMSOILS and MEPAS; however, fluxes to the river are predicted by all three models.

The fluxes shown in Figs. 9.31 and 9.32 resemble the fluxes from PSZ2 to SZ predicted by the three models (compare Fig. 9.31 to Fig. 9.9 and Fig. 9.32 to Fig. 9.11). These similarities are expected since the travel times to the edge of the river are not very different from the travel time through the unsaturated zone. For example, for MEPAS a shift of only about 10 yrs exists in the methylene chloride fluxes between Figs. 9.9 and 9.31 to account for the travel time through the groundwater.

The models' predictions of concentrations, dose, and risks are shown in Table 9.19. Predicted methylene chloride concentrations are higher for MEPAS than for MMSOILS, since more flux is moving through the groundwater and into the river, whereas the reverse is true for uranium-238. For the decay products of uranium-238, only MEPAS predictions are provided, since MMSOILS does not simulate the decay products. The activities shown are once again predicted using the Bateman equation, so that activities of a number of the decay products are identical. However, the concentrations in the river are orders of magnitude less than the concentrations in the groundwater due to the diluting effect of the river. The flow rate and the dilution factor of the river are $1.79 \times 10^{9} \mathrm{~m}^{3} \mathrm{yr}^{-1}$ and $4.7 \times 10^{7}$, respectively (the following equation box presents the calculations).

\section{Dilution and Uranium-238 Concentrations in Surface Water}

Flow rate of river: $0.61 \mathrm{~m} \mathrm{~s}^{-1} \times 3.048 \mathrm{~m} \times 30.48 \mathrm{~m} \times 86,400 \mathrm{~s} \times 365$ day $\mathrm{yr}^{-1}=1.79 \times 10^{9} \mathrm{~m}^{3} \mathrm{yr}^{-1}$

Flow rate of contaminated water that enters landfill: $0.0127 \mathrm{~m} \mathrm{yr}^{-1} \times 12.2 \mathrm{~m} \times 243.8 \mathrm{~m}^{2}=$ $37.8 \mathrm{~m}^{3} \mathrm{yr}^{-1}$ 
Dilution Factor: $1.79 \times 10^{9} / 37.8=4.7 \times 10^{7}$

After complete mixing with the river, the peak uranium-238 activity in the river, $C_{R}$, is,

$$
C_{r}=\frac{M}{Q_{g w}+Q_{r}}
$$

where

$$
\begin{aligned}
& C_{r}=\begin{array}{l}
\text { concentration of uranium-238 in river after complete lateral and vertical mixing } \\
\left(\mathrm{pCi} \mathrm{L} \mathrm{L}^{-1}\right)
\end{array} \\
& \mathrm{Q}_{\mathrm{qw}}=\text { flow rate of groundwater intercepted }\left(\mathrm{m}^{3} \mathrm{yr}^{-1}\right) \\
& \mathrm{Q}_{\mathrm{v}}=\text { flow rate of water }\left(\mathrm{m}^{3} \mathrm{yr}^{-1}\right) \\
& \mathrm{M}=\text { peak mass flux of groundwater plume that intercepts river }\left(\mathrm{pC}_{\mathrm{i}} \mathrm{yr}^{-1}\right)
\end{aligned}
$$

Supplying the appropriate data, $\mathrm{C}_{\mathrm{R}}$ becomes:

$$
\mathrm{C}_{\mathrm{R}}=\frac{1.8 \times 10^{7} \mathrm{pCi} \mathrm{yr}^{-1}}{1.79 \times 10^{9} \mathrm{~m}^{3} \mathrm{yr}^{-1}} \times 10^{-3} \mathrm{~m}^{3} \mathrm{~L}^{-1}=1.0 \times 10^{-5} \mathrm{pCi} \mathrm{L}^{-1}
$$

where the flux of $1.8 \times 10^{7} \mathrm{pCi} \mathrm{yr}^{-1}$ is the MMSOILS-predicted flux from Fig. 9.32. This value of $\mathrm{C}_{\mathrm{R}}$ is very close to the value reported in Table 9.19.

For MEPAS, a parallel calculation is performed:

$$
\mathrm{C}_{\mathrm{R}}=\frac{2 \times 10^{6} \mathrm{pCi} \mathrm{yr}^{-1}}{1.79 \times 10^{9} \mathrm{~m}^{3} \mathrm{yr}^{-1}} \times 10^{-3} \mathrm{~m}^{3} \mathrm{~L}^{-1}=1.1 \times 10^{-6} \mathrm{pCi} \mathrm{L}^{-1}
$$

where the flux that enters the river $\left(2 \times 10^{6} \mathrm{pCi} \mathrm{yr}^{-1}\right)$ is taken from Fig. 9.32.

Note that this activity is less than half the reported value in Table 9.19 for MEPAS $\left(2.8 \times 10^{-6} \mathrm{pCi} \mathrm{L}^{-1}\right)$; this is because MEPAS is a two-dimensional model that accommodates lateral mixing. At the location of prediction ( $100 \mathrm{~m}$ downstream of the plume interception point and along the side of the river where the plume is discharged), complete mixing across the river has not occurred.

The risks of ingestion of fish and dermal contact with the river water are shown in Table 9.19. All risks are below $10^{-10}$. These low risks are consistent with the low exposure concentrations.

\subsubsection{Total Risks to Multimedia Receptors}

Total risks to the two multimedia receptors are provided in Tables 9.20 and 9.21 . The risks are reported separately for groundwater, air, and surface water. The risks are associated with the exposure times reported previously in Tables 9.13 (groundwater), 9.17 (air), and 9.19 (surface water). The risks are not summed within pathways or across pathways due to the different exposure times involved. 
For most pathways, the predicted risks generally agree to within 1 to 2 orders of magnitude. The highest four predicted risks at the onsite receptor, for each model, are:

RESRAD

1. Drinking water ingestion of methylene chloride at onsite well

2. Ingestion of vegetables contaminated with methylene chloride by irrigation with water from onsite well

3. Drinking water ingestion of lead-210 at onsite well

4. Drinking water ingestion of polonium-210 at onsite well

\section{MMSOILS}

1. Drinking water ingestion of methylene chloride at onsite well

2. Ingestion of nonleafy vegetables contaminated with methylene chloride by irrigation with water from onsite well

3. Inhalation of ambient air that contains methylene chloride at onsite receptor location

4. Ingestion of leafy vegetables contaminated with methylene chloride by irrigation with water from onsite well $\underline{\text { Risk }}$

$2.5 \times 10^{-3}$

$3.6 \times 10^{-4}$

$2.3 \times 10^{-5}$

$2.1 \times 10^{-5}$

$1.3 \times 10^{-4}$

$7.7 \times 10^{-6}$

$6.7 \times 10^{-8}$

$5.4 \times 10^{-8}$

\section{MEPAS}

1. Drinking water ingestion of methylene chloride at onsite well

$4.9 \times 10^{-4}$

2. Ingestion of nonleafy vegetables contaminated with methylene chloride

$4.5 \times 10^{-5}$ by irrigation with water from onsite well

3. Ingestion of leafy vegetables contaminated with methylene chloride by $9.9 \times 10^{-6}$ irrigation with water from onsite well

4. Inhalation of uranium-238 at onsite receptor location (dusty site) $8.1 \times 10^{-6}$

The single highest risk $\left(2.5 \times 10^{-3}\right)$ predicted by RESRAD (for ingestion of water that contains methylene chloride) is higher for RESRAD because RESRAD uses the maximum concentration at the well to calculate risk, which is much greater than the peak concentration used by MMSOILS or the 70-yr average used by MEPAS.

\subsection{CONCLUSIONS}

RESRAD, MMSOILS, and MEPAS have been applied to a hypothetical landfill, where predictions of both contaminant transport through multimedia and human health risks have been made. The risks result from exposure to methylene chloride and uranium-238 and its progeny. The models simulate the 
multimedia transport pathways through the partially saturated zone, groundwater, atmosphere, and surface water. Risks are predicted at two receptor locations shown in Figs. 9.2 and 9.3. At each location, each receptor is exposed to contaminated groundwater from a nearby well, and risks result from:

- ingestion of drinking water,

- ingestion of vegetables that are irrigated with well water, and

- ingestion of meat and milk from livestock that ingest well water.

Receptors are also exposed to contaminated air, and risks results from:

- inhalation of ambient air,

- ingestion of vegetables that uptake contaminants from atmospheric deposition and from root uptake,

- ingestion of meat and milk from livestock that ingest contaminated soil and fodder,

- soil dermal contact, and

- external gamma radiation from soil.

Finally, receptors are exposed to contaminated surface water, and risks result from:

- fish ingestion and

- dermal contact while swimming.

The following conclusions are the results of the multimedia benchmarking scenario:

- all models simulate transport through all media specific to this benchmarking test, with the exception of RESRAD, which does not simulate transport through rivers;

- both RESRAD and MEPAS predict contaminant transport and risks from methylene chloride and radionuclides, while MMSOILS predicts contaminant transport and risks from methylene chloride and contaminant transport for uranium-238 (although it does not consider adsorbed phase decay) but does not predict risks from any of the radionuclides;

- RESRAD, MMSOILS, and MEPAS couple predicted volatile and aqueous phase emissions from the landfill so that the total mass emitted equals the initial inventory;

- predictions of total methylene chloride mass that volatilizes differs by a factor of 10 between models (this occurs because MEPAS uses a different volatilization algorithm than the other two models and because all three models use different soil water contents; however, a specific investigation of the differences between the algorithms was not conducted);

- predicted travel times through the unsaturated zone are much longer than travel times through the saturated zone and dominate the total time for contaminated water to move to both wells and to the river; 
- MMSOILS- and MEPAS-predicted advective travel times and times-to-peak concentrations are generally comparable through the unsaturated and saturated zones and through the river, and RESRAD's predictions of advective travel times are typically $25 \%$ of those predicted by the other two models;

- for the saturated zone, MMSOILS considers dissolved phase decay only, not absorbed phase decay, and contaminants that decay in both phases may have overestimated concentrations at significant distances from the source (e.g., uranium-238, the radionuclide simulated in this scenario, has a long half-life, and the effects of not considering absorbed phase decay in this analysis are minimal);

- the highest predicted risks occur from groundwater exposure to methylene chloride through drinking water ingestion [RESRAD predicts the highest onsite risk $\left(2.5 \times 10^{-3}\right)$ followed by MEPAS $\left(4.9 \times 10^{-4}\right)$ and MMSOILS $\left(1.3 \times 10^{-4}\right)$. The RESRAD results are based on a peak concentration that is much greater than the concentration that is sustained over 70 yrs. Although MMSOILS also uses a peak concentration, the peak concentration is similar to the 70-yr-average concentration because of dispersion. Only MEPAS actually calculates the 70-yr-average concentration for use in the risk calculation.];

- predicted concentrations in the river are much less than those in the groundwater due to the dilutional effect of the river (a dilution of $4.7 \times 10^{7}$ at complete mixing), so the predicted risks due to exposure to river water are small (the maximum risk is $7.2 \times 10^{-10}$, predicted by MEPAS for exposure to methylene chloride);

- the RESRAD-predicted risk from onsite air exposure to methylene chloride is $2.1 \times 10^{-6}$ (Both MMSOILS and MEPAS predict risks of less than $7.1 \times 10^{-8}$. This difference occurs primarily because RESRAD uses a peak methylene chloride concentration to predict risks whereas the other models use 70-yr-average concentrations to predict risks.); and

- for atmospheric transport of uranium-238, equivalent risks are produced by RESRAD and MEPAS when similar surface soil conditions are assumed (However, the matching of total soil surface erosion rates in the RESRAD and MEPAS runs resulted in an order of magnitude difference in air-pathway risks. Although both RESRAD and MEPAS consider surface runoff processes, in this multimedia scenario RESRAD sends most of the surface material to surface runoff, and MEPAS removes all the material to soil suspension.).

\subsection{CHAPTER REFERENCES}

Bateman, H., 1910. The solution of a system of differential equations occurring in the theory of radioactive transformations: Proc. Cambridge Philos. Soc., v. 15, Pt V, p. 423-247.

Browne, E. and R. Firestone. 1986. Table of Radioisotopes, John Wiley \& Sons, New York.

Buck, J. W., G. Whelan, J. G. Droppo Jr., D. L. Strenge, K. J. Castleton, J. P. McDonald, C. Sato, and G. P. Streile. 1995. Multimedia Environmental Pollutant Assessment System (MEPAS) Application Guidance: Guidelines for Evaluating MEPAS Input Parameters for Version 3.1, PNL-10395. Pacific Northwest Laboratory, Richland, WA.

Campbell, G. S. 1974. A simple model for determining unsaturated conductivity from moisture retention data, Soil Science, Vol. 177, pp. 311-314. 
Darwin, R. 1990. Soil Ingestion by Dairy Cattle, PNL-SA-17918 HEDR. Pacific Northwest Laboratory, Richland, WA.

Ebert, E. S., N. W. Harrington, K. J. Boyle, J. W. Knight, and R. E. Keenan. Estimating Consumption of Freshwater Fish Among Maine Anglers, North American Journal of Fish Management. 13(4), 737-745 (1993),

Eckerman, K. F., A. B. Wolbarst, and A. C. B. Richardson. 1988. Limiting Values of Radionuclide Intake and Air Concentration and Dose Conversion Factors for Inhalation, Submersion, and Ingestion, Federal Guidance Report No. 11, EPA-520/1-88-020, U.S. Environmental Protection Agency, Washington, DOE.

Eckerman, K. F. and J. Ryman. 1993. External Exposure to Radionuclides in Air, Water, and Soil, Federal Guidance Report No. 12, EPA-402-R-93-081, U.S. Environmental Protection Agency, Washington, DOE.

EPA (U.S. Environmental Protection Agency). 1986. Development of Advisory Levels for Polychlorinated Biphenyls (PCBs) Cleanup, Office of Health and Environmental Assessment, Exposure Assessment Group, Washington, D.C., EPA/600/6-86/002, NTIS PB86-232774.

EPA. 1988. Superfund Exposure Assessment Manual, EPA/540/1-88/001, OSWER Directive 9285.51, Washington, D.C.

EPA. 1989. Risk Assessment Guidance for Superfund. Human Health Evaluation Manual, Part A, EPA/540/1-89/002, Office of Emergency and Remedial Response, Toxics Integration Branch, Washington, D.C.

EPA. 1991a. Risk Assessment Guidance for Superfund. Volume I: Human Health Evaluation Manual. Supplemental Guidance. 'Standard Default Exposure Factors" Interim Final, OSWER Directive 9285.6-03, Office of Emergency and Remedial Response, Toxics Integration Branch, Washington, D.C.

EPA. 1991b. Supplemental Risk Assessment Guidance for Superfund, Region X, Seattle, WA.

EPA. 1992a. Dermal Exposure Assessment: Principles and Applications EPA/600/8-91/011B, Office of Research and Development.

EPA. 1992b. MMSOILS: Multimedia Contaminant Fate, Transport, and Exposure Model, Documentation and User's Manual, Washington, D.C.

EPA. 1994. Health Effects Assessment Summary Tables (HEAST), Office of Solid Waste and Emergency Response, Washington D.C. EPA/540/R-94/020.

Gelhar, L. W., A. Mantoglou, C. Welty, and K. R. Rehfeldt. 1985. A Review of Field Scale Physical Solute Transport Processes in Saturated and Unsaturated Porus Media," EPRI EA-4190, Project 2485-5, Palo Alto, California.

Healy, W. B. 1968. Ingestion of Soil by Dairy Cows, New Zeal J Agric Res. 11:487-499. 
International Commission on Radiological Protection (ICRP). 1975. Report of the Task Group on Reference Man, ICRP Publication 23, Pergamon Press, New York.

International Commission on Radiological Protection (ICRP). 1979-1988. Limits for Intakes of Radionuclides by Workers, ICRP Publication 30, Parts 1-4 (and supplements) Vol. 2 (No. 3/4), Vol. 4 (No. 3/4), Vol. 6 (No. 2/3), and Vol. 19 (No. 4), Pergamon Press, New York.

King, M. B. 1969. Phase Equilibrium in Mixtures, Pergamon Press.

Lide, David R., Ed. 1993. CRC Handbook of Chemistry and Physics, 74th edition, CRC Press, Boca Raton, Florida (standard reference for physical data and mathematical information).

Nuclear Regulatory Commission. 1977. Regulatory Guide 1.109, U.S. Nuclear Regulatory Commission, Washington D.C.

Soldat, J. K. and R. D. Harr. 1971. Radiation Dose Model pp. 81-175 in (J.F. Fletcher and W.L. Dotson, compilers) HERMES - A Digital Computer Code for Estimating Regional Radiological Effects from the Nuclear Power Industry, USAEC Report HEDL-TME-71-68. Hanford Engineering Development Laboratory, Richland, WA.

Streile, G. P. 1995. Processes and Theory to be Implemented in the Source-Term Mass Budget Code (with a Special Focus on Volatilization), prepared for the PNL MEPAS Development Team.

Thibodeaux, L. J. and S.T. Hwang. 1982. Landfarming of Petroleum Wastes - Modeling the Air Emission Problem, Environ. Prog. 1(1):42-46.

Yu, C., A. J. Zielen, J.-J. Cheng, Y. C. Yuan, L. G. Jones, D. J. LePoire, Y. Y. Wang, C. O. Loureiro, E. Gnanapragasam, E. Faillace, A. Wallo III, W. A. Williams, and H. Peterson. 1993. Manual for Implementing Residual Radioactive Material Guidelines Using RESRAD, Version 5.0, Environmental Assessment Division, Argonne National Laboratory, Distribution Category UC-902. 
Table 9.1. Characteristics of the landfill

\begin{tabular}{lcc}
\hline Source Characteristic & Units & Value \\
\hline Length & $\mathrm{m}$ & 243.8 \\
Width & $\mathrm{m}$ & 12.2 \\
Thickness of contaminated layer & $\mathrm{m}$ & 3.8 \\
Depth of overburden & $\mathrm{m}$ & 0.8 \\
Total soil porosity & - & 0.40 \\
b coefficient & - & 7.75 \\
Ratio of N-S to E-W & - & 20 \\
\hline
\end{tabular}

'Soil-specific exponent parameter representing the moisture retention relationship.

'Indicates that the source is located such that the longest side is along the N-S line.

Table 9.2a. Characteristics of contaminants at the site

\begin{tabular}{|c|c|c|}
\hline Chemical Characteristic & Methylene Chloride & Uranium-238 \\
\hline Inventory & $10^{8} \mathrm{~g}$ & $6 \mathrm{Ci}$ \\
\hline $\mathrm{K}_{\mathrm{d}}$ (source) & $0.01 \mathrm{~mL} \mathrm{~g}^{-1}$ & $75 \mathrm{~mL} \mathrm{~g}^{-1}$ \\
\hline $\mathrm{K}_{\mathrm{d}}(\mathrm{PSZ1})^{*}$ & $0.01 \mathrm{~mL} \mathrm{~g}^{-1}$ & $75 \mathrm{~mL} \mathrm{~g}^{-1}$ \\
\hline $\mathrm{K}_{\mathrm{d}}(\mathrm{PSZ2})^{\mathrm{a}}$ & $0.008 \mathrm{~mL} \mathrm{~g}^{-1}$ & $60 \mathrm{~mL} \mathrm{~g}^{-1}$ \\
\hline $\mathrm{K}_{\mathrm{d}}(\mathrm{SZ})^{\mathbf{2}}$ & $0.005 \mathrm{~mL} \mathrm{~g}^{-1}$ & $30 \mathrm{~mL} \mathrm{~g}^{-1}$ \\
\hline Soil concentration & $6,320 \mathrm{mg} \mathrm{kg}^{-1}$ & $379.2 \mathrm{pCi} \mathrm{g}^{-1}$ \\
\hline Initial leachate concentration & $\begin{array}{c}15,300 \mathrm{mg} \mathrm{L}^{-1} \\
\text { (assumed solubility at } 25^{\circ} \mathrm{C} \text { ) }\end{array}$ & $\begin{array}{c}5,057 \mathrm{pCi} \mathrm{L}^{-1} \text { and } 4,440 \mathrm{pCi} \mathrm{L}^{-1} \\
\text { user specified for MMSOILS } \\
\text { and MEPAS, respectivelyc (see } \\
\text { footnote d for RESRAD) }\end{array}$ \\
\hline Henry's Law coefficient & $0.003125 \mathrm{~atm} \mathrm{~m}^{3} \mathrm{~mol}^{-1}$ (at $25^{\circ} \mathrm{C}$ ) & $0 \mathrm{~atm} \mathrm{~m} \mathrm{~mol}^{-1}$ \\
\hline Saturated vapor pressure & $436 \mathrm{mmHg}\left(\right.$ at $\left.25^{\circ} \mathrm{C}\right)$ & $0 \mathrm{mmHg}$ \\
\hline Molecular weight & $84.93 \mathrm{~g} \mathrm{~mol}^{-1}$ & $238 \mathrm{~g} \mathrm{~mol}^{-1}$ \\
\hline Radionuclide half-life & $N A^{b}$ & $4.46 \times 10^{9} \mathrm{yrs}$ \\
\hline Specific activity & NA & $3.36 \times 10^{5} \mathrm{pCi} \mathrm{g}^{-1}$ \\
\hline
\end{tabular}

PSZ1 = Partially saturated zone 1.

PSZ2 = Partially saturated zone 2 .

$\mathrm{SZ}=$ Saturated zone.

(See Fig. 9.1 for the relationship between PSZ1, PSZ2, and SZ.)

'NA = Not applicable.

The reason for this difference is that MMSOILS uses a source bulk density of $1.4 \mathrm{~g} \mathrm{~cm}^{-3}$, and MEPAS uses a source bulk density of $1.59 \mathrm{~g} \mathrm{~cm}^{-3}$.

RESRAD calculates the initial uranium-238 concentration as discussed in Sect. 9.2.2.2, based on data supplied in

Tables 9.1,9.2, and 9.3. 
Table 9.2b. Soil-water distribution coefficients $\left(K_{d}\right.$ values") for decay products of uranium-238

\begin{tabular}{lcccccc}
\hline & \multicolumn{3}{c}{ RESRAD } & & \multicolumn{3}{c}{ MEPAS } \\
\cline { 2 - 7 } Contaminant & $\begin{array}{c}\mathrm{K}_{\mathrm{d}} \\
(\mathrm{PSZ1}) \\
\left(\mathrm{mL} \mathrm{g}^{-1}\right)\end{array}$ & $\begin{array}{c}\mathrm{K}_{\mathrm{d}} \\
(\mathrm{PSZ}) \\
\left(\mathrm{mL} \mathrm{g}^{-1}\right)\end{array}$ & $\begin{array}{c}\mathrm{K}_{\mathrm{d}} \\
(\mathrm{SZ}) \\
\left(\mathrm{mL} \mathrm{g}^{-1}\right)\end{array}$ & $\begin{array}{c}\mathrm{K}_{\mathrm{d}}^{\mathrm{b}} \\
(\mathrm{PSZ} 1) \\
\left(\mathrm{mL} \mathrm{g}^{-1}\right)\end{array}$ & $\begin{array}{c}\mathrm{K}_{\mathrm{d}}^{\mathrm{b}} \\
(\mathrm{PSZ2}) \\
\left(\mathrm{mL} \mathrm{g}^{-1}\right)\end{array}$ & $\begin{array}{c}\mathrm{K}_{\mathrm{d}}^{\mathrm{b}} \\
(\mathrm{SZ}) \\
\left(\mathrm{mL} \mathrm{g}^{-1}\right)\end{array}$ \\
\hline Thorium-234 & $\mathrm{NA}^{\mathrm{c}}$ & $\mathrm{NA}$ & $\mathrm{NA}$ & 75 & 60 & 30 \\
Uranium-234 & 75 & 60 & 30 & 75 & 60 & 30 \\
Thorium-230 & 80 & 50 & 30 & 75 & 60 & 30 \\
Radium-226 & 20 & 15 & 7 & 75 & 60 & 30 \\
Radon-222 & $\mathrm{NA}$ & $\mathrm{NA}$ & $\mathrm{NA}$ & 75 & 60 & 30 \\
Lead-210 & 25 & 12 & 6 & 75 & 60 & 30 \\
Bismuth-210 & $\mathrm{NA}$ & $\mathrm{NA}$ & $\mathrm{NA}$ & 75 & 60 & 30 \\
Polonium-210 & 6 & 4 & 2 & 75 & 60 & 30 \\
\hline aAlK
\end{tabular}

All $\mathrm{K}_{d}$ values are specific to this multimedia scenario and are not transferable to other sites.

${ }^{6} \mathrm{~K}_{\mathrm{d}}$ values for decay products are assumed by MEPAS to be the same as parent contaminants for groundwater transport.

Not analyzed.

Table 9.3. Characteristics of vadose zone soils at the facility

\begin{tabular}{llll}
\hline Property & Units & PSZ1 $^{\mathrm{b}}$ & PSZ2 \\
\hline Thickness & $\mathrm{m}$ & $10.4^{\mathrm{c}}$ & 100 \\
Bulk density & $\mathrm{g} \mathrm{cm}^{-3}$ & 1.4 & 1.5 \\
Total porosity & dimensionless & 0.486 & 0.43 \\
$\begin{array}{l}\text { Effective porosity } \\
\text { (used by RESRAD only) }\end{array}$ & dimensionless & 0.12 & 0.11 \\
Field capacity & dimensionless & 0.375 & 0.32 \\
$\begin{array}{l}\text { Saturated } \\
\text { hydraulic conductivity }\end{array}$ & $\mathrm{cm}$ hr-1 & 45.8 & 2.32 \\
b coefficient & dimensionless & 7.75 & 10.4 \\
Percent organic matter & dimensionless & 0.002 & 0 \\
Soil erodibility factor & dimensionless & 0.37 & 0.14 \\
Linear dispersivity & $\mathrm{m}$ & 0.15 & 1 \\
Wilting point & dimensionless & 0.210 & 0.210 \\
Depth of root zone & $\mathrm{cm}$ & 10 & $\mathrm{NA}$ \\
\hline
\end{tabular}

Soil-specific exponent parameter representing the moisture retention relationship.

bAlso properties of overburden.

From base of source. Total thickness of PSZI, including the thickness of the source $(3.8 \mathrm{~m})$ and overburden $(0.8 \mathrm{~m})$ is $15 \mathrm{~m}$. 
Table 9.4. Characteristics of saturated zone soils and the aquifer at the facility

\begin{tabular}{|c|c|c|}
\hline Property & Units & Value \\
\hline Thickness & $\mathrm{m}$ & 120 \\
\hline Bulk density & $\mathrm{g} \mathrm{cm}^{-3}$ & 1.5 \\
\hline Total porosity & dimensionless & 0.43 \\
\hline Effective porosity & dimensionless & 0.18 \\
\hline Hydraulic conductivity & $\mathrm{m} \mathrm{yr}^{-1}$ & 1314 \\
\hline Groundwater pore water velocity & $\mathrm{m} \mathrm{yr}^{-1}$ & 146 \\
\hline Hydraulic gradient & dimensionless & 0.02 \\
\hline $\mathrm{b}$ coefficient & dimensionless & 4.38 \\
\hline Percent organic matter & dimensionless & 0 \\
\hline Longitudinal dispersivity & $\mathbf{m}$ & $\begin{array}{l}\text { scale dependent: } \alpha_{L}=0.1 \mathrm{x} \text {, where } \\
\mathrm{x}=\text { distance to receptor in meters }\end{array}$ \\
\hline Transverse dispersivity & $\mathbf{m}$ & scale dependent: $\alpha_{\mathrm{T}}=0.2 \alpha_{\mathrm{L}}$ \\
\hline Vertical dispersivity & $\mathrm{m}$ & scale dependent: $\alpha_{v}=1.16 \times 10^{-3} \alpha_{L}$ \\
\hline
\end{tabular}

Soil-specific exponent parameter representing the moisture retention relationship. 
Table 9.5. Monthly climatological data for the site

\begin{tabular}{|c|c|c|c|c|c|c|c|}
\hline Stati & Elevation: & & & & & & \\
\hline AneI & meter Height & & & & & & \\
\hline Stati & latitude: & & & & & & \\
\hline Top & il Moisture Ca & acity & & & & & \\
\hline SCS & urve Number & & & & & & \\
\hline Month & $\begin{array}{c}\text { Temperature } \\
\left({ }^{\circ} \mathrm{C}\right)\end{array}$ & $\begin{array}{l}\text { Precipitatio } \\
\text { (cm) }\end{array}$ & $\begin{array}{l}\text { Wind } \\
\text { Speed } \\
\left(\mathrm{m} \mathrm{s}^{-1}\right)\end{array}$ & $\begin{array}{l}\text { Cloud } \\
\text { Cover } \\
\text { (10ths) }\end{array}$ & $\begin{array}{l}\text { Precipitation } \\
\text { Days } \\
\text { (\#) }\end{array}$ & $\begin{array}{c}\text { Maximum } \\
\text { Humidity } \\
(\%)\end{array}$ & $\begin{array}{c}\text { Minimum } \\
\text { Humidity } \\
\text { (\%) }\end{array}$ \\
\hline $\operatorname{Jan}$ & 1.67 & 1.17 & 5.81 & 5.2 & 4.1 & 71 & 48 \\
\hline Feb & 3.89 & 1.45 & 6.30 & 5.2 & 4.4 & 71 & 42 \\
\hline Mar & 7.78 & 2.21 & 6.93 & 5.3 & 4.7 & 68 & 35 \\
\hline Apr & 13.3 & 2.74 & 6.93 & 5.0 & 5.0 & 67 & 31 \\
\hline May & 18.3 & 7.09 & 6.57 & 5.1 & 8.2 & 73 & 36 \\
\hline Jun & 23.9 & 8.89 & 6.39 & 4.3 & 8.2 & 76 & 39 \\
\hline Jul & 25.6 & 6.86 & 5.63 & 4.5 & 8.3 & 72 & 37 \\
\hline Aug & 25.0 & 7.49 & 5.41 & 4.3 & 8.3 & 77 & 42 \\
\hline Sep & 21.1 & 4.37 & 5.81 & 4.1 & 5.8 & 79 & 44 \\
\hline Oct & 15.0 & 3.53 & 5.81 & 4.0 & 5.0 & 72 & 42 \\
\hline Nov & 7.22 & 1.47 & 5.86 & 4.4 & 3.3 & 73 & 48 \\
\hline Dec & 3.33 & 1.24 & 5.81 & 4.9 & 3.8 & 70 & 48 \\
\hline & Total & & & Total days & & & \\
\hline & Precipitation: & 48.5 & & precipitatio & 69.2 & & \\
\hline
\end{tabular}


Table 9.6. Joint frequency wind speed data for the facility

\begin{tabular}{|c|c|c|c|c|c|c|c|}
\hline \multirow[b]{2}{*}{ Stability } & \multirow[b]{3}{*}{ Direction } & \multicolumn{5}{|c|}{ Wind speed $\left(\mathrm{m} \mathrm{s}^{-1}\right)$} & \multirow{3}{*}{$>21$} \\
\hline & & $1-3$ & $4-6$ & $7-10$ & $11-16$ & $17-21$ & \\
\hline Class & & & & & & & \\
\hline $\bar{A}$ & $\mathbf{N}$ & 0.00218 & 0.000205 & $\mathbf{0}$ & 0 & 0 & $\mathbf{0}$ \\
\hline (very & NNE & 0.000075 & 0.000137 & 0 & 0 & 0 & 0 \\
\hline \multirow[t]{14}{*}{ unstable) } & $\mathrm{NE}$ & 0 & 0 & $\mathbf{0}$ & 0 & 0 & $\mathbf{0}$ \\
\hline & ENE & 0.000075 & 0.000137 & 0 & 0 & 0 & 0 \\
\hline & E & 0.000037 & 0.000068 & 0 & 0 & 0 & 0 \\
\hline & ESE & 0.000112 & 0.000205 & 0 & 0 & 0 & 0 \\
\hline & SE & 0.000181 & 0.000137 & 0 & 0 & 0 & 0 \\
\hline & SSE & 0.000037 & 0.000068 & 0 & 0 & 0 & $\mathbf{0}$ \\
\hline & $\mathbf{s}$ & 0.000149 & 0.000274 & 0 & 0 & 0 & 0 \\
\hline & SSW & 0.000249 & 0.000068 & 0 & 0 & 0 & 0 \\
\hline & sw & 0.000037 & 0.000068 & 0 & 0 & 0 & 0 \\
\hline & wsw & 0.000181 & 0.000137 & 0 & 0 & 0 & 0 \\
\hline & w & 0.000181 & 0.000137 & 0 & 0 & 0 & 0 \\
\hline & WNW & 0 & 0 & 0 & 0 & 0 & 0 \\
\hline & NW & 0.000249 & 0.000068 & 0 & 0 & 0 & 0 \\
\hline & $\mathrm{NNW}$ & 0 & 0 & 0 & 0 & 0 & 0 \\
\hline B & $\mathbf{N}$ & 0.000104 & 0.00089 & 0.000137 & 0 & 0 & 0 \\
\hline \multirow[t]{15}{*}{ (unstable) } & NNE & 0.000032 & 0.000274 & 0.000342 & $\mathbf{0}$ & 0 & 0 \\
\hline & NE & 0.000125 & 0.000411 & 0.000411 & $\mathbf{0}$ & 0 & 0 \\
\hline & ENE & 0.000141 & 0.000548 & 0.000137 & $\mathbf{0}$ & 0 & 0 \\
\hline & E & 0.000451 & 0.001233 & 0.000548 & $\mathbf{0}$ & 0 & 0 \\
\hline & ESE & 0.000201 & 0.000411 & 0.000068 & 0 & 0 & 0 \\
\hline & SE & 0.000141 & 0.000548 & 0.000753 & 0 & 0 & 0 \\
\hline & SSE & 0.000141 & 0.000548 & 0.000479 & $\mathbf{0}$ & 0 & 0 \\
\hline & $\mathbf{S}$ & 0.000334 & 0.00089 & 0.001027 & 0 & 0 & 0 \\
\hline & SSW & 0.000048 & 0.000411 & 0.000685 & 0 & 0 & 0 \\
\hline & sw & 0.000117 & 0.000342 & 0.000685 & 0 & 0 & 0 \\
\hline & WSW & 0.000048 & 0.000411 & 0.000822 & 0 & 0 & 0 \\
\hline & W & 0.00072 & 0.000616 & 0.000685 & 0 & 0 & 0 \\
\hline & WNW & 0.000141 & 0.000548 & 0.000753 & $\mathbf{0}$ & 0 & 0 \\
\hline & NW & 0.000342 & 0.000959 & 0.00089 & $\mathbf{0}$ & 0 & 0 \\
\hline & NNW & 0.000165 & 0.000753 & 0.000685 & 0 & 0 & 0 \\
\hline
\end{tabular}


Table 9.6. (continued)

\begin{tabular}{|c|c|c|c|c|c|c|c|}
\hline \multirow[b]{2}{*}{$\begin{array}{l}\text { Stability } \\
\text { Class }\end{array}$} & \multirow[b]{2}{*}{ Direction } & \multicolumn{6}{|c|}{ Wind speed $\left(\mathrm{m} \mathrm{s}^{-1}\right)$} \\
\hline & & $1-3$ & $4-6$ & $7-10$ & $11-16$ & $17-21$ & $>21$ \\
\hline c & $\mathbf{N}$ & 0.000066 & 0.000822 & 0.004452 & 0.00089 & 0.000342 & 0.000068 \\
\hline (slightly & NNE & 0.000112 & 0.000479 & 0.001781 & 0.000411 & 0.000274 & 0.000068 \\
\hline \multirow[t]{14}{*}{ unstable) } & $\mathrm{NE}$ & 0.000049 & 0.000616 & 0.001301 & 0.001233 & 0.000274 & 0.000068 \\
\hline & ENE & 0.000022 & 0.000274 & 0.00226 & 0.000342 & 0.000068 & 0 \\
\hline & E & 0.000044 & 0.000548 & 0.001986 & 0.000411 & 0.000068 & 0 \\
\hline & ESE & 0.000033 & 0.000411 & 0.001301 & 0.000342 & 0.000068 & 0 \\
\hline & SE & 0.000044 & 0.000548 & 0.001781 & 0.000822 & 0 & 0 \\
\hline & SSE & 0.000181 & 0.000411 & 0.002397 & 0.001301 & 0.000205 & 0.00205 \\
\hline & $\mathbf{s}$ & 0.000049 & 0.000616 & 0.005753 & 0.003356 & 0.001781 & 0.00548 \\
\hline & SSW & 0.000077 & 0.000959 & 0.004658 & 0.00411 & 0.001986 & 0.00342 \\
\hline & sw & 0.000161 & 0.001096 & 0.004178 & 0.003425 & 0.001507 & 0.000411 \\
\hline & WsW & 0.000161 & 0.001096 & 0.00271 & 0.001507 & 0.000479 & 0.00342 \\
\hline & w & 0.000145 & 0.00089 & 0.003493 & 0.001096 & 0.000205 & 0.000548 \\
\hline & WNW & 0.00023 & 0.001027 & 0.002603 & 0.000342 & 0 & 0.000068 \\
\hline & NW & 0.000093 & 0.001164 & 0.004726 & 0.00089 & 0 & 0.000068 \\
\hline & $\mathrm{NNW}$ & 0.000178 & 0.001301 & 0.00226 & 0.000616 & 0.000068 & 0.000137 \\
\hline D & $\mathrm{N}$ & 0.000048 & 0.001233 & 0.003493 & 0.014315 & 0.008904 & 0.005548 \\
\hline \multirow[t]{15}{*}{ (neutral) } & NNE & 0.000013 & 0.000342 & 0.00226 & 0.006849 & 0.004315 & 0.002466 \\
\hline & $\mathrm{NE}$ & 0.000027 & 0.000685 & 0.001712 & 0.004589 & 0.001918 & 0.000685 \\
\hline & ENE & 0.000095 & 0.000616 & 0.001849 & 0.002808 & 0.001233 & 0 \\
\hline & E & 0.000032 & 0.000822 & 0.002877 & 0.003562 & 0.000616 & 0 \\
\hline & ESE & 0.000029 & 0.000753 & 0.001575 & 0.002877 & 0.000616 & 0.000342 \\
\hline & SE & 0.000103 & 0.000822 & 0.002329 & 0.006096 & 0.002808 & 0.000822 \\
\hline & SSE & 0.000035 & 0.00089 & 0.00226 & 0.007603 & 0.003356 & 0.001644 \\
\hline & $\mathbf{S}$ & 0.000125 & 0.00137 & 0.004658 & 0.024863 & 0.018699 & 0.006781 \\
\hline & SSW & 0.000024 & 0.000616 & 0.003973 & 0.01774 & 0.009932 & 0.003425 \\
\hline & sw & 0.000122 & 0.001301 & 0.003904 & 0.01774 & 0.009932 & 0.002808 \\
\hline & WSW & 0.000111 & 0.001027 & 0.002945 & 0.01137 & 0.006438 & 0.004521 \\
\hline & W & 0.000032 & 0.000822 & 0.002192 & 0.006575 & 0.004178 & 0.003152 \\
\hline & WNW & 0.000019 & 0.000479 & 0.002397 & 0.004589 & 0.00137 & 0.000616 \\
\hline & NW & 0.000045 & 0.001164 & 0.003425 & 0.006438 & 0.001096 & 0.000959 \\
\hline & NNW & 0.000235 & 0.000548 & 0.002123 & 0.00589 & 0.002671 & 0.000247 \\
\hline
\end{tabular}




\section{$9-50$}

Table 9.6. (continued)

\begin{tabular}{|c|c|c|c|c|c|c|c|}
\hline \multirow[b]{2}{*}{$\begin{array}{l}\text { Stability } \\
\text { Class }\end{array}$} & \multirow[b]{2}{*}{ Direction } & \multicolumn{6}{|c|}{ Wind speed $\left(\mathrm{m} \mathrm{s}^{-1}\right)$} \\
\hline & & $1-3$ & $4-6$ & $7-10$ & $11-16$ & $17-21$ & $>21$ \\
\hline $\mathrm{E}$ & $\mathbf{N}$ & 0.000232 & 0.000959 & 0.005342 & 0.011918 & 0.007055 & 0.000452 \\
\hline (slightly & NNE & 0.000104 & 0.000342 & 0.003973 & 0.008014 & 0.004178 & 0.001507 \\
\hline \multirow[t]{14}{*}{ stable) } & NE & 0.000167 & 0.000205 & 0.003836 & 0.006438 & 0.001986 & 0.000411 \\
\hline & ENE & 0.00011 & 0.000411 & 0.002192 & 0.00363 & 0.000205 & 0.000137 \\
\hline & $E$ & 0.000157 & 0.000959 & 0.003219 & 0.003904 & 0.000274 & 0.000137 \\
\hline & ESE & 0.000265 & 0.000479 & 0.00363 & 0.003699 & 0.000685 & 0.000068 \\
\hline & SE & 0.000139 & 0.000753 & 0.00696 & 0.009863 & 0.002397 & 0.001027 \\
\hline & SSE & 0.000065 & 0.000753 & 0.008493 & 0.020822 & 0.004178 & 0.001096 \\
\hline & $s$ & 0.000232 & 0.000959 & 0.014041 & 0.046507 & 0.016301 & 0.002466 \\
\hline & SSW & 0.000041 & 0.000479 & 0.008151 & 0.021986 & 0.006164 & 0.000548 \\
\hline & sw & 0.000098 & 0.000274 & 0.006849 & 0.019178 & 0.003963 & 0.000616 \\
\hline & WSW & 0.000172 & 0.000274 & 0.003151 & 0.010548 & 0.001918 & 0.001164 \\
\hline & W & 0.000098 & 0.000274 & 0.001849 & 0.004589 & 0.002945 & 0.002123 \\
\hline & WNW & 0.000035 & 0.000411 & 0.001301 & 0.003082 & 0.000685 & 0.000411 \\
\hline & $N W$ & 0.000178 & 0.000342 & 0.003356 & 0.006233 & 0.001233 & 0.000822 \\
\hline & NNW & 0.000098 & 0.000274 & 0.001644 & 0.004726 & 0.002123 & 0.001164 \\
\hline F & $\mathbf{N}$ & 0 & 0.001918 & 0.007192 & 0 & 0 & 0 \\
\hline \multirow[t]{15}{*}{ (stable) } & NNE & 0 & 0.000685 & 0.003699 & 0 & 0 & 0 \\
\hline & $\mathrm{NE}$ & 0 & 0.000548 & 0.002562 & 0 & 0 & 0 \\
\hline & ENE & 0 & 0.000479 & 0.003288 & 0 & 0 & 0 \\
\hline & $E$ & 0 & 0.000548 & 0.004795 & 0 & 0 & 0 \\
\hline & ESE & 0 & 0.00089 & 0.003562 & 0 & 0 & 0 \\
\hline & SE & 0 & 0.001438 & 0.007603 & 0 & 0 & 0 \\
\hline & SSE & 0 & 0.001096 & 0.011096 & 0 & 0 & 0 \\
\hline & $\mathbf{S}$ & 0 & 0.002808 & 0.025274 & 0 & 0 & 0 \\
\hline & SsW & 0 & 0.001507 & 0.015959 & 0 & 0 & 0 \\
\hline & sw & 0 & 0.002123 & 0.020822 & 0 & 0 & 0 \\
\hline & Wsw & 0 & 0.001027 & 0.01 & 0 & 0 & 0 \\
\hline & w & 0 & 0.000959 & 0.006027 & 0 & 0 & 0 \\
\hline & WNW & 0 & 0.000685 & 0.00637 & 0 & 0 & 0 \\
\hline & NW & 0 & 0.001233 & 0.008973 & 0 & 0 & 0 \\
\hline & NNW & 0 & 0.000548 & 0.004658 & 0 & 0 & 0 \\
\hline
\end{tabular}


$9-51$

Table 9.6. (continued)

\begin{tabular}{|c|c|c|c|c|c|c|c|}
\hline \multirow[b]{2}{*}{$\begin{array}{l}\text { Stability } \\
\text { Class }\end{array}$} & \multirow[b]{2}{*}{ Direction } & \multicolumn{6}{|c|}{ Wind speed $\left(\mathrm{m} \mathrm{s}^{-1}\right)$} \\
\hline & & $1-3$ & $4-6$ & $7-10$ & $11-16$ & $17-21$ & $>21$ \\
\hline G & $\mathbf{N}$ & 0.000885 & 0.003493 & $\mathbf{0}$ & 0 & 0 & 0 \\
\hline (very & NNE & 0.000408 & 0.001781 & $\mathbf{0}$ & 0 & 0 & 0 \\
\hline \multirow[t]{14}{*}{ stable) } & $\mathrm{NE}$ & 0.000369 & 0.002055 & 0 & 0 & 0 & 0 \\
\hline & ENE & 0.000272 & 0.00137 & 0 & 0 & 0 & 0 \\
\hline & E & 0.000243 & 0.001164 & 0 & 0 & 0 & 0 \\
\hline & ESE & 0.00034 & 0.001301 & 0 & 0 & 0 & 0 \\
\hline & SE & 0.000457 & 0.002123 & 0 & $\mathbf{0}$ & 0 & 0 \\
\hline & SSE & 0.00033 & 0.001781 & 0 & 0 & 0 & 0 \\
\hline & $s$ & 0.001362 & 0.005205 & 0 & 0 & 0 & 0 \\
\hline & SSW & 0.001098 & 0.005548 & 0 & 0 & $\mathbf{0}$ & 0 \\
\hline & sw & 0.000777 & 0.004384 & 0 & 0 & 0 & 0 \\
\hline & wsw & 0.000543 & 0.003288 & 0 & 0 & 0 & 0 \\
\hline & W & 0.001001 & 0.004315 & 0 & 0 & 0 & 0 \\
\hline & WNW & 0.000563 & 0.003425 & 0 & 0 & 0 & 0 \\
\hline & NW & 0.000817 & 0.003562 & 0 & 0 & 0 & 0 \\
\hline & NNW & 0.000329 & 0.002329 & $\mathbf{0}$ & 0 & 0 & 0 \\
\hline
\end{tabular}


Table 9.7. Characteristics of river downgradient of the source

\begin{tabular}{lcc}
\hline Characteristic & Units & Value \\
\hline Width of river & $\mathrm{m}$ & 30.48 \\
Depth of river & $\mathrm{m}$ & 3.048 \\
$\begin{array}{l}\text { Annual average velocity } \\
\mathrm{m} \mathrm{s}^{-1}\end{array}$ & 0.61 \\
$\begin{array}{l}\text { Distance of river from center of source } \\
\begin{array}{l}\text { Distance to surface water receptor } \\
\text { from point of contaminated } \\
\text { groundwater interception }\end{array}\end{array}$ & $\mathrm{m}$ & 2000 \\
\hline
\end{tabular}


Table 9.8. Exposure and intake parameters for the multimedia modeling scenario

\begin{tabular}{|c|c|c|c|}
\hline Parameter & Units & Value & Reference \\
\hline Drinking water consumption & $\mathrm{L}_{\text {day }}{ }^{-1}$ & 2 & 1 \\
\hline Air inhalation & $\mathrm{m}^{3}$ day $^{-1}$ & 20 & 1 \\
\hline Meat consumption & $\mathrm{kg}$ day $^{-1}$ & 0.27 & 1 \\
\hline Milk consumption & L day ${ }^{1}$ & 0.76 & 1 \\
\hline $\begin{array}{l}\text { Leafy vegetable } \\
\text { consumption (wet weight) }\end{array}$ & $\mathrm{kg}$ day $^{-1}$ & 0.082 & 1 \\
\hline $\begin{array}{l}\text { Other vegetable consumption } \\
\text { (nonleafy vegetables, wet } \\
\text { weight) }\end{array}$ & $\mathrm{kg}_{\text {day }}{ }^{-1}$ & 1.75 & 1 \\
\hline Fish consumption & $\mathrm{kg}$ day $^{-1}$ & 0.012 & 9 \\
\hline Soil consumption & kg day ${ }^{-1}$ & $1.00 \times 10^{-4}$ & 1 \\
\hline Skin area for water exposure & $\mathrm{cm}^{2}$ & 23,000 & 2 \\
\hline $\begin{array}{l}\text { Duration of showering } \\
\text { exposure event }\end{array}$ & hr & 0.167 & 5 \\
\hline Showering events frequency & showers day-1 & 1 & 2 \\
\hline $\begin{array}{l}\text { Duration of swimming } \\
\text { exposure event }\end{array}$ & hr event ${ }^{-1}$ & $0.5^{\circ}$ & 4 \\
\hline Swimming events per year & events $y^{-1}$ & $24^{2}$ & 4 \\
\hline Skin area for soil exposure & $\mathrm{cm}^{2}$ & 5,800 & 2 \\
\hline $\begin{array}{l}\text { Dust (soil) adherence } \\
\text { factor }\end{array}$ & $\mathrm{mg} \mathrm{cm}^{-2}$ & 1 & 2 \\
\hline $\begin{array}{l}\text { Soil dermal exposure } \\
\text { frequency }\end{array}$ & exposures day ${ }^{-1}$ & 1 & 3 \\
\hline Average body weight & $\mathrm{kg}$ & 70 & 1 \\
\hline Average lifetime & $\mathrm{yr}$ & 70 & 3 \\
\hline $\begin{array}{l}\text { Fraction retained on plant } \\
\text { surfaces }\end{array}$ & dimensionless & 0.25 & 4 \\
\hline $\begin{array}{l}\text { Translocation factor } \\
\text { nonleafy vegetable } \\
\text { leafy vegetable } \\
\text { fodder }\end{array}$ & dimensionless & $\begin{array}{l}0.1 \\
1.0 \\
1.0\end{array}$ & $\begin{array}{l}4 \\
4 \\
4\end{array}$ \\
\hline
\end{tabular}


Table 9.8. (continued)

\begin{tabular}{|c|c|c|c|}
\hline Parameter & Units & Value & Reference \\
\hline Yield (wet weight) & $\mathrm{kg} \mathrm{m}^{-2}$ & & \\
\hline nonleafy vegetable & & 0.7 & 10 \\
\hline leafy vegetable & & 1.5 & 10 \\
\hline fodder & & 1.1 & 10 \\
\hline $\begin{array}{l}\text { Weathering decay half-life of } \\
\text { contaminants on crops }\end{array}$ & days & 12.6 & $\begin{array}{c}10 \\
\text { (also see footnote } b \text { ) }\end{array}$ \\
\hline Length of growing season & days & & \\
\hline nonleafy vegetable & & 60 & 4 \\
\hline leafy vegetable & & 90 & 4 \\
\hline fodder & & 30 & 4 \\
\hline Soil intake rate for meat animal & $\mathrm{kg}_{\mathrm{day}}{ }^{-1}$ & 0.5 & 6 \\
\hline Soil intake rate for milk animal & $k g$ day ${ }^{-1}$ & 0.5 & 7 \\
\hline $\begin{array}{l}\text { Feed rate for meat animal (wet } \\
\text { weight) }\end{array}$ & $\mathrm{kg}$ day $^{-1}$ & 68 & 8 \\
\hline $\begin{array}{l}\text { Feed rate for milk animal (wet } \\
\text { weight) }\end{array}$ & $\mathrm{kg}_{\mathrm{day}}{ }^{-1}$ & 55 & 8 \\
\hline Water intake by meat animal & $L$ day $^{-1}$ & 50 & 8 \\
\hline Water intake by milk animal & $L$ day $^{-1}$ & 60 & 8 \\
\hline $\begin{array}{l}\text { Fraction of feed contaminated } \\
\text { (meat and milk animals) }\end{array}$ & dimensionless & 1 & Assumption \\
\hline Agricultural areal soil density & $\mathrm{kg} \mathrm{m}^{-2}$ & 225 & See footnote c \\
\hline Irrigation rate & $\mathrm{cm} \mathrm{yr}^{-1}$ & 5.26 & Assumption \\
\hline
\end{tabular}

The total annual duration of swimming is $12 \mathrm{hr}$, in accordance with Nuclear Regulatory Commission, 1977.

MEPAS uses a fixed value of 14.

This value is calculated from product of assumed soil density $\left(1.5 \times 10^{3} \mathrm{~kg} \mathrm{~m}^{-3}\right)$ and soil plow layer depth $(0.15 \mathrm{~m})$.

References:

1. EPA, 1991a.

2. EPA, 1992a.

3. EPA, 1989.

4. Nuclear Regulatory Commission, 1977.

5. EPA, 1991b.

6. Darwin, 1990

7. Healy, 1968.

8. Soldat and Harr, 1971.

9. Ebert et al., 1993.

10. Yu et al. (1993). 
Table 9.9a. Contaminant-dependent transfer, dose conversion, and slope factors used by RESRAD and MMSOILS

\begin{tabular}{|c|c|c|c|c|c|c|c|}
\hline Parameter & $\begin{array}{r}\text { Methylene } \\
\text { Chloride" }\end{array}$ & Uranium-238, & Uranium-234" & Thorium-230 & Radium-226,o & Lead-210,d & Polonium-210 \\
\hline $\begin{array}{l}\text { Dose conversion factor, ingestion } \\
\left.\text { (mrem } \mathrm{pCi}^{-1}\right)\end{array}$ & - & $2.5 \times 10^{-4}$ & $2.6 \times 10^{-4}$ & $5.3 \times 10^{-4}$ & $1.1 \times 10^{-3}$ & $5.1 \times 10^{-3}$ & $1.6 \times 10^{-3}$ \\
\hline 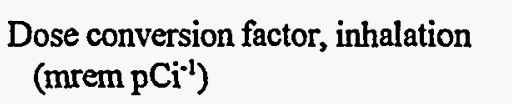 & - & $1.2 \times 10^{-1}$ & $1.3 \times 10^{-1}$ & $3.2 \times 10^{-1}$ & $7.9 \times 10^{-3}$ & $1.3 \times 10^{-2}$ & $8.1 \times 10^{-3}$ \\
\hline Slope factor, oral & $\begin{array}{l}0.0075 \\
\mathrm{~kg} \text { day mg-1 }\end{array}$ & $\begin{array}{l}2.8 \times 10^{-11} \\
\text { risk pCi.-1 }\end{array}$ & $\begin{array}{l}1.6 \times 10^{-11} \\
\text { risk pCi.-1 }\end{array}$ & $\begin{array}{l}1.3 \times 10^{-11} \\
\text { risk pCi }-.1\end{array}$ & $\begin{array}{l}1.2 \times 10^{-10} \\
\text { risk } \mathrm{pCi}^{-1}\end{array}$ & $\begin{array}{l}5.1 \times 10^{-10} \\
\text { risk } \mathrm{pCi}^{-1}\end{array}$ & $\begin{array}{l}1.5 \times 10^{-10} \\
\text { risk pCi-1 }\end{array}$ \\
\hline Slope factor, inhalation & $\begin{array}{l}0.0016 \\
\mathrm{~kg} \text { day } \mathrm{mg}-1\end{array}$ & $\begin{array}{l}5.2 \times 10^{-8} \\
\text { risk pCi-1 }\end{array}$ & $\begin{array}{l}2.6 \times 10^{-8} \\
\text { risk pCi-1 }\end{array}$ & $\begin{array}{l}2.9 \times 10^{-8} \\
\text { risk pCi-1 }\end{array}$ & $\begin{array}{l}3.0 \times 10^{-9} \\
\text { risk } \mathrm{pCi}^{-1}\end{array}$ & $\begin{array}{l}1.4 \times 10^{-9} \\
\text { risk } \mathrm{pCi}^{-1}\end{array}$ & $\begin{array}{l}2.6 \times 10^{-9} \\
\text { risk } \mathrm{pCi}^{-1}\end{array}$ \\
\hline Slope factor, dermal & $\begin{array}{c}0.0075 \\
\mathrm{~kg} \text { day } \mathrm{mg}^{-1}\end{array}$ & - & - & - & - & - & - \\
\hline $\begin{array}{l}\text { Slope factor, external gamma } \\
\left.\text { radiation (risk } \mathrm{yr}^{-1}\right)-\left(\mathrm{pCi}^{-1}\right)\end{array}$ & - & $5.1 \times 10^{-8}$ & $3.0 \times 10^{-11}$ & $5.4 \times 10^{-11}$ & $6.0 \times 10^{-6}$ & $1.3 \times 10^{-10}$ & $2.9 \times 10^{-11}$ \\
\hline Skin permeability constant $\left(\mathrm{cm} \mathrm{hr}^{-1}\right)$ & 0.0045 & - & - & - & - & - & - \\
\hline Cattle transfer factor $\left(\mathrm{d} \mathrm{kg}^{-1}\right)$ & $5.0 \times 10^{-7}$ & $3.4 \times 10^{-4}$ & $3.4 \times 10^{-4}$ & $1.0 \times 10^{-4}$ & $1.0 \times 10^{-3}$ & $8.0 \times 10^{-4}$ & $5.0 \times 10^{-3}$ \\
\hline Milk transfer factor $\left(\mathrm{d} \mathrm{L}^{-1}\right)$ & $1.6 \times 10^{-7}$ & $6.0 \times 10^{-4}$ & $6.0 \times 10^{-4}$ & $5.0 \times 10^{-6}$ & $1.0 \times 10^{-3}$ & $3.0 \times 10^{-4}$ & $3.4 \times 10^{-4}$ \\
\hline $\begin{array}{l}\text { Uptake from soil to plant } \\
\text { (mg dry soil)-(mg wet wt plant)-l }\end{array}$ & 1.71 & $2.5 \times 10^{-3}$ & $2.5 \times 10^{-3}$ & $1.0 \times 10^{-3}$ & 0.04 & 0.01 & $1.0 \times 10^{-3}$ \\
\hline
\end{tabular}


Table 9.9b. Contaminant-dependent transfer, dose conversion, and slope factors used by MEPAS and MMSOILS

\begin{tabular}{|c|c|c|c|c|c|c|c|c|c|c|}
\hline Parameter & $\begin{array}{l}\text { Methylene } \\
\text { Chloride" }\end{array}$ & $\begin{array}{c}\text { Uranium- } \\
238^{*} \\
\end{array}$ & $\begin{array}{c}\text { Thorium- } \\
234^{2,6}\end{array}$ & $\begin{array}{c}\text { Uranium- } \\
234^{2}\end{array}$ & $\begin{array}{c}\text { Thorium- } \\
230^{2}\end{array}$ & $\begin{array}{c}\text { Radium- } \\
226^{*}\end{array}$ & $\begin{array}{l}\text { Radon- } \\
222^{2, c}\end{array}$ & $\begin{array}{l}\text { Lead- } \\
210^{2}\end{array}$ & $\begin{array}{l}\text { Bismuth- } \\
210^{:} \\
\end{array}$ & $\begin{array}{l}\text { Polonium- } \\
210^{*} \\
\end{array}$ \\
\hline $\begin{array}{l}\text { Dose conversion factor, } \\
\text { ingestion (mrem } \mathrm{pCi}^{-1} \text { ) }\end{array}$ & - & $2.6 \times 10^{-4}$ & $1.4 \times 10^{-5}$ & $2.8 \times 10^{-4}$ & $5.5 \times 10^{-4}$ & $1.3 \times 10^{-3}$ & 0 & $5.4 \times 10^{-3}$ & $6.4 \times 10^{-6}$ & $1.9 \times 10^{-3}$ \\
\hline $\begin{array}{l}\text { Dose conversion factor, } \\
\left.\text { inhalation (mrem } \mathrm{pCi}^{-1}\right)\end{array}$ & - & $1.2 \times 10^{-1}$ & $3.5 \times 10^{-5}$ & $1.3 \times 10^{-1}$ & $3.3 \times 10^{-1}$ & $8.6 \times 10^{-3}$ & 0 & $1.4 \times 10^{-2}$ & $2.0 \times 10^{-4}$ & $9.4 \times 10^{-3}$ \\
\hline 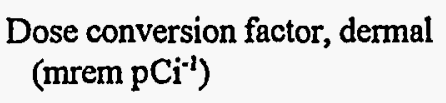 & - & $5.5 \times 10^{-3}$ & $3.9 \times 10^{-5}$ & $6.1 \times 10^{-3}$ & $2.5 \times 10^{0}$ & $5.5 \times 10^{-3}$ & 0 & $3.0 \times 10^{-2}$ & $2.7 \times 10^{-5}$ & $1.9 \times 10^{-2}$ \\
\hline Slope factor, oral & $\begin{array}{l}0.0075 \\
\mathrm{~kg} \text { day } \mathrm{mg}\end{array}$ & $\begin{array}{c}1.6 \times 10^{-11} \text { risk } \\
\mathrm{pCi}^{-1}\end{array}$ & $\begin{array}{l}4.0 \times 10^{-12} \\
\text { risk pCi-1 }\end{array}$ & $\begin{array}{c}1.6 \times 10^{-11} \text { risk } \\
\mathrm{pCi}^{-1}\end{array}$ & $\begin{array}{l}1.3 \times 10^{-11} \text { risk } \\
\mathrm{pCi}^{-1}\end{array}$ & $\begin{array}{l}1.2 \times 10^{-10} \\
\text { risk } \mathrm{pCi}^{-1}\end{array}$ & $\begin{array}{l}1.4 \times 10^{-12} \\
\text { risk pCi-1 }\end{array}$ & $\begin{array}{l}5.1 \times 10^{-10} \\
\text { risk } \mathrm{pCi}^{-1}\end{array}$ & $\begin{array}{l}1.6 \times 10^{-12} \\
\text { risk } \mathrm{pCi}^{-1}\end{array}$ & $\begin{array}{l}1.5 \times 10^{-10} \\
\text { risk } \mathrm{pCi}^{-1}\end{array}$ \\
\hline Slope factor, inhalation & $\begin{array}{c}0.0016 \\
\text { kg day mg }\end{array}$ & $\begin{array}{l}5.2 \times 10^{-8} \\
\text { risk } \mathrm{pCi}^{-1}\end{array}$ & $\begin{array}{l}3.2 \times 10^{-11} \\
\text { risk pCi-1 }\end{array}$ & $\begin{array}{c}2.6 \times 10^{-8} \text { risk } \\
\mathrm{pCi}^{-1}\end{array}$ & $\begin{array}{l}2.9 \times 10^{-8} \\
\text { risk } \mathrm{pCi}^{-1}\end{array}$ & $\begin{array}{l}3.0 \times 10^{-9} \\
\text { risk } \mathrm{pCi}^{-1}\end{array}$ & $\begin{array}{l}7.3 \times 10^{-13} \\
\text { risk pCi-1 }\end{array}$ & $\begin{array}{l}1.3 \times 10^{-9} \\
\text { risk } \mathrm{pCi}^{-1}\end{array}$ & $\begin{array}{l}8.0 \times 10^{-11} \\
\text { risk pCi-1 }\end{array}$ & $\begin{array}{l}2.6 \times 10^{-9} \\
\text { risk } \mathrm{pCi}^{-1}\end{array}$ \\
\hline Slope factor, dermal & $\begin{array}{c}0.0075 \\
\mathrm{~kg} \text { day } \mathrm{mg}\end{array}$ & - & - & - & - & - & - & - & - & - \\
\hline $\begin{array}{l}\text { Slope factor, external gamma } \\
\left.\text { radiation (risk yr-1)-(pCi g }{ }^{-1}\right)\end{array}$ & - & $2.1 \times 10^{-11}$ & $5.1 \times 10^{-8}$ & $3.0 \times 10^{-11}$ & $5.4 \times 10^{-11}$ & $6.0 \times 10^{-6}$ & $5.9 \times 10^{-6}$ & $1.3 \times 10^{-10}$ & $2.2 \times 10^{-9}$ & $2.9 \times 10^{-41}$ \\
\hline $\begin{array}{l}\text { Skin permeability constant } \\
\left(\mathrm{cm} \mathrm{h} r^{-1}\right)\end{array}$ & 0.0045 & 0.001 & 0.001 & 0.001 & 0.001 & 0.001 & 0.001 & $4.0 \times 10^{-6}$ & 0.001 & 0.001 \\
\hline Bioconcentration factor $\left(\mathrm{L} \mathrm{kg}^{-1}\right)$ & 5.0 & 10.0 & 100 & 10 & 100 & 50 & 0 & 300 & 15 & 100 \\
\hline Cattle transfer factor $\left(\mathrm{d} \mathrm{kg}^{-1}\right)$ & $5.0 \times 10^{-7}$ & $3.4 \times 10^{-4}$ & $1.0 \times 10^{-4}$ & $3.4 \times 10^{-4}$ & $1.0 \times 10^{-4}$ & $1.0 \times 10^{-3}$ & 0 & $8.0 \times 10^{-4}$ & $4.0 \times 10^{-4}$ & $5.0 \times 10^{-3}$ \\
\hline Milk transfer factor $\left(\mathrm{d} \mathrm{L}^{-1}\right)$ & $1.6 \times 10^{-7}$ & $6.0 \times 10^{-4}$ & $5.0 \times 10^{-6}$ & $6.0 \times 10^{-4}$ & $5.0 \times 10^{-6}$ & $1.0 \times 10^{-3}$ & 0 & $3.0 \times 10^{-4}$ & $5.0 \times 10^{-4}$ & $3.4 \times 10^{-4}$ \\
\hline $\begin{array}{l}\text { Uptake from soil to plant } \\
\text { (mg dry soil)-(mg wet wt } \\
\text { plant)-1 }\end{array}$ & 1.71 & $2.5 \times 10^{-3}$ & $1.0 \times 10^{-3}$ & $2.5 \times 10^{-3}$ & $1.0 \times 10^{-3}$ & 0.04 & 0 & 0.01 & $8.0 \times 10^{-4}$ & $1.0 \times 10^{-3}$ \\
\hline
\end{tabular}


Table 9.10. Summary of tables and figures that contain benchmarking results

Table/Figure No.

Table 9.11

Table 9.12

Table 9.13

Table 9.14

Table 9.16

Table 9.17

Table 9.18

Table 9.19

Table 9.20

Table 9.21

Figures 9.6 through 9.12

Figures 9.8 through 9.16

Figures 9.17 through 9.26

Figure 9.28, 9.29

Figures 9.30

Figures $9.31,9.32$
Benchmark Description

Travel time in partially saturated zones 1 and 2

Time to peak concentration at onsite and offsite wells

Maximum chemical concentrations in groundwater at onsite and offsite wells

Maximum dose and risk to onsite and offsite receptors - groundwater pathway

Maximum air concentration, maximum $\mathrm{chi}^{-1}$, and maximum deposition rates at the maximum offsite exposure point: $810 \mathrm{~m}$ northeast of the center of the source ${ }^{2}$

Maximum dose and risk to the receptor located at the facility boundary, $366 \mathrm{~m}$ to the north of center of source - air pathway

Maximum dose and risk at the maximum offsite exposure point, located $810 \mathrm{~m}$ to the northeast of source - air pathway

Maximum surface water concentration, dose, and risk to surface water receptor

Total multimedia risk at onsite receptor

Total multimedia risk at offsite receptor

Chemical fluxes from landfill

Chemical fluxes from PSZ1 to PZ2, and from PSZ2 to SZ

Chemical concentrations in onsite and offsite wells

Chemical emission rates to atmosphere

Time series of atmospheric methylene chloride concentrations at maximum exposure point $(810 \mathrm{~m}$ northeast of center of source)

Chemical emission rates from SZ to SW

$$
\text { chi } q^{-1}=\frac{C_{a}}{E_{a}}
$$

where

$$
\begin{aligned}
& \text { chi } \mathrm{q}^{-1}=\text { emission normalized air concentration }\left(\mathrm{s} \mathrm{m}^{-3}\right) \\
& \mathrm{C}_{\mathrm{a}}=\text { chemical concentration in air }\left(\mathrm{mg} \mathrm{m}^{-3} \text { or pCi m} \mathrm{m}^{-3}\right) \\
& \mathrm{E}_{\mathrm{a}}=\text { air emission rate }\left(\mathrm{mg} \mathrm{s}^{-1} \text { or } \mathrm{pCi} \mathrm{s}\right)
\end{aligned}
$$


Table 9.11. Travel time in partially saturated zones 1 and 2

\begin{tabular}{lccc|ccc}
\hline & \multicolumn{3}{c|}{ Travel Time (yr) - PSZ1 } & \multicolumn{3}{c}{ Travel Time (yx) - PSZ2 } \\
\cline { 2 - 7 } \multicolumn{1}{c}{ Contaminant } & RESRAD & MMSOILS & MEPAS & RESRAD & MMSOILS & MEPAS \\
\hline Methylene chloride & 52.4 & 214 & 318 & 601 & 2,156 & 2,612 \\
Uranium-238 & 21,300 & 86,200 & 86,300 & 182,000 & 630,713 & 711,100 \\
Thorium-234 & NA & NA & NR & NA & NA & NR \\
Uranium-234 & 21,300 & NA & NR & 182,000 & NA & NR \\
Thorium-230 & 22,700 & NA & NR & 152,000 & NA & NR \\
Radium-226 & 5,720 & NA & NR & 45,900 & NA & NR \\
Radon-222 & NA & NA & NR & NA & NA & NR \\
Lead-210 & 7,130 & NA & NR & 36,900 & NA & NR \\
Bismuth-210 & NA & NA & NR & NA & NA & NR \\
Polonium-210 & 1,750 & NA & NR & 12,700 & NA & NR \\
\hline
\end{tabular}

$\mathrm{NR}=$ Not reported.

$\mathrm{NA}=$ Not analyzed.

Table 9.12. Time to peak concentration at onsite and offsite wells

\begin{tabular}{lccc|ccc}
\hline & \multicolumn{3}{c|}{ Time to Peak (yr) at Onsite Well } & \multicolumn{3}{c}{ Time to Peak (yr) at Offsite Well } \\
\cline { 2 - 7 } \multicolumn{1}{c}{ Contaminant } & RESRAD & MMSOIL & MEPAS & RESRAD & MMSOILS & MEPAS \\
\hline Methylene chloride & 657 & 2,430 & 2,970 & 659 & 2,430 & 2,973 \\
Uranium-238 & 204,000 & 754,000 & 788,000 & 204,000 & 754,000 & 788,000 \\
Thorium-234 & NA & NA & 788,000 & NA & NA & 788,000 \\
Uranium-234 & 204,000 & NA & 798,000 & 204,000 & NA & 798,000 \\
Thorium-230 & 204,000 & NA & 798,000 & 204,000 & NA & 798,000 \\
Radium-226 & 204,000 & NA & 798,000 & 204,000 & NA & 798,000 \\
Radon-222 & NA & NA & 798,000 & NA & NA & 798,000 \\
Lead-210 & 204,000 & NA & 798,000 & 204,000 & NA & 798,000 \\
Bismuth-210 & NA & NA & 798,000 & NA & NA & 798,000 \\
Polonium-210 & 204,000 & NA & 798,000 & 204,000 & NA & 798,000 \\
\hline
\end{tabular}

$\mathrm{NA}=$ Not analyzed. 
Table 9.13. Maximum contaminant concentrations in groundwater at onsite and offsite wells

\begin{tabular}{lccc|ccc}
\hline & \multicolumn{3}{c|}{ Concentration at Onsite Well } & \multicolumn{3}{c}{ Concentration at Offsite Well } \\
\cline { 2 - 7 } \multicolumn{1}{c}{ Contaminant } & RESRAD & MMSOIS & MEPAS & RESRAD & MMSOILS & MEPAS \\
\hline Methylene chloride, mg L-1 & 11.90 & 0.58 & 2.3 & 6.42 & 0.16 & 0.67 \\
Uranium-238, pCi L-1 & 3.93 & 0.64 & 0.064 & 2.15 & 0.18 & 0.019 \\
Thorium-234, pCi L-1 & NA & NA & 0.064 & NA & NA & 0.019 \\
Uranium-234, pCi L-1 & 1.72 & NA & 0.058 & 0.94 & NA & 0.017 \\
Thorium-230, pCi L-1 & 0.24 & NA & 0.055 & 0.13 & NA & 0.016 \\
Radium-226, pCi L-1 & 0.76 & NA & 0.055 & 0.42 & NA & 0.016 \\
Radon-222, pCi L-1 & NA & NA & 0.055 & NA & NA & 0.016 \\
Lead-210, pCi L-1 & 0.89 & NA & 0.055 & 0.49 & NA & 0.016 \\
Bismuth-210, pCi L-1 & NA & NA & 0.055 & NA & NA & 0.016 \\
Polonium-210, pCi L-1 & 2.71 & NA & 0.055 & 1.48 & NA & 0.016 \\
\hline
\end{tabular}

$\mathrm{NA}=$ Not analyzed. 

Table 9.14. Maximum dose ${ }^{a}$ and risk ${ }^{\mathrm{a}}$ to onsite and offsite receptors .

\begin{tabular}{|c|c|c|c|c|c|c|c|c|c|c|c|c|}
\hline & & & & & & & \multicolumn{6}{|c|}{ Onsite receptor } \\
\hline & \multicolumn{3}{|c|}{ Methylene Chloride } & \multicolumn{2}{|c|}{ Uranium-238 } & \multicolumn{2}{|c|}{ Thorium-234 } & \multicolumn{2}{|c|}{ Uranium-234 } & \multicolumn{2}{|c|}{ Thorium-230 } & \multirow[b]{2}{*}{ RI } \\
\hline & RESRAD & MMSOILS & MEPAS & RESRA & MEPAS & RESRA & MEPAS & RESRAD & MEPAS & RESRAD & MEPAS & \\
\hline \multicolumn{13}{|l|}{ Intake/Dase } \\
\hline Drinking Water Ingestion & 0.34 & $1.7 \times 10^{-2}$ & $6.5 \% 10^{-2 b}$ & 0.72 & $1.2 \times 10^{-2}$ & INC. & $6.4 \% 10^{-4}$ & 0.33 & $1.2 \times 10^{-2}$ & $9.3 \times 10^{-2}$ & $2.1 \times 10^{-2}$ & \\
\hline Leafy Vegetable Ingestion & NR & $7.3 \times 10^{-6}$ & $1.3 \times 10^{-3 \mathrm{~h}}$ & NR & $2.6 \times 10^{-4}$ & INC. & $7.7 \% 10^{-6}$ & NR & $2.4 \times 10^{-4}$ & NR & $4.6 \times 10^{-4}$ & \\
\hline Non-leafy Vegetable Ingestion & NR & $1.0 \times 10^{-3}$ & $6.0 \% 10^{.3 h}$ & NR & $1.3 \times 10^{-3}$ & INC. & $6.6 \times 10^{-6}$ & NR & $1.3 \times 10^{-3}$ & NR & $2.3 \times 10^{-3}$ & \\
\hline Total Vegetable Ingestion & $4.8 \times 10^{-2}$ & NR & NR & $7 \times 10^{-2}$ & NR & INC. & NR & $3.2 \times 10^{-2}$ & NR & $9.1 \times 10^{-3}$ & NR & 6 \\
\hline Meal Ingestion & $1.9 \times 10^{-6}$ & $5.7 \times 10^{-8}$ & $3.7 \times 10^{-7 b}$ & $2.7 \times 10^{-3}$ & $4.9 \times 10^{-3}$ & INC. & $4.7 \times 10^{-4}$ & $1.2 \times 10^{-3}$ & $4.4 \% 10^{-1}$ & $1.0 \times 10^{-4}$ & $3.9 \times 10^{-1}$ & 6 \\
\hline Milk Ingestion & $1.8 \div 10^{-6}$ & $5.2 \times 10^{-8}$ & $3.5 \% 10^{-7 b}$ & $1.4 \times 10^{-2}$ & $4.3 \times 10^{-3}$ & INC. & $1.6 \times 10^{-3}$ & $6.4 \% 10^{-3}$ & $1.6 \times 10^{-3}$ & $1.5 \times 10^{-5}$ & $1.2 \times 10^{-3}$ & 2 \\
\hline Total & NR & NR & NR & 0.8 & NR & INC. & NR & 0.37 & NR & 0.1 & NR & \\
\hline \multicolumn{13}{|l|}{ Risk } \\
\hline Drinking Water Ingestion & $2.5 \times 10^{-3}$ & $1.3 \times 10^{-4}$ & $4.9 \times 10^{-4}$ & $5.6 \times 10^{-6}$ & $5.3 \times 10^{-8}$ & INC. & $1.3 \% 10^{-8}$ & $1.4 \times 10^{-5}$ & $4.7 \times 10^{-8}$ & $1.6 \times 10^{-7}$ & $3.6 \times 10^{-8}$ & 4 \\
\hline Leafy Vegetable Ingestion & NR & $5.4 \times 10^{-8}$ & $9.9 \% 10^{-4 \pi}$ & NR & $1.1 \times 10^{-4}$ & INC. & $1.6 \times 10^{-10}$ & NR & $9.8 \times 10^{-10}$ & NR & $7.8 \times 10^{-10}$ & \\
\hline Non-leafy Vegetable Ingestion & NR & $7.7 \times 10^{-4}$ & $4.5 \% 10^{-5}$ & NR & $5.8 \times 10^{-9}$ & INC. & $1.3 \times 10^{-10}$ & NR & $5.0 \times 10^{-4}$ & NR & $4.4 \times 10^{-9}$ & \\
\hline Total Vegetable Ingestion & $3.6 \times 10^{-4}$ & NR & NR & $5.5 \times 10^{-7}$ & NR & INC. & NR & $1.4 \times 10^{-7}$ & NR & $1.6 \times 10^{-8}$ & NR & 4 \\
\hline Meat Ingestion & $1.4 \times 10^{-*}$ & $4.3 \times 10^{-10}$ & $2.8 \times 10^{-4}$ & $2.1 \times 10^{-8}$ & $2.9 \times 10^{-8}$ & INC. & $2.8 \times 10^{-9}$ & $5.3 \% 10^{-9}$ & $2.6 \times 10^{-9}$ & $1.7 \times 10^{-10}$ & $2.3 \times 10^{-4}$ & 5 \\
\hline Milk Ingestion & $1.3 \times 10^{.8}$ & $3.9 \times 10^{-10}$ & $2.6 \% 10^{.4}$ & $1.1 \times 10^{-7}$ & $2.6 \times 10^{-8}$ & INC. & $9.7 \times 10^{.9}$ & $2.8 \times 10^{-8}$ & $9.1 \times 10^{-4}$ & $2.6 \times 10^{-11}$ & $7.7 \times 10^{.9}$ & 1. \\
\hline \multirow[t]{2}{*}{ Total } & $2.9 \times 10^{-3}$ & NR & NR & $6.3 \times 10^{-5}$ & NR & INC. & NR & $1.6 \times 10^{-4}$ & NR & $1.8 \times 10^{-7}$ & NR & 5 \\
\hline & & & & & & & \multicolumn{6}{|c|}{ Offsite receptor } \\
\hline \multicolumn{13}{|l|}{ Intake/Dose } \\
\hline Drinking Water Ingestion & $1.8 \times 10^{-1}$ & $4.5 \times 10^{-3}$ & $1.9 \% 10^{-2 \mathrm{t}}$ & $3.9 \times 10^{-1}$ & $3.4 \times 10^{-3}$ & INC. & $1.9 \times 10^{-4}$ & $1.8 \times 10^{-1}$ & $3.4 \times 10^{-3}$ & $5.1 \times 0^{-2}$ & $6.4 \times 10^{-3}$ & 3. \\
\hline Leafy Vegetable Ingestion & NR & $2.0 \times 10^{-6}$ & $3.9 \times 10^{-4 h}$ & NR & $7.3 \times 10^{-5}$ & INC. & $2.3 \times 10^{-6}$ & NR & $7.1 \times 10^{-5}$ & NR & $1.3 \times 10^{-4}$ & \\
\hline Non-leafy Vegetable Ingestion & NR & $2.8 \times 10^{-4}$ & $1.7 \% 10^{.3 \mathrm{~b}}$ & NR & $3.7 \times 10^{-4}$ & INC. & $1.9 \times 10^{-6}$ & NŔ & $3.7 \times 10^{-4}$ & NR & $6.4 \times 10^{-4}$ & \\
\hline Total Vegetable Ingestion & $2.6 \% 10^{-2}$ & NR & NR & $3.8 \times 10^{-2}$ & NR & INC. & NR & $1.7 \times 10^{-2}$ & NR & $5.0 \times 10^{-3}$ & NR & 3. \\
\hline Meat Ingestion & $1.0 \times 10^{-6}$ & $1.5 \times 10^{-8}$ & $1.1 \times 10^{.7 b}$ & $1.5 \% 10^{-3}$ & $1.4 \times 10^{-3}$ & INC. & $1.4 \times 10^{-4}$ & $6.7 \times 10^{-4}$ & $1.3 \times 10^{-4}$ & $5.6 \times 10^{-5}$ & $1.1 \times 10^{-4}$ & 3. \\
\hline Milk Ingestion & $9.7 \% 10^{-7}$ & $1.7 \times 10^{-8}$ & $1.0 \times 10^{-7 b}$ & $7.7 \% 10^{-3}$ & $1.2 \% 10^{-3}$ & INC. & $4.7 \times 10^{-1}$ & $3.5 \% 10^{-3}$ & $4.4 \times 10^{-4}$ & $8.3 \times 10^{-6}$ & $3.6 \times 10^{-4}$ & 1. \\
\hline Total & NR & NR & NR & $4.4 \times 10^{-1}$ & NR & INC. & NR & $2.0 \% 10^{-1}$ & NR & $5.6 \times 10^{-2}$ & NR & 3.: \\
\hline \multicolumn{13}{|l|}{ Risk } \\
\hline Drinking Water Ingestion & $1.4 \times 10^{.3}$ & $3.4 \times 10^{-5}$ & $1.4 \times 10^{-4}$ & $3.1 \times 10^{-6}$ & $1.5 \times 10^{-8}$ & INC. & $3.8 \times 10^{-9}$ & $7.7 \times 10^{-7}$ & $1.4 \times 10^{-8}$ & $8.7 \times 10^{-8}$ & $1.1 \times 10^{-8}$ & 2. \\
\hline Leafy Vegetable Ingestion & NR & $1.5 \times 10^{-8}$ & $2.9 \% 10^{-6}$ & NR & $3.3 \times 10^{-310}$ & INC. & $4.6 \times 10^{-11}$ & NR & $2.8 \% 10^{-10}$ & NR & $2.3 \times 10^{-10}$ & \\
\hline Non-lcafy Vegetable Ingestion & NR & $2.1 \times 10^{-6}$ & $1.3 \times 10^{-5}$ & NR & $1.7 \times 10^{-9}$ & INC. & $3.9 \times 10^{-11}$ & NR & $1.5 \times 10^{-4}$ & NR & $1.3 \times 10^{.9}$ & \\
\hline Total Vegetable Ingestion & $2.0 \% 10^{-4}$ & NR & NR & $3.0 \times 10^{-7}$ & NR & INC. & NR & $7.5 \% 10^{-8}$ & NR & $8.5 \times 10^{-9}$ & NR & $2 .:$ \\
\hline Meat Ingestion & $7.9 \times 10^{4}$ & $1.2 \times 10^{-10}$ & $8.3 \% 10^{-113}$ & $1.2 \times 10^{-8}$ & $8.4 \times 10^{-4}$ & INC. & $8.2 \times 10^{-10}$ & $2.9 \times 10^{-4}$ & $7.6 \times 10^{-111}$ & $9.7 \times 10^{-11}$ & $6.7 \times 10^{-101}$ & 2.8 \\
\hline Milk Ingestion & $7.3 \% .10^{.4}$ & $1.3 \times 10^{-10}$ & $7.7 \times 10^{-10}$ & $6.0 \times 10^{-8}$ & $7.6 \times 10^{-9}$ & INC. & $2.8 \times 10^{-9}$ & $1.5 \times 10^{-4}$ & $2.6 \times 10^{-9}$ & $1.4 \times 10^{-11}$ & $2.2 \times 10^{-4}$ & 8.2 \\
\hline Total & $1.6 \times 10^{3}$ & NR & NR & $3.5 \times 10^{-6}$ & NR & INC. & NR & $8.6 \times 10^{-7}$ & NR & $9.6 \times 10^{8}$ & NR & 2. \\
\hline
\end{tabular}

NR $=$ Not Reported.

INC. = Included in parent (thorium-234 is included in uranium-238, and bismuth-210 is included in lead-210).

'Units:

Intake/dose: $\mathrm{mg} \mathrm{kg}^{-1} \mathrm{day}^{-1}$ for methylene chloride and mrem $\mathrm{yr}^{-1}$ for radionuclides.

Risk: excess lifetime cancer risks.

"Not reported by MEPAS. Computed by dividing risk by the appropriate slope factor. 


\section{Onsite receptor}

\begin{tabular}{|c|c|c|c|c|c|c|c|c|c|c|c|c|c|c|}
\hline \multirow{2}{*}{$\begin{array}{l}\text { ium-234 } \\
1 \quad \text { MEPAS } \\
\end{array}$} & \multirow{2}{*}{\multicolumn{2}{|c|}{$\begin{array}{c}\text { Uranium-234 } \\
\text { RESRAD MEPAS } \\
\end{array}$}} & \multirow{2}{*}{\multicolumn{2}{|c|}{$\begin{array}{c}\text { Thorium-230 } \\
\text { RESRAD MEPAS } \\
\end{array}$}} & \multicolumn{2}{|c|}{ Radium-226 } & \multicolumn{2}{|c|}{ Radon-222 } & \multicolumn{2}{|c|}{ Lead-210 } & \multicolumn{2}{|c|}{ Bismuth-210 } & \multicolumn{2}{|c|}{ Polonium-210 } \\
\hline & & & & & RESRAD & MEPAS & RESRA & MEPAS & RESRA & MEPAS & RESRAD & MEPAS & RESRAD & MEPAS \\
\hline $6.4 \% 10^{-1}$ & 0.33 & $1.2 \times 10^{-2}$ & $9.3 \times 10^{-2}$ & $2.1 \times 10^{-2}$ & 0.61 & $5.3 \times 10^{-2}$ & NR & 0.0 & 3.3 & 0.21 & INC. & $2.6 \times 10^{-4}$ & 3.16 & $7.6 \times 10^{-2}$ \\
\hline $7.7 \% 10^{-4}$ & NR & $2.4 \times 10^{-1}$ & NR & $4.6 \times 10^{-4}$ & NR & $1.7 \times 10^{-3}$ & NR & $1.1 \times 10^{-4}$ & NR & $4.7 \times 10^{-3}$ & INC. & $2.0 \times 10^{-5}$ & INC. & $1.4 \times 10^{.3}$ \\
\hline $6.6 \% 10^{-4}$ & NR & $1.3 \times 10^{.3}$ & NR & $2.3 \times 10^{-3}$ & NR & $2.0 \times 10^{-2}$ & NR & $7.9 \times 10^{-61}$ & NR & $2.7 \times 10^{-2}$ & INC. & $5.9 \times 10^{-5}$ & NR & $4.6 \times 10^{-3}$ \\
\hline NR & $3.2 \times 10^{-2}$ & NR & $9.1 \times 10^{-3}$ & NR & $6.0 \times 10^{-2}$ & NR & NR & NR & 0.32 & NR & INC. & NR & 0.31 & NR \\
\hline $4.7 \% 10^{-1}$ & $1.2 \% 10^{.3}$ & $4.4 \% 10^{-4}$ & $1.0 \times 10^{-4}$ & $3.9 \times 10^{-4}$ & $6.7 \times 10^{-3}$ & $7.9 \times 10^{-4}$ & NR & $3.7 \times 10^{-3}$ & $2.9 \times 10^{-2}$ & $4.9 \times 10^{-3}$ & INC. & $2.3 \times 10^{-3}$ & 0.18 & $3.9 \times 10^{-3}$ \\
\hline $1,6 \% 10^{3}$ & $6.4 \% 10^{-3}$ & $1.6 \% 10^{-3}$ & $1.5 \times 10^{-5}$ & $1.2 \times 10^{-3}$ & $2.0 \times 10^{-2}$ & $2.1 \times 10^{-3}$ & NR & $2.0 \times 10^{-3}$ & $3.2 \times 10^{-2}$ & $2.9 \times 10^{-3}$ & INC. & $5.9 \times 10^{-4}$ & $3.5 \times 10^{-2}$ & $8.3 \times 10^{-4}$ \\
\hline NR & 0.37 & NR & 0.1 & NR & 0.69 & NR & NR & NR & 3.7 & NR & INC. & NR & 3.7 & NR \\
\hline $1.3 \% 10^{-k}$ & $1.4 \% 10^{4 h}$ & $4.7 \times 10^{-8}$ & $1.6 \times 10^{-7}$ & $3.6 \times 10^{-8}$ & $4.6 \times 10^{-6}$ & $3.3 \times 10^{-7}$ & NR & $4.8 \times 10^{-9}$ & $2.3 \times 10^{-5}$ & $1.4 \times 10^{-6}$ & INC. & $4.5 \times 10^{.4}$ & $2.1 \times 10^{-5}$ & $4.2 \times 10^{-7}$ \\
\hline $1.6 \% 10^{-10}$ & NR & $9.8 \times 10^{-111}$ & NR & $7.8 \times 10^{-110}$ & NR & $1.1 \times 10^{-8}$ & NR & $2.2 \times 10^{-11}$ & NR & $3.1 \times 10^{-8}$ & INC. & $1.2 \times 10^{-10}$ & NR & $7.5 \times 10^{.9}$ \\
\hline $1,3 \times 10^{-10}$ & NR & $5.0 \times 10^{-9}$ & NR & $4.4 \times 10^{-9}$ & NR & $1.2 \times 10^{-7}$ & NR & $5.1 \times 10^{-11}$ & NR & $1.8 \times 10^{-7}$ & INC. & $3.3 \times 10^{-110}$ & NR & $2.5 \times 10^{-8}$ \\
\hline NR & $1.4 \% 10^{-7}$ & NR & $1.6 \times 10^{-8}$ & NR & $4.6 \times 10^{-7}$ & NR & NR & NR & $2.3 \times 10^{-5}$ & NR & INC. & NR & $2.0 \% 10^{-s}$ & NR \\
\hline $2.8 \times 10^{4}$ & $5.3 \times 10^{-4}$ & $2.6 \% 10^{-9}$ & $1.7 \times 10^{-10}$ & $2.3 \times 10^{-9}$ & $5.1 \times 10^{-8}$ & $5.0 \times 10^{-9}$ & NR & $2.2 \times 10^{-8}$ & $2.1 \times 10^{.7}$ & $2.9 \times 10^{-8}$ & INC. & $1.3 \times 10^{-8}$ & $1.1 \times 10^{-5}$ & $2.1 \times 10^{-8}$ \\
\hline $9.7 \% 10^{-4}$ & $2.8 \% 10^{-8}$ & $9.1 \times 10^{-4}$ & $2.6 \times 10^{-11}$ & $7.7 \times 10^{-9}$ & $1.5 \times 10^{-7}$ & $1.4 \times 10^{-8}$ & NR & $1.3 \times 10^{-8}$ & $2.3 \times 10^{-7}$ & $1.8 \times 10^{-8}$ & INC. & $3.2 \times 10^{.9}$ & $2.3 \times 10^{-7}$ & $4.6 \times 10^{.9}$ \\
\hline NR & $1.6 \% 10^{-6}$ & NR & $1.8 \times 10^{-7}$ & NR & $5.3 \times 10^{-6}$ & NR & NR & NR & $2.5 \times 10^{-5}$ & NR & INC. & NR & $2.4 \times 10^{-5}$ & NR \\
\hline \multicolumn{15}{|c|}{ Offsite receptor } \\
\hline $1.9 \times 10^{-4}$ & $1.8 \times 10^{-1}$ & $3.4 \% 10^{-3}$ & $5.1 \times 0^{-2}$ & $6.4 \times 10^{-3}$ & $3.3 \times 10^{-1}$ & $1.6 \times 10^{-2}$ & NR & 0.0 & 1.8 & $6.3 \times 10^{-2}$ & INC. & $7.4 \times 10^{-5}$ & 1.7 & $2.1 \times 10^{-2}$ \\
\hline $2.3 \times 10^{-6}$ & NR & $7.1 \% 10^{-5}$ & NR & $1.3 \times 10^{-4}$ & NR & $5.1 \times 10^{-4}$ & NR & $3.3 \times 10^{-7}$ & NR & $1.4 \times 10^{-3}$ & INC. & $5.7 \times 10^{-6}$ & NR & $4.0 \times 10^{-4}$ \\
\hline $1.9 \% 10^{\circ}$ & NR & $3.7 \times 10^{-4}$ & NR & $6.4 \times 10^{-4}$ & NR & $5.7 \times 10^{-3}$ & NR & $2.3 \times 10^{-5}$ & NR & $8.0 \times 10^{-3}$ & INC. & $1.7 \times 10^{-5}$ & NR & $1.3 \times 10^{-3}$ \\
\hline NR & $1.7 \% 10^{-2}$ & NR & $5.0 \times 10^{-3}$ & NR & $3.0 \% 10^{-2}$ & NR & NR & NR & $1.8 \times 10^{-1}$ & NR & INC. & NR & $1.7 \times 10^{-1}$ & NR \\
\hline $1.4 \times 10^{-4}$ & $6.7 \% 10^{-4}$ & $1.3 \% 10^{-4}$ & $5.6 \times 10^{-5}$ & $1.1 \times 10^{-4}$ & $3.7 \times 10^{-3}$ & $2.3 \times 10^{-4}$ & NR & $1.1 \times 10^{-3}$ & $1.6 \times 10^{-2}$ & $1.4 \times 10^{-3}$ & INC. & $6.7 \times 10^{-4}$ & $9.6 \% 10^{-2}$ & $1.1 \times 10^{-3}$ \\
\hline $4.7 \% 10^{-4}$ & $3.5 \% 10^{.3}$ & $4.4 \% 10^{-1}$ & $8.3 \times 10^{-4}$ & $3.6 \times 10^{-4}$ & $1.1 \times 10^{-2}$ & $6.4 \times 10^{-5}$ & NR & $6.0 \times 10^{-4}$ & $1.8 \% 10^{-2}$ & $8.4 \times 10^{-4}$ & INC. & $1.7 \times 10^{-4}$ & $1.9 \times 10^{-2}$ & $2.4 \times 10^{-4}$ \\
\hline NR & $2.0 \% 10^{-1}$ & NR & $5.6 \times 10^{-2}$ & NR & $3.8 \times 10^{-1}$ & NR & NR & NR & 2.0 & NR & INC. & NR & 2.0 & NR \\
\hline $3.8 \% 10^{44}$ & $7.7 \times 10^{-7}$ & $1.4 \% 10^{-8}$ & $8.7 \times 10^{-8}$ & $1.1 \times 10^{-8}$ & $2.5 \times 10^{-5}$ & $9.7 \times 10^{-8}$ & NR & $1.4 \times 10^{-4}$ & $1.3 \times .10^{-5}$ & $4.1 \times 10^{-7}$ & INC. & $1.3 \times 10^{-4}$ & $1.1 \% 10^{-5}$ & $1.2 \times 10^{-7}$ \\
\hline $4.6 \% 10^{-11}$ & NR & $2.8 \% 10^{-110}$ & NR & $2.3 \times 10^{-10}$ & NR & $3.3 \times 10^{-9}$ & NR & $6.3 \times 10^{-12}$ & NR & $9.1 \times 10^{-9}$ & INC. & $3.5 \times 10^{-11}$ & NR & $2.2 \times 10^{.4}$ \\
\hline $3.9 \% 10^{.11}$ & NR & $1.5 \times 10^{-4}$ & NR & $1.3 \times 10^{-9}$ & NR & $3.7 \times 10^{-8}$ & NR & $1.5 \times 10^{-11}$ & NR & $5.3 \times 10^{-8}$ & INC. & $3.7 \times 10^{-11}$ & NR & $7.3 \times 10^{-4}$ \\
\hline NR & $7.5 \% 10^{-4}$ & NR & $8.5 \times 10^{-9}$ & NR & $2.5 \times 10^{-7}$ & NR & NR & NR & $1.2 \times 10^{-6}$ & NR & INC. & NR & $1.1 \times 10^{-6}$ & NR \\
\hline $8.2 \% 10^{\text {(1) }}$ & $2.9 \% 10^{.4}$ & $7.6 \times 10^{-111}$ & $9.7 \times 10^{-11}$ & $6.7 \times 10^{-111}$ & $2.8 \times 10^{-8}$ & $1.5 \times 10^{-9}$ & NR & $6.3 \% 10^{-9}$ & i. $1 \times 10^{-7}$ & $8.4 \times 10^{-4}$ & INC. & $3.7 \times 10^{-4}$ & $6.3 \times 10^{-7}$ & $6.2 \times 10^{-9}$ \\
\hline $2.8 \times 10^{.4}$ & $1.5 \% 10^{-8}$ & $2.6 \times 10^{-4}$ & $1.4 \times 10^{-11}$ & $2.2 \times 10^{-9}$ & $8.3 \times 10^{-8}$ & $4.1 \times 10^{-4}$ & NR & $3.8 \times 10^{-9}$ & $1.2 \times 10^{-7}$ & $5.4 \% 10^{-9}$ & INC. & $9.4 \times 10^{-111}$ & $1.3 \times 10^{-7}$ & $1.3 \times 10^{.4}$ \\
\hline NR & $8.6 \% 10^{-7}$ & NR & $9.6 \times 10^{-8}$ & NR & $2.9 \times 10^{-6}$ & NR & NR & NR & $1.4 \times 10^{-5}$ & NR & INC. & NR & $1.3 \times 10^{-5}$ & NR \\
\hline
\end{tabular}

end-210). 


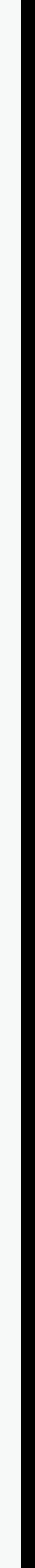


Table 9.15. Comparison of MEPAS and RESRAD surface erosion rates

\begin{tabular}{|c|c|c|c|}
\hline \multirow[b]{2}{*}{ Analysis Case } & \multicolumn{2}{|c|}{ Soil Erosion } & \multirow{2}{*}{$\begin{array}{c}\text { Uranium-238 Erosion } \\
\text { Computed Initial Emission } \\
\text { Rate to the Air, } \mathrm{pCi} \mathrm{yr}^{-1}\end{array}$} \\
\hline & $\begin{array}{l}\text { Assumed Loss of the Cover } \\
\text { Layer of Clean Soil, } \mathrm{g} \mathrm{s}^{-1}\end{array}$ & $\begin{array}{l}\text { Contaminated Soil } \\
\text { Suspension Rate, } \mathrm{g} \mathrm{s}^{-1}\end{array}$ & \\
\hline $\begin{array}{l}\text { MEPAS Scenario \#1 } \\
\text { (dusty site") }\end{array}$ & 0.13 & 0.13 & $1.6 \times 10^{9}$ \\
\hline $\begin{array}{l}\text { MEPAS Scenario \#2 } \\
\text { (stabilized site) }\end{array}$ & 0.13 & $6.3 \times 10^{-4}$ & $7.1 \times 10^{6}$ \\
\hline RESRAD & 0.13 & $3.0 \times 10^{-4}$ & $7.0 \times 10^{6}$ \\
\hline
\end{tabular}

'The main MEPAS multimedia run: Air suspension rates for the contaminated soil are computed for a dusty site with a surface roughness of $4.0 \mathrm{~cm}$ and a 0.25 fraction of the surface covered by a nonerodible crust.

'Special MEPAS run: Air suspension rates for the contaminated soil are computed by MEPAS for a site with a smooth stable surface (surface cover

roughness of $0.1 \mathrm{~cm}$ and a 0.98 fraction of the surface covered by a nonerodible crust).

Equivalent values of parameters from RESRAD runs for the multimedia benchmarking case are listed for comparision purposes. 
Table 9.16. Maximum air concentration, maximum chi $q^{-1}$, and maximum deposition rates at the maximum offsite exposure point: $810 \mathrm{~m}$ northeast of the center of the source

\begin{tabular}{|c|c|c|}
\hline & \multicolumn{2}{|c|}{ Contaminant } \\
\hline & Methylene Chloride & Uranium-238 \\
\hline \multicolumn{3}{|l|}{ Time (yr) } \\
\hline RESRAD & $0+$ & 800 \\
\hline MMSOILS & $0+$ & NA \\
\hline MEPAS & $0+$ & 800 \\
\hline \multicolumn{3}{|c|}{ Maximum Concentration } \\
\hline RESRAD & $6.9 \times 10^{-4} \mathrm{mg} \mathrm{m}^{-3}$ & $4.0 \times 10^{-7} \mathrm{pCi} \mathrm{m}^{-3}$ \\
\hline MMSOILS & $2.2 \times 10^{-3} \mathrm{mg} \mathrm{m}^{-3}$ & NA \\
\hline MEPAS & $3.3 \times 10^{-7} \mathrm{mg} \mathrm{m}^{-3}$ & $\begin{array}{l}4.0 \times 10^{-5} \mathrm{pCi} \mathrm{m}^{-3 \mathrm{a}} \\
1.8 \times 10^{-7} \mathrm{pCi} \mathrm{m}^{-3 b}\end{array}$ \\
\hline \multicolumn{3}{|c|}{ Maximum chi $q^{-1}\left(s-m^{-3}\right)$} \\
\hline RESRAD & $4.1 \times 10^{-6}$ & $3.6 \times 10^{-6}$ \\
\hline MMSOILS & $8.8 \times 10^{-7}$ & NA \\
\hline MEPAS & $1.6 \times 10^{-6}$ & $8.4 \times 10^{-7}$ \\
\hline \multicolumn{3}{|c|}{ Maximum Deposition Rate } \\
\hline RESRAD & NA & $4.0 \times 10^{-10} \mathrm{pCi} \mathrm{m}^{-2} \mathrm{~s}^{-1}$ \\
\hline MMSOILS & $1.7 \times 10^{-9} \mathrm{mg} \mathrm{m}^{-2} \mathrm{~s}^{-1}$ & NA \\
\hline MEPAS & $2.2 \times 10^{-12} \mathrm{mg} \mathrm{m}^{-2} \mathrm{~s}^{-1}$ & $\begin{array}{l}1.7 \times 10^{-6} \mathrm{pCi} \mathrm{m}^{-2} \mathrm{~s}^{-1 \mathrm{a}} \\
7.5 \times 10^{-9} \mathrm{pCi} \mathrm{m}^{-2} \mathrm{~s}^{-1 \mathrm{~b}}\end{array}$ \\
\hline
\end{tabular}


Table 9.17. Maximum dose and risk to the receptor located at the facility boundary, $366 \mathrm{~m}$ to the north of source - air pathway

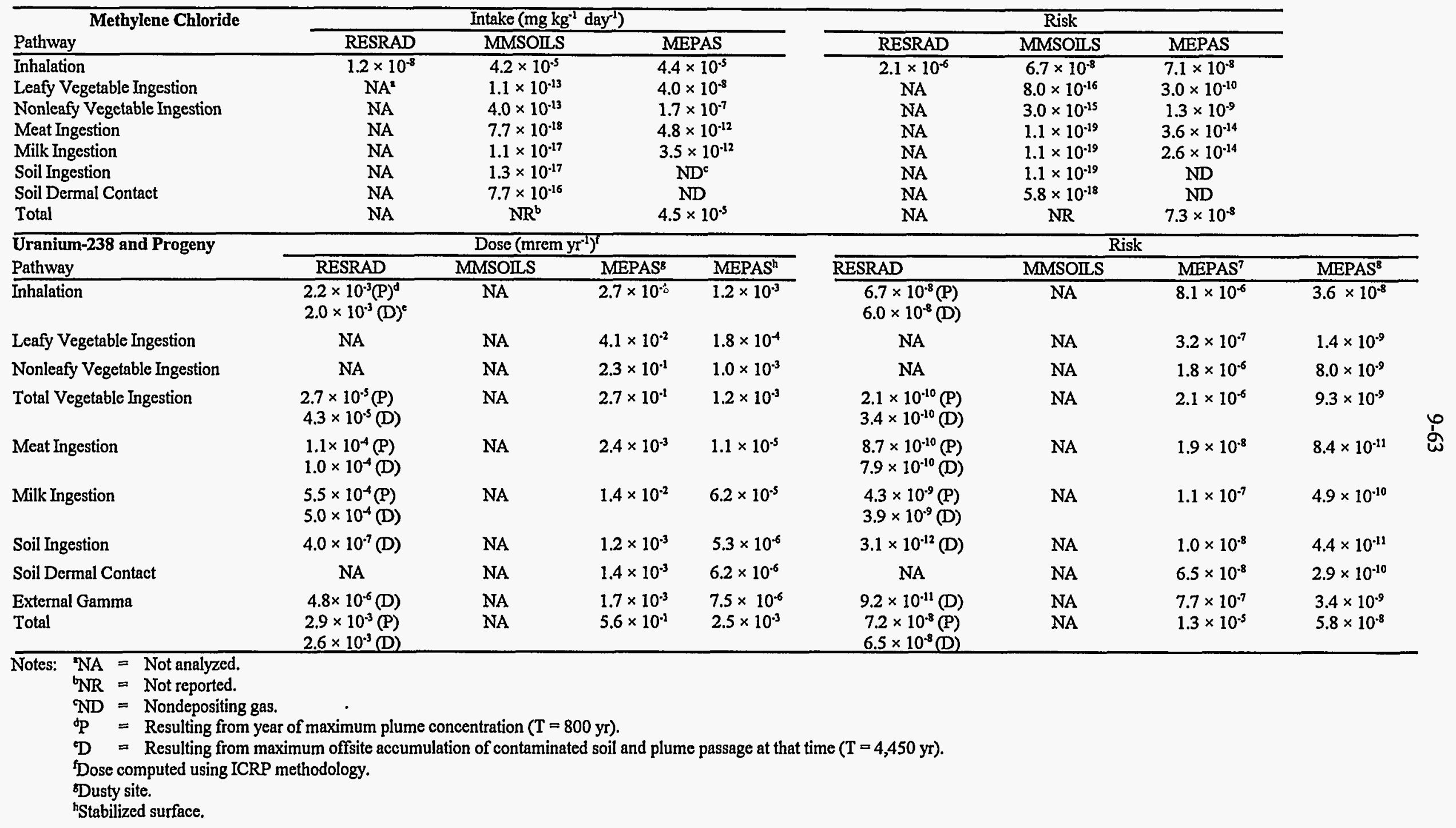


Table 9.18. Maximum dose and risk at the maximum offsite exposure point, located $810 \mathrm{~m}$

to the northeast of source- air pathway

\begin{tabular}{|c|c|c|c|c|c|c|c|c|c|}
\hline \multirow{2}{*}{$\begin{array}{l}\text { Methylene Chloride } \\
\text { Pathway }\end{array}$} & \multicolumn{4}{|c|}{ Intake (mg kg $\left.{ }^{-1} \mathrm{day}^{-1}\right)$} & \multicolumn{4}{|c|}{ Risk } & \\
\hline & RESRAD & MMSOILS & \multicolumn{2}{|l|}{ MEPAS } & RESRAD & MMSOILS & \multicolumn{2}{|c|}{ MEPAS } & \\
\hline Inhalation & $2.0 \times 10^{-4}$ & $9.6 \times 10^{-6}$ & \multicolumn{2}{|l|}{$8.1 \times 10^{-7}$} & $3.2 \times 10^{-7}$ & $1.5 \times 10^{-8}$ & \multicolumn{2}{|c|}{$1.3 \times 10^{.9}$} & \\
\hline Leafy Vegetable Ingestion & $\mathrm{NA}^{\prime}$ & $2.4 \times 10^{-14}$ & \multicolumn{2}{|l|}{$7.5 \times 10^{-10}$} & NA & $1.8 \times 10^{-16}$ & \multicolumn{2}{|c|}{$5.6 \times 10^{-12}$} & \\
\hline Nonleafy Vegetable Ingestion & NA & $9.0 \times 10^{-14}$ & \multicolumn{2}{|l|}{$3.2 \times 10^{-9}$} & NA & $6.7 \times 10^{-16}$ & \multicolumn{2}{|c|}{$2.4 \times 10^{-11}$} & \\
\hline Meat Ingestion & NA & $1.7 \times 10^{-18}$ & \multicolumn{2}{|l|}{$8.9 \times 10^{-14}$} & NA & 0 & \multicolumn{2}{|c|}{$6.7 \times 10^{-16}$} & \\
\hline Milk Ingestion & NA & $2.5 \times 10^{.18}$ & \multicolumn{2}{|l|}{$6.4 \times 10^{-14}$} & NA & 0 & \multicolumn{2}{|c|}{$4.8 \times 10^{-16}$} & \\
\hline Soil Ingestion & NA & $3.0 \times 10^{-18}$ & \multicolumn{2}{|l|}{$\mathrm{ND}^{3}$} & NA & 0 & \multicolumn{2}{|c|}{ ND } & \\
\hline Soil Dermal Contact & NA & $1.7 \times 10^{-16}$ & \multicolumn{2}{|l|}{ ND } & NA & $1.3 \times 10^{-18}$ & \multicolumn{2}{|c|}{ ND } & \\
\hline Total & NA & $\mathrm{NR}^{2}$ & \multicolumn{2}{|l|}{$8.2 \times 10^{-7}$} & NA & NR & \multicolumn{2}{|c|}{$1.3 \times 10^{.9}$} & \\
\hline Uranium-238 and Progeny & \multicolumn{4}{|c|}{ Dose $\left(\mathrm{mrem} \mathrm{yr}^{-1}\right)^{6}$} & \multicolumn{5}{|c|}{ Risk } \\
\hline Pathway & RESRAD & MMSOILS & MEPAS $^{7}$ & MEPAS $^{8}$ & & $\mathrm{RAD}$ & MMSOILS & MEPAS $^{7}$ & MEPAS $^{8}$ \\
\hline Inhalation & $\begin{array}{l}3.3 \times 10^{-4}(\mathrm{P})^{4} \\
3.0 \times 10^{-4}(\mathrm{D})^{5}\end{array}$ & NA & $3.4 \times 10^{-2}$ & $1.5 \times 10^{-4}$ & & $\begin{array}{l}0^{-8}(\mathrm{P}) \\
0^{-9}(\mathrm{D})\end{array}$ & NA & $1.1 \times 10^{-6}$ & $4.8 \times 10^{-9}$ \\
\hline Leafy Vegetable Ingestion & NA & NA & $5.3 \times 10^{-3}$ & $2.4 \times 10^{-5}$ & & & NA & $4.2 \times 10^{-8}$ & $1.9 \times 10^{-10}$ \\
\hline Nonleafy Vegetable Ingestion & NA & NA & $3.0 \times 10^{-2}$ & $1.3 \times 10^{4}$ & & A & NA & $2.3 \times 10^{.7}$ & $1.0 \times 10^{-9}$ \\
\hline Total Vegetable Ingestion & $\begin{array}{l}4.1 \times 10^{-6}(\mathrm{P}) \\
6.4 \times 10^{-6}(\mathrm{D})\end{array}$ & NA & $3.5 \times 10^{-2}$ & $1.6 \times 10^{-4}$ & & $\begin{array}{l}0^{-11}(\mathrm{P}) \\
0^{-11}(\mathrm{D})\end{array}$ & NA & $2.7 \times 10^{-7}$ & $1.2 \times 10^{-9}$ \\
\hline Meat Ingestion & $\begin{array}{l}1.7 \times 10^{-5}(\mathrm{P}) \\
1.5 \times 10^{-5}(\mathrm{D})\end{array}$ & NA & $3.1 \times 10^{-4}$ & $1.4 \times 10^{-6}$ & & $\begin{array}{l}0^{-10}(\mathrm{P}) \\
0^{-10}(\mathrm{D})\end{array}$ & NA & $2.4 \times 10^{-9}$ & $1.1 \times 10^{-11}$ \\
\hline Milk Ingestion & $\begin{array}{l}8.3 \times 10^{-5}(\mathrm{P}) \\
7.5 \times 10^{-5}(\mathrm{D})\end{array}$ & NA & $1.9 \times 10^{-3}$ & $8.4 \times 10^{-6}$ & & $\begin{array}{l}0^{-10}(\mathrm{P}) \\
0^{-10}(\mathrm{D})\end{array}$ & NA & $1.4 \times 10^{-8}$ & $6.2 \times 10^{.11}$ \\
\hline Soil Ingestion & $\frac{N A}{6.0 \times 10^{-8}(D)}$ & NA & $1.4 \times 10^{-4}$ & $6.2 \times 10^{-7}$ & & $\begin{array}{l}A \\
0^{-13}(D)\end{array}$ & NA & $1.2 \times 10^{.9}$ & $5.3 \times 10^{.12}$ \\
\hline $\begin{array}{l}\text { Soil Dermal Contact } \\
\text { External Gamma }\end{array}$ & $\begin{array}{c}\mathrm{NA} \\
1.0 \times 10^{-6}(\mathrm{D})\end{array}$ & $\begin{array}{l}\text { NA } \\
\text { NA }\end{array}$ & $\begin{array}{l}1.9 \times 10^{-4} \\
8.1 \times 10^{-2}\end{array}$ & $\begin{array}{l}8.4 \times 10^{-7} \\
3.6 \times 10^{-4}\end{array}$ & & $\begin{array}{l}A \\
0^{-11}(\mathrm{D})\end{array}$ & $\begin{array}{l}\text { NA } \\
\text { NA }\end{array}$ & $\begin{array}{l}7.8 \times 10^{-8} \\
9.3 \times 10^{-8}\end{array}$ & $\begin{array}{l}3.5 \times 10^{-10} \\
4.1 \times 10^{-10}\end{array}$ \\
\hline Total & $\begin{array}{l}4.4 \times 10^{-4}(\mathrm{P}) \\
4.0 \times 10^{-4}(\mathrm{D})\end{array}$ & NA & $1.5 \times 10^{-1}$ & $6.7 \times 10^{-4}$ & & $\begin{array}{l}10^{-8}(\mathrm{P}) \\
0^{-9}(\mathrm{D})\end{array}$ & NA & $1.7 \times 10^{-6}$ & $7.5 \times 10^{.9}$ \\
\hline
\end{tabular}

Notes: 'NA $=$ Not analyzed.

${ }^{2} \mathrm{NR}=$ Not reported.

${ }^{3} \mathrm{ND}=$ Nondepositing gas

${ }^{4} \mathrm{P}=$ Resulting from year of maximum plume concentration $(\mathrm{T}=800 \mathrm{yr})$.

${ }^{5} \mathrm{D}=$ Resulting from maximum offsite accumulation of contaminated soil and plume passage at that time $(\mathrm{T}=4,500 \mathrm{yr})$.

${ }^{6}$ Dose computed using ICRP methodology.

${ }^{7}$ Dusty site.

${ }^{8}$ Stabilized surface. 
Table 9.19. Maximum surface water concentration, dose, and risk to surface water receptor

\begin{tabular}{|c|c|c|c|c|c|c|c|c|c|c|c|c|}
\hline & \multicolumn{2}{|c|}{ Methylene Chloride } & \multicolumn{2}{|c|}{ Uranium-238 } & \multirow{2}{*}{\begin{tabular}{|c|} 
Thorium-234 \\
MEPAS \\
\end{tabular}} & \multirow{2}{*}{\begin{tabular}{|c|} 
Uranium-234 \\
MEPAS \\
\end{tabular}} & \multirow{2}{*}{\begin{tabular}{|c|} 
Thorium-230 \\
MEPAS \\
\end{tabular}} & \multirow{2}{*}{\begin{tabular}{|c|} 
Radium-226 \\
MEPAS \\
\end{tabular}} & \multirow{2}{*}{$\frac{\text { Radon-222 }}{\text { MEPAS }}$} & \multirow{2}{*}{$\frac{\text { Lead-210 }}{\text { MEPAS }}$} & \multirow{2}{*}{\begin{tabular}{|c|} 
Bismuth-210 \\
MEPAS \\
\end{tabular}} & \multirow{2}{*}{\begin{tabular}{|c|} 
Polonium-210 \\
MEPAS
\end{tabular}} \\
\hline & MMSOILS & MEPAS & MMSOILS & MEPAS & & & & & & & & \\
\hline Maximum Concentration & $8.9 \times 10^{6}$ & $1.0 \times 10^{-4}$ & $9.9 \times 10^{-6}$ & $2.8 \times 10^{-5}$ & $2.8 \times 10^{4}$ & $2.5 \times 10^{-5}$ & $2.4 \times 10^{4}$ & $2.4 \times 10^{5}$ & $2.4 \times 10^{4}$ & $2.4 \times 10^{8}$ & $2.4 \times 10^{5}$ & $2.4 \times 10^{8}$ \\
\hline Time of Maximum & 2,440 & 2,983 & 750,000 & 798,000 & 798,000 & 798,000 & 798,000 & 798,000 & 798,000 & 798,000 & 798,000 & 798,000 \\
\hline \multicolumn{13}{|l|}{ Maximum Intake/Dose } \\
\hline Ingestion of Fish & $1.0 \times 10^{4}$ & $8.5 \times 10^{46}$ & NA & $2.2 \times 10^{-9}$ & $1.2 \times 10^{-9}$ & $2.2 \times 10^{\circ}$ & $4.0 \times 10^{-4}$ & $4.8 \times 10^{-4}$ & 0 & $1.2 \times 10^{5}$ & $7.1 \times 10^{-11}$ & $1.4 \times 10^{\circ}$ \\
\hline $\begin{array}{l}\text { Dermal Contact while } \\
\text { Swimming }\end{array}$ & $1.5 \times 10^{4}$ & $1.0 \times 10^{-4 b}$ & NA & $3.0 \times 10^{.10}$ & $2.1 \times 10^{.12}$ & $3.0 \times 10^{.10}$ & $1.2 \times 10^{.7}$ & $2.6 \times 10^{.30}$ & 0 & $5.6 \times 10^{-12}$ & $1.3 \times 10^{-12}$ & $8.8 \times 10^{-10}$ \\
\hline Total & $2.5 \times 10^{4}$ & NR & NA & NR & NR & $\mathrm{NR}$ & NR & NR & 0 & NR & NR & NR \\
\hline \multicolumn{13}{|l|}{ Risk } \\
\hline Ingestion of Fish & $5.7 \times 10^{.11}$ & $6.4 \times 10^{.10}$ & NA & $1.4 \times 10^{.13}$ & $3.5 \times 10^{.13}$ & $1.2 \times 10^{.13}$ & $9.6 \times 10^{.13}$ & $4.4 \times 10^{.12}$ & 0 & $1.1 \times 10^{.10}$ & $1.8 \times 10^{.44}$ & $1.1 \times 10^{.11}$ \\
\hline $\begin{array}{l}\text { Dermal Contact while } \\
\text { Swimming }\end{array}$ & $3.2 \times 10^{.12}$ & $7.7 \times 10^{-11}$ & NA & $2.2 \times 10^{.13}$ & $1.6 \times 10^{.13}$ & $2.2 \times 10^{.13}$ & $8.5 \times 10^{.11}$ & $1.9 \times 10^{-13}$ & 0 & $4.1 \times 10^{.15}$ & $9.2 \times 10^{.16}$ & $6.5 \times 10^{.13}$ \\
\hline Total & $6.0 \times 10^{.11}$ & $7.2 \times 10^{.10}$ & NA & $3.6 \times 10^{.13}$ & $5.1 \times 10^{.13}$ & $3.4 \times 10^{.23}$ & $8.5 \times 10^{.11}$ & $4.6 \times 10^{.12}$ & 0 & $1.1 \times 10^{.10}$ & $1.8 \times 10^{.14}$ & $1.1 \times 10^{.11}$ \\
\hline
\end{tabular}

Concentrations: $\mathrm{mg} \mathrm{L}^{-1}$ for methylene chloride, $\mathrm{pCi} \mathrm{L}^{-1}$ for all radionuclides.

Times: years since beginning of leachate generation from landfill.

Intake/dose: $\mathrm{mg} \mathrm{kg}^{-1} \mathrm{~d}^{-1}$ for methylene chloride; mrem $\mathrm{yr}^{-1}$ for all radionuclides.

Risks: excess lifetime cancer risks.

Wot reported by MEPAS. Computed by dividing risk by appropriate slope factor.

NA $=$ Not Analyzed.

$\mathrm{NR}=$ Not Reported. 
Table 9.20. Total multimedia risk at onsite receptor

\begin{tabular}{|c|c|c|c|c|c|c|c|c|c|}
\hline \multirow[b]{2}{*}{ Contaminant } & \multicolumn{3}{|c|}{ Groundwater } & \multicolumn{3}{|c|}{$\mathrm{Air}^{\circ}$} & \multicolumn{3}{|c|}{ Surface Water } \\
\hline & RESRAD & MMSOILS & MEPAS & RESRAD & MMSOILS & MEPAS $^{\circ}$ & RESRAD & MMSOILS & $\mathrm{MEPAS}^{\circ}$ \\
\hline Methylene Chloride & $2.9 \times 10^{-3}$ & $1.3 \times 10^{-4}$ & $5.5 \times 10^{-1}$ & $2.1 \times 10^{-6}$ & $6.7 \times 10^{-8}$ & $8.9 \times 10^{-9}$ & NA & $1.9 \times 10^{-10}$ & $7.2 \times 10^{.10}$ \\
\hline Uranium-238 & $6.3 \times 10^{-6}$ & NA & $1.1 \times 10^{-7}$ & $7.2 \times 10^{-8}$ & NA & $1.6 \times 10^{.5}$ & NA & NA & $1.4 \times 10^{-13}$ \\
\hline Thorium-234 & $\mathrm{NA}^{\mathrm{b}}$ & NA & $2.6 \times 10^{-8}$ & NR & $\mathrm{NA}$ & NA & NA & NA & $3.5 \times 10^{-13}$ \\
\hline Uranium-234 & $1.6 \times 10^{-6}$ & $\mathrm{NA}$ & $6.4 \times 10^{-8}$ & NR & NA & $\mathrm{NA}$ & NA & $\mathrm{NA}$ & $1.2 \times 10^{-13}$ \\
\hline Thorium-230 & $1.8 \times 10^{-7}$ & $\mathrm{NA}$ & $5.1 \times 10^{-8}$ & NR & NA & NA & NA & $\mathrm{NA}$ & $9.6 \times 10^{-13}$ \\
\hline Radium-226 & $5.3 \times 10^{-6}$ & $\mathrm{NA}$ & $4.6 \times 10^{-7}$ & NR & NA & NA & NA & NA & $4.4 \times 10^{-12}$ \\
\hline Radon-222 & NA & NA & $3.5 \times 10^{-8}$ & NR & NA & NA & NA & NA & 0 \\
\hline Lead-210 & $2.5 \times 10^{-5}$ & NA & $1.6 \times 10^{-6}$ & NR & NA & NA & NA & $\mathrm{NA}$ & $1.1 \times 10^{-10}$ \\
\hline Bismuth-210 & NA & NA & $2.0 \times 10^{-8}$ & NR & NA & NA & NA & NA & $1.8 \times 10^{.14}$ \\
\hline Polonium-210 & $2.4 \times 10^{-4}$ & NA & $4.7 \times 10^{-7}$ & NR & $\mathrm{NA}$ & NA & $\mathrm{NA}$ & $\mathrm{NA}$ & $1.1 \times 10^{-11}$ \\
\hline
\end{tabular}

Table 9.21. Total multimedia risk at offsite receptor

\begin{tabular}{|c|c|c|c|c|c|c|c|c|c|}
\hline \multirow[b]{2}{*}{ Contaminant } & \multicolumn{3}{|c|}{ Groundwater } & \multicolumn{3}{|c|}{$\mathrm{Air}^{\mathrm{c}}$} & \multicolumn{3}{|c|}{ Surface Water } \\
\hline & RESRAD & MMSOILS & $\mathrm{MEPAS}^{\circ}$ & RESRAD & MMSOILS & MEPAS & RESRAD & MMSOILS & MEPAS ${ }^{\circ}$ \\
\hline Methylene Chloride & $1.6 \times 10^{-3}$ & $3.4 \times 10^{-5}$ & $1.6 \times 10^{-4}$ & $3.2 \times 10^{-7}$ & $1.5 \times 10^{-8}$ & $1.4 \times 10^{-9}$ & NA & $1.9 \times 10^{-10}$ & $7.2 \times 10^{-10}$ \\
\hline Uranium-238 & $3.5 \times 10^{-6}$ & $\mathrm{NA}$ & $3.3 \times 10^{-8}$ & $1.1 \times 10^{-8}$ & NA & $1.9 \times 10^{-6}$ & NA & NA & $1.4 \times 10^{-13}$ \\
\hline Thorium-234 & $\mathrm{NA}$ & NA & $6.4 \times 10^{-9}$ & NR & NA & NA & NA & NA & $3.5 \times 10^{-13}$ \\
\hline Uranium-234 & $8.6 \times 10^{-7}$ & $\mathrm{NA}$ & $1.8 \times 10^{-8}$ & NR & $\mathrm{NA}$ & NA & $\mathrm{NA}$ & NA & $1.2 \times 10^{-13}$ \\
\hline Thorium-230 & $9.6 \times 10^{-8}$ & $\mathrm{NA}$ & $1.5 \times 10^{-8}$ & NR & NA & NA & NA & NA & $9.6 \times 10^{-13}$ \\
\hline Radium-226 & $2.9 \times 10^{-6}$ & $\mathrm{NA}$ & $1.4 \times 10^{-7}$ & NR & NA & NA & $\mathrm{NA}$ & NA & $4.4 \times 10^{-12}$ \\
\hline Radon-222 & NA & NA & $1.2 \times 10^{-8}$ & NR & NA & $\mathrm{NA}$ & NA & NA & 0 \\
\hline Lead-210 & $1.4 \times 10^{-5}$ & NA & $4.6 \times 10^{-7}$ & NR & NA & NA & NA & NA & $1.1 \times 10^{-10}$ \\
\hline Bismuth-210 & NA & NA & $1.1 \times 10^{-8}$ & NR & NA & NA & NA & NA & $1.8 \times 10^{-14}$ \\
\hline Polonium-210 & $1.3 \times 10^{-5}$ & NA & $1.2 \times 10^{-7}$ & NR & NA & NA & NA & NA & $1.1 \times 10^{-11}$ \\
\hline
\end{tabular}

'See Table 9.13 for the times associated with these risks.

${ }^{b} \mathrm{NA}=$ Not analyzed; $\mathrm{NR}=$ Not reported.

'See Table 9.16 for the times associated with these risks.

${ }^{d}$ See Table 9.19 for the times associated with these risks.

'Dusty site assumed. 


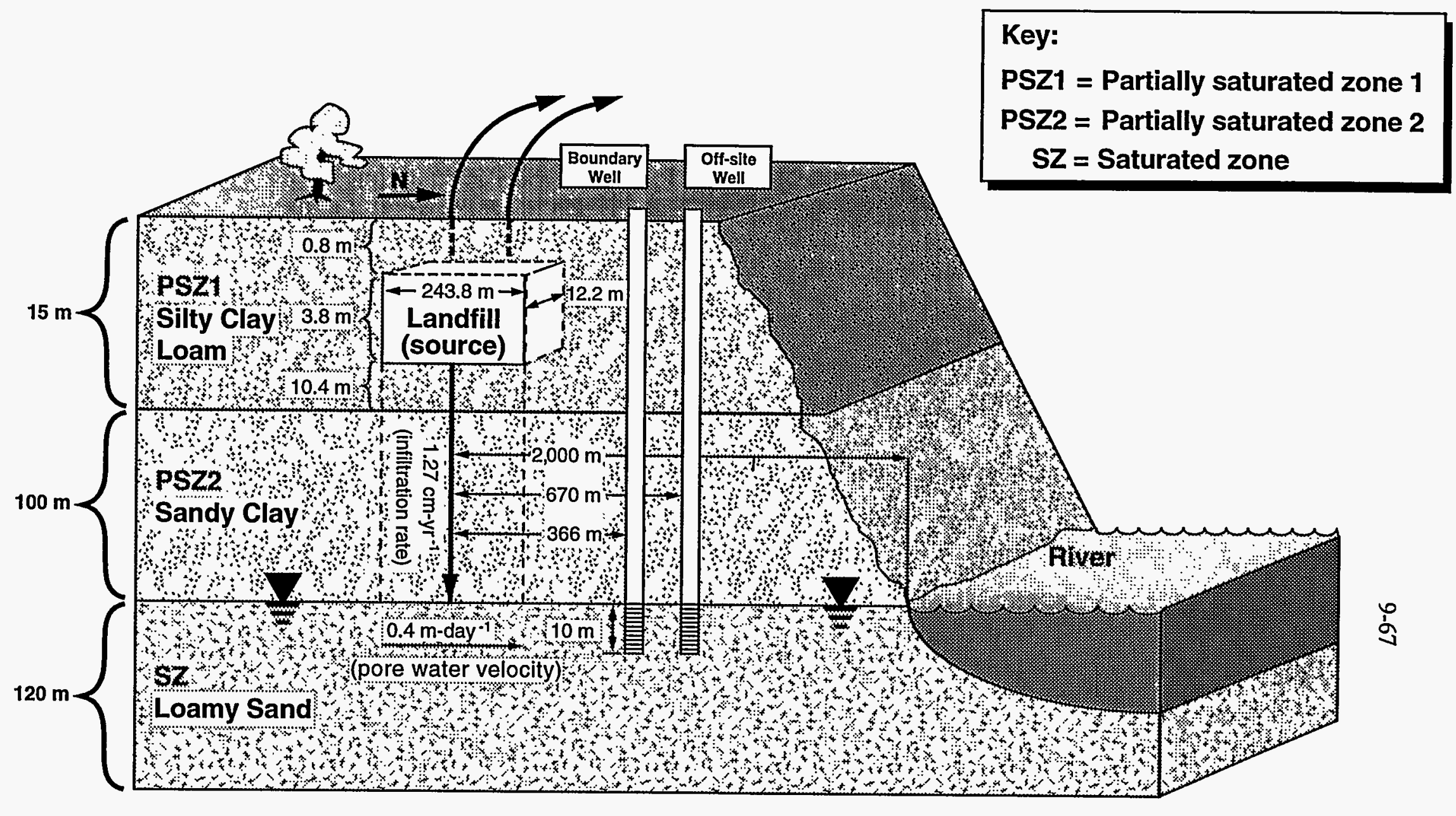

Note: Drawing not to scale.

Fig. 9.1. Schematic of the Landfill Source, Soil Strata, and Locations of Wells and River. 


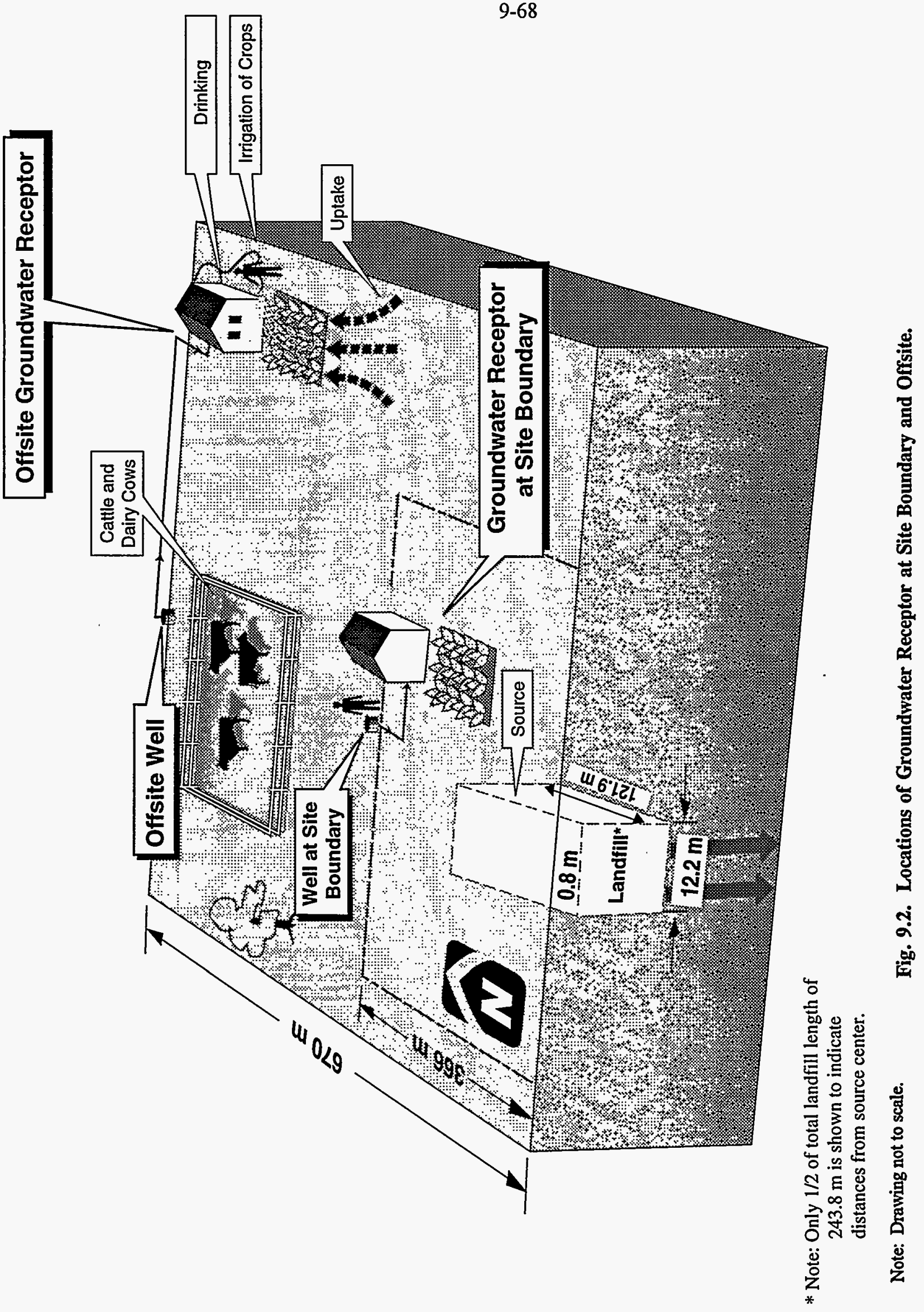




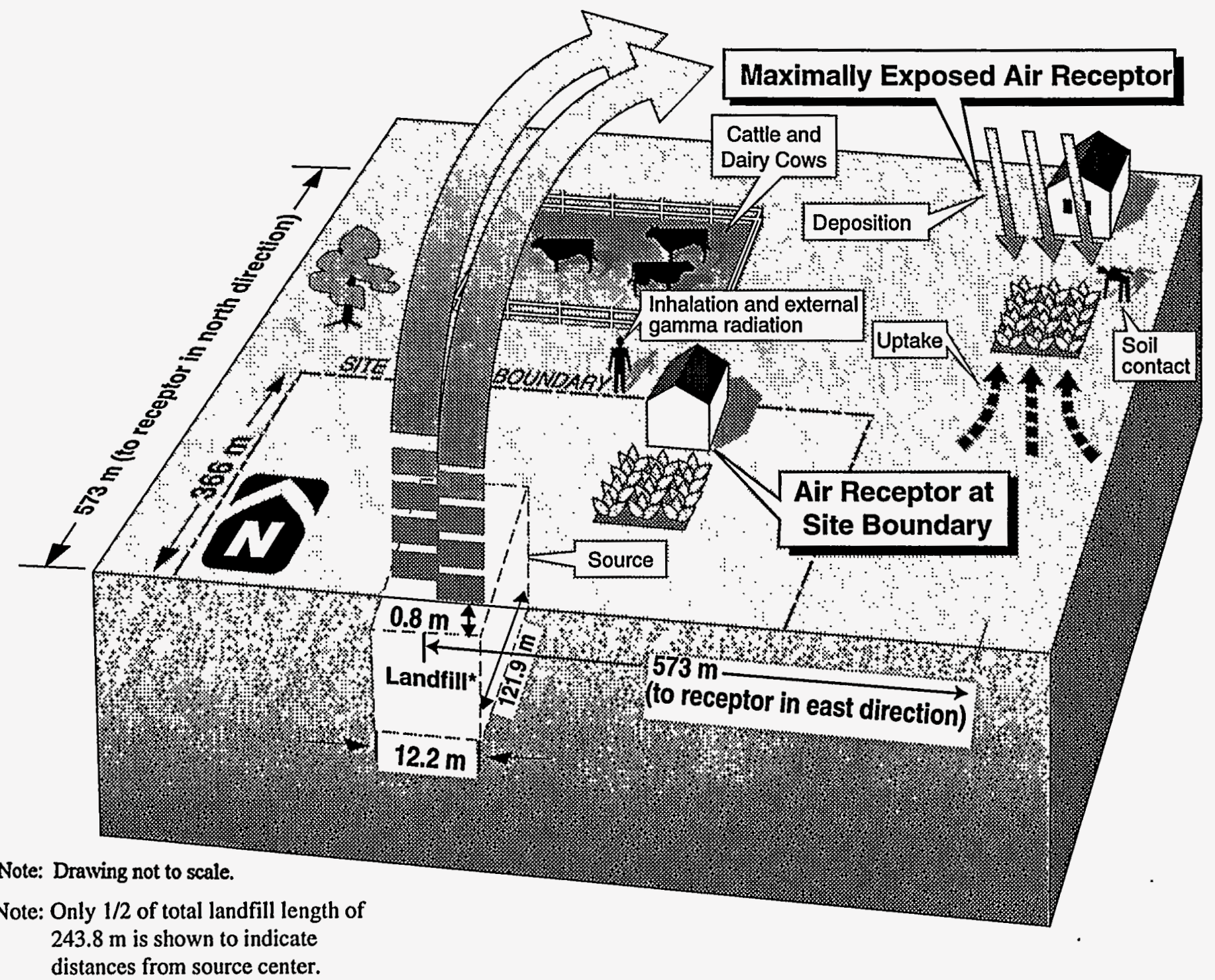

Fig. 9.3. Locations of Air Receptor at Site Boundary and Maximally Exposed Individual, 


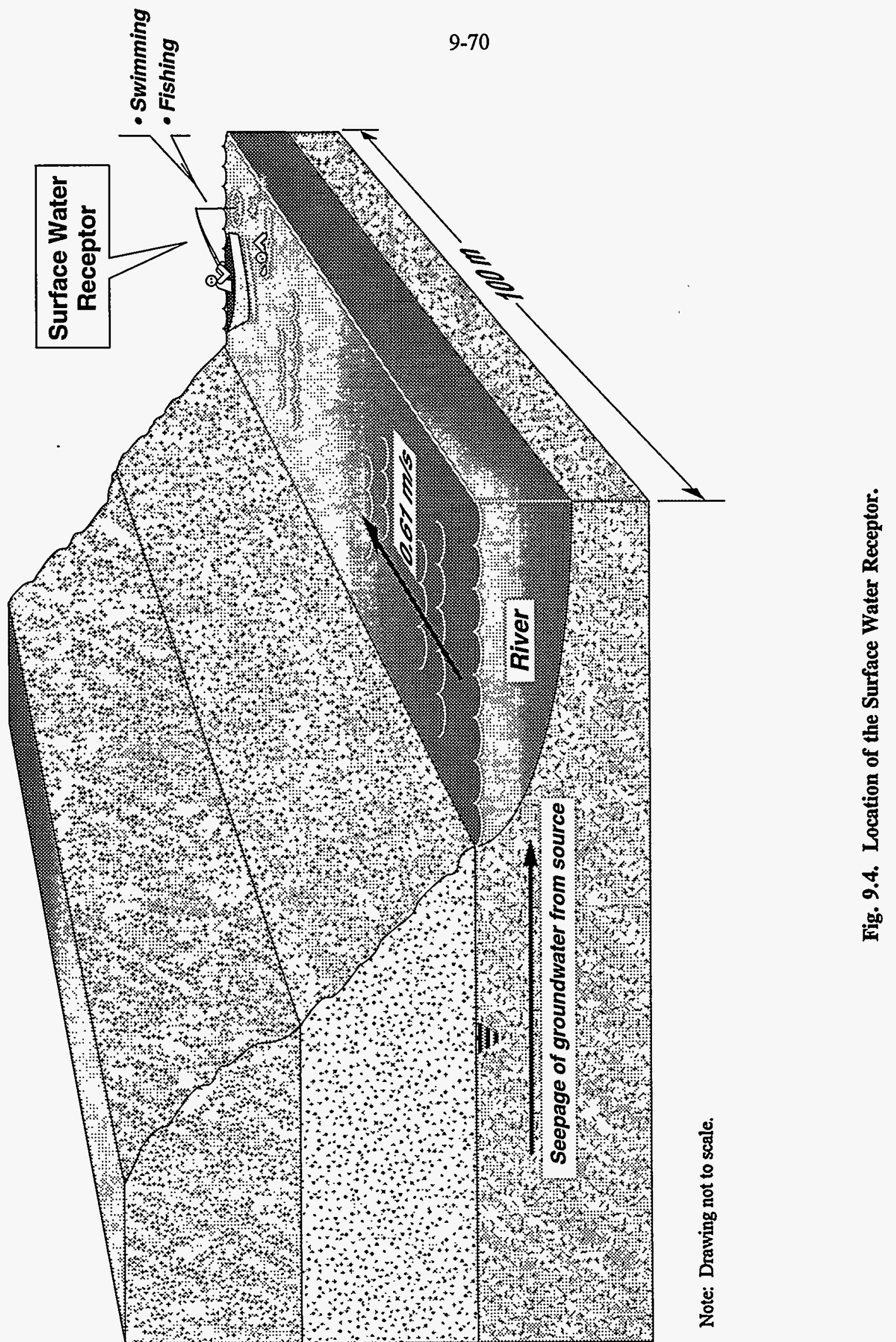




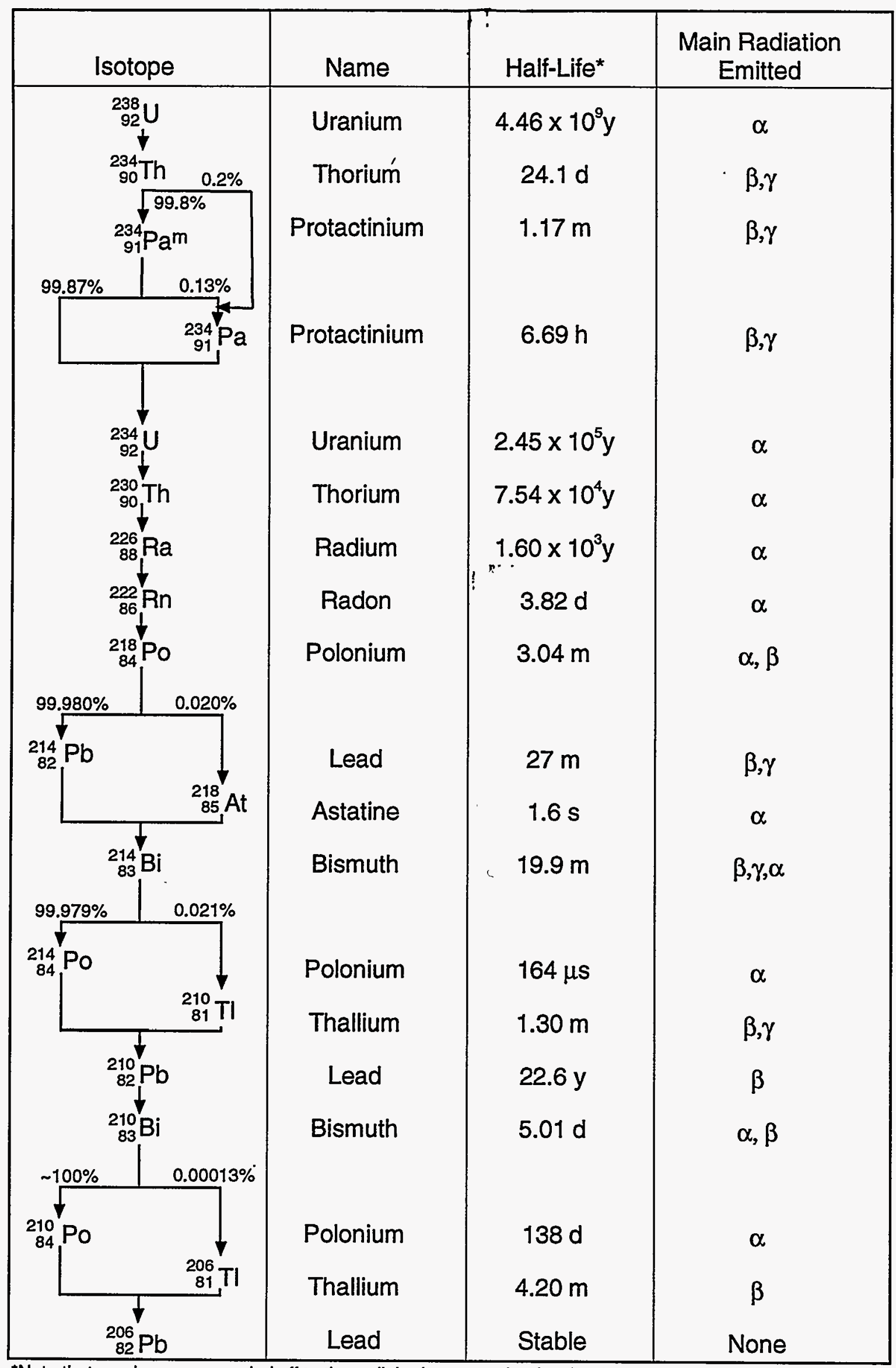

${ }^{*}$ Note that numbers are rounded off to three digits ( $y=$ year, $d=$ day, $h=$ hour, $m=$ minute, $s=$ second). Source: Browne, Egardo, and Firestone, 1986; Lide, 1993.

Fig. 9.5. The Natural Radioactive Decay Chain Beginning with Uranium-238 and Ending with Lead-206. 
Multimedia Scenario

Methylene Chloride - Flux from Landfill to PSZ1

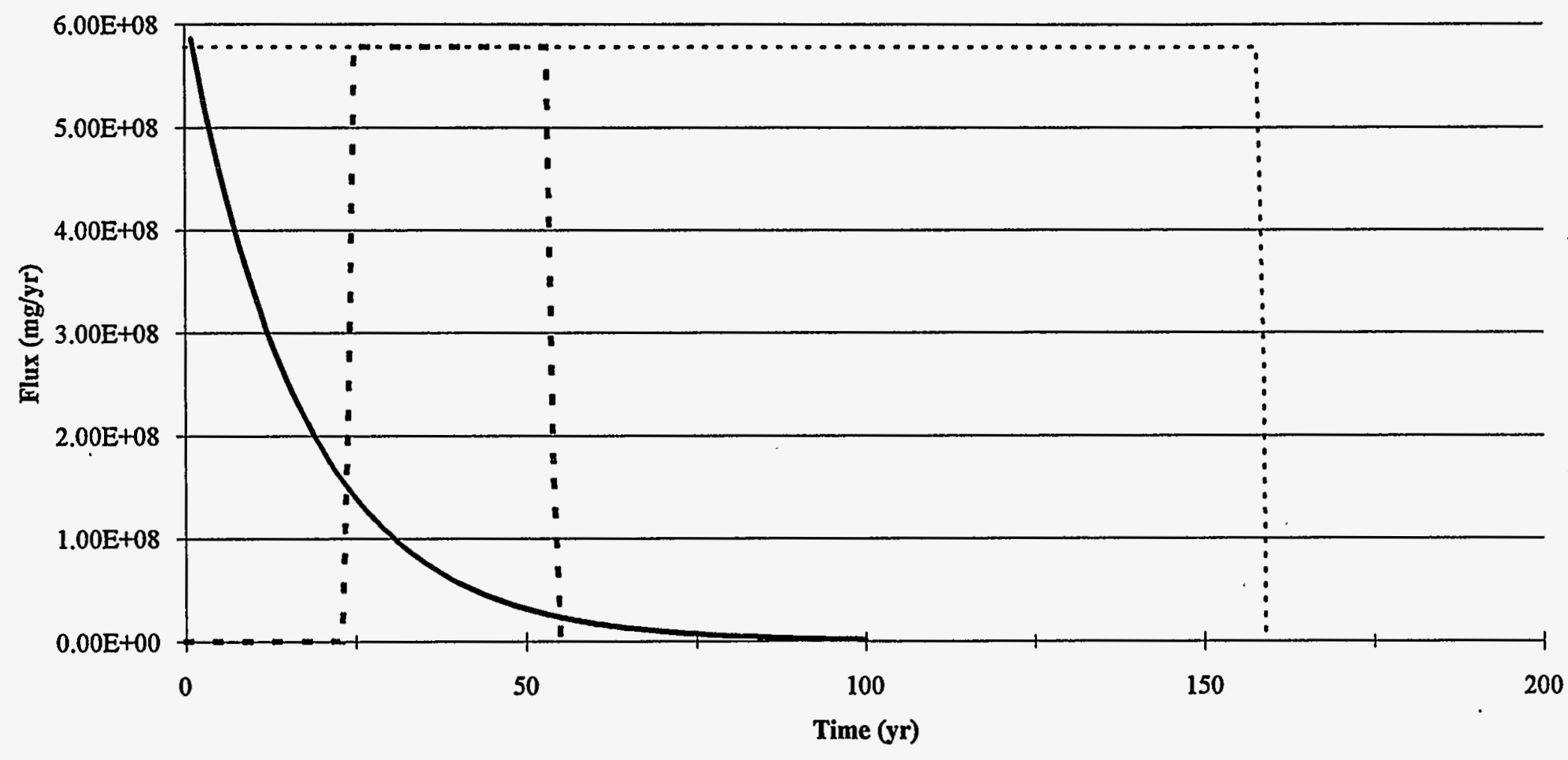

Fig. 9.6. Time-Varying Fluxes of Methylene Chloride from Landfill to PSZ1 for RESRAD, MMSOILS, and MEPAS. 


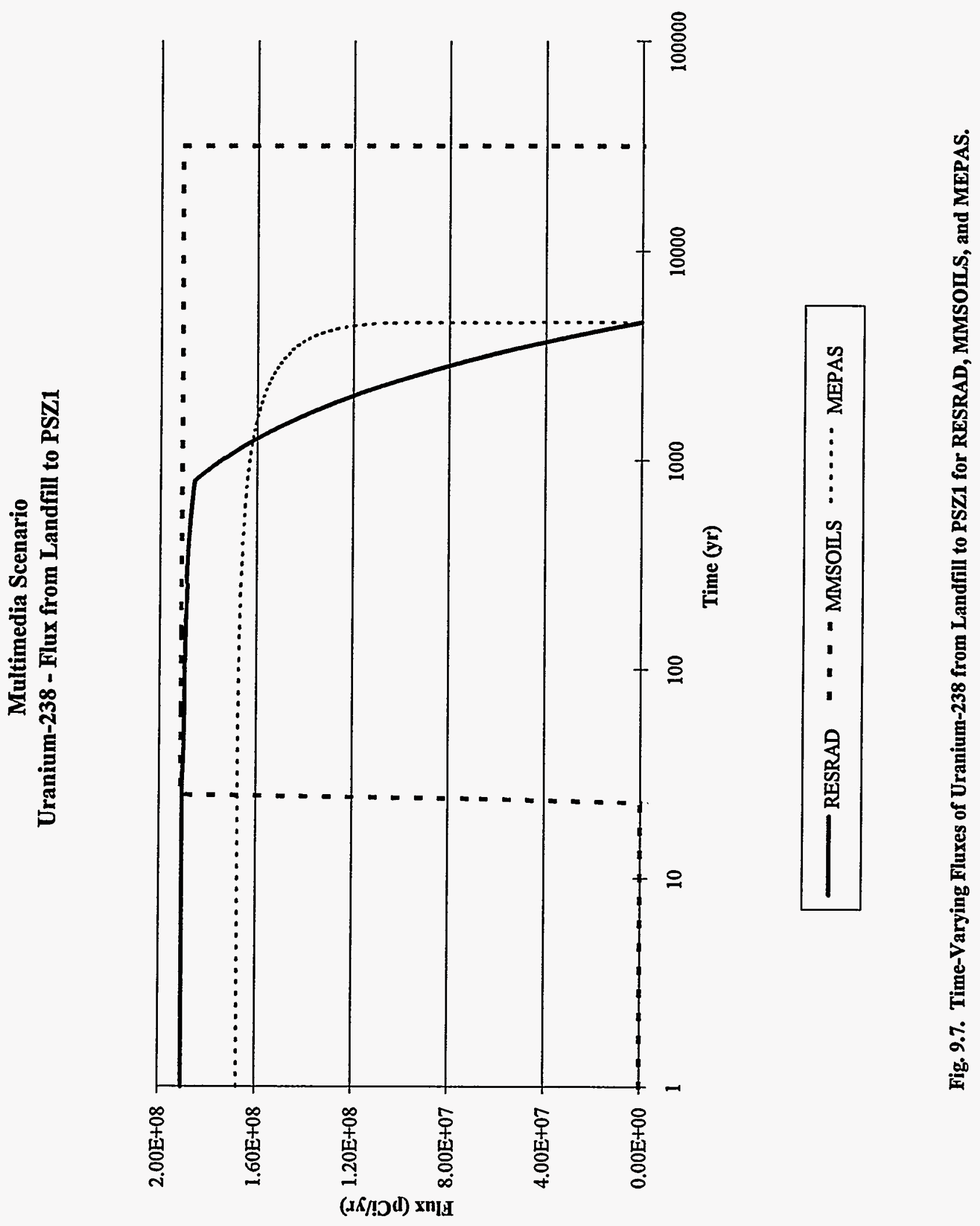


Multimedia Scenario

Methylene Chloride - Flux from PSZ1 to PSZ2

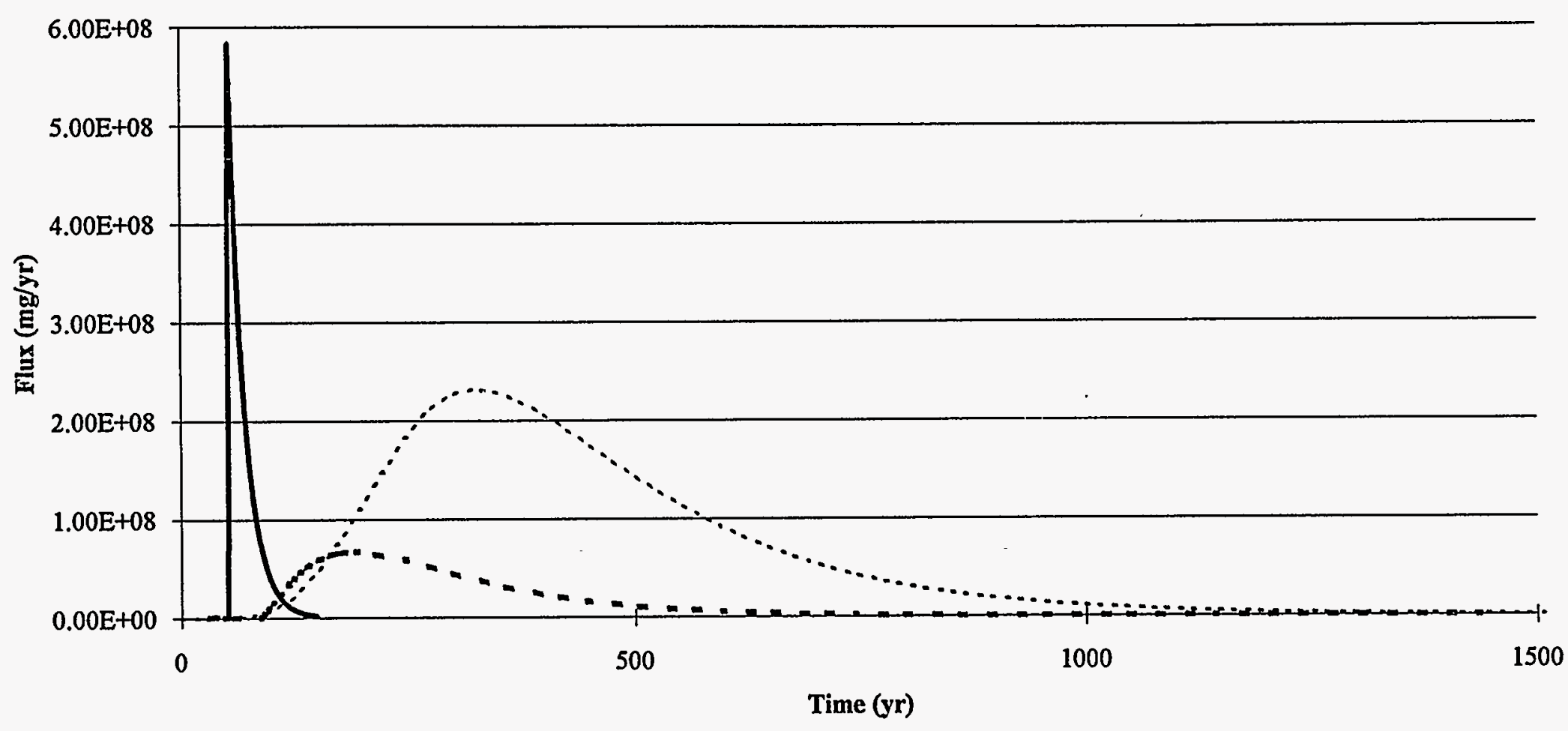

Fig. 9.8. Time-Varying Fluxes of Methylene Chloride from PSZ1 to PSZ2 for RESRAD, MMSOILS, and MEPAS. 


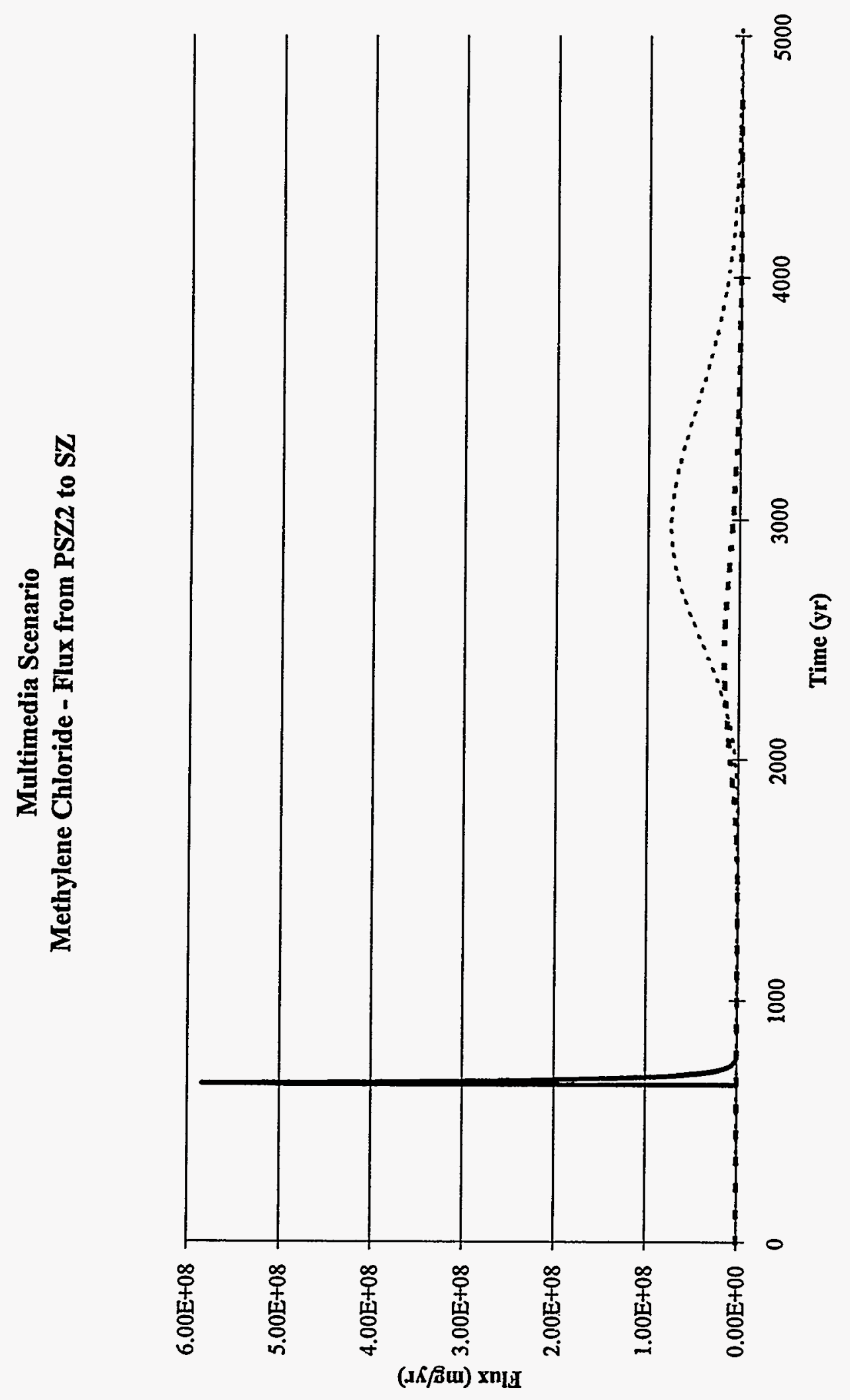

言 


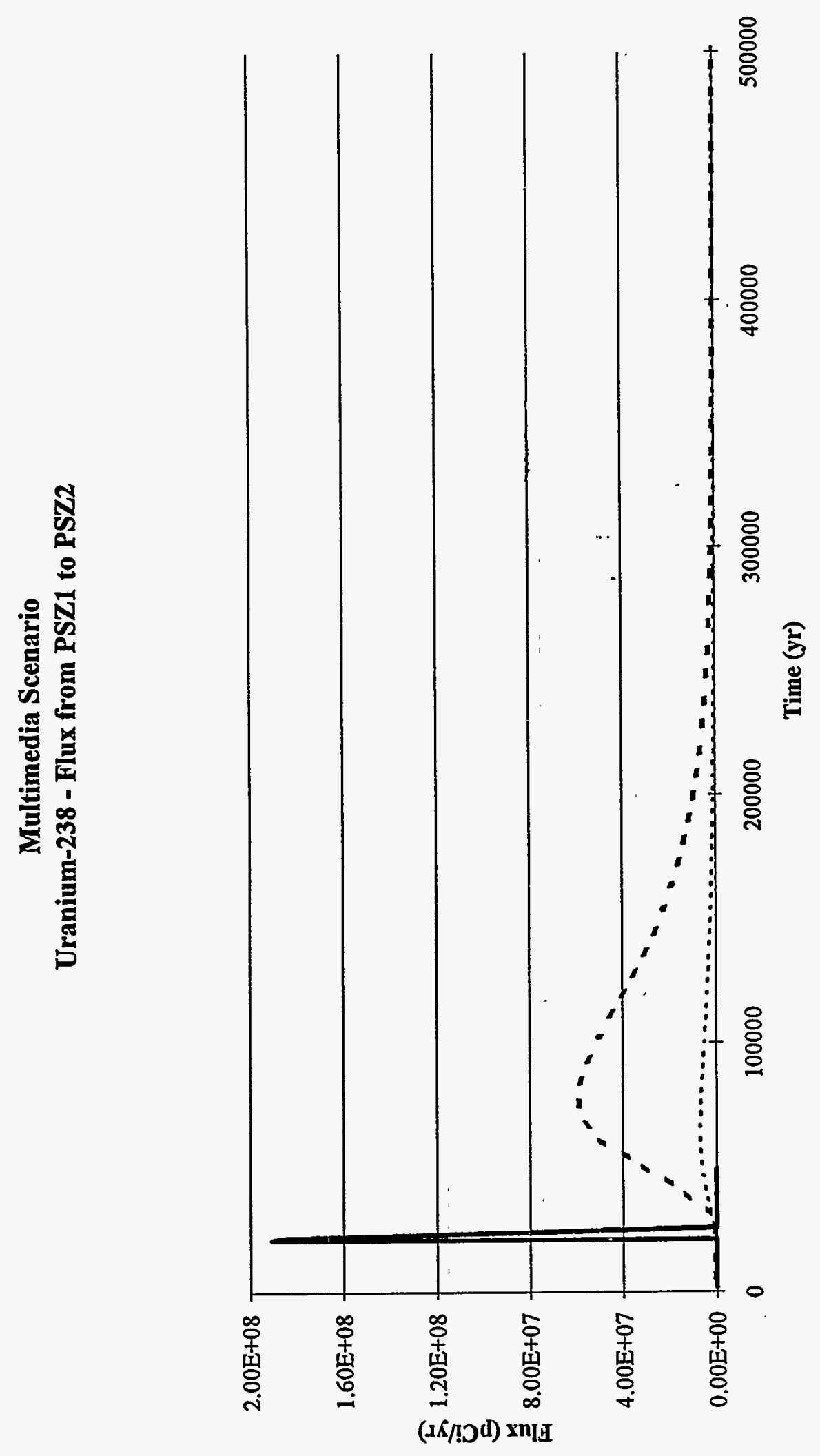

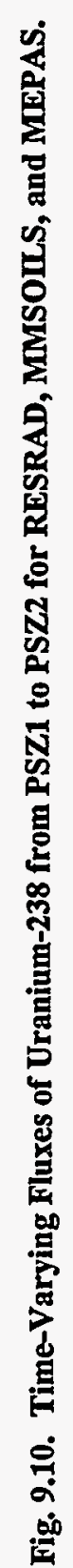




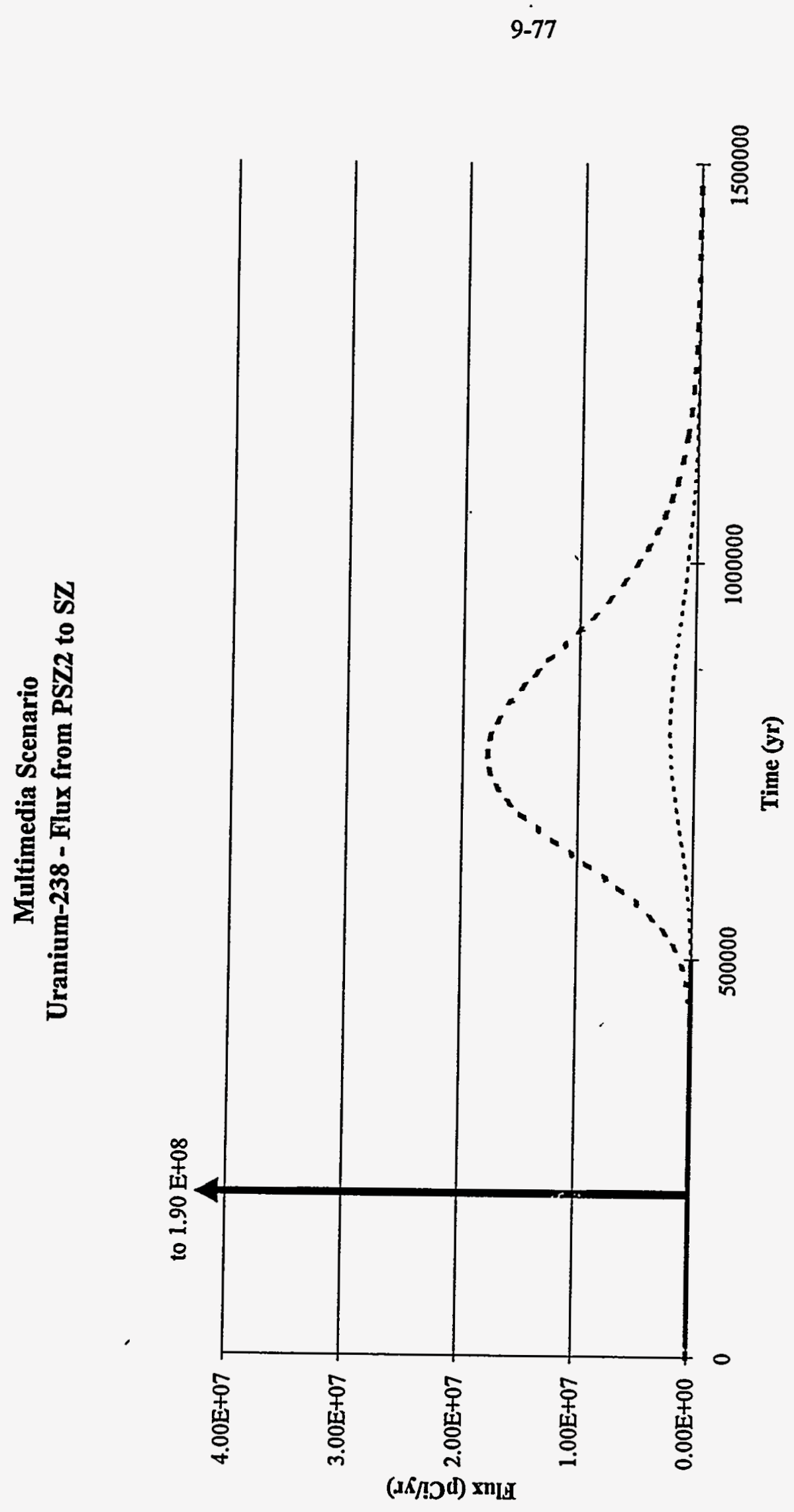

焉 
Multimedia Scenario

Uranium-234 - Flux at Three Locations in the Unsaturated Zone

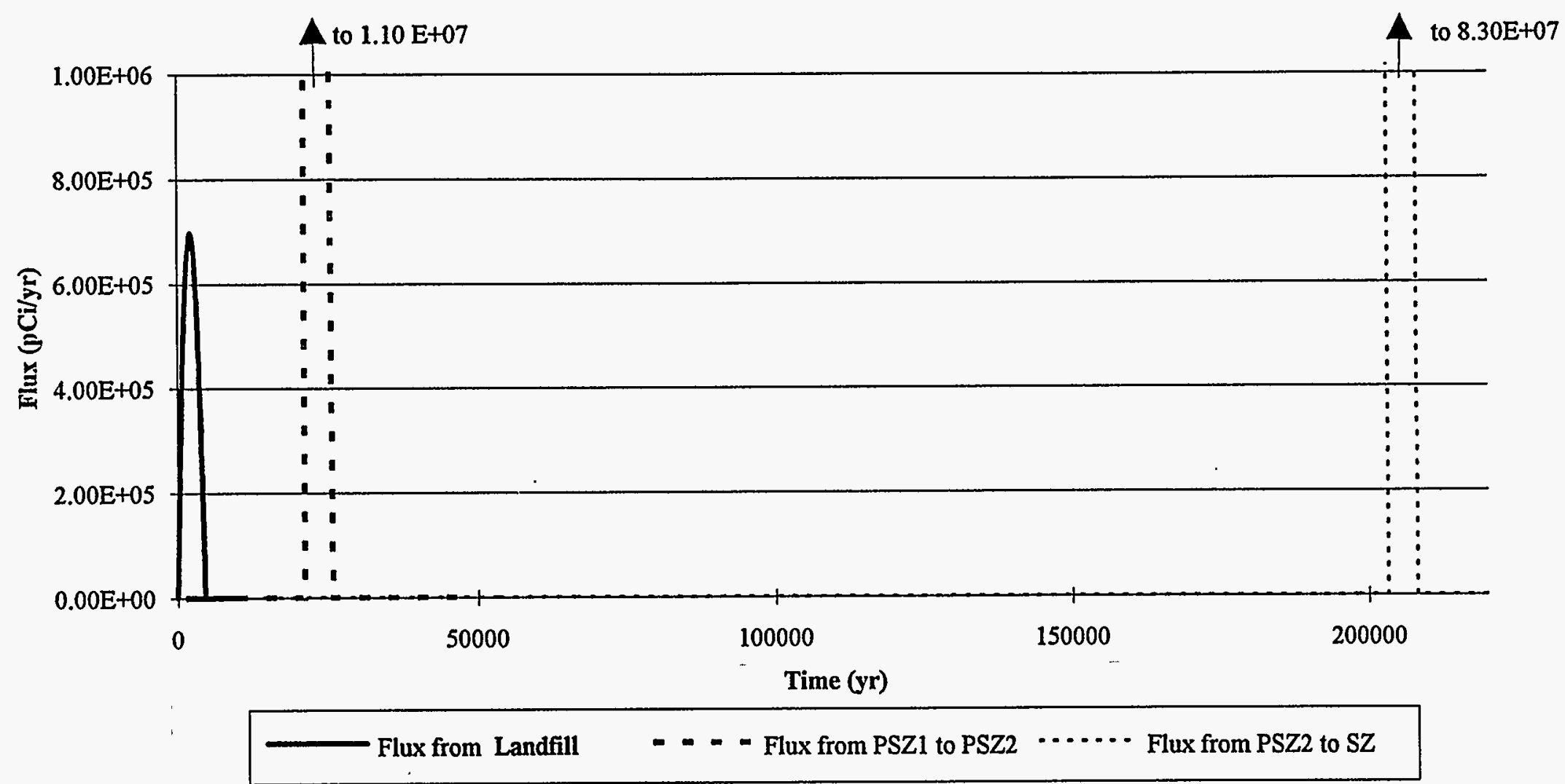

Fig. 9.12. Time-Varying Fluxes of Uranium-234 at Three Locations in the Unsaturated Zone for RESRAD. 
Multimedia Scenario

Thorium-230 - Flux at Three Locations in the Unsaturated Zone

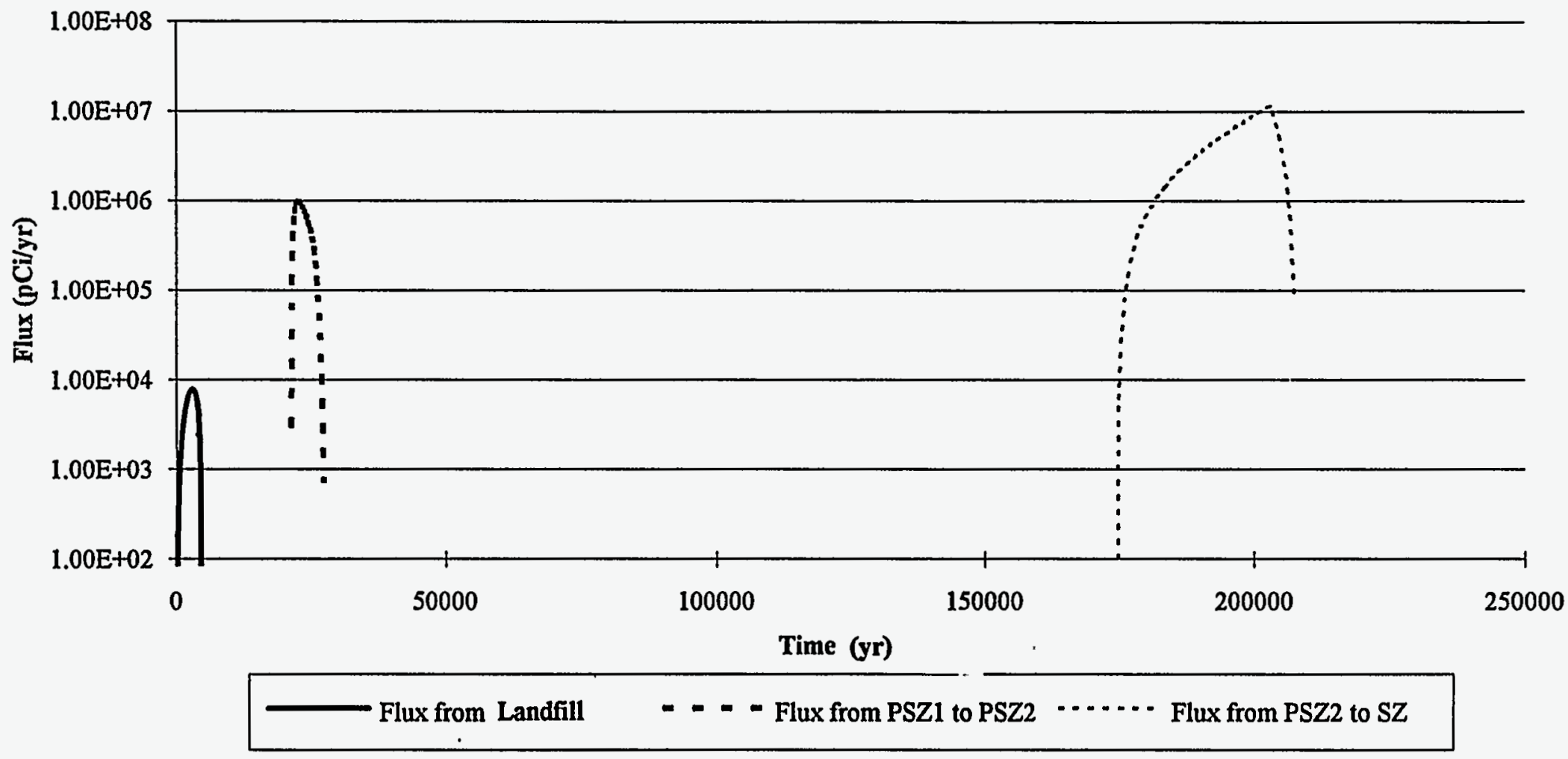


N

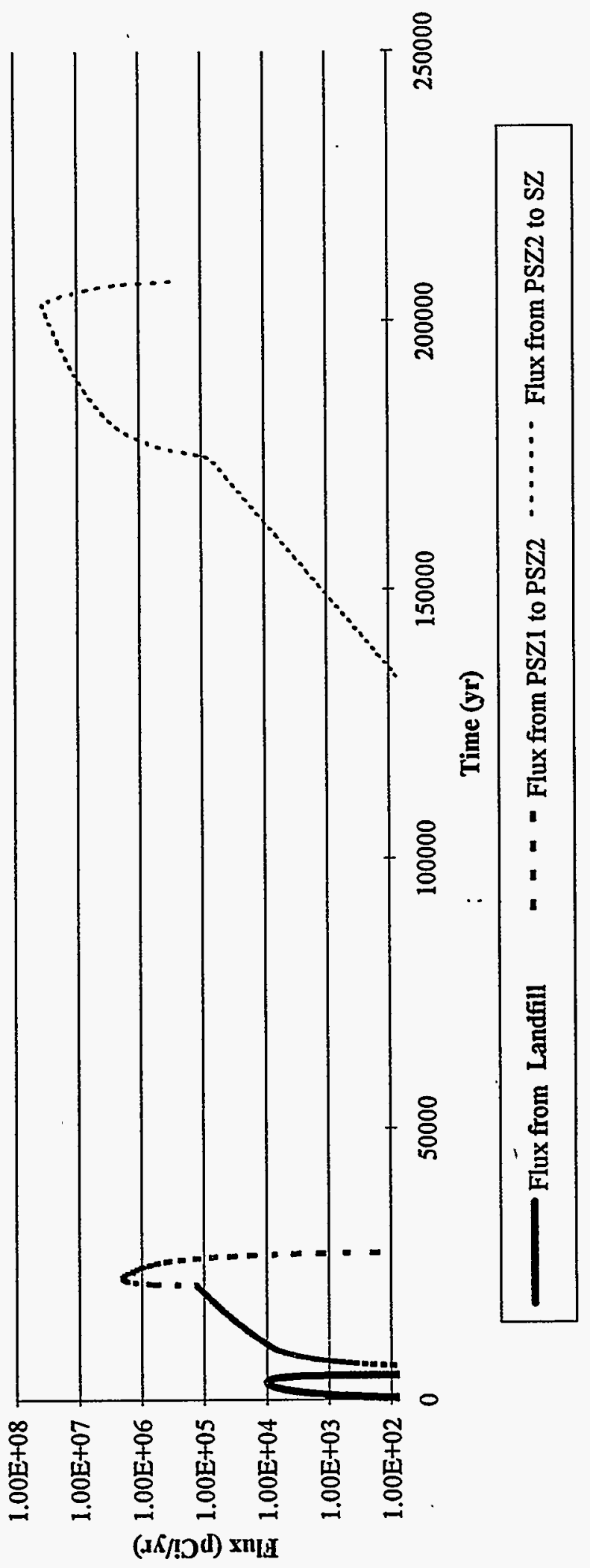

定 
Multimedia Scenario

Lead-210 - Flux at Three Locations in the Unsaturated Zone

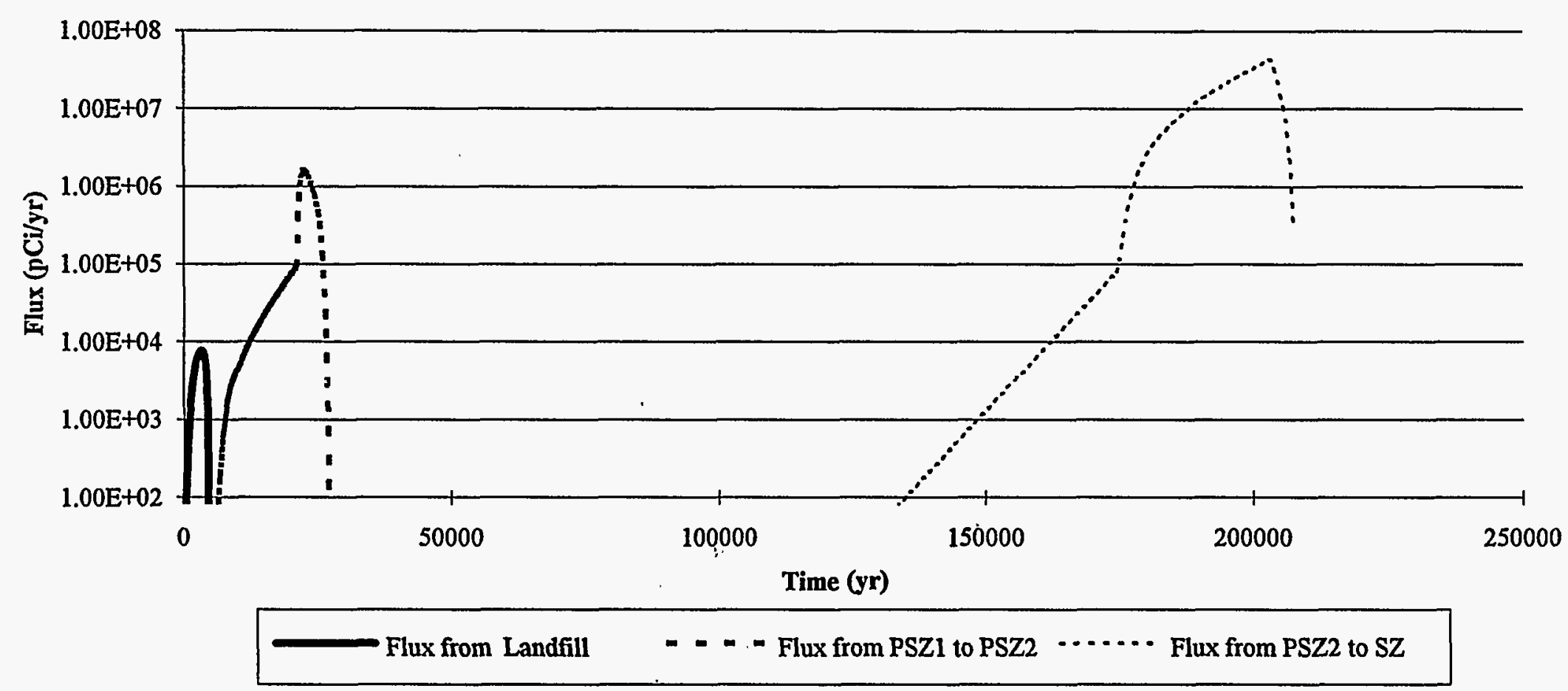

Fig. 9.15. Time-Varying Fluxes of Lead-210 at Three Locations in the Unsaturated Zone for RESRAD. 
Multimedia Scenario

Polonium-210 - Flux at Three Locations in the Unsaturated Zone

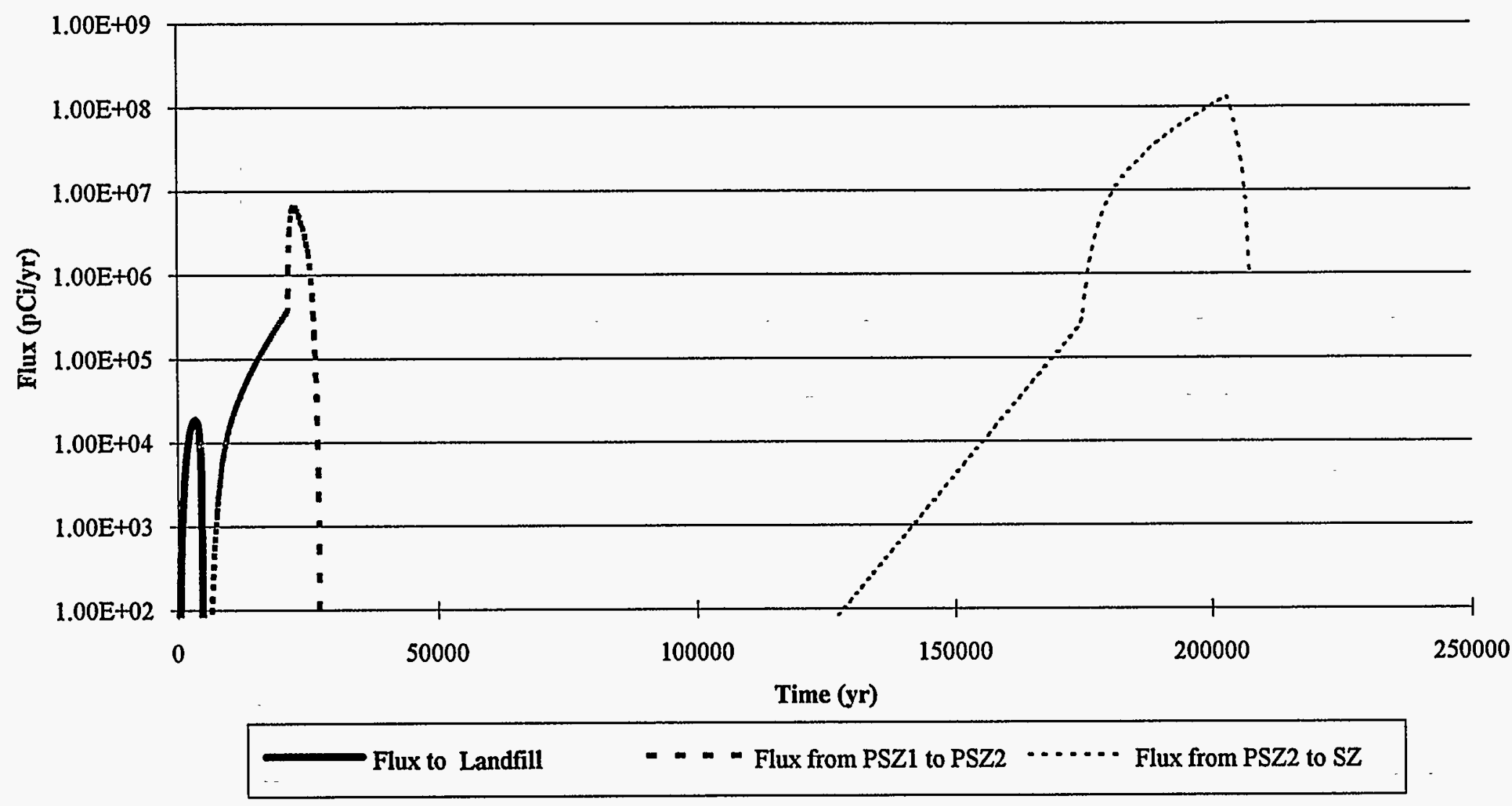

Fig. 9.16. Time-Varying Fluxes of Polonium-210 at Three Locations in the Unsaturated Zone for RESRAD. 
Multimedia Scenario

Methylene Chloride - Concentrations for Onsite Well

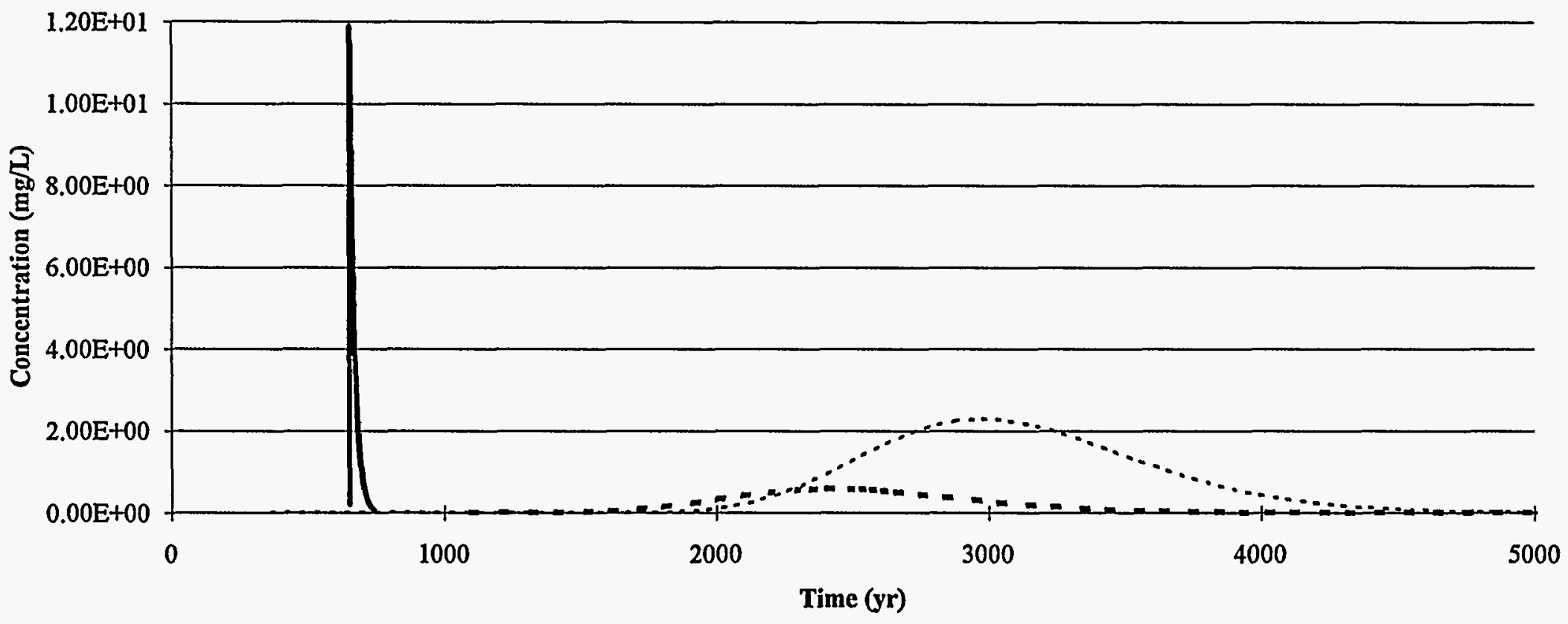

Fig. 9.17a. Time-Varying Concentrations of Methylene Chloride in Groundwater for Onsite Well for RESRAD, MMSOILS, and MEPAS. 
Multimedia Scenario

Methylene Chloride - Concentrations for Offsite Well

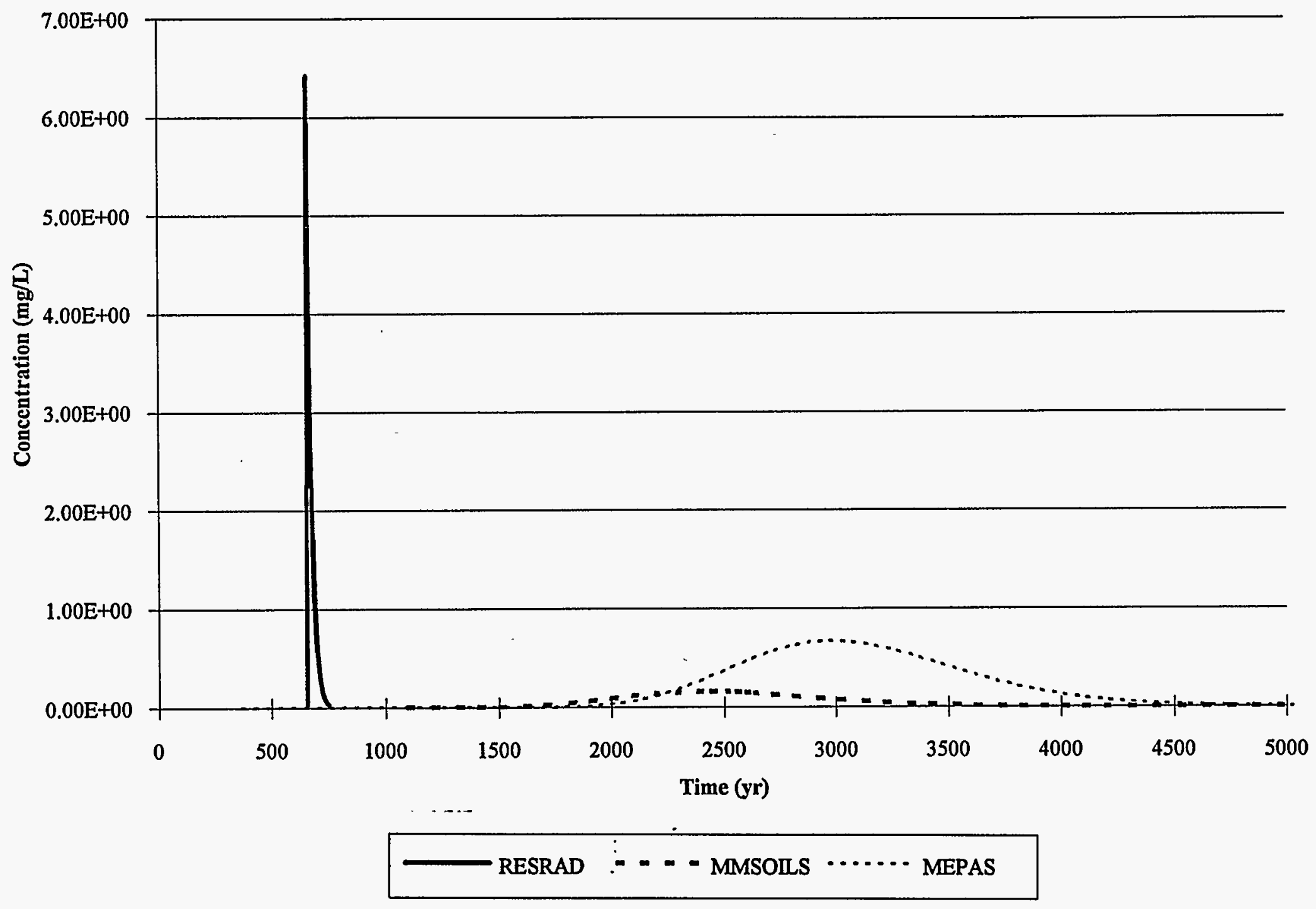

Fig. 9.17b. Time-Varying Concentrations of Methylene Chloride in Groundwater for Offsite Well for RESRAD, MMSOILS, and MEPAS. 


\section{Multimedia Scenario}

Uranium-238 - Concentrations for Onsite Well

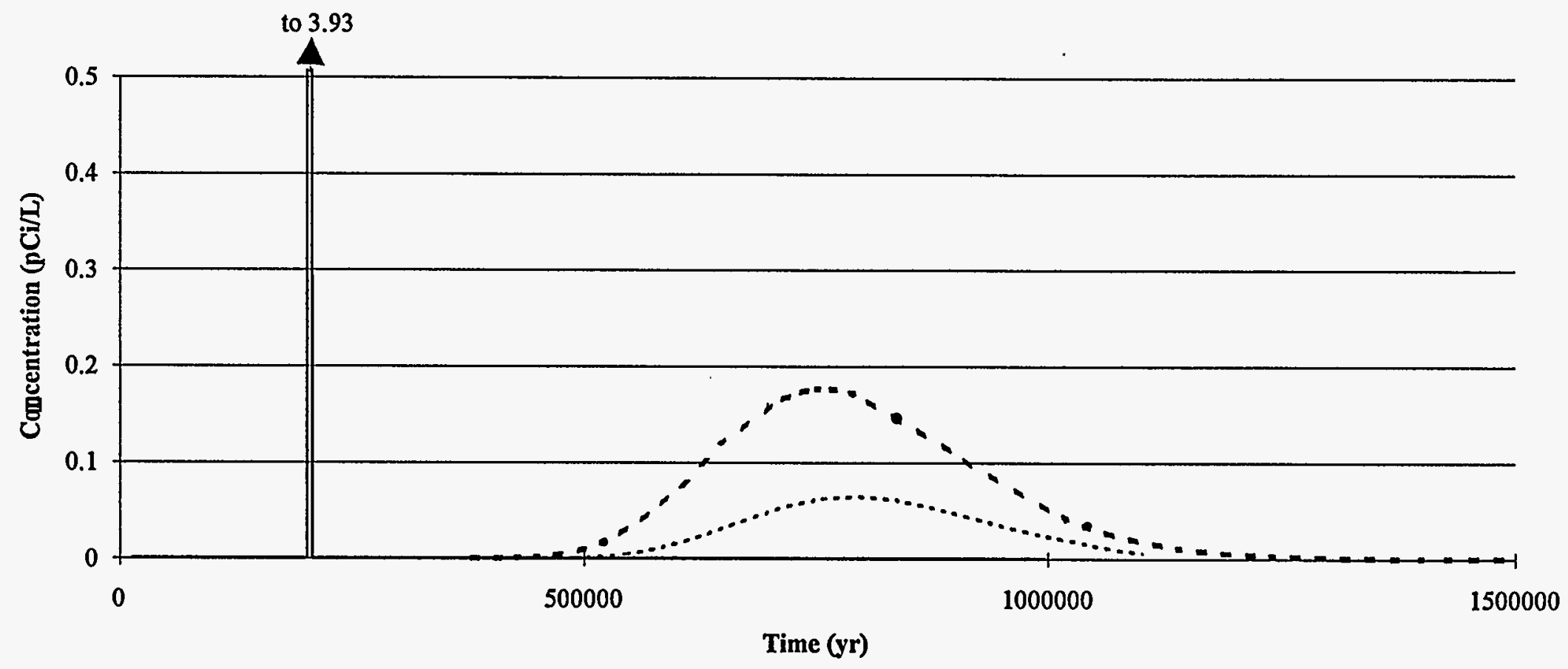

Fig. 9.18a. Time-Varying Concentrations of Uranium-238 in Groundwater for Onsite Well for RESRAD, MMSOILS, and MEPAS. 


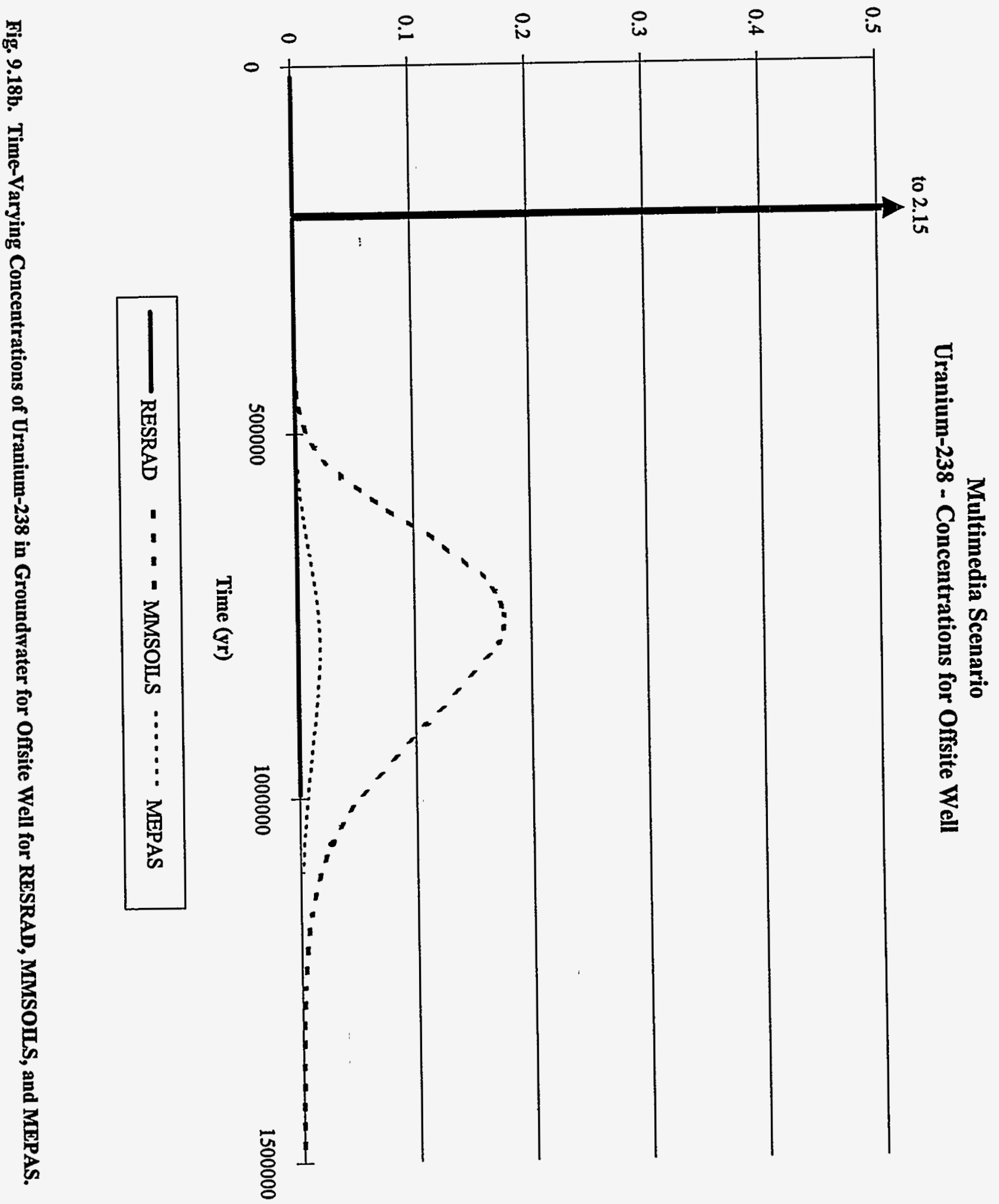


Multimedia Scenario

Thorium-234 - Concentrations for Onsite and Offsite Wells

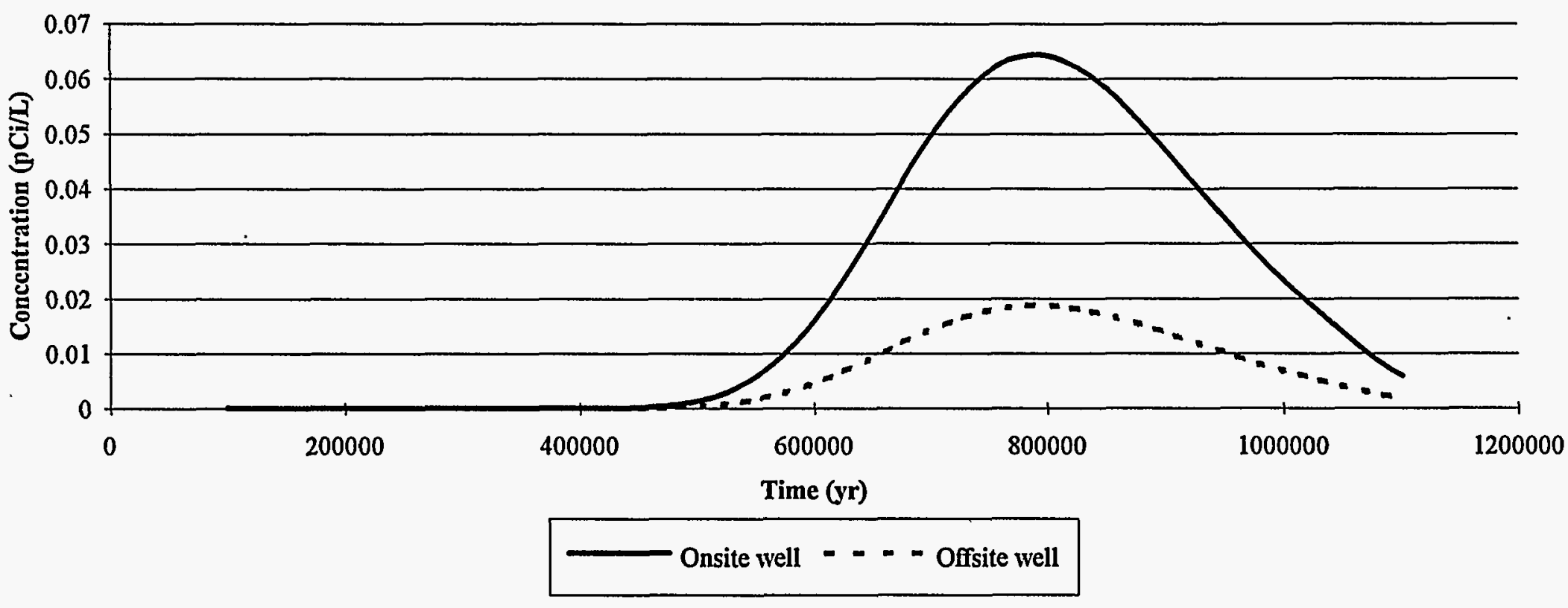

Fig. 9.19. Time-Varying Concentrations of Thorium-234 for Onsite and Offsite Wells for MEPAS. 
Multimedia Scenario

Uranium-234 - Concentrations for Onsite Well

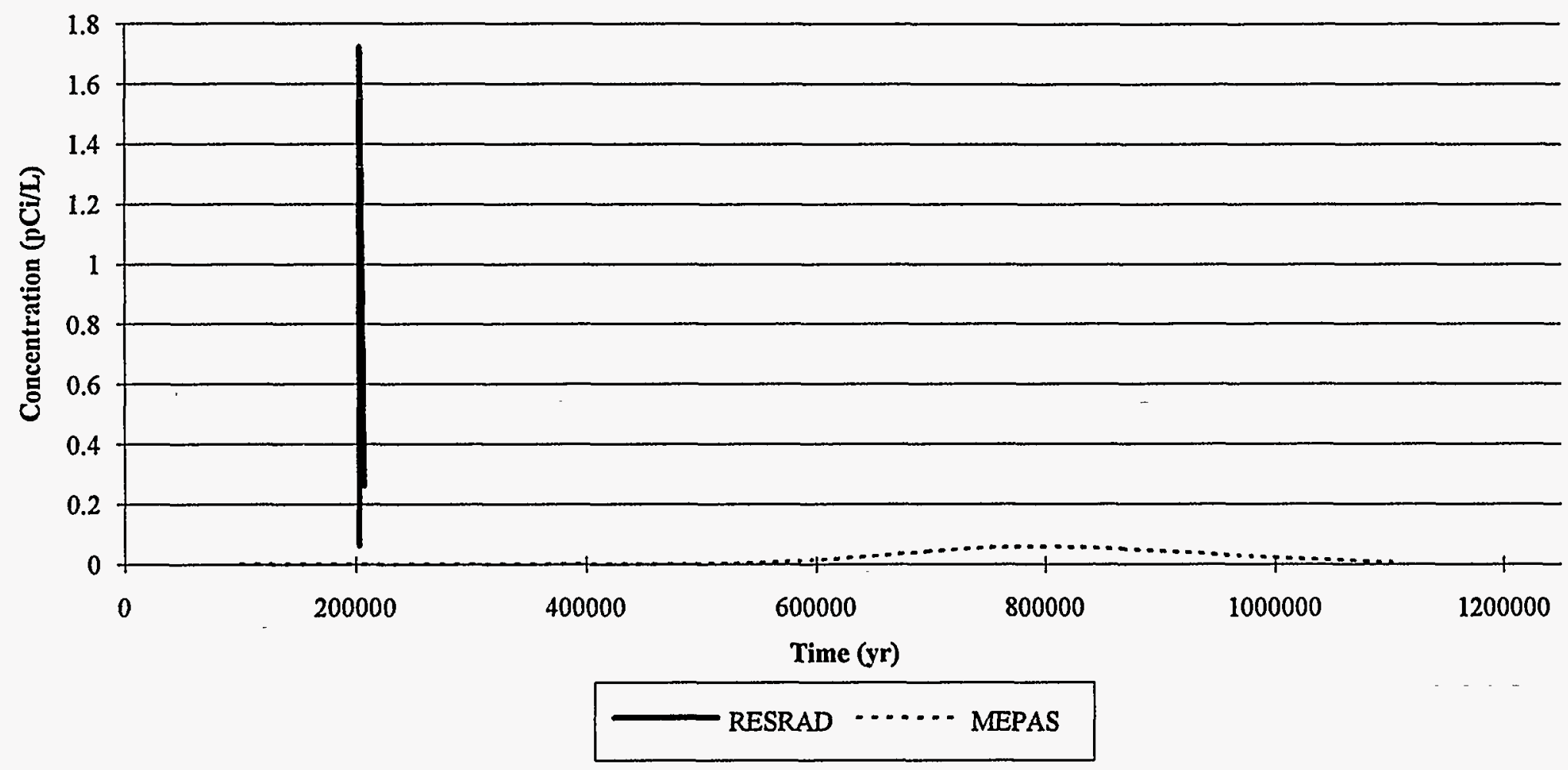

Fig. 9.20a. Time-Varying Concentrations of Uranium-234 in Groundwater for Onsite Well for RESRAD and MEPAS. 


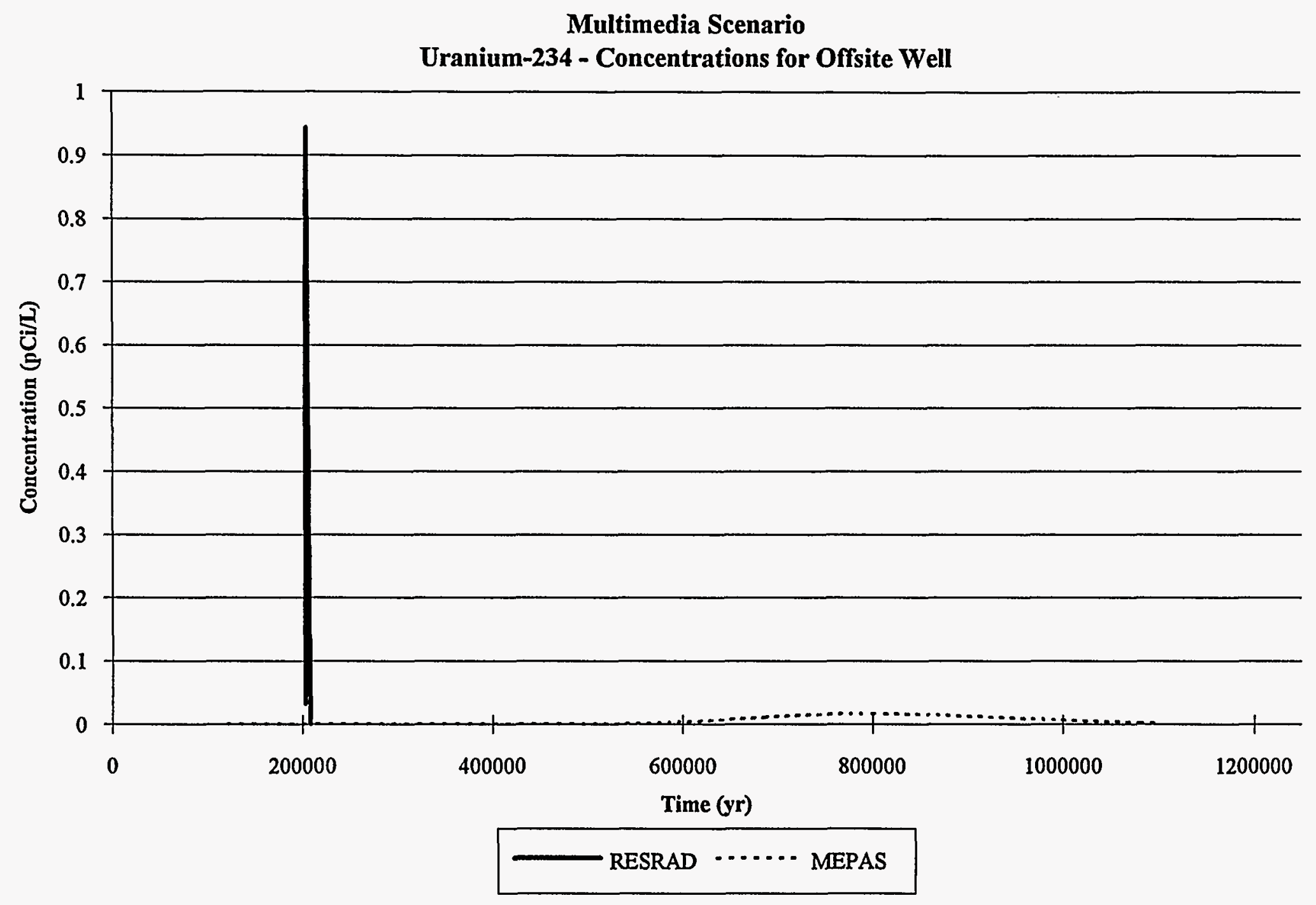

Fig. 9.20b. Time-Varying Concentrations of Uranium-234 in Groundwater for Offsite Well for RESRAD and MEPAS. 
Multimedia Scenario

Thorium-230 - Concentrations for Onsite Well

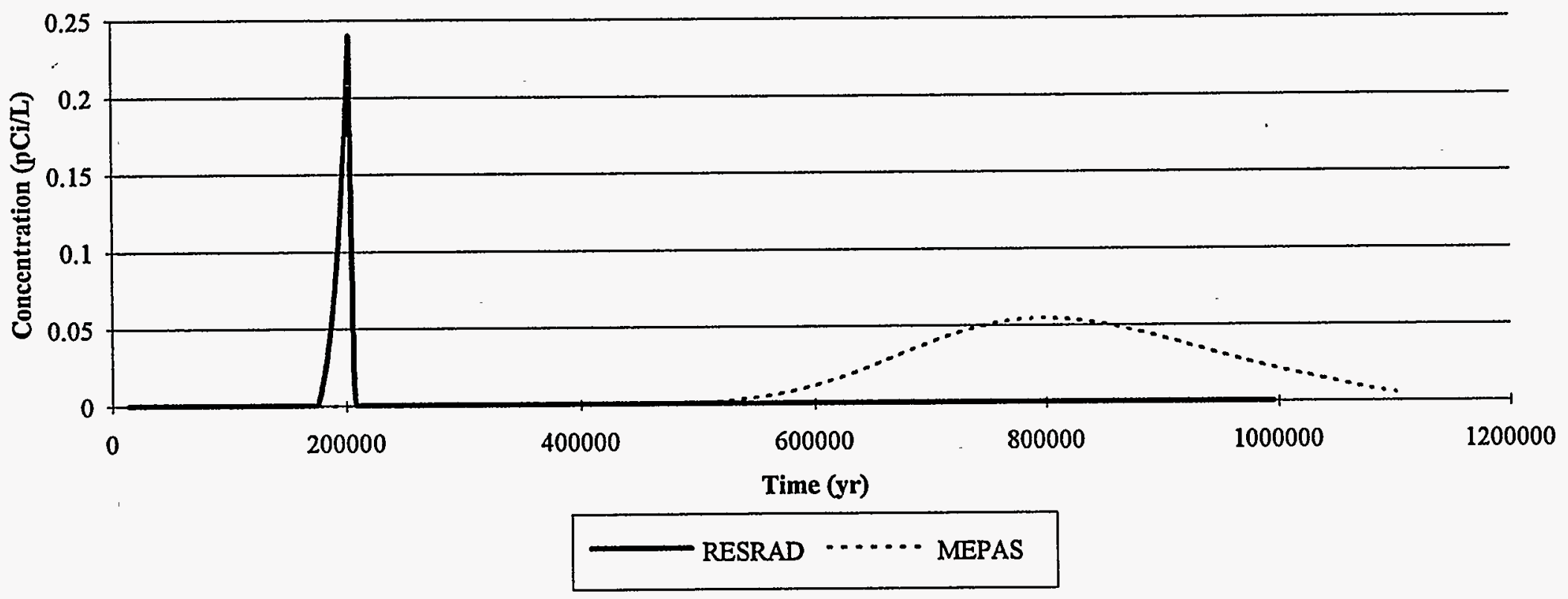

Fig. 9.21a. Time-Varying Concentrations of Thorium-230 in Groundwater for Onsite Well for RESRAD and MEPAS. 
Multimedia Scenario

Thorium-230 - Concentrations for Offsite Well

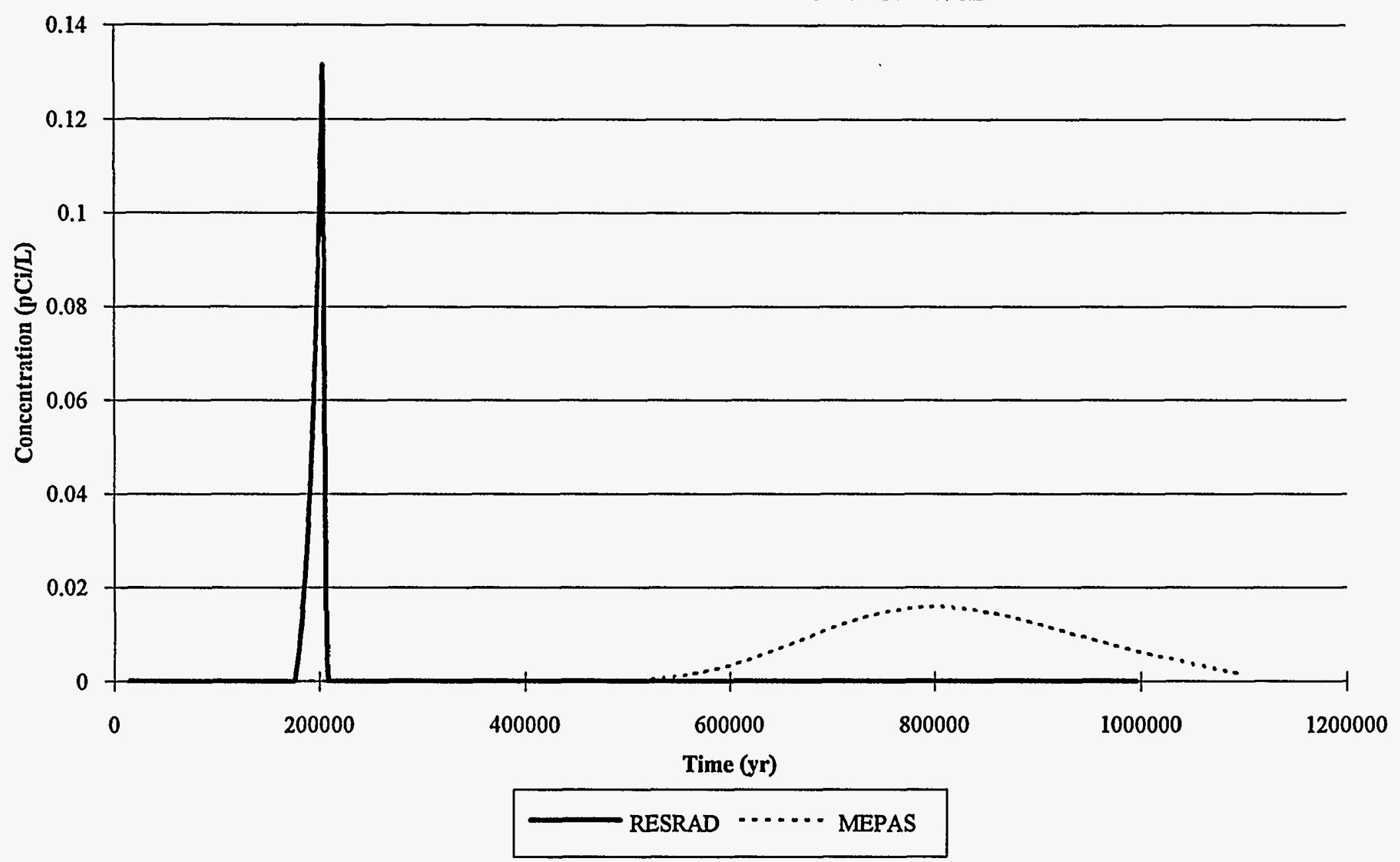

Fig. 9.21b. Time-Varying Concentrations of Thorium-230 in Groundwater for Offsite Well for RESRAD and MEPAS. 
Multimedia Scenario

Radium-226 - Concentrations for Onsite Well

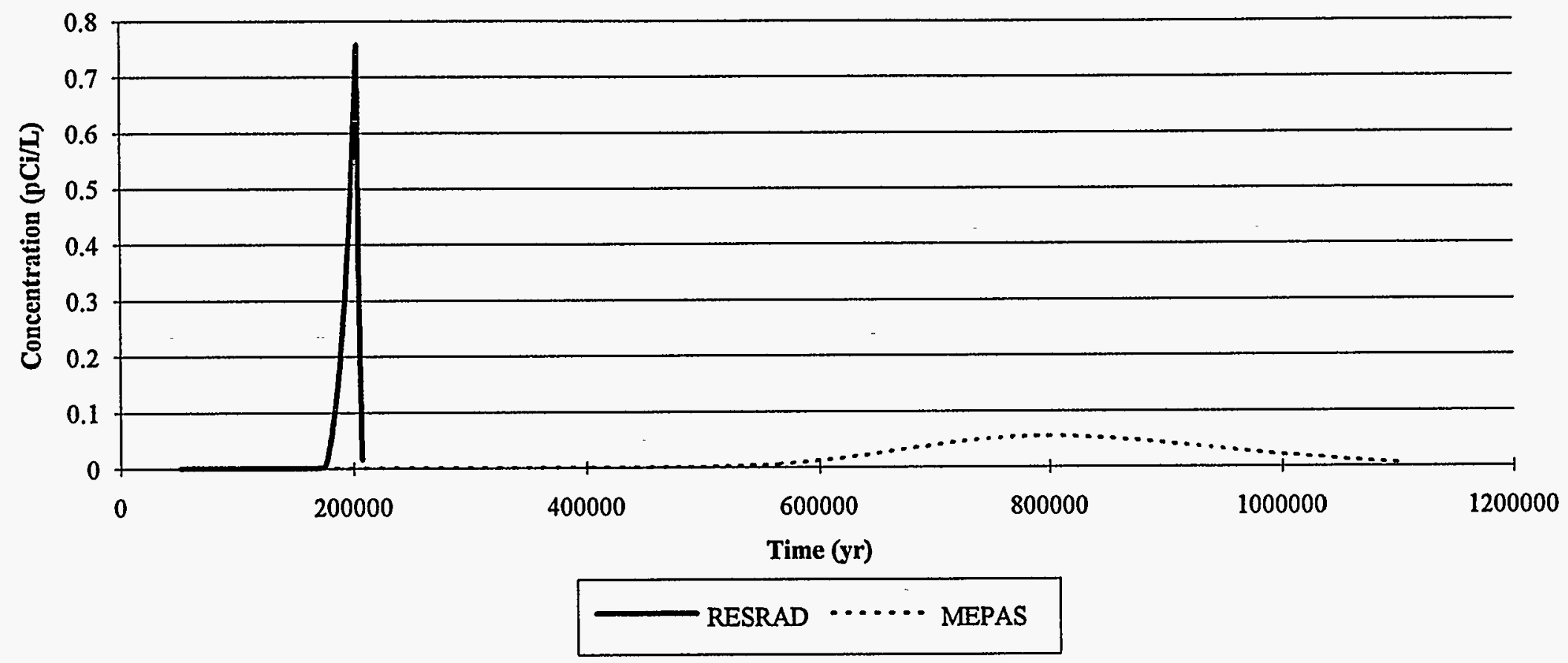

Fig. 9.22a. Time-Varying Concentrations of Radium-226 in Groundwater for Onsite Well for RESRAD and MEPAS. 


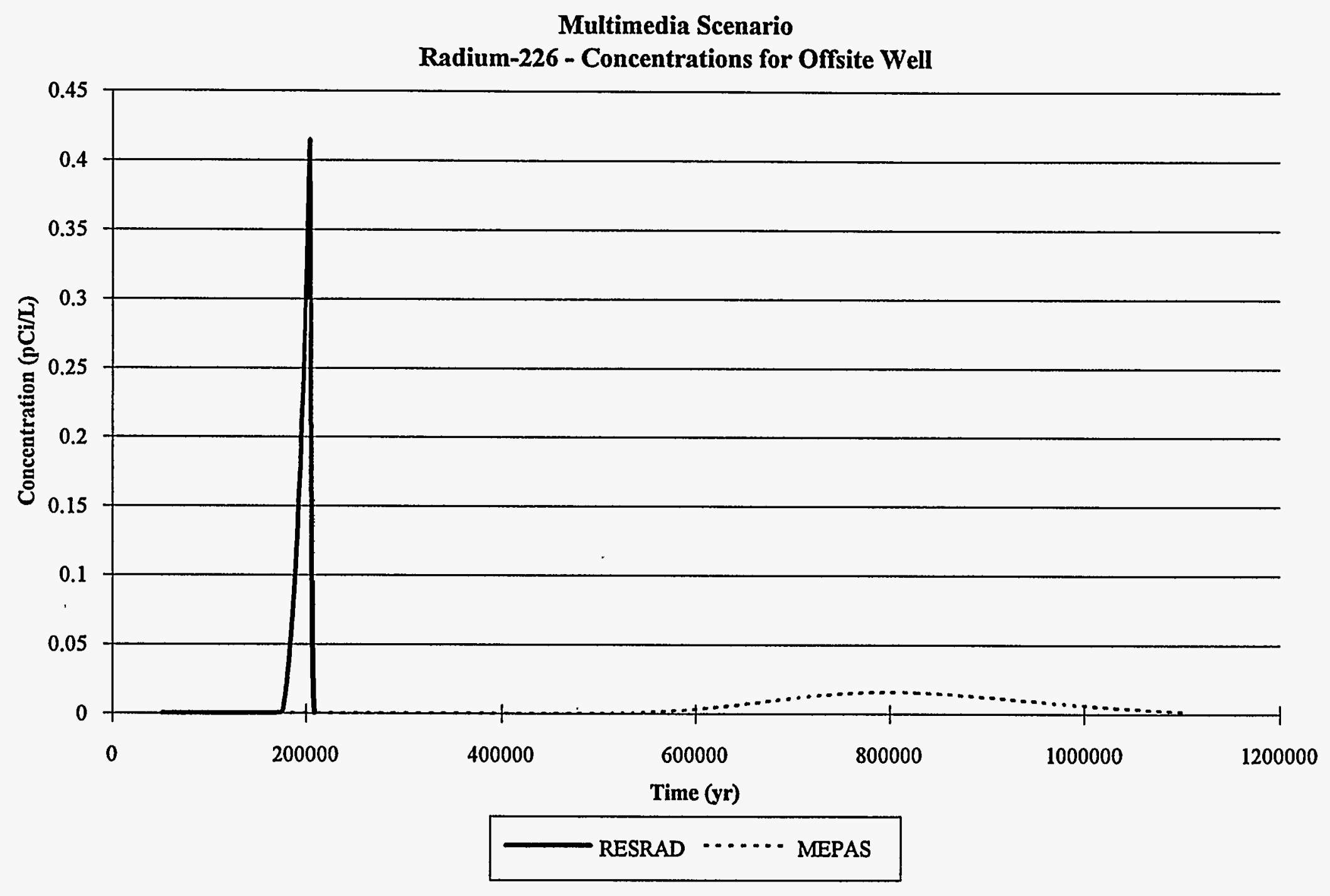

Fig. 9.22b. Time-Varying Concentrations of Radium-226 in Groundwater for Offsite Well for RESRAD and MEPAS. 


\section{Multimedia Scenario}

Radon-222 - Concentrations for Onsite and Offsite Wells

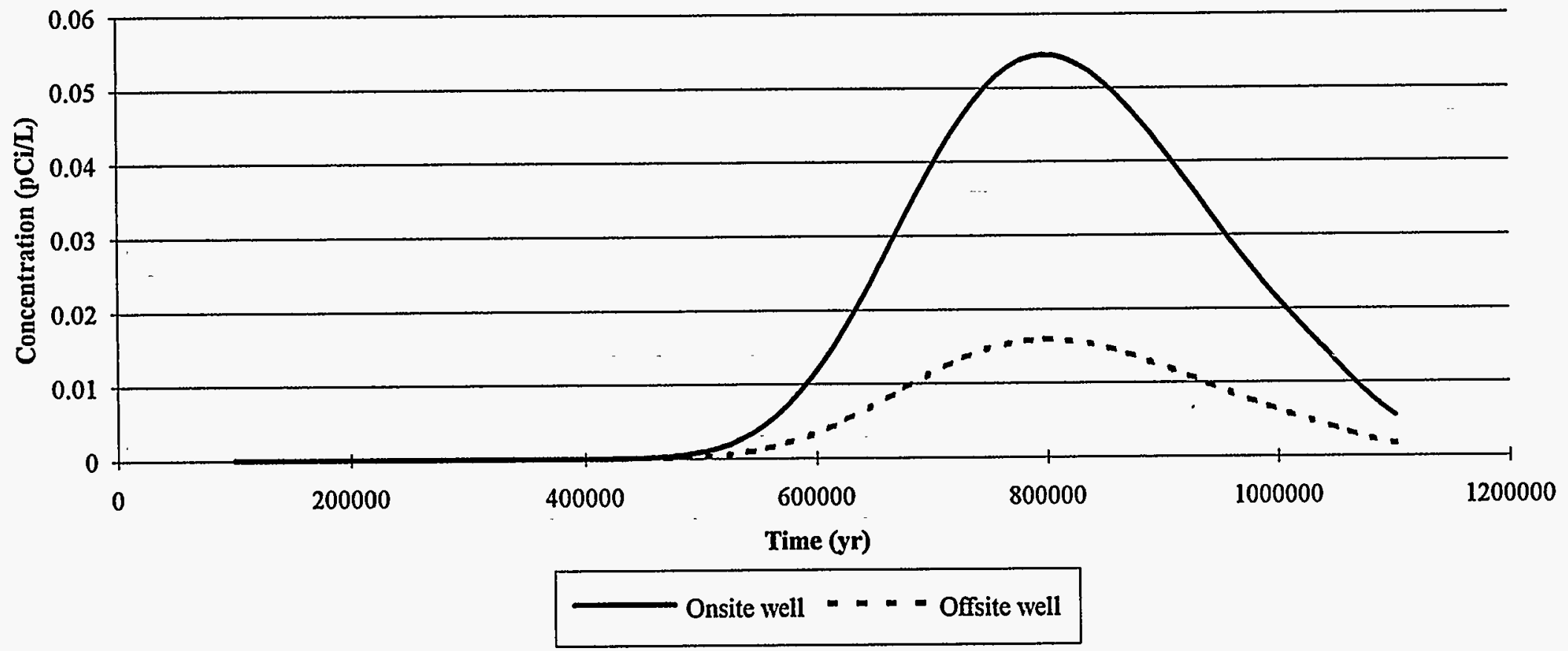

Fig. 9.23. Time-Varying Concentrations of Radon-222 for Onsite and Offsite Wells for MEPAS. 
Multimedia Scenario

Lead-210 - Concentrations for Onsite Well

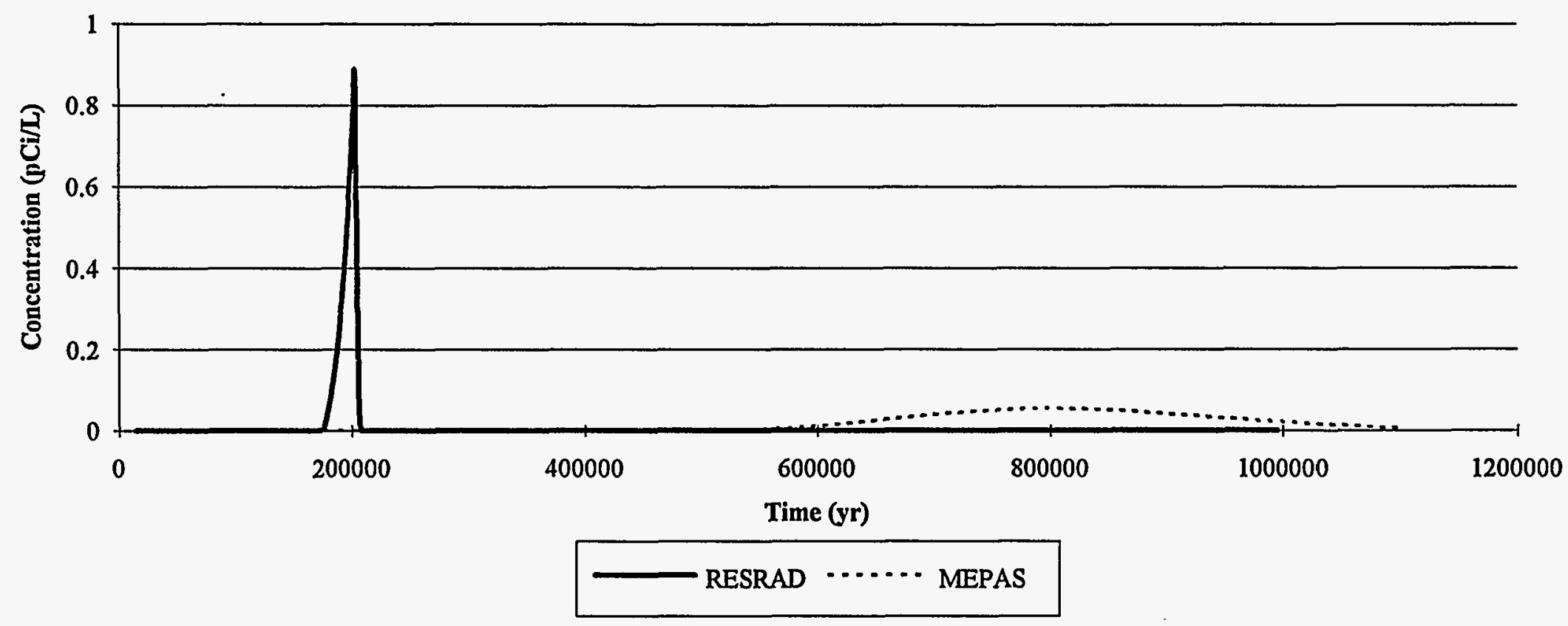

Fig. 9.24a. Time-Varying Concentrations of Lead-210 in Groundwater for Onsite Well for RESRAD and MEPAS. 


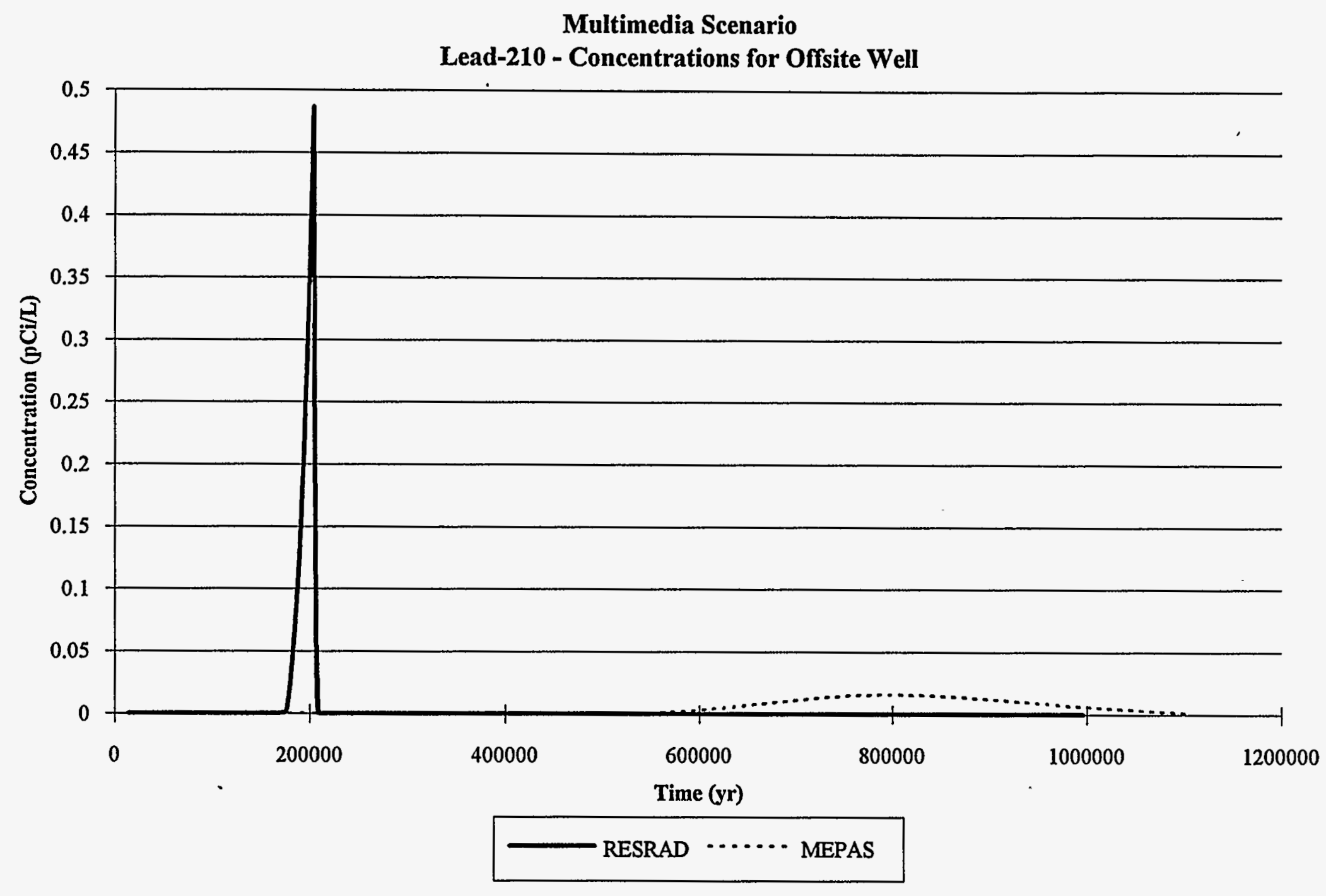

Fig. 9.24b. Time-Varying Concentrations of Lead-210 in Groundwater for Offsite Well for RESRAD and MEPAS. 


\section{Multimedia Scenario}

Bismuth-210 - Concentrations for Onsite and Offsite Wells

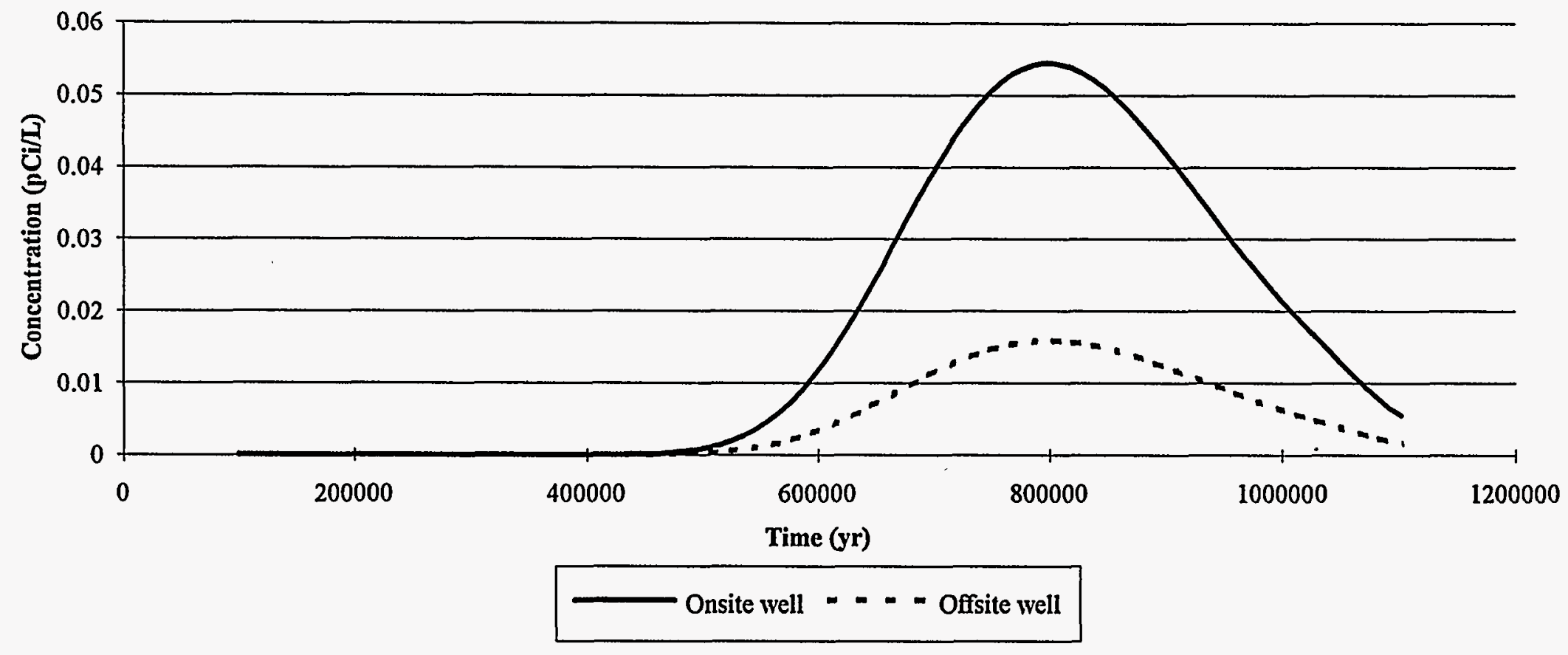

Fig. 9.25. Time-Varying Concentrations of Bismuth-210 for Onsite and Offsite Wells for MEPAS. 
Multimedia Scenario

Polonium-210 - Concentrations for Onsite Well

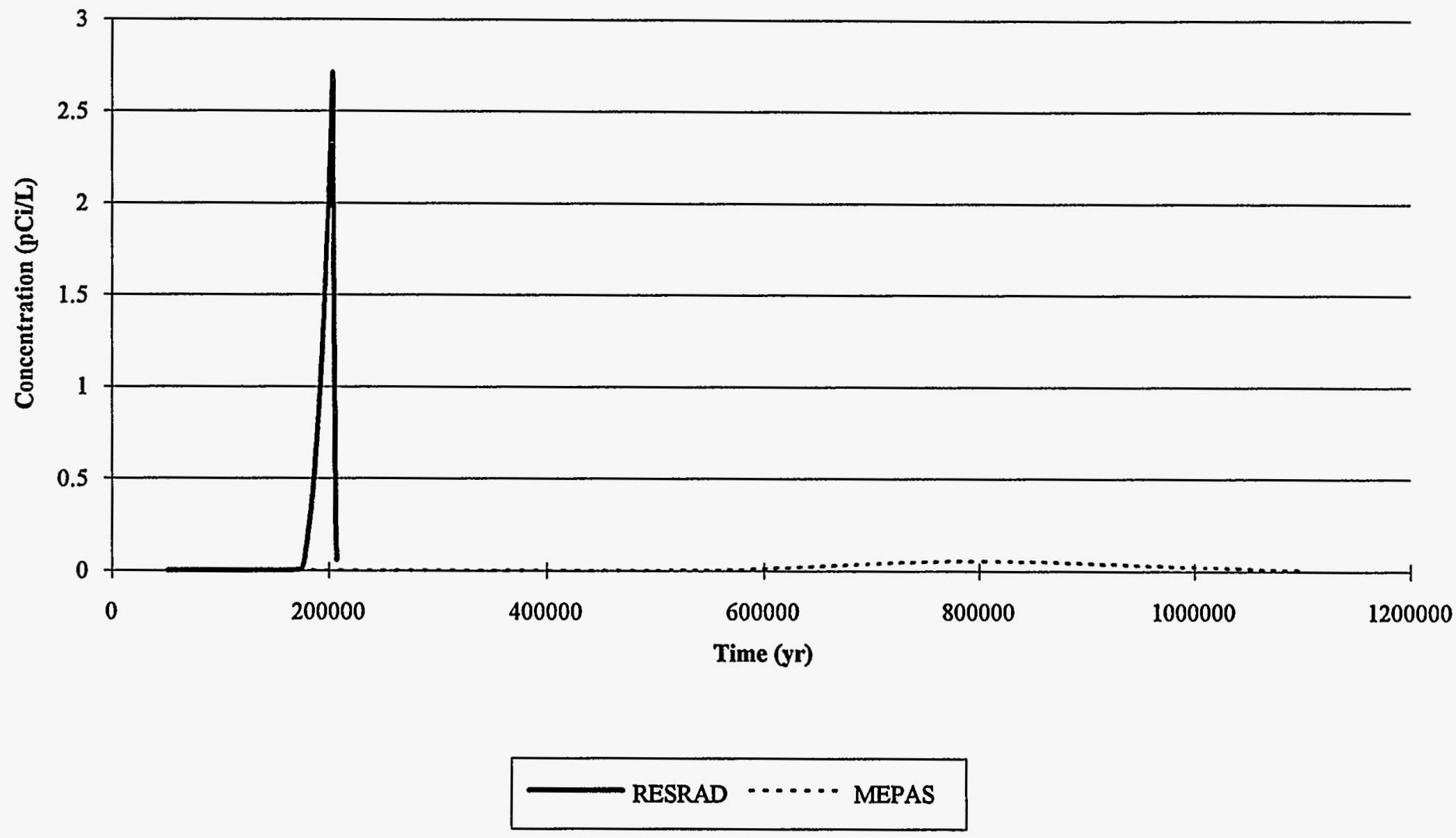

Fig. 9.26a. Time-Varying Concentrations of Polonium-210 in Groundwater for Onsite Well for RESRAD and MEPAS. 


\section{Multimedia Scenario}

Polonium-210 - Concentrations for Offsite Well

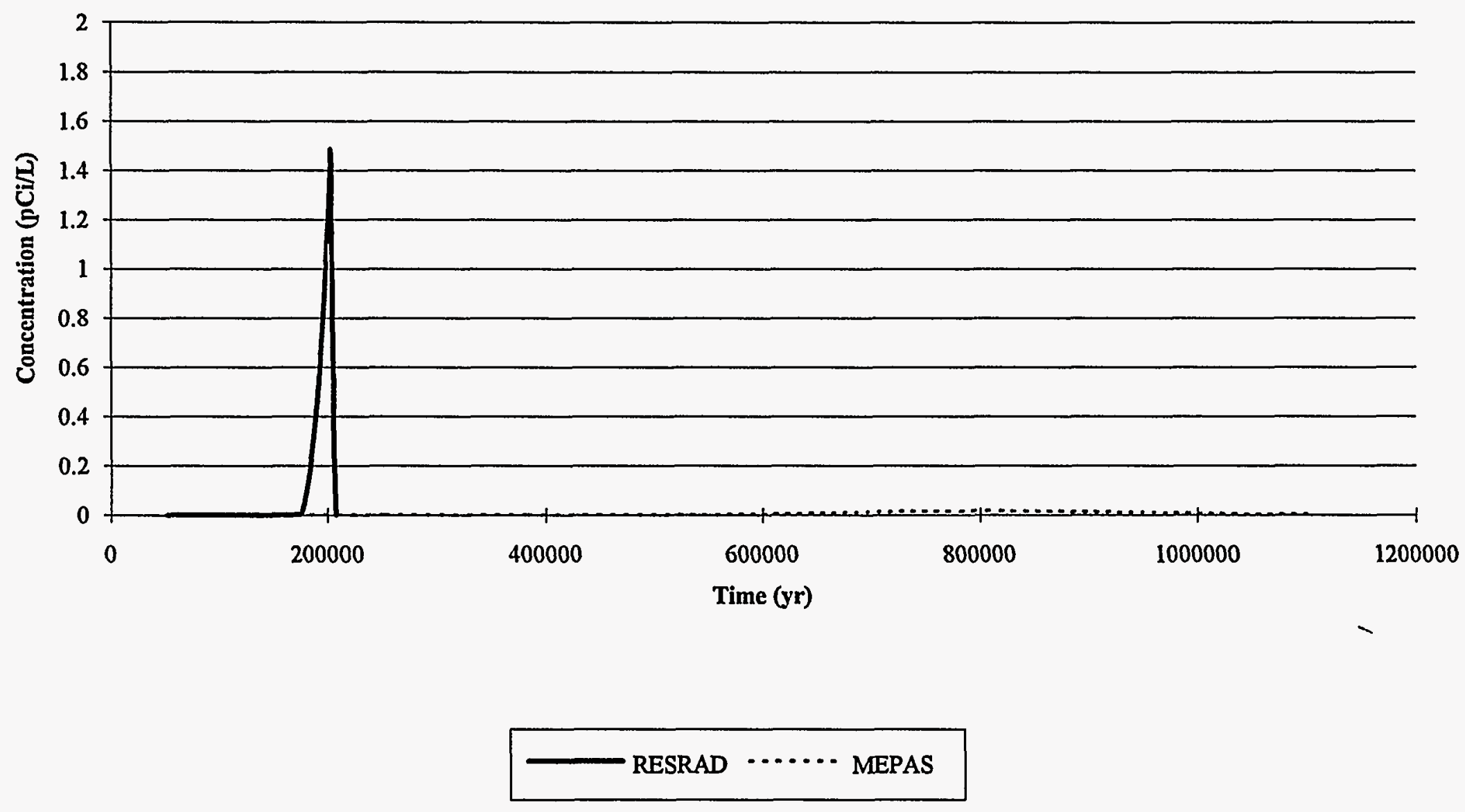

Fig. 9.26b. Time-Varying Concentrations of Polonium-210 in Groundwater for Offsite Well for RESRAD and MEPAS. 
Multimedia Scenario

Uranium-238 and Thorium-234 - Concentrations

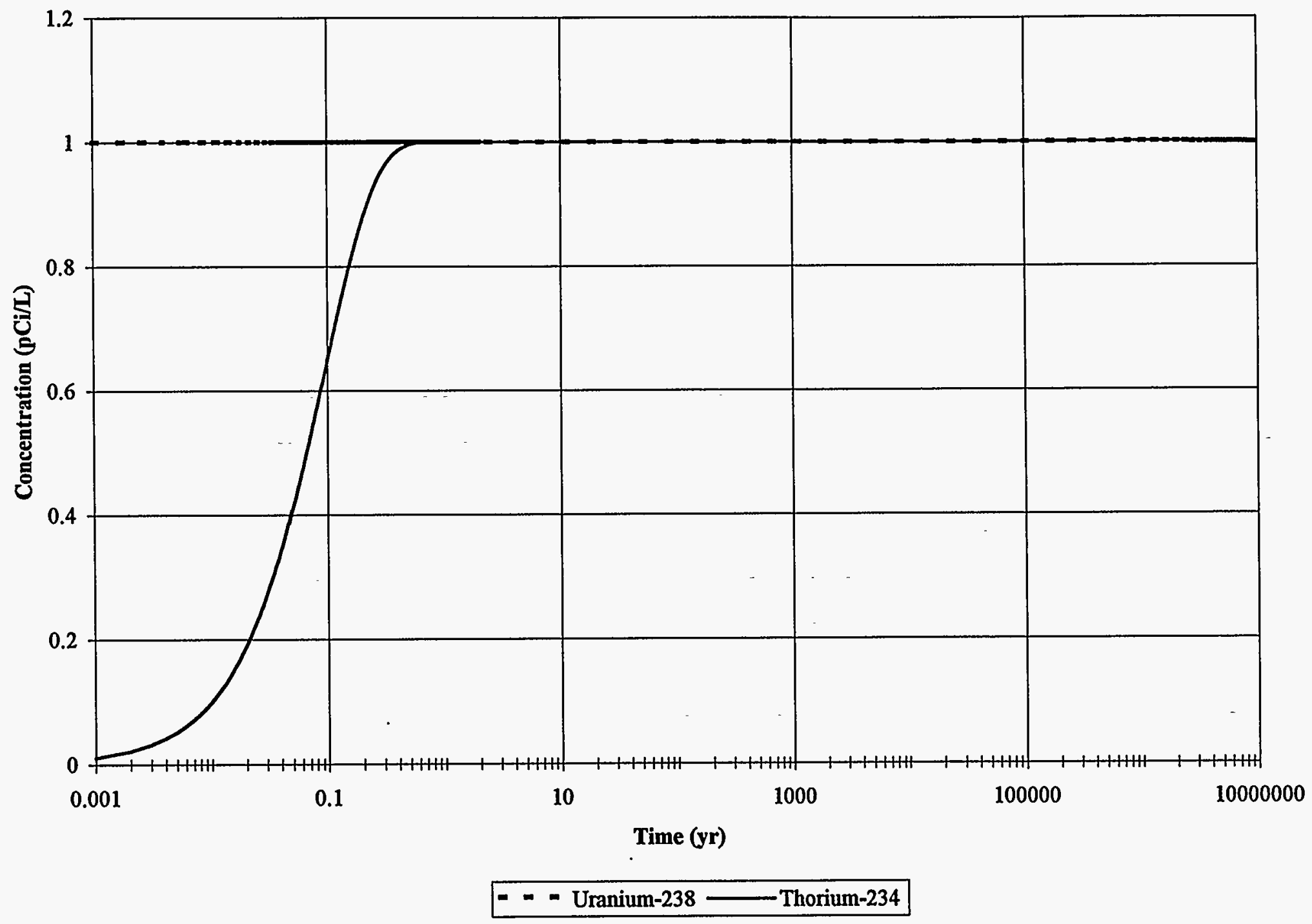

Fig. 9.27a. Time-Varying Concentrations of Uranium-238 and Thorium-234 Based on an Initial Uranium-238 Concentration of $1 \mathrm{pCi} / \mathrm{L}$.

[Plots developed by solving the Bateman equations] 


\section{Multimedia Scenario}

Uranium-234 and Thorium-230 - Concentrations

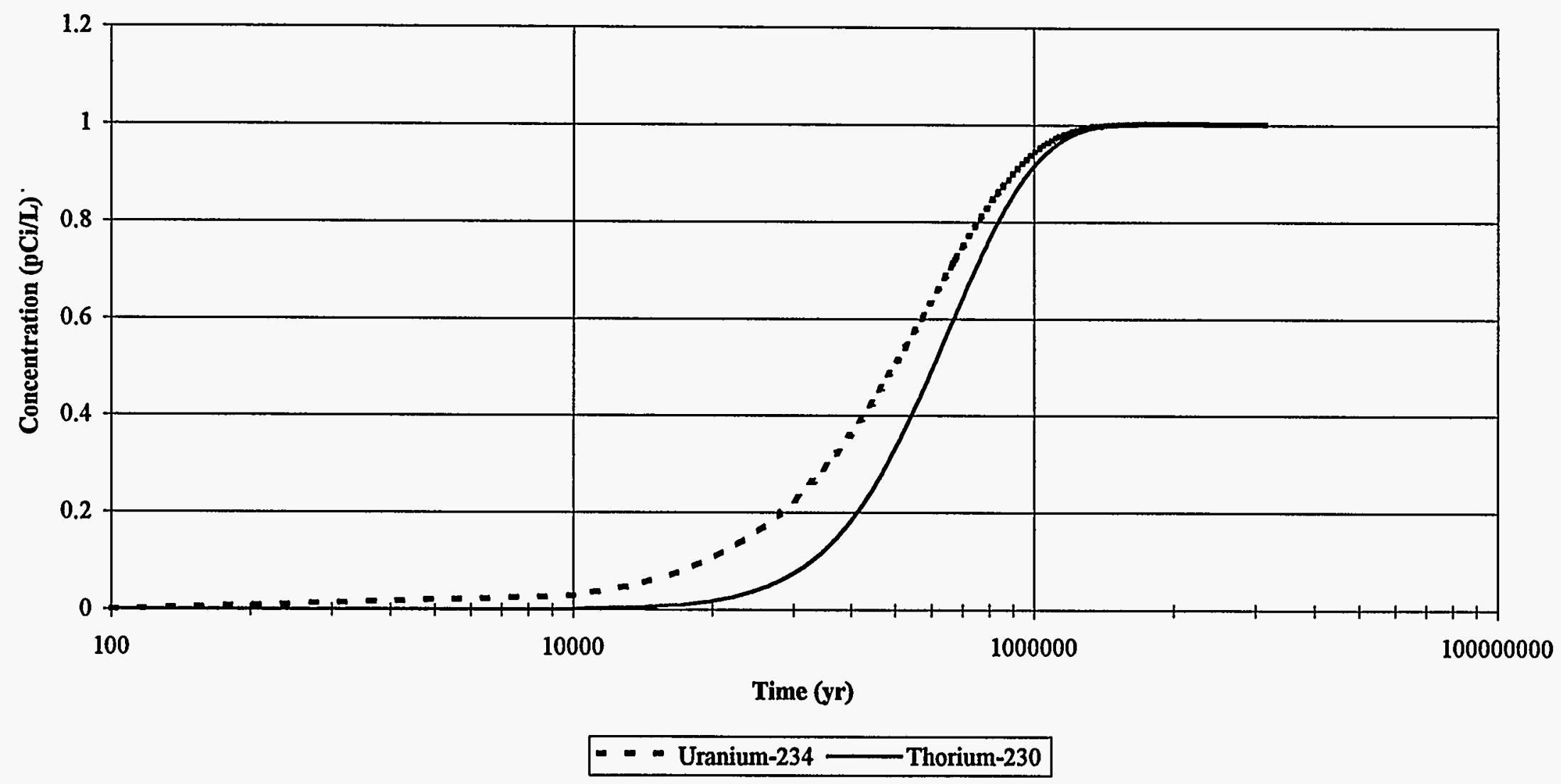

Fig. 9.27b. Time-Varying Concentrations of Uranium-234 and Thorium-230 Based on an Initial Uranium-238 Concentration of 1 pCi/L.

[Plots developed by solving the Bateman equations] 
Multimedia Scenario

Radium-226 and Radon-222 - Concentrations

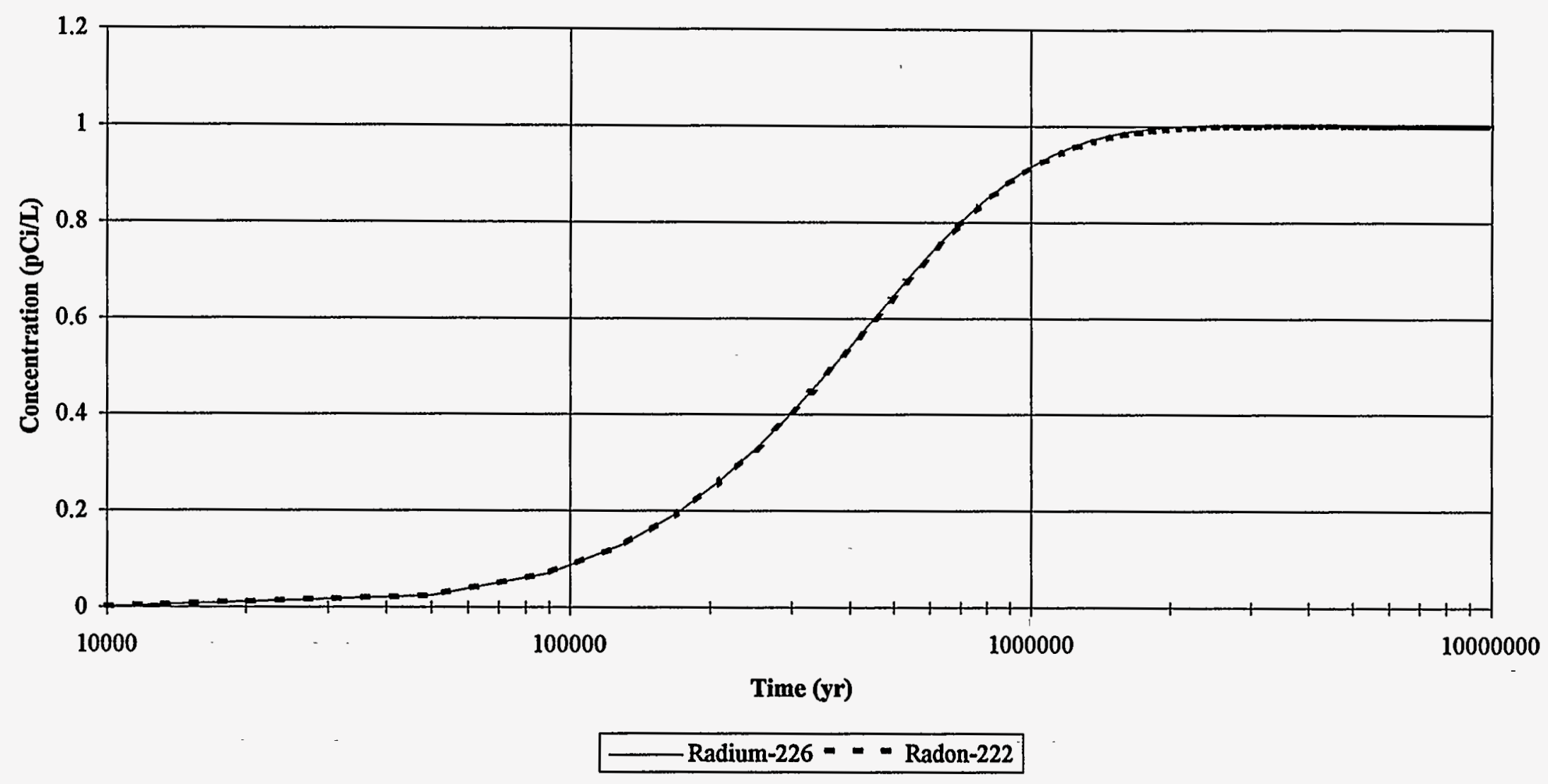

Fig. 9.27c. Time Varying Concentrations of Radium-226 and Radon-222 Based on an Initial Uranium-238 Concentration of 1 pCi/L.

[Plots developed by solving the Bateman equations] 
Multimedia Scenario

Lead-210, Bismuth-210, and Polonium-210 - Concentrations

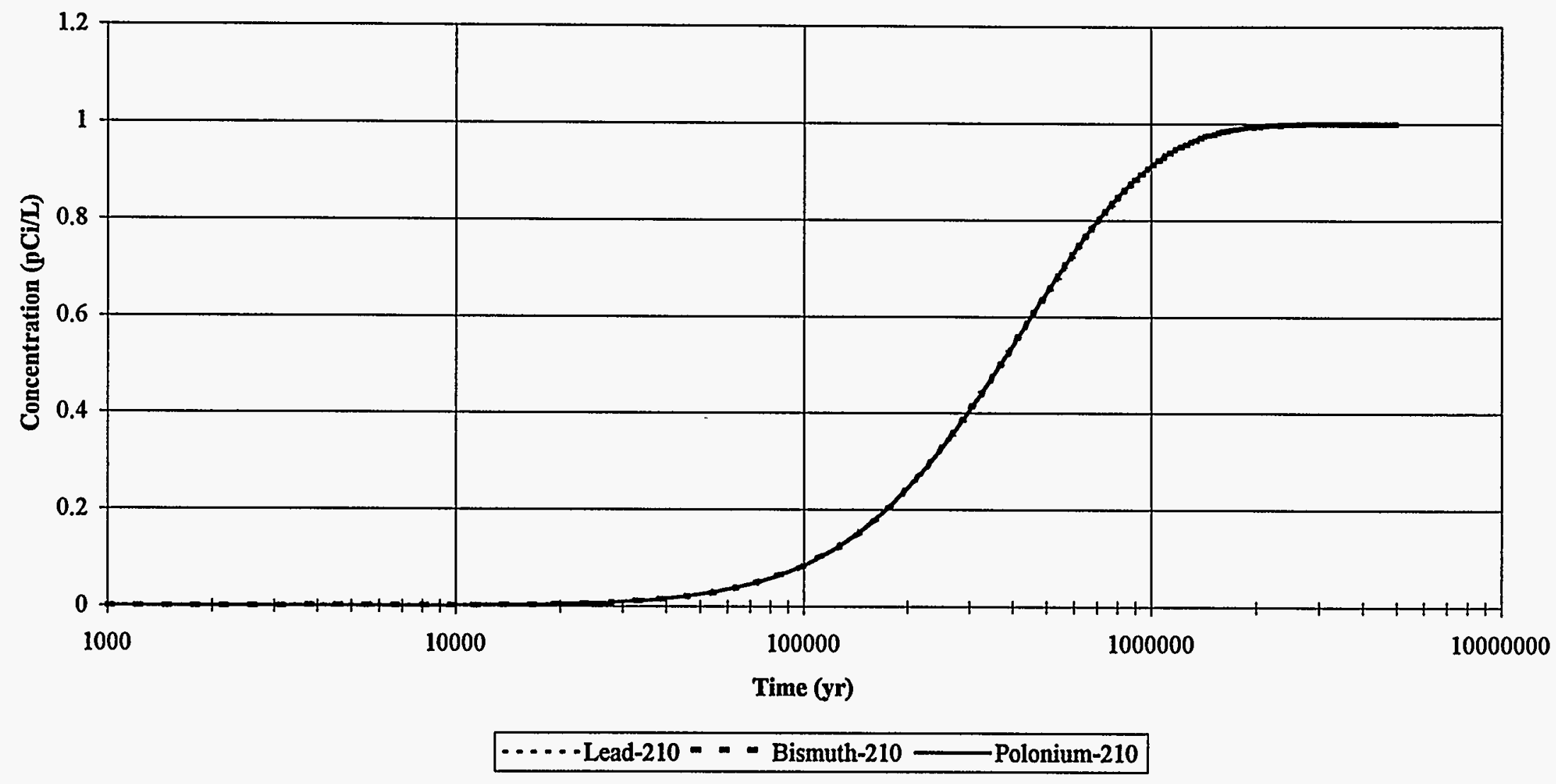

Fig. 9.27d. Time-Varying Concentrations of Lead-210, Bismuth-210, and Polonium-210 Based on an Initial Uranium-238 Concentration of 1 pCi/L.

[Plots developed by solving the Bateman equations] 
Multimedia Scenario

Lead-206 - Concentrations

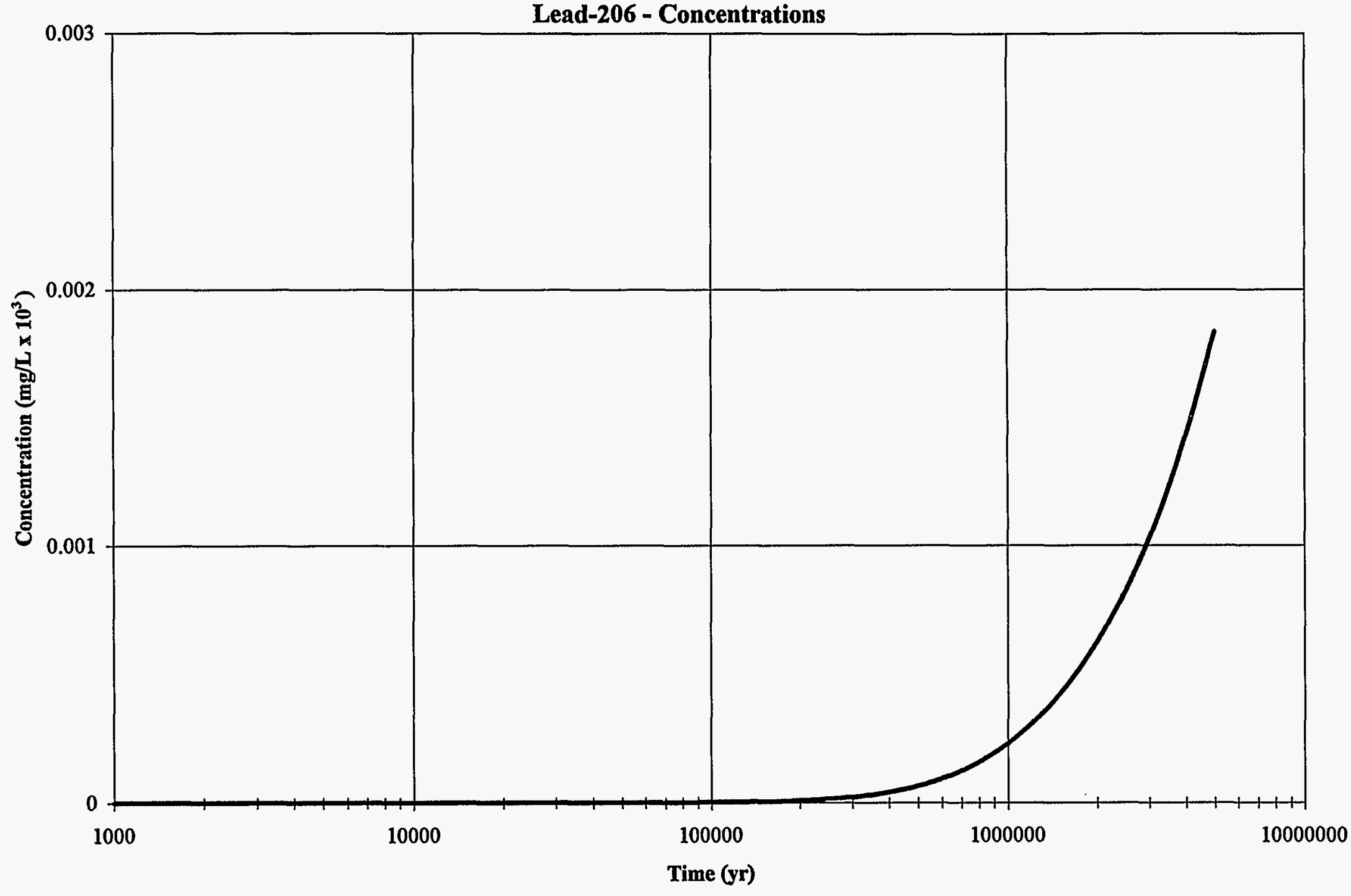

Fig. 9.27e. Time-Varying Concentrations of Lead-206 Based on an Initial Uranium-238 Concentration of $1 \mathrm{pCi} / \mathrm{L}$.

[Plots developed by solving the Bateman equation] 


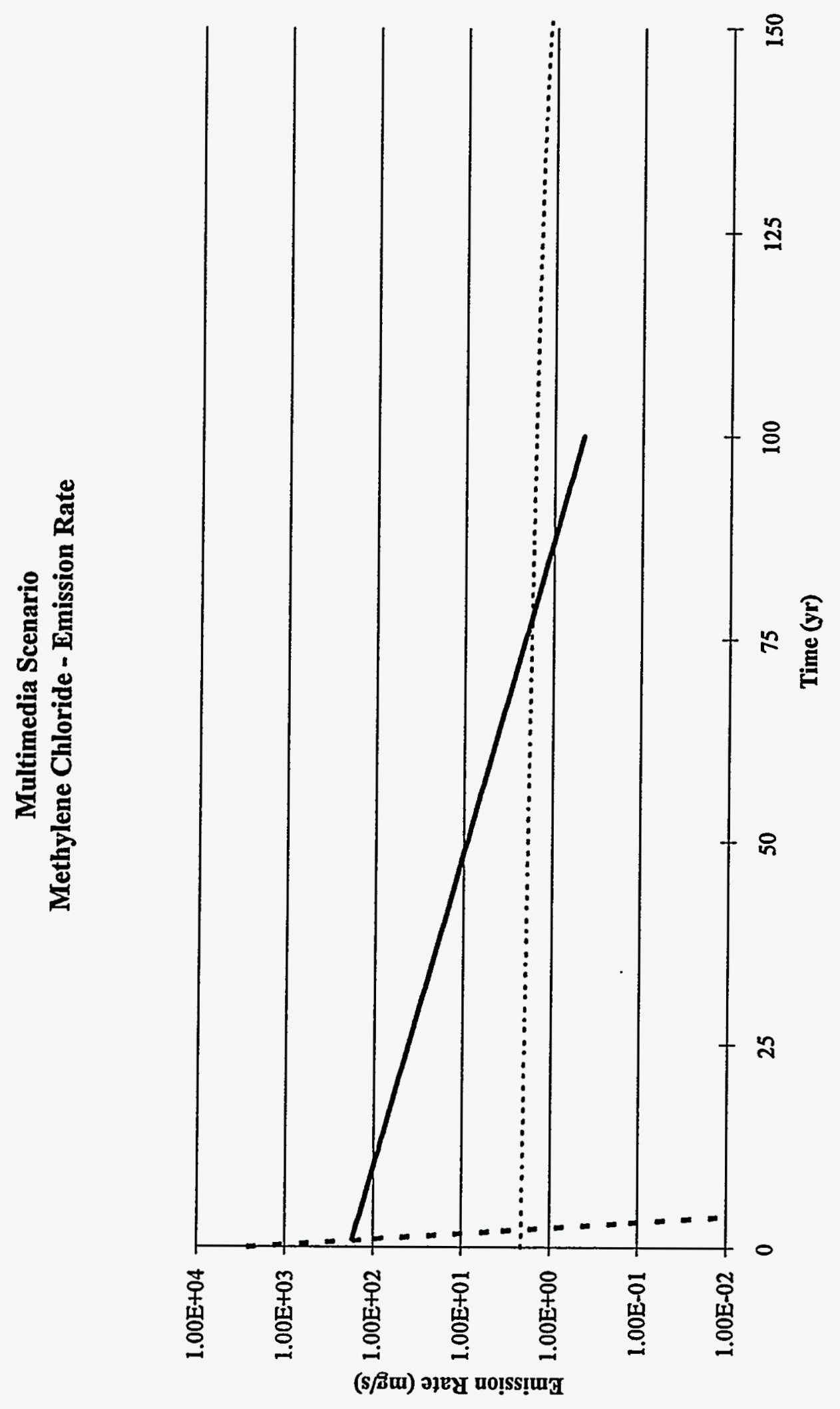

空 
Multimedia Scenario

Uranium-238 - Emission Rate

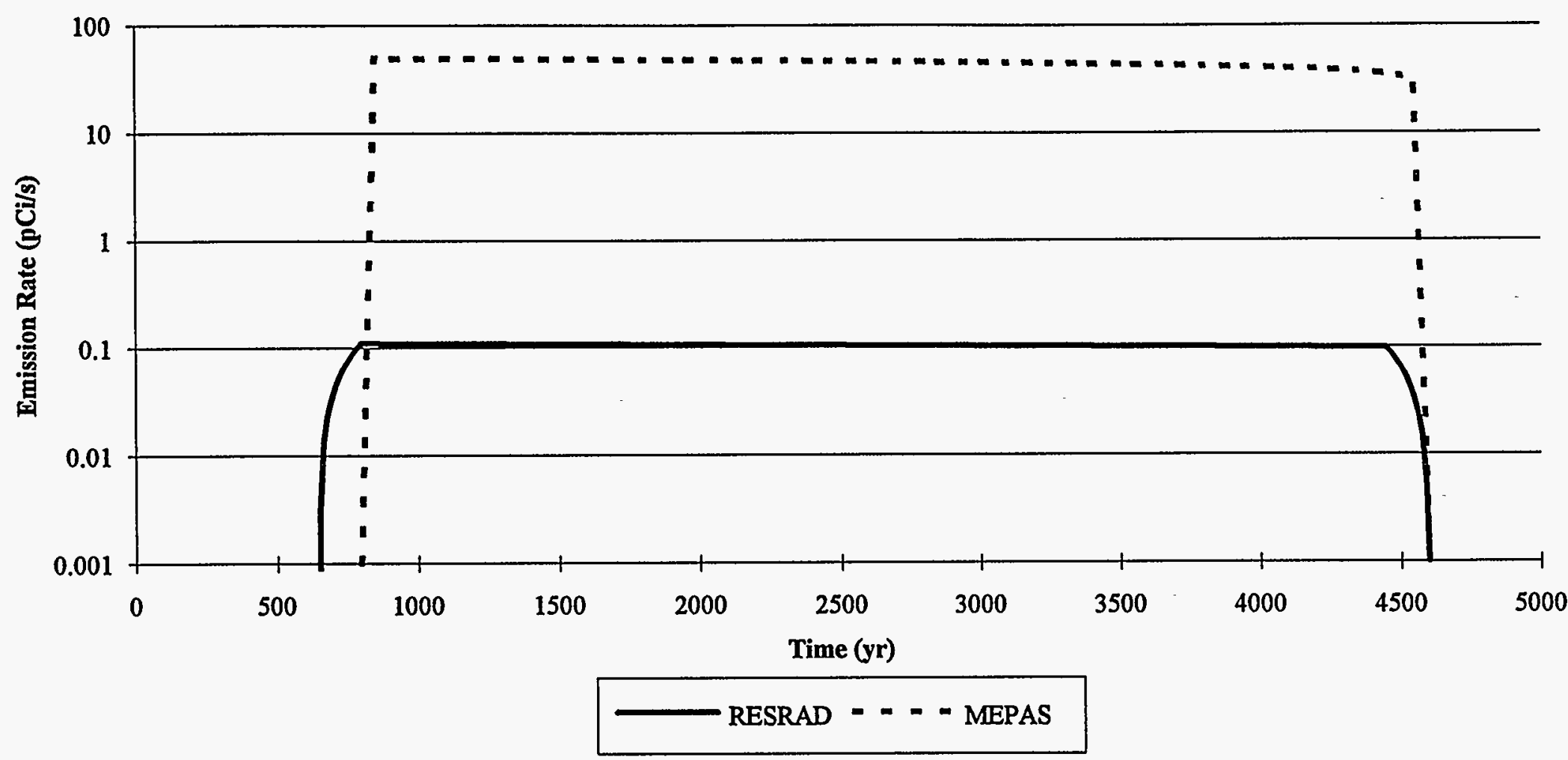

Fig. 9.29. Time-Varying Air Emission Rate for Uranium-238 for RESRAD and MEPAS. 


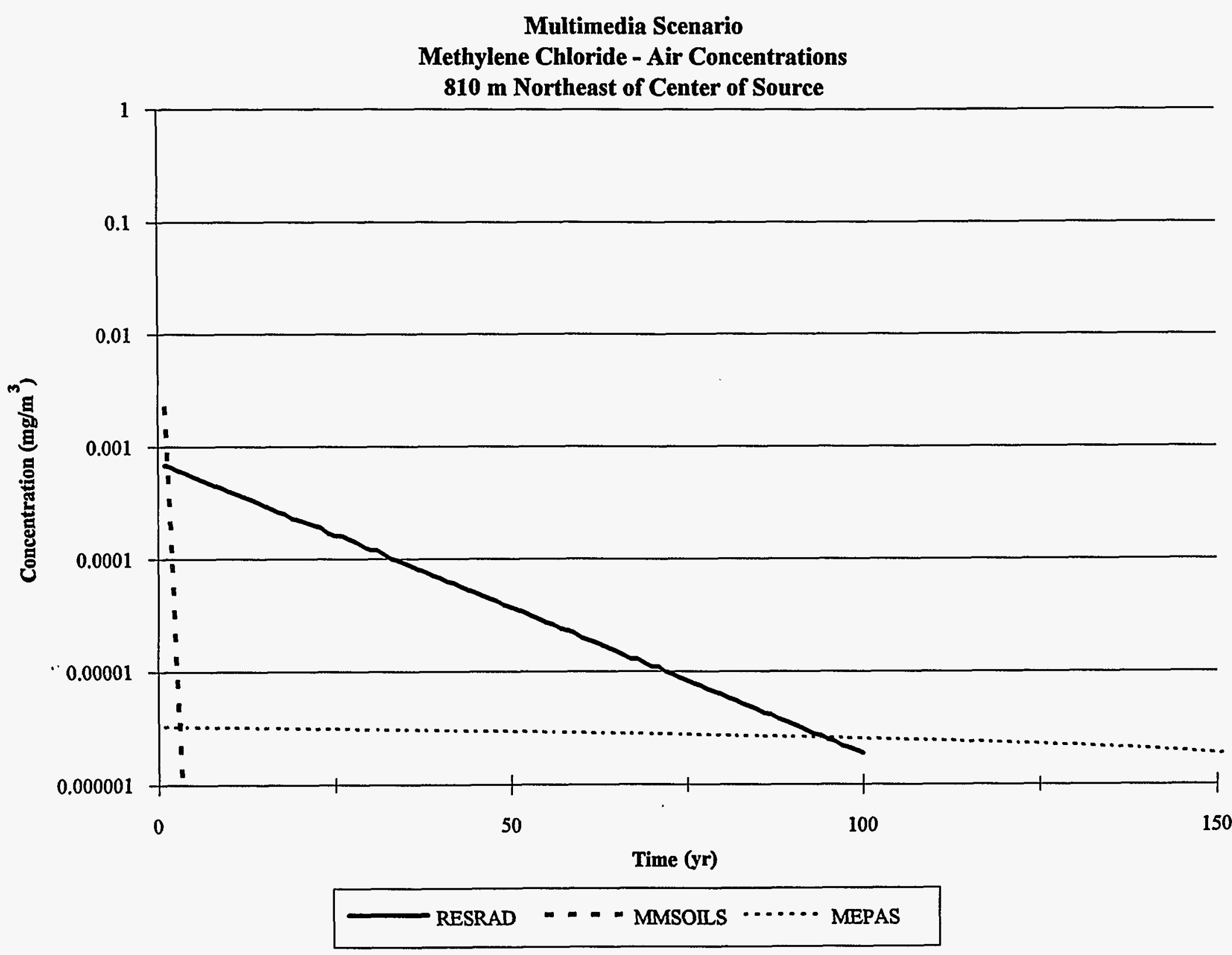

Fig. 9.30. Time-Varying Air Concentrations of Methylene Chloride at Maximum Offsite Exposure Point for RESRAD, MMSOUS, and MEPAS. 
Multimedia Scenario

Methylene Chloride - Flux from SZ to SW

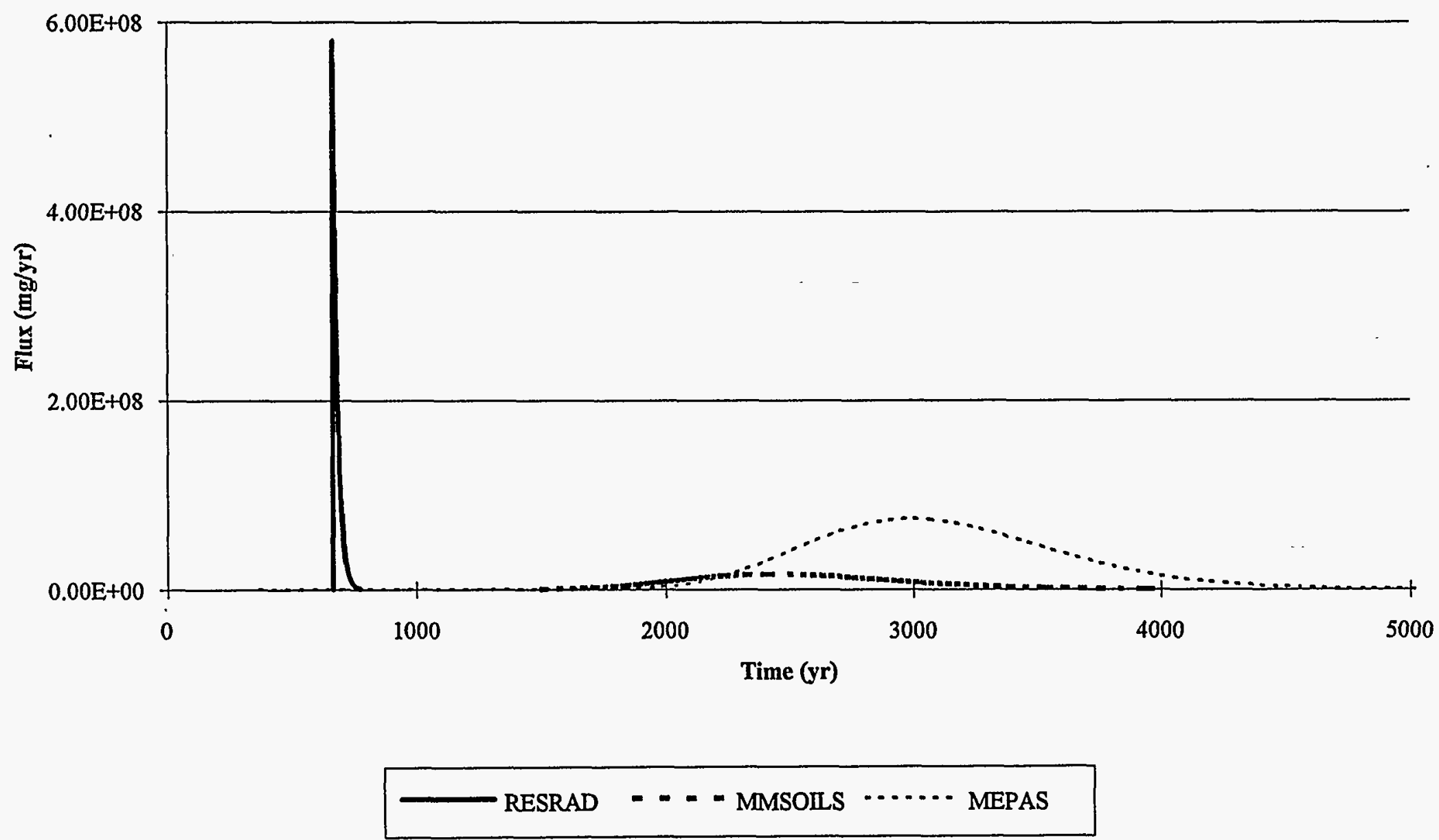

Fig. 9.31. Time-Varying Fluxes of Methylene Chloride from SZ to SW for RESRAD, MMSOILS, and MEPAS. 
Multimedia Scenario

Uranium-238 - Flux from SZ to SW

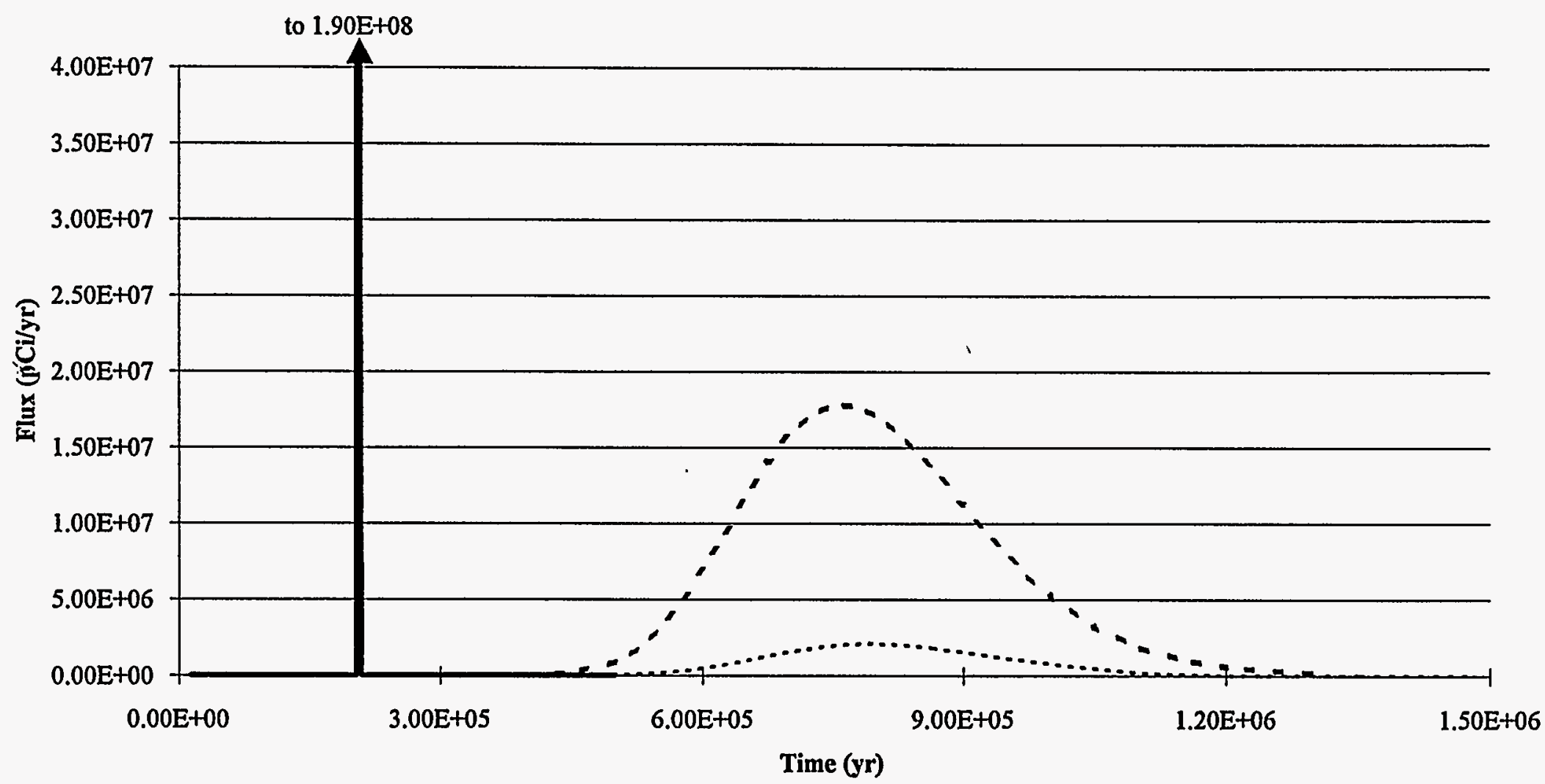

Fig. 9.32. Time-Varying Fluxes of Uranium-238 from SZ to SW for RESRAD, MMSOILS, and MEPAS. 


$$
9-110
$$




\section{SUMMARY AND CONCLUSIONS}

In response to EPA's regulations for the protection of human health and ecological systems, DOE and EPA have developed risk assessment programs that use computer modeling to estimate exposure and risk. Environmental systems simulation modeling is used as a tool to assess potential adverse impacts to human health and the environment from exposure to both chemical and radiological contaminants. The need has arisen for the development of a standardized approach to environmental systems modeling that ensures consistency in the application and proper implementation of the models.

To this end, a benchmarking study has been conducted that compares the technical formulation and performance characteristics of three widely used multimedia models: RESRAD, MMSOLS, and MEPAS. Model endpoint comparisons are used to demonstrate the effects of differing model formulations when applied to hypothetical direct releases to specific transport zones and to hypothetical integrated multimedia releases. Protocols for the execution of the models are established. Methods for evaluating and comparing a standard set of outputs to determine the sources of inconsistencies in modeling estimates of exposure and risk are examined. This benchmarking effort elucidates the assumptions, constraints, and abilities of available multimedia models.

The objectives of this chapter are to (1) summarize the benchmarking tests conducted, (2) describe key comparative results, and (3) document conclusions concerning the benchmarking exercise.

\subsection{SCENARIO-SPECIFIC SUMMARY AND CONCLUSIONS}

A comprehensive benchmarking comparison of the formulation and performance of the three multimedia models (RESRAD, MMSOILS, and MEPAS) is accomplished by first isolating and benchmarking each principal model component (e.g., air, vadose zone, saturated zone, surface water, exposure routes, etc.) and then benchmarking the integrated multimedia systems. The following sections detail the results of these analyses.

\subsubsection{Direct Biosphere Exposure Summary and Conclusions}

The direct biosphere exposure scenario is used to isolate the exposure/risk components of the models and compare the manner in which the models compute exposure. Results from the direct exposure scenario demonstrate model functions related to accumulation of contaminants in the agricultural area, contaminant transfer to the food chain, bioaccumulation, and exposure evaluation. Cancer incidence risks caused by specified concentrations of contaminants initially present in soil and water are estimated; risks caused by contaminated dust were not considered.

The direct biosphere exposure scenario consists of several test cases, each involving one initially contaminated medium, one contaminant, and one segregate transfer and exposure pathway, all of which facilitate the pinpointing of model differences. The exposure pathways considered are:

- dermal contact,

- inhalation of volatiles,

- ingestion of tainted food (leafy and nonleafy vegetables, meat, milk, water, and fish),

- incidental ingestion of soil, and

- external radiation. 
The transfer pathways considered are:

- swimming, showering, and soil contact for dermal exposure;

- $\quad$ showering for inhalation of volatiles;

- root uptake and irrigation of vegetables and animal feed (i.e., fodder);

- livestock consumption of water, fodder, and soil (incidental) for ingestion of meat and milk; and

- bioaccumulation in fish for ingestion.

The contaminants used for all but the external radiation test scenario are carbon tetrachloride, chosen to represent a volatile chemical carcinogen, and uranium-234, chosen to represent a typical radionuclide. The external radiation from the contaminated soil scenario uses cobalt- 60 and uranium234. The risk computations do not include the contributions of any transformation products formed during the exposure period of 70 yrs.

A summary of the major conclusions for the direct biosphere exposure scenario follows:

- The model predictions for test scenarios that did not involve dermal absorption, irrigation, or external radiation are in agreement.

- The three models used different formulations to compute the accumulation of contaminants in agricultural soil following irrigation with contaminated water.

- RESRAD and MEPAS allow a choice between overhead (sprinkler) irrigation and ditch irrigation; MMSOILS permits ditch irrigation.

- RESRAD and MEPAS formulations for dermal absorption from water include consideration of the higher absorption rates during the initial transient state before equilibrium is established and are consequently higher than the MMSOILS risk estimate, which is based on the equilibrium absorption rate.

- The RESRAD formulation for external radiation includes consideration of the thickness of the contamination and shielding caused by the cover.

- MMSOILS and MEPAS use the "one-hit equation" to estimate excess cancer risk from chemical carcinogens, while RESRAD used the linear exposure-risk relationship. RESRAD and MEPAS use the linear exposure-risk relationship to estimate radiological excess cancer risk.

- RESRAD provides the option to estimate the absorption fraction for computations involving dermal contact with soil.

- MEPAS includes a gastrointestinal tract absorption fraction to account for contaminants taken in by dermal absorption reaching the blood directly.

\subsubsection{Direct Air Release Summary and Conclusions}

The direct release to air scenario involves steady state emissions from a source area with constant concentration of thorium-228 for $10 \mathrm{yrs}$. The thorium-228 is assumed to decay over time, generating decay products and reducing the parent concentration. 
All three models are used to simulate the direct release to air scenario (base case). Two additional enhanced deposition scenarios are examined to determine the influence of deposition parameters:

1. special case using a larger particle size with MEPAS and

2. special case using a larger deposition velocity with MMSOILS.

The comparison endpoints are:

- air concentrations estimated at locations downwind of the release area and

- soil concentrations from plume deposition that are estimated at locations downwind of the release area.

The conclusions garnered from the direct air release scenario are:

- all models use nearly identical formulations for transport and dispersion that produce only small differences in air concentration values (MMSOILS does use a different method for the initial dispersion near the source thereby producing lower air concentration estimates at the closest distance) and

- the models' estimated soil deposition concentrations do not agree as closely as their predicted air concentrations (the time-varying soil deposition concentration plots determined by RESRAD/CAP88 and MMSOILS have the same shape and agree within a factor of 2, although RESRAD/CAP88 predicts slightly higher cumulative soil concentrations than either MMSOILS or MEPAS; the MEPAS deposition values vary with assumed surface roughness and fall within the range of the other two model estimates).

\subsubsection{Direct Release to the Vadose Zone Summary and Conclusions}

The vadose (unsaturated) zone is bounded above by the land surface and below by the water-table surface. The direct release to the vadose zone scenario simulates the direct release of contaminants from an unlined landfill waste site to a vadose zone with two homogeneous layers.

The contaminants selected for release from the landfill are methylene chloride and uranium-238. The contaminants are assumed to move in a one-dimensional vertical direction from the waste site through the vadose zone to the water-table surface which separates the vadose zone from the saturated zone. The direct release to the vadose zone scenario is constructed assuming no volatilization, no surface resuspension, no erosion, no ponding at the surface, no progeny formation, and no overland runoff.

The endpoints for the vadose zone study are:

- time-varying contaminant fluxes from the source to the first vadose zone layer,

- time-varying fluxes at the interface of the two vadose zone layers,

- time-varying contaminant fluxes at the water-table surface,

- peak fluxes, and

- $\quad$ times to peak. 
Differences in model design and performance characteristics contribute to differences in endpoint estimates. Mathematical construct differences among the models impact the temporal and spatial distribution of the contaminants. Examples of these technical formulation differences follow:

- The moisture content, an element that impacts the contaminant concentration levels, is computed differently for each model and is used for determining retardation factors, pore-water and contaminant velocities, plug-flow travel times, and dispersion coefficients. Differences in the computed moisture content affect the endpoint estimates. The mathematical algorithms. for calculating and using moisture content help explain why RESRAD will almost always predict shorter travel times and higher concentrations than MMSOILS and MEPAS.

- Differences in the flow equations used by the models contribute to differences in the estimated endpoint values. MMSOILS and MEPAS simulate the distribution of contaminants by implementing a one-dimensional advective-dispersive equation, while RESRAD simulates transport through pure translation. RESRAD assumes pure translation (i.e., advection) in transporting contaminants throught the vadose zone. MMSOLS and MEPAS assume advection with dispersion. Dispersion coefficients govern the degree of spread connected with movement of contaminants in the flow direction. By including the natural processes of dispersion, the contaminant leaving the source and progressing toward the water-table surface would be redistributed in space and time, resulting in potentially lower contaminant levels as compared to those which include the impacts from advection only.

- Different methods of computing dispersion coefficients lead to slightly longer times to peak for MEPAS when compared to MMSOILS; however, at the interface of the two vadose zone layers, MMSOILS and MEPAS produce comparable endpoint values due to the similarity of algorithms used in the simulation.

- Variations in source term releases produce differences in the transport results for the three models. These differences depend upon the nature of the time-varying release from the source (i.e., exponential or constant-pulse). RESRAD assumes that the contaminant leaching is linearly proportional to the source inventory and takes the form of a decreasing exponential function. The MMSOILS model user must construct the desired leaching pattern through manipulating sourceterm input parameters. MEPAS provides users with the option of choosing the form of release (e.g., steady state, exponential, log-normal, etc.) or accepting the constant-pulse (i.e., step function) release scenario.

- Travel times are defined differently for each benchmark model. Differences in plug-flow travel time equations lead MEPAS to predict the longest travel time followed by MMSOILS and RESRAD. For cases where degradation and decay are important factors, RESRAD may produce elevated flux values exiting the first and second vadose zone due to the shorter travel time.

\subsubsection{Direct Release to the Saturated Zone Summary and Conclusions}

The direct release to the saturated zone (i.e., groundwater) scenario entails the release of contaminants from an active-operational, unlined waste site into a homogeneous, isotropic, single-layered aquifer. The contaminants are released from the waste site and migrate through the saturated zone at a constant rate for 25 yrs. The groundwater flow is assumed to be unidirectional toward the receptor wells. Decay-product formation at the source is not addressed under this scenario.

The contaminants released from the landfill are nitrate and uranium-234. Contaminant concentrations are estimated at three locations (e.g., $0 \mathrm{~m}, 150 \mathrm{~m}$, and $1500 \mathrm{~m}$ ) measured from the downgradient edge of the waste site. 
The endpoints for this scenario are:

- time-varying contaminant fluxes from the source to the saturated zone,

- time-varying contaminant concentrations at the three receptor locations,

- peak concentrations, and

- times to peak concentrations.

Variations in model capabilities and functions contribute to differences in endpoint estimates. A summary of observations made during this analysis is as follows:

- All three models estimate time-varying fluxes from the source to the saturated zone. For the benchmark case, MEPAS assumes a constant release (i.e., step function), while RESRAD computes a nearly constant exponential release with a small rate coefficient. MMSOILS allows the user to construct a constant-leaching pattern.

- For the 0-m receptor location, MEPAS estimates higher centerline maximum concentrations than does RESRAD or MMSOILS. This is due to the domination of advection over the vertical dispersion causing the contaminants to not become fully mixed at such a close distance. RESRAD and MMSOILS are more capable of simulating fully mixed conditions at this distance.

- Differences in computed decay-product concentrations in RESRAD and MEPAS are derived from differences in considering progeny formation at the source, retardation factors, contaminant velocities, travel times, approaches for mixing the contaminants, and approaches to computing ingrowth. While RESRAD simulates radionuclide decay during transit, allowing the progeny to move at speeds different from the parent, MEPAS computes ingrowth and decay at the end of the journey and assumes that the progeny move with the same speed as the parent.

- RESRAD produces long, flat time-varying concentration curves for the transformation products due to the inclusion of ingrowth and decay during transit and due to the slower travel rate of the first transformation product, thorium-230, relative to the parent uranium-234. The results for MEPAS show decay product curves similar to the parent's curve because MEPAS assumes that the parent and transformation product nuclides travel at the same speed.

- For the 150-m and 1500-m receptor locations, MMSOILS and MEPAS assume a fully mixed condition over the aquifer depth. The fact that RESRAD is a plug-flow model (instead of a plug-flow-with-dispersion model) produces differences in endpoint results, since contaminant concentrations are impacted by longitudinal dispersion. MMSOILS and MEPAS incorporate longitudinal dispersion producing differences in the temporal distribution of the contaminants, in comparison to the RESRAD results. Contaminants moving quickly through the aquifer produce a pseudo-steady-state condition, whereas contaminants traveling more slowly produce a Gaussian shape with a reduced peak concentration. The RESRAD model is manually modified to account for lateral dispersion and predicts higher concentrations over a shorter duration. MEPAS and MMSOILS estimate lower concentrations over longer durations.

- RESRAD uses pure translation (i.e., advection) to transport contaminants in the saturated zone. RESRAD assumes that a pumping well withdraws contaminated water from the aquifer. To approximate the effects of dilution from pumping, the aquifer concentrations are reduced by a dilution factor. MMSOILS and MEPAS use advection and dispersion to redistribute the contaminant in the aquifer and calculate aquifer concentrations, which are unaffected by a pumping well (giving a dilution factor of unity). Therefore, the pumping rate assumed in a RESRAD 
simulation could have a significant impact on lowering the aquifer concentration as compared to those predicted by MMSOILS or MEPAS.

\subsubsection{Direct Release to Surface Water Summary and Conclusions}

The direct release to surface water scenario addresses only the riverine environment, excluding seas, oceans, wetlands, holding ponds, impoundments, etc. For $16 \mathrm{yrs,} \mathrm{three} \mathrm{contaminants} \mathrm{are} \mathrm{discharged} \mathrm{in}$ liquid form from a point source (e.g., pipe) on a riverbank into a small, straight, steady state river with constant unidirectional flow. The contaminants migrate downstream, becoming mixed laterally as they travel. The contaminants considered are ethylene glycol, thorium-228, and tritium.

The following assumptions are made for the direct release to surface water scenario: no source degradation (only environmental degradation), no volatilization of contaminants, no adsorption/desorption of contaminants, no meandering, no secondary flow patterns, and no thorium-228 decay products. RESRAD does not include a river model; therefore, a comparison is made between the MEPAS and MMSOILS endpoints. Although MEPAS can account for radionuclide progeny, this ability was not used to accommodate the test case scenario.

Two surface water receptor scenarios are examined: (1) spatially near-field (100 m downstream from the center of the discharge point) and (2) spatially far-field (10,000 m downstream from the center of the discharge point.) For the near-field scenario, the contaminant plume has not fully mixed across the width of the river. In the far-field scenario, fully mixed conditions in the lateral direction are assumed.

The endpoints for the direct release to surface water scenario include:

- time-varying contaminant fluxes into the river,

- time-varying contaminant fluxes at the near-field receptor location, and

- time-varying contaminant fluxes at the far-field receptor location. estimates.

Differences in the models' abilities and performance traits contribute to variations in endpoint

The following observations can be made for the surface water scenario analysis:

- Because MMSOILS assumes instantaneous full mixing in the lateral and vertical directions at all in-stream locations, the river concentrations remain constant at all locations if degradation/decay is insignificant. When degradation/decay is important, downstream concentrations will be lower than upstream concentrations.

- Because MEPAS simulates the migration of a contaminant plume laterally across the river, the upstream (i.e., near-field) concentrations are always greater than the downstream (i.e., far-field) concentrations, until the plume is fully mixed across the river. The near-field concentrations in MEPAS will always be larger than the near-field concentrations in MMSOILS. Because both models assume fully mixed conditions in the far-field case, both models predict the same downstream concentrations.

- For the far-field scenario, the conditions are assumed to be fully mixed for both models, and the results match closely. 


\subsubsection{Surface Water Hydrology Summary and Conclusions}

The objective of the surface water hydrology test is to quantitatively compare the manner in which the models simulate water balance at the soil surface and in the upper layer of soil (i.e., root zone). While each model requires a precipitation-related infiltration rate and runoff to simulate contaminant movement in the vadose zone and via overland runoff, only MEPAS and MMSOILS include algorithms for estimating infiltration and runoff. Therefore, for the purposes of this study, only MEPAS and MMSOILS are included in the surface water hydrology analysis.

Both MMSOILS and MEPAS employ similar methods for simulating water balance at the soil surface. The models process average monthly meteorological data to estimate monthly average runoff, evapotranspiration, and infiltration. The models sum the monthly values to produce average annual values of water flux from the surface to either a waste unit (e.g., landfill), the unsaturated zone, or offsite locations via runoff.

Surface water balance is analyzed under two conditions to illustrate the primary differences in modeling methods used by MMSOILS and MEPAS: (1) high rainfall/high permeability conditions and (2) low rainfall/high permeability conditions.

Model inputs include monthly meteorology and surface soil characteristics. The model outputs or endpoints for the surface hydrology scenario include:

- average annual and average monthly potential evapotranspiration,

- actual evapotranspiration,

- runoff, and

- infiltration.

In reviewing the results of the surface hydrology benchmark tests the following general observations are made:

- All of the model simulations provide similar estimates of potential evapotranspiration, actual evapotranspiration, runoff, and infiltration on both a monthly and annual basis.

- While MEPAS and MMSOILS use different techniques for computing monthly soil moisture storage fluctuations, the end result in this benchmarking scenario is similar estimates.

- If site-specific pan evaporation data are not available, the only option for estimating potential evapotranspiration for MMSOILS is the Thornwaite method. While this method provides reasonable estimates for some regions, it does not provide for consistency of estimation as does the MEPAS model which applies three methods for estimating potential evapotranspiration at each site and selects the lowest value for further application.

- The scenarios presented do not allow for any conclusions to be rendered regarding the models methods for estimating runoff. Both scenarios include high potential evapotranspiration and therefore a minimum likelihood of runoff. It would be useful in the future to add a scenario where runoff is potentially significant (e.g., a site where high rainfall is matched with relatively low permeability soils.)

- MEPAS differentiates between snowfall and rainfall while MMSOILS does not. The benchmarking tests included here do not address this difference. The effect of sub-zero temperatures on runoff and 
infiltration may well be important for applications in the northern United States. Future benchmarking efforts should explicitly include this capability.

\subsubsection{Multimedia Scenario Summary and Conclusions}

RESRAD, MMSOILS, and MEPAS have been applied to a hypothetical landfill, where predictions of both contaminant transport through multimedia and human health risks have been made. The risks result from exposure to methylene chloride and uranium-238 and its progeny. The models simulate the multimedia transport pathways through the partially saturated zone, groundwater, atmosphere, and surface water. Risks are predicted at two receptor locations shown in Figs. 9.2 and 9.3. At each location, each receptor is exposed to contaminated groundwater from a nearby well, and risks result from:

- ingestion of drinking water,

- ingestion of vegetables that are irrigated with well water, and

- ingestion of meat and milk from livestock that ingest well water.

Receptors are also exposed to contaminated air, and risks result from:

- inhalation of ambient air,

- ingestion of vegetables that uptake contaminants from atmospheric deposition and from root uptake,

- ingestion of meat and milk from livestock that ingest contaminated soil and fodder,

- dermal contact with soil, and

- external gamma radiation from soil.

Finally, receptors are exposed to contaminated surface water, and risks result from:

- fish ingestion and

- dermal contact while swimming.

The following conclusions are the results of the multimedia benchmarking scenario:

- All models simulate transport through all media specific to this benchmarking test, with the exception of RESRAD, which does not simulate transport through rivers.

- Both RESRAD and MEPAS predict contaminant transport and risks from methylene chloride and radionuclides, while MMSOILS predicts contaminant transport and risks from methylene chloride and contaminant transport for uranium-238, although it does not consider adsorbed phase decay or risks from any of the radionuclides.

- $\quad$ RESRAD, MMSOILS, and MEPAS couple predicted volatile and aqueous phase emissions from the landfill so that the total mass emitted equals the initial inventory,

- Predictions of total methylene chloride mass that volatilizes differs by a factor of 10 between models. This occurs because MEPAS uses a different volatilization algorithm than the other two models and because all three models use different soil water contents; however, a specific investigation of the differences between the algorithms was not conducted. 
- Predicted travel times through the unsaturated zone are much longer than travel times through the saturated zone and dominate the total time for contaminated water to move to both wells and to the river;

- MMSOILS- and MEPAS-predicted advective travel times and times-to-peak concentrations are generally comparable through the unsaturated and saturated zones and through the river, and RESRAD's predictions of advective travel times are typically $25 \%$ of those predicted by the other two models.

- For the saturated zone, MMSOILS considers dissolved phase decay only, not absorbed phase decay, and contaminants that decay in both phases may have overestimated concentrations at significant distances from the source (e.g., for the case simulated herein, uranium-238, the radionuclide simulated in this scenario, has a long half-life, and the effects of not considering absorbed phase decay in this analysis are minimal).

- The highest predicted risks occur from groundwater exposure to methylene chloride through drinking water ingestion. RESRAD predicts the highest onsite risk $\left(2.5 \times 10^{-3}\right)$ followed by MEPAS $\left(4.9 \times 10^{-4}\right)$ and MMSOILS $\left(1.3 \times 10^{-4}\right)$. The RESRAD results are based on a peak concentration that is much greater than the concentration that is sustained over 70 yrs. Although MMSOLS also uses a peak concentration, the peak concentration is similar to the 70-yr-average concentration because of dispersion. Only MEPAS actually calculates the 70-yr-average concentration for use in the risk calculation.

- Predicted concentrations in the river are much less than those in the groundwater due to the dilutional effect of the river (a dilution of $4.7 \times 10^{7}$ at complete mixing), so the predicted risks due to exposure to river water are small (the maximum risk is $7.2 \times 10^{-10}$, predicted by MEPAS for exposure to methylene chloride).

- The RESRAD-predicted risk from onsite air exposure to methylene chloride is $2.1 \times 10^{-6}$. Both MMSOILS and MEPAS predict risks of less than $7.1 \times 10^{-8}$. This difference occurs primarily because RESRAD uses a peak methylene chloride concentration to predict risks whereas the other models use 70-yr-average concentrations to predict risks.

- For atmospheric transport of uranium-238, the MEPAS predictions in a dusty site are more than an order of magnitude higher than the risks predicted by RESRAD, primarily because the MEPAS simulation essentially allows all the eroded soil-containing uranium-238 to be re-entrained into the atmosphere. RESRAD allows surface runoff to remove most of the uranium-238 and has a much lower assumed air emission rate. The MEPAS run, assuming a stabilized surface cover, results in risks comparable to RESRAD. 
10-10 
Appendix A

STEP-BY-STEP ANALYSIS OF THE MULTIMEDIA MODELS 


\section{A. STEP-BY-STEP ANALYSIS OF THE MULTIMEDIA MODELS}

In this appendix, overviews of how the models are applied to the multimedia scenario are provided. This information is intended to convey the steps required and difficulties encountered in applying each of the three models.

\section{A.1 RESRAD STEP-BY-STEP ANALYSIS}

\section{Data preparation}

The input data required by RESRAD were listed and the required information was extracted from the scenario description. Most of the required inputs were specified directly in the scenario description. In some cases, the data were obtained by manipulating the information in the specification; for example, the total contaminant inventory and the dimensions and density of the contaminated zone were used to compute the contaminant concentration in soil.

If the required parameters were not specified in the scenario, reasonable estimates of these input parameters were made using the information available in the scenario description following the guidance in the data collection handbook. For example, the effective porosities of the partially saturated strata were estimated using the soil classification/composition. When the missing information was strongly site specific (e.g., soil-water distribution coefficient) the input values were obtained from the developers of the scenario. Some of the information in the description was not input but was the result of intermediate computations in RESRAD. In this case, the inputs were selected to ensure agreement between the specifications and the RESRAD computations; e.g., the values for evapotranspiration and runoff coefficients were selected to yield the specified infiltration rate. Some of the information in the scenario description was at odds with the assumptions of the RESRAD conceptual model. In this case, the specified information was modified for application in RESRAD.

The scenario description specified a well that penetrated $15 \mathrm{~m}$ into the saturated zone, with the lower $10 \mathrm{~m}$ being screened. A $10 \mathrm{~m}$-deep fully screened well was assumed to conform with the RESRAD conceptual model. The description also contained some information that is not considered in the RESRAD conceptual model. The default RESRAD input file was used as a template to build the input files to model the scenario. Further data manipulation, as described in Appendix $\mathrm{K}$ of the RESRAD manual, was necessary to predict offsite risk, intakes, radiological doses, and concentrations using RESRAD, currently an onsite model. The dose and risk factor libraries were modified to reflect the values specified in Table 9.9 of this report when necessary.

\section{Groundwater Step 1: Model runs}

Whereas a single run of RESRAD would be sufficient to estimate multimedia risk and dose to an onsite individual from atmospheric and groundwater releases, two separate runs are required to estimate the same quantities to an offsite individual. Therefore, two sets of runs each were required for the two offsite (off contamination) receptors at $366 \mathrm{~m} \mathrm{~N}$ and $810 \mathrm{~m} \mathrm{NE}$. The procedure for evaluating endpoints associated with the groundwater release are discussed in this section; the procedure for the atmospheric release is discussed in the following section. ON.DAT and OF.DAT are the input files for these runs.

In addition to the regular RESRAD outputs of media concentrations, intake rates, radiological doses, and excess cancer risk, the contaminant flux at various locations in the subsurface was also determined. These fluxes were obtained by performing separate runs to determine the aqueous concentrations at the specified locations and by multiplying these by the water flux. Therefore, a total of four runs (CZ.DAT, UZ.DAT, SZ.DAT, SUR.DAT) were required to determine the contaminant fluxes at the bottom of the contaminated zone, the interface between the two unsaturated zones, the water table, and the river. 
Two sets of input files with the same names were used in RESRAD and RESRAD-CHEM to obtain the results for the uranium-238 transformation chain and for methylene chloride, respectively. An additional RESRAD-CHEM run using VOL.DAT was performed to estimate the volatile flux emanating from the contaminated zone.

\section{Groundwater Step 2: Procuring and processing the output}

The time-flux and time-concentration data files were obtained from within the view plots menu of RESRAD and the view text files menu of RESRAD-CHEM. The intakes, radiological doses, and excess cancer risks were obtained from the appropriate view output files menu. Rather than obtaining the concentration at the four specified locations and then multiplying these by the water flux, the multiplication factor was applied to the input soil concentration to obtain the flux as the concentration output.

\section{Air Step 1: Base file preparation (uranium-238)}

ARESRAD input file called AIR.DAT was prepared with all the site-specific data listed in Tables 9.1, 9.2, 9.8, $9.9 \mathrm{a}$, and 9.10 of this report.

\section{Air Step 2: Surface soil concentrations (uranium-238)}

Release of airbome particulates can occur only from the surface layer of soil exposed to wind erosion. The AIR.DAT file was run, and from the graphics menu, a text file was created with a tabulation of surface soil concentrations of uranium-238 in $\mathrm{pCi}^{-1}$ as a function of time. The dose and risk from plume passage is zero until $650 \mathrm{yrs}$, reaches a maximum at $800 \mathrm{yrs}$, decreases slightly until $4450 \mathrm{yrs}$, and drops to zero after $4600 \mathrm{yrs}$. The doses and risks from plume passage at $800 \mathrm{yrs}$ (time of maximum plume concentration) and $4450 \mathrm{yrs}$ (time of maximum deposition, see Steps 7 and 8 ) are tabulated in the EXCEL spreadsheet.

\section{Air Step 3: Contaminant emission rates (uranium-238)}

Equation K.1 in the RESRAD manual was used to estimate the emission rate of particulates in $\mathrm{g} \mathrm{s}^{-1}$ from the contaminated area. When this number is multiplied by the surface soil concentrations of uranium-238 tabulated in the EXCEL spreadsheet, the result is the emission rate of uranium-238 in $\mathrm{pCi} \mathrm{s}^{-1}$ as a function of time.

\section{Air Step 4: Dispersion factors at the receptor locations (uranium-238 and methylene chloride)}

Prior to performing any runs involving air pathways to receptors not residing immediately above the contaminated landfill, the dispersion factors were derived using the CAP-88 PC code. The joint frequency distribution data of wind speed, direction, and atmospheric stability provided in Table 9.6 was first converted to a STAR-formatted file (*.STR) using EXCEL and saved as an ASCII text file under the name JFD.STR. This file was then converted to the file format used in CAP-88 PC (*.WND) by using the GETWIND routine provided in CAP-88 PC. This reformatted file was named JFD.WND.

A run was performed on CAP-88 PC, modeling the site as a circular area source with a ground-level release. Distances to receptors were entered as $366 \mathrm{~m}$ and $810 \mathrm{~m}$ from the center of the area. The wind file specified in the nun was JFD.WND. Unit curie releases of uranium- 238 and ${ }^{3} \mathrm{H}$ were entered. The ${ }^{3} \mathrm{H}$, which is assumed by CAP-88 $\mathrm{PC}$ to be nondepositing, was used to simulate the methylene chloride release. At the end of the run, only the chi $\mathrm{q}^{-1}$ values (dispersion factors) were selected for output. The values corresponding to the dispersion factors for uranium-238 and ${ }^{3} \mathrm{H}$ at $366 \mathrm{~m} \mathrm{~N}$ and $810 \mathrm{~m} \mathrm{NE}$ were selected from the output table. It is important to note that CAP-88 PC does not allow the user to name files explicitly with the DOS naming convention (the program keeps track of common files associated with the user-specified site or run name and assigns them filenames in alphabetical sequence such as a.*, b.*, c.*, etc., where each letter corresponds to each site or run).

\section{Air Step 5: Contaminant concentrations in air at the receptor locations}

The dispersion factors calculated in Step 4 are in units of $\mathrm{s} \mathrm{m}^{-3}$. When multiplied by the time-dependent emission rates calculated in Step 3, the result is the concentration of dust (in $\mathrm{g} \mathrm{m}^{3}$ ) and uranium- $238\left(\mathrm{pCi} \mathrm{m}^{-3}\right)$ originating 
from the landfill at the two receptor locations as a function of time. These results were also tabulated in the EXCEL spreadsheet.

\section{Air Step 6: Dose and risk from plume passage (uranium-238)}

To calculate the dose and risk contribution from direct passage of a contaminated dust plume at the two receptor locations, five exposure pathways were considered: (1) inhalation of particulates, (2) inhalation of radon, (3) ingestion of plants, (4) ingestion of meat, and (5) ingestion of milk. The AIR.DAT file generated in Step I was run with these five pathways active, suppressing the external gamma and the fish, soil, and water ingestion pathways. The root depth was set to zero to eliminate the contribution from root uptake and consider only the contamination of plants due to foliar deposition of contaminants. Since RESRAD simulates only onsite exposures (i.e., a receptor directly over the contaminated zone), the dose and risk numbers that were generated were scaled by the ratio of onsite dust concentration to the concentrations of dust in the plume at the receptor locations calculated in Step 5. The dose and risk from plume passage is zero until $650 \mathrm{yrs}$, reaches a maximum at $800 \mathrm{yrs}$, decreases slightly until $4450 \mathrm{yrs}$, and drops to zero after $4600 \mathrm{yrs}$. The doses and risks from plume passage at $800 \mathrm{yrs}$ (time of maximum plume concentration) and 4450 yrs (time of maximum deposition, see Steps 7 and 8 ) are tabulated in the EXCEL spreadsheet.

\section{Air Step 7: Dose and risk from contaminant deposition (uranium-238)}

Deposition of uranium-238 from the plume results in a buildup over time in the soil at the two receptor locations. This buildup starts after 650 yrs and continues until 4600 yrs have passed. The bulk of the deposition occurs between 800 and $4450 \mathrm{yrs}$, at which time the soil at the receptor location is assumed to have reached a maximum concentration. The total deposition is accounted for by multiplying the deposition rate of contaminated dust from the plume by the concentration of dust in the plume (from Step 5) over 3800 yrs. This deposited dust is then assumed to be uniformly mixed in a $15-\mathrm{cm}$ layer of surface soil at the receptor locations. The ratio of deposited contaminated dust (in $\mathrm{g} \mathrm{m}^{2}$ ) to areal soil density of the mixing layer at the receptor locations is then multiplied by the initial concentration of uranium-238 in the landfill to obtain the concentration of uranium-238 to be used as input to two files named AIR366.DAT and AIR810.DAT. These two files are identical to AIR.DAT except: (1) the concentrations of uranium-238 are the ones calculated due to deposition at each receptor location, (2) the cover thickness is set to zero, (3) the thickness of the contaminated zone is assumed to be $15 \mathrm{~cm}$, (4) the net erosion rate of the contaminated zone is assumed to be zero (i.e., constant 15-cm-thick contaminated zone), (5) all pathways except fish and drinking water ingestion are active, (6) the root depth parameter is set to $15 \mathrm{~cm}$ to account for root uptake, and (7) dose and risk are calculated at 4450 yrs only. To simulate the leaching of the uranium-238 at the source, the same soil properties of the source are assumed to be present at the receptor locations. It should be noted that, for this step, doses and risks from inhalation and foliar deposition contributions to plant, meat, and milk ingestion are due to dust originating from the deposited contamination, not from plume passage.

Air Step 8: Summation of dose and risk from deposition and plume passage (uranium-238)

The doses and risks at 4450 yrs from both plume passage and deposition are summed for each applicable pathway at each receptor location (note: there is no contribution from external gamma or soil ingestion from plume passage). These doses and risks are then compared to the doses and risks from plume passage alone at $800 \mathrm{yrs}$ and reported in the EXCEL spreadsheet.

\section{A.2 MMSOILS STEP-BY-STEP ANALYSIS}

\section{Step 1: Data input}

The first step in applying MMSOILS is to create the input data files. MMSOILS input data are contained in nine different files. The files and the data they contain are as follows:

- chemprp.123-contains all chemical properties, soil concentration, and leaching concentration. 
- landfil.123-contains information about the landfill source.

- infiltr.123—contains information for soil layers in the vadose zone and meteorological data.

- atmsprm.123-contains all atmospheric parameters including receptors.

- swtpath.123-contains all surface water parameters including location and times for output of surface water concentrations.

- gwtranp.123-contains all groundwater parameters including locations and times for output of concentration in wells.

- foodchn.123-contains all information used in calculating chemical concentration in beef, milk, and soil (except transfer factors, which are contained in chemprp.123).

$\therefore \quad$ control.123-contains control parameters for running the model.

- intakes.123-contains human intake and risk parameters.

Data are entered into a specific format in these files. For this application, an example input file was created from a preliminary evaluation of the site and was edited to create the revised data set.

\section{Step 2: Running the model}

To achieve all benchmarking endpoints, MMSOILS was run multiple times. Typically, execution times are 1 minute for MMSOILS, so satisfying this requirement was easy. The reasons for running MMSOILS multiple times are as follows:

1. Although MMSOILS does allow multiple chemicals to be run at once, it is not feasible to run the chemicals methylene chloride and uranium-238 in one simulation. This is due to the fact that the travel times for the chemicals are so disparate that different times for output of concentrations in the wells must be specified.

2. The three pathways (groundwater, air, and surface water) are analyzed in separate model runs. This is because the desired risk results for the site are separated by these categories. Otherwise, MMSOILS would have added the risks from the various pathways. For example, for ingestion of leafy vegetables, the contributions from irrigation with groundwater and deposition from the atmosphere would have been added together.

3. Different runs are conducted to generate concentration versus time output and exposure concentration output. This is because, for groundwater and surface water, MMSOILS examines a particular point of the output to generate exposure concentrations, and for this application, the peak was desired.

4. Generating exposure concentrations for meat and milk involves running MMSOILS twice, since the water and feed intake are different values for the cattle and dairy cow.

5. Within each transport pathway, MMSOILS is also run separately for the onsite and offsite receptors. This is required for the groundwater pathway since the dispersivities for each receptor well are different.

Additionally, risk calculations are performed using a separate executable, EXPOSE. MMSOILS outputs exposure point concentrations to a file, expconc.123, which is then used as input, along with intakes. 123 file, to the EXPOSE routine.

During the model execution, the user is prompted for several pieces of information, such as whether to use the field capacity as the minimum moisture content; whether to use a constant penetration depth, whether to input saturated zone integration data, whether to input the mixing depth and decay rate for the agricultural field and the time for 
calculation of soil concentration due to depositional flux, and whether to use an existing intakes.123 file. These information requests represent changes to MMSOILS made specifically to accommodate the benchmarking effort. For this example, the corresponding answers to the questions are: no, no, yes (use $\Delta t=17$ yrs for onsite well, $\Delta t$ $=38 \mathrm{yrs}$ for offsite well, and $\Delta t=130$ yrs for the river), no, 70 , and yes.

\section{Step 3: Running the benchmarking case}

The following steps illustrate the procedure for running the MMSOILS benchmarking case for each transport pathway.

\section{Step 3a: Groundwater pathway}

For the groundwater pathway, two gwtranp. 123 files are created, one for the onsite case and one for the offsite case. These files are identical except for the dispersivities and the location of the receptor well.

First, the onsite well is analyzed using the appropriate gwtranp.123 file. MMSOILS is run, generating the concentration at the well versus time. This involves several iterations to ensure that the times selected for output are appropriate and that the time of the peak concentration is included. This generates output of fluxes versus time from the WMU, from PSZ1 to PSZ2, and from PSZ2 to SZ, as well as the concentration in the onsite well versus time.

Then, the risks from using the onsite well water are determined. The gwtranp. 123 file for the onsite well is modified to request output for the peak well concentration only. MMSOILS uses the first and second requested times to calculate the exposure point concentrations, which are then output to the expconc.123 file. The EXPOSE routine is then run to calculate the risks for the onsite groundwater pathway.

Finally, the risks due to ingestion of milk are run separately, since MMSOILS assumes that the water and feed intake for both cattle and dairy cows are the same (not true for this application). Running the risks due to ingestion of milk involves modifying the foodchn.123 file appropriately and then running MMSOILS and EXPOSE again to generate the risks.

The risks from the offsite well are calculated in the same manner, except that the gwtranp. 123 file for the offsite well is used.

\section{Step 3b: Atmospheric pathway}

For the atmospheric pathway, two separate atmsprm.123 files are created, one each for the onsite and offsite receptor. The data in these files are identical except for the receptor information (location and stability data). In this case, the two receptors are run separately to keep track of the risks generated for each receptor.

To run the model for the onsite receptor, the appropriate atmsprm.123 file is used in the MMSOILS run. This generates output of flux to the atmosphere and concentration at the receptor versus time. Exposure point concentrations for the onsite atmospheric receptor are also generated based on a 70-yr-average concentration to the receptor and output to the expconc.123 file. (The number of years over which MMSOILS averages the concentration is input by the user in the control.123 file.) Finally, the risks for the onsite receptor are calculated using the EXPOSE routine.

The offsite atmospheric receptor is analyzed in the same manner except the atmsprm. 123 file for the offsite receptor is used.

\section{Step 3c: Surface water pathway}

For the surface water pathway, several MMSOILS restrictions require the model to be run multiple times. First, the times at which surface water concentrations are desired are input by the user. Therefore, to generate a curve encompassing the entire concentration distribution, MMSOILS is run several times. In addition, MMSOILS 
generates surface water concentrations every year. Therefore, for methylene chloride, a period of $2500 \mathrm{yrs}$ is simulated to get results. However, for uranium-238, a period of over 100,000 yrs would need to be simulated, which would take an enormous amount of computer time and disk space to store the results. Therefore, selected times from this time frame are run instead, and each requires a separate MMSOILS simulation.

MMSOILS does not directly output the flux from the saturated zone to the surface water. The flux over time, required as a benchmarking end point is calculated based on the river flow rate and the concentrations in the river at the point of interception with the groundwater.

To generate risks for the surface water pathway, MMSOILS is run with the requested time for surface water results representing the peak concentration. This generates the exposure point concentrations; then EXPOSE was run to generate the risks.

\section{Step 4: Processing of output}

Output from MMSOILS is contained in the following files:

- results.123-contains all output except risks.

- expconc.123-intermediate output file. Contains exposure point concentrations. Used as input to EXPOSE.

- hum_dos.123-risk output.

To generate tables and plots, the data are copied from these files into Microsoft Excel. The only additional calculations required to generate the required results are unit conversions and calculation of the flux from the saturated zone to the surface water.

\section{A.3 MEPAS STEP-BY-STEP ANALYSIS}

MEPAS is a system of several executables which are designed to communicate with each other (i.e., the output files of one program are the input files to the next). Interaction between a user and the MEPAS programs occurs through a user-friendly interface. In this manner, data are entered, the codes are executed, and output results are examined entirely from the user-interface. For many of the benchmarking assessments, this was the procedure used. However, the interface does not allow a user to fully access all the capabilities of the executables. Some of these capabilities outside the user-friendly shell were used in the benchmarking, and some specific changes were made by hand to the executable input files to meet the constructs of comparing and testing different models. The changes that were made by hand were not implemented to run the model. The procedure used to run each benchmarking assessment is as follows:

Multimedia Scenario. The mass of contaminant at the source was distributed among the various transport pathways using a beta version source term code. This code is in the testing phase and is not fully coupled as of this benchmarking under the MEPAS umbrella. Because it was specifically developed and written as a component of the MEPAS methodology, it will be available in the next version of MEPAS.

Coupling and implementation of the multimedia scenario was a two-step process. The output from the source term code includes time-varying constituent inventories that account for individual source emission rates to each transport medium receiving contamination. The emission rates generated by the source-term module were reformatted using a spreadsheet and text editor to create the appropriate input file to the main model, which has the capability of reading emission rates from an external file. Source term, transport, and exposure data are entered into the user-interface from which the transport calculations were executed.

The air emission rates for volatilization of methylene chloride and suspension of uranium-238 were computed by MEPAS based on site characteristics. The benchmarking scenario did not explicitly define the stability of the surface to wind suspension. The range of predicted suspension rates spanned the RESRAD air emission rate (i.e., site with a relatively well stabilized surface) and the total erosion rate as an air emission (site with an unstabilized surface). The modelers assumed that MEPAS would simulate a site with an unstabilized surface with an air-filled 
porosity that is assumed to be equal to the total porosity minus the moisture content. The MEPAS option for using a known 70-yr average air emission rate was selected. The 70-yr emission rate for methylene chloride was computed using the first $70 \mathrm{yrs}$ of annual emission rates. The emission rate for uranium-238 varied so slowly that the initial emission rate for the first 70 yrs following the removal of clean overburden was selected. According to the RESRAD simulation, 800 yrs was selected as the time period to remove the clean overburden. Standard outputs are based on 70-yr average values; peak concentrations and risk values are obtained from intermediate output files.

Separate runs are made for each receptor location to provide the detailed concentration, dose, and risk information required by the benchmarking. These cases were relatively straightforward to enter and run. MEPAS does not have a separate model for onsite atmospheric dispersion (i.e., within $100 \mathrm{~m}$ of the center of the waste site). The onsite receptor is modeled as the exposure located $100 \mathrm{~m}$ from the center of the source area, which is generally assumed to be the closest distance allowed with the Gaussian dispersion model). For the selected location to the north, this computation is for an onsite location about $20 \mathrm{~m}$ inside the edge of the contaminated area.

Under the benchmarking exercise, it was requested that MEPAS use two different exposure settings: EPA slope factors and ICRP dose factors. As such, two implementations were performed, which the user has direct access to through the user interface: one using slope factors and one using ICRP dose factors. MEPAS also contains an option that allows the user to specify any exposure/risk assessment scenario. To ensure that the exposure scenarios were consistent between models, it was easiest to modify the MEPAS default exposure values to match those of the other models because MEPAS was specifically designed to allow the user to define their own scenarios. The MEPAS database editor [Multimedia Environmental Database Editor (MMEDE)] was used to define all pollutantspecific values to match those of the other models. The exposure values were also modified in the RISK.SET file to match those of the other models (e.g., crop growing period, cow and human ingestion rates, plant yield values, skin areas for dermal contact, adherence factors, etc.).

After using MMEDE and updating the RISK.SET file, the MEPAS shell was exercised to perform the transport and exposure analyses. For each case (groundwater, surface water, or atmospheric), the appropriate values and exposure pathways are automatically updated and implemented.

Direct Release to Vadose and Saturated Zones. For the direct release to the vadose zone and the saturated zones, input data were entered, and MEPAS was executed entirely through the user-interface. No additional steps were required.

Direct Release to Surface Water. This benchmarking exercise requested that MEPAS input the exact input data generated by MMSOILS for the benchmarking comparison. To accommodate this request, source-term fluxes were manually entered into the input file, so that they would exactly match those used by MMSOILS. The source-term fluxes were not entered through the user-interface because the number of flux values exceeded the capacity allowed for by the user-interface. The final simulation was performed by interactively executing the batch file created by the user-interface.

Direct Release to Atmosphere. For the direct release to the atmosphere, input data were entered, and MEPAS was executed entirely through the user-interface. No additional steps were required.

Direct Exposure. Under the benchmarking exercise, it was requested that MEPAS use different exposure settings, other than those associated with its default values. MEPAS contains an option that allows the user to specify any exposure/risk assessment scenario. To ensure that the exposure scenarios were consistent between models, it was easiest to modify the MEPAS default exposure values to match those of the other models because MEPAS was specifically designed to allow the user to define his own scenarios. MMEDE was used to define all pollutant specific values to match those of the other models.

The direct exposure scenarios involve 12 pathways related to use of contaminated water and 9 pathways related to contaminated soil. Risks for these 21 pathways were evaluated with 9 MEPAS runs. For each run, the parameter values were reviewed, and if necessary, a special file (filename.DFL) was created to provide changes to default MEPAS values. 
After using MMEDE and updating the filename.DFL file, the MEPAS shell was exercised to perform the exposure analyses. For each case (groundwater, surface water, or soil) the appropriate values and exposure pathways are updated automatically and implemented at the time of the run using values from the special files. 
Appendix B

ADDITIONAL MODEL INFORMATION 


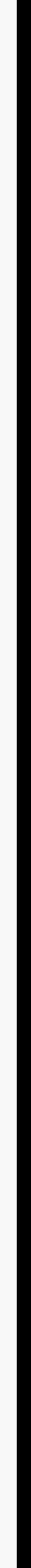




\title{
B. ADDITIONAL MODEL INFORMATION
}

\section{B.1 ADDITIONAL INFORMATION FOR RESRAD}

Contact: $\quad$ For additional information on RESRAD and other RESRAD family of codes, please contact:

\author{
Dr. Charley Yu \\ Argonne National Laboratory \\ EAD-900 \\ 9700 S. Cass Avenue \\ Argonne, IL 60439 \\ Phone: (708) 252-5589 \\ Fax: (708) 252-4624 \\ EMail: yuc@smtplink.eid.anl.gov
}

\section{References:}

More than 80 publications are available for RESRAD; these include supplemental documents and application reports. Selected publications are listed as follows:

Cheng, J.-J. and C. Yu. 1993. Using the RESRAD Computer code to Evaluate Human Health Risks from Radionuclides and Hazardous Chemicals, J. Hazardous Materials, 35:353-367.

Cheng, J.-J., C. Yu, and A. J. Zielen. 1991. RESRAD Sensitivity Analysis, ANL/EAIS-3, Argonne National Laboratory, Argonne, Ill.

Faillace, E. R, J.-J. Cheng, and C. Yu. 1994. RESRAD Benchmarking Against Six Radiation Exposure Pathway Models, ANL/EAD/TM-24, Argonne National Laboratory, Argonne, Ill.

Gilbert, T. L., C. Yu, Y. C. Yuan, A. J. Zielen, M. J. Jusko, and A. Wallo. 1989. A Manual for Implementing Residual Radioactive Material Guidelines, ANLES-160, DOE/CH/8901, prepared by Energy and Environmental Systems Division, Argonne National Laboratory, Argonne, IIl., for the U.S. Department of Energy, Office of Remedial Action and Waste Technology.

Halliburton NUS Corp. 1994. Verification of RESRAD, HNUS-ARPD-94-174, Halliburton NUS Corporation.

Wang, Y. Y., B. M. Biwer, and C. Yu. 1993. A Compilation of Radionuclide Transfer Factors for the Plant, Meat, Milk, and Aquatic Food Pathways and the Suggested Default Values for the RESRAD Code, ANL/EAIS/TM-103, Argonne National Laboratory, Argonne, Ill.

Yu, C., A. J. Zielen, J.-J. Cheng, Y. C. Yuan, L. G. Jones, D. J. LePoire, Y. Y. Wang, C. O. Loureiro, E. Gnanapragasam, E. Faillace, A. Wallo III, W. A. Williams, and H. Peterson, Jr. 1993. Manual for Implementing Residual Radioactive Material Guidelines Using RESRAD, Version 5.0, ANL/EAD/LD-2, Argonne National Laboratory, Argonne, Ill.

Yu, C., C. O. Loureiro, J.-J. Cheng, L. G. Jones, Y. Y. Wang, Y. P. Chia, and E. Faillace. 1993. Data Collection Handbook to Support Modeling the Impacts of Radioactive Material in Soil, ANL/EAIS-8, Argonne National Laboratory, Argonne, Ill.

Yu, C., D. J. LePoire, C. O. Loureiro, L. G. Jones, and S. Y. Chen. 1994. RESRAD-BUILD: A Computer Model for Analyzing the Radiological Doses Resulting from the Remediation and Occupancy of Buildings Contaminated with Radioactive Material, ANL/EAD/LD-3, Argonne National Laboratory. 
Yu, C. and E. Gnanapragasam. 1995. Testing RESRAD Predictions with Chernobyl Data, IAEA-SM-339/129, International Symposium on Environmental Impact of Radioactive Releases, Vienna, Austria.

Yu, C., Development of the RESRAD family of Codes for Environmental Risk Assessment, Invited paper presented at the third International Conference on Nuclear Applications (III ENAN), Aquas de Lindoia, Brazil (August 1995).

Kamboj, S., D. LePoire, and C. Yu, External Exposure Model for Various Geometries of Contaminated Soil, Health Physics Society 40th Annual Meeting, Supp. Vol. 68, No. 6, p. S69 (June 1995).

Nabelssi, B., C. Yu, E. Dovel, D. LePoire, and D. Swider, RESRAD-RECYCLE: A Computer Code for Dose Assessment From the Recycle and Reuse of Contaminated Material, Health Physics Society 40th Annual Meeting, Supp. Vol. 68, No. 6, p. S60 (June 1995).

Cheng, J.-J., C. Yu, L. Jones, and E. Dovel, RESRAD-BASELINE: A computer Code for Baseline Risk Assessment, Health Physics Society 40th Annual Meeting, Supp. Vol. 68, No. 6, p. S60 (June 1995).

Yu, C., A. Wallo III, H. Peterson, Jr., and W. A. Williams, The RESRAD Family of Computer Codes for Risk Assessment, Health Physics Society 40th Annual Meeting, supp. Vol. 68, No. 6, p. S61 (June 1995).

Cheng, J.-J., E. Euskirchen, I. Hlohowskyj, C. Yu, and S.Y. Chen, RESRAD-ECORISK: A Computer Code for Ecological Risk Assessment, presented at ER '95, Denver, Colorado (August 1995).

Cheng, J.-J. and C. Yu, Applying RESRAD-CHEM for Chemical Risk Assessment, proc. Mid-America Chinese Professional Annual Convention (MACPAC), pp. 139-142 (1995).

Cheng, J.-J., C. Yu, E. Dovel, T. Kotek, L. Jones, and D. Swider, Developing RESRAD-BASELINE for Environmental Baseline Risk Assessment, presented at ER '95, Denver, Colorado (August 1995).

Peterson, H.T., Jr. and A. Wallo III, Development of Cleanup Criteria for DOE Nuclear Facilities, DDER '94, Vol. 1, pp. 229-232 (November 1994).

Yu, C., D.J. LePoire, L.G. Jones, S.Y. Chen, and C.O. Loureiro, RESRAD-BUILD: A Computer Model for Assessing Human Health Risks Resulting From Building Decontamination Activities, DDER'94, Vol. 2, pp. 461467 (November 1994).

Yu, C.D. LePoire, E. Dovel, B. Biwer, B. Nabelssi, and A.J Zielen, Development of the Stochastic RESRAD Code, Health Physics Society 39th Annual Meeting, Supp. Vol. 66, No. 6, p. S69 (June 1994).

Yu, C., Development of Uncertainty Analysis Capability for the RESRAD Computer Code, ANS Trans., 69:30-31 (November 1993)

Yu, C., A. Wallo III, W.A. Williams, H. Peterson, Jr., Methodology for Setting Cleanup Criteria, ANS Trans., 69:36-37 (November 1993).

Yu, C., J.-J. Cheng, A.J. Zielen, L.G. Jones, D.J. LePoire, Y.Y. Wang, Y.C. Yuan, C.O. Loureiro, A. Wallo III, W.A. Williams, H. Peterson, RESRAD Update, ANS Trans., 68A:41-42 (June 1993)

Yu, C., J.-J. Cheng, and A.J. Zielen, Sensitivity Analysis of the RESRAD, A Dose Assessment Code, ANS Trans., 64:73-74 (November 1991).

Yu, C. A Computer Program for Deriving Soil Cleanup Criteria, ANS Trans., 62:463-464 (November 1990). 
Yu, C., T.L. Gilbert, Y.C. Yuan, A.J. Zielen, and A. Wallo, RESRAD, A Computer Model for Deriving Residual Radioactive Material Guidelines, ANS Trans., 60:112-114 (November 1989).

Yu, C., J.M. Peterson, and Y.C. Yuan, Residual Radioactivity Guidelines: A Cost-Benefit Consideration, ANS Trans., 55:112-114 (November 1987).

Cheng, J.-J., C. Yu, H.M. Hartmann, L.G. Jones, B.M. Biwer, and E.S. Dovel, October 1993, RESRAD-CHEM -A Computer Code for Chemical Risk Assessment, Proceedings of Environmental Remediation 1993 Conference Meeting the Challenge, Augusta, Georgia, (October 1993).

Cheng, J.-J., and C. Yu, , Assessment of Environmental Radiological Health Risks: An Updated Feature of RESRAD, Health Physics Society Annual Meeting, Atlanta, Georgia, (July 1993).

Yu, C., J.-J. Cheng, L.G. Jones, A.J. Zielen, D.J. Lepoire, Y.Y. Wang, E.R. Faillace, A. Wallo III, W.A. Williams, and H. Peterson, Jr., RESRAD Update - A Computer Code for Risk and Pathway Analysis, Health Physics Annual Meeting, Atlanta, Georgia, (July 1993).

Nimmagadda, M. and C. Yu, Dose Assessment for a Former Uranium Ore Storage Site, 26th Midyear Topical Meeting of the Health Physics Society (January 24-28, 1993).

Wang, Y.Y. and C. Yu, Effects of Solution pH and Complexing Reagents on Uranium and Thorium Desorption Under Saturated Equilibrium Conditions, Proc. of the International Topical Meeting on Nuclear and Hazardous Waste Management Spectrum '92 (August 23-27, 1992).

Yu, C., J.-J. Cheng, and A. Wallo III, Effect of Radon Dose on Cleanup Criteria and Using RESRAD for Chemical Risk Assessment, Proceedings of the Environmental Remediation '91 pp. 833-837 (September 8-11, 1991).

Chen, S.Y. D. LePoire, S. Schafetz, P. Mehta, and C. Yu, SOILD: A Computer Model for Calculating the Effective Dose Equivalent From External Exposure to Distributed Gamma Sources in Soil, Proceedings of the Environmental Remediation '91, pp. 889-890 (September 8-11, 1991).

Yu, C., A.J. Zielen, J-.J. Cheng, L. Jones, C. Loureiro, A. Wallo, W.A. Williams, and Y.C. Yuan, RESRAD-A Pathway Analysis Computer Code, 36th Annual Meeting of the Health Physics Society, Vol. 60, Supp. 2, p. S47 (July 21-26, 1991).

Cheng, J.-J., C. Yu, and A.J. Zielen, RESRAD Code Sensitivity Analysis, 36th Annual Meeting of the Health Physics Society, Vol. 60, Supp. 2, p. S47, (July 21-26, 1991).

Duvall, K.C., A. Wallo III, and C. Yu, Development of Residual Radioactive Material Guidelines for Soil Using RESRAD Computer Modeling, 36th Annual Meeting of the Health Physics Society, Vol. 60, Supp. 2, p. S87, (July 21-26, 1991).

Wang, Y.Y., C. Yu, B.G. Lewis, Distribution of Uranium and Thorium in Different Geochemical Phases of Three Contaminated Soils, Proc. of the International Topical Meeting on Nuclear and Hazardous Waste Management Spectrum '90, pp. 411-415 (Sept. 30-Oct. 4, 1990).

Yu, C., Cleanup Criteria and Dose Calculations Using RESRAD, Proc. of Department of Energy Remedial Action Program Conference, Albuquerque, New Mexico Vol. 1, pp. 257-280 (April 16-19, 1990).

Yu, C., Y.C. Yuan, A.J. Zielen, and A. Wallo, Demonstration of A Computer Model for Residual Radioactive Material Guidelines, RESRAD, Proc. of the INMM 30th Annual Meeting, Orlando, Florida, Vol. XVIII, pp. 401-407 (July 1989). 
Yu, C., Y.C. Yuan, A.J. Zielen, and A. Wallo III, Residual Radioactive Material Guidelines: Methodology and Applications, Waste Management '89, Tucson, Ariz. (February 1989).

Nimmagadda, M., and C. Yu, Derivation of Strontium -90 and Cesium -137 Residual Radioactive Material Guidelines for the Laboratory for Energy-Related Health Research, University of California, Davis, ANL/EAIS/TM-94, prepared by the Environmental Assessment and Information Sciences Division, Argonne National Laboratory, for the U.S. Department of Energy (April 1993).

Nimmagadda, M. and C. Yu, Postremediation Dose Assessment for the Elza Gate Site, Oak Ridge, Tennessee, ANL/EAIS/TM-89, prepared by the Environmental Assessment Information Sciences Division, Argonne National Laboratory for the U.S. Department of Energy (March 1993).

Monette, F., L. Jones, and C. Yu, Derivation of Uranium Residual Radioactive Material Guidelines for the Aliquippa Forge Site, prepared by the Environmental Assessment and Information Sciences Division, Argonne National Laboratory, for the U.S. Department of Energy (September 1992).

Loureiro, C., C. Yu, and L. Jones, Derivation of Uranium Residual Radioactive Material Guidelines for the Ventron Site, prepared by Environmental Assessment and Information Sciences Division, Argonne National Laboratory, for the U.S. Department of Energy, Former Sites Restoration Division (March 1992).

Jones, L., M. Nimmagadda, and C. Yu, Derivation of Cesium-137 Residual Radioactive Material Guidelines for the Peek Street Site, Schenectady, New York, prepared by Environmental Assessment and Information Sciences Division, Argonne National Laboratory, for the U.S. Department of Energy (January 1992).

Cheng, J.-J., C. Yu, F. Monette, and L. Jones, Derivation of Uranium Residual Radioactive Material Guidelines for the Shpack Site, prepared by the Environmental Assessment and Information Sciences Division, Argonne National Laboratory, for the U.S. Department of Energy (August 1991).

Nimmagadda, M. and C. Yu, Preliminary Dose Assessment for the Palmerton Ore Storage Site, Palmerton, Pennsylvania, ANL/EAIS/TM-42, prepared by Environmental Assessment and Information Sciences Division, Argonne National Laboratory, for the U.S. Department of Energy, Office of Environmental Restoration and Waste Management (February 1991).

Cheng, J.-J., C. Yu, and J.S. Devgun, Derivation of Uranium Residual Radioactive Material Guidelines for the Elza Gate Site, prepared by the Environmental Assessment and Information Sciences Division, for the U.S. Department of Energy (February 1991).

Devgun, J.S., G. Hyatt, and C. Yu, Derivation of Uranium Residual Radioactive Material Guidelines for the Linde Air Products Site, prepared by the Environmental Assessment Information Sciences Division, for the U.S. Department of Energy (October 1990).

Yu, C., Uranium Guidelines for the Peek Street Site, Schenectady, New York, prepared by Environmental Assessment and Information Sciences Division, Argonne National Laboratory, for the U.S. Department of Energy, Office of Remedial Action and Waste Technology (September 1989).

Boggs-Mayes, C., and C. Yu, Derivation of Uranium Residual Radioactive Material Guidelines for The Three St. Louis FUSRAP Sites: St. Louis Downtown Site, St. Louis Airport Site, and Latty Avenue Properties, prepared by Energy and Environmental Systems Division, Argonne National Laboratory, for U.S. Department of Energy, Oak Ridge Operations (January 1989).

Yu, C., J.M. Peterson, and Y.C. Yuan, Derivation of Uranium and Cesium-137 Residual Radioactive Materials Guidelines for the Niagara Falls Storage Site, prepared by Energy and Environmental Systems Division, Argonne National Laboratory, for U.S. Department of Energy, Oak Ridge Operations (August 1988). 
Yu, C., J.M. Peterson, and Y.C. Yuan, Derivation of Uranium Residual Radioactive Material Guidelines for the Ashland 1 and 2 Sites, prepared by Energy and Environmental Systems Division, Argonne National Laboratory, for U.S. Department of Energy, Oak Ridge Operations (August 1988).

Yu, C., and J.M. Peterson, Derivation of a Uranium Residual Radioactivity Guideline for the National Guard Armory in Chicago, Illinois, Prepared by Energy and Environmental Systems Division, Argonne National Laboratory, for U.S. Department of Energy, Oak Ridge Operations (May 1987).

\section{Computer Requirements:}

$\underline{\text { Required hardware and software }}$

- IBM or compatible 386,486 , or Pentium computers

- Disk operating system (DOS) 3.1 or higher

- $3 \mathrm{M}$ bytes of free RAM with $500 \mathrm{~K}$ bytes of conventional memory

- $4 \mathrm{MB}$ of hard disk storage space

- A mathematics coprocessor

Optional hardware

- A printer capable of 132-column output

- A color monitor

- A mouse

\section{Preferred hardware and software}

IBM or compatible 486 or Pentium PCs with a hard disk drive of more than $6 \mathrm{MB}$ of storage space, $4 \mathrm{MB}$ of memory, a color monitor, and a mouse, running under DOS 5 or higher.

\section{Availability of RESRAD Software}

The RESRAD computer program is distributed with appropriate restrictions by the following two software centers:

(1) Radiation Shielding Information Center Oak Ridge National Laboratory

P.O. Box 2008

Oak Ridge, TN 37831-6362

Phone: 615-574-6176

Fax: 615-574-6182

(2) Energy Science and Technology Software Center

P.O. Box 1020

Oak Ridge, TN 37831-1020

Phone: 615-576-2606

For federal and state agencies and their contractors, the RESRAD family of codes may be obtained from Argonne National Laboratory for testing and evaluation purposes.

\section{Major Applications:}

(1) RESRAD has been used by the U.S. Department of Energy and its contractors to derive residual radioactive material guidelines since 1989. Subsequently, RESRAD was cited in DOE Order 5400.5 in 1990 for the evaluation of residual radioactive material in soil. Soil clean-up criteria were derived using RESRAD at more than 300 sites. 


\section{B-8}

(2) RESRAD has been widely used by U.S. Nuclear Regulatory Commission and it's contractors. NRC has approved the following use of the RESRAD code:

(a) dose evaluations by licensees involved in decommissioning

(b) NRC staff evaluation of licensee waste disposal requests

(c) dose evaluations of sites being reviewed by NRC staff

(3) RESRAD has been used by the U.S. Environmental Protection Agency and its contractors in the evaluation of contaminated sites. Currently, the EPA Science Advisory Board is reviewing RESRAD.

(4) RESRAD has been used by federal and state agencies and their contractors to evaluate contaminated sites; RESRAD is used as a dose/risk assessment tool for various applications including waste disposal, soil cleanup, NORM, low level waste, mixed waste, and uranium mill tailings.

(5) RESRAD is referenced in the NRC technical position entitled "Site Characterization for Decommissioning Sites," and RESRAD is used by EPA in the development of clean-up regulations for radioactively contaminated soils, aquifers, and buildings.

(6) RESRAD has undergone several benchmarking analyses and has been included in the International Atomic Energy Agency's VAMP and BIOMOVS II projects. These two projects involve international efforts to compare environmental transport models. The results of these studies are currently being published as IAEA TECDOC reports.

(7) RESRAD has been used by several universities as a teaching tool for dose/risk assessment and pathway analysis.

(8) RESRAD training workshops have been conducted regularly at various locations throughout the United States. The workshops were held at DOE, NRC, and EPA Headquarters and Regional Offices. About 500 people have attended these workshops.

\section{B.2 ADDITIONAL INFORMATION FOR MMSOILS}

\section{References:}

EPA (United States Environmental Protection Agency). 1992. Summary of Review and Evaluation of the Technical Approach to Corrective Action Regulatory Impact Analysis: Fate and Transport Components, compiled by G. Laniak, Athens, GA.

ICF. 1989. Methodology for Estimating Multimedia Exposure to Soil Contamination, prepared for U.S. Environmental Protection Agency, Exposure Assessment Group, Office of Health and Environmental Assessment.

Schmelling, S. G., S. R. Kraemer, J. W. Weaver, J. R. Acree, and R. Varadhan. 1992. Review of the Regulatory Impact Analysis of the Proposed RCRA Subpart S Corrective Action Rule, a U.S. Environmental Protection Agency ORD Internal Report prepared for the Office of Solid Waste.

Streicher, J. and B. Templeman. 1991 Evaluation of the Atmospheric Transport Component of the Multimedia Model, MMSOILS, draft report prepared for the U.S. Environmental Protection Agency, Environmental Research Laboratory, Athens, GA.

Tetra Tech, Inc. 1991. Review and Evaluation of MMSOILS Multimedia Model for RCRA Corrective Action Applications, draft report prepared for the U.S. Environmental Protection Agency, Environmental Research Laboratory, Athens, GA. 
Tetra Tech, Inc. 1991. MMSOILS Unsaturated Zone Analyses, draft report prepared for the U.S. Environmental Protection Agency, Environmental Research Laboratory, Athens, GA.

Tetra Tech, Inc. 1991. Unsaturated Zone Transient Flow and Transport Analyses, draft report prepared for the U.S. Environmental Protection Agency, Environmental Research Laboratory, Athens, GA.

Tetra Tech, Inc. 1991. Addition of VADOFT Transport to MMSOILS, draft report prepared for the U.S. Environmental Protection Agency, Environmental Research Laboratory, Athens, GA.

Tetra Tech, Inc. 1991. Implementation of a Time Series of Depths of Penetration into MMSOILS, draft report prepared for the U.S. Environmental Protection Agency, Environmental Research Laboratory, Athens, GA.

Tetra Tech, Inc. 1992. Analysis of Inappropriate Application of Scale Dependent Dispersity on Solute Mass Balance in Porous Media, draft report prepared for the U.S. Environmental Protection Agency, Environmental Research Laboratory, Athens, GA.

\section{System Requirements:}

MMSOILS was developed to operate on an IBM or $100 \%$ compatible personal computer system. The minimum system requirements are as follows:

- IBM or compatible personal computer

- $512 \mathrm{~KB}$ available random access memory

- one $3 \frac{1}{2}$ - or $5^{1 / 4-i n}$. floppy disk drive

- one hard disk drive (2.0 MB storage available)

- DOS 3.x or higher

Because of the extensive computations involved in MMSOILS, it will operate most effectively on a 386,486 , or Pentium series computer equipped with a math coprocessor.

\section{Contact:}

Mr. Gerard F. Laniak, P.E.

U.S. Environmental Protection Agency

Office of Research and Development

National Exposure Research Laboratory

960 College Station Road

Athens, Georgia 30605-2700

\section{B.3 ADDITIONAL INFORMATION FOR MEPAS}

\section{Selected Documents:}

Buck, J. W., G. Whelan, J. G. Droppo, Jr., D. L. Strenge, K. J. Castleton, J. P. McDonald, C. Sato, and G. P. Streile. 1995. Multimedia Environmental Pollutant Assessment System (MEPAS) Application Guidance, Guidelines for Evaluating MEPAS Input Parameters for Version 3.1. PNL-10395, Pacific Northwest Laboratory, Richland, Washington.

Buck, J. W., M. S. Peffers, and S. T. Hwang. 1991. Preliminary Recommendations on the Design of the Characterization Program for the Hanford Site Shingle-Shell Tanks - A System Analysis: Volume 2 -- Closure Related Analyte Priorities, Concentration Thresholds, and Detection Limit Goals Based on Public Health Concerns, PNL-7573, Pacific Northwest Laboratory, Richland, Washington. 
Doctor, P. G., T. B. Miley, and C. E. Cowan. 1990. Multimedia Environmental Pollutant Assessment System (MEPAS) Sensitivity Analysis of Computer Codes, PNL-7296, Pacific Northwest Laboratory, Richland, Washington.

DOE. 1988. Environmental Survey Preliminary Summary Report of the Defense Production Facilities, DOE/EH0072, U.S. Department of Energy, Environment, Safety, and Health; Office of Environmental Audit; Washington, D.C.

Droppo, J. G., Jr., and B. L. Hoopes. 1990. Remedial Action Priority and Multimedia Environmental Pollutant Assessment Systems. In Expert Systems for Environmental Applications, ed. J. M. Hushon, American Chemical Society.

Droppo, J. G., Jr., D. L. Strenge, J. W. Buck, B. L. Hoopes, R. D. Brockhaus, M. B. Walter, and G. Whelan. 1989. Multimedia Environmental Pollutant Assessment System (MEPAS) Application Guidance Volume 1 - User's Guide, PNL-7216, Pacific Northwest Laboratory, Richland, Washington.

Droppo, J. G., Jr., G. Whelan, J. W. Buck, D. L. Strenge, B. L. Hoopes, and M. B. Walter. 1989. Supplemental Mathematical Formulations: The Multimedia Environmental Pollutant Assessment System (MEPAS), PNL-7201, Pacific Northwest Laboratory, Richland, Washington.

Droppo, J. G. Jr., J. W. Buck, D. L. Strenge, and B. L. Hoopes. 1993. Risk computation for environmental restoration activities, Journal of Hazardous Materials, 35,(1993)341-352.

Droppo, J. G., Jr., J. W. Buck, D. L. Strenge, and M. R. Siegel. 1990. Analysis of Health Impact Inputs to the U.S. Department of Energy's Risk Information System, PNL-7432, Pacific Northwest Laboratory, Richland, Washington.

Droppo, J. G., Jr., J. W. Buck, G. Whelan, D. L. Strenge, K. J. Castleton, and G. M. Gelston. 1995. Large-Scale Multimedia Modeling Applications, American Institute of Chemical Engineers. Boston, Massachusetts.

Droppo, J.G, Jr, J.W. Buck, J.S. Wilbur, D.L. Strenge, and M.D. Freshley. 1991. Single-Shell Tanks Constituent Rankings for Use in Preparing Waste Characterization Plans, PNL-7572. Pacific Northwest Laboratory, Richland, Washington.

Ecology. 1990. Draft Environmental Impact Statement - Cleanup Standards, Prepared by Toxics Cleanup Program, Washington State Department of Ecology, Olympia, Washington.

Health and Welfare Canada. 1992. Review and Assessment of Two Multimedia Exposure Models: MEPAS and MULTIMED, Prepared by Intera Information Technologies Corp., Environmental Sciences Division, Nepean, Ontario, Canada.

Holmes, J. A., B. F. Lyon, M. R. Patterson, R Phillipi, C. C. Travis, and T. C. Tucker. 1994. Description, Analysis, and comparison of MEPAS and Other Multimedia Models for Atmospheric, Groundwater, Food Chain Transport, and Exposure Pathways, ORNL/TM-12421, Oak Ridge National Laboratory, Oak Ridge, Tennessee.

Lewis, R. E., T. T. Jarvis, M. R. Jarvis, G. Whelan. 1994. Eielson Air force Base Operable Unit 2 Baseline Risk Assessment, PNL-8752, Pacific Northwest Laboratory, Richland, Washington.

Martin, W. J., and G. Whelan. 1994. Modeling of Radioactive Transport for Decommissioned Nuclear Reactor Waste, In: Proceeding on Embedded Topical Meeting on Decommissioning, Decontamination, and Environmental Restoration - DDER '94, American Nuclear Society. Washington, D.C., November 13-17, 1994.

Michel, KL. 1992. An Overview of the Multimedia Environmental Pollutant Assessment System, ES/ER/TM-14, Oak Ridge National Laboratory, Oak Ridge, Tennessee. 
Morris, S. C., and A. F. Meinhold. 1988. Report of Technical Support for the Hazardous Waste Remedial Action Program on Health and Environmental Risks of Inactive Hazardous Waste Sites, BNL-42339, Brookhaven National Laboratory, Long Island, New York.

Streile, G. P., and J. L. Stroh. 1993. Accounting for Time-Varying Vadose-Zone Water Fluxes Caused by Infiltration Caps Using the MEPAS Transport, Exposure, and Risk Assessment Model, In Proceedings of the ER'93 Environmental Remediation Conference, October 24-28, 1993, Augusta, Georgia.

Strenge, D. L., and P. J. Chamberlain II 1995. Multimedia Environmental Pollutant Assessment System (MEPAS): Exposure Pathway and Human Health Impact Assessment Models, PNL-10523. Pacific Northwest Laboratory, Richland, Washington.

Strenge, D. L., and S. R. Peterson. 1989. Chemical Data Bases for the Multimedia Environmental Pollutant Assessment System (MEPAS): Version 1, PNL-7145, Pacific Northwest Laboratory, Richland, Washington.

Stroh, J. L., G. P. Streile, and G. Whelan. 1995. Theory and Implementation of the Source-Term Mass Budget Module of MEPAS, Pacific Northwest Laboratory, Richland, Washington (Draft).

Whelan, G., B. L. Steelman, D. L. Strenge, and J. G. Droppo, Jr. 1986. "Overview of the Remedial Action Priority System (RAPS), In Pollutants in a Multimedia Environment, ed. Y. Cohen, Plenum Publishing, New York.

Whelan, G., D. L. Strenge, and J. G. Droppo, Jr. 1988. The Remedial Action Priority System (RAPS): Comparison Between Simulated and Observed Environmental Contaminant Levels, In Superfund '88, Proceedings of 9 th National Conference, November 28-30, 1988, Washington, D.C.

Whelan, G., D. L. Strenge, J. G. Droppo, Jr., and B. L. Steelman. 1987. The Remedial Action Priority System (RAPS): Mathematical Formulations, PNL-6200, Pacific Northwest Laboratory, Richland, Washington.

Whelan, G., J. G. Droppo, Jr., D. L. Strenge, M. B. Walter, and J. W. Buck. 1989. A Demonstration of the Applicability of Implementing the Enhanced Remedial Action Priority System (RAPS) for Environmental Releases, PNL-7102, Pacific Northwest Laboratory, Richland, Washington.

Whelan, G., J. P. McDonald, C. Sato. 1994. Environmental Consequences to Water Resources From Alternatives of Managing Spent Nuclear Fuel at Hanford, PNL-10053, Pacific Northwest Laboratory, Richland, Washington.

Whelan, G., J. W. Buck, and A. Nazarali. 1994. Modular Risk Analysis for Assessing Multiple Waste Sites, PNLSA-24239. In Proceedings of the U.S. DOE Integrated Planning Workshop, U.S. Department of Energy, Idaho National Engineering Laboratory, Idaho Falls, Idaho. June 1-2, 1994.

Whelan, G., J. W. Buck, D. L. Strenge, J. G. Droppo, Jr., and B. L. Hoopes. 1992. Overview of the Multimedia Environmental Pollutant Assessment System (MEPAS), Hazardous Waste \& Hazardous Materials, Vol. 9, No. 2, pp. 191-208.

Whelan, G., R. D. Brockhaus, D. L. Strenge, J. G. Droppo, Jr., M. B. Walter, and J. W. Buck. 1987. Application of the Remedial Action Priority System To Hazardous Waste Sites, In Superfund '87, Proceedings of 8th National Conference, November 28-30, 1987, Washington, D.C.

\section{Applications:}

1. Applications on 20 CERCLA sites (1986-1987)

2. Private clients use MEPAS to assess potential risks (1986-1995)

3. DOE Preliminary Environmental Survey uses MEPAS for 16 Installations (1987-1988)

4. Hanford Single Shell Tanks assess relative constituent rankings (1989)

5. MEPAS sensitivity study analyzes important input variables (1990) 
6. DOE RIS report ranking issues including uncertainty (1990)

7. Hanford Grout studies hazardous waste risks (1990)

8. DOE Survey uses MEPAS for 36 Installations (1988-1990)

9. State of Washington Risk-Based standards (1990)

10. U. of Indiana, U. of Washington, Washington State U., and Mesa State College (Colorado) using MEPAS as a teaching tool (1991-1994)

11. Graduate theses/dissertations utilize MEPAS (1991-1994)

12. Linkage with Remedial Action Assessment System (RAAS) (1991-1994)

13. OMB Pilot Study by ORNL at selected DOE sites (1991)

14. Hanford 100-Area Study groundwater plume risk maps (1992)

15. DOE Programmatic Environmental Impact Statement (PEIS) using MEPAS (1992-1994)

16. Hanford Mission Plan (HMP) -- Site Integrated Risk (1992-1993)

17. Eielson Air Force Base Superfund Sites -- Fate and Transport Modeling (1992-1995)

18. Hanford Remedial Action Environmental Impact Statement (HRA-EIS) -- Transport and Risk Computations (1993-1994)

19. DOE Spent Nuclear Fuels Environmental Impact Statement (SNF-EIS) -- Transport and Risk Calculations (1993-1994)

20. Risk-Based Preliminary Assessment Supporting Closure of the Hanford Site Single-Shell Tanks as Landfills (1993-1994)

21. Evaluation of Decontamination \& Decommissioning (D\&D) of Hanford Nuclear Reactors -- Probabilistic Transport and Risk Assessment (1994)

22. Unit-Risk-Factor Application in Support of the DOE Complex-Wide Baseline Environmental Management Report (BEMR) (1994-1995)

23. Integrated Risk Assessment Program (IRAP) uses MEPAS to develop unit risk factors for prioritizing waste-related activities at Hanford (1994-1995)

24. Application of MEPAS to Support the Arctic Nuclear Waste Assessment Program for the Assessment of the Contamination of the Kara Sea from Radionuclide Transport through the $\mathrm{Ob}$ and Yenisei River Systems (1994-1995)

25. Complex-Wide (Installation-by-Installation) Risk Assessment at Russian Nuclear Installations for the Analysis of the Safety of Populations in the Vicinity of Russian Nuclear Installations (1994-1995)

26. DOE K-Basins Spent Nuclear Fuels Environmental Impact Statement (K Basin-EIS) -- Transport and Fate and Risk Calculations (1995)

27. Preliminary Risk Assessment in Support of the RI/FS at the Laboratory for Energy-Related Health Research (LEHR) at the University of California at Davis (UC-Davis) -- Transport and Risk Assessment (1995)

\section{Technical Peer Reviews:}

1. Independent, external, technical peer review of original formulations (1986)

2. EPA tests RAPS/MEPAS as prioritization methodology (1986-1987)

3. DOE selects MEPAS for Environmental Survey (1986)

4. Idaho National Engineering Laboratory reviews and selects MEPAS for risk screening applications (1989)

5. National Academy of Sciences reviews MEPAS as part of Single Shell Tank Analysis (1989)

6. EPA reviews MEPAS as part of DOE Priority System (1991)

7. Health and Welfare, Canada selects MEPAS as a result of their independent review of 22 multimedia models (1992)

8. National Academy of Sciences review MEPAS as part of DOD Prioritization System (1992)

9. Oak Ridge National Laboratory reviews models and selects MEPAS for the DOE Programmatic Environmental Impact Statement Program (1992)

10. Hanford selects MEPAS for DOE Spent Nuclear Fuels Environmental Impact Statement (1993)

11. Russia's Ministry of Atomic Energy (MINATOM) selects MEPAS as the template for development of a Russian version (1993) 


\section{B-13}

12. Independent, external peer-review panel reviews MEPAS with respect to other multimedia models (19931994)

13. Advanced Sciences, Incorporated selects MEPAS for DOE Hanford Remedial Action Environmental Impact Statement (1993-1994)

14. U.S. Environmental Protection Agency's Office of Radiation and Indoor Air contracts Brookhaven National Laboratory to Review, Compare, and Contrast MEPAS, MMSOLS, and PRESTO (1993-1994)

\section{Computer Requirements:}

486K bytes of free DOS memory; $3 \mathrm{M}$ bytes of disk space for software; minimum of $20 \mathrm{M}$ bytes of free disk space; will operate on a $286,386 \mathrm{sx} / \mathrm{dx}, 486 \mathrm{sx} / \mathrm{dx}$, or Pentium processor, math co-processor highly recommended; MS-DOS 3.0 or higher.

\section{Contact:}

Ms. Lynda Gordon, Battelle, Box 999, K6-55, Richland, WA 99352 [509-376-1817 (W), 509-373-0335 (F), 1_gordon@ccmail.pnl.gov (E:Mail)]. 
B-14

$--$ 
Appendix C

LIST OF PARAMETERS AND UNITS FOR EQUATIONS PRESENTED IN CHAPTERS 5, 6, AND 9 
$+$ 


\section{PARAMETERS AND UNITS ASSOCIATED WITH CHAPTERS 5, 6, AND 9}

\section{Chapter 5: Vadose Zone}

\begin{tabular}{|c|c|}
\hline$\Theta$ & moisture content (fraction) \\
\hline $\mathrm{K}_{\theta}$ & hydraulic conductivity $\left(\mathrm{m} \mathrm{yr}^{-1}\right)$ \\
\hline $\mathrm{K}_{3}$ & saturated hydraulic conductivity $\left(\mathrm{m} \mathrm{yr}^{-1}\right)$ \\
\hline $\mathbf{n}$ & total porosity (fraction) or number of vadose-zone layers \\
\hline $\mathbf{m}$ & empirically based parameter that is a function of soil properties (dimensionless) \\
\hline $\mathbf{v}_{\mathbf{d}}$ & Darcy velocity $\left(\mathrm{m} \mathrm{yr}^{-1}\right)$ \\
\hline i & infiltration rate $\left(\mathrm{m} \mathrm{yr}^{-1}\right)$ or index on the number of vadose-zone layers \\
\hline$\Theta_{0}$ & effective moisture content (fraction) \\
\hline $\mathbf{n}_{0}$ & effective porosity (fraction) \\
\hline$v_{\mathrm{p}}$ & pore-water velocity $\left(\mathrm{m} \mathrm{yr}^{-1}\right)$ \\
\hline $\mathbf{R}_{\mathbf{f}}$ & retardation factor (dimensionless) \\
\hline$B_{d}$ & soil bulk density $\left(\mathrm{g} \mathrm{cm}^{-3}\right)$ \\
\hline $\mathrm{K}_{\mathrm{d}}$ & distribution coefficient $\left(\mathrm{mL} \mathrm{g}^{-1}\right)$ \\
\hline $\mathbf{v}_{\mathbf{c}}$ & contaminant velocity $\left(\mathrm{m} \mathrm{yr}^{-1}\right)$ \\
\hline D & hydrodynamic dispersion coefficient $\left(\mathrm{m}^{2} \mathrm{yr}^{-1}\right)$ \\
\hline $\mathrm{D}_{\text {mec }}$ & mechanical dispersion coefficient $\left(\mathrm{m}^{2} \mathrm{yr}^{-1}\right)$ \\
\hline $\mathrm{D}_{\mathrm{mol}}$ & molecular diffusion coefficient $\left(\mathrm{m}^{2} \mathrm{yr}^{-1}\right)$ \\
\hline$\alpha$ & dispersivity (m) \\
\hline $\mathrm{H}_{\mathrm{i}}$ & thickness of vadose-zone layer $\mathrm{i}(\mathrm{m})$ \\
\hline$t_{p}$ & plug-flow-with-dispersion time to peak concentration (yr) \\
\hline & plug-flow travel time (yr) \\
\hline$t_{\text {MMR }}$ & ratio of plug-flow travel times between MMSOILS and RESRAD (dimensionless) \\
\hline$t_{M / R}$ & ratio of plug-flow travel times between MEPAS and RESRAD (dimensionless) \\
\hline$t_{M M M}$ & ratio of plug-flow travel times between MEPAS and MMSOILS (dimensionless) \\
\hline & moisture content at filed capacity (fraction) \\
\hline
\end{tabular}

\section{Chapter 6: Saturated Zone}

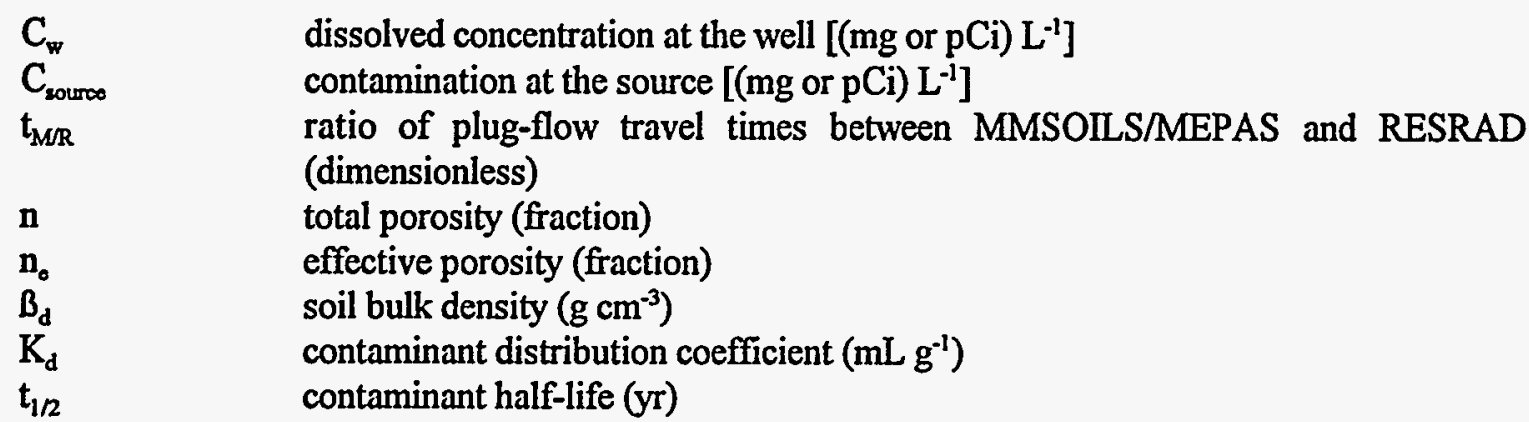




\section{Chapter 9: Multimedia Scenario}

\begin{tabular}{|c|c|}
\hline A & planar area of landfill, $\mathrm{m}^{2}$ \\
\hline AT & averaging time [period over which exposure is averaged (yrs)] \\
\hline b & coefficient of moisture retention \\
\hline BW & body weight, $\mathrm{kg}$ \\
\hline $\mathrm{C}_{\mathrm{a}}$ & chemical concentration or activity in air, $\mathrm{mg}-\mathrm{m}^{-3}$ or $\mathrm{pCi} \mathrm{m}$ \\
\hline$C_{d}$ & dissolved phase concentration, $\mathrm{mg} \mathrm{L}^{-1}$ \\
\hline CFY & conversion factor $\left(365 \mathrm{~d} \mathrm{yr}^{-1}\right)$ \\
\hline chi $\mathrm{q}^{-1}$ & emission normalized air concentration, $\mathrm{s} \mathrm{m}^{-3}$ \\
\hline $\mathrm{C}_{\mathrm{o}}$ & initial leachate concentration, $\mathrm{mg} \mathrm{L}^{-1}$ \\
\hline$C_{m \varepsilon}^{s}$ & methylene chloride concentration in aqueous, vapor, and soil phases, $\mathrm{mg} \mathrm{kg}^{-1}$ \\
\hline$C_{m c}^{t}$ & total methylene concentration in all phases, $\mathrm{mg} \mathrm{kg}^{-1}$ \\
\hline CW & chemical concentration in drinking water, $\mathrm{mg} \mathrm{L}^{-1}$ \\
\hline $\mathrm{D}_{\mathrm{eff}}$ & effective vapor diffusion coefficient, $\mathrm{m}^{2} \mathrm{yr}^{-1}$ \\
\hline DF & dose conversion factor \\
\hline $\mathrm{Di}$ & molecular diffusion coefficient, $\mathrm{m}^{2} \mathrm{yr}^{-1}$ \\
\hline$\dot{E}$ & soil erosion rate, $\mathrm{m} \mathrm{yr}^{-1}$ \\
\hline$E_{a}$ & atmospheric emission rate, $\mathrm{mg} \mathrm{s}^{-1}$ or $\mathrm{pCi} \mathrm{s}^{-1}$ \\
\hline ED & exposure duration (yrs) \\
\hline $\mathrm{EF}$ & exposure frequency, days $\mathrm{yr}^{-1}$ \\
\hline $\mathrm{H}$ & initial source thickness, $\mathrm{m}$ \\
\hline INR & inhalation rate of air, $\mathrm{m}^{3}$ day ${ }^{-1}$ \\
\hline IRW & ingestion rate of water, $\mathrm{L} \mathrm{day}^{-1}$ \\
\hline k & Ieach coefficient, $\mathrm{yr}^{-1}$ \\
\hline$K_{d}$ & soil-water distribution coefficient, $\mathrm{L} \mathrm{kg-}^{\mathrm{l}}$ \\
\hline$K_{h}$ & dimensionless Henry's Law constant \\
\hline$K_{s}$ & saturated hydraulic conductivity, $\mathrm{m} \mathrm{yr}^{-1}$ \\
\hline $\mathbf{m}$ & exponent in Campbell's equation \\
\hline $\mathbf{M}$ & initial inventory ( $\mathrm{g}$ or $\mathrm{Ci}$ ) \\
\hline$\dot{M}$. & $\begin{array}{l}\text { mass or activity flux ( }\left(\mathrm{g} \mathrm{yr}^{-1} \text { or } \mathrm{Ci} \mathrm{yr}^{-1}\right) \\
\left.\text { deposition rate ( } \mathrm{mg} \mathrm{m}^{-2} \mathrm{~s}^{-1} \text { or } \mathrm{pCi} \mathrm{m}^{-2} \mathrm{~s}^{-1}\right)\end{array}$ \\
\hline PSZ & partially saturated zone \\
\hline $\mathbf{q}$ & infiltration rate (Darcy velocity) through the unsaturated zone ( $\mathrm{m} \mathrm{yr}^{-1}$ ) \\
\hline Q & mean river flow rate, $\mathrm{m}^{3} \mathrm{~s}^{-1}$ \\
\hline $\mathbf{R}_{\mathbf{d}}$ & retardation coefficient \\
\hline SF & slope factor \\
\hline SWMU & solid waste management unit \\
\hline SZ & saturated zone \\
\hline $\mathbf{t}$ & time, yr \\
\hline $\begin{array}{l}T_{8 w} \\
T_{\text {las }}\end{array}$ & $\begin{array}{l}\text { advective chemical travel time through the groundwater, yr } \\
\text { time required in MMSOILS for water content in layer above the source to fill from } \\
\text { an initially dry condition to field capacity, yr }\end{array}$ \\
\hline $\mathrm{T}_{\text {MEPAS }}$ & advective chemical travel time predicted by MEPAS, yr \\
\hline $\mathrm{T}_{\text {MMSOIS }}$ & advective chemical travel time predicted by MMSOILS, yr \\
\hline $\mathrm{T}_{\text {RESRAD }}$ & advective chemical travel time predicted by RESRAD, yr \\
\hline$V_{d}$ & deposition velocity, $\mathrm{m} \mathrm{s}^{-1}$ \\
\hline$V_{p}$ & pore water velocity, $\mathrm{m} \mathrm{yr}^{-1}$ \\
\hline WMU & waste management unit \\
\hline
\end{tabular}




\section{C-5}

$\begin{array}{ll}\alpha_{\mathrm{I}} & \text { longitudinal dispersivity, } \mathrm{m} \\ \alpha_{\mathrm{v}} & \text { vertical dispersivity, } \mathrm{m} \\ \alpha_{\mathrm{T}} & \text { lateral dispersivity, } \mathrm{m} \\ \rho_{\mathrm{b}} & \text { bulk density, } \mathrm{kg} \mathrm{L}^{-1} \\ \rho_{\mathrm{mc}} & \text { methylene chloride liquid phase density, } \mathrm{mg} \mathrm{L}^{-1} \\ \theta_{\mathrm{c}} & \text { effective porosity } \\ \theta_{\mathrm{fc}} & \text { moisture content at field capacity } \\ \theta_{\mathrm{t}} & \text { total soil porosity } \\ \theta_{\mathrm{w}} & \text { soil water content } \\ \theta_{\mathrm{mc}} & \text { soil free-product content for methylene chloride } \\ \tau & \text { half-life, } \mathrm{yr}\end{array}$




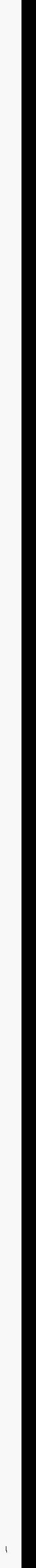

